University of New Hampshire

University of New Hampshire Scholars' Repository

Spring 1994

\title{
The utilization of municipal solid waste combustion bottom ash as a paving material
}

Xishun Zhang

University of New Hampshire, Durham

Follow this and additional works at: https://scholars.unh.edu/dissertation

\section{Recommended Citation}

Zhang, Xishun, "The utilization of municipal solid waste combustion bottom ash as a paving material" (1994). Doctoral Dissertations. 1801.

https://scholars.unh.edu/dissertation/1801

This Dissertation is brought to you for free and open access by the Student Scholarship at University of New Hampshire Scholars' Repository. It has been accepted for inclusion in Doctoral Dissertations by an authorized administrator of University of New Hampshire Scholars' Repository. For more information, please contact Scholarly.Communication@unh.edu. 


\section{INFORMATION TO USERS}

This manuscript has been reproduced from the microfilm master. UMI films the text directly from the original or copy submitted. Thus, some thesis and dissertation copies are in typewriter face, while others may be from any type of computer printer.

The quality of this reproduction is dependent upon the quality of the copy submitted. Broken or indistinct print, colored or poor quality illustrations and photographs, print bleedthrough, substandard margins, and improper alignment can adversely affect reproduction.

In the unlikely event that the author did not send UMI a complete manuscript and there are missing pages, these will be noted. Also, if unauthorized copyright material had to be removed, a note will indicate the deletion.

Oversize materials (e.g., maps, drawings, charts) are reproduced by sectioning the original, beginning at the upper left-hand corner and continuing from left to right in equal sections with small overlaps. Each original is also photographed in one exposure and is included in reduced form at the back of the book.

Photographs included in the original manuscript have been reproduced xerographically in this copy. Higher quality 6" x 9" black and white photographic prints are available for any photographs or illustrations appearing in this copy for an additional charge. Contact UMI directly to order.

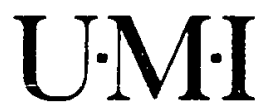

University Microfitms International A Bell \& Howell Information Company 300 North Zeeb Road. Ann Arbor. MI 48106-1346 USA $313: 761.4700 \quad 800: 521-0600$ 
Reproduced with permission of the copyright owner. Further reproduction prohibited without permission. 
Order Number 9506486

The utilization of municipal solid waste combustion bottom ash as a paving material

Zhang, Xishun, Ph.D.

University of New Hampshire, 1994

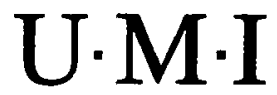

300 N. Zeeb Rd.

Ann Arbor, MI 48106 
Reproduced with permission of the copyright owner. Further reproduction prohibited without permission. 


\title{
THE UTILIZATION OF MUNICIPAL SOLID WASTE COMBUSTION BOTTOM ASH AS A PAVING MATERIAL
}

BY

XISHUN ZHANG

B.S.C.E. Beijing Polytechnic University, P.R. China, 1982

M.S.C.E. Beijing Polytechnic University, P.R. China, 1985

M.S.C.E. Southern Illinois University at Edwardsville, 1989

\section{DISSERTATION}

\section{Submitted to the University of New Hampshire in Partial Fulfillment of the Requirements for the Degree of}

\author{
Doctor of Philosophy \\ in
}

Engineering

May, 1994 
This dissertation has been examined and approved.

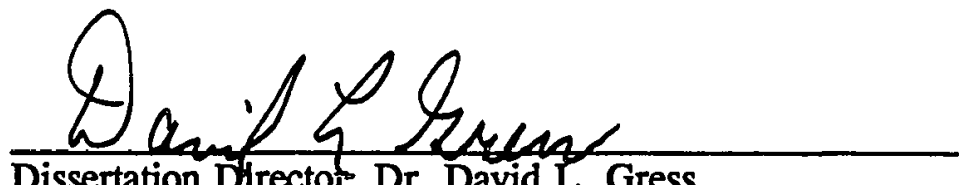

Dissertation Director, Dr. David L. Gress

Professor of Civil Engineering

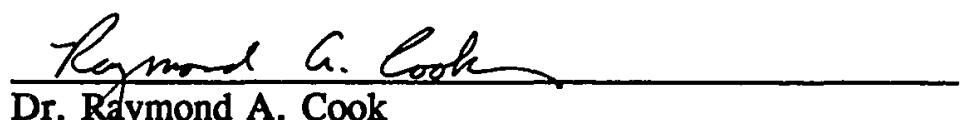

Dr. Ratymond A. Cook

Assistant Professor of Civil Engineering

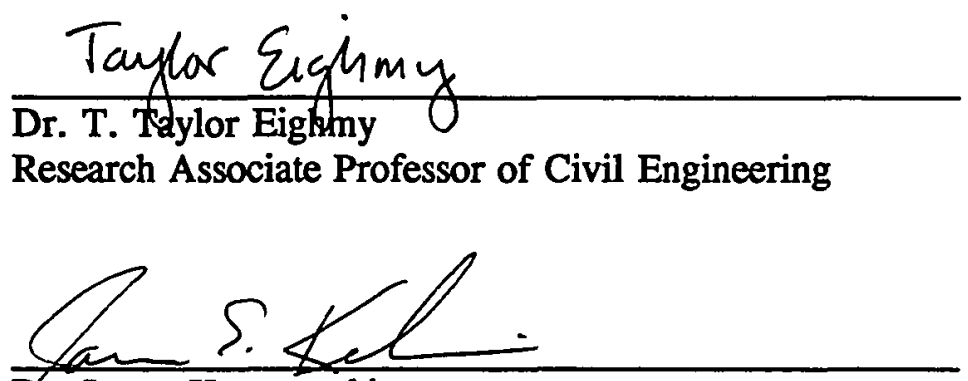

Dr. James Krzanowski

Associate Professor of Mechanical Engineering

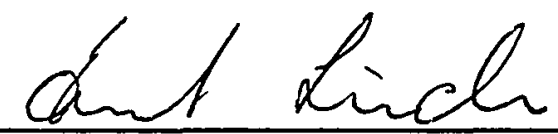

Dr. Ernst Linder

Associate Professor of Mathematics

$\frac{15 \text { Nov. } 93}{\text { Date }}$




\section{DEDICATION}

To Mom \& Dad

iii

Reproduced with permission of the copyright owner. Further reproduction prohibited without permission. 


\section{ACKNOWLEDGMENTS}

Many people have provided me with their assistance. I would like to express my sincerest appreciation to my advisor, Dr. David Gress, for his support, guidance and friendship during my four years of study at University of New Hampshire. My special thanks go to Dr. Taylor Eighmy for his support and friendship during the three years of research. I also acknowledge the other dissertation committee members, Dr. Ray Cook, Dr. James Krzanowski and Dr. Ernst Linder for their invaluable inputs in this research. Many thanks also go to Dr. Nancy Kinner, Dr. Wailace Bothner and Mrs. Nancy Cherim for their assistance in microscopy.

I would like to thank the Maine Department of Transportation Materials Laboratory for allowing me to use their Gyratory Testing Machine to accomplish the important part of my dissertation work. Special thanks go to Rollan and Elizabeth for their assistance while I performed GTM work at Maine DOT. I also acknowledge the Pike Industries, Inc. Materials Laboratory for letting me use their Marshall equipment in the development of preliminary hot mix asphalt designs. Thanks go to Rich and Dave who were very helpful with the Marshall work.

I wish to recognize the sponsors of this research, the Concord Regional Solid Waste/Resource Recovery Cooperative and Wheelabrator Environmental Systems, Inc.

for providing the resources to continue my education. I would also like to thank Scott Tarr and Ingrid Whitehead for their work on this project. 
My appreciation is also extended to the helpful staff, Elayne Ketel of the Environmental Research Group and my buddy Nikhil Murdeshwar.

Finally, I would like to thank my wife Jiaping Yue for her understanding, sacrifices and support, without whom, I would never have accomplished this research. Thanks to my son Peiyuan Zhang for being a good boy. I would also acknowledge my parents and brothers who have supported all of my endeavors. 


\section{TABLE OF CONTENTS}

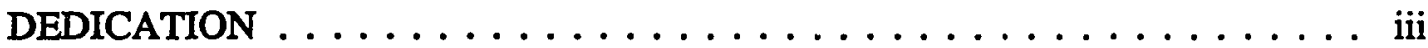

ACKNOWLEDGMENTS $\ldots \ldots \ldots \ldots \ldots \ldots \ldots \ldots \ldots$ iv

LIST OF TABLES $\ldots \ldots \ldots \ldots \ldots \ldots \ldots \ldots \ldots \ldots \ldots \ldots$

LIST OF FIGURES $\ldots \ldots \ldots \ldots \ldots \ldots \ldots \ldots \ldots \ldots \ldots \ldots$

ABSTRACT $\ldots \ldots \ldots \ldots \ldots \ldots \ldots \ldots \ldots \ldots \ldots \ldots \ldots \ldots \ldots \ldots \ldots$

$\begin{array}{ll}\text { CHAPTER } & \text { PAGE }\end{array}$

I. INTRODUCTION $\ldots \ldots \ldots \ldots \ldots \ldots \ldots \ldots \ldots \ldots \ldots \ldots \ldots \ldots$

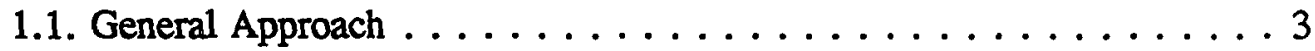

1.1.1. Physical Properties ................. . . . . . . . . . . . . . . . . . . . .

1.1.2. Engineering Properties ................ 4

1.1.3. Environmental Properties . . . . . . . . . . . . . 4

1.2. Objectives of Research . . . . . . . . . . . . . . . . 5

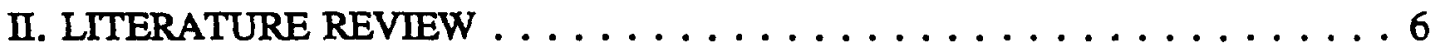

2.1. The History of Ash Utilization ................ . . 6

2.1.1. Ash Utilization in the United States ... . . . . . . . 6

2.1.2. Ash Utilization in Other Countries ............ . . 10

2.2. Current Research Projects on Ash Utilization ... . . . . . . . . 14

2.3. The Environmental Impact and Life Cycle Issues . . . . . . . . . . . . 14

2.4. The Mix Design Methods of Asphaltic Concrete . . . . . . . . . . 16

2.4.1. Marshall Mix Design Method . . . . . . . . . . . . . . 16

2.4.2. Hveem Mix Design Method . . . . . . . . . . . . . . 17

2.4.3. The Limitations of Marshall and Hveem Design Methods . . 18

2.5. The Improved Mix Design and Evaluation Methods . . . . . . . . . 20

2.5.1. National Cooperative Highway Research

Program (NCHRP) . . . . . . . . . . . . 20

2.5.2. The Strategic Highway Research Program (SHRP)

Asphalt Program . . . . . . . . . . . . . . . 20

2.5.2.1. Binder Specification .............. 23

2.5.2.2. The Mix Specification ............ 25

III. THE BOTTOM ASH SAMPLING AND TESTING PROGRAM $\ldots \ldots \ldots$

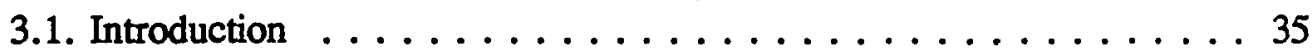

3.2. Waste-to-Energy Facility $\ldots \ldots \ldots \ldots \ldots \ldots$

3.3. Bottom Ash Sampling Program . . . . . . . . . . . . . . 37

3.4. Bottom Ash Testing Program ... . . . . . . . . . . . 43

vi 
IV. THE EVALUATION OF BOTTOM ASH PHYSICAL PROPERTIES . . . . 50

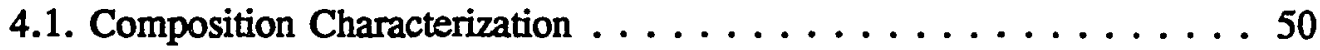

4.1.1. Visual Classification . . . . . . . . . . . 50

4.1.2. Moisture Content ............... 52

4.1.3. Loss on ignition (LOI) $\ldots \ldots \ldots \ldots \ldots \ldots \ldots$

4.2. Gradation Characterization $\ldots \ldots \ldots \ldots \ldots \ldots \ldots \ldots$

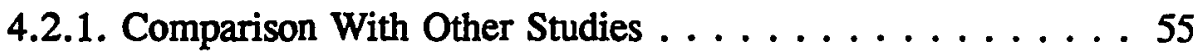

4.2.2. Uniformity Coefficient $\ldots \ldots \ldots \ldots \ldots \ldots . \ldots 58$

4.2.3. Washed versus Dry Sieving . . . . . . . . . 58

4.3. Gravimetric Characterization ...............6 61

4.3.1. Specific Gravity and Absorption of Coarse

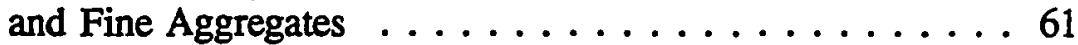

4.3.2. Unit Weight and Voids . . . . . . . . . . . 63

4.4. Field Behavior . . . . . . . . . . . . . . . 63

4.4.1. Proctor Density or Moisture-Density Testing . . . . . . 63

4.4.2. California Bearing Ratio (CBR) . . . . . . . . . . . 64

4.5. Toughness and Abrasion Resistance $\ldots \ldots \ldots \ldots \ldots \ldots \ldots$

4.6. Durability and Soundness . . . . . . . . . . . . 73

4.7. Conclusions $\ldots \ldots \ldots \ldots \ldots \ldots \ldots \ldots \ldots \ldots \ldots$

V. THE STATISTICAL ANALYSIS OF BOTTOM ASH

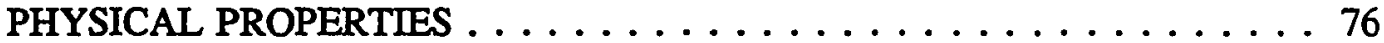

5.1. Particle Size Distribution $\ldots \ldots \ldots \ldots \ldots \ldots \ldots$

5.1.1. Hourly Samples . . . . . . . . . . . . . . 76

5.1.1.1. Two-way Analysis of Variance

(Two-way ANOVA) . . . . . . . . . 77

5.1.1.2. One-way Analysis of Variance . . . . . . . . 88 8

5.1.1.3. Confidence Intervals . . . . . . . . . . . 83

5.1.2. Daily Composite Samples . . . . . . . . . . . . 96

5.1.3. Source of Variation . . . . . . . . . . . . 110

5.2. Other Physical Properties ................ 111

5.2.1. Hourly Sample . . . . . . . . . . . . . . 111

5.2.1.1. Two-way Analysis of Variance

(Two-way ANOVA) . . . . . . . . . 111

5.2.1.2. One-way Analysis of Variance

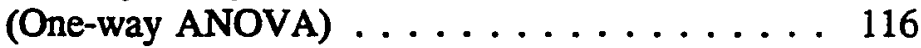

5.2.1.3. Confidence Intervals . . . . . . . . . . . . 116

5.2.2. Daily Composite Samples . . . . . . . . . . . . . 137

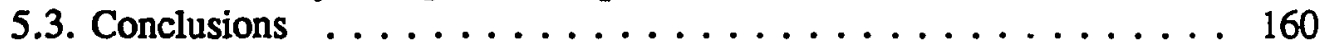

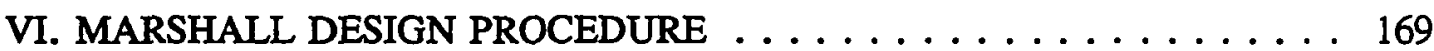

6.1. Introduction . . . . . . . . . . . . . . . . . . . . . 169

6.2. Materials and Methods . . . . . . . . . . . . . 170

6.3. Results and Discussions . . . . . . . . . . . . . 175

vii 
6.3.1. Aggregate Blends . . . . . . . . . . . . . 175

6.3.2. Asphalt Concrete Mixes . . . . . . . . . . . . 175

6.3.2.1. Unit Weight (or Density) . . . . . . . . . 179

6.3.2.2. Stability $\ldots \ldots \ldots \ldots \ldots \ldots \ldots \ldots \ldots 181$

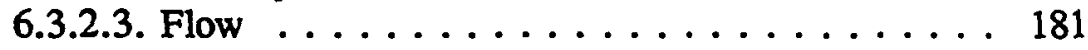

6.3.2.4. VMA and VFA ............ 183

6.3.2.5. Air Voids . . . . . . . . . . . . . . . 187

6.3.2.6. Absorbed and Effective Asphalt . . . . . . . 190

6.3.2.7. Water Absorption by Bituminous Mixes . . . . . 193

6.4. Selection of Mix Design . . . . . . . . . . . . . . . 193

6.5. Regression Analysis . . . . . . . . . . . . . . . . 196

6.6. Bottom Ash Degradation . . . . . . . . . . . . . . . 205

6.7. Conclusion . . . . . . . . . . . . . . . . . 213

VII. GYRATORY TESTING MACHINE DESIGN PROCEDURE $\ldots \ldots \ldots .215$

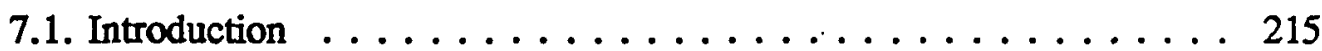

7.2. Materials and Mix Preparation . . . . . . . . . . . 219

7.3. Mix Compaction and Tests ............... 221

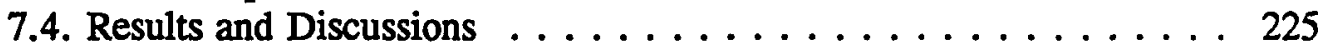

7.4.1. Unit Weight . . . . . . . . . . . . . 225

7.4.2. Gyratory Compactibility Index (GCI) _ . . . . . . . 229

7.4.3. Air Voids . . . . . . . . . . . . . . . . 229

7.4.4. VMA and VFA .............. 237

7.4.5. Absorbed and Effective Asphalt . . . . . . . . . 244

7.4.5.1. Percent Asphalt on Volume Basis . . . . . . . 244

7.4.5.2. Absorbed Asphalt . . . . . . . . . . . 246

7.4.5.3. Effective Asphalt . . . . . . . . . . . . 249

7.4.6. Water Absorption by Bituminous Specimens . . . . . . 252

7.4.7. Gyratory Shear $\left(S_{g}\right) \ldots \ldots \ldots \ldots . \ldots \ldots 252$

7.4.7.1. The Development of Formula

for Gyratory Shear . . . . . . . . . . . . . . 254

7.4.7.2. Results and Discussion . . . . . . . . 256

7.4.8. Gyratory Shear Factor (GSF) . . . . . . . . . . 258

7.4.9. Gyratory Stability Index (GSD) . . . . . . . . . . . 263

7.4.10. Gyratory Shear Modulus (GSM) . . . . . . . . . . 265

7.4.11. Gyratory Compressive Modulus (GCM) . . . . . . . 272

7.4.12. Gyratory Compressive Strain (GCS) . . . . . . . . . 275

7.4.13. Bottom Ash Degradation in Asphaltic Mixes . . . . . . 275

7.4.14. Marshall Stability and Flow . . . . . . . . . . . 278

7.5. Selection of Optimum Asphalt Content . . . . . . . . 284

7.6. Summary and Conclusion . . . . . . . . . . . . . 293

VIII. ASPHALT ABSORPTION . . . . . . . . . . . . . . . . 295

8.1. Introduction . . . . . . . . . . . . . . . . 295

viii 
8.2. Materials . . . . . . . . . . . . . . . . . . . . 298

8.3. Methods and Procedures . . . . . . . . . . . . . . . . 299

8.3.1. Absorption by Bulk Impregnated Method . . . . . . . . . 299

8.3.2. Absorption by Rice Method . . . . . . . . . . . . . 300

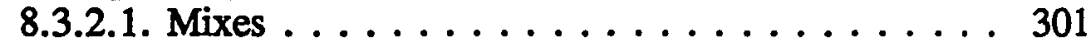

8.3.2.2. Aging $\ldots \ldots \ldots \ldots \ldots \ldots \ldots \ldots \ldots 2$

8.3.2.3. Modification . . . . . . . . . . . 302

8.4. Results and Discussions . . . . . . . . . . . . . . 303

8.4.1. Absorption by Bulk Impregnated Method . . . . . . . 303

8.4.2. Absorption by Rice Method . . . . . . . . . . . . 307

8.4.3. Suitability of The Two Methods . . . . . . . . . 310

8.4.3.1. Rice Method . . . . . . . . . . . . . 310

8.4.3.2. Bulk Impregnation Method . . . . . . . . . . . 320

8.5. Conclusions and Recommendations . . . . . . . . . 320

IX. MICROSCOPIC STUDY $\ldots \ldots \ldots \ldots \ldots \ldots \ldots \ldots \ldots \ldots \ldots$

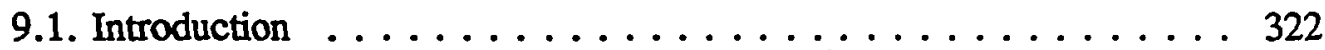

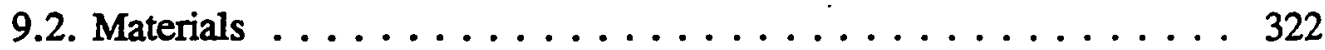

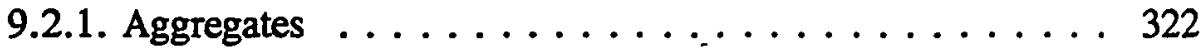

9.2.2. Asphalt Mixes $\ldots \ldots \ldots \ldots \ldots \ldots \ldots \ldots \ldots \ldots$

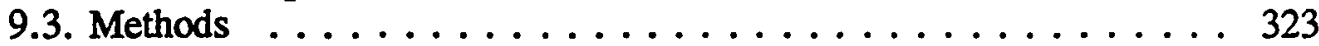

9.3.1. Scanning Electron Microscopy (SEM) . . . . . . . . 323

9.3.2. Petrographic Analysis . . . . . . . . . . . . . . . 324

9.3.2.1. Procedures of Making An Aggregate

Thin Section . . . . . . . . . . . 324

9.3.2.2. Procedures of Making An Asphalt

Concrete Thin Section . . . . . . . . . 325

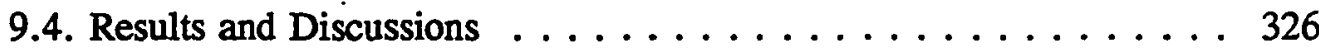

9.4.1. Aggregates . . . . . . . . . . . . . 326

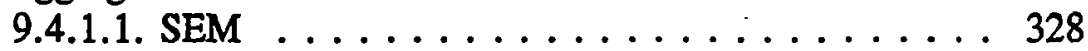

9.4.1.2. Petrographic Analysis . . . . . . . . . 337

9.4.2. Asphalt Concrete . . . . . . . . . . . . . 341

9.4.2.1. Uncompacted Samples . . . . . . . . . . 341

9.4.2.2. Compacted Samples . . . . . . . . . . . . 343

9.5. Conclusion . . . . . . . . . . . . . . . 343

X. CONCLUSIONS AND RECOMMENDATIONS $\ldots \ldots \ldots \ldots \ldots . \ldots 347$

10.1. Conclusions . . . . . . . . . . . . . . . . . . . 347

10.1.1. Evaluation of Bottom Ash Properties . . . . . . . . . 347

10.1.2. The Statistical Analysis of Physical Properties . . . . . 349

10.1.3. Marshall Procedure . . . . . . . . . . . 352

10.1.4. GTM Procedure . . . . . . . . . . . . . . 353

10.1.5. Asphalt Absorption . . . . . . . . . . . . 355

10.1.6. Microscopic Study . . . . . . . . . . . . . 356

ix 
10.2. Recommendations . . . . . . . . . . . . . . . . . 356

10.2.1. Laboratory Studies . . . . . . . . . . . . . 357

10.2.2. Field Studies . . . . . . . . . . . . . . . 357

10.2.3. Other . . . . . . . . . . . . . . . . 358

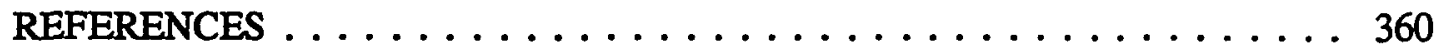

APPENDICES

A. SIEVE ANALYSIS DATA OF BOTTOM ASH $\ldots \ldots \ldots$

B. BOTTOM ASH PHYSICAL PROPERTIES . . . . . . . . . . . . 372 


\section{LIST OF TABLES}

TABLE

PAGE

2.1 Earlier Combustion Residue Road Demonstrations in the U.S. . . . . . . . 8

2.2 Bottom Ash Utilization in other Countries $\ldots \ldots \ldots \ldots \ldots$

2.3 Bottom Ash Utilization Guidelines/Regulations . . . . . . . . . . 13

2.4 Compilation of Planned Ash/Asphalt Utilization Demonstration . . . . . 15

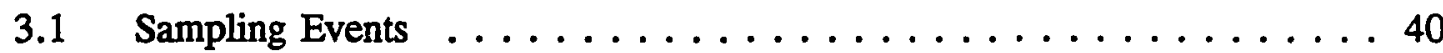

3.2 Physical Testing Methods and Frequencies . . . . . . . . . . . . . 44

5.1 Table for Two-way ANOVA ................ 77

5.2 The Analysis of Variance Table $\ldots \ldots \ldots \ldots \ldots \ldots$

5.3 One-Way ANOVA Table $\ldots \ldots \ldots \ldots \ldots$

5.4 Statistics of Gradation (Percent Passing) . . . . . . . . . . . . . 95

5.5 Bottom Ash Gradation Variation . . . . . . . . . . . . . . . . 97

5.6 Gradation Statistics for Daily Composites . . . . . . . . . . . . . 98

$5.7 \quad$ Statistics of Physical Properties $\ldots \ldots \ldots \ldots \ldots$

$5.8 \quad$ Physical Properties for Daily Composites $\ldots \ldots \ldots$. . . . . . . . . 141

5.9 Physical Properties for Daily Composites (Continued) . . . . . . . . . . 154

6.1 Physical Properties of Control Aggregates and Bottom Ash . . . . . . . 171

6.2 Gradation and Proportion of Control Aggregates in Control Mix . . . . 172

$6.3 \quad$ Asphalt Properties $\ldots \ldots \ldots \ldots \ldots \ldots \ldots$

$\mathbf{x i}$ 
6.4 Optimum Asphalt Content and Mix Properties . . . . . . . . . . . . . . . 197

6.5 Optimum Asphalt Content by the Asphalt Institute Criteria . . . . . . . 198

7.1 The VMA and VFA Guidelines ................... 238

7.2 Properties of the Optimum Mix Designs . . . . . . . . . . . . . 289

7.3 Types of Compaction and Average Optimum Asphalt Content . . . . . 292

8.1 Asphalt Absorption by Bulk Impregnation Method . . . . . . . . . . . 304 


\section{LIST OF FIGURES}

$\begin{array}{ll}\text { FIGURE } & \text { PAGE }\end{array}$

3.1 Quality Control Concept ..................... 36

3.2 Penacook, NH Waste-to-Energy Facility $\ldots \ldots \ldots \ldots$

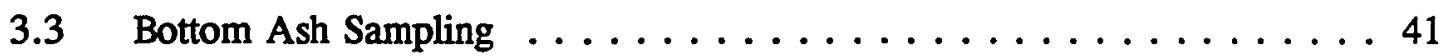

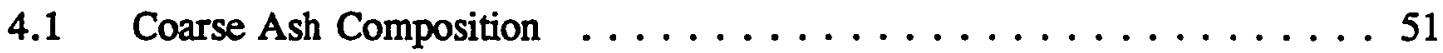

$4.2 \quad$ LOI versus Particle Size ....................... 54

4.3 Ash Studies (Average Gradation) $\ldots \ldots \ldots \ldots$

$4.4 \quad$ Ash Studies (Continued) $\ldots \ldots \ldots \ldots \ldots \ldots \ldots$

4.5 Gradation of Unwashed and Washed Ash . . . . . . . . . . . . 59

4.6 Gradation of Unwashed and Washed Control .............. 60

4.7 Density versus Moisture Content by Proctor Test . . . . . . . . . . . . 65

$4.8 \quad$ Ash Degradation From Proctor Test ................. 66

4.9 CBR (Unsoaked) at $16 \%$ Moisture versus Test Day . . . . . . . . . 68

4.10 Stress versus Penetration (CBR Test) . . . . . . . . . . . . . . 69

4.11 CBR and Density versus $\%$ Moisture $\ldots \ldots \ldots \ldots \ldots \ldots$

4.12 Ash Degradation From CBR Test . . . . . . . . . . . . . 72

$5.1 \quad$ F-Ratio of Two-way ANOVA. versus Particle Size (Between Day Comparison) . . . . . . . . . . . . . . . 80

5.2 F-Ratio of Two-way ANOVA versus Particle Size (Between Hour Comparison) ................... 81

xiii 
5.3 F-Ratio of One-way ANOVA versus Particle Size

(Between Day Comparison) . . . . . . . . . . . . . 84

5.4 Percent Passing of $3 / 4^{\prime \prime}$ Ash versus Sampling Day $\ldots \ldots \ldots 6$

5.5 Percent Passing of $1 / 2^{\prime \prime}$ Ash versus Sampling Day $\ldots \ldots \ldots . \ldots . . .87$

5.6 Percent Passing of $3 / 8^{\prime \prime}$ Ash versus Sampling Day $\ldots \ldots \ldots$. . . 88

5.7 Percent Passing of No.4 Ash versus Sampling Day . . . . . . . . . . 89

5.8 Percent Passing of No.10 Ash versus Sampling Day . . . . . . . . 90

5.9 Percent Passing of No.20 Ash versus Sampling Day . . . . . . . . 91

5.10 Percent Passing of No.40 Ash versus Sampling Day $\ldots \ldots \ldots 2$

5.11 Percent Passing of No.80 Ash versus Sampling Day . . . . . . . . 93

5.12 Percent Passing of No.200 Ash versus Sampling Day . . . . . . . . 94

5.13 Average Gradation (Daily Composite) . . . . . . . . . . . . . . . 99

5.14 Percent Passing of 3/4" Ash versus Sampling Day (Daily Composite) . . 100

5.15 Percent Passing of $1 / 2^{n}$ Ash versus Sampling Day (Daily Composite) . . 101

5.16 Percent Passing of 3/8" Ash versus Sampling Day (Daily Composite) . . 102

5.17 Percent Passing of No.4 Ash versus Sampling Day (Daily Composite) . . 103

5.18 Percent Passing of No.10 Ash versus Sampling Day (Daily Composite) . 104

5.19 Percent Passing of No.20 Ash versus Sampling Day (Daily Composite) . 105

5.20 Percent Passing of No.40 Ash versus Sampling Day (Daily Composite) . 106

5.21 Percent Passing of No.80 Ash versus Sampling Day (Daily Composite) . 107

5.22 Percent Passing of No.200 Ash versus Sampling Day (Daily Composite) 108

5.23 Variation of Gradation (Daily Composite) $\ldots \ldots \ldots$. . . . . . . 109

5.24 F-Ratio of Two-way ANOVA versus Physical Property

xiv 
(Between Day Comparison) $\ldots \ldots \ldots \ldots \ldots \ldots \ldots \ldots \ldots$

5.25 F-Ratio of Two-way ANOVA versus Physical Property

(Between Day Comparison, Continued) . . . . . . . . . . . 113

5.26 F-Ratio of Two-way ANOVA versus Physical Property

(Between Hour Comparison) $\ldots \ldots \ldots \ldots \ldots \ldots \ldots \ldots$

5.27 F-Ratio of Two-way ANOVA versus Physical Property

(Between Hour Comparison, Continued) . . . . . . . . . . 115

5.28 F-Ratio of One-way ANOVA versus Physical Property

(Between Day Comparison) . . . . . . . . . . . . . . 117

5.29 F-Ratio of One-way ANOVA versus Physical Property

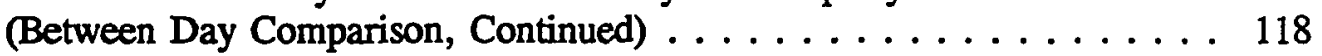

5.30 Mass Rejected versus Sampling Day . . . . . . . . . . . 120

5.31 Mass $\left(<3 / 4^{\prime \prime}\right)$ versus Sampling Day $\ldots \ldots \ldots \ldots \ldots \ldots \ldots \ldots$

5.32 Moisture Content versus Sampling Day . . . . . . . . . . . 123

5.33 Uniformity Coefficient versus Sampling Day $\ldots \ldots \ldots \ldots \ldots . \ldots 124$

5.34 Effective Size versus Sampling Day . . . . . . . . . . . . 125

5.35 Bulk (Dry) Specific Gravity of Fine Ash versus Sampling Day . . . . . 126

5.36 Bulk (Dry) Specific Gravity of Coarse Ash versus Sampling Day . . . . 127

5.37 Bulk (SSD) Specific Gravity of Fine Ash versus Sampling Day $\ldots \ldots 128$

5.38 Bulk (SSD) Specific Gravity of Coarse Ash versus Sampling Day . . . . 129

5.39 Apparent Specific Gravity of Fine Ash versus Sampling Day . . . . . 130

5.40 Apparent Specific Gravity of Coarse Ash versus Sampling Day $\ldots . .131$

5.41 Absorption of Fine Ash versus Sampling Day . . . . . . . . . 132

5.42 Absorption of Coarse Ash versus Sampling Day $\ldots \ldots \ldots \ldots$

5.43 LOI versus Sampling Day $\ldots \ldots \ldots \ldots \ldots \ldots \ldots \ldots \ldots$ 
5.44 Ferrous Content versus Sampling Day $\ldots \ldots \ldots \ldots \ldots \ldots \ldots$

5.45 Gradation of Ferrous Particle . . . . . . . . . . . . . 140

5.46 Uniformity Coefficient versus Sampling Day (Daily Composite) . . . . . 142

5.47 Effective Size versus Sampling Day (Daily Composite) $\ldots \ldots \ldots$. . . 143

5.48 Bulk (Dry) Specific Gravity of Fine Ash versus Sampling Day (Daily Composite) . . . . . . . . . . . . . . . . . . . 144

5.49 Bulk (Dry) Specific Gravity of Coarse Ash versus Sampling Day (Daily Composite) . . . . . . . . . . . . . . . . . 145

5.50 Bulk (SSD) Specific Gravity of Fine Ash versus Sampling Day (Daily Composite) . . . . . . . . . . . . . . . . 146

5.51 Bulk (SSD) Specific Gravity of Coarse Ash versus Sampling Day (Daily Composite) . . . . . . . . . . . . . . . . 147

5.52 Apparent Specific Gravity of Fine Ash versus Sampling Day (Daily Composite) . . . . . . . . . . . . . . . . . . 148

5.53 Apparent Specific Gravity of Coarse Ash versus Sampling Day (Daily Composite) . . . . . . . . . . . . . . . . . . . . . . 149

5.54 Absorption of Fine Ash versus Sampling Day (Daily Composite) . . . . . . . . . . . . . . . . 150

5.55 Absorption of Coarse Ash versus Sampling Day (Daily Composite) . . . . . . . . . . . . . . . . 151

5.56 LOI versus Sampling Day

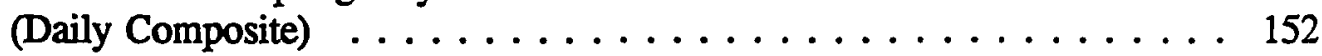

5.57 Ferrous Content versus Sampling Day (Daily Composite) . . . . . . . . . . . . . . . . . 153

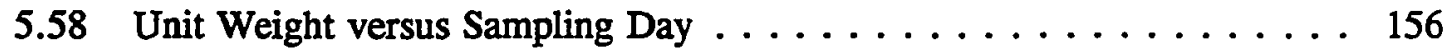

5.59 Voids in Aggregate versus Sampling Day . . . . . . . . . . 157

5.60 Optimum Moisture Content versus Sampling Day . . . . . . . . . 158

xvi 
5.61 Proctor Density versus Sampling Day . . . . . . . . . . . . . . . . . 159

5.62 CBR at $0.1^{n}$ Penetration versus Sampling Day $\ldots \ldots \ldots \ldots 1$

5.63 CBR at $0.2^{n}$ Penetration versus Sampling Day $\ldots \ldots \ldots \ldots$

5.64 LA Abrasion versus Sampling Day $\ldots \ldots \ldots \ldots$

5.65 Sodium Sulfate Soundness versus Sampling Day $\ldots \ldots \ldots$. . . . . . . 164

6.1 Gradation of Test Blends $\ldots \ldots \ldots \ldots \ldots \ldots$

6.2 Unit Weight \& Void Content versus \% Bottom Ash . . . . . . . . . . 176

6.3 Specific Gravity \& Effective Porosity versus \% Bottom Ash . . . . . . . 177

6.4 Water Absorption by Aggregate Blends . . . . . . . . . . . . . 178

6.5 Unit Weight versus Asphalt Content . . . . . . . . . . . . . . 180

6.6 Stability versus Asphalt Content $\ldots \ldots \ldots \ldots \ldots$

6.7 Flow versus Asphalt Content . . . . . . . . . . . . . . . . . . 184

6.8 VMA versus Asphalt Content $\ldots \ldots \ldots \ldots \ldots \ldots$

6.9 VFA versus Asphalt Content $\ldots \ldots \ldots \ldots \ldots \ldots$

6.10 Air Voids versus Asphalt Content . . . . . . . . . . . . . . . . . . 189

6.11 Absorbed Asphalt versus Asphalt Content ............... . 191

6.12 Effective Asphalt versus Asphalt Content . . . . . . . . . . . . . . . 194

6.13 Absorbed Water versus Asphalt Content . . . . . . . . . . . . 195

6.14 Water Absorption of Aggregate Blends . . . . . . . . . . . . . . 200

6.15 Unit Weight of Asphalt Mix (Air Voids $=4 \%$ ) . . . . . . . . . 201

6.16 Absorbed Asphalt versus \% Bottom Ash (Air Voids = 4\%) . . . . . 202

6.17 Water Absorption of Asphalt Mixes (Air Voids = 4\%) . . . . . . . 203

xvii 
6.18 Asphalt Content at 4\% Air Voids versus \% Bottom Ash . . . . . . . . . . 204

6.19 Degradation of the Control . . . . . . . . . . . . . . . . 207

6.20 Degradation of the $25 \%$ Ash . . . . . . . . . . . . . . . 208

6.21 Degradation of the $50 \%$ Ash ................... 209

6.22 Degradation of the $75 \%$ Ash . . . . . . . . . . . . . 210

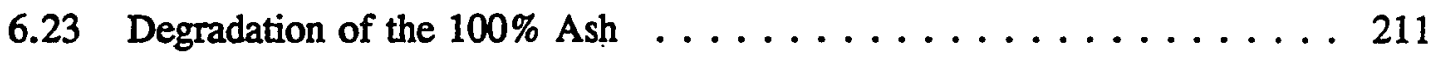

6.24 Ash Degradation $\ldots \ldots \ldots \ldots \ldots \ldots \ldots \ldots \ldots \ldots \ldots$

7.1 Gradation of Test Blends . . . . . . . . . . . . . . . . 220

7.2 Gyratory Testing Machine . . . . . . . . . . . . . . . . . 222

7.3 Schematic View of the Gyrating Mechanism . . . . . . . . . . . . 223

7.4 Unit Weight versus Revolution . . . . . . . . . . . . . . . . 226

7.5 Unit Weight versus Asphalt Content . . . . . . . . . . . . . . 227

7.6 Gyratory Compactibility Index versus Asphalt Content . . . . . . . . . . 230

7.7 Relation Between Mix Properties and Air Voids . . . . . . . . . . 231

$7.8 \quad \mathrm{G}_{\mathrm{mm}}$ versus Asphalt Content . . . . . . . . . . . . . . . 233

$7.9 \quad$ Air Voids versus Revolution $\ldots \ldots \ldots \ldots \ldots \ldots \ldots \ldots$

7.10 Initial Air Voids versus Asphalt Content $(60 \mathrm{R}) \ldots \ldots . \ldots . \ldots$

7.11 Final Air Voids versus Asphalt Content . . . . . . . . . . . . . 236

7.12 VMA versus Revolution ...................... 239

7.13 VMA versus Asphalt Content . . . . . . . . . . . . . . . 240

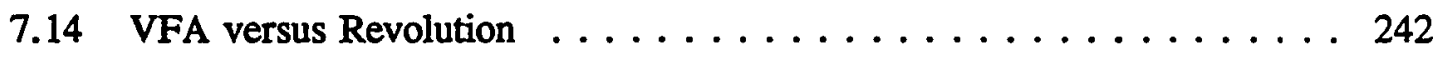

7.15 VFA versus Asphalt Content $\ldots \ldots \ldots \ldots \ldots \ldots \ldots$

xviii 
7.16 \% Asphalt by Vol. of Mix versus \% Asphalt by Wt. of Mix . . . . . . 245

7.17 Absorbed Asphalt versus Asphalt Content . . . . . . . . . . . . 247

7.18 Absorbed Asphalt by Volume of Mix . . . . . . . . . . . . . . 248

7.19 Effective Asphalt versus Asphalt Content . . . . . . . . . . . . . 250

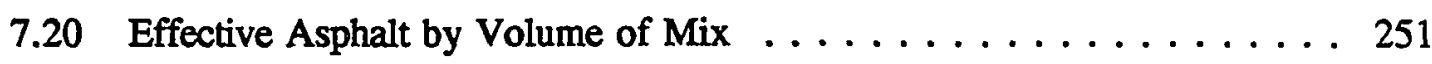

7.21 Water Absorption of Asphalt Mixes .................. . 253

7.22 Development of Formula for Gyratory Shear . . . . . . . . . . . 255

7.23 Gyratory Shear versus Revolution . . . . . . . . . . . . . 257

7.24 Gyratory Shear versus Asphalt Content . . . . . . . . . . . . . . . 259

7.25 GSF versus Revolution $(50 \%$ Ash Mix) $\ldots \ldots \ldots \ldots$

7.26 GSF versus Revolution (Control Mix) . . . . . . . . . . . . . 261

7.27 GSF versus Asphalt Content . . . . . . . . . . . . . . . . . 262

7.28 A Typical Gyrograph . . . . . . . . . . . . . . . . . . . . . 264

7.29 GSI versus Revolution (50\% Ash Mix) . . . . . . . . . . . . . 266

7.30 GSI versus Revolution (Control Mix) . . . . . . . . . . . . . . . . . 267

7.31 GSI versus Asphalt Content . . . . . . . . . . . . . . . . . 268

7.32 GSM versus Revolution $\ldots \ldots \ldots \ldots \ldots \ldots$

7.33 GSM versus Asphalt Content . . . . . . . . . . . . . . . . 271

7.34 GCM versus Revolution ..................... 273

$7.35 \mathrm{GCM}$ versus Asphalt Content . . . . . . . . . . . . . . . . 274

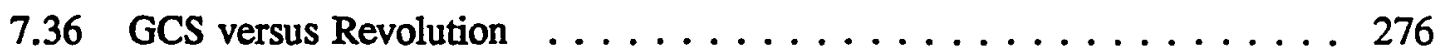

7.37 GCS versus Asphalt Content . . . . . . . . . . . . . . 277

xix 


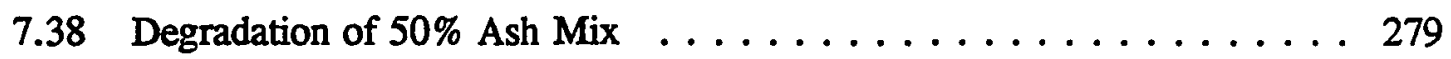

7.39 Degradation of Control Mix . . . . . . . . . . . . . . 280

7.40 Ash Degradation $\ldots \ldots \ldots \ldots \ldots \ldots \ldots \ldots \ldots \ldots \ldots \ldots$

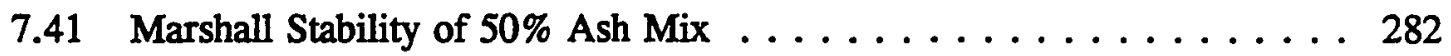

7.42 Marshall Stability of Control Mix $\ldots \ldots \ldots \ldots \ldots \ldots \ldots$

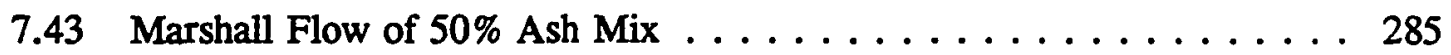

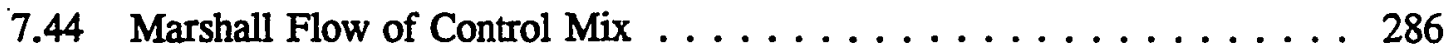

7.45 Allowable Range of Asphalt Content $\ldots \ldots \ldots \ldots \ldots$. . . . . 287

7.46 Ash Test Patch in Franklin Landfill, NH . . . . . . . . . . . . . 290

7.47 Optimum Asphalt Content versus \% Bottom Ash . . . . . . . . . 291

8.1 Water Absorption and Asphalt Absorption (Bulk Impregnation Method) . 305

8.2 Absorbed Asphalt versus Absorbed Water (Bulk Impregnation Method) . 306

8.3 Asphalt Absorption versus Aging Time (Rice Method) . . . . . . . 308

8.4 Asphalt Absorption of Coarse Aggregate versus Aging Time . . . . . . 309

8.5 $\mathrm{P}_{\mathrm{a}}, \mathrm{P}_{\mathrm{ba}}$ and $\mathrm{P}_{\mathrm{be}}$ versus Aging Time (Control) $\ldots \ldots \ldots \ldots \ldots$

8.6 $P_{a}, P_{b a}$ and $P_{b e}$ versus Aging Time (Coarse Control) $\ldots \ldots \ldots 312$

8.7 $P_{a}, P_{b a}$ and $P_{b c}$ versus Aging Time (Bottom Ash) $\ldots \ldots \ldots \ldots 313$

$8.8 \quad P_{a}, P_{b a}$ and $P_{b e}$ versus Aging Time (Coarse Ash) $\ldots \ldots \ldots \ldots$

$8.9 \mathrm{G}_{\mathrm{sb}}, \mathrm{G}_{\mathrm{se}}$ and $\mathrm{G}_{\mathrm{mm}}$ versus Aging Time (Control) $\ldots \ldots \ldots \ldots$

$8.10 \mathrm{G}_{\mathrm{sb}}, \mathrm{G}_{\mathrm{sc}}$ and $\mathrm{G}_{\mathrm{mm}}$ versus Aging Time (Coarse Control) $\ldots \ldots \ldots 317$

$8.11 \mathrm{G}_{\mathrm{sb}}, \mathrm{G}_{\mathrm{se}}$ and $\mathrm{G}_{\mathrm{mm}}$ versus Aging Time (Bottom Ash) $\ldots \ldots \ldots$

$8.12 \mathrm{G}_{\mathrm{sb}}, \mathrm{G}_{\mathrm{se}}$ and $\mathrm{G}_{\mathrm{mm}}$ versus Aging Time (Coarse Ash) . . . . . 319

$\mathbf{X X}$ 
9.1 Bottom Ash (Received) $\ldots \ldots \ldots \ldots \ldots \ldots \ldots \ldots$

9.2 Bottom Ash (Washed and Separated) $\ldots \ldots \ldots \ldots \ldots \ldots \ldots$

9.3 No.80 Bottom Ash (SEM Photograph) $\ldots \ldots \ldots \ldots . \ldots . \ldots . \ldots 329$

9.4 No.80 Bottom Ash (SEM Photograph) $\ldots \ldots \ldots \ldots \ldots \ldots$

$9.5 \quad$ No.80 Bottom Ash (SEM Photograph) $\ldots \ldots \ldots \ldots \ldots \ldots$

9.6 No.200 Bottom Ash (SEM Photograph) $\ldots \ldots \ldots \ldots \ldots \ldots$

9.7 No.200 Bottom Ash (SEM Photograph) $\ldots \ldots \ldots \ldots \ldots \ldots \ldots$

9.8 No.200 Bottom Ash (SEM Photograph) $\ldots \ldots \ldots \ldots \ldots \ldots \ldots 31$

9.9 No.200 Bottom Ash (SEM Photograph) $\ldots \ldots \ldots \ldots \ldots \ldots \ldots$

$9.10<$ No.200 Bottom Ash (SEM Photograph) $\ldots \ldots \ldots \ldots \ldots \ldots \ldots$

$9.11<$ No.200 Bottom Ash (SEM Photograph) $\ldots \ldots \ldots \ldots \ldots 33$

$9.12<$ No.200 Bottom Ash (SEM Photograph) $\ldots \ldots \ldots \ldots \ldots \ldots 33$

9.13 No.80 Control (SEM Photograph) $\ldots \ldots \ldots \ldots \ldots \ldots \ldots \ldots$

9.14 No.80 Control (SEM Photograph) $\ldots \ldots \ldots \ldots \ldots \ldots \ldots \ldots$

9.15 No.200 Control (SEM Photograph) $\ldots \ldots \ldots \ldots \ldots \ldots \ldots$

$9.16<$ No.200 Control (SEM Photograph) $\ldots \ldots \ldots \ldots \ldots \ldots \ldots$

$9.17<$ No.200 Control (SEM Photograph) $\ldots \ldots \ldots \ldots \ldots \ldots \ldots$

$9.181 / 2^{n}$ Bottom Ash (Thin Section Photograph) $\ldots \ldots \ldots \ldots \ldots \ldots$

$9.193 / 8^{n}$ Bottom Ash (Thin Section Photograph) . . . . . . . . . 338

9.20 No.20 Bottom Ash (Thin Section Photograph) . . . . . . . . . . 339

9.21 No.40 Bottom Ash (Thin Section Photograph) . . . . . . . . . . 339

9.22 No.40 Bottom Ash (Thin Section Photograph) . . . . . . . . . . . 340

$\mathbf{x x i}$ 
9.23 No.80 Control (Thin Section Photograph) . . . . . . . . . . . 340

9.24 Uncompacted 100\% Ash Mix (Thin Section Photo) . . . . . . . . 342

9.25 Uncompacted 100\% Ash Mix (Thin Section Photo) $\ldots \ldots \ldots \ldots . .342$

9.26 Uncompacted Control Mix (Thin Section Photo) . . . . . . . . . . 344

9.27 Marshall 100\% Ash Sample (Thin Section Photo) . . . . . . . . . 344

9.28 GTM 50\% Ash Sample (Thin Section Photo) . . . . . . . . . 345

9.29 GTM Control Sample (Thin Section Photo) . . . . . . . . . . 345

xxii 


\section{ABSTRACT \\ THE UTILIZATION OF MUNICIPAL SOLID WASTE COMBUSTION BOTTOM ASH AS A PAVING MATERIAL}

by

\section{Xishun Zhang}

University of New Hampshire, May, 1994

A research project was conducted to investigate the potentials of using municipal solid waste combustion bottom ash as a paving material. The effort focused on i) characterization of the time-dependent properties of the bottom ash, ii) bottom ash utilization as an unbound material in road subbase and base application, and iii) bottom ash utilization as an aggregate substitution in hot mixture asphalt. A series of standard or non-standard procedures were employed to evaluate bottom ash behavior.

Results indicate that variability of the physical properties of the bottom ash produced during the two years study period is relatively small in view of the fact that the bottom ash is a uncontrolled waste material. In comparison to conventional aggregates bottom ash shows more variation. The bottom ash is a heterogeneous, well graded, highly absorptive, porous and lightweight aggregate material. The abrasion resistance and durability of the bottom ash as measured by the Los Angeles abrasion and sodium sulfate soundness tests pass ASTM requirements. The California Bearing Ratio tests show that the bottom ash has an excellent bearing capacity and would make an excellent subbase and base material in road application.

xxiii 
Gyratory Testing Machine (GTM) and Marshall mix design methods were employed to study the properties of hot mix asphalt. Results show that the bottom ash can be used as an aggregate substitute in hot mix asphalt. Results also indicate that GTM and Marshall methods do not make much difference in developing the optimum mix design for the conventional aggregate mix. However, they make a significant difference for the bottom ash mix. The GTM method results in much lower optimum asphalt content than the Marshall method for the bottom ash mix. GTM, unlike Marshall, is an unique tool in predicting the mix performance. It is anticipated that the bottom ash mix developed with the GTM method will perform much better than a mix developed with the Marshall method.

A bottom ash test road at $50 \%$ substitution designed with the GTM method was successfully installed in Laconia, NH in May of 1993. The long term performance of the test road is being evaluated with various destructive and nondestructive testing techniques. 


\section{INTRODUCTION}

Approximately 180 million tons of municipal solid waste (MSW) are generated each year in the United States (1). The majority of the waste is currently landfilled. The amount of municipal solid waste annually generated in this country is expected to reach approximately 190 million tons by the year 2000 (2); and by the year 1995, about $45 \%$ of the nation's landfills are expected to reach capacity and close (3). Additionally, municipal sanitary landfills are becoming more difficult to site and permit due to operational costs and opposition of the public sector living nearby the proposed landfill. These occurrences have ultimately raised disposal costs for the wastes generated in the United States. The modern dilemma we have to face is: what do we do with waste we generate every day?

The combustion of MSW is a viable method of managing MSW in that volume reduction can be as much as $80 \%$ to $90 \%$, depending on the relative amounts of combustible and non-combustible material in the MSW waste stream (4). The $10 \%$ to $20 \%$ by volume which remains after the combustion process is referred to as ash or residue. This residue can be subdivided into basic fractions: bottom ash and fly ash/scrubber residue. Bottom ash is a dark grey to black, coarse material which remains on or passes through the burning grate, located in the combustion chamber of the facility. It typically contains clinker and slagged material and constitutes $75 \%-85 \%$ by weight 
of the total amount of residue produced (5). Frequently, grate siftings and riddlings are combined with the bottom ash. Fly ash is a light grey to brown material which refers to those particles removed from the flue gas stream in energy recovery units or air pollution control devices. The heavier particles are usually collected in the energy recovery units (i.e., economizer section) and typically are added to the bottom ash residue. Lighter particles which remain entrained in the flue gas stream are collected, along with acid gas scrubber residues, in the air pollution control devices (i.e., dry scrubber, fabric filters, or electrostatic precipitators). These residues are usually combined with bottom ash for ultimate disposal (5). A small amount of MSW ash is currently being utilized, but it is doubtful that the amount exceeds $1 \%$ of the total U.S. MSW ash produced. This is in contrast to coal fly ash, where over $25 \%$ of such ash is being utilized despite lower disposal costs than MSW ash. One potential concern regarding ash utilization is that the trace metals, and salts are present in the ash at concentrations that can be viewed as problematic under certain utilization scenarios. Bottom ash is widely recognized as containing lower concentrations of heavy metals than fly ash $(6,7)$. Hence the utilization of bottom ash as viable construction materials has been of great interest. Possible bottom ash utilization as a construction material includes structural fill, stabilized base, and bituminous paving applications (both wearing course and binder course). Further, if bottom ash is treated by chemical and mechanical means (high temperature fusing, crushing, etc.), the potential for bottom ash utilization is even greater.

Although research has been conducted and successful results have been obtained, the utilization of bottom ash in the United States has been hampered by social, economical 
and technical issues. The public has not become acquainted with its potential reuse and the environmental and economical incentive to minimize landfill space has only recently developed. Additionally, construction specifications to encourage the use of ash have not been established.

A researchi project, entitled Bottom Ash Reuse, is being conducted at the University of New Hampshire, Durham, NH with the sponsorship of the Concord Regional Solid Waste/Resource Recovery Cooperative and Wheelabrator Environmental Systems. Bottom ash utilized in this research was generated at the 500 ton per day (TPD) waste-to-energy facility in Penacook, New Hampshire. The facility is designed with two process trains, each train having a nominal capacity of 250 TPD. A train consists of Von Roll reciprocating stoker grates, furnace and boiler, and a dry hydrated lime $\left[\mathrm{Ca}(\mathrm{OH})_{2}\right]$ injection scrubber/fabric filter system. The bottom ash from each boiler is discharged into its own enclosed quench tank. A drag chain is used to remove the bottom ash to a rolloff. Scrubber residue is deposited on the drag chain during normal operation. Modifications to the facility allow for bottom ash from either boiler to be collected from either drag chain. Electric power generated by a steam-driven turbine-generator is sold to Public Service of New Hampshire. Each furnace has an independent primary under-fire and secondary over-fire combustion air system to ensure maximum combustion $\left(2500^{\circ} \mathrm{F}\right)$.

\subsection{General Approach}

The study of using bottom ash as paving materials was investigated at three levels: 


\subsubsection{Physical Properties}

The physical properties of bottom ash and its paving mixture was investigated. The mix properties are significantly affected by the material properties of the mix components: the bottom ash differs from conventional materials in several aspects, the current testing methods developed for conventional materials may not apply to ash materials directly; and some modification needs to be made and new methods need to be developed to better characterize ash and ash mixes. It is necessary to evaluate the variability of bottom ash properties with time in order to assure that the properties are within usable ranges.

\subsubsection{Engineering Properties}

The engineering properties of bituminous paving mixtures depend upon the properties of the aggregates, asphalt cement, and interaction between the two materials. The decision regarding the use of bottom ash as a substitute in conventional materials is made on the basis of its engineering properties.

\section{i.1.3. Environmental Properties}

The environmental issues are getting more and more attention from the public than ever before. Thus, the environmental properties of the bottom ash in its final form must be evaluated. A focus in this study is the evaluation of leaching behavior and the modeling of leaching mechanisms. Modeling is desirable to interpret large, timedependent leaching databases that relate more-controlled laboratory leaching studies to 
field leaching scenarios.

\subsection{Objectives of Research}

The objectives of this bottom ash utilization study were:

1) to characterize the time-dependent physical, and environmental properties of the bottom ash as it is produced at the Penacook facility.

2) to characterize the physical properties and engineering properties of the bottom ash and bottom ash/aggregate/asphalt mixtures for justifying the replacement of natural aggregate with bottom ash in asphalt binder or base-course applications.

3) to characterize the environmental and leaching properties of the bottom ash and bottom ash/aggregate/asphalt mixtures for assessing the potential environmental impact of full-scale utilization.

The specific objectives of the research presented in this dissertation were:

1) to evaluate the time-dependent physical properties of the bottom ash process stream as it is produced at the Penacook facility.

2) to examine the physical and engineering properties of bottom ash asphaltic concrete.

3) to investigate the mechanism of asphalt absorption of bottom ash and other mineral aggregates.

4) to characterize the microstructural features of bottom ash and bottom ash asphaltic concrete. 


\section{LITERATURE REVIEW}

This chapter reviews the literature pertaining to:

1) the history of ash utilization.

2) current research projects on ash utilization.

3) the environmental impact and life cycle issues.

4) the mix design methods of asphaltic concrete.

5) the improved mix design and evaluation methods.

\subsection{The History of Ash Utilization}

\subsubsection{Ash Utilization in the United States}

The commercial burning of municipal solid waste (MSW) in the United States dates back to the turn of the century. The first significant wave of construction of MSW facilities began in the 1940's. In an effort to overcome war-related shortages, the ash residue from some plants was utilized for embankment and subbase construction at various sites in Pennsylvania and New York during the war years (8). As per ASTM committee E-38 definition, ash residue is all of the solid material collected after the burning is completed; comprised of ash, metal, glass, ceramics, and unburned organic substances. 
In the 1960's and 1970's, with the push to construct large, centrally located MSW facilities, interest in the technology of ash residue utilization was revived as an answer to the problem of ash disposal. Several studies were performed and demonstration projects built to evaluate the technical feasibility of using ash residue as a total or partial aggregate replacement in paving mixtures. Additionally, a process was developed for fusing ash residue to produce a high quality aggregate material $(9,10)$. Material produced using this process performed well in a bituminous surface course in Harrisburg, PA (11).

The most comprehensive effort addressing the potential for using ash residue in various highway application was completed by the Federal Highway Administration (FHWA) in December $1976(12,13)$. In this study, a nationvide survey of locations and types of MSW facilities was made, samples of residues were collected and characterized physically and chemically, bituminous mixture designs were developed for base and surface course application, and field tests were constructed. These projects were wearing surfaces comprised of an equal blend of residue and natural aggregate, which were placed in Philadelphia, PA; Delaware County, PA; and Harrisburg, PA $(12,13)$. The first two test roads performed satisfactorily during the monitoring period (one year) while the Harrisburg test roads suffered considerable stripping (loss of bond) of asphalt from the residue. None of the test roads was subjected to heavy traffic. Before, and subsequent to, the study discussed above, several test roads using ash residue as an aggregate were constructed. A summary of the demonstration projects, including those undertaken by the FHWA, and their performance evaluations is shown in Table 2.1 (14). Evaluation of these demonstration test results, along with test evaluations of other possible applications, 
Table 2.1 Earlier Combustion Residue Road Demonstration in the U.S.

\begin{tabular}{|c|c|c|c|c|}
\hline Project & Job Mix & Test Strip & Performance & Reference \\
\hline $\begin{array}{l}1974 \\
\text { Houston, TX }\end{array}$ & $\begin{array}{l}<1 " C R \\
9 \% \text { AC } \\
2 \% \text { Lime } \\
100 \% \mathrm{CR}\end{array}$ & $\begin{array}{l}200^{\prime} \text { of } 6^{\prime \prime} \text { base } \\
\text { course }\end{array}$ & $\begin{array}{l}\text { Excellent } \\
(7 \text { years) }\end{array}$ & $(15,16,17)$ \\
\hline $\begin{array}{l}1975 \\
\text { Philadelphia, PA }\end{array}$ & $\begin{array}{l}<5 / 8^{*} \mathrm{CR} \\
7.5 \% \mathrm{AC} \\
2.5 \% \text { Lime } \\
50 \% \mathrm{CR} \\
50 \% \mathrm{NA}\end{array}$ & $\begin{array}{l}100^{\prime} \text { of } 1.5^{\circ} \\
\text { surface course }\end{array}$ & $\begin{array}{l}\text { Acceptable } \\
\text { (1 year) }\end{array}$ & (12) \\
\hline $\begin{array}{l}1975 \\
\text { Delaware Co., PA }\end{array}$ & $\begin{array}{l}<1 / 2^{\circ} \mathrm{CR} \\
7 \% \text { AC } \\
2.5 \% \text { Lime } \\
50 \% \text { CR } \\
50 \% \text { NA }\end{array}$ & $\begin{array}{l}60^{\prime} \text { of } 1.5^{\prime \prime} \\
\text { surface } \\
\text { course }\end{array}$ & $\begin{array}{l}\text { Acceptable } \\
\text { (1 year) }\end{array}$ & (12) \\
\hline $\begin{array}{l}1975 \\
\text { Harrisburg, PA }\end{array}$ & $\begin{array}{l}<1 / 2^{\circ} \mathrm{CR} \\
7.5 \% \mathrm{AC} \\
2.5 \% \text { Lime } \\
50 \% \mathrm{CR} \\
50 \% \mathrm{NA}\end{array}$ & $\begin{array}{l}240^{\prime} \text { of } 1.5^{\circ} \\
\text { surface course }\end{array}$ & $\begin{array}{l}\text { Poor } \\
\text { (1 year) }\end{array}$ & (12) \\
\hline $\begin{array}{l}1977 \\
\text { Washington, DC }\end{array}$ & $\begin{array}{l}<1{ }^{\circ} \mathrm{CR} \\
9 \% \text { AC } \\
1.5 \% \text { lime } \\
70 \% \text { CR } \\
30 \% \text { NA }\end{array}$ & $\begin{array}{l}400^{\prime} \text { of } 4.5^{\circ} \text { base } \\
\text { course }\end{array}$ & $\begin{array}{l}\text { Good } \\
\text { (1 year) }\end{array}$ & (18) \\
\hline $\begin{array}{l}1980 \\
L_{\text {ynn, }} \text { MA }\end{array}$ & $\begin{array}{l}6.5 \% \text { AC } \\
2 \% \text { Lime } \\
50 \% \text { CR } \\
50 \% \mathrm{NA}\end{array}$ & $\begin{array}{l}1500^{\prime} \text { of } 1.5^{\circ} \\
\text { surface course }\end{array}$ & $\begin{array}{l}\text { Excellent } \\
\text { (10 years) }\end{array}$ & (19) \\
\hline
\end{tabular}

In Table 2.1, AC = Asphait Content, $C R=$ Combustion Residue, and NA = Natural Aggregate 
including portland cement mixes, lime- and cement- stabilized ash residue for base course applications, controlled fill and subgrade use, resulted in the following conclusions and recommendations (14-20).

1. Ash residue can be mixed, placed, and compacted using conventional bituminous construction apparatus and procedures.

2. Residues should be well burned-out (less then 10 percent loss on ignition).

3. Ash residue can be used in lime- or cement-stabilized base course mixtures.

4. The use of ash residue in portland cement mixtures is not recommended (excessive volume changes result from the reaction of aluminum with alkalies producing hydrogen).

5. Fly ashes should not be incorporated into ash residues.

6. Vibrators on feed bins are necessary.

7. Plant combustion temperature control is important given the moisture content of the residues.

8. The optimum mixes for hot mix work can contain $50 \%$ to $75 \%$ bottom ash though the absorption of asphalt cement may be high.

It should be pointed out that, generally, these studies utilized residues from facilities that are not viewed today as state-of-the-art; they focused on the use of ash as an aggregate substitute in asphaltic mixtures; and they focused on the physical properties of the materials, and not on the environmental performance of the materials. These earlier studies do, however, differ from European directions in that the ash is used in an encapsulated form.

A few studies have looked at using fused or treated residues as aggregate substitutes 
$(21,22)$. Work by Chesner et al. (4) has shown that bottom ash from the Southwest Brooklyn, New York combustor can be used as aggregate substitute; they found a 30\% bottom ash substitution to perform as well as controls in Marshall testing.

Recent evaluations of bottom ash use by Chesner (23) have examined economic, regulatory, and environmental issues associated with the use of bottom ash. It appears that the institutional issues may be the largest impediment to active use in the United States despite the fact that its use is technically and economically feasible.

\subsubsection{Ash Utilization in Other Countries}

MSW bottom ash is utilized extensively in western Europe. In $1989,5.71 \times 10^{6}$ tons of bottom ash were produced in the Netherlands, Denmark, Switzerland, Sweden and western Germany. Approximately $3.14 \times 10^{6}$ tons (55\%) were used in road subbase construction, wind barriers, sound barriers, land reclamation, and in paving block (asphaltic and portland cement concrete construction). The most recently available data on utilization in Europe and Japan is summarized by Eighmy et al. (24), as shown in Table 2.2.

Many of the utilization scenarios involve the use of processed, aged ash in granular applications (road subbase, structural fills). Processing initially involves in-plant process stream separation of quenched bottom ash and grate siftings from all boiler ash, fly ash, and acid-gas scrubber residues. The bottom ash stream is then subjected to magnetic separation (ferrous removal), grizzly separation (oversize and nonferrous removal), and trommelling to produce material less than 1.0 inch. The quenched bottom ash is then 
Table 2.2 Bottom Ash Utilization in other Countries ${ }^{\mathrm{a}}$

\begin{tabular}{|c|c|c|c|c|c|c|c|}
\hline Country & $\begin{array}{l}\text { HSW }{ }_{\text {Generated }} \\
\left(10^{6} \text { ton } / y r\right)\end{array}$ & $\begin{array}{l}\text { MSW } \text { Conbusted } \\
\left(10^{6} \text { ton/yr) }\right.\end{array}$ & $\begin{array}{l}\text { Bottom Ash } \\
\text { Produced } \\
\left(10^{6} \text { ton/yr) }\right. \\
\end{array}$ & $\begin{array}{l}\text { Bottom Ash Used } \\
\text { (106 ton/yr) }\end{array}$ & $\begin{array}{l}\text { Percent } \\
\text { Used }\end{array}$ & Application & Reference \\
\hline Mether lands & 9.45 & 3.31 & 0.83 & 0.50 & 60 & $\begin{array}{l}\text { Subbase, } \\
\text { embankments }\end{array}$ & (25) \\
\hline Denmark & 6.33 & 1.98 & 0.47 & 0.33 & 72 & $\begin{array}{l}\text { Subbase, } \\
\text { embankments, } \\
\text { land reclamat ion }\end{array}$ & (26) \\
\hline $\begin{array}{l}\text { Western } \\
\text { Germany }\end{array}$ & 24.58 & 8.11 & 3.31 & 1.65 & 50 & $\begin{array}{l}\text { Subbase, } \\
\text { embankments }\end{array}$ & (27) \\
\hline Switzerland & 4.08 & 2.54 & 0.66 & $0.33^{\mathrm{a}}$ & $250^{c}$ & $\begin{array}{l}\text { Subbase, } \\
\text { embankments }\end{array}$ & (28) \\
\hline Sweden & 2.76 & 1.38 & 0.44 & 0.33 & 75 & $\begin{array}{l}\text { Subbase, } \\
\text { embankments }\end{array}$ & (29) \\
\hline Japan & 47.36 & 34.02 & $\ldots$ & $\ldots$ & $\ldots$ & Landfill Liner & (30) \\
\hline
\end{tabular}

a some caution should be used in interpreting these numbers as definitions of MSU may vary between countries.

b The Data for Denmark include the use of oversize ferrous in the listed percentage, the other countries do not specify

if ferrous recycling is included in the percentage.

c Reflects anticipated usage, not presently used. 
allowed to age. At least four important weathering reactions take place (24). All require the ash to have an initial moisture content. One involves the oxidation of $\mathrm{Fe}, \mathrm{Al}, \mathrm{Pb}, \mathrm{Zn}$, $\mathrm{Cu}$ to the more thermodynamically stable oxidized forms $\left(\mathrm{Fe}^{3+}, \mathrm{Al}^{3+}, \mathrm{Pb}^{2+}, \mathrm{Zn}^{2+}\right.$, $\left.\mathrm{Cu}^{2+}\right)$. The kinetics of these reactions are not well understood. They are frequently coupled with hydrogen gas evolution. The second class of reactions involve the exothermic hydrolysis of metal cations to various hydrolysis products (metal hydroxides). Such exothermic reactions liberally generate heat $\left(50\right.$ to $80^{\circ} \mathrm{C}$ is observed in large piles) and force evaporative processes to occur. They are frequently associated with swelling reactions (crystal growth). The third set of reactions involve the uptake of atmospheric $\mathrm{CO}_{2}$ into the alkaline matrix. Metal carbonates (e.g. $\mathrm{CaCO}_{3}, \mathrm{MgCO}_{3}, \mathrm{Na}_{2} \mathrm{CO}_{3}, \mathrm{NaHCO}_{3}$ ) form as diagenic reactions take place. The fourth set of reactions involve the specific, high affinity adsorption of metal cations to anionic surface charges, usually iron and manganese oxide and oxyhydroxide surfaces, that form in the ash as it weathers.

All of these reactions tend to stabilize the residue with regard to potential contaminant release, and to allow chemically poised reactions to take place that cause poorly understood but beneficial strength-developing reactions to occur. Residual organic carbon in the ash can also be beneficially mineralized by bacteria in the ash. The general consensus is that ash can take 1 to 3 months to age sufficiently for to use.

In Europe, guidelines have been established for utilization of processed, granular bottom ash as shown in Table 2.3 (24). There are usually aging requirements and criteria for leachability, loss on ignition, and total element content. 
Table 2.3 Bottom Ash Utilization Guidelines/Regulations ${ }^{a}$

\begin{tabular}{|c|c|c|c|c|c|c|c|c|c|c|c|c|}
\hline Country & c.c. & $\begin{array}{l}\text { Groundwater } \\
\text { or Hell } \\
\text { Separation }\end{array}$ & $\begin{array}{l}\text { Total } \\
\text { Element }\end{array}$ & $\begin{array}{l}\text { Organics } \\
(x)\end{array}$ & $\begin{array}{l}\text { Ferrous } \\
\text { (\%) }\end{array}$ & $\begin{array}{l}\text { Grain } \\
\text { Size }\end{array}$ & $\begin{array}{l}\text { PH/ALka- } \\
\text { linity }\end{array}$ & $\begin{array}{l}\text { Moisture } \\
(x)\end{array}$ & \multicolumn{3}{|c|}{$\begin{array}{r}\text { Solfd L.T. Storsge } \\
\text { (weeks) }\end{array}$} & Ref. \\
\hline Netherlands & Yes & $0.5 \mathrm{~m}$ to GHT & Ho & $\begin{array}{l}<6 \% \text { LOI } \\
<2 \% \text { TOC }\end{array}$ & $<5 \%$ & Yes & No & Ho & No & Yes & is & (25) \\
\hline Denmark & No & $\begin{array}{l}1.0 \mathrm{~m} \text { to GHT, } \\
20 \mathrm{~m} \text { to well }\end{array}$ & $\begin{array}{l}<3000 \mathrm{ppm} \mathrm{Pb} \\
<10 \mathrm{ppm} \mathrm{Cd} \\
<0.5 \mathrm{ppm} \mathrm{Hg} \\
\end{array}$ & $<10 \%$ LOI & No & Yes & $\begin{array}{r}\mathrm{pH}>9.0 \\
\mathrm{TA}>1.5 \\
\mathrm{eq} / \mathrm{kg} \\
\end{array}$ & $\begin{array}{l}17 \%>W C \\
<25 \%\end{array}$ & No & No & 4 & (26) \\
\hline $\begin{array}{l}\text { Hestern } \\
\text { Germany }\end{array}$ & No & Ho & $\begin{array}{l}\text { chloride } \\
\text { content }\end{array}$ & $<2 \%$ LOI & No & No & No & No & $<1 X$ TDS & Yes & 12. & (27) \\
\hline Switzerland & b & b & b & $\begin{array}{l}<3 \% \text { LOI } \\
<3 \% \text { TOC } \\
\end{array}$ & b & b & b & b & b & Yes & Yes & (28) \\
\hline Sweden & c & $c$ & c & c & c & $c$ & c & c & $c$ & c & c & (29) \\
\hline
\end{tabular}

In Table 2.3, c.c. = Combustor Certification

L.T. = Leach Test

For use in non-monolithic or unencapsulated form.

$b$ Many of the regulations are canton-specific, and are more detailed than shown here.

c Under development. 


\subsection{Current Research Projects on Ash Utilization}

As shown in Table 2.4 (24), a number of full scale demonstrations of using ash in asphalt concrete are either planned or are presently under evaluation in the United States or Europe. Most of these studies incorporate proposed development of job mix formulations as well as some degree of laboratory and field physical and environmental testing.

\subsection{The Environmental Impact and Life Cycle Issues}

Eighmy et al. (24) pointed out the environmental impact/life cycle issues. The life cycle of bottom ash utilization in a road involves a number of stages, including production, processing, utilization, reuse, and disposal. Under proper management scenarios, the in-place use of the material in road construction is the most lengthy (15 years), potentially uncontrolled aspect of the life cycle. Fugitivity associated with vehicle wear in wearing courses will produce very low mass loadings of ash to road soil and environs.

A binder course is not subjected to traffic abrasion. The in-place leaching under unsaturated or intermittently saturated conditions is a scenario that deserves a more thorough examination (24). Leaching from bottom ash is orders of magnitude less problematic than leaching of fly ash or scrubber residue, and not likely to cause significant impact except for some possible salt contamination (24). Leaching of bottom ash/aggregate/asphalt is of similar magnitude to leaching of natural aggregate/asphalt and not expected to be problematic (24). Nevertheless, scientific evaluation is required to 
Table 2.4 Compilation of Planned Ash/Asphalt Utilization Demonstration

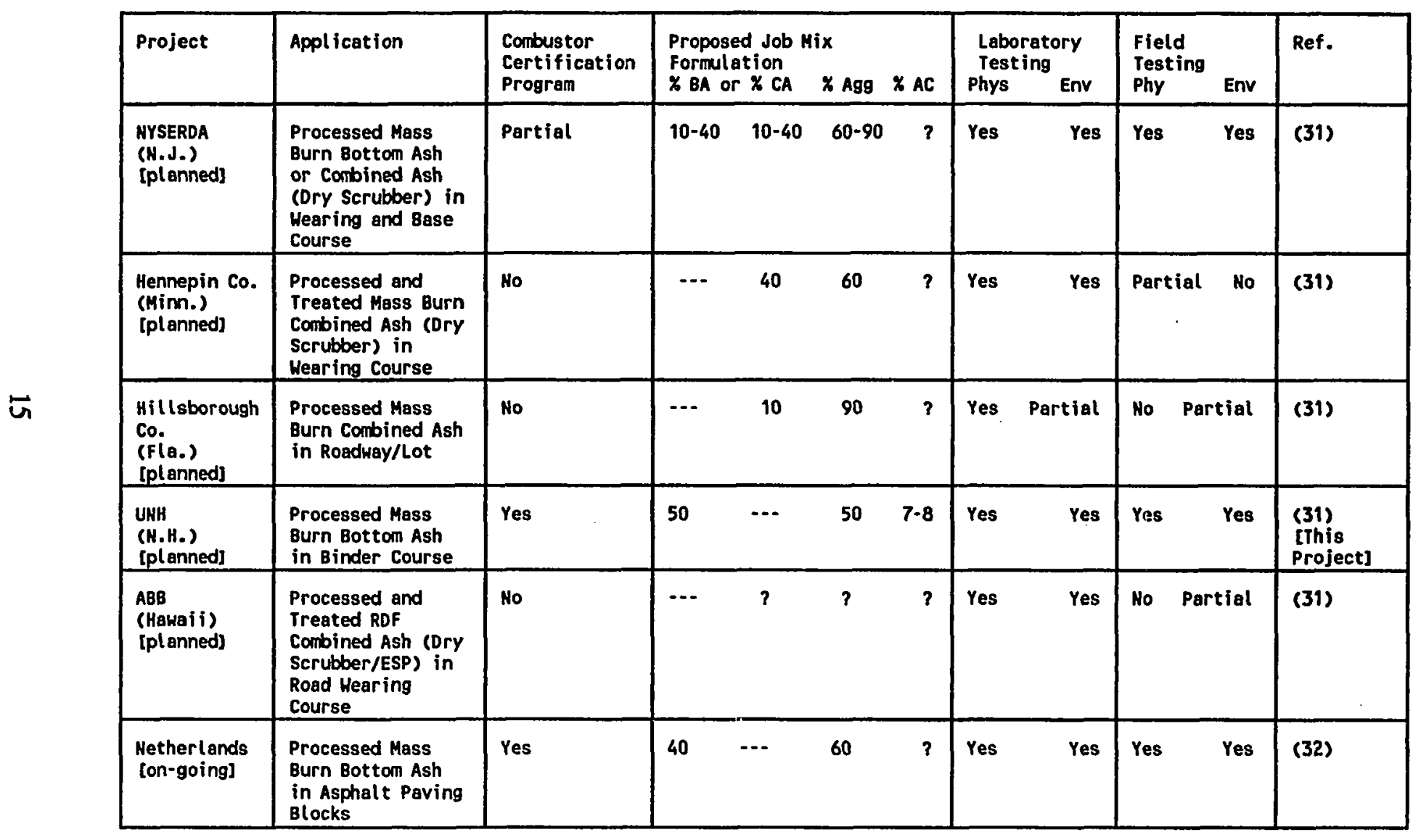

In table 2.4, BA = Bottom Ash, $C A=$ Combined Ash, Agg $=$ Aggregate, $A C=$ Asphalt Content, Phy $=$ Physical, and Env $=$ Environmental. 
understand fundamental leaching mechanisms and to help in the formulation of utilization guidelines.

\subsection{The Mix Design Methods of Asphaltic Concrete}

Since the 1940's most hot mix asphalt (HMA) mixtures have been designed using either the Marshall or Hveem mixture design methods (described below). According to a 1984 survey (33), 38 states used some version of the Marshall method while 10 states used some variation of the Hveem method.

\subsubsection{Marshall Mix Design Method}

The earliest version of the Marshall mix design method was developed at the Mississippi Highway Department by Bruce Marshall around 1939 (34). The U.S. Corps of Engineers, through extensive research and correlation studies, improved and added certain features to the Marshall's test procedure, and ultimately developed mix design criteria (34). The Marshall test procedures have been standardized by the American Society of Testing and Materials (ASTM). Procedures are given by ASTM Designation D1559, Resistance to Plastic Flow of Bituminous Mixtures Using Marshall Apparatus. The Marshall Method has been around and in use for over 50 years and much is known about the various properties that can be measured on mixes formulated by the Marshall method, and what the ranges or limits of those properties need to be in order to ensure a durable mixture. In spite of all this experience, the Marshall mix design is still very much a recipe approach. Basically the objectives of Marshall method are to develop a mix 
having (35):

1. Sufficient asphalt to ensure a durable pavement.

2. Sufficient mix stability to satisfy the traffic loads without distortion.

3. Sufficient voids in the total compacted mix to allow for a slight amount of additional compaction under traffic loading without bleeding and loss of stability, yet low enough to keep out harmful air and moisture.

4. Sufficient workability to permit efficient placement of mix without segregation.

To achieve the above objectives, the aggregate has to meet gradation requirements and the tests performed on hot asphalt mixtures include: bulk specific gravity, stability and flow, density and voids analysis.

The heated aggregate and asphalt are mixed and compacted. The compaction effort depends on the design traffic level. The optimum mix design is determined based on Marshall criteria. The Marshall criteria used by the various states vary considerably. Generally, the criteria used by most states include a minimum amount of voids in the mineral aggregates (VMA), a range of acceptable air void contents, a minimum stability, and a range or minimum flow values. Some states also add a requirement that the percentage of voids filled with asphalt (VFA) be within a specified range.

\subsubsection{Hveem Mix Design Method}

The concepts of the Hveem method of designing paving mixtures have been advanced and developed under the direction of Francis N. Hveem for the California Division of Highways (34). The Hveem method has been developed through extensive research and 
correlation studies on asphalt highway pavements. Hveem method test procedures have been standardized by the American Society for Testing and Materials (ASTM) D1560 (Resistance to Deformation and Cohesion of Bituminous Mixtures by Means of Hveem Apparatus), and ASTM D1561 (Preparation of Test Specimens of Bituminous Mixtures by Means of California Kneading Compactor). The Hveem mix design is performed in much the same way as Marshall mix design. The aggregate used has to meet gradation requirements, the aggregate and asphalt mix is compacted with a kneading compactor, and then the following tests and analyses are performed: swell, stabilometer, bulk density, and density and voids analysis. The optimum mix design formulation is determined based on Hveem design criteria such as minimum stabilometer value, maximum swell value, and a range of air voids.

\subsubsection{The Limitations of Marshall and Hveem Design Methods}

Von Quintus et al. have discussed the limitations of these two methods (36). Both Marshall and Hveem methods are empirical procedures that were developed many years ago. The philosophies behind the asphaltic concrete mix design using the Marshall and Hveem methods are reasonable, and the basic principles of providing proper air voids, adequate stability, and accounting for aggregate absorption are adequate. The mixtures designed by these two processes have generally served well under traffic. However, today's asphaltic concrete mixtures contain asphalts that are produced from different crudes and by a variety of different processes, involve the use of a variety of additives,

can be produced using drum mixers rather than only batch or continuous plants, are 
placed with new paving and compaction equipment and, more importantly, are subjected to larger loads and higher tire pressures, than those in use when the methods were developed.

Premature distress in many flexible pavements suggests that these empirical mixture design procedures are inadequate, or at least do not measure mixture properties that are pertinent for some distresses. It has been found that neither the impact compaction of the Marshall method nor the kneading compaction used in the Hveem method simulate construction compaction (36).

The two methods of mix design do not produce the compacted HMA mixtures that are related to field performance since both are based on empirical relationships.

Currently, the structural design and the mixture design are considered independently. The structural design of asphaltic concrete pavements is based on assumed material properties (layer stiffness coefficient, resilient modulus, fatigue, and permanent deformation constants). After the structural design has been completed, materials are submitted and a mixture design is completed. The question then becomes: does the asplaced mixture meet the assumptions initially used for the structural design? Unfortunately, the engineering properties used in structural design are not those dealt with or measured in these empirical mixture design procedures. Certainly, asphaltic concrete mixture design and analyses need to be related to those factors that affect asphalt pavement performance. Mixture design and structural design need to be tied together and based on the same criteria and parameters for compatibility (36). 


\subsection{The Improved Mix Design and Evaluation Methods}

\subsubsection{National Cooperative Highway Research Program (NCHRP)}

The highway community has recognized that there is a need for improved procedures and analysis systems for the design of asphaltic concrete mixtures that are resistant to heavy truck loads, to the use of higher tire pressures, and to the wide extremes of climate encountered in the United States. To design mixtures based on performance-related criteria it is necessary to use a test that measures those engineering properties and the characteristics of an asphaltic concrete mixture that are related to a distress or performance measures. In response to this need, research was initiated under National Cooperative Highway Research Program (NCHRP) Project 9-6(1) to develop an AsphaltAggregate Mixture Analysis System (AAMAS) for the laboratory evaluation of asphaltic concrete mixtures based on performance related criteria (30). The distress mechanisms selected for incorporation into AAMAS include rutting, fatigue cracking, low temperature cracking, and moisture damage. Secondary consideration is given to disintegration, such as raveling and loss of skid resistance. Five tests were selected as tools for mixture evaluation in AAMAS, because they measure those properties required by most structural models. These are the diametral resilient modulus test, the indirect tensile strength test, the gyratory shear strength test, and the indirect tensile and uniaxial unconfined compression creep tests.

\subsubsection{The Strategic Highway Research Program (SHRP) Asphalt Program}


The purpose of the Strategic Highway Research Program (SHRP) Asphalt Program was to achieve a breakthrough in the performance of asphalt pavements. Specific products were improved specifications for asphalt binders and asphalt-aggregate mixtures. The mixture specifications were supported by accelerated performance-related tests that can be used in an asphalt-aggregate mixture analysis system $(37,38,39)$. The SHRP five year asphalt program was initiated in 1987 and was completed in March 1993. The asphalt program was organized into seven main asphalt research contracts (38).

1. A-001: Improved Asphaltic Materials, Experiment Design, Coordination and Control of Experimental Materials

Mission of A-001 and A-006: Prepare model, performance-based specifications for asphalt binders and asphalt-aggregate mixtures, respectively, using the validated results of contracts A-002A, A-003A, A-003B, A-004 and A-005.

2. A-002A: Binder Characterization and Evaluation

Mission: Identify the chemical and physical properties of asphalt binder believed to influence the performance of asphalt-aggregate pavement systems. Refine into test methods those chemical and physical characterization processes that appear to offer the most practical basis for specification testing in terms of: correlation between binder properties, mixture performance and pavement performance established by contracts A-003A and A-005; reliability; cost; and ease of use.

3. A-003A: Performance Related Testing and Measuring of Asphalt-Aggregate Interaction and Mixtures

Mission: Validate in asphalt-aggregate mixtures the candidate relationships 
identified in contract A-002A (and to a lesser extent, A-003B and A-004) between the physical and chemical properties of asphalt binder and asphalt pavement performance (first-stage validation). Develop standardizable, accelerated test methods for asphaltaggregate mixtures that may be employed in a mixture analysis system to support a performance-based specification for mixtures.

4. A-003B: Fundamental Properties of Asphalt-Aggregate Interactions Including Adhesion and Absorption

Mission: Develop a fundamental understanding of the chemistry of the asphaltaggregate bond and how it affects adhesion and water sensitivity. Develop a fundamental understanding of the mechanical and chemical basis of asphalt absorption into highly porous aggregates. Prepare reliable, practical test methods that measure asphalt-aggregate adhesion, water sensitivity and absorption and estimate their effects on pavement performance.

\section{A-004: Asphalt Modification}

Mission: Adapt, as necessary, performance-related methods for binders and mixtures to permit their use with the full range of modified systems. Explore innovative refinery processes to enhance the performance of modified asphalt binders. Develop a modifier evaluation protocol to permit evaluation and selection of modified binder systems that remedy specific pavement performance gaps.

6. A-005: Performance Models and Validation of Test Results

Mission: Validate relationships between asphalt binder and asphalt-aggregate mixture properties and pavement performance (second-stage validation). Establish, on the basis 
of documented field performance data, criteria, limits and requirements that may be used for asphalt binder and asphalt-aggregate mixture specifications. Develop performance prediction models incorporating the properties of asphalt binders and asphalt-aggregate mixtures.

7. A-006: Performance-Based Specifications for Asphalt-Aggregate Mixtures

The SHRP five year asphalt program was completed in 1993. The SHRP tentative binder and mix specifications are being finalized.

\subsubsection{Binder Specification}

The SHRP specification has undergone a number of changes since the first draft. The draft 7G which is the most updated is summarized as follows $(40,41)$ :

The test methods associated with the specification specifically address three distress mechanisms: low temperature cracking, fatigue cracking, and permanent deformation. In addition, an asphalt binder conditioning step is included to simulate long term oxidation of the pavement. The draft 7G identifies 14 different performance grades. These are all based on the maximum seven day average pavement temperature and the lowest anticipated pavement temperature. The number of grading levels reflects more realistic temperature variations and combinations. In addition, many of the new features of this specification, noted below, were included to estimate performance more closely and to make the testing applicable to modified as well as unmodified binders.

1. Dynamic shear measurements are made on neat and thin film oven test (TFOT) or rolling thin film oven test (RTFOT) conditioned samples. Testing is conducted under 
conditions mimicking the highest temperature that the pavement is likely to experience. Specified are minimum stiffness values. These values for the neat and conditional asphalt binders are to ensure that pavements constructed with these binders will not be susceptible to tenderness and permanent deformations, respectively. The tenderness issue arises from the fact that occasionally laboratory aging (TFOT/RTFOT) overestimates the actual aging the asphalt binder undergoes in the hot-mix plant.

2. The dynamic shear theometer is also used to determine the dissipated energies $\left(G^{*}\right.$ $\sin \delta$ ) for aged asphalt binders prepared in a pressure aging vessel at intermediate temperatures where fatigue is a primary distress mechanism.

3. The direct tension test is used to monitor the failure properties of the binders at low temperatures. The tensile failure properties have been found to relate to the fatigue properties of the binder.

4. Low-temperature stiffness properties of the asphalt binder are used to calculate the slope of a mastercurve. The stiffness is related to thermal cracking, and the slope provides insight as to thermal shrinkage cracking, fatigue resistance, and overall binder quality.

5. An upper limit is placed on the viscosity of the asphalt binder at $165^{\circ} \mathrm{C}$ to insure constructability of the mix during mixing and compaction.

6. A maximum mass loss specification is provided to ensure that the binders do not harden excessively as a consequence of volatile losses.

7. From safety considerations, a minimum flash point temperature is included in the specification which is the same for all grades of binders. 
The final version of asphalt binder specification is expected from SHRP in the near future.

\subsubsection{The Mix Specification}

SHRP has developed the SUPERPAVE (Superior Performing Asphalt Pavements) Mix Design System. SUPERPAVE is a comprehensive system for the design of paving mixes tailored to the unique performance requirements dictated by the traffic, environment (climate), and structural section at a pavement site. It facilitates the selection and combination of asphalt binder, aggregate and, where necessary, a modifier to enhance pavement performance (42).

SUPERPAVE (43) encompasses three vertically integrated levels, each more complex then the next, that are intended to address different levels of traffic from low- to highvolume pavements. By incorporating all three mix design levels, predictions are made for rutting, fatigue cracking, and low temperature cracking. The three mix design levels are:

1. Volumetric mix design: A design based on air voids, VMAs, etc., commonly used today.

2. Threshold mix design: Some performance-based tests (which test elastic properties, stiffness, damage, strength/relaxation) are used to decide if a mix is usable.

3. Full-depth performance-based mix design (the highest level of mix design): Performance-based tests (volumetric (hyro-static) test, uni-axial strain test, simple shear test, frequency sweep test, repeated load shear, and indirect tensile) are performed and researchers can predict performance, with time, for given traffic, for given structures, 
and for temperatures to which a given pavement is subjected.

It is the specifying agency which decides what level of mix design a specific pavement requires. SUPERPAVE is applicable to new and recycled, densely graded, hot mixed asphalt mixtures, with or without modified asphalt cement, for use in new construction and overlays. The SUPERPAVE mix design system permits the informed selection of materials and design of paving mixes that meet the requirements contained in performance-based specifications for asphalt binders and asphalt-aggregate mixtures. It provides a compaction method and a series of conditioning procedures and accelerated performance tests to characterize the engineering capabilities of a paving mix. Leahy discussed the procedures and equipments used in the SUPERPAVE in detail (42), a summary of which follows:

\section{Laboratory Compaction}

Gyratory compaction was chosen for several reasons. Testing showed that it simulates field compaction reasonably well. Equipment size and cost make it suitable for both central lab and field control operations. Its use permits "real-time" determination of specific gravity and air voids content during compaction. The SHRP gyratory compactor is very similar in size and appearance to the Texas Gyratory Compactor. Specimens are compacted using a $1^{\circ}$ angle of gyration at a rate of 30 gyrations per minute. Vertical pressure during compaction is 86 psi.

2. Conditioning Procedures for Aging and Moisture Sensitivity

a. Aging: The aging of asphalt-aggregate mixes is very complex but is considered to be the result of two time-related mechanisms acting upon the asphalt binder: the loss of 
volatile components during plant mixing and construction, and the in-situ oxidation of asphalt in the pavement. Aging proceeds for the life of a pavement. The greatest changes however occur during production, laydown, and in the first several years of service.

The primary control on aging in the SUPERPAVE system is through the use of the thin film oven (or rolling thin film oven) test and the pressure aging vessel to measure the long-term propensity of the asphalt binder to aging. Since laboratory mixtures are made with unaged asphalt binders the mixture conditioning must mimic both plant and pavement aging.

The recommended aging procedure for mixtures consists of placing loose mix in a tray (immediately after mixing) to a uniform depth. The mix is held in a forced draft oven for 4 hours at $135^{\circ} \mathrm{C}$, after which the mix is brought to the appropriate compaction temperature and the specinen is compacted. Based upon field validation data, this procedure simulates the aging that takes place through HMA production and about 3 to 5 years of pavement service.

b. Moisture Damage: Moisture damage significantly influences pavement performance, since the effects of moisture on the asphalt-aggregate bond and the integrity of the asphalt binder itself are important in the development of pavement distress in the form of rutting, bleeding and/or ravelling. Therefore, a moisture conditioning procedure for the SUPERPAVE system was developed with two objectives in mind: to determine the susceptibility of an asphalt-aggregate combination to moisture-induced damage; and, assuming the mix surpassed the criteria dictated by the preceding, to moisture condition the specimen for use in performance-based tests for permanent deformation, fatigue and 
low temperature cracking.

The equipment developed for this purpose is referred to as the Environmental Conditioning System (ECS). Essentially, the ECS is a modified triaxial test unit in which the dynamic resilient modulus of a cylindrical or prismatic mixture specimen can be continually measured as moisture is forced through it. The ECS permits evaluation of several factors including:

- degree of saturation;

- water versus vapor as the conditioning fluid;

- temperature cycling including freezing;

- volume change effects (i.e., oversaturation);

- repeated versus static loading; and

- aggregate coating and stripping.

Typical steps in the testing and conditioning of a mixture specimen using the ECS would be the following:

1) after physical parameters are measured (density, voids, etc.), the specimen is placed in a modified triaxial cell.

2) preconditioned (i.e., original) resilient modulus and air permeability are measured.

3) the specimen is saturated to the desired level and its water permeability is measured.

4) the resilient modulus $\left(\mathrm{M}_{R}\right)$ and water permeability $(k)$ are measured at $25^{\circ} \mathrm{C}$ following each conditioning cycle (the number and type of conditioning cycles used are dependent upon the climate anticipated at the site, and may include exposure of the 
specimen to elevated and sub-freezing temperatures).

5) upon completion of the conditioning, the specimen may be visually examined to determine the degree of stripping.

\section{Accelerated Performance Test}

a. Permanent Deformation: Permanent deformation (rutting) in asphalt concrete is caused principally by shear deformation (plastic deformation without volume change) resulting from high shear stresses near the pavement surface. The repeated application of these stresses under conditions of comparatively low mix stiffness is responsible for the accumulation of permanent deformation in the form of longitudinal ruts at the pavement surface. Hence, test equipment and a series of test methods that duplicate the state of stress in the upper portion of the asphalt-bound layer is included in SUPERPAVE to define the propensity of a mix to rut under repeated loading.

The test equipment used in the SUPERPAVE system to measure the permanent deformation and stiffness characteristics of bituminous mixes is termed the simple shear test device. The simple shear test device and specimen configuration have been selected to permit the application of comparatively high shear stresses that exist near the pavement surface at the edges of the tires that may lead to lateral as well as vertical deformation.

The primary components of the simple shear test device are load frame, vertical and horizontal actuators, environmental and confining pressure control systems, and a computer-controlled test operation and data acquisition system. For permanent deformation testing the recommended specimen size is $15 \mathrm{~cm}$ in diameter and 6 to 7.5 $\mathrm{cm}$ in height. However, the simple shear test device can accommodate specimens as large 
as $20 \mathrm{~cm}$ in diameter and $25 \mathrm{~cm}$ in height.

The permanent deformation response of the mix is defined by measuring its nonlinear viscous and elastic material behavior by means of a series of simple shear test on a single specimen. These tests capture critical aspects of this material behavior: specifically, dilatancy in shear, stiffening with increased confining stress, and temperature and rate dependence. In addition, the accumulation of damage in the specimen under repetitive shear stress is determined. A brief description of each simple shear test follows. Non-linear Elastic Behavior - Three test are required to describe the non-linear elastic response of the mix: the simple shear with constant height; the uniaxial; and volumetric. All are conducted at $40^{\circ} \mathrm{C}$.

Simple Shear (Constant Height Test) -- A specimen (15 cm in diameter and 6.3 $\mathrm{cm}$ in height) is maintained at constant height while a very fast shear load $(0.002$ strain per second) is applied. The load is applied very rapidly to ensure that only the elastic response is measured (i.e., virtually no creep occurs in the specimen); and yet slowly enough to avoid inertial effects. The shear siress causes a horizontal displacement, and the axial load is varied to maintain the specimen at constant height.

Uniaxial Strain Test -- The uniaxial strain test is conducted with the same specimen and setup as the simple shear (constant height) test. A circumferential confining pressure is applied to the specimen at a rate of $35 \mathrm{kPa}$ per second, causing its sides to deform. Simultaneously, an axial load is applied to maintain the specimen at constant height. 
Volumetric (Hydrostatic) Test - For the volumetric test the same specimen is used, but it is completely surrounded by a rubber membrane. A ring LVDT is placed around the circumference of the specimen to monitor lateral deformation. A confining pressure is applied to all specimen surfaces at a rate of $35 \mathrm{kPa}$ per second, and the change in perimeter is recorded.

Viscous Behavior -- A single test is required to determine the viscous response of the mix: a frequency sweep in shear mode. The specimen and loading configuration are identical to that of the simple shear (constant height) test, but there is no confining pressure and the test is conducted at several loads frequencies and temperatures. From this test the phase angle $(\phi)$ and complex shear modulus $\left(G^{*}\right)$ of the mix are determined. Damage -- To determine the accumulated damage in shear, the test set-up is identical to that used for simple shear (constant height) test described above. However, the test requires the application of a haversine shear pulse ( 0.1 second $\mathrm{ON}, 0.6$ second OFF) while maintaining constant height. Typically 4000 load applications are applied. The test is conducted at $40^{\circ} \mathrm{C}$.

This series of tests provides material properties that are used in the SUPERPAVE pavement performance prediction models to estimate the amount of rutting of a specific mix in the pavement structure under particular traffic and environmental conditions.

b. Fatigue Cracking: Fatigue cracking in asphalt pavements results from the repeated application of a tensile stress or strain (of less magnitude than the fracture stress or strainat-break under one load application) until failure. There is a unique relationship between the magnitude of the applied stress or strain and the number of cycles to failure. Cracking 
may also result from repetitive stress (or strain) applications when either the total energy or strain energy of distortion reaches some limiting value regardless of the mode of loading.

Since in-service pavements are subject to bending stresses, flexure is a reasonable mode of loading to define the fatigue response in the laboratory. Indeed, a substantial amount of SHRP-sponsored research has been conducted with the well-known flexural beam fatigue apparatus in both the validation and test development areas. However, the practical considerations of routine mix design require a surrogate test for fatigue cracking in the SUPERPAVE system that employs cylindrical specimens and that may be conducted more quickly than the flexural beam test.

The surrogate test selected for estimation of fatigue cracking in the SUPERPAVE system is the same frequency sweep as in a shear mode employed to determine the viscous behavior of the mixture for characterization of permanent deformation. This test, conducted in the simple shear device, measures the mix stiffness and phase angle $\left(S_{\operatorname{mix}}\right.$ and $\phi$ ) over a range of frequencies and temperatures.

The results of this surrogate test are used in regression relationships developed from a database of flexural beam fatigue test results on both unmodified and modified mixtures. These regression relationships permit the correlation of the initial strain level, mixture stiffness and phase angle to the initial dissipated energy per loading cycle and, ultimately, to an estimate of the number of loading cycles at which failure will occur. The test protocol is essentially that described above in the section under Permanent Deformation titled Viscous Behavior. 
c. Thermal Cracking: Low temperature cracking of asphalt pavements occurs when the tensile stress, caused by a drop in temperature, exceeds the tensile strength of the paving mixture. Low temperature cracking may also occur as a result of thermal cycling at temperatures above the low temperature fracture point. In this case, failure does not occur immediately, as in the first instance, but develops over an extended period of time aralogous to the time required for load-induced fatigue cracking to develop in asphalt concrete.

A substantial amount of SHRP-sponsored research has been undertaken in both the validation and test development areas using the thermal stress restrained specimen test (TSRST). The TSRST permits measurement of the temperature at which low-temperature fracture occurs; it also permits an estimation of the fracture strength of the mixture as well as the slope of the stress-temperature relationship. However, it requires 4 to 8 hours to complete a test, and yields test results that are difficult to use in the mechanistic models produced to estimate the development of low-temperature cracking over the service life of asphalt pavements.

Therefore, the indirect tensile creep test (IDTC) has been selected for routine mix design in the SUPERPAVE system. The IDTC test employs cylindrical specimens and a complete test sequence for mix design purposes can be conducted in about 1 hour. The IDTC test results yield the master compliance curve and failure limits (strength, strain or energy) of the mix as a function of temperature.

IDTC specimens are typically tested at $0,-10$ and $-20^{\circ} \mathrm{C}$. The testing is conducted in two steps: a short term creep test followed by a test to failure (at each temperature) at a 
constant rate of deformation. In the creep test, a constant diametral compressive load is held on the specimen for 1000 seconds; the horizontal and vertical deformation strains are measured near the center of both flat faces. Loads are selected to keep strains in the linear viscoelastic range (typically below 300 microstrain). The failure portion of the test follows immediately thereafter. Without releasing the creep load, the specimen is failed by applying a constant rate of deformation to failure.

The test results are the average 1000 -second creep compliance curves at three temperatures (from which a master compliance curve is obtained) and the average tensile strengths at three temperatures. These data are transformed to produce a master relaxation modulus curve and the relationship between failure strength and temperature. These transformed material properties can be used in a computational model to predict an initial cracking temperature as well as the amount (or frequency) of cracking as a function of time over the anticipated service life of the pavement.

\section{Field Control Tests}

Field control tests and procedures are also being developed to enable the user agency and contractor to ensure compliance of the mix and in-place pavement with the design requirements. At present, the use of volumetric parameters and the SHRP gyratory compactor is anticipated as the primary control tools. Production of a field version of the simple shear test device is also being explored. This topic will receive continued attention in the post-SHRP period through the new NCHRP Project 9-7 (44), Field Procedures and Equipment to implement SHRP Asphalt Specification. 


\section{THE BOTTOM ASH SAMPLING AND TESTING PROGRAM}

\subsection{Introduction}

Variations in test results on paving materials and mixtures, to some extent, depend on variability of materials. Hence, it is necessary to evaluate variability of bottom ash as it is produced.

Good quality control and quality assurance practices are essential if bottom ash as produced in a MSW facility is to be accepted as a satisfactory product. Figure 3.1 presents the quality control concept (45). A manufacturing process (1) leads to immediate or end products (2). Information (3) is acquired about the process and product, and decisions (4) are reached as to whether the product is satisfactory or not. For many reasons it is impossible to acquire complete information about a process or product. Thus decisions must necessarily be based on partial information. Finally, decisions will ordinarily lead to actions (5) such as product acceptance or rejection and perhaps to changes in the manufacturing process.

This chapter presents the bottom ash sampling and testing program and Chapters IV and $V$ present the data evaluation.

\subsection{Waste-to-Energy Facility}

The Wheelabrator-Concord L.P. waste-to-energy facility is a 500 ton per day, mass 


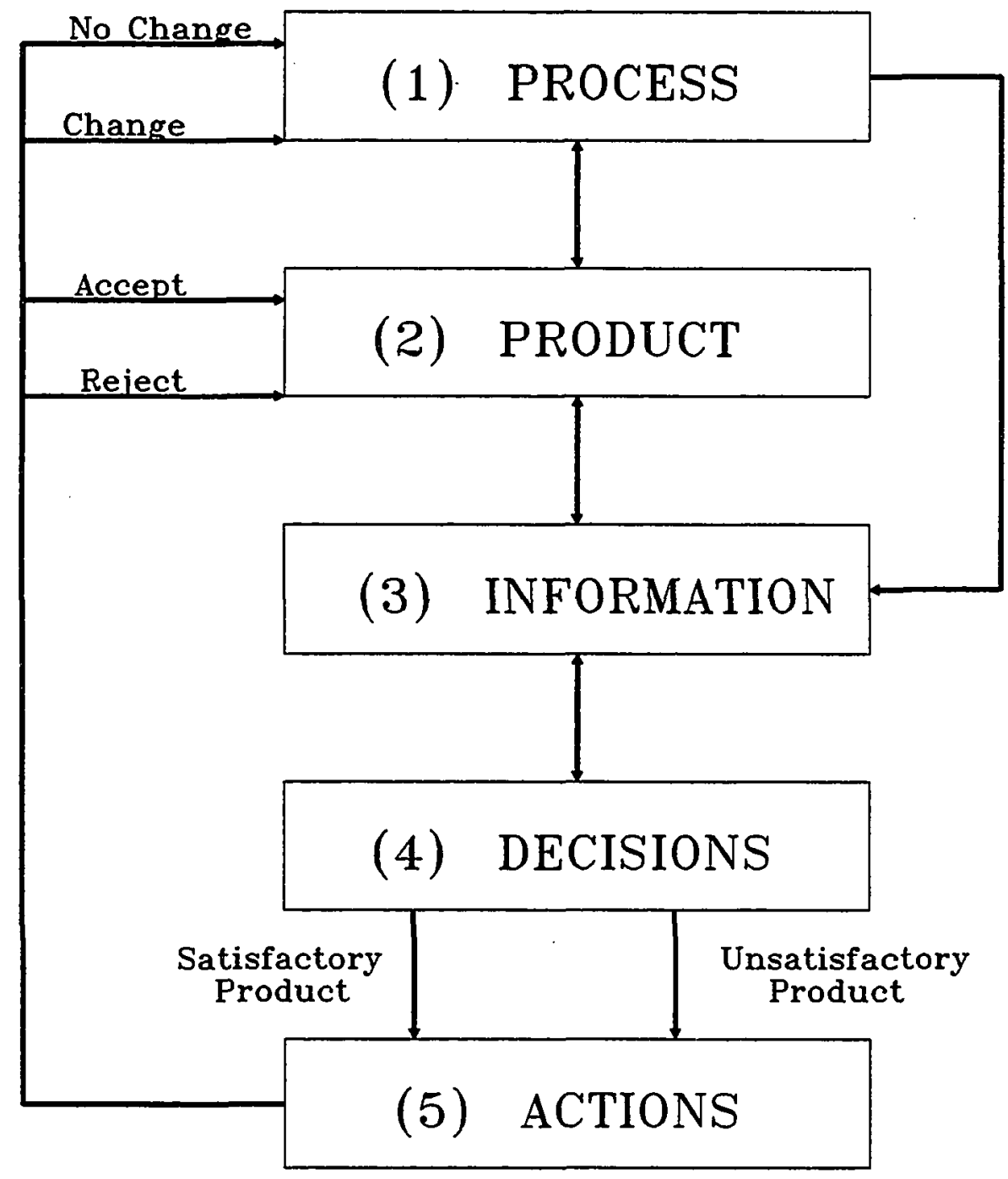

Figure 3.1 Quality Control Concept (Ref. 45) 
burn facility located in Penacook, NH. It services the 27 member communities of the Concord Regional Solid Waste/Resource Recovery Cooperative. The plant, in operation since 1989 , presently disposes its various ash residue in a secure, dedicated ash landfill in Franklin, $\mathbf{N H}$.

The waste-to-energy facility consists of two combustor and air pollution control trains; each consisting of crane-fed ram loaders, von Roll reciprocating stoker grates with primary underfire and secondary overfire combustion control, Babcock and Wilcox superheater, boiler, and economizer heat-exchangers, dry lime venturi scrubbers, and pulse-cleaned Wheelabrator Air Pollution Control fabric filter modules in bag houses. Each unit has a quench tank and drag chain conveyor to quench the bottom ash stream (containing bottom ash, grate siftings, riddlings, and economizer ash). Figure 3.2 graphically illustrates the Waste-to-Energy Facility in Penacook, NH.

The plant produces approximately 170 tons per day of wet bottom ash containing oversize ferrous, non-ferrous, and uncombusted material. During sampling, the economizer heat exchange double door was kept closed to prevent this ash from entering the bottom ash process stream. Prior to sampling, the quench tank was cleaned so only representative bottom ash from the specified combustor was sampled.

\subsection{Bottom Ash Sampling Program}

With the goal of achieving a representative sample which should be physically and chemically equivalent to the whole, the sampling program was designed to evaluate hourly, daily, weekly, monthly, and yearly physical and chemical characteristics of the 


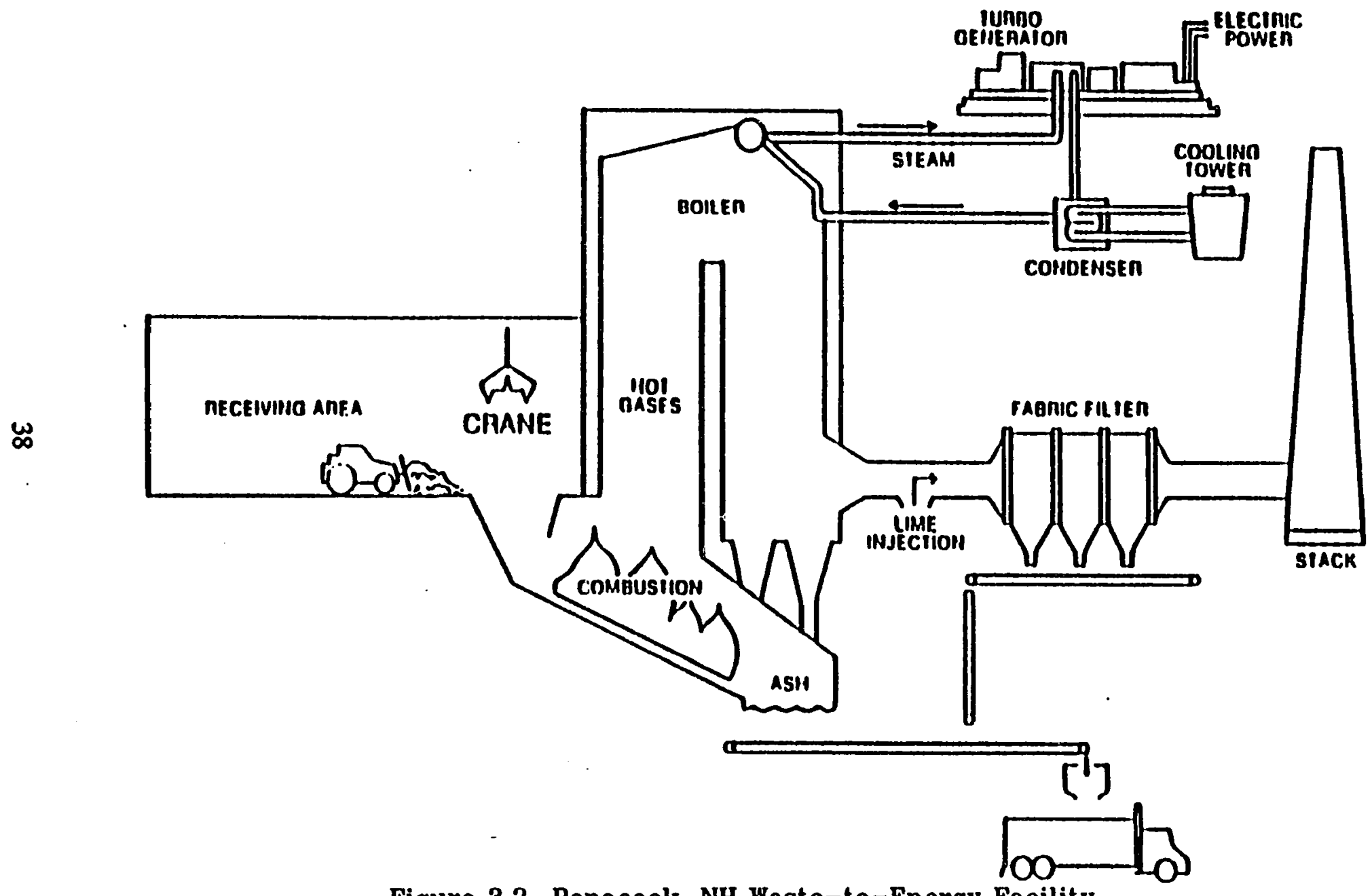

Figure 3.2 Penacook, NH Waste-to-Energy Facility 
bottom ash as it was produced at the facility. Facility personnel assisted in the sampling and temporary storage of the materials at the plant. A secure storage room at UNH was utilized to store the samples collected on a scheduled basis.

As shown in Table 3.1, 18 different sampling events were conducted from October, 1990 through April, 1992. The sampling dates were distributed on the days of the week as follows: Monday, 3; Tuesday, 4; Wednesday, 4; Thursday, 3; Friday, 4. Sampling was not conducted on Saturday or Sunday because of manpower requirements at the plant. The sampling data had the following monthly distribution: January, 1; March 2; April, 2; June, 1; August, 1; October, 5; November, 4; December, 2. This provided a balanced distribution between months, seasons, and times when incoming MSW to the plant was predicted to vary due to moisture.

All sampling was conducted over a four to five hour consecutive period usually beginning the morning of the sampling day. Sampling one unit while diverting scrubber residue to the other unit tended to be a necessary but significant disruption to existing plant operation. Sampling during morning hours was a compromise between disruption and completely randomized sampling.

Figure 3.3 depicts the sampling protocol that was used for each of the sampling visits. The four hour period was separated into four consecutive hourly sampling events. For each hourly sampling event, plant personnel randomly collected 40 to $60 \mathrm{lbs}$ of bottom ash off of the drag chain conveyor during the first 3 to 4 minutes of a ten minute period. This was repeated for the second, third, fourth, fifth, and sixth ten minute periods of the hour. A shovel was used to randomly collect material off the flights as they moved 
Table 3.1 Sampling Events

\begin{tabular}{|l|l|l|l|l|l|l|}
\hline $\begin{array}{l}\text { Sampling } \\
\text { Event } \\
\text { Number }\end{array}$ & Date & Day of Heek & $\begin{array}{l}\text { Time of } \\
\text { Sampling }\end{array}$ & $\begin{array}{l}\text { Combustor } \\
\text { Unit Sampled }\end{array}$ & $\begin{array}{l}\text { Total Sample } \\
\text { Collected } \\
\text { (b (kg) }\end{array}$ & Comment $^{\text {a }}$ \\
\hline 1 & $10 / 3 / 90$ & Hed. & $10: 45-14: 50$ & 1 & $1,510(685)$ & 1 \\
\hline 2 & $10 / 11 / 90$ & Thur. & $09: 35-13: 45$ & 182 & $1,051(477)$ & 1 \\
\hline 3 & $10 / 19 / 90$ & Fri. & $11: 50-15: 50$ & 1 & $1,080(490)$ & 1 \\
\hline 4 & $10 / 29 / 90$ & Mon. & $09: 45-14: 15$ & 2 & $1,058(480)$ & 2 \\
\hline 5 & $11 / 5 / 90$ & Mon. & $09: 20-13: 20$ & 2 & $705(321)$ & 1 \\
\hline 6 & $11 / 29 / 90$ & Thur. & $10: 00-14: 00$ & 2 & $813(369)$ & 1 \\
\hline 7 & $12 / 7 / 90$ & Fri. & $10: 00-14: 00$ & 2 & $887(403)$ & 1 \\
\hline 8 & $1 / 29 / 91$ & Tues. & $09: 30-13: 30$ & 2 & $1,045(474)$ & 2 \\
\hline 9 & $3 / 26 / 91$ & Tues. & $11: 30-16: 00$ & 2 & $937(425)$ & 2 \\
\hline 10 & $4 / 24 / 91$ & Hed. & $09: 00-13: 00$ & 2 & $939(426)$ & 1 \\
\hline 11 & $6 / 17 / 91$ & Mon. & $10: 45-14: 45$ & 2 & $956(434)$ & 1 \\
\hline 12 & $8 / 2 / 91$ & Fri. & $14: 30-17: 30$ & 2 & $1,280(581)$ & 2 \\
\hline 13 & $10 / 1 / 91$ & Tue. & $09: 30-14: 10$ & 1 & $1,006(456)$ & 1 \\
\hline 14 & $11 / 5 / 91$ & Tues. & $09: 30-13: 40$ & 2 & $1,039(472)$ & 2 \\
\hline 15 & $11 / 20 / 91$ & Hed. & $11: 00-14: 00$ & 2 & $1,047(475)$ & 1 \\
\hline 16 & $12 / 18 / 91$ & Hed. & $11: 20-15: 20$ & 2 & $1,050(477)$ & 3 \\
\hline 17 & $3 / 20 / 92$ & Fri. & $08: 40-12: 40$ & 2 & $1,750(794)$ & 3 \\
\hline 18 & $4 / 2 / 92$ & Thur. & $09: 15-13: 05$ & 2 & $810(367)$ & 1 \\
\hline & & & & & \\
\hline
\end{tabular}

a The comments are subjective evaluations of the degree of burnout based on the relative presence of unburned material on the drag chain and/or sieve screen. $1=$ good, 2 = fair, and $3=$ Marginal. 


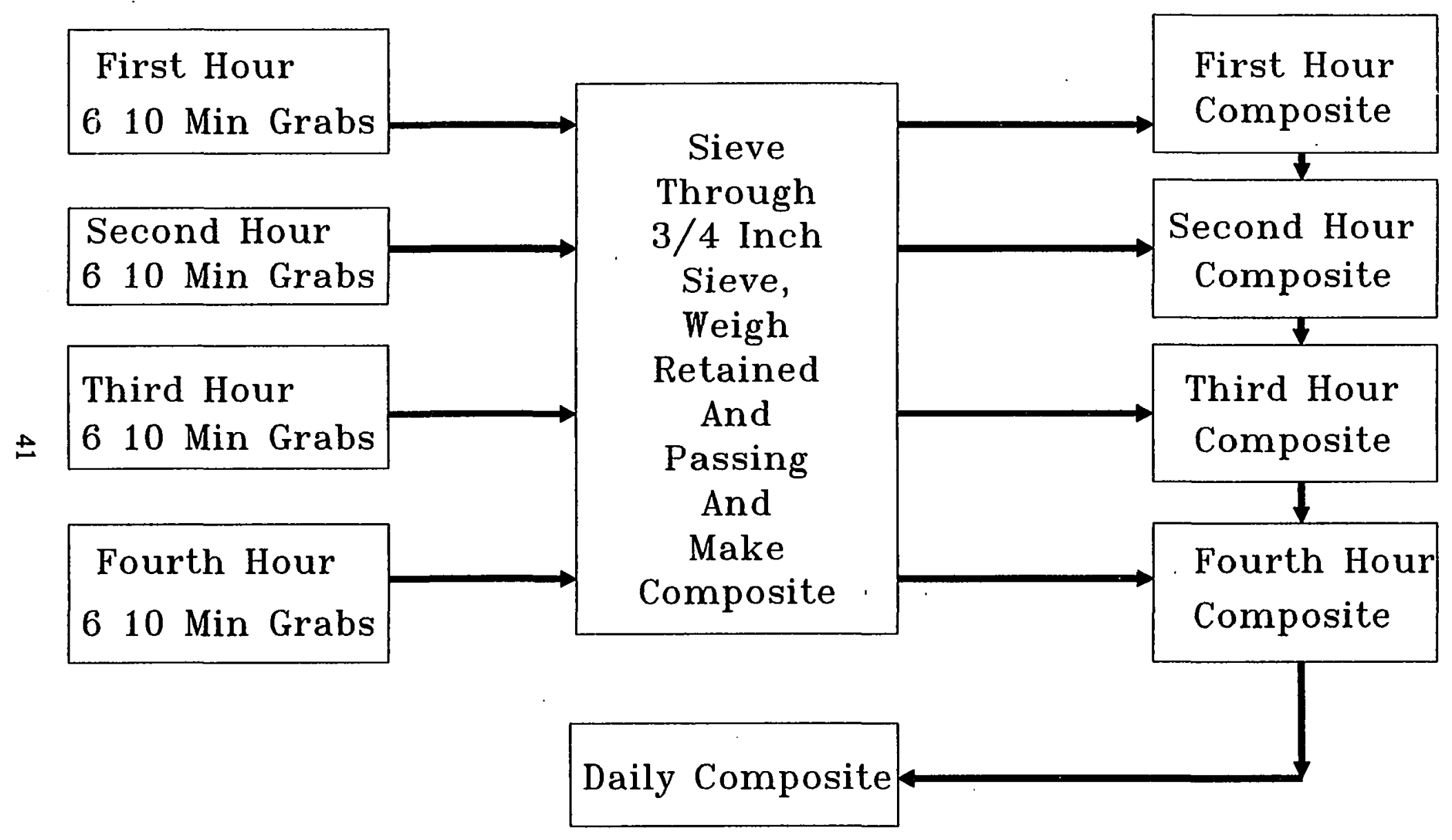

Figure 3.3 Bottom Ash Sampling 
past the station. Objects larger than the shovel were not collected.

For each of the six 10 minute increments during the hour, the material was sieved as received through a $3 / 4^{\prime \prime}$ sieve over a large barrel, producing a stream passing the sieve and a stream being rejected from the sieve. At the end of the hour, 240 to $360 \mathrm{lbs}$ were sieved, producing approximately $200 \mathrm{lbs}$ of wet $<3 / 4^{n}$ bottom ash and $150 \mathrm{lbs}$ of rejected $\geq 3 / 4^{n}$ material. Scales were used to weigh both the passed and rejected material. Approximately $4 \%$ of the total bottom ash process stream from the combustor was collected each hour for sieving.

It was noticed that ash samples were collected at high moisture content due to the ash being processed through a quench tank after dropping out of the boiler. The collected bottom ash was dumped onto a plastic tarp and throughly hand-mixed with shovels to mix the sample. At that time a $10 \mathrm{lb}$ subsample was collected for moisture determination. It was stored in two zip-lock bags to create an hourly composite. The $<3 / 4^{\text {n }}$ material was then transferred to four or five clean 5 gallon (18 liter) pails for transport back to the University.

This process was repeated again for the second, third, and fourth hours. Table 3.1

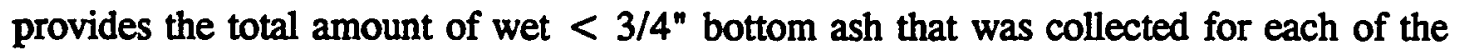
eighteen days.

Combustor operation was monitored for each sampling event. This included evaluation of combustion temperature; air preheat temperature; over and underfire airflow; economizer outlet temperature; and economizer outlet opacity, $\mathrm{CO}, \mathrm{O}_{2}$.

As indicated in Figure 3.3, the four hourly composites were sampled to generate a 
daily composite. Approximately $30 \mathrm{lbs}$ were collected from the four to five sample buckets from each hourly composite, added to a concrete mixer, and blended to make a daily composite containing approximately $120 \mathrm{lbs}$ of bottom ash. Large subsamples of the hourly and daily composites were collected and dried in a large drying oven for subsequent analysis. The remaining hourly and daily composites were stored wet as archived samples.

\subsection{Bottom Ash Testing Program}

Physical and environmental tests were conducted on the bottom ash collected during the 18 sampling events. Only the physical tests are included in this dissertation. The physical tests were selected to characterize the material's fundamental properties, behavior in asphaltic concrete, and behavior as granular material in subbase, stabilized base or other applications. The physical tests undertaken in this study are mostly standard tests specified by the American Society for Testing and Materials (ASTM). Some physical tests were performed based on modified ASTM methods. The modified and special tests were selected over standard tests to better characterize the bottom ash properties. Some of the tests results were used for production rate and economical evaluation. Table 3.2 provides the selected tests, ASTM method and the frequency of analysis. The majority of the methods were conducted on each hourly composite (72 analyses) and each daily composite (18 analyses). Some of the more intensive analyses were conducted on selected daily composites. The methods listed in Table 3.2 are briefly discussed:

Mass < 3/4": Separation on the 3/4n sieve was selected to create bottom ash that 
Table 3.2 Physical Testing Methods and Frequencies

\begin{tabular}{|c|c|c|c|}
\hline Test No. & Parameter & Method & Frequency \\
\hline 1 & Mass $<3 / 4^{\prime \prime}$ & 3/4" Wet Sieve & $\mathbf{H}$ \\
\hline 2 & Moisture Content & ASTM D2216 & $\mathbf{H}$ \\
\hline 3 & Bulk (Dry) Specific Gravity, Fine & ASTM C128 & $\mathrm{H}, \mathrm{D}$ \\
\hline 4 & Bulk (Dry) Specific Gravity, Coarse & ASTM C128 & H,D \\
\hline 5 & Bulk (SSD) Specific Gravity, Fine & ASTM C128 & $\mathrm{H}, \mathrm{D}$ \\
\hline 6 & Bulk (SSD) Specific Gravity, Coarse & ASTM C127 & H,D \\
\hline 7 & Apparent Specific Gravity, Fine & ASTM C128 & $\mathrm{H}, \mathrm{D}$ \\
\hline 8 & Apparent Specific Gravity, Coarse & ASTM C127 & H,D \\
\hline 9 & Absorption, Fine & ASTM C128 & H,D \\
\hline 10 & Absorption, Coarse & ASTM C127 & $\mathrm{H}, \mathrm{D}$ \\
\hline 11 & Loss on Ignition & ASTM C114 & $\mathrm{H}, \mathrm{D}$ \\
\hline 12 & Ferrous Content & Hand Magnet & H,D \\
\hline 13 & $\begin{array}{l}\text { Grain Size Distribution of Fine and } \\
\text { Coarse Aggregates }\end{array}$ & ASTM C136 & $\mathrm{H}, \mathrm{D}$ \\
\hline 14 & Uniformity Coefficient & ASTM C136 & $\mathrm{H}, \mathrm{D}$ \\
\hline 15 & Effective Size & ASTM C136 & $\mathrm{H}, \mathrm{D}$ \\
\hline 16 & The Los Angeles Abrasion (Grade B) & ASTM C131 & $\mathbf{s}$ \\
\hline 17 & The Los Angeles Abrasion (Grade C) & ASTM C131 & $\mathbf{s}$ \\
\hline 18 & Soundness, Fine & ASTM C88 & $\mathbf{s}$ \\
\hline 19 & Soundness, Coarse & ASTM C88 & $\mathbf{s}$ \\
\hline 20 & CBR at 0.1 inch & ASTM D1883 & D \\
\hline 21 & CBR at 0.2 inch & ASTM D1883 & D \\
\hline 22 & Optimum Proctor Moisture Content & ASTM D1557 & D \\
\hline 23 & Maximum Proctor Density & ASTM D1557 & $\mathbf{D}$ \\
\hline 24 & Unit Weight and Voids in Aggregate & ASTM C29 & $\mathbf{D}$ \\
\hline
\end{tabular}

- $\mathrm{H}=$ every hourly composite, $\mathrm{D}=$ every daily composite, and $\mathrm{S}=$ selected daily composites. 
could meet NH DOT type B binder or base course mixes. The upper limit of aggregate size is $3 / 4^{n}$ for a type B binders. The $3 / 4^{n}$ sieve used was the U.S. standard sieve Gilson tray with a dimension of $18^{\prime \prime}$ (width) $\times 26^{\prime \prime}$ (length) $\times 2.5^{\prime \prime}$ (Height). The wire screen meets the requirements of ASTM Designation E11. About one quarter of the bottom ash collected over a period of every $10 \mathrm{~min}$ was processed at a time. The $3 / 4^{\prime \prime}$ sieve with the bottom ash in it was vibrated by hand by two operators until no noticeable materials passed through (approximately $2 \mathrm{~min}$.).

Moisture Content (ASTM 2216): This test was performed as per ASTM D2216 modified slightly to allow for twice the amount of oven time as it was observed that a 24 hour period was not long enough to dry the center of the ash clusters. Moisture measurements are required to evaluate the ability to process the materials, and to understand bottom ash carrying capacity, aging reactions, handling and drying requirements for asphaltic concrete batching.

Specific Gravity and Absorption of Coarse Aggregate and Fine Aggregate (ASTM C127 and C128, respectively): The bulk specific gravity, apparent specific gravity, the bulk specific gravity (saturated-surface dry (SSD)) and absorption after 24 hours soaking in water were determined with the methods described below. The bottom ash was separated into coarse aggregate and fine aggregate fractions with the No.4 sieve. The tests were conducted per ASTM C127 and ASTM C128, respectively.

1). Bulk Specific Gravity, Dry: This is the ratio of the oven dry weight in air of a unit volume of a permeable material (including both permeable and impermeable voids) at a stated temperature to the weight of an equal volume of gas-free water at a stated 
temperature.

Bulk specific gravity (dry) is used in the computations of the voids in mineral aggregate (VMA) and absorbed asphalt in asphalt concrete design. Bulk specific gravity is also used in the computation of voids in aggregate.

2). Bulk Specific Gravity, SSD: This is the ratio of the saturated surface dry (SSD), weight in air of a unit volume of a permeable material (including both permeable and impermeable voids of the material) at a stated temperature to the weight of an equal volume of gas-free water at a stated temperature.

Bulk specific gravity (SSD) is not required in the design of asphalt concrete. However, it was used in this study in an attempt to better understand the porous aggregate properties of the residues.

3). Apparent Specific Gravity: This is the ratio of the oven dry weight in air of a unit volume of a material neglecting all permeable voids at a stated temperature to the weight of an equal volume of gas-free water at a stated temperature. In the design of asphalt concrete, this value is normally used for weight to volume calculations of the mineral filler only, since bulk specific gravity values of this fraction are very difficult to obtain. This information was gathered for data completeness.

4). Absorption: Absorption values are used to calculate the change in the weight of an aggregate due to water absorbed in the permeable pore spaces within the constituent particles. The absorption of water can be used to predict the potential for excess asphalt absorption. As water absorption increases, the asphalt absorption increases.

Loss on Ignition (ASTM C114): This is the percent weight loss of an oven dry 
material ignited in a muffle furnace at a controlled temperature. ASTM C114 procedures are modified to better characterize bottom ash. Ten grams of material passing a No.4 sieve were ashed at $550-600^{\circ} \mathrm{C}$ temperature. The loss is assumed to represent the organic content in the materials. Loss on Ignition (LOI) affects the engineering properties of materials.

Ferrous Content: A test procedure involving a small but powerful magnet to remove the ferrous material. The material is oven-dried at $110^{\circ} \mathrm{C}$ for 48 hours and then about 800 $\mathrm{g}$ of moisture-free material is used. The magnet was passed slightly over as well as through the sample until it no longer picks up any ferrous material. The metal is removed, weighed, and expressed as a percent of the total dry weight.

Ferrous content measurements help to determine the potential for additional metal recovery and for quantification of potential oxide surfaces.

Grain Size Distribution of Fine and Coarse Aggregates (ASTM C136): The grain size distribution is determined by passing the material through a standard series of sieves stacked with progressively smaller openings from top to bottom and weighing the material retained on each sieve. The gradation of an aggregate is normally expressed as percent passing various sieve sizes. The bottom ash contains both coarse aggregate and fine aggregate fractions. The ASTM test was followed with a modification made to allow for a sieve analysis to be run on the entire ash sample at once instead of performing two tests, splitting the bottom ash into coarse $(\geq$ No.4) and fine ( $<$ No.4) aggregate samples as specified. That is, about 800 to $1000 \mathrm{~g}$ of moisture free bottom ash (coarse and fine) was sieved through a set of NH state specified sieves $\left(3 / 4^{n}, 1 / 2^{n}, 3 / 8^{n}\right.$, No.4, No.10, 
No.20, No.40, No.80, No.200).

The effective size and the uniformity coefficient are calculated based on the sieve analysis results. The effective size is the grain diameter (in $\mathrm{mm}$ ) corresponding to the size which has $10 \%$ passing by weight. Coefficient of uniformity is the ratio of the grain diameter (in $\mathrm{mm}$ ) corresponding to $60 \%$ passing by weight to the effective size (in $\mathrm{mm}$ ).

The Los Angeles (L.A.) Abrasion Test (ASTM C131): This test is performed by mixing $5000 \mathrm{~g}$ of aggregate blended to meet one of several gradations with a charge of $6-12\left(1.84^{\prime \prime}\right.$ in diameter) steel balls (10 were used in this project). This mix is tumbled inside a $28^{n}$ steel drum for 500 revolutions at a speed of $30-33 \mathrm{rpm}$. After tumbling, the fines that pass a No.12 sieve are weighed, and the percentage loss by weight of original sample is calculated as the Los Angeles abrasion. Initially, none of the material passes No.12 sieve as required of the test.

The L.A. abrasion test is a measure of degradation of aggregate resulting from a combination of actions including abrasion (attrition), impact and grinding in the steel drum. This test can be used to obtain an indication of the toughness and abrasion characteristics of a granular material.

Soundness Test (ASTM C88): This test involves submerging the aggregate in a solution of sodium or magnesium sulfate (sodium sulfate in this project). Salt crystals grow after drying in the permeable pores and cause particles to disintegrate. Five cycles of drying and thawing were used in this project.

The California Bearing Ratio (ASTM D1883): This test is a penetration test wherein a standardized piston, having a circular end area of 3 inch $^{2}$ is caused to penetrate 
laboratory-compacted specimens at a standard rate of 0.05 inches per minute. The stresspenetration curve is plotted and the California Bearing Ratio (CBR) is computed as the ratio of an arbitrarily selected stress to that of a standard. The standard values were obtained by testing a high-quality crushed-stone material. The stress generally taken for design is at 0.1 inches penetration. However, if the value at 0.2 inches penetration is higher than that at the 0.1 inches penetration, the value at 0.2 inches penetration should be used. The test is primarily intended for evaluating the strength of cohesive materials having maximum particle sizes less than $3 / 4$ inch. The test is useful if bottom ash is used for base, subbase, or stabilized base materials. The CBR test can be conducted instantly after compaction or after 96 hours of soaking. The reported CBR value should be specified as either soaked or unsoaked.

Proctor Density (ASTM D1557): This laboratory compaction method is intended for determining the relationship between the moisture content and the density of granular material when compacted in a mold of a given size with a $10 \mathrm{lb}$ hammer dropped from a height of 18 inches. The optimum moisture content is the moisture content at which the maximum dry density is obtained. The test is useful if bottom ash is used for base, subbase or stabilized base materials.

Unit Weight and Voids in Aggregate (ASTM C29): This is intended for determining unit weight in compacted or loose condition (compacted in this project), and calculated voids in aggregate. The unit weights are used for determining mass/volume relationships. The test is useful if the bottom ash is used as aggregate in portland cement concrete. 


\section{THE EVALUATION OF BOTTOM ASH PHYSICAL PROPERTIES}

Sieve analysis and physical property results of the current research are presented in APPENDICES A and B. In this chapter, physical properties of bottom ash are evaluated and compared with those of other studies and of conventional paving materials. Aspects related to mix design and performance are also discussed.

\subsection{Composition Characterization}

The composition characterization was investigated by looking at visual classification, moisture content and loss on ignition (LOI).

\subsubsection{Visual Classification}

To test the potential heterogeneous nature of ash, a representative sample was created by blending 18 daily samples. The composite was screened through a No.4 sieve to remove any materials with particles smaller than No.4 $(4.75 \mathrm{~mm})$ because it is difficult to visually identify $<$ No.4 particles. The results for the material retained on the screen indicated bottom ash contained $32.2 \%$ clinker, $36.6 \%$ clinker with iron, $22.9 \%$ glass, 4.1\% iron, $1.6 \%$ ceramics and $2.5 \%$ other materials including non-ferrous metals (aluminum, copper, etc.), rock, brick pieces, concrete, wood, bone fragments, paper, chalk etc., as shown in Figure 4.1. The average composition of ash residues of $2^{n}$ to 


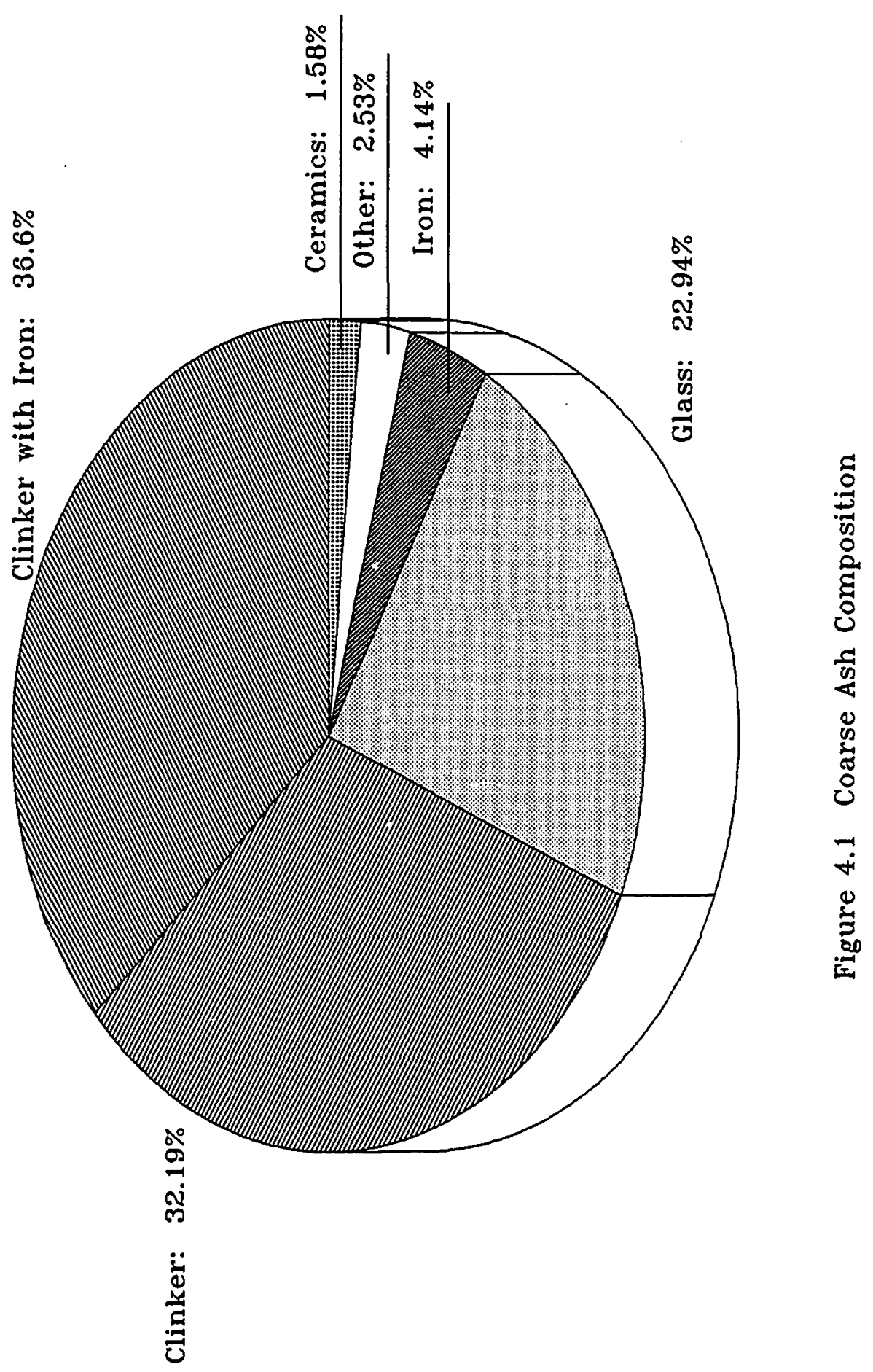


$0.25^{\mathrm{n}}$ fraction reported by Fiesinger et al. (46) comprises of $41.3 \%$ minerals $\&$ ash, $29.2 \%$ ferrous, $22.1 \%$ glass, $3.1 \%$ ceramics, $2.8 \%$ non-ferrous, and $1.4 \%$ combustibles. The composition of ash residue as determined from the U.S. Bureau of Mines Study (47) are, on average, $17.6 \%$ mineral matter, $28 \%$ ferrous, $44 \%$ glass, $9 \%$ combustibles, $1.4 \%$ non-ferrous metal. Ash is a heterogeneous material. The composition of ash varies from sample to sample and facility to facility, and is a function of particle size.

Ferrous content of 72 hourly samples ranged from 11.9 to $39.6 \%$, with an average of $25.9 \%$. However, true ferrous contents are lower than the data collected here show. It was found that the non-ferrous materials which were combined with the ferrous materials such as clinkers (or fused ash) were also picked up by the magnet. Hence, these clinkers containing ferrous materials were classified as "clinker with ferrous". The ferrous content provided by other study (48) ranges from approximately 9 to $23 \%$ based on visual classification.

Ferrous content measurements are evaluated to determine the potential for additional metal recovery and for quantification of potential oxide surfaces.

\subsubsection{Moisture Content}

Moisture content of 72 hourly samples ranged from 22.4 to $60.6 \%$, with an average of $37.9 \%$. This data compares fairly well with the finding of Collins, et al. in which moisture content of residue samples ranges from 15 to $60 \%$ (12). The moisture content of ash from different plants reported by Fiesinger et al. ranges from 16 to $92 \%$ (46).

It was observed in this study that the freshly-collected bottom ash contained an excess 
of moisture (free water) on the particle surfaces.

The moisture content of natural aggregate materials used in construction application is typically found to be in the range of 3 to $10 \%$ (48). Hence, the moisture content of quenched ash is significantly higher than that of natural aggregate materials used in construction.

\subsubsection{Loss On Ignition (LOD}

LOI of 72 hourly samples ranged from 3.2 to $10.0 \%$, with an average of $6.4 \%$. Another study conducted on combined ash (bottom ash and fly ash) reported LOI values ranging from 4 to $20 \%$ (40). Ormsby suggested that the LOI should be less $10 \%$ for ash to be used as construction materials (14). LOI of the ash used is strongly associated with particle size, increasing significantly with the decreased particie size as shown in Figure 4.2. It was felt that LOI could be lowered by increasing the efficiency of burning. An efficient facility should be capable of achieving LOI below $5 \%$ (46).

The presence of organic materials in aggregates used for construction can affect the performance of the material. The presence of organic impurities in aggregates used in portland cement concrete will affect the hardening and strength development of the concrete (48). The presence of organic impurities in aggregates used as fill, subbase or base material will interfere with selected construction characteristics of the material, such as compressibility and strength (48). Though the presence of organic impurities does not directly affect the physical or environmental performance of the bottom ash in hot mix asphalt, high loss on ignition values can indicate an increased absorptivity of the bottom 
Loss On Ignition, \%

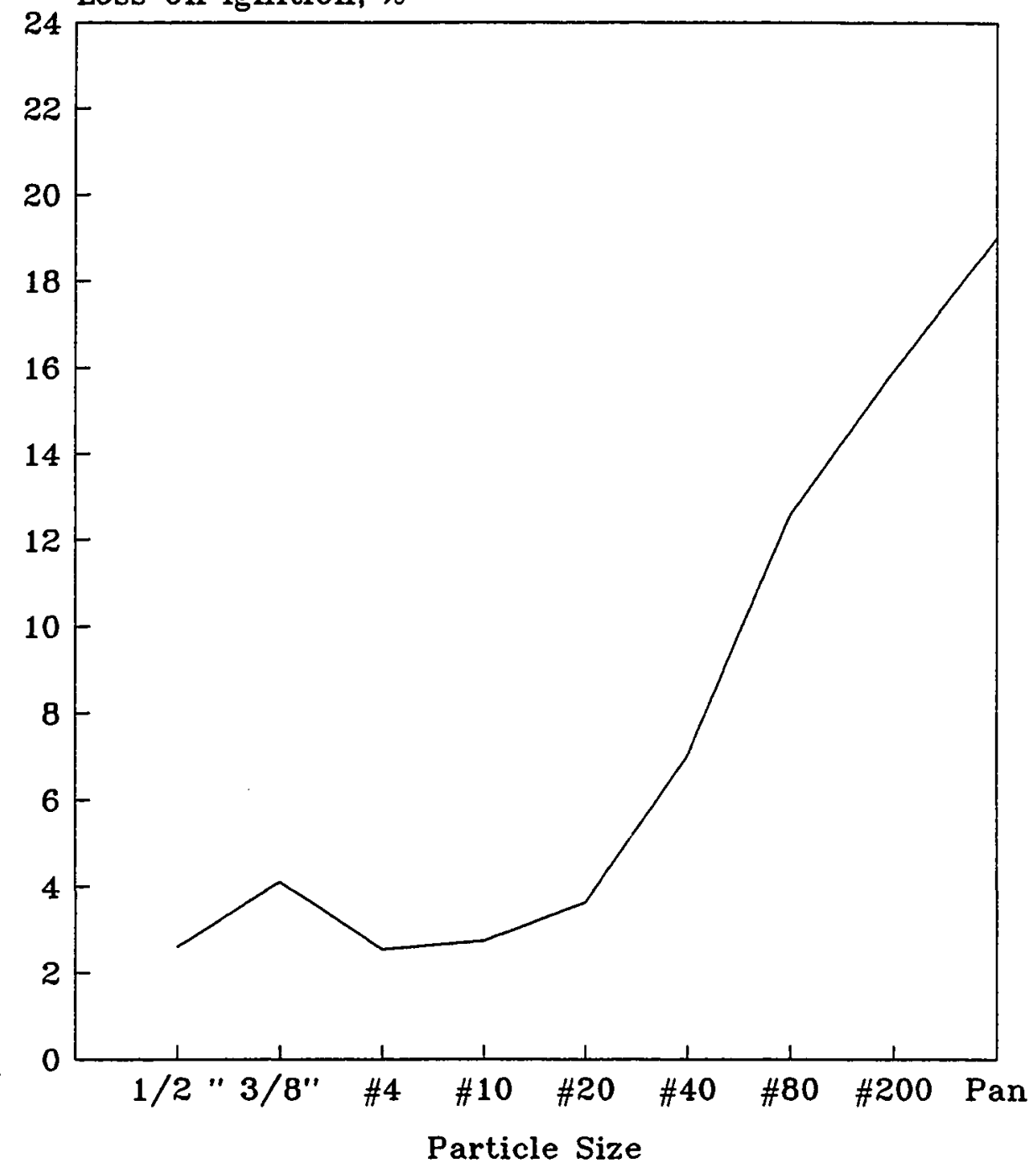

Figure 4.2 LOI versus Particle Size

54 
ash of both water and asphalt cement.

The conventional aggregates (Pike aggregates) used in this study, which will be described in Chapter VI, has a LOI of $0.51 \%$. The LOI of bottom ash was much higher than that of the conventional aggregates.

\subsection{Gradation Characterization}

\subsubsection{Comparison With Other Studies}

Gradation is one of the most important properties of an aggregate. It directly or indirectly affects almost all the properties of an asphalt concrete, including stiffness, stability, durability, permeability, workability, fatigue resistance, skid resistance, and resistance to moisture damage (34). In portland cement concrete, it affects aggregate proportions, cement and water requirements, pumpability, economy, porosity, shrinkage, and durability of concrete (48). In unbound granular bases and subbases, it affects the stability and the frost susceptibility of the bases or subbases (48).

Figures 4.3 and 4.4 compare the average gradation of 72 hourly bottom ash samples from the Penacook facility with a New Hampshire specification for type B base or binder mix and those provided from a number of other studies $(4,10,12,15,16,17,18,48)$.

The gradation of bottom ash meets $\mathrm{NH}$ specification. This suggests that, based on gradation alone, bottom ash passing $3 / 4$ inch could provide $100 \%$ of the aggregate in a job mix formulation. All gradation curves are quite similar, suggesting that bottom ash tends to be well graded. 


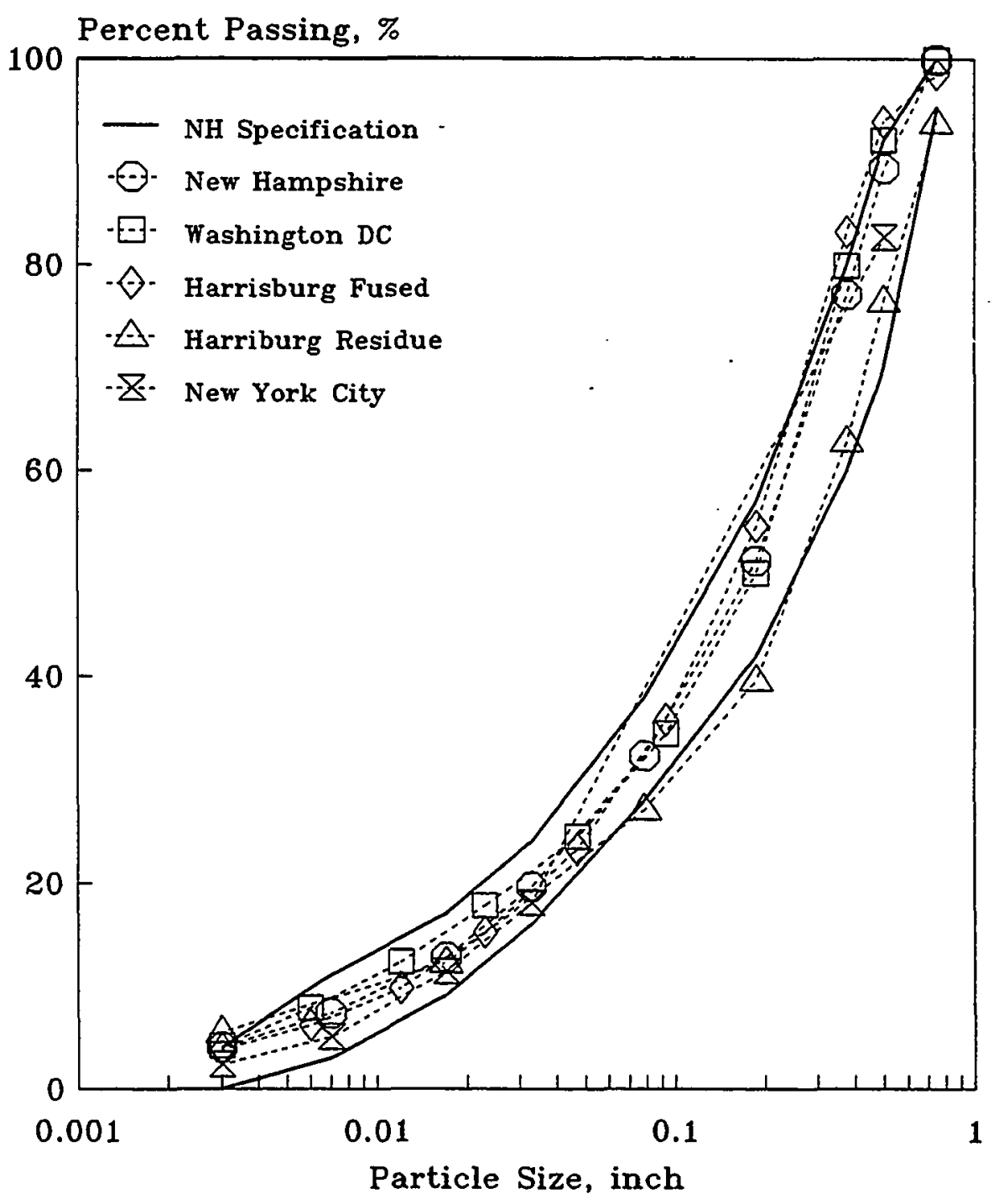

Figure 4.3 Ash Studies (Average Gradation) 


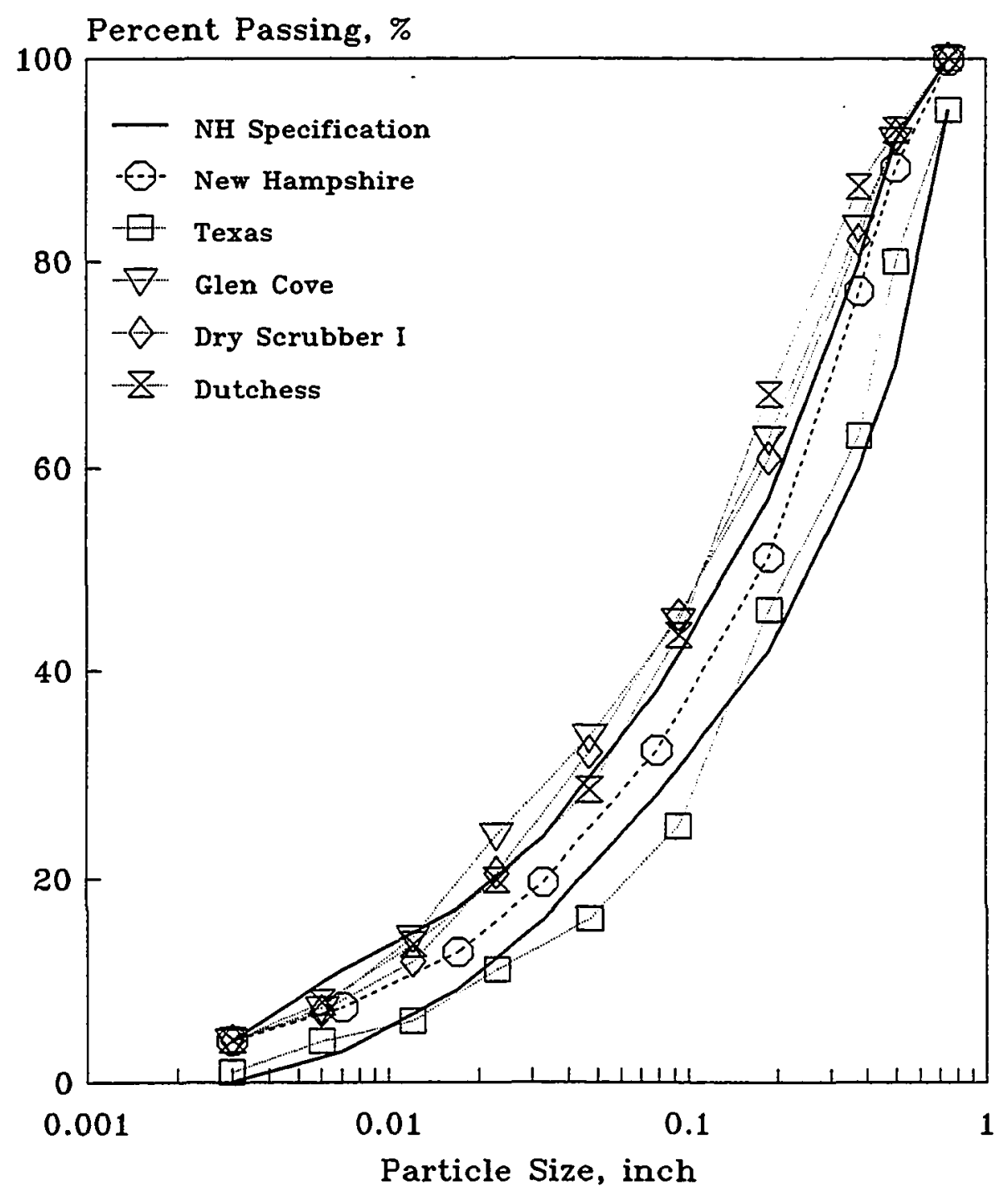

Figure 4.4 Ash Studies (Continued) 


\subsubsection{Uniformity Coefficient}

Uniformity coefficient is sometimes used as a measure of the relative distribution of particle sizes in a soil sample. A well-graded mixed soil containing particle sizes ranging from gravel to clay will have a uniformity coefficient of 25 or greater. A well-graded sand will have a uniformity coefficient greater than 6 (48).

Uniformity coefficient of 72 hourly samples ranged from 8.3 to 34.0 , with an average of 21.7. The uniformity coefficient was found sensitive to gradation variation. It would be more informative to look at gradation curve rather than uniformity coefficient.

\subsubsection{Washed versus Dry Sieving}

In that small particles can cling to or clog the screen during sieving or stick to big particles, a washed sieve analysis was also conducted to determine the accurate gradation of ash samples. Aggregate samples were washed through the test screens and then dried in an oven. The oven-dry samples were sieved through test screens. The washed sieve analysis was performed on bottom ash and control samples which will be described in Chapter VI. The unwashed (dry) sieve analysis of the materials was conducted prior to washed analysis. The bottom ash sample was created by blending all ash from 18 sampling events. Figures 4.5 and 4.6 present the unwashed and washed gradations of bottom ash and control samples respectively.

The difference between washed and unwashed gradation increases with decreasing particle size, and the ash sample varies more here than does the control sample. The 


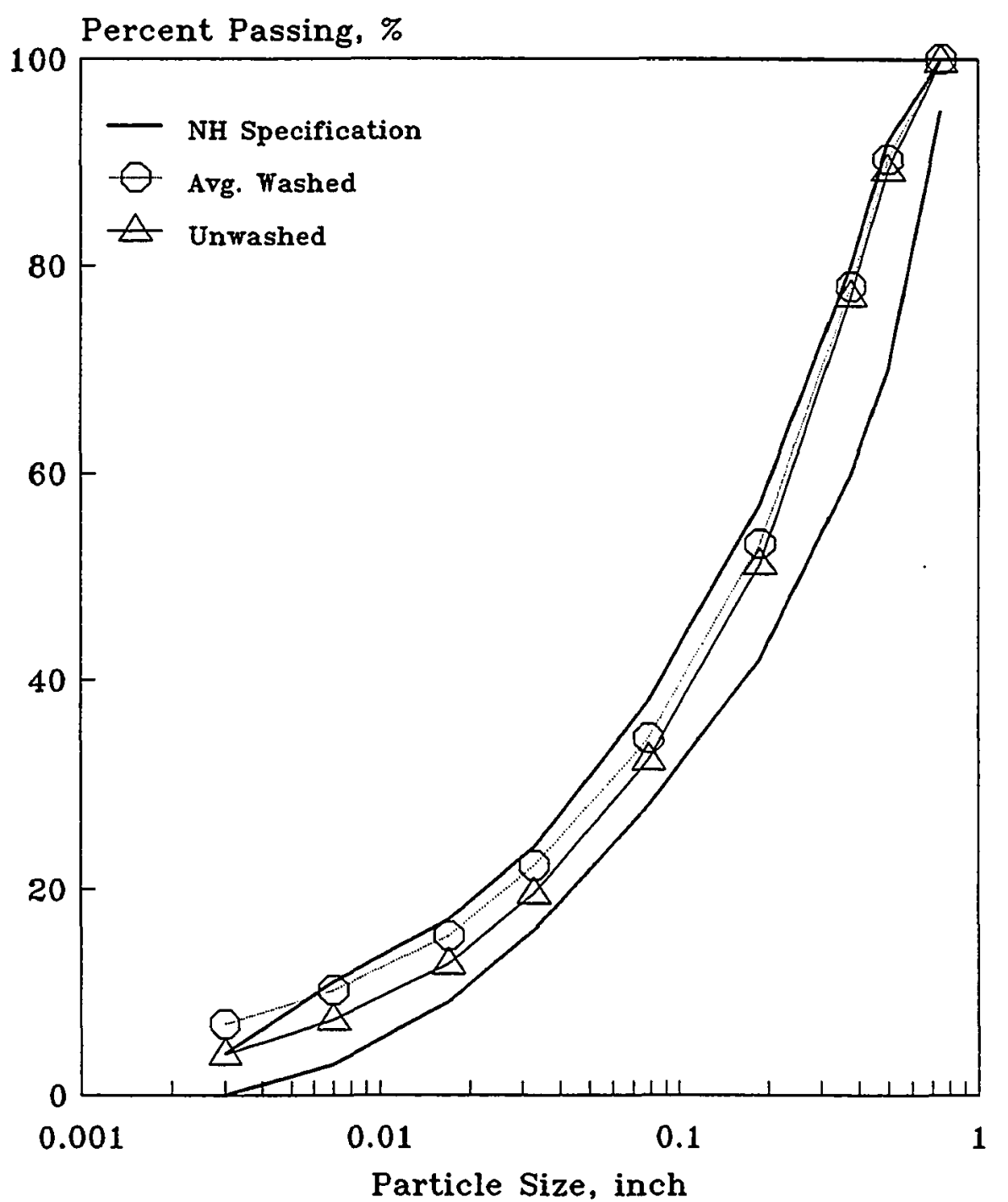

Figure 4.5 Gradation of Unwashed and Washed Ash 


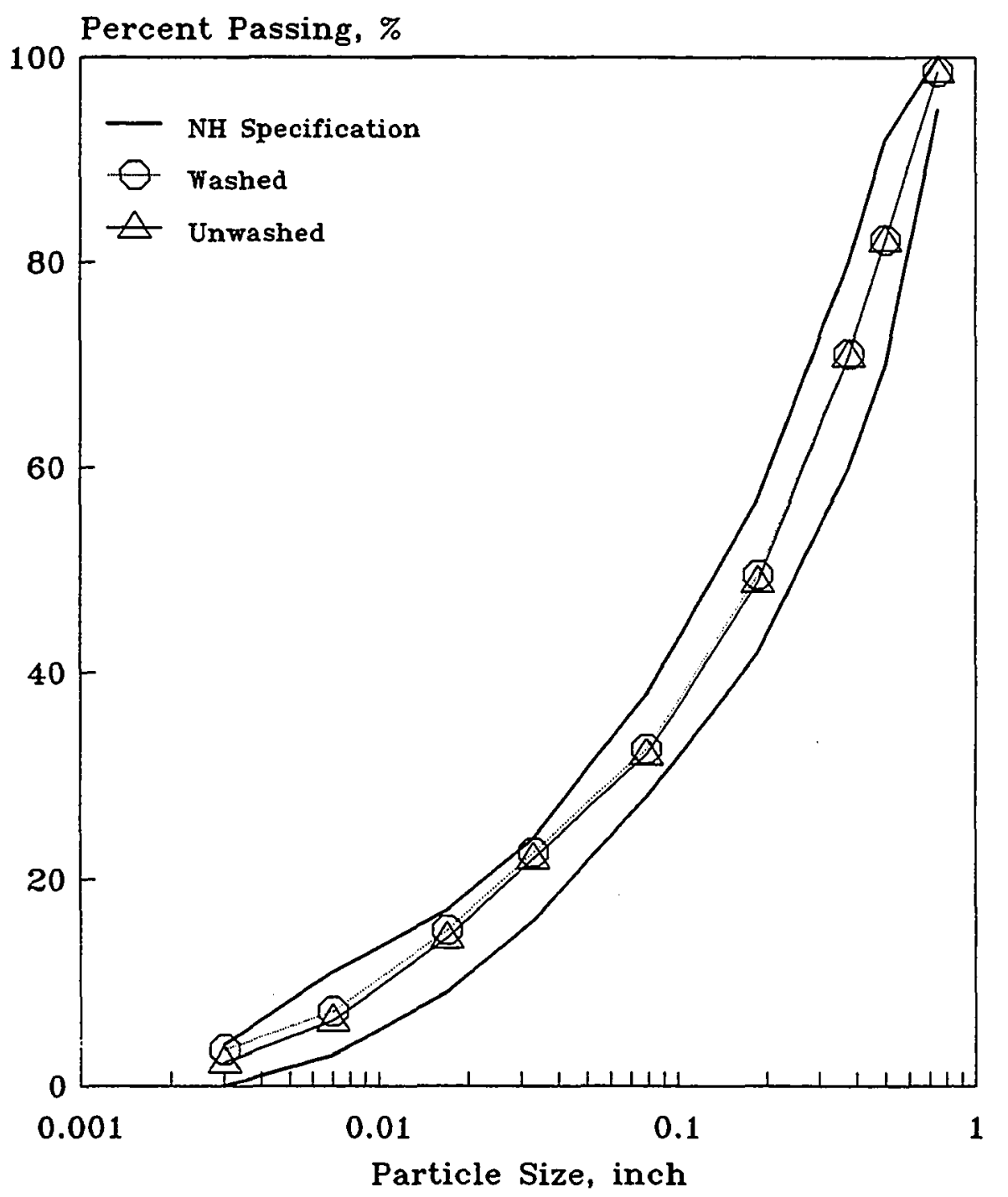

Figure 4.6 Gradation of Unwashed and Washed Control 60 
percent passing No.200 sieve for the control sample changes from $2.29 \%$ (unwashed) to $3.5 \%$ (washed), resulting in a 53\% increase, and that for the ash samples changes from $3.97 \%$ (unwashed) to $6.87 \%$ (washed), bringing about a $73 \%$ increase. Compared with NH specification for type B binder mix, the gradations after washed for control and ash are still meet NH specification with the exception that the material passing No.200 sieve for the ash sample is excessive.

In asphaltic concrete, large amounts of fine material can result in a low asphalt content leading to higher stability but lower durability and vice-versa. Typically, the amount of minus 200 material is limited to value between 3 to 7 percent by weight for high tire pressures (>100 psi) or heavy traffic load (36). It should be pointed out that the washed sieve analysis is accurate but not practical since the aggregates in asphalt plant are always batched on the basis on dry sieving. However, in that the bottom ash is somewhat different from conventional materials, the unwashed and washed sieve analyses

for bottom ash materials should be performed in a laboratory to establish a relationship between these two methods, and the results should be taken into account in mix design.

\subsection{Gravimetric Characterization}

Gravimetric characterization was measured by two methods: 1) Specific Gravity and Absorption of Coarse Aggregate and Fine Aggregate, and 2) Unit Weight and Voids.

\subsubsection{Specific Gravity and Absorption of Coarse Aggregate and Fine Aggregate}

Bulk (dry) specific gravity of 72 hourly fine ash samples ranged from 1.55 to 2.22 , 
with an average of 1.86 , and that of coarse ash ranged from 1.93 to 2.44 , with an average of 2.20. Since fine ash has lower bulk (dry) specific gravity than coarse ash, fine ash is less dense and has more porosity (impermeable voids plus permeable voids) than coarse ash. The bulk (dry) specific gravity of the conventional aggregates from Pike Industries Inc., which was used as control in developing mix design, was 2.6 for both fine and coarse fractions. Bottom ash is less dense than Pike aggregates.

Bulk (SSD) specific gravity of 72 hourly fine ash samples ranged from 1.89 to 2.41 , with an average of 2.13 , and that of coarse ash ranged from 2.11 to 2.58 , with an average of 2.32. Bottom ash has a lower bulk (SSD) specific gravity than Pike aggregates which has a value of 2.6 .

Apparent specific gravity of 72 hourly fine ash samples ranged from 2.20 to 2.98 , with an average of 2.56 , and that of coarse ash ranged from 2.32 to 2.76 , with an average of 2.51. The apparent specific gravity of fine ash is, on average, higher than that of coarse ash, indicating that the former has less impermeable voids than the latter. Bottom ash has a lower apparent specific gravity than Pike aggregates which has a value of 2.7

Absorption of 72 hourly fine ash samples ranged from 6.8 to $24.7 \%$, with an average of $14.7 \%$, and that of coarse ash ranged from 1.8 to $12.3 \%$, with an average of $5.7 \%$. Absorption is a measure of relative volume of permeable voids. Fine ash is more absorptive than coarse ash. Absorption of Pike aggregates ranged from 0.8 to $1.0 \%$. Bottom ash is much more absorptive than Pike aggregates. 


\subsubsection{Unit Weight and Voids}

Unit weight (dry, rodded) of 18 daily bottom ash samples ranged from 70.6 to 73.8 $\mathrm{lb} / \mathrm{ft}^{3}$, with an average of $72.2 \mathrm{lb} / \mathrm{ft}^{3}$. Void in aggregate of 18 daily bottom ash samples ranged from 41.2 to $43.7 \%$, with an average of $42.4 \%$. Typical dry unit weight for natural materials are as follows (48):

Well graded gravels - 125 to $130 \mathrm{lb} / \mathrm{ft}^{3}$

Well graded sands - 110 to $125^{\circ} \mathrm{lb} / \mathrm{ft}^{3}$

Silts and clay - 80 to $110 \mathrm{lb} / \mathrm{ft}^{3}$

Volcanic rock (pumice) and

Blast furnace slag - 50 to $80 \mathrm{lb} / \mathrm{ft}^{3}$

Typical values of void content or porosity of solid-type material range from approximately 45 to $65 \%$ by total volume occupied by the sample.

Unit weight values of bottom ash are typical of materials such as pumice or blast furnace slag which are classified as lightweight materials by Portland Cement Association (49). Hence, bottom ash is similar to a lightweight material with high porosity. This finding is similar to other ash studies.

\subsection{Field Behavior}

Field behavior of unbound bottom ash was measured by two test methods: 1) Proctor Density or Moisture-Density Testing, and 2) California Bearing Ratio (CBR).

\subsubsection{Proctor Density or Moisture-Density Testing}


The moisture-density test is a procedure designed to determine moisture and compaction requirements that will result in maximum density of the material when compacted in the field. From an engineering viewpoint it is desirable to compact a soil to its maximum density in order to decrease future settlement, increase shear strength, decrease permeability, and develop high strength.

Proctor density of 18 daily bottom ash samples ranged from 106.9 to $110.2 \mathrm{lb} / \mathrm{ft}^{3}$, with an average of $108.6 \mathrm{lb} / \mathrm{ft}^{3}$. The optimum moisture content of 18 daily bottom ash samples ranged from 14.7 to $16.1 \%$, with an average of $15.4 \%$, which is lower than the moisture content of bottom ash as received. Part of the moisture content of the bottom ash as received is required to be removed if bottom ash is compacted at the optimum moisture content. The maximum dry density for natural materials ranges from 90 to 135 $\mathrm{lb} / \mathrm{ft}^{3}$ and the optimum moisture content for natural materials ranges 10 to $30 \%$. Another study (46) indicates that the values of maximum dry density for ash range from 80 to 100 $\mathrm{lb} / \mathrm{ft}^{3}$, and those of optimum moisture content range from 12 to $16 \%$.

Figure 4.7 presents a density-moisture curve for a typical ash. Figure 4.8 presents a comparison of gradation before and after Proctor density test. There is a significant difference in gradation before and after this test, indicating that ash degradation occurs. The effect of ash degradation on performance is not known, but not expected to be of major concern.

\subsubsection{California Bearing Ratio (CBR)}

CBR test is a penetration test where a standardized piston, having an end area of 3 


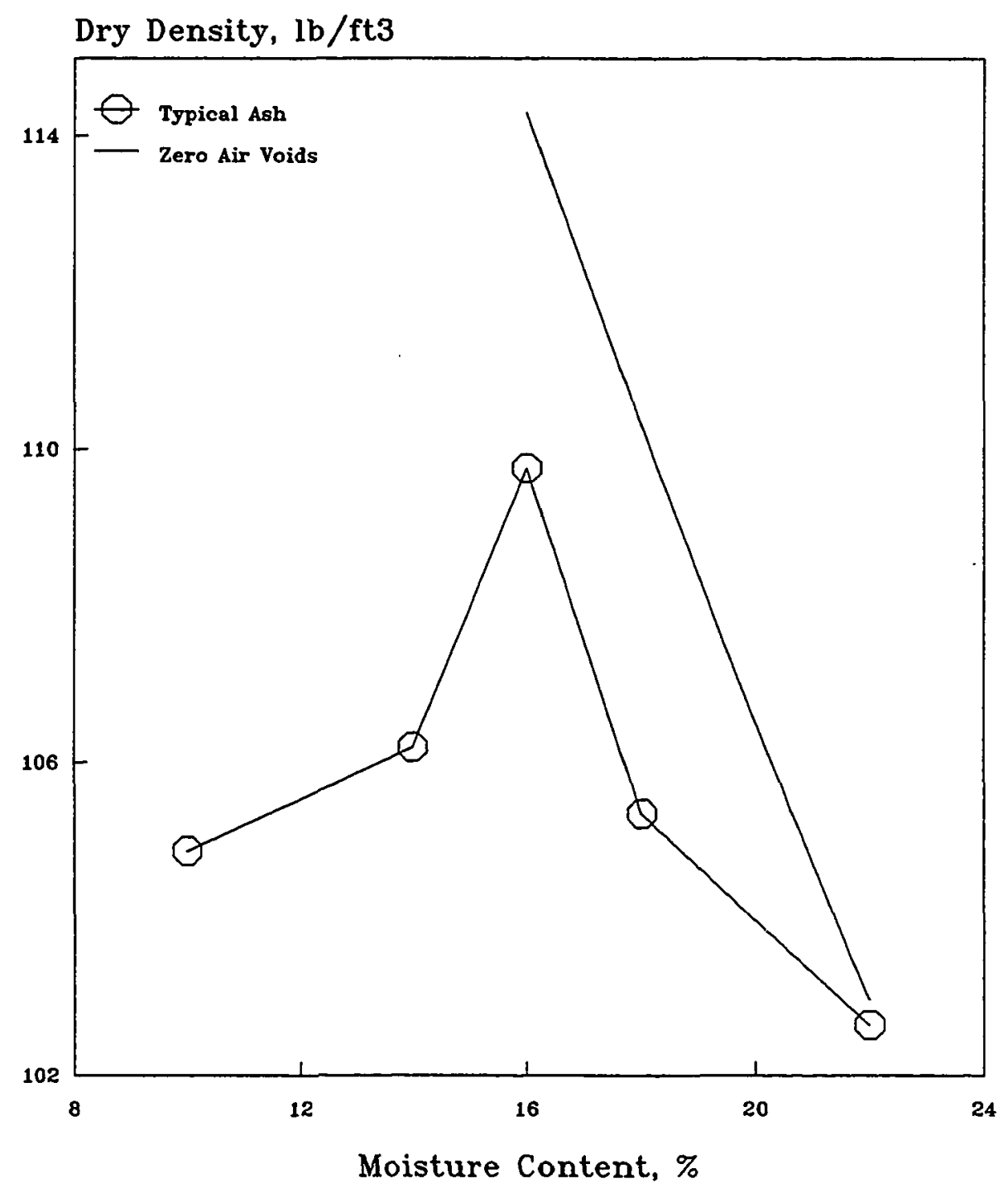

Figure 4.7 Density versus Moisture Content by Proctor Test 


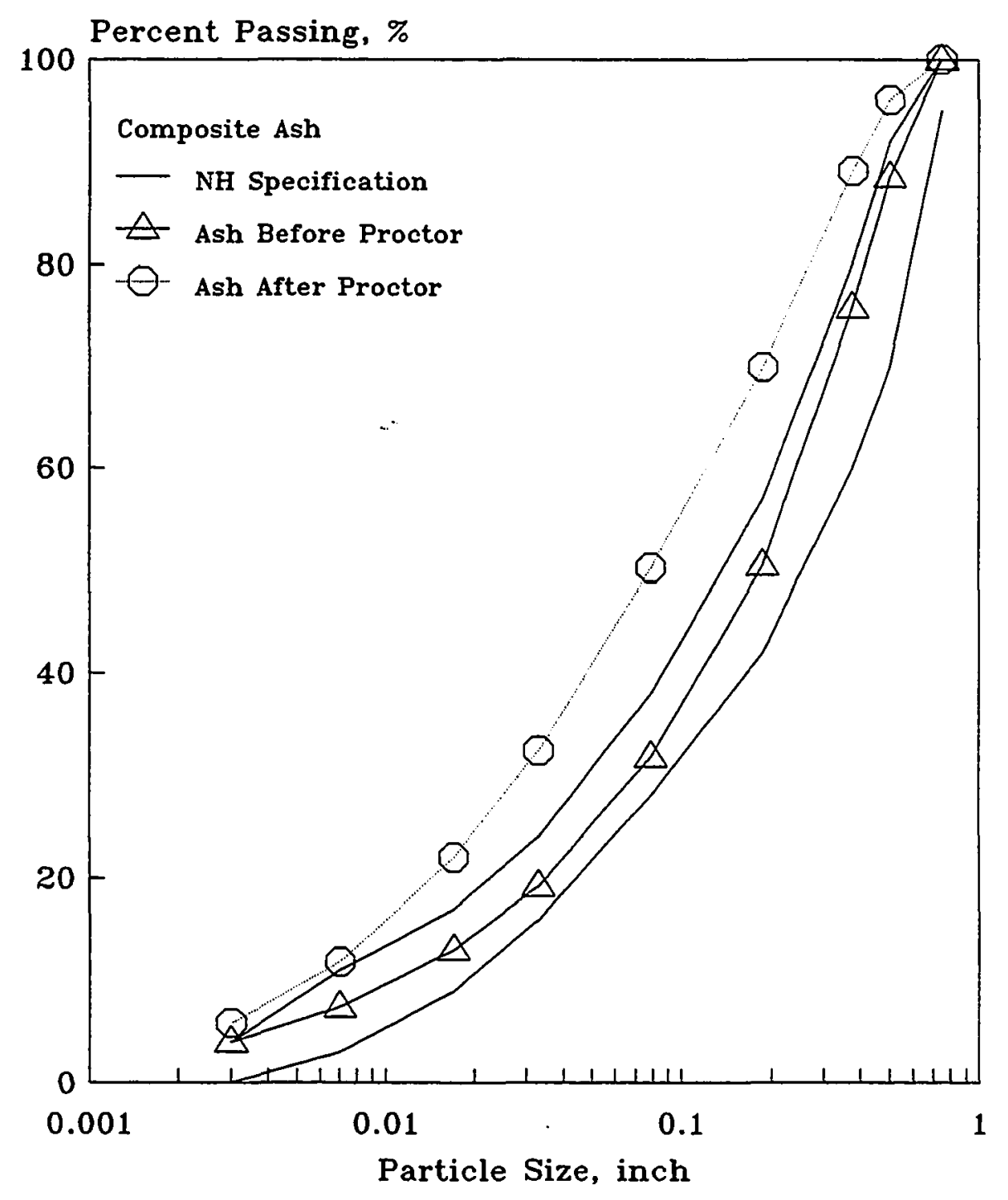

Figure 4.8 Ash Degradation From Proctor Test 
inch $^{2}$ is caused to penetrate laboratory-compacted specimens at a standard rate of 0.05 inches per minute. The stress-penetration curve is plotted and the CBR is computed as the ratio of an arbitrarily selected stress to that of a standard. The standard values were obtained by testing a high-quality crushed-stone material.

The CBR of 18 daily bottom ash samples at 0.1 inch penetration ranged from 74.0 to $85.5 \%$, with an average of $79.8 \%$. At 0.2 inch penetration the CBR varied from 104.5 to $116.1 \%$, with an average of $110.3 \%$. The CBR data reported is unsoaked and compacted at the Proctor optimum moisture content of $16 \%$. Figure 4.9 presents CBR versus test day. CBR value at 0.2 inch penetration is consistently higher than at 0.1 inch penetration.

CBR value for natural coarse gravel-type materials ranges from 20 to $80 \%$. CBR values for crushed stone may have values that vary from 100 up to $250 \%$. The typical minimum specification for road base is $100 \%$. Hence, bottom ash meets CBR requirements for road base if compacted at optimum moisture content. Based on CBR alone, the bottom ash could be successfully used as subbase and base course materials.

Figure 4.10 presents stress-penetration curves for a typical bottom ash under soaked and unsoaked conditions. The bottom ash samples were compacted at the optimum moisture content of $16 \%$. Added to this plot is another curve from testing a standard high-quality crushed-stone material (50). The trace of unsoaked sample is near that of soaked sample. In comparison to standard crushed stone materials the curves of bottom ash are under that of standard material for penetration of less than 0.18 inch (soaked) and 0.21 inch (unsoaked) but above for penetration above those values, indicating that as 


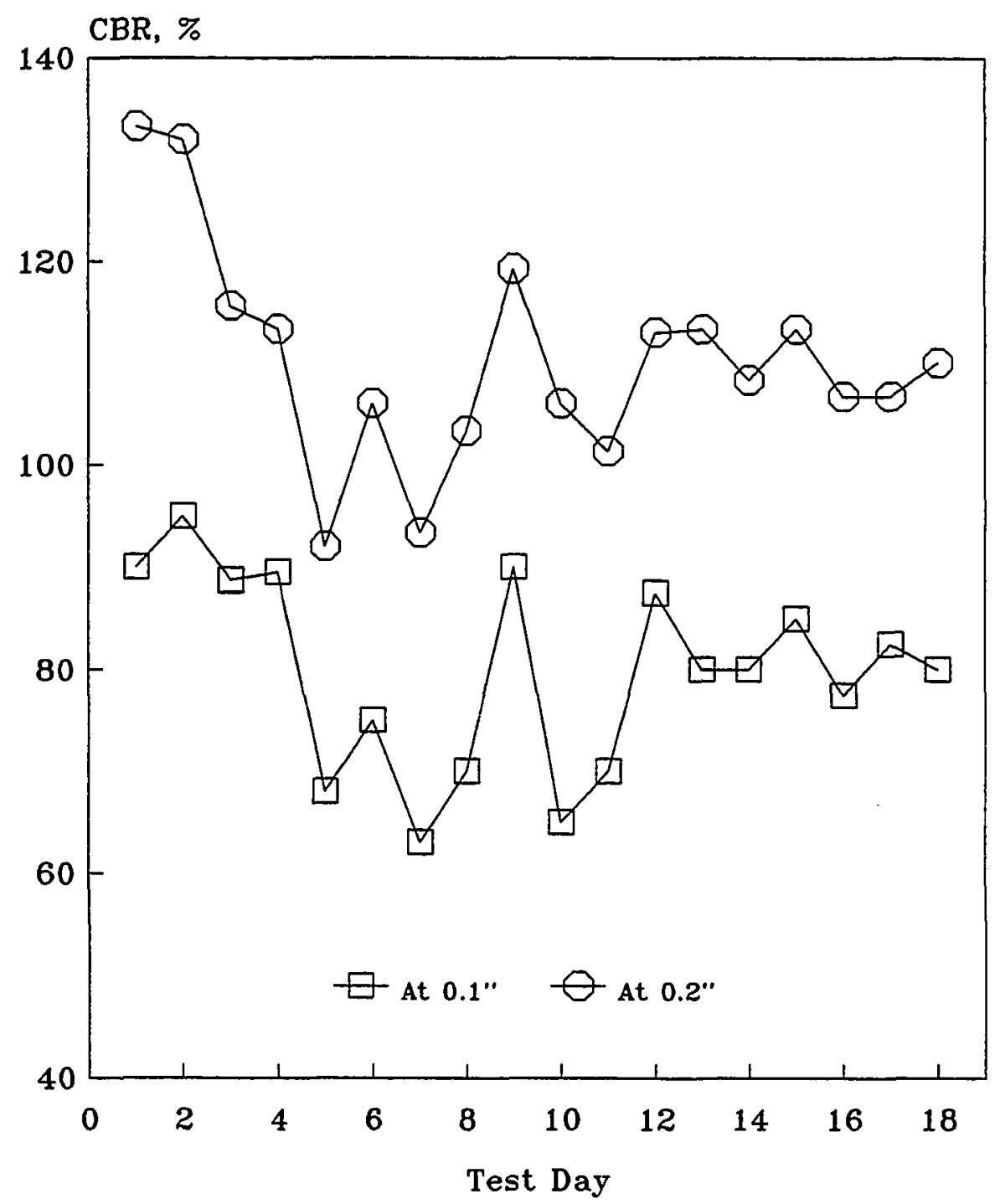

Figure 4.9 CBR (Unsoaked) at $16 \%$ Moisture versus Test Day 68 


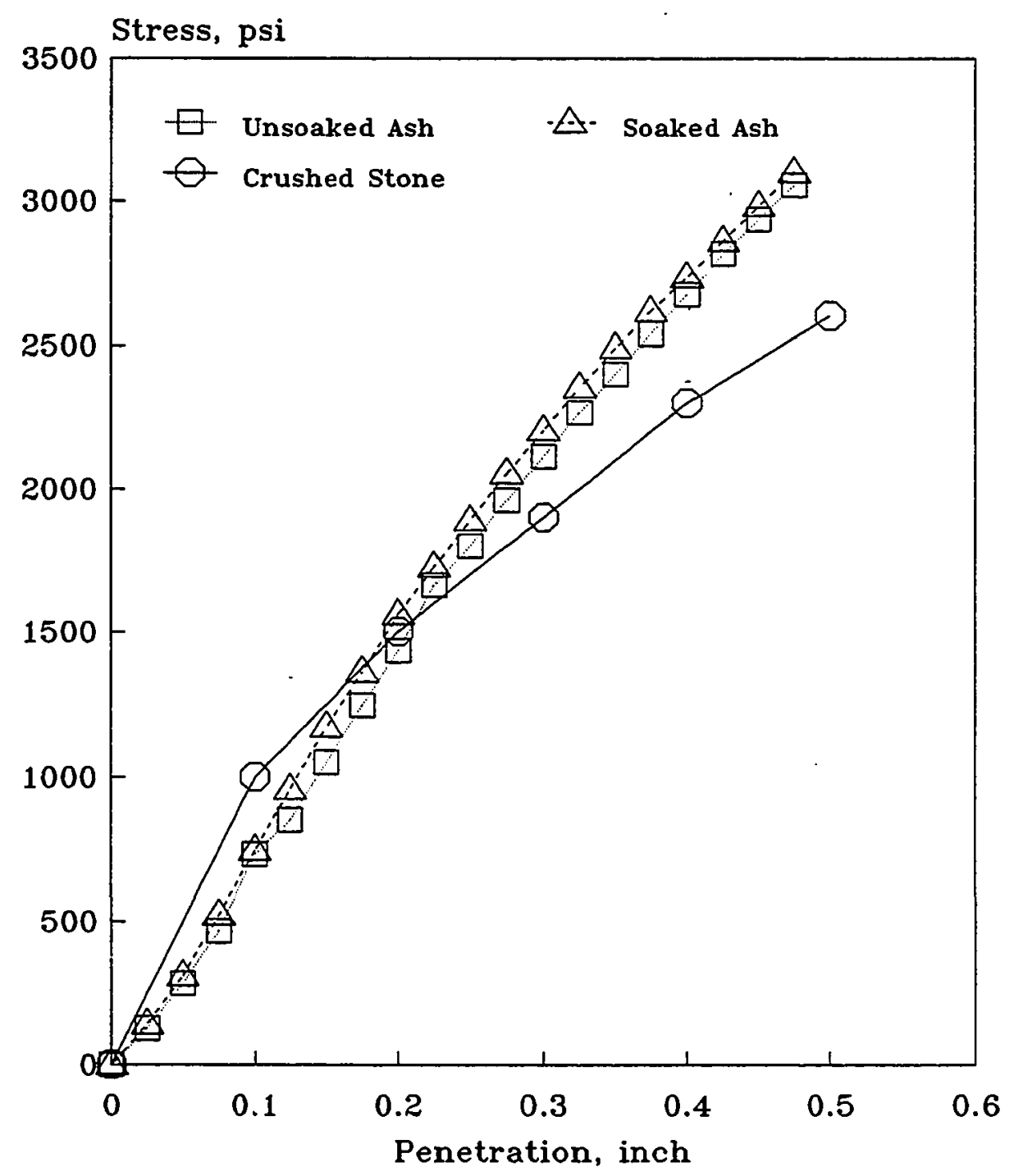

Figure 4.10 Stress versus Penetration (CBR Test)

69 
penetration increases the shear resistance for bottom ash sample increases, and at some point, exceeds that for a standard material. The high shear resistance of bottom ash is the result of the good gradation and high density achieved at optimum moisture content as well as inter-locking between angular particles of bottom ash.

Figure 4.11 shows the CBR and density as a function of moisture. A peak value of density is noted at $16 \%$ moisture, but that of CBR at 0.1 inch penetration is noted at $12 \%$ moisture. The CBR, as molded or unsoaked, generally decreases as the moisture increases as shown by the 0.2 inch penetration curve.

The degradation occurs to bottom ash as a result of compaction and penetration in the CBR test as shown by Figure 4.12, which is not expected to be of major concern.

\subsection{Toughness and Abrasion Resistance}

The Los Angeles (L.A.) abrasion test is most often used to obtain an indication of the desired toughness and abrasion characteristics (34). Typical test values range from $10 \%$ for extremely hard igneous rocks to $60 \%$ for soft limestones and sandstones. This test does not appear to be fully satisfactory for use with slags, cinders, and other lightweight aggregates. Experience has shown that many aggregates such as slag and soft limestones provide excellent performance even though the L.A. abrasion is high.

It is considered to be overly aggressive for the pavement applications considered here because of the brittle, glassy nature of some of the bottom ash components.

Only two daily composites samples were selected for this test. Data were consistent, with an average of $47.3 \%$ and $43.4 \%$ for Grade B and Grade C, respectively. The results 


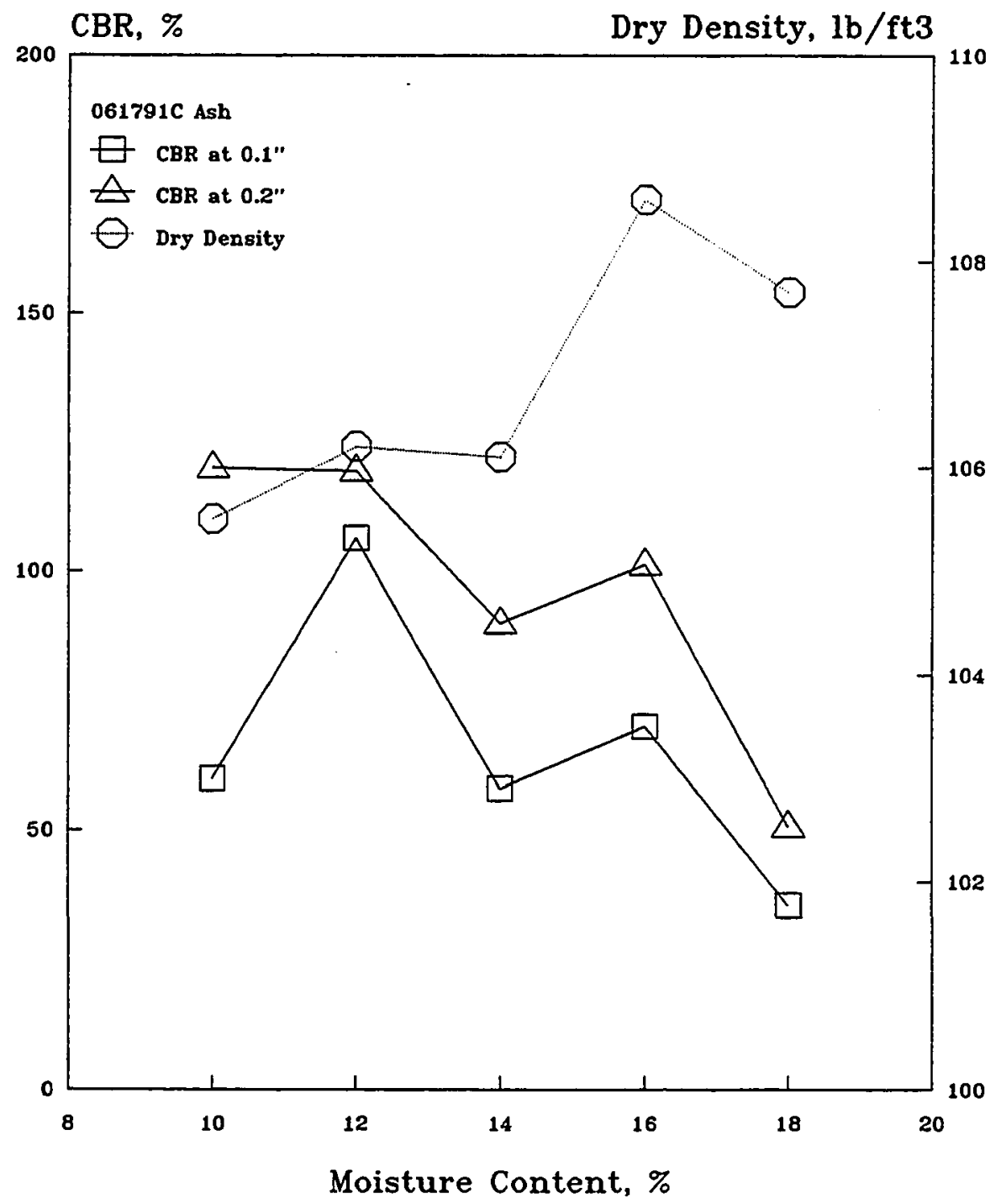

Figure 4.11 CBR and Density versus \% Moisture 


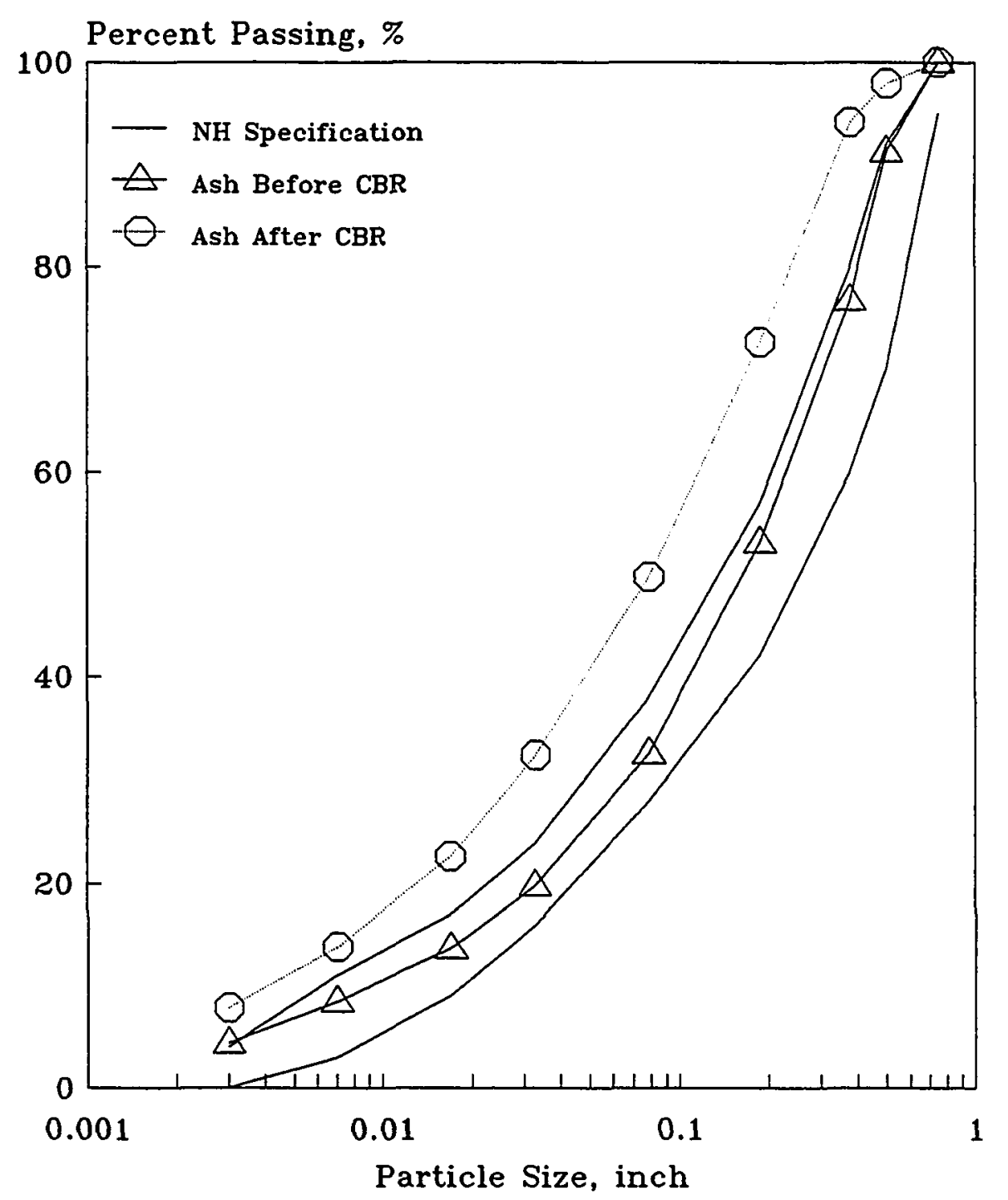

Figure 4.12 Ash Degradation From CBR Test 
meet the ASTM D692 maximum 50\% requirement for use in bituminous paving mixtures.

\subsection{Durability and Soundness}

Aggregate must be resistant to breakdown or under action of wetting and drying and/or freezing and thawing (weathering). Soundness test is an empirical screening test that is intended to provide an indication of durability due to weathering and is useful for evaluating new sources of aggregate for which no service records are available. This is considered an overly aggressive durability test and is known to reject aggregates which in fact show good field performance.

Four daily composites samples were selected for this test for fine materials and two daily composites samples for coarse materials. The data for fine materials ranged from 10.4 to $14.3 \%$, with an average of $11.9 \%$, that for coarse materials ranged from 2.5 to $2.8 \%$, with an average of $2.6 \%$. The sodium sulfate soundness test for coarse fraction of ash meets the ASTM D692 specification of maximum 12\%. The fine fraction of ash is less dense and not as strong. However, since the fine fraction of the ash comprises approximately $50 \%$ of the bottom ash the natural combination of the coarse and fine fractions passes the ASTM requirement.

\subsection{Conclusions}

The following conclusions can be drawn from the evaluation of bottom ash properties.

1. Bottom ash was a heterogeneous material. Visual classification indicated that coarse 
fraction of bottom Ash ( $\geq$ No.4) comprised, on average, $32.2 \%$ clinker, $36.6 \%$ clinker with ferrous, $22.9 \%$ glass, $4.1 \%$ ferrous, $1.6 \%$ ceramics and $2.5 \%$ other materials including non-ferrous metals (aluminum, copper, etc.), rock, brick pieces, concrete, wood, bone fragments, paper, chalk, etc.

2. Moisture content of bottom ash exceeded that normally associated with conventional aggregate materials.

3. LOI of bottom ash exceeded that normally associated conventional materials for construction applications. LOI was also strongly associated with particle size, increasing significantly with decreased particle size.

4. The bottom ash met NH gradation specifications for a type B binder mix, indicating that ash was a well graded aggregate material.

5. Washed-sieving differed from dry-sieving in that the former generated more fine materials that the latter. The percent passing No.200 sieve for control sample increased by $53 \%$ from dry to washed sieving, and that for ash samples increased by $73 \%$.

6. Specific gravity and absorption measurements indicated bottom ash was a lightweight, highly absorptive and porous material when compared to natural aggregate materials. The high absorptive nature of bottom ash was primarily associated with the fine fraction $(<$ No.4) of bottom ash.

7. Unit weight measurements indicated that bottom ash was a lightweight aggregate material. Unit weight values of bottom ash are typical of materials such as pumice or blast fumace slag.

8. The energy applied during Proctor density testing resulted in the degradation of 
bottom ash.

9. Bottom ash CBR was well above the range of values for most natural materials, indicating that bottom ash had an excellent bearing capacity and would make an excellent subbase material for road construction. Degradation of bottom ash occurred as a result of compaction and penetration in the CBR test.

10. L.A. abrasion results of bottom ash met the ASTM D692 maximum $50 \%$ requirement for use in bituminous paving mixtures. This test was considered to be overly aggressive for the pavement applications considered here because of the brittle, glassy nature of some of the bottom ash components.

11. The sodium sulfate soundness of the coarse fraction of bottom ash met the ASTM D692 specification of maximum $12 \%$ and the fine fraction of bottom ash had marginal durability characteristics as measured by the test procedure. However, since the fine fraction of bottom ash comprised approximately $50 \%$ of the bottom ash the natural combination of the coarse and fine fractions should pass the ASTM requirement. 


\section{THE STATISTICAL ANALYSIS OF BOTTOM ASH PHYSICAL PROPERTIES}

There are at least two reasons for statistically evaluating variation of bottom ash properties. First, a measure of confidence that the property under test is within a certain range of values can be established. Physical tests that are made at frequent intervals without using statistics can only be judged on a go, no-go basis. The possibility strongly exists that by judging based on individual tests, one may reject or discredit a material which is, to a reasonable degree of confidence, within the specification or the desired range. Secondly, statistical analysis may give guidance about future testing frequencies which helps to better characterize bottom ash and/or to save the cost of unnecessary and costly sampling. Sometimes, it is impossible to conduct the tests at the desired frequencies for various reasons. Statistical analysis may reduce the testing frequencies while maintaining the same level of confidence on the results.

\subsection{Particle Size Distribution}

\subsubsection{Hourly Samples}

The objectives of this study are three-fold: (1) to identify whether the variations of bottom ash properties between sampling days and between sampling hours are significantly greater than the variation due to the random error of measurements, (2) to 
identify the reasons if there is a significant variation, and (3) to establish the confidence intervals at certain confidence levels.

\subsubsection{Two-way Analysis of Variance (Two-way ANOVA)}

Two-way ANOVA (51) is used to separate the three sources of variation for particle size distribution: between sampling day variation, between sampling hour variation and random variation due to experimental errors. The F-test is used to test whether the variances between days and hours are significant.

In two-way ANOVA tests presented here, each measurement, $x_{i j}$, is classified according to two factors, sampling day and sampling hour, as shown in Table 5.1.

Table 5.1 Table for Two-way ANOVA

\begin{tabular}{|c|c|c|c|c|c|c|c|}
\hline & \multicolumn{6}{|c|}{ Sampling Day (Treatment) } \\
\hline & & 1 & 2 & $\bullet \bullet$ & $\mathbf{i}$ & $\bullet \bullet \bullet$ & 18 \\
\hline & 1 & $x_{11}$ & $x_{21}$ & $\cdots$ & $x_{i 1}$ & $\bullet$ & $\mathrm{x}_{181}$ \\
\hline Hour & 2 & $x_{12}$ & $x_{22}$ & ..॰ & $x_{i 2}$ & ..• & $\begin{array}{l}\mathbf{x}_{182} \\
\text {. }\end{array}$ \\
\hline (Block) & 3 & $x_{13}$ & $x_{23}$ & •.• & $x_{i 3}$ & •.• & $x_{183}$ \\
\hline & 4 & $x_{14}$ & $x_{24}$ & •.• & $x_{i 4}$ & •.• & $\mathrm{x}_{184}$ \\
\hline
\end{tabular}

The two-way ANOVA model is written herein,

$$
\begin{array}{ll}
\mathrm{x}_{\mathrm{ij}}=\mu_{\mathrm{ij}}+\varepsilon_{\mathrm{ij}} & \mathrm{i}=1,2,3, \ldots, 18 \text { (sampling day); and } \\
\mathrm{j}=1,2,3,4 \text { (sampling hour). }
\end{array}
$$

where,

$\mu_{\mathrm{ij}}$ is the mean of the response variable for day $i$ and hour $\mathrm{j}$; and 
$\varepsilon_{\mathrm{ij}}$ is the error of the observation $x_{\mathrm{ij}}$.

Testing for a difference in the means for different sampling days and sampling hours requires the use of the following test statistic:

$$
\begin{aligned}
F_{\text {day }} & =M S_{\text {day }} / M S_{e} \\
F_{\text {hour }} & =M_{\text {hour }} / M_{e}
\end{aligned}
$$

The Null hypotheses of no variation are rejected if $F>F_{\text {critical }}$.

The analysis of variance table summarizes these tests as follows:

Table 5.2 The Analysis of Variance Table

\begin{tabular}{lccll}
\hline Source of Variation & D.F. & S.S. & M.S. & F-Ratio \\
\hline sampling day & $\mathrm{k}-1=17$ & $\mathrm{SS}_{\text {day }}$ & $\mathrm{MS}_{\text {day }}$ & $\mathrm{MS}_{\text {day }} / \mathrm{MS}_{\mathrm{e}}$ \\
sampling hour & $\mathrm{m}-1=3$ & $\mathrm{SS}_{\text {hour }}$ & $\mathrm{MS}_{\text {hour }}$ & $\mathbf{M S}_{\text {hour }} / \mathbf{M S}_{\mathrm{e}}$ \\
$\begin{array}{l}\text { error (residual) } \\
\text { total }\end{array}$ & $(\mathrm{k}-1)(\mathrm{m}-1)=51$ & $\mathrm{SS}_{\mathrm{e}}$ & $\mathrm{MS}_{\mathrm{e}}$ & \\
\hline
\end{tabular}

The between-sampling day estimate of variance $\left(\mathrm{MS}_{\mathrm{day}}\right)$ and the between-sampling hour estimate of variance $\left(\mathrm{MS}_{\text {hour }}\right)$ are compared with the variance estimated from the random errors $\left(\mathrm{MS}_{e}\right)$ in order to decide whether the sampling days and sampling hours produce significantly different results. The sensitivity of the experiment depends on the size of the random variation (error): the smaller the random variation, the smaller the difference between the sampling days or between the sampling Hours which can be detected.

Two-way ANOVA was conducted for each particle size. Figures 5.1 and 5.2 graphically present the comparison of the calculated $F$ ratio with the critical $F$ values for 
sampling days and sampling hours, respectively.

Between Sampling Days: As evidenced in Figure 5.1 the F value increases with decreased particle size. This indicates the variation of particle size distribution increases with decreasing particle size. The variation for $3 / 4^{n}$ and $1 / 2^{n}$ bottom ash is not significant at any confidence levels between $75 \%$ and $99.5 \%$. But the variation for bottom ash with particle size less than No.10 is significant at the above confidence levels. Whether the variation for ash with size ranging from $3 / 8^{n}$ to No. 10 bottom ash is significant or not depends on the confidence levels. The variation is not significant for $3 / 8^{n}$ ash at $<90 \%$ confidence level, No.4 ash at $<97.5 \%$ level and No.10 ash at $<99.5 \%$ level.

Between Sampling Hours: $F$ value varied with ash size. However, the F values for all sizes of ash was smaller than $F_{\text {critical }}$ at any confidence levels between $75 \%$ and $99.5 \%$ (Figure 5.2), which indicates the variation between sampling hours is not significant. That is, the variation between sampling hours is due to random errors only. It is worth mentioning that the insignificance of variation in a statistical sense does not mean that the variation of material properties meet the project specification and vice-versa.

Since the hour-to-hour variations are not significant, the designed two-way ANOVA can be treated as a one-way ANOVA. Only one factor, sampling day, is considered.

Inspection of Variance: Two-way analysis of variance is based on the assumptions that the errors are 1) homoscedastic (i.e. have constant variance in both ways, across sampling day and sampling hour), 2) normally distributed, and 3) statistically independent, particularly over time.

The homoscedasticity can be inspected in various ways (52) such as inspecting 


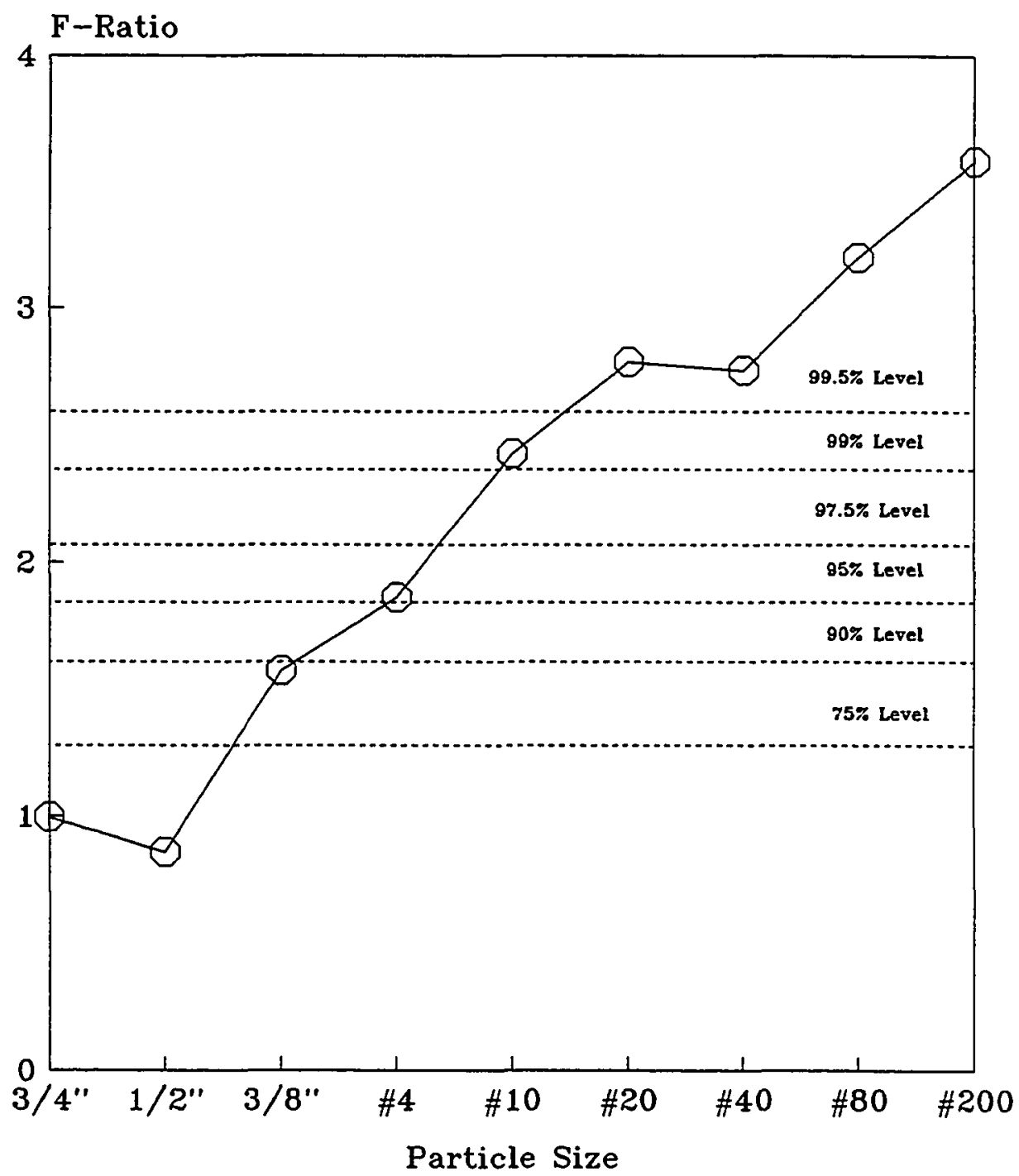

Figure 5.1 F-Ratio of Two-way ANOVA versus Particle Size (Between Day Comparison)

80 


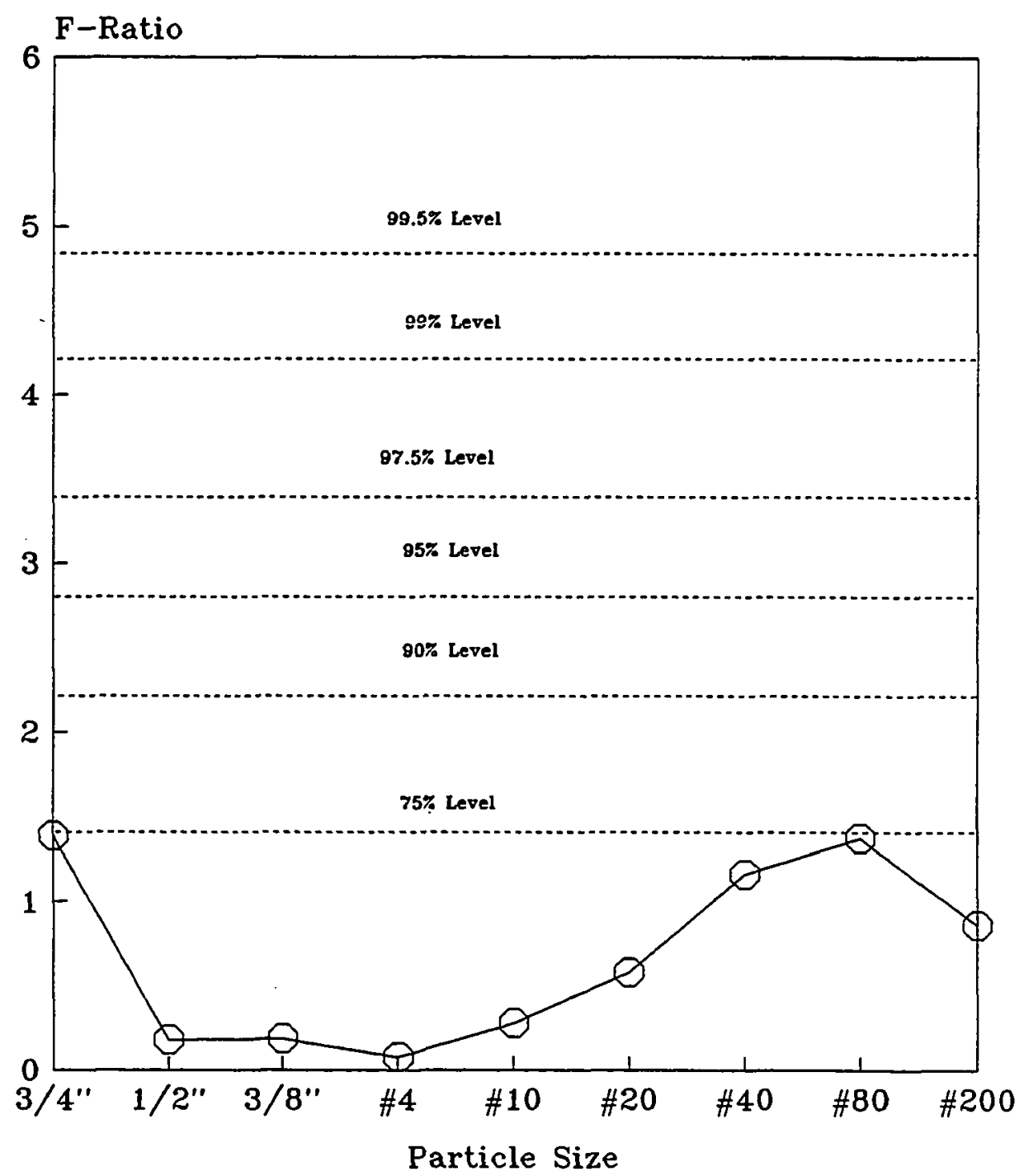

Figure 5.2 F-Ratio of Two-way ANOVA versus Particle Size (Between Hour Comparison)

81 
residuals, applying Bartlett's test, and Cochran's range test, etc. Inspecting residuals was selected in this study. Residuals calculated with Minitab (a statistical software) (53) are plotted against sampling days and sampling hours. The residuals for each sieve size are reasonably random in both ways, that is, across sampling days and sampling hours. Hence, the assumption of homoscedasticity is reasonable.

The normality of variance is inspected by plotting a histogram of residuals. The histograms of residuals for each sieve size do not indicate a violation of the normal assumption. The normal assumption is less crucial for the validity of the ANOVA procedure.

The independence of the errors is inspected by plotting the residuals against test sequence. The residuals for each sieve size are randomly distributed. The assumption of independence is reasonable.

\subsubsection{One-way Analysis of Variance}

Since the variations between sampling hours are not significant, the 4 hourly samples for each sampling day can be treated as 4 replicates. One-way analysis is conducted. We only consider test statistic:

$$
\mathrm{F}=\mathrm{MS}_{\mathrm{day}} / \mathrm{MS}_{\mathrm{e}}
$$

The formulas used are the same as in the two-way ANOVA except for those of SS $_{e}$ and $\mathrm{MS}_{\mathrm{e}}$. The resulting one-way ANOVA table is shown in Table 5.3.

One-way ANOVA was conducted on all particle sizes of bottom ash. Figure 5.3 presents the graphical comparison of the calculated $F$ ratios with critical $F$ values. 
Table 5.3 One-Way ANOVA Table

\begin{tabular}{lrlll}
\hline Source of Variation & D.F. & S.S. & M.S. & F-Ratio \\
\hline sampling day & $\mathrm{k}-1=17$ & $\mathrm{SS}_{\text {day }}$ & $\mathrm{MS}_{\text {day }}$ & $\mathrm{MS}_{\text {day }} / \mathrm{MS}_{\mathrm{e}}$ \\
error & $\mathrm{k}(\mathrm{n}-1)=54$ & $\mathrm{SS}_{\mathrm{e}}$ & $\mathrm{MS}_{\mathrm{e}}$ & \\
total & $\mathrm{N}-1=71$ & $\mathrm{SS}_{\text {total }}$ & & \\
& & & \\
\hline
\end{tabular}

It was found that $\mathrm{F}$ increases as ash particle size decreases. This means that betweensampling day variations become significant as the bottom ash particle decreases. This observation is similar to that from two-way ANOVA. Whether the between-sampling day variation is significant or not, compared to critical values, depends on the confidence level. The variation for $3 / 4^{n}$ and $1 / 2^{n}$ bottom ash is not significant at any confidence levels between $75 \%$ and $99.5 \%$. The variation for bottom ash with particle size less than No. 10 is significant at the above confidence level. Whether the variation for ash with size ranging from $3 / 8^{n}$ to No. 10 bottom ash is significant or not depends on confidence level. The variation is not significant for $3 / 8^{n}$ ash at $<95 \%$ confidence level (as opposed to $90 \%$ for two way ANOVA), No.4 ash at $<97.5 \%$ level and No.10 ash at $<99.5 \%$ level and vice-versa.

It was concluded that the assumptions of homoscedasticity, normality, independence of errors are reasonable by looking at residuals in the same way as in two-way ANOVA.

\subsubsection{Confidence Intervals}

The confidence intervals for the mean percent passing for each test day is calculated as follows: 


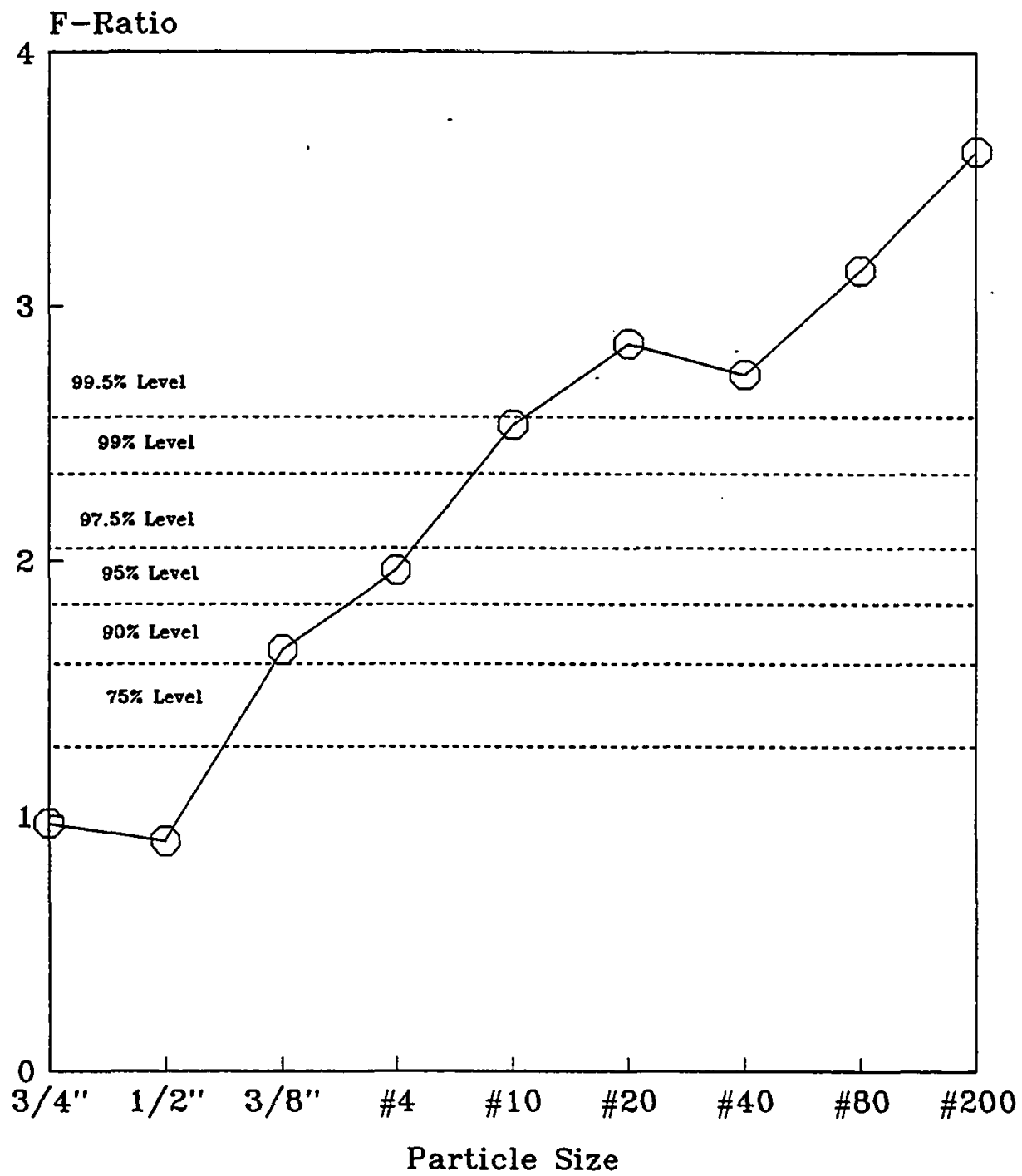

Figure 5.3 F-Ratio of One-way ANOVA versus Particle Size (Between Day Comparison)

84 


$$
\left[\bar{x}-\frac{t_{\alpha} s}{\sqrt{n}}<\mu_{\text {day }}<\bar{x}+\frac{t_{\alpha} s}{\sqrt{n}}\right]
$$

where,

$$
s=s_{\text {pooled }}=\sqrt{\mathrm{MS}_{e}}, \mathrm{MS}_{\mathrm{e}} \text { is from one-way ANOVA; }
$$

$\mathrm{n}=4$, the number of measurements; and

$t_{\alpha}$ is the $(1-\alpha) 100$ percentile of the $t$-distribution with $k(n-1)=54$ degrees of

freedom. This produces a confidence interval as the 1-2 $\alpha$ confidence level.

Figure 5.4 through Figure 5.12 presents $95 \%$ confidence intervals and average versus test day for each particle size of bottom ash. The New Hampshire gradation specification for type B binder mix are also included for comparison.

The statistics of particle size is summarized in Table 5.4. The 95\% level range over all sampling days was calculated as follows:

$$
\begin{aligned}
& \text { lower value }=\text { lowest day average }-\frac{t_{\alpha} \sqrt{M S}}{\sqrt{n}} \\
& \text { upper value }=\text { highest day average }+\frac{t_{\alpha} \sqrt{M S}}{\sqrt{n}}
\end{aligned}
$$

It was found that the day average of percent passing is randomly scattered around the overall average; while the maximum and minimum of ranges are not all within the New Hampshire gradation specification the overall average falls within the specification. Hence, bottom ash is well graded as required by NH specification.

It is worth mentioning that bottom ash gradation does not necessarily have to meet New Hampshire specification since bottom ash can always be blended with conventional materials to create a mix that meets NH specification. The reason that the gradation of 


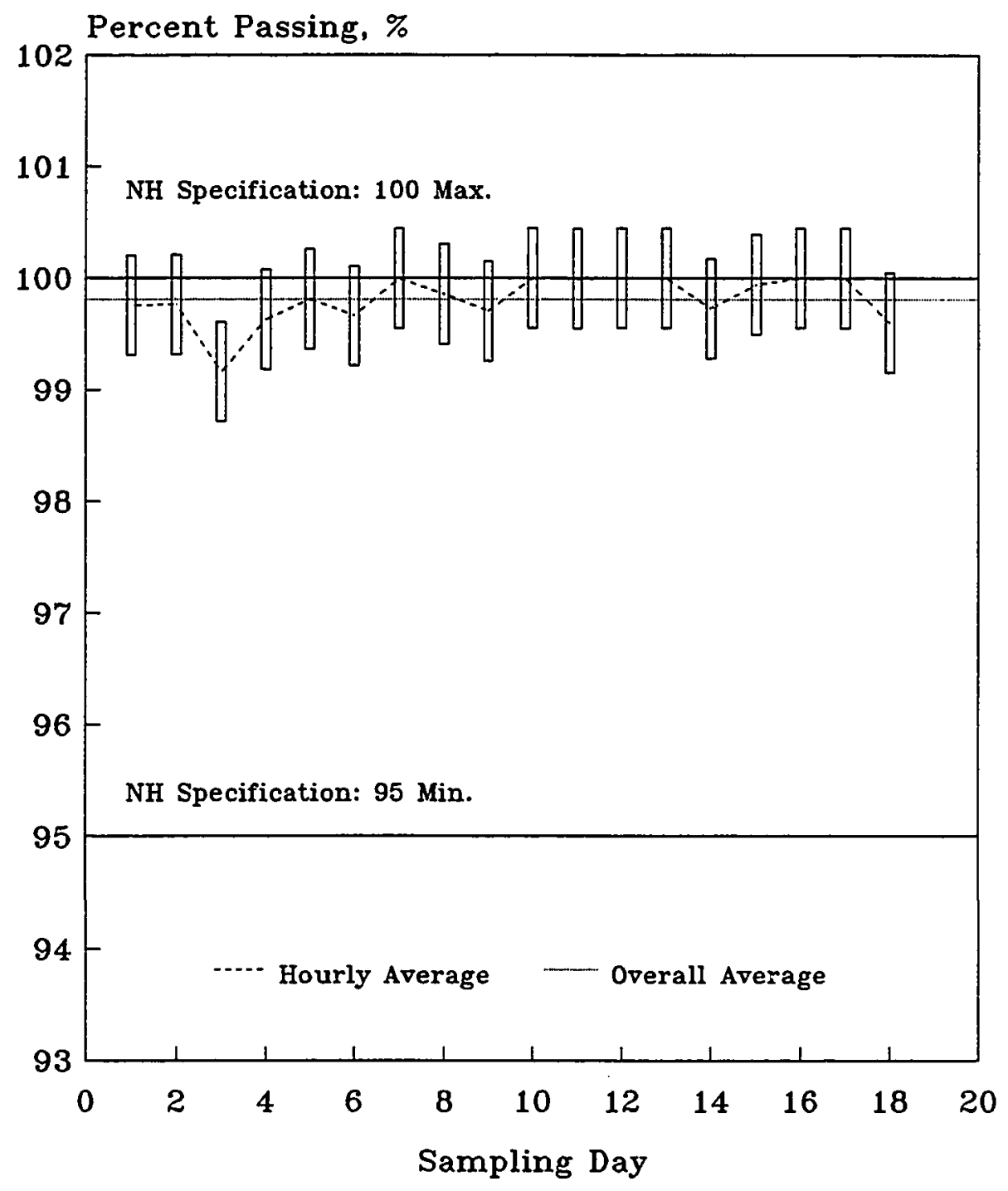

Figure 5.4 Percent Passing of 3/4" Ash versus Sampling Day 


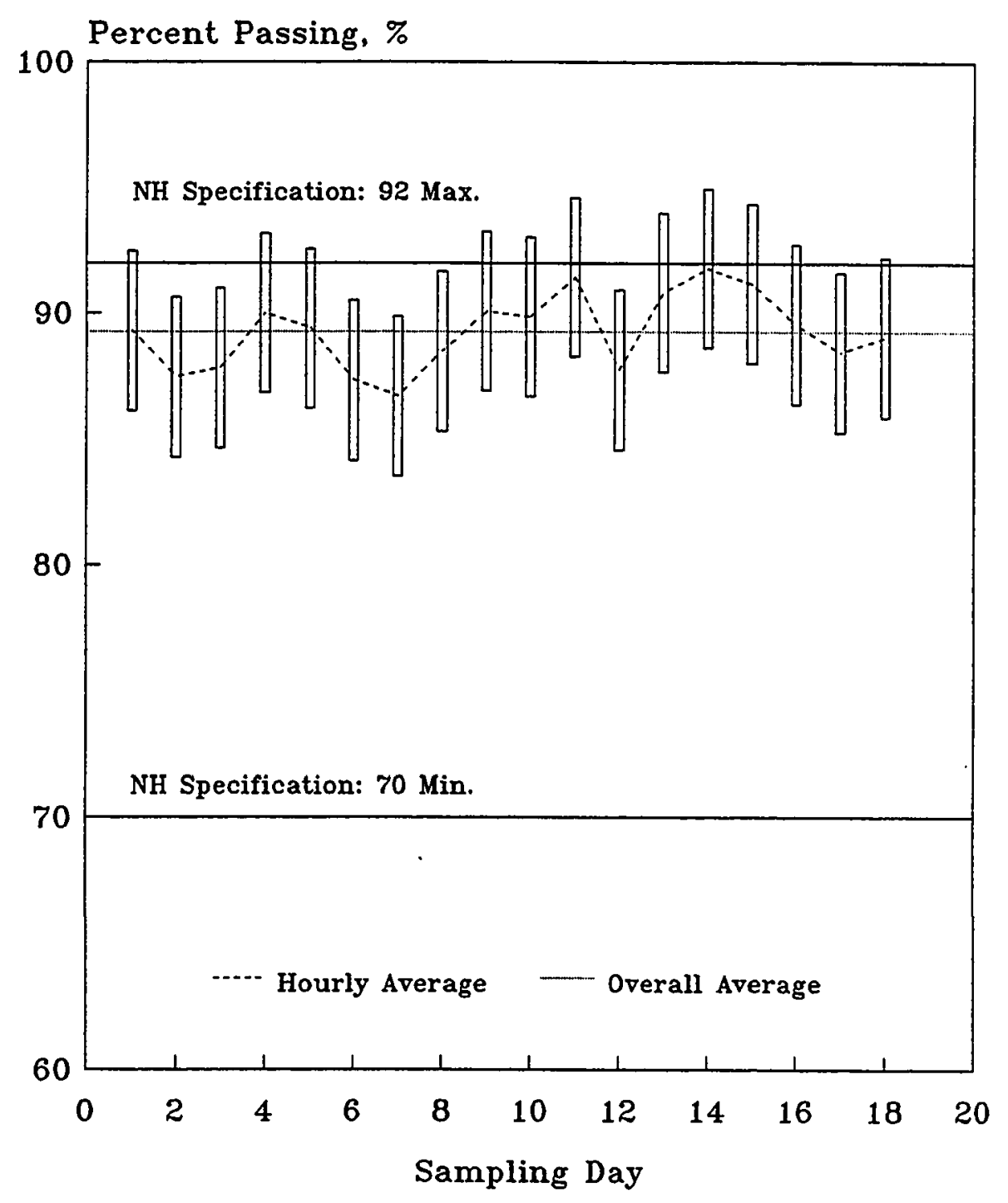

Figure 5.5 Percent Passing of $1 / 2 "$ Ash versus Sampling Day 87 


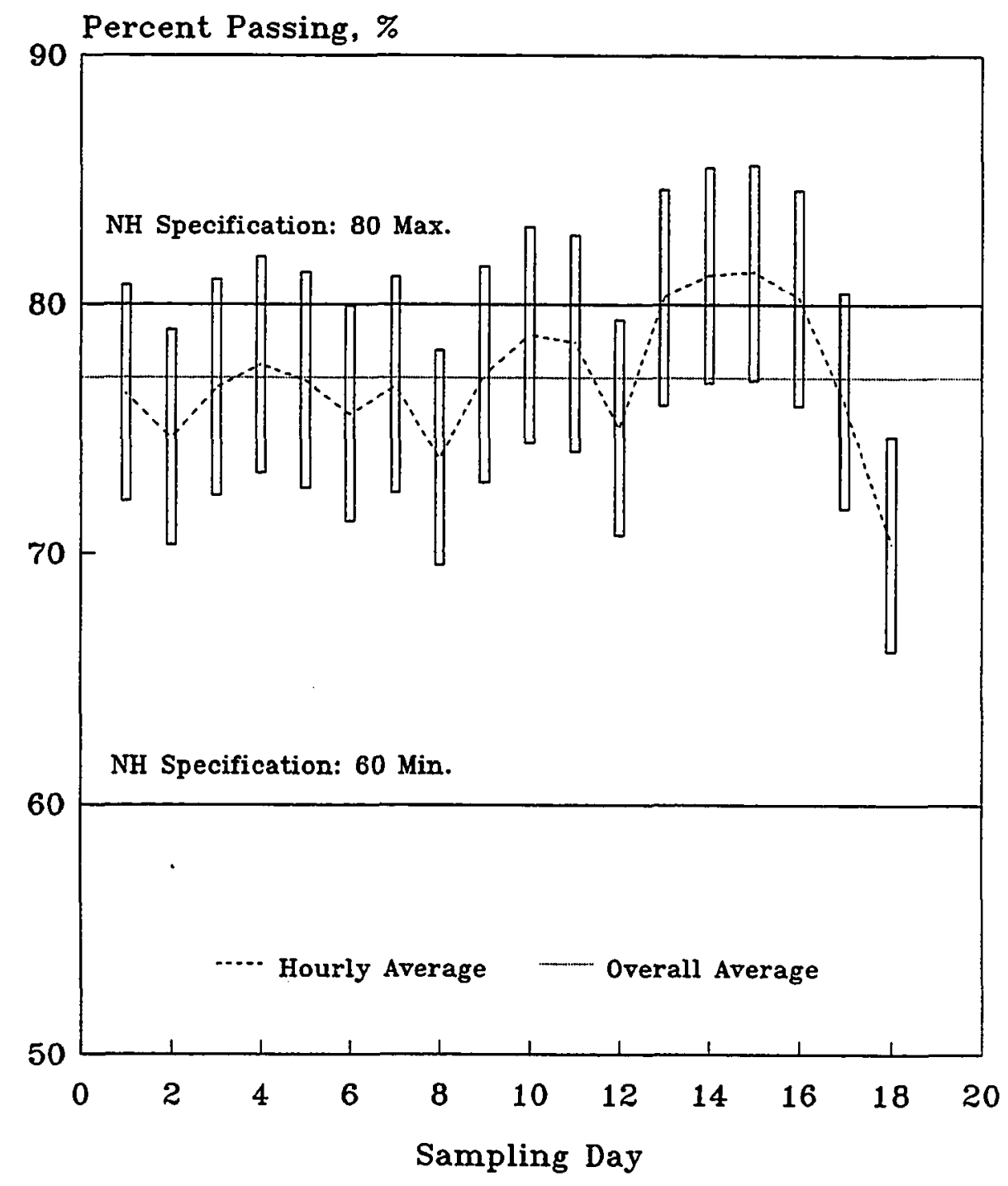

Figure 5.6 Percent Passing of 3/8" Ash versus Sampling Day 


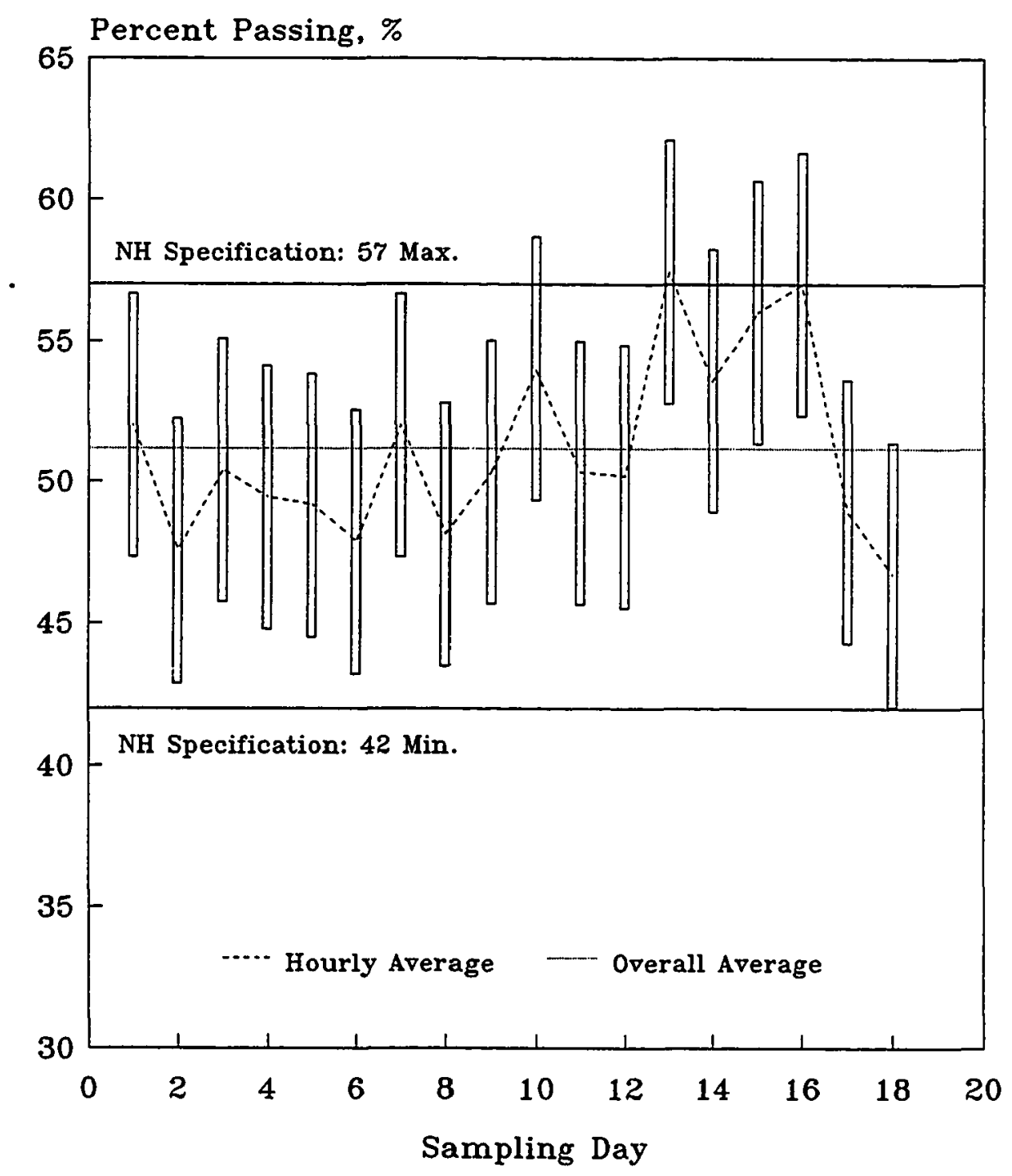

Figure 5.7 Percent Passing of No.4 Ash versus Sampling Day 
Percent Passing, \%

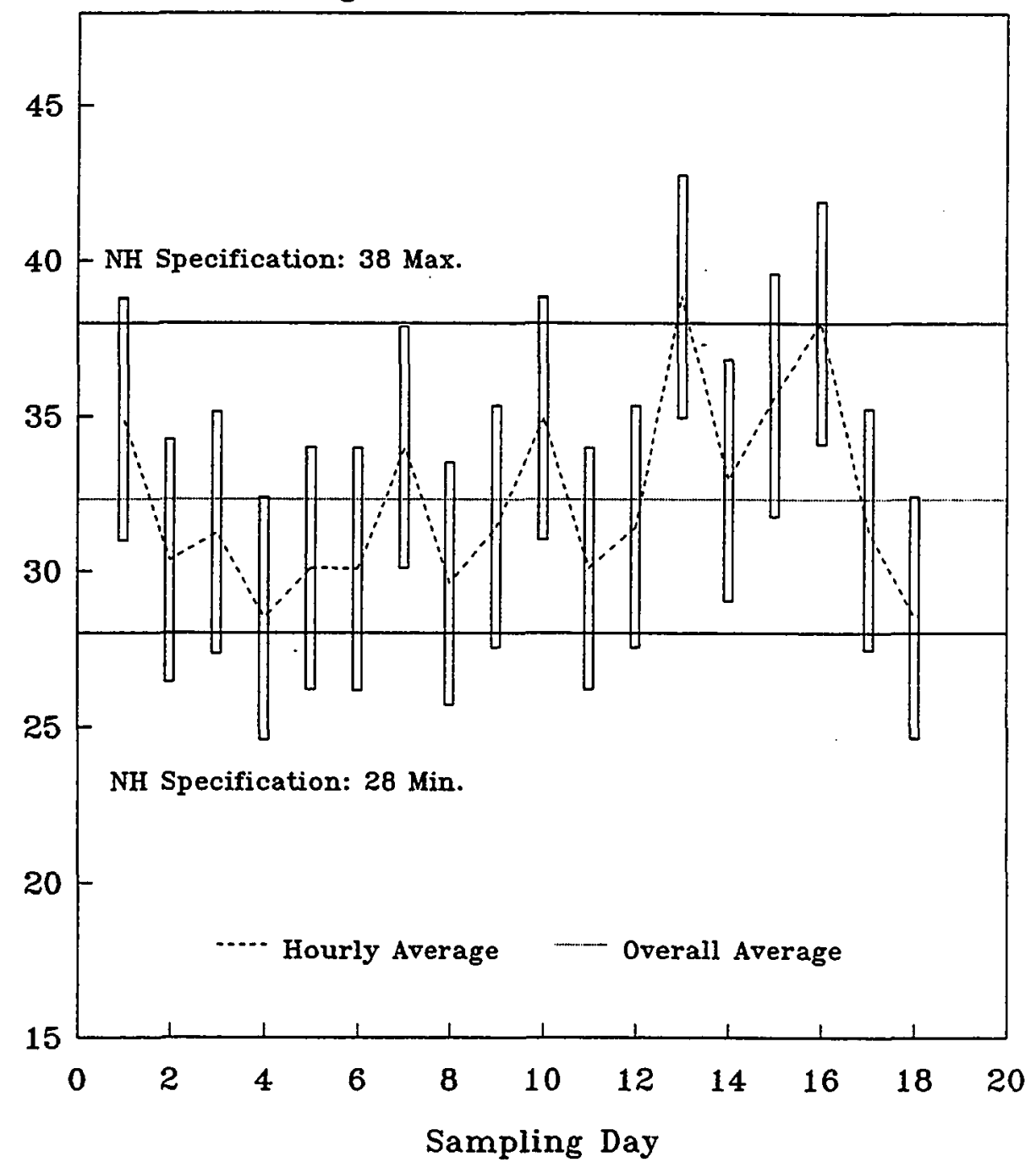

Figure 5.8 Percent Passing of No.10 Ash versus Sampling Day 


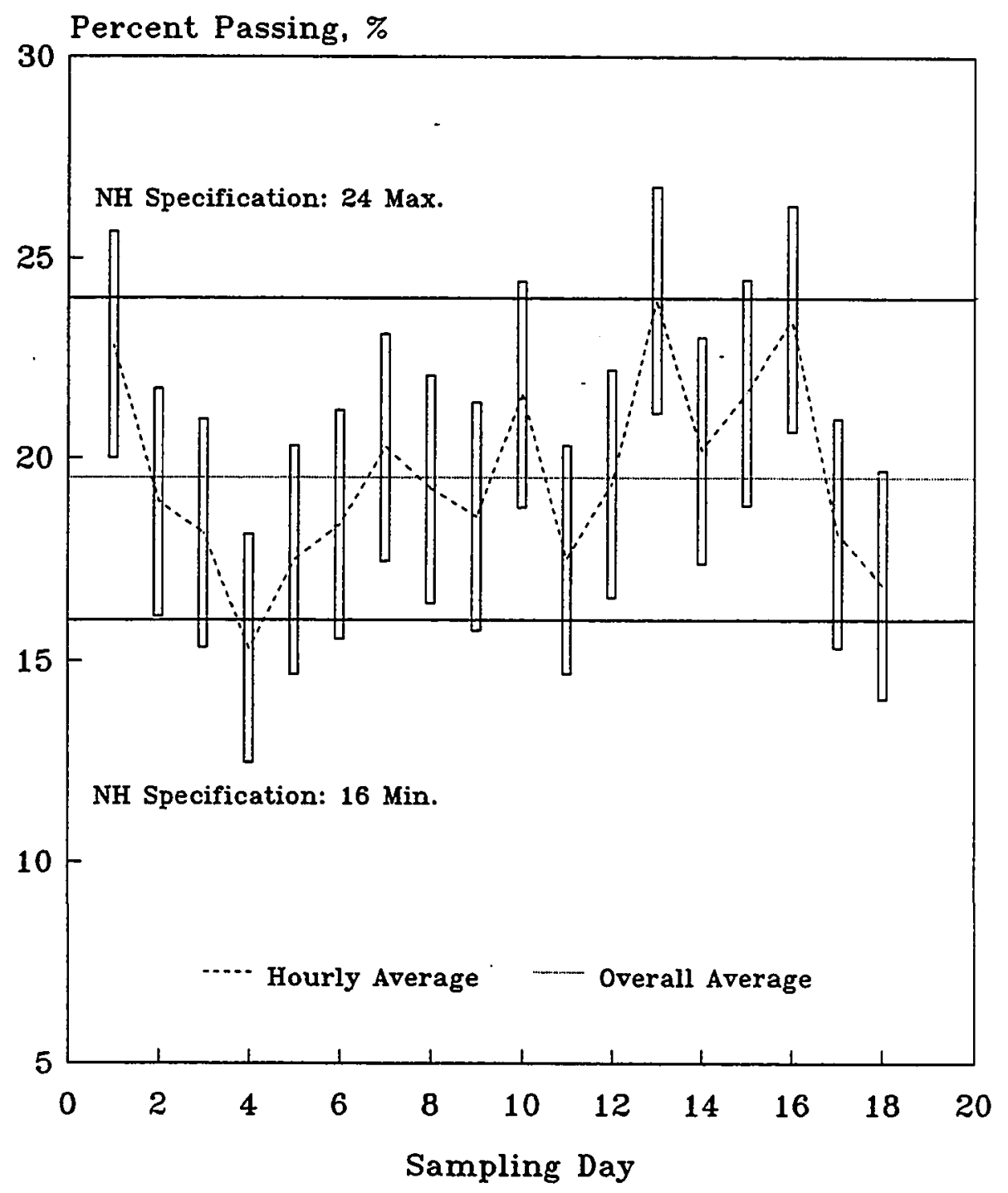

Figure 5.9 Percent Passing of No.20 Ash versus Sampling Day 91 


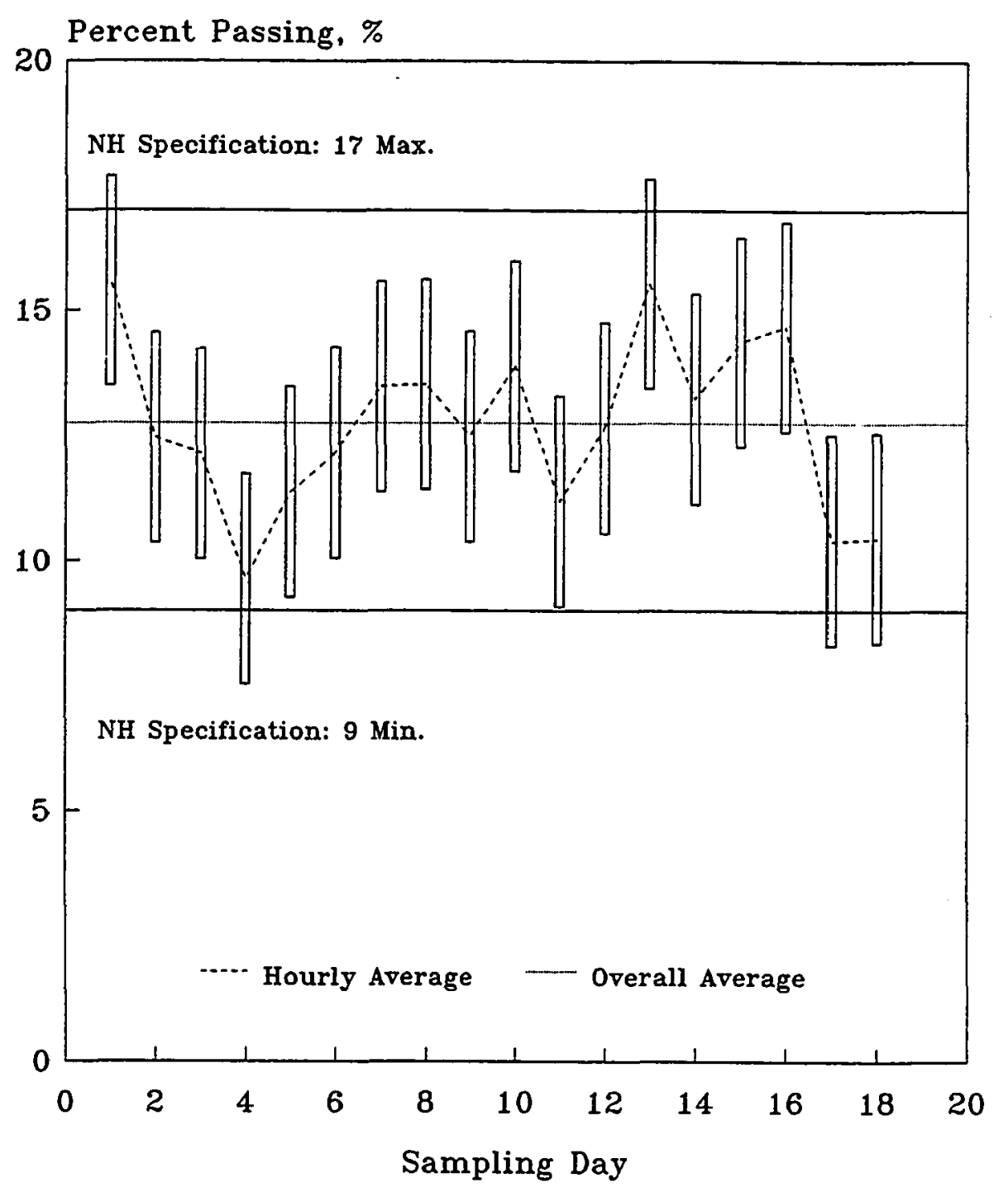

Fig. 5.10 Percent Passing of No.40 Ash versus Sampling Day 92 


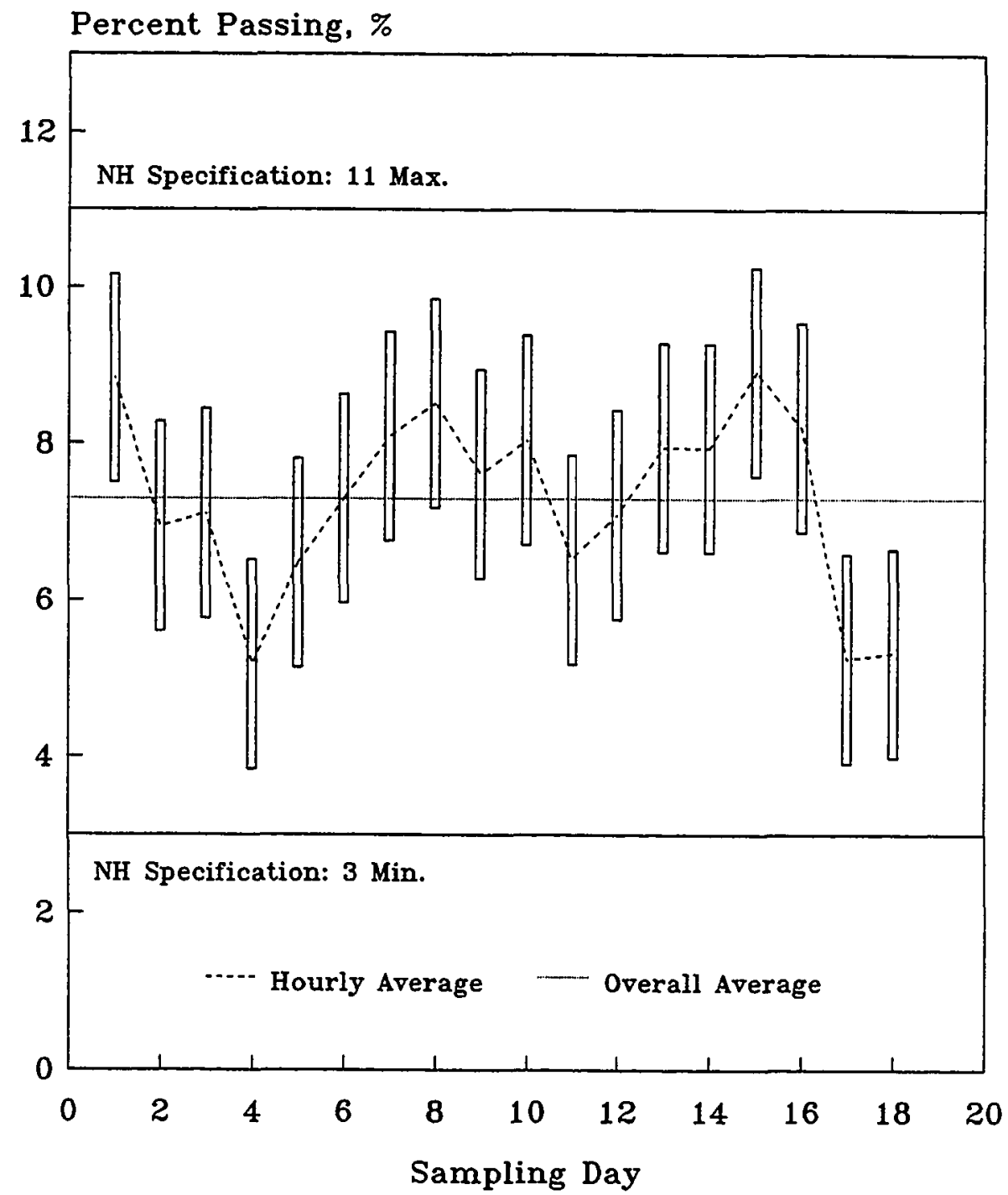

Fig. 5.11 Percent Passing of No.80 Ash versus Sampling Day 


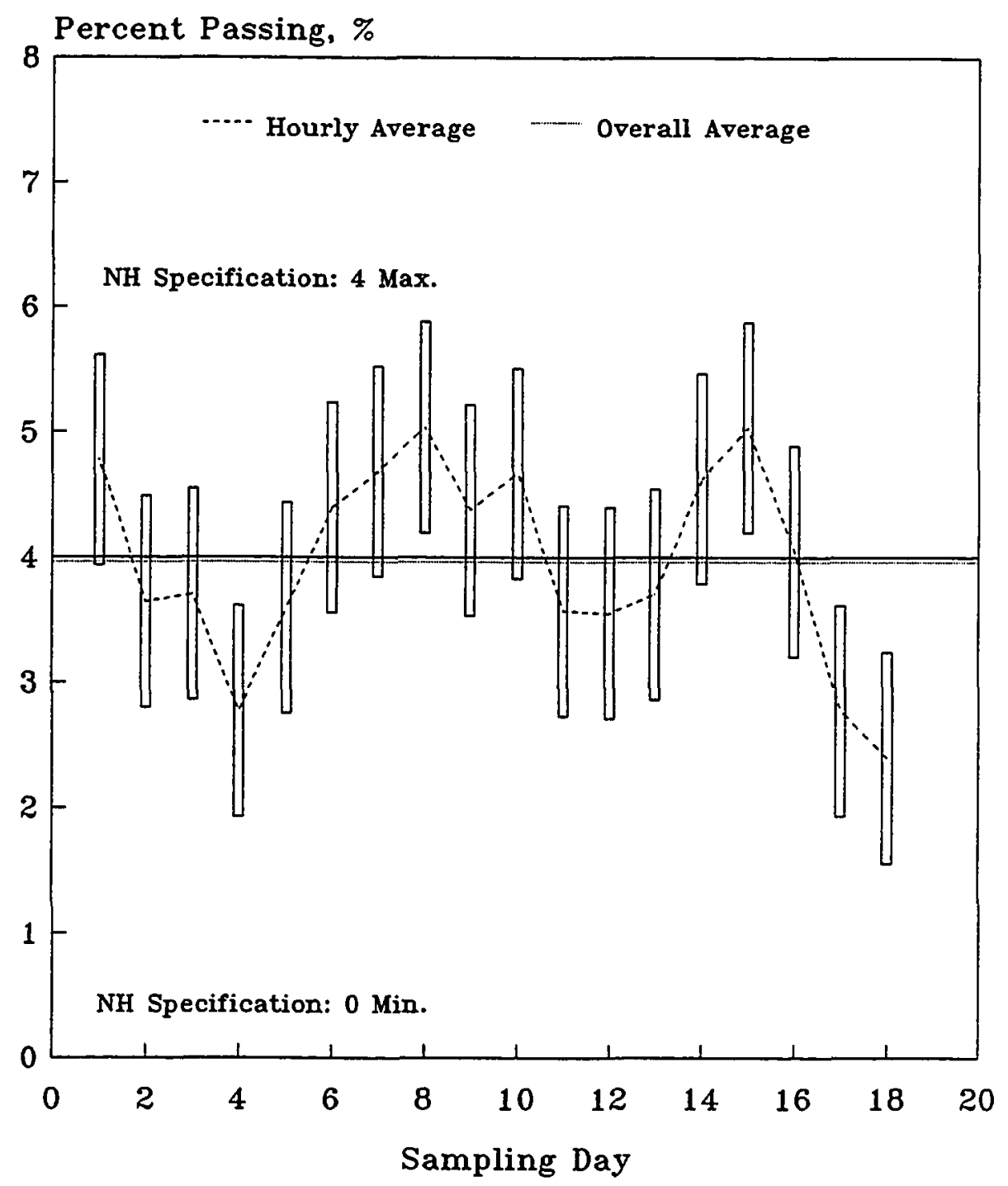

Fig. 5.12 Percent Passing of No.200 Ash versus Sampling Day 
Table 5.4 Statistics of Gradation (Percent Passing)

\begin{tabular}{|l|l|l|c|c|c|}
\hline \multirow{2}{*}{$\begin{array}{l}\text { Particle } \\
\text { Size }\end{array}$} & \multirow{2}{*}{ Average } & \multirow{2}{*}{ Range } & \multicolumn{3}{|c|}{ NH Specification } \\
\cline { 4 - 6 } & & & $\min$. & $\max$. & desired \\
\hline $3 / 4^{n}$ & 99.81 & $98.71-100.0$ & 95 & 100 & 100 \\
\hline $1 / 2^{n}$ & 89.25 & $83.51-94.99$ & 70 & 92 & 81 \\
\hline $3 / 8^{n}$ & 77.10 & $66.10-85.61$ & 60 & 80 & 71 \\
\hline$\# 4$ & 51.17 & $42.04-62.10$ & 42 & 57 & 50 \\
\hline$\# 10$ & 32.34 & $24.60-42.75$ & 28 & 38 & 32 \\
\hline$\# 20$ & 19.55 & $12.48-26.77$ & 16 & 24 & 20 \\
\hline$\# 40$ & 12.73 & $7.54-17.69$ & 9 & 17 & 13 \\
\hline$\# 80$ & 7.30 & $3.84-10.26$ & 3 & 11 & 7 \\
\hline$\# 200$ & 3.97 & $1.56-5.88$ & 0 & 4 & 3 \\
\hline
\end{tabular}


bottom ash is compared with $\mathrm{NH}$ specification is to investigate how well the ash is graded.

Variation of gradation is more important than the actual gradation. The comparison of NH allowable variation and bottom ash variation is presented in Table 5.5. The variations of $3 / 4^{n}, 1 / 2^{n}, 3 / 8^{n}$ and No.80 bottom ash are within the NH allowable variation. The variations of the other bottom ash sizes are not within the $\mathrm{NH}$ allowable. The above discussion was based on a $95 \%$ confidence level.

\subsubsection{Daily Composite Samples}

The daily composite sample was created from 4 hourly samples. One daily composite can be treated as one measurement. If there are $\mathrm{n}$ measurements, the average of the daily composite is: $\quad \bar{x}=\frac{\sum_{i=1}^{n} x_{i}}{n}$

A $(1-2 \alpha) 100 \%$ confidence interval for the mean percent passing is:

$$
\left[\bar{x}-\frac{t_{\alpha} s}{\sqrt{n}}<\mu<\bar{x}+\frac{t_{\alpha} s}{\sqrt{n}}\right]
$$

where,

$t_{\alpha}$ is the critical $t$ value with $n-1$ degrees of freedom.

Table 5.6 presents the statistical data of daily composite samples and $\mathrm{NH}$ gradation specification for type B binder mix. Figure 5.13 through Figure 5.23 presents the comparison of bottom ash gradation and NH specification. It was found that:

1. The average gradation falls within the New Hampshire gradation specification with the exception of the materials passing No.200 in which case the mean lies slightly outside 
Table 5.5 Bottom Ash Gradation Variation

\begin{tabular}{|l|c|c|}
\hline $\begin{array}{l}\text { Particle } \\
\text { Size }\end{array}$ & $\mathrm{NH}_{\max }-\mathrm{NH}_{\min }$ & High Limit - Low Limit \\
\hline $3 / 4^{n}$ & 5 & 1.29 \\
\hline $1 / 2^{n}$ & 22 & 11.48 \\
\hline $3 / 8^{n}$ & 20 & 19.51 \\
\hline$\# 4$ & 15 & 20.06 \\
\hline$\# 10$ & 10 & 18.15 \\
\hline$\# 20$ & 8 & 14.29 \\
\hline$\# 40$ & 8 & 10.15 \\
\hline$\# 80$ & 8 & 6.41 \\
\hline$\# 200$ & 4 & 4.32 \\
\hline
\end{tabular}


Table 5.6 Gradation Statistics for Daily Composites

\begin{tabular}{|c|c|c|c|c|c|c|c|c|c|c|}
\hline \multirow[t]{2}{*}{$\begin{array}{l}\text { Sieve } \\
\text { Size }\end{array}$} & \multirow[t]{2}{*}{ No. } & \multirow[t]{2}{*}{ Mean } & \multicolumn{2}{|c|}{$\begin{array}{l}\text { New Hampshire } \\
\text { Specification } \\
\end{array}$} & \multicolumn{6}{|c|}{ Confidence Interval } \\
\hline & & & Desired & Range & $75 \%$ & $90 \%$ & 95\% & $97.5 \%$ & $99 \%$ & $99.5 x$ \\
\hline $3 / 4^{\prime \prime}$ & 20 & 99.84 & 100 & $95-100$ & $99.73-99.95$ & $99.68-100$ & $99.65-100.00$ & $99.62-100.00$ & $99.58-100.00$ & $99.55-100.00$ \\
\hline $1 / 2^{11}$ & 20 & 91.15 & 81 & $70-92$ & 90.33-91.96 & $89.96-92.34$ & $89.71-92.59$ & $89.47-92.82$ & $89.18-93.11$ & $88.96-93.33$ \\
\hline 3/8" & 20 & 79.58 & 71 & $60-80$ & $78.29-80.87$ & $77.70-81.47$ & $77.30-81.86$ & $76.93-82.23$ & $76.47-82.70$ & $76.13-83.04$ \\
\hline$\$ 4$ & 20 & 53.82 & 50 & 42-57 & $52.40-55.24$ & $51.75-55.89$ & $51.31-56.33$ & $50.90-56.74$ & $50.39-57.25$ & $50.02-57.62$ \\
\hline$\# 10$ & 20 & 34.45 & 32 & 28-38 & $33.42-35.48$ & 32.95-35.95 & $32.63-36.27$ & $32.34-36.57$ & $31.96-36.94$ & $31.69-37.21$ \\
\hline$\# 20$ & 20 & 21.78 & 20 & $16-24$ & $21.15-22.41$ & $20.86-22.69$ & $20.67-22.89$ & $20.49-23.07$ & $20.27-23.29$ & $20.10-23.46$ \\
\hline$\# 0$ & 20 & 15.01 & 13 & 9-17 & $14.59-15.42$ & $14.40 \cdot 15.61$ & 14.29-15.74 & $14.16 \cdot 15.85$ & $14.01-16.00$ & $13.90-16.11$ \\
\hline$\# 80$ & 20 & 8.79 & 7 & $3 \cdot 11$ & $8.52-9.06$ & 8.39-9.19 & $8.31-9.27$ & $8.23-9.35$ & $8.13-9.45$ & $8.06-9.52$ \\
\hline$\# 200$ & 20 & 4.14 & 3 & $0-4$ & $4.10-4.71$ & $3.95-4.86$ & $3.86-4.95$ & $3.77-5.04$ & $3.66-5.15$ & $3.58-5.23$ \\
\hline
\end{tabular}




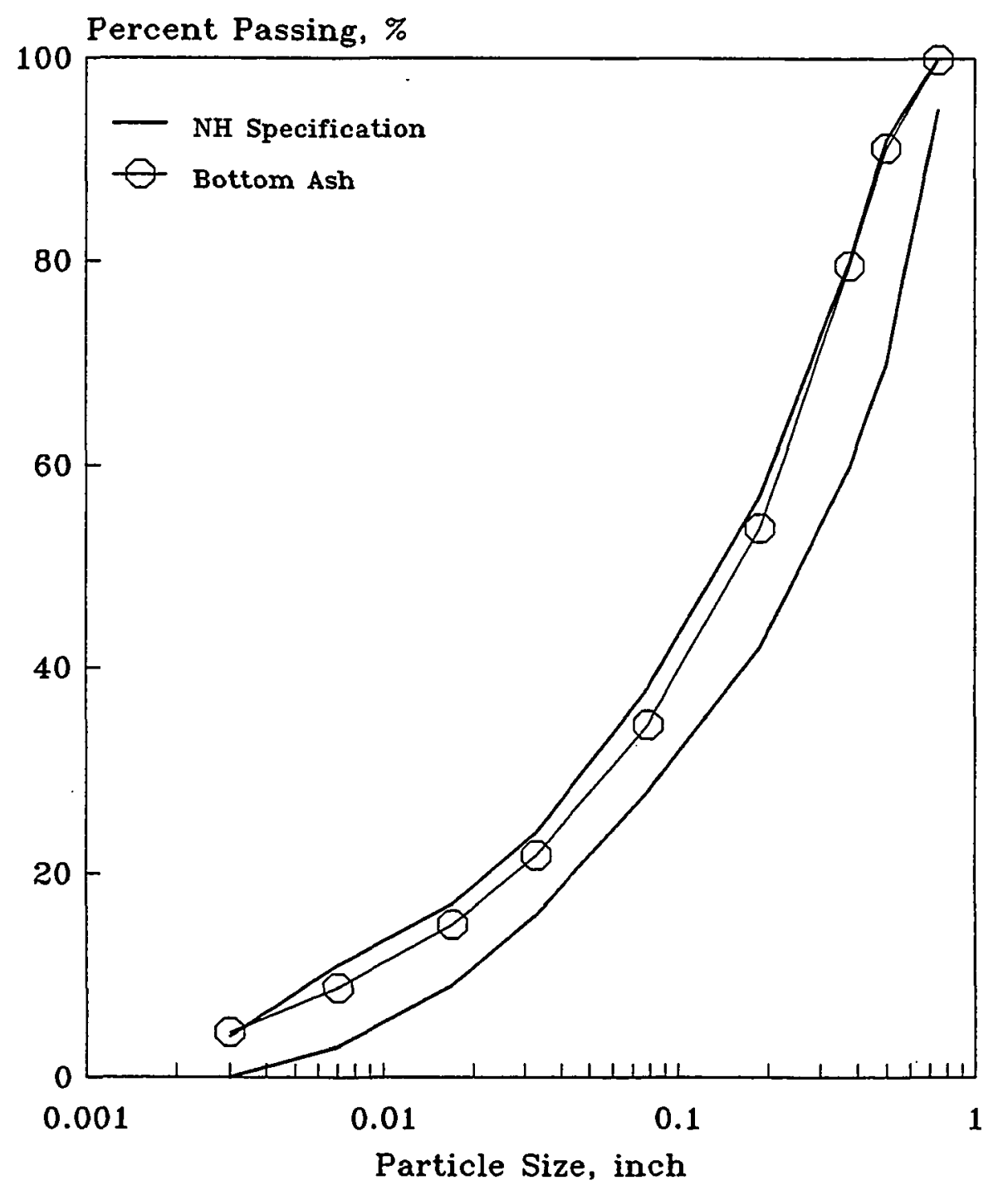

Figure 5.13 Average Gradation (Daily Composite) 


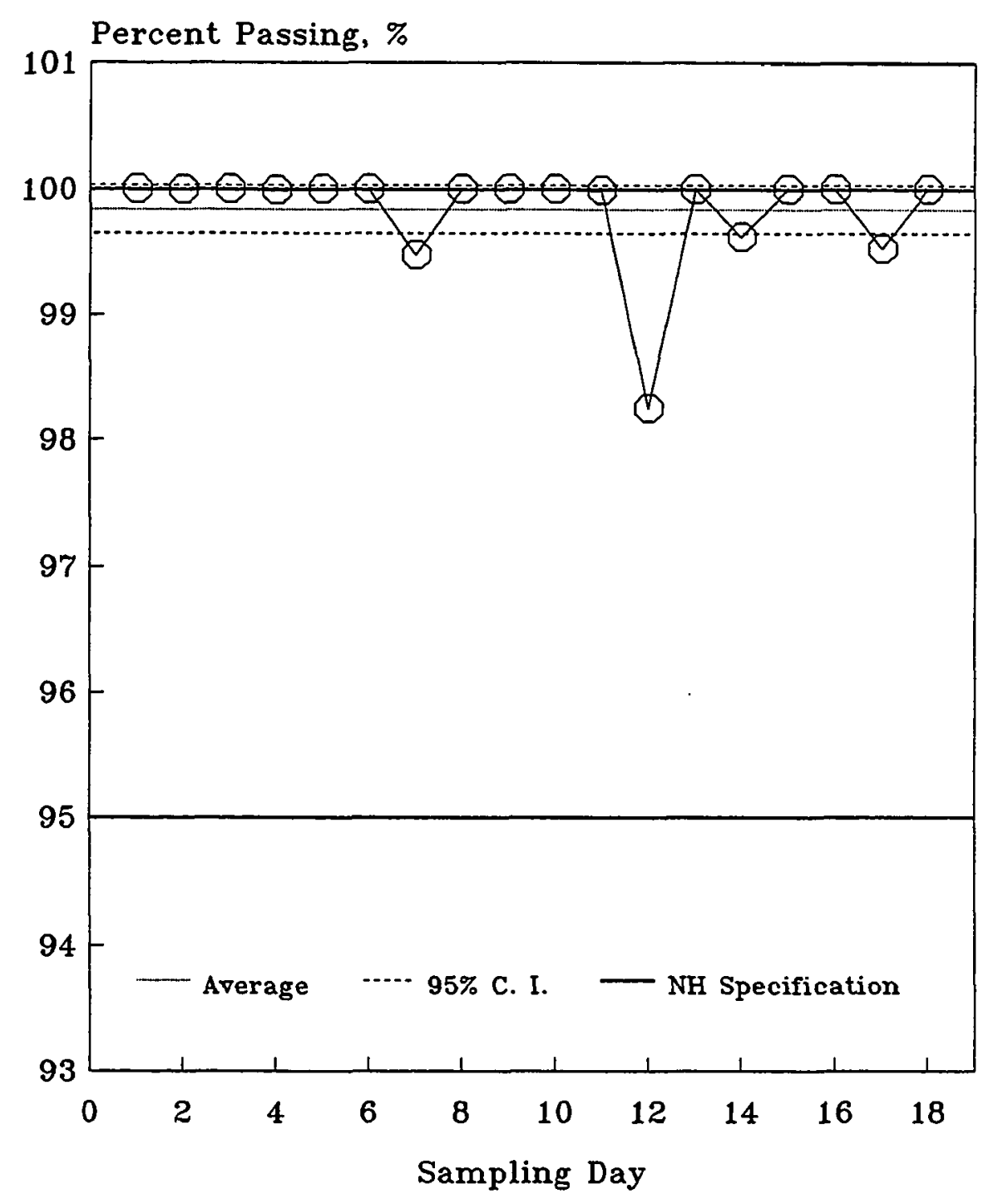

Figure 5.14 Percent Passing of 3/4" Ash versus Sampling Day (Daily Composite)

100 


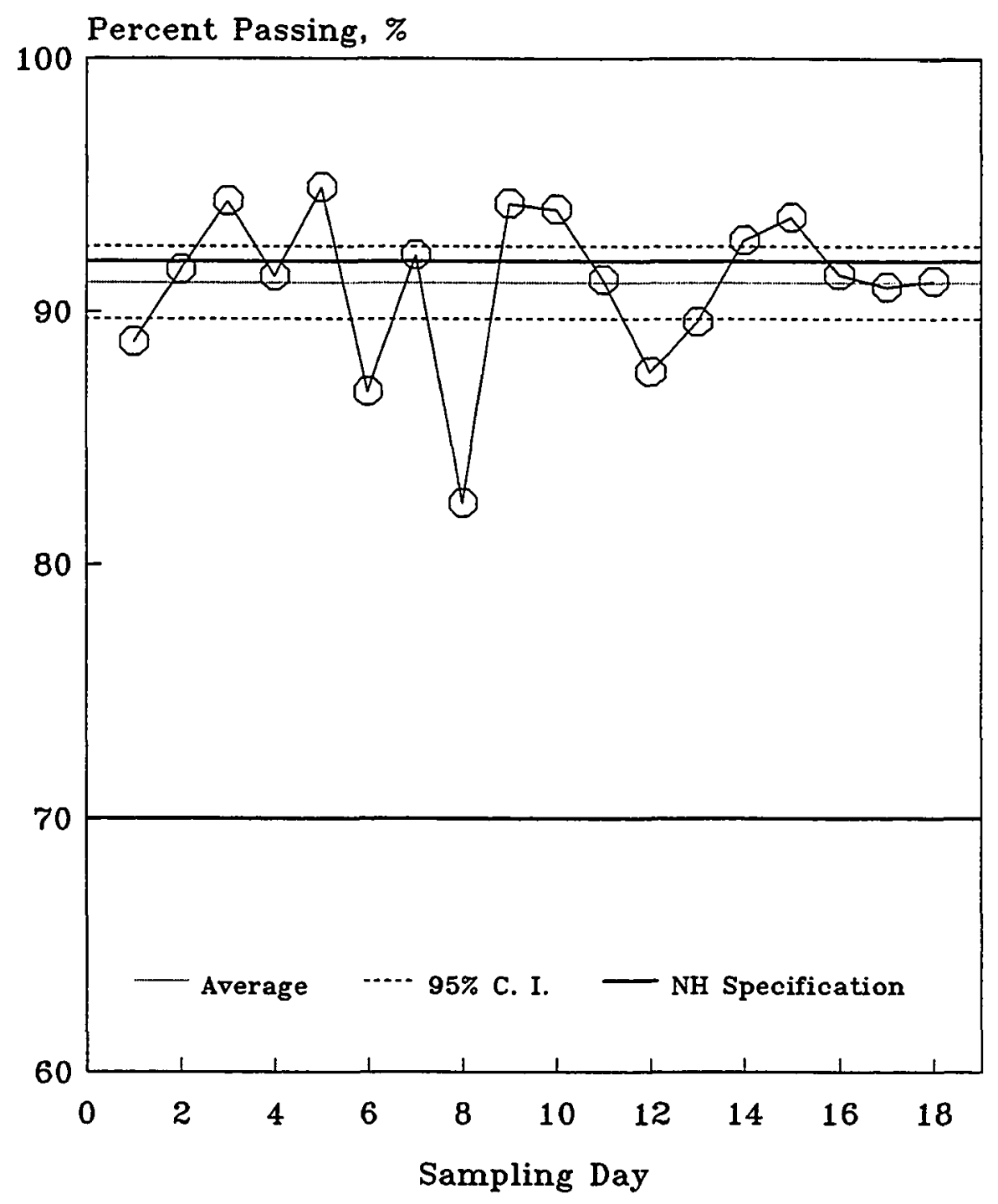

Figure 5.15 Percent Passing of 1/2" Ash versus Sampling Day (Daily Composite)

101 


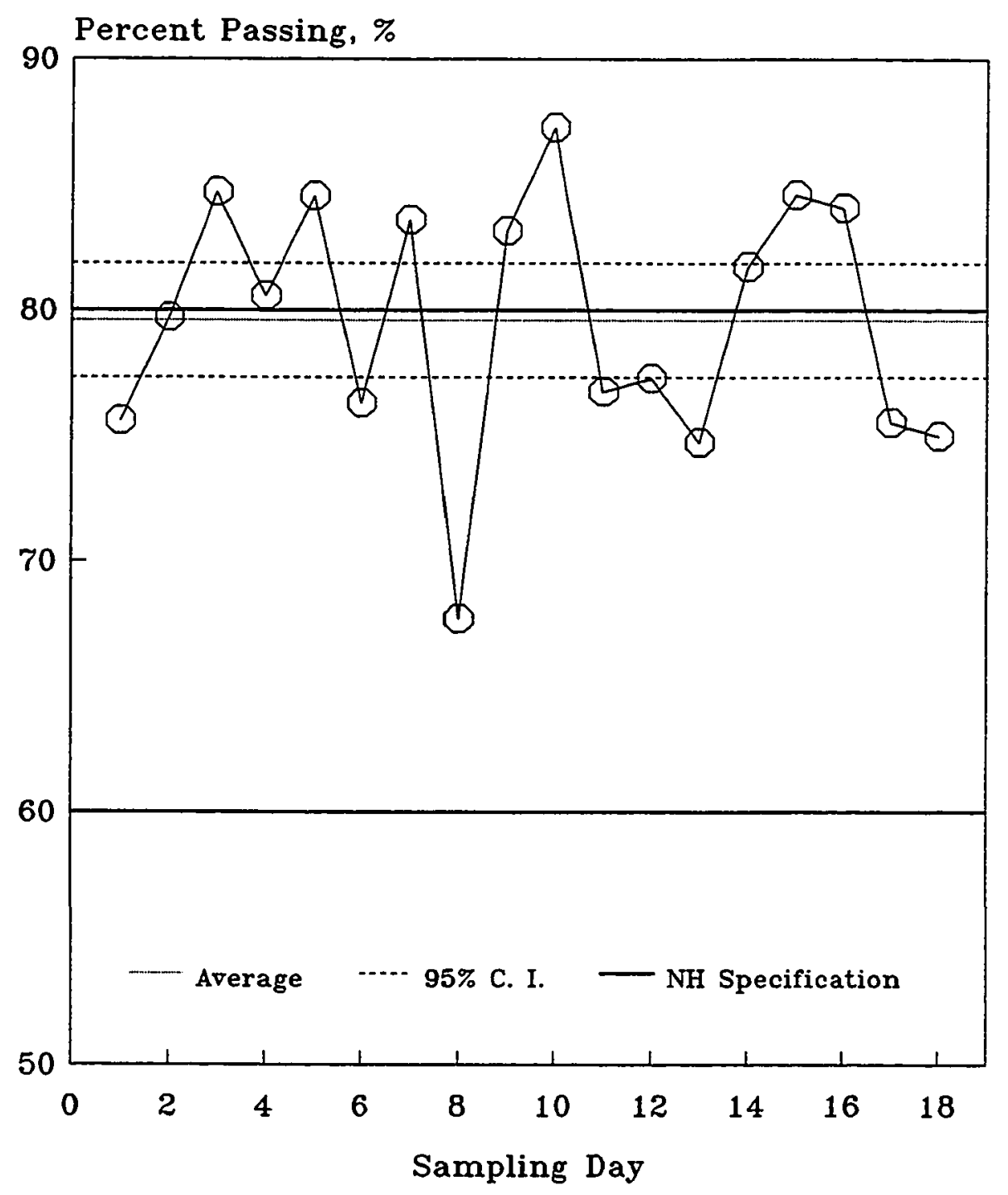

Figure 5.16 Percent Passing of 3/8" Ash versus Sampling Day (Daily Composite) 102 


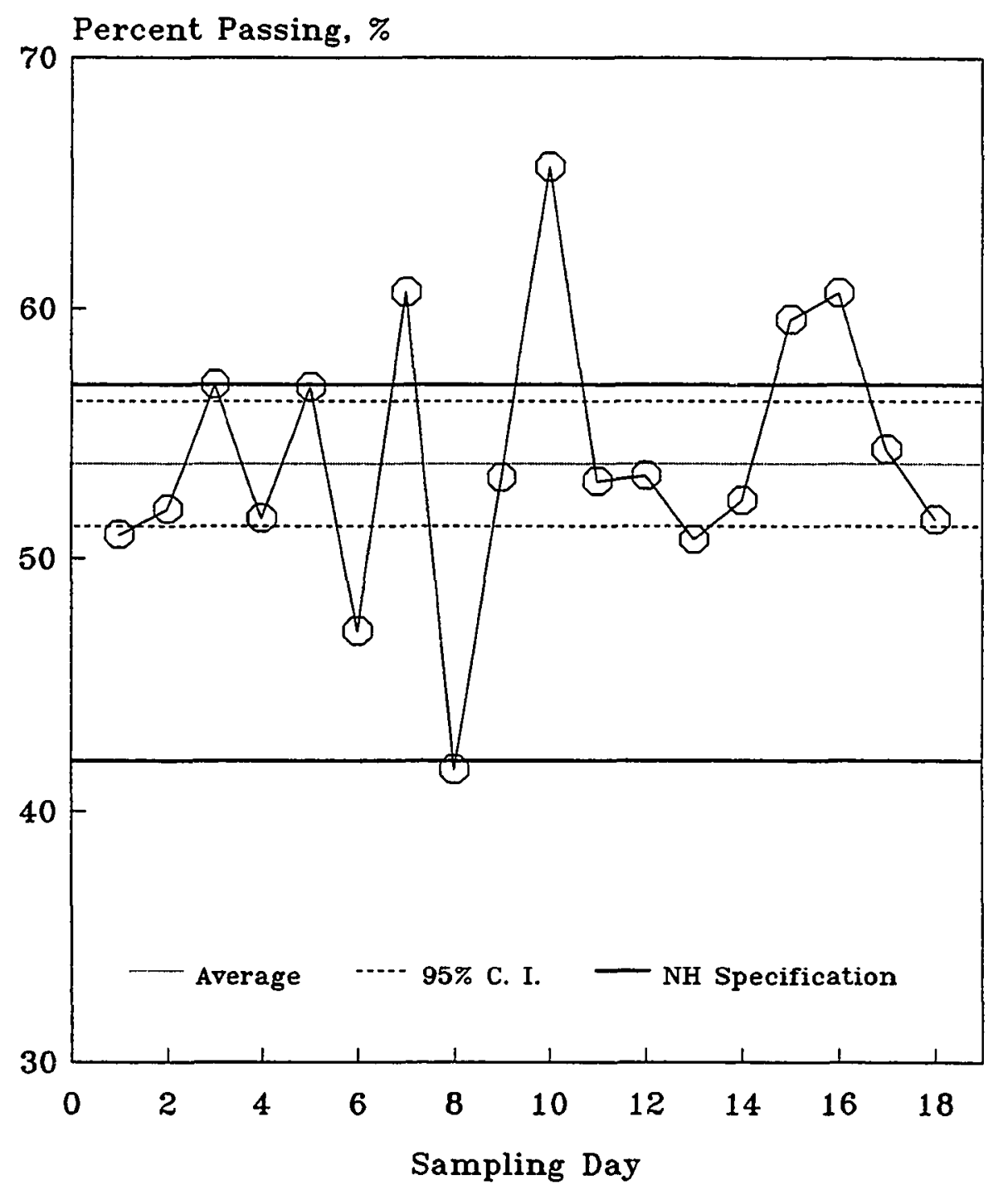

Figure 5.17 Percent Passing of No.4 Ash versus Sampling Day (Daily Composite)

103 


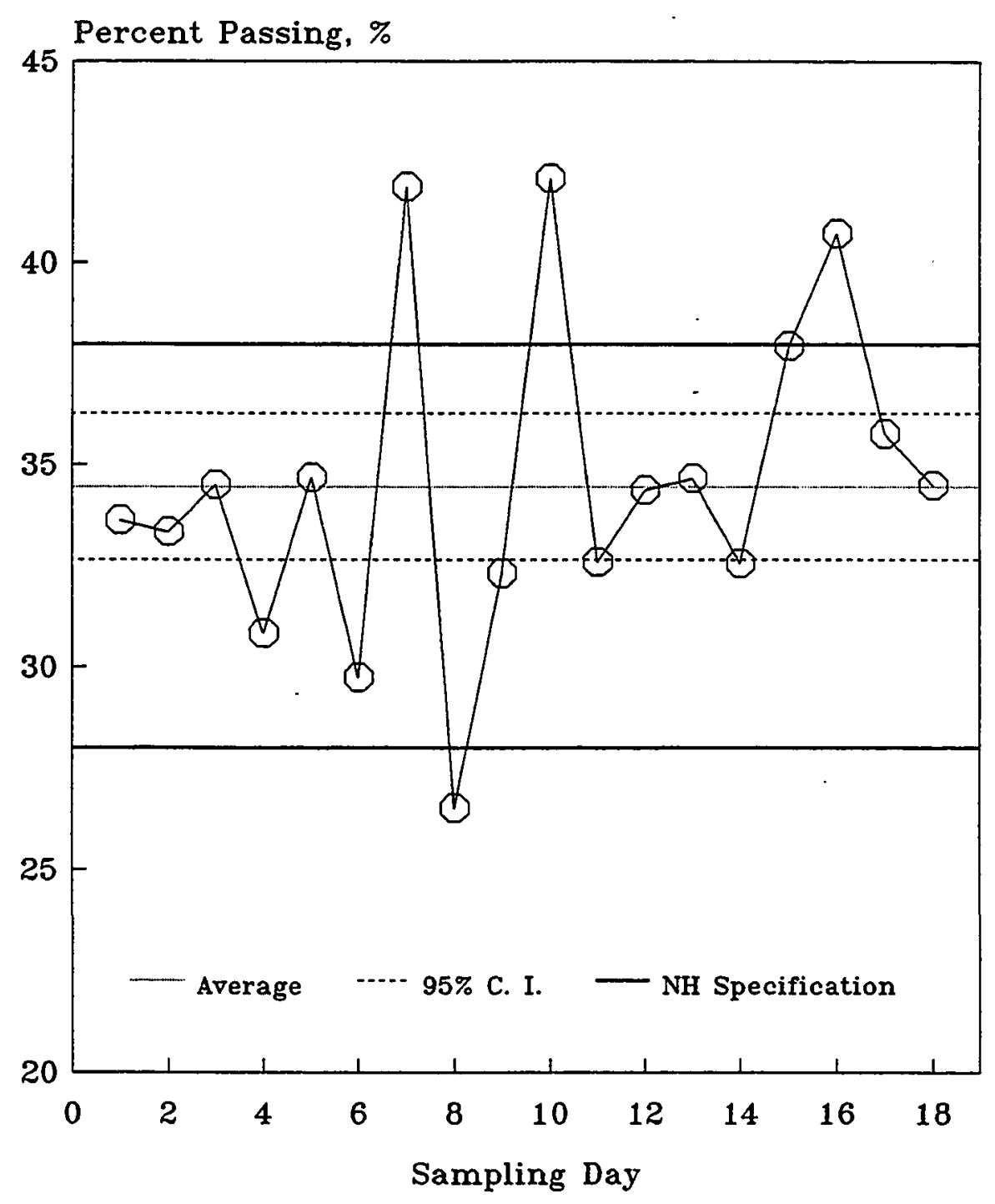

Fig. 5.18 Percent Passing of No.10 Ash versus Sampling Day (Daily Composite)

104 


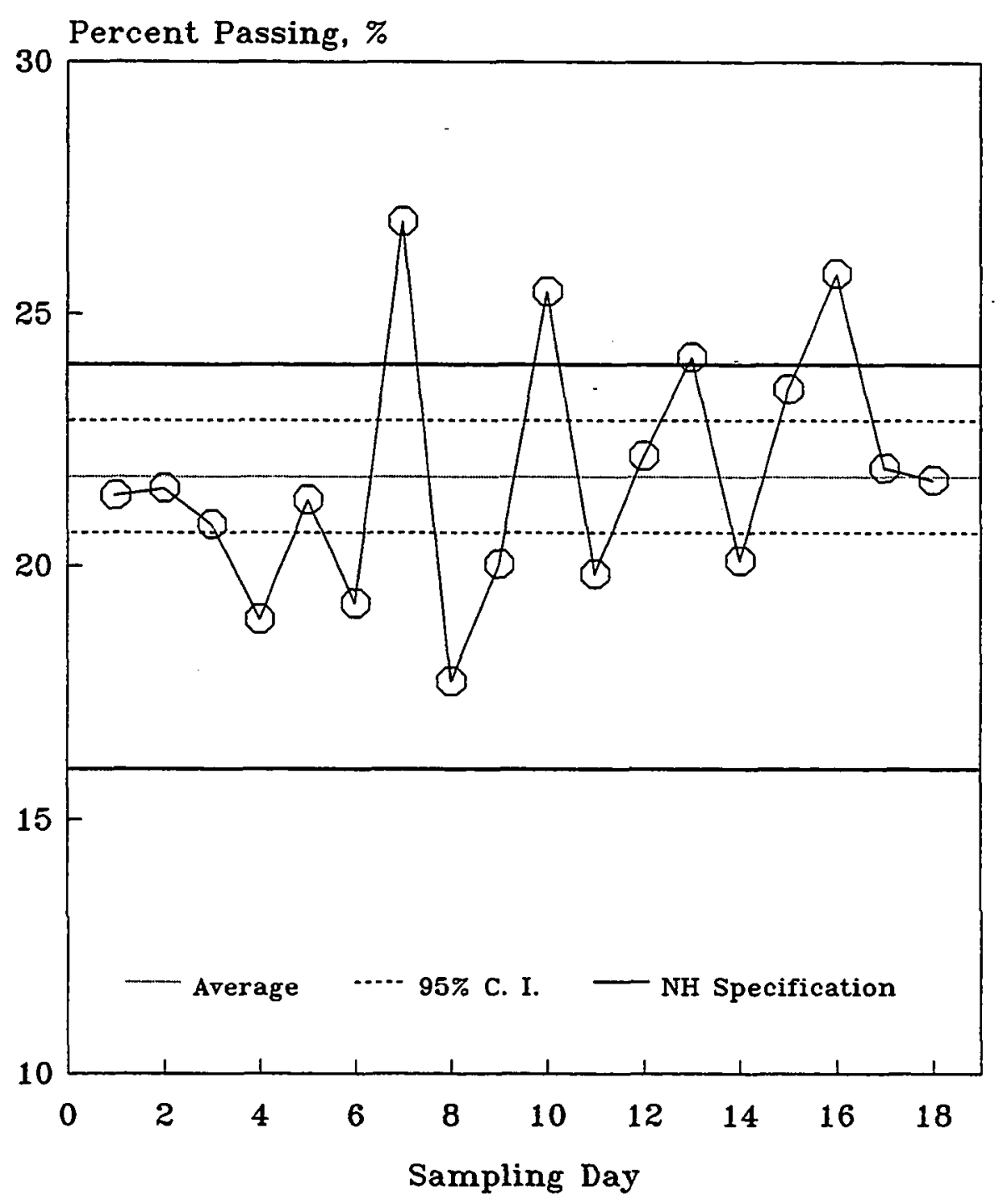

Fig. 5.19 Percent Passing of No.20 Ash versus Sampling Day (Daily Composite) 105 


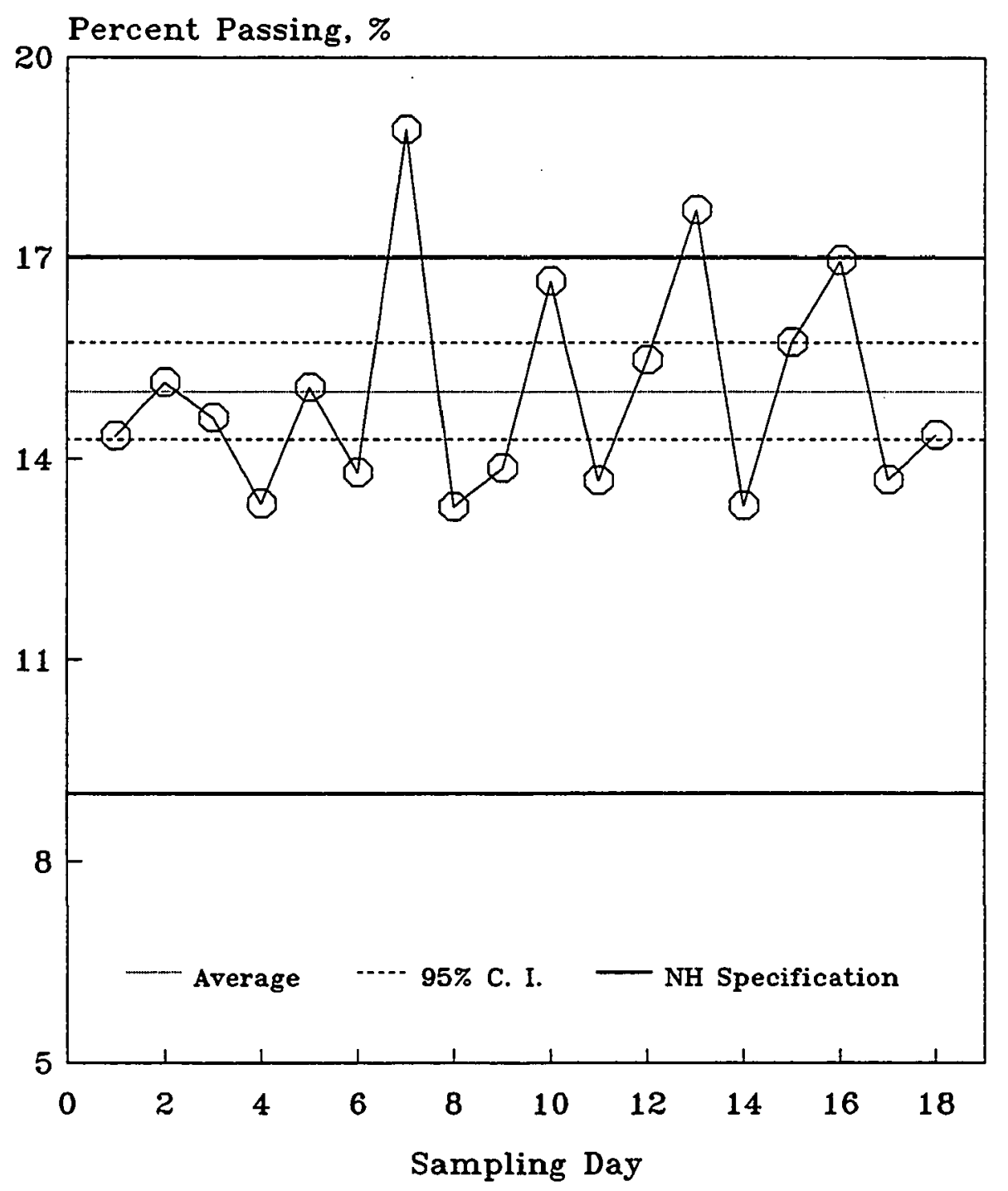

Fig. 5.20 Percent Passing of No.40 Ash versus Sampling Day (Daily Composite) 106 


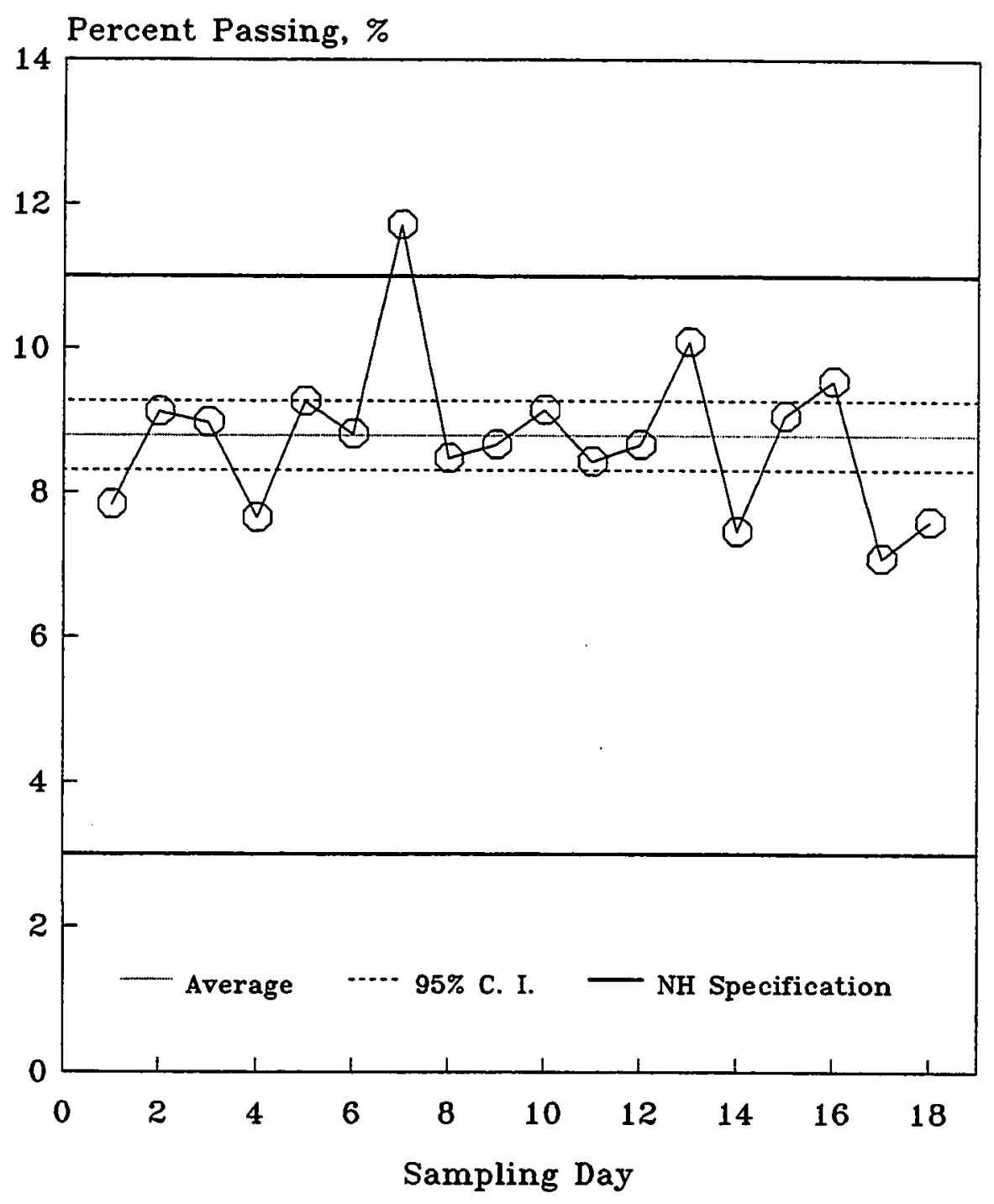

Fig. 5.21 Percent Passing of No.80 Ash versus Sampling Day (Daily Composite) 


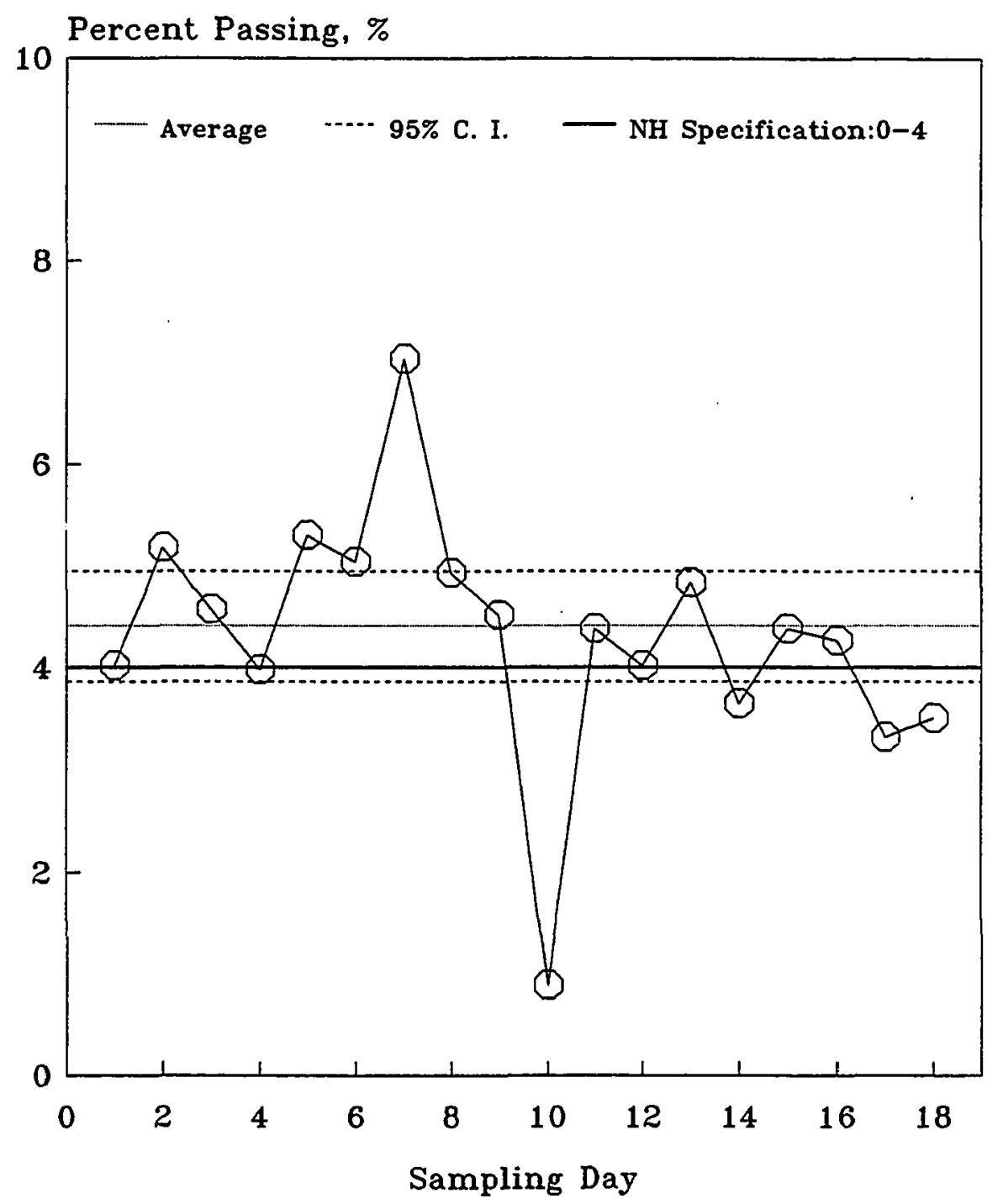

Fig. 5.22 Percent Passing of No.200 Ash versus Sampling Day (Daily Composite)

108 


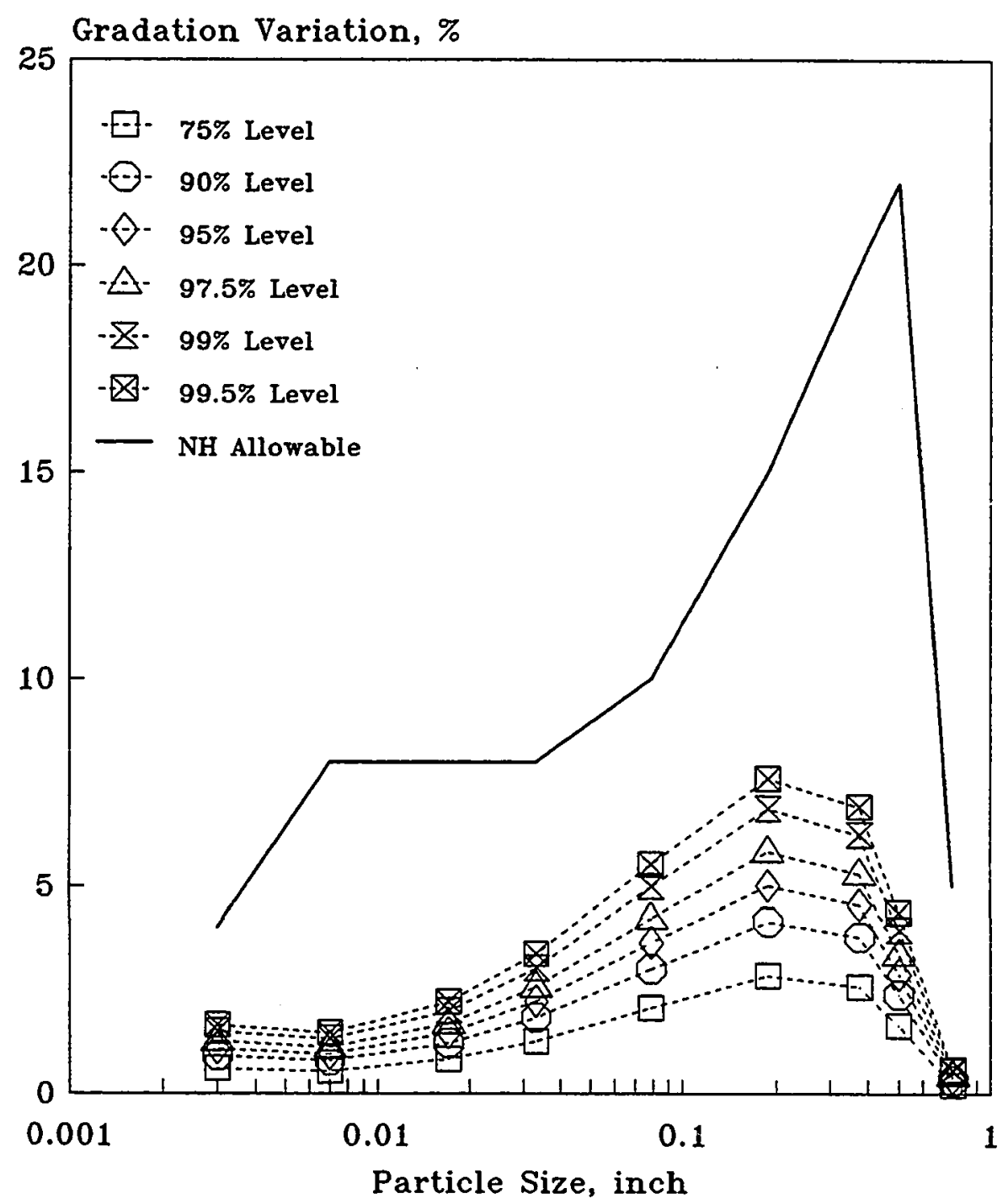

Figure 5.23 Gradation Variation (Daily Composite) 
the specification.

2. Bottom ash contains more fine materials in comparison to the $\mathrm{NH}$ desired gradation.

3. Gradation variations of bottom ash are small in comparison to $\mathrm{NH}$ allowable variation. The variation of the daily composite is much smaller than that from hourly samples.

4. The average gradation of daily composites is close to that from hourly samples.

\subsubsection{Source of Variation}

All ash samples show variation in gradation. The variation could be contributed by two sources.

\section{Sample Representativeness}

The bottom ash collected was fully mixed before they were trucked to the University of New Hampshire. A 800-1000 g ash sample was collected for sieve analysis. The sieve analysis was run on the entire sample including both coarse fraction ( $\geq$ No.4) and fine fraction (< No.4). ASTM C136 requires $500 \mathrm{~g}$ materials for fine fraction and $8000 \mathrm{~g}$ materials for coarse fraction. Hence, the amount of bottom ash used for sieve analysis in this project might not be well representative of bottom ash population.

2. Sieve Analysis Method

Aggregate gradation is the distribution of particle sizes expressed as a percent of the total weight. The gradation as a percent of the total volume is of most importance, but expressing gradation as a percent by weight is much easier and is standard practice. The gradation by volume and weight is approximately the same as long as the specific 
gravities of the various aggregates being used are approximately equal. If there are large differences in the specific gravity of aggregates being used for a particular mix, then the gradation should be determined as a percent of total volume. As shown in Figure 4.1, approximately $92 \%$ of coarse bottom ash are glass, clinker, and clinker with iron. The specific gravity of glass, clinker, and clinker with iron is $2.32,2.04$, and 2.74 respectively. The difference in the specific gravity of these materials is significant. Therefore, it would be more appropriate that the gradation of bottom ash is calculated based on total volume. However, doing so is not practical. The variation of ash compositions and the significant difference in the specific gravity of ash compositions result in some variability of test results.

\subsection{Other Physical Properties}

\subsubsection{Hourly Sample}

\subsubsection{Two-way Analysis of Variance (Two-way ANOVA)}

The between-day variation and between-hour variation of bottom ash properties are investigated with two-way analysis of variance. Figure 5.24 through Figure 5.27 presents the between-day and between-hour comparisons of calculated $F$ values with critical values at different confidence levels respectively.

Between Sampling Days: The variation of all physical properties is significant at any confidence level, with the exception that variation of uniformity coefficient and effective 


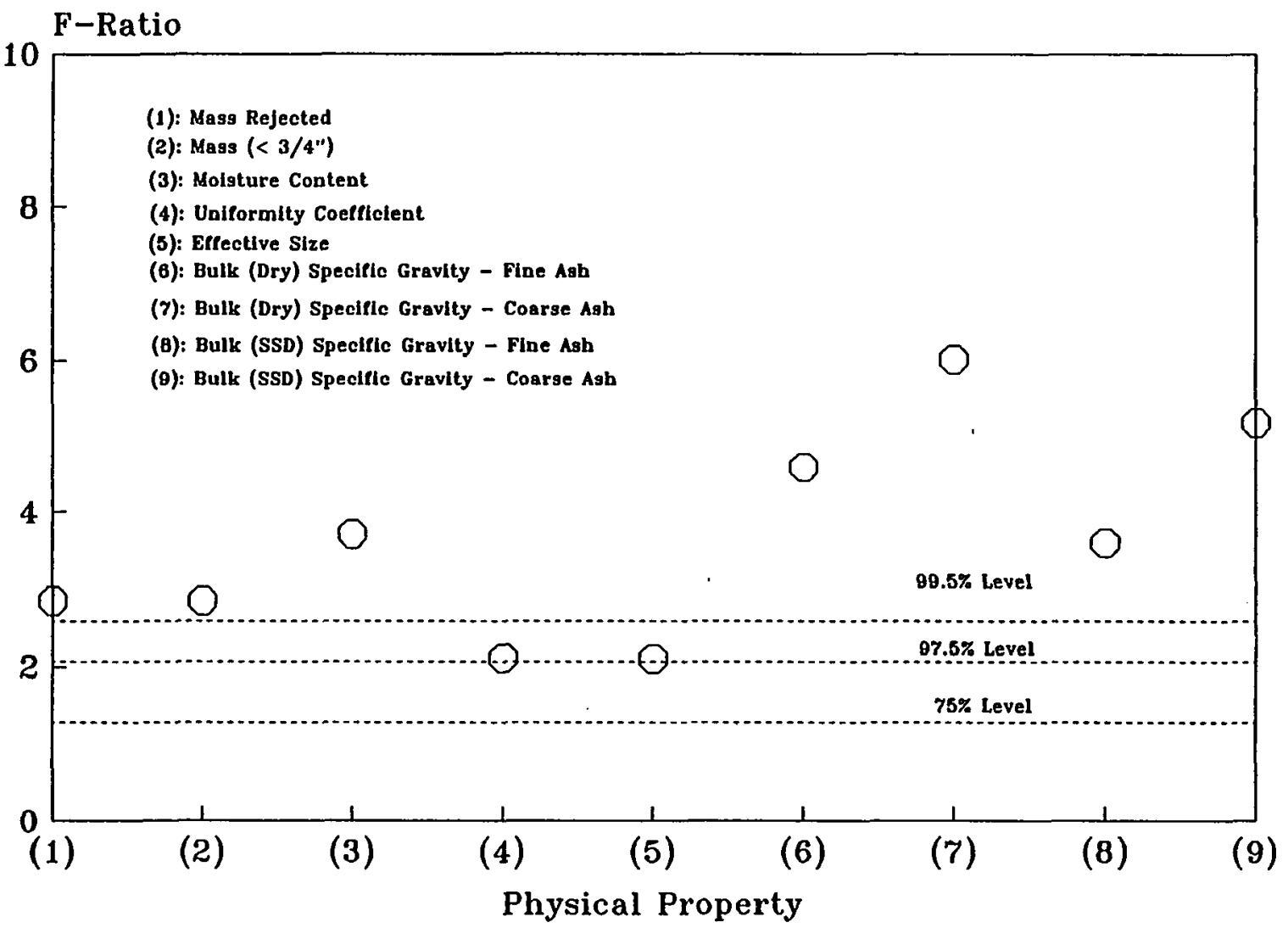

Fig. 5.24 F-Ratio of Two-way ANOVA versus Physical Property (Between Day Comparison) 


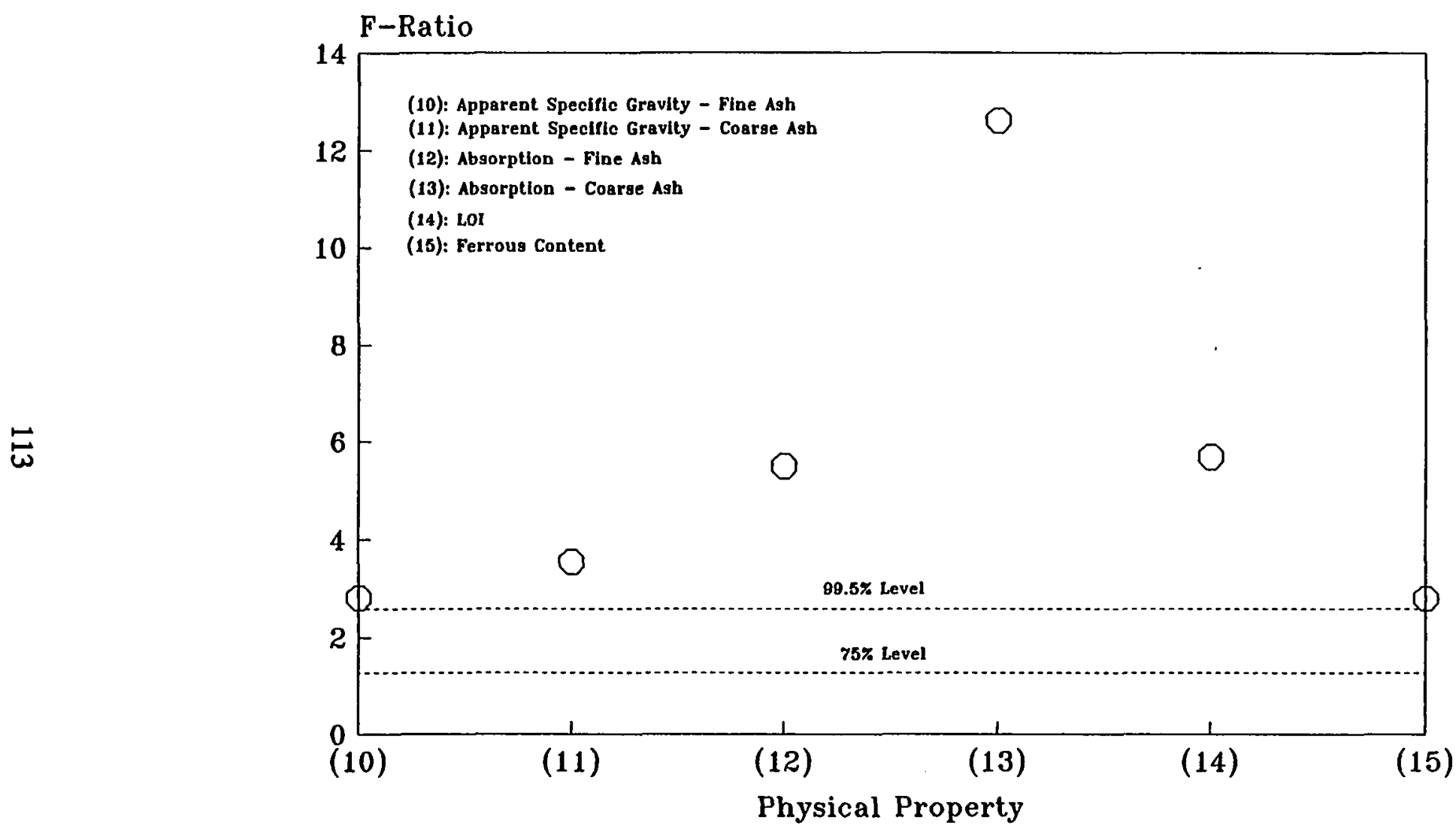

Fig. 5.25 F-Ratio of Two-way ANOVA versus Physical Property (Between Day Comparison, Continued) 


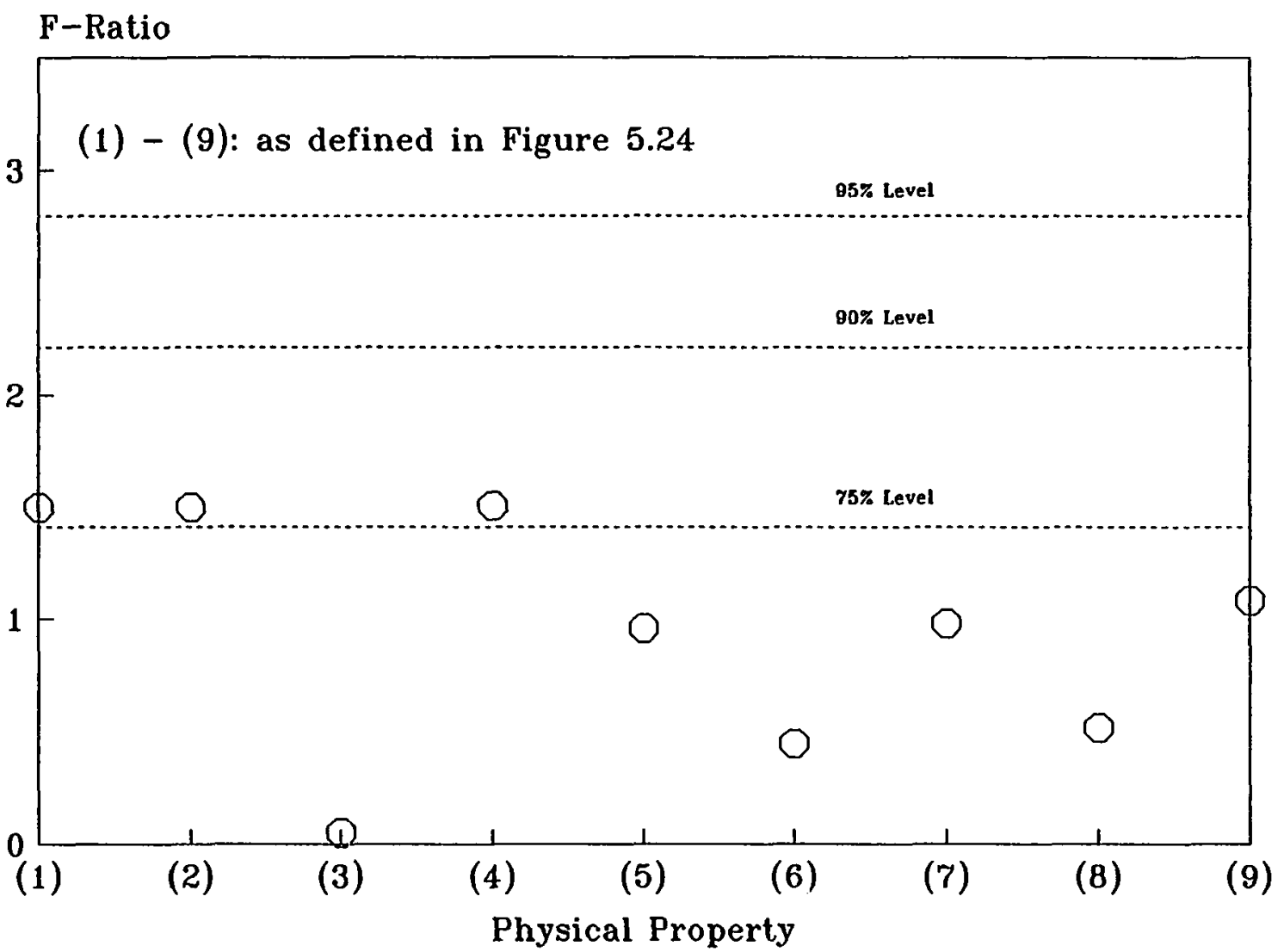

Fig. 5.26 F-Ratio of Two-way ANOVA versus Physical Property (Between Hour Comparison) 


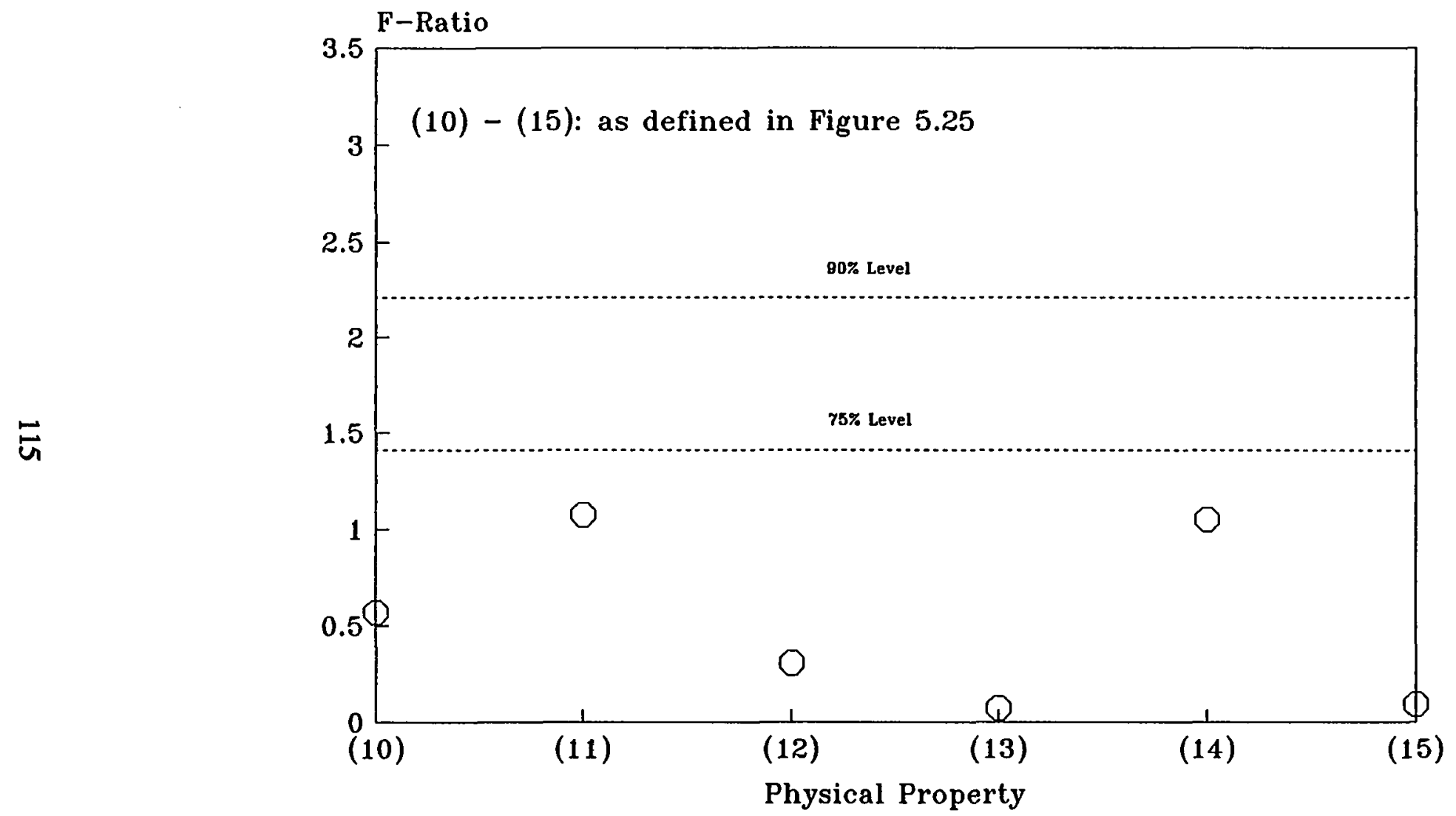

Fig. 5.27 F-Ratio of Two-way ANOVA versus Physical Property (Between Hour Comparison, Continued) 
size is not significant at $99 \%$ and $99.5 \%$ confidence levels.

Between Sampling Hours: The variation of all physical properties is not significant at any of the given confidence levels, with the exception that mass $\geq 3 / 4^{n}$, mass $<3 / 4^{n}$, and uniformity coefficient are marginal at $75 \%$ confidence level.

Inspection of Variance: It was concluded that the assumptions of homoscedasticity, normality, independence of errors are reasonable by looking at residuals in the same way as in 5.1 (particle size distribution).

\subsubsection{One-way Analysis of Variance (One-way ANOVA)}

Since the variations between sampling hours are not significant, the 4 hourly samples for each sampling day are treated as 4 replicates. One way analysis is conducted.

Figures 5.28 and 5.29 present the graphical comparison of the calculated F ratios with critical $\mathrm{F}$ values. The variation of all physical properties is significant at any of the given confidence level, with the exception that variation of uniformity coefficient and effective size is not significant at $99 \%$ and $99.5 \%$ confidence levels. This observation is similar to that from two-way ANOVA.

It was concluded that the assumptions of homoscedasticity, normality, independence of variance are reasonable by looking at residuals in the same way as in 5.1 (particle size distribution).

\subsubsection{Confidence Intervals}

The (1-2 $\alpha) 100 \%$ confidence intervals for each test day are calculated as before. 


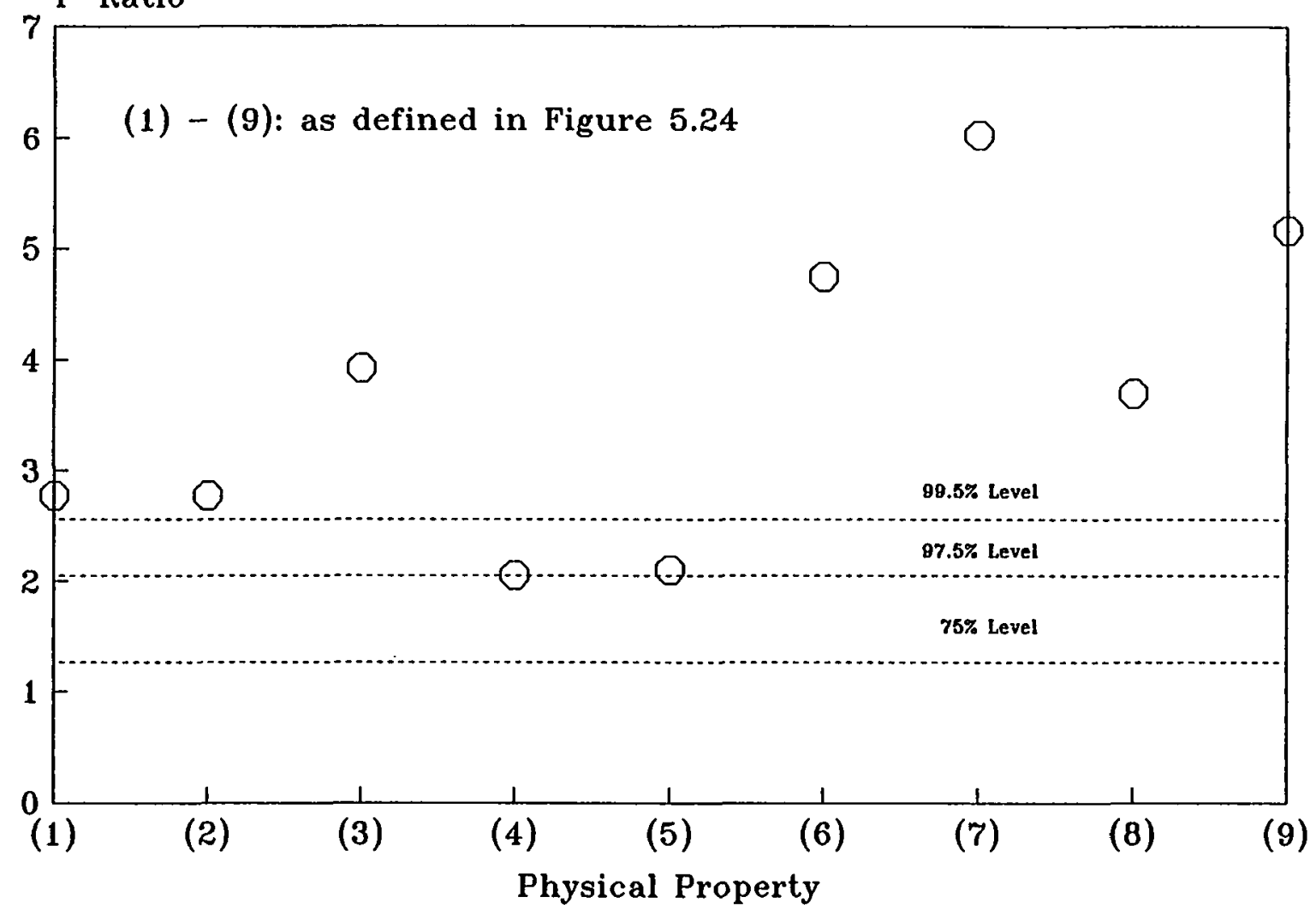

Fig. 5.28 F-Ratio of One-way ANOVA versus Physical Property (Between Day Comparison) 


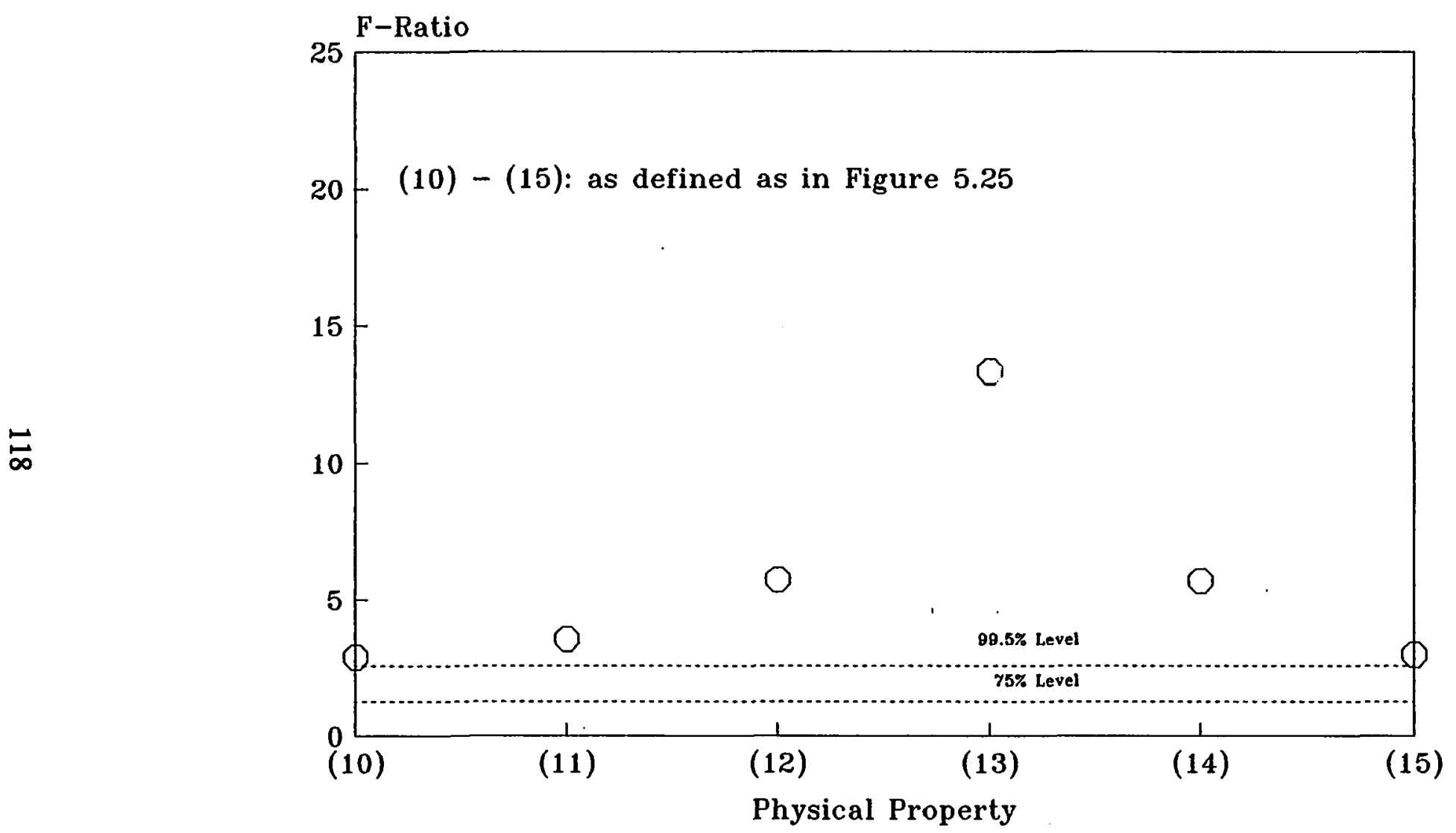

Fig. 5.29 F-Ratio of One-way ANOVA versus Physical Property (Between Day Comparison, Continued) 
Figure 5.30 through Figure 5.44 presents the $95 \%$ confidence intervals and average value versus test day for the physical properties of bottom ash. The statistics of physical properties is summarized in Table 5.7. Range was calculated as above.

Mass Rejected ( $\left(3 / 4^{n}\right)$ : Mass ( $\left(\geq 3 / 4^{n}\right)$ ranged from 20.8 to $50.2 \%$, with an average of 32.9\%. All data scatter randomly around the average value, which is shown in Figure 5.30. The relatively significant variability is from the uncontrolled nature of incoming solid waste and the way in which the bottom ash was collected. It was difficult to obtain a representative sample by shovelling off the belt. The sieving process generated a larger fraction of $3 / 4^{n}-2^{n}$ materials that has good aggregate properties. This material is mainly a fused ash with high porosity. It accounts for a small percentage of the wet bottom ash raw fraction. The use of this fraction is not required for a NH type B binder course. Nevertheless, it does constitute a potential process stream fraction that has beneficial characteristics. It might be possible to crush this material into smaller particles such that more bottom ash could be used. The bulk of the rejected material was ferrous and nonferrous, fused materials, large pieces of slag, and unburned material.

Mass ( $<3 / 4^{\prime \prime}$ ): The bottom ash passing the $3 / 4^{n}$ sieve ranged from 49.8 to $79.2 \%$, with an average of $67.1 \%$. This size cut-off was chosen to comply with New Hampshire type B base course mix specification. Figure 5.31 indicates that variation with time in a way that the individual values scatter randomly around an average value of $67.1 \%$. The plant should be able to routinely generate, on average, $67 \%$ wet bottom ash as usable material. The variation is in part due to the uncontrolled quality of incoming solid waste.

Moisture Content: Moisture content ranged from 22.4 to $60.6 \%$, with an average 


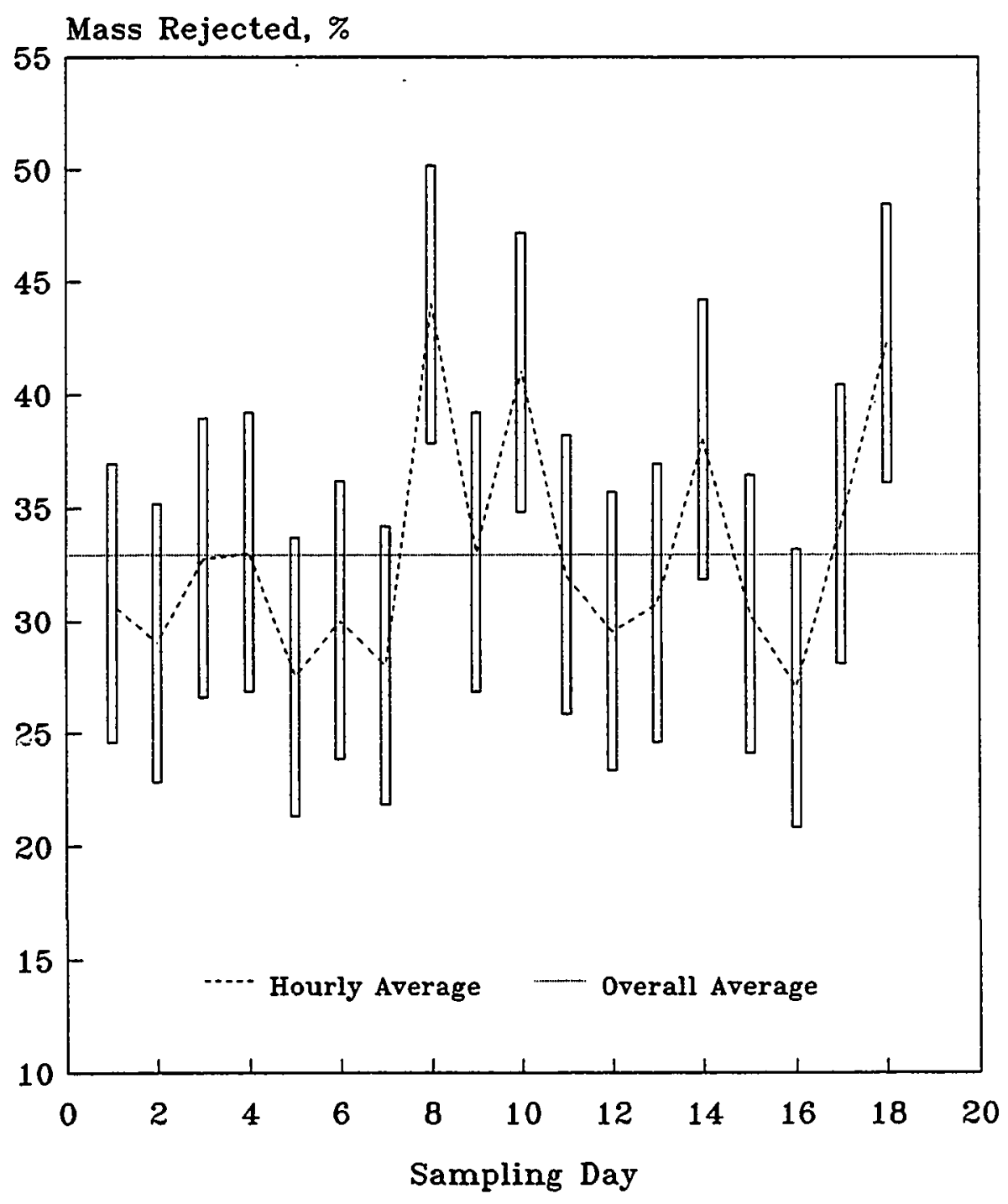

Figure 5.30 Mass Rejected versus Sampling Day 


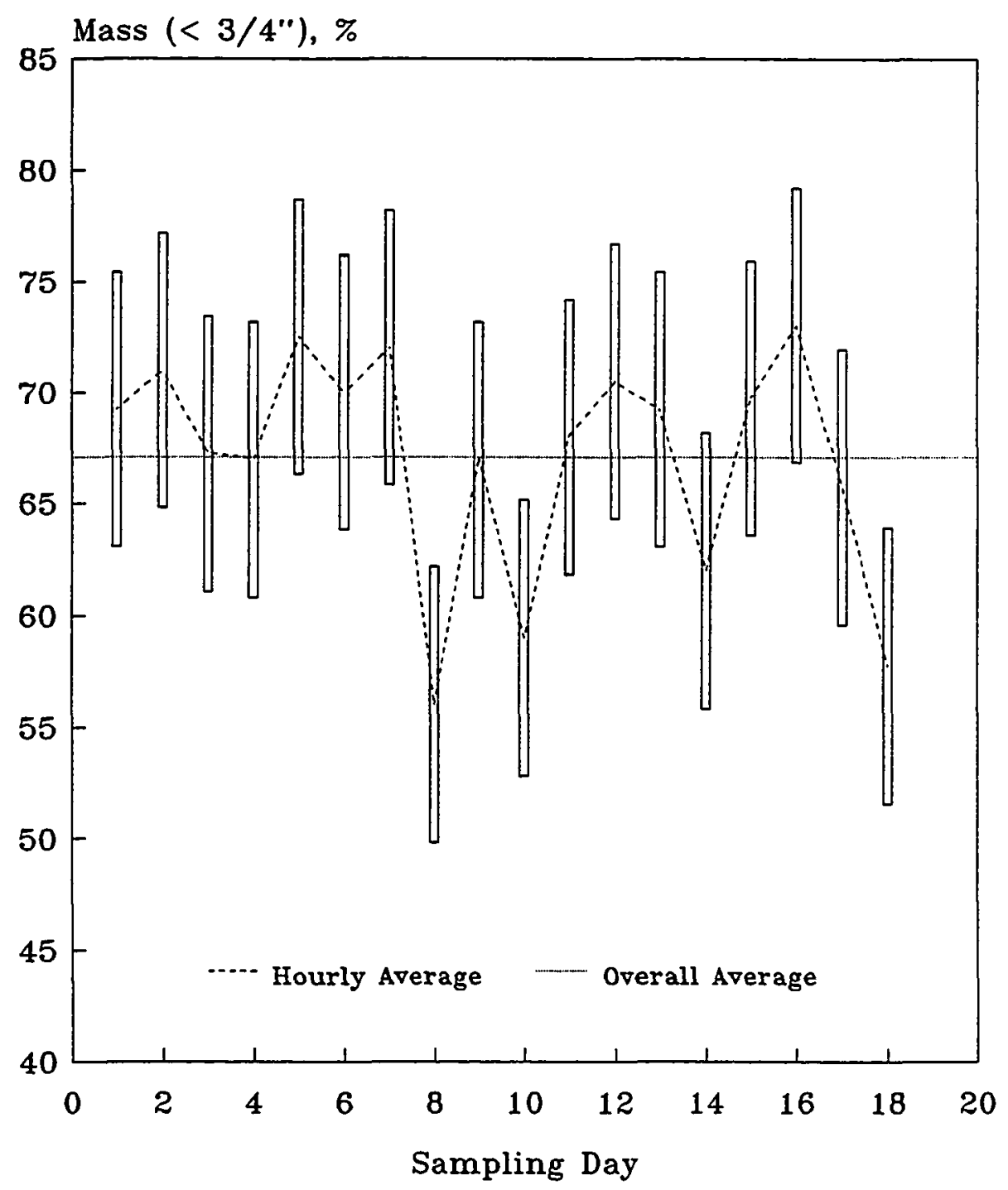

Figure 5.31 Mass $\left(<3 / 4^{\prime \prime}\right)$ versus Sampling Day

121 
of $37.9 \%$. Requirement for precision and accuracy for this test have not yet been developed by ASTM. The water content of the passing 3/4" bottom ash was determined in an engineering sense (weight of water/dry weight of solids). The moisture content versus sampling day plot in Figure 5.32 indicates the variation is random. The variability between hours is less than the variability between days, suggesting that variation in MSW properties or combustor operation influence water content. This water content is typical for a quenched bottom ash. Bottom ash aging can allow evaporative processes to reduce moisture content.

Uniformity Coefficient and Effective Size: Uniformity coefficient ranged from 8.34 to 34.04 , with an average of 21.68. Effective size ranged from 0.12 to $0.52 \mathrm{~mm}$, with an average of $0.29 \mathrm{~mm}$. Both uniformity coefficient and effective size were calculated based on sieve analysis data. Hence, any factors that affect the sieve analysis results affect these two properties. These two properties scatter randomly, which are shown in Figures 5.33 and 5.34.

Specific Gravity and Absorption of Coarse Aggregate and Fine Aggregate: Figure 5.35 through Figure 5.42 graphically presents the specific gravity and absorption versus time.

Bulk (Dry) Specific Gravity: Buik (dry) specific gravity for fine ash ranged from 1.55 to 2.22 , with an average of 1.86 , and that for coarse ash ranged from 1.93 to 2.44 , with an average of 2.20 .

Bulk (SSD) Specific Gravity: Bulk (SSD) specific gravity for fine ash ranged from 1.89 to 2.41 , with an average of 2.13 , and that for coarse ash ranged from 2.11 to 2.58 , 


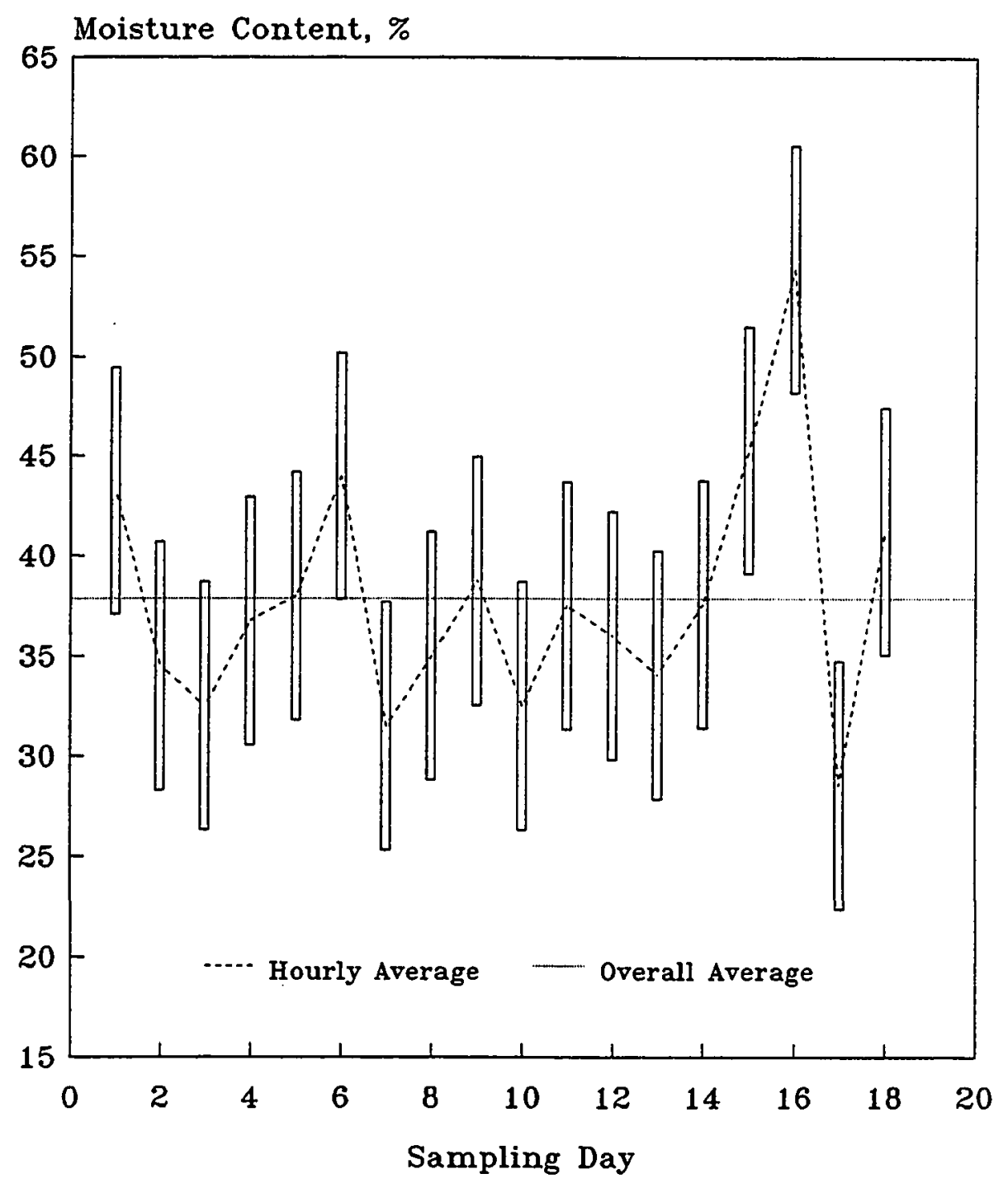

Figure 5.32 Moisture Content versus Sampling Day

123 


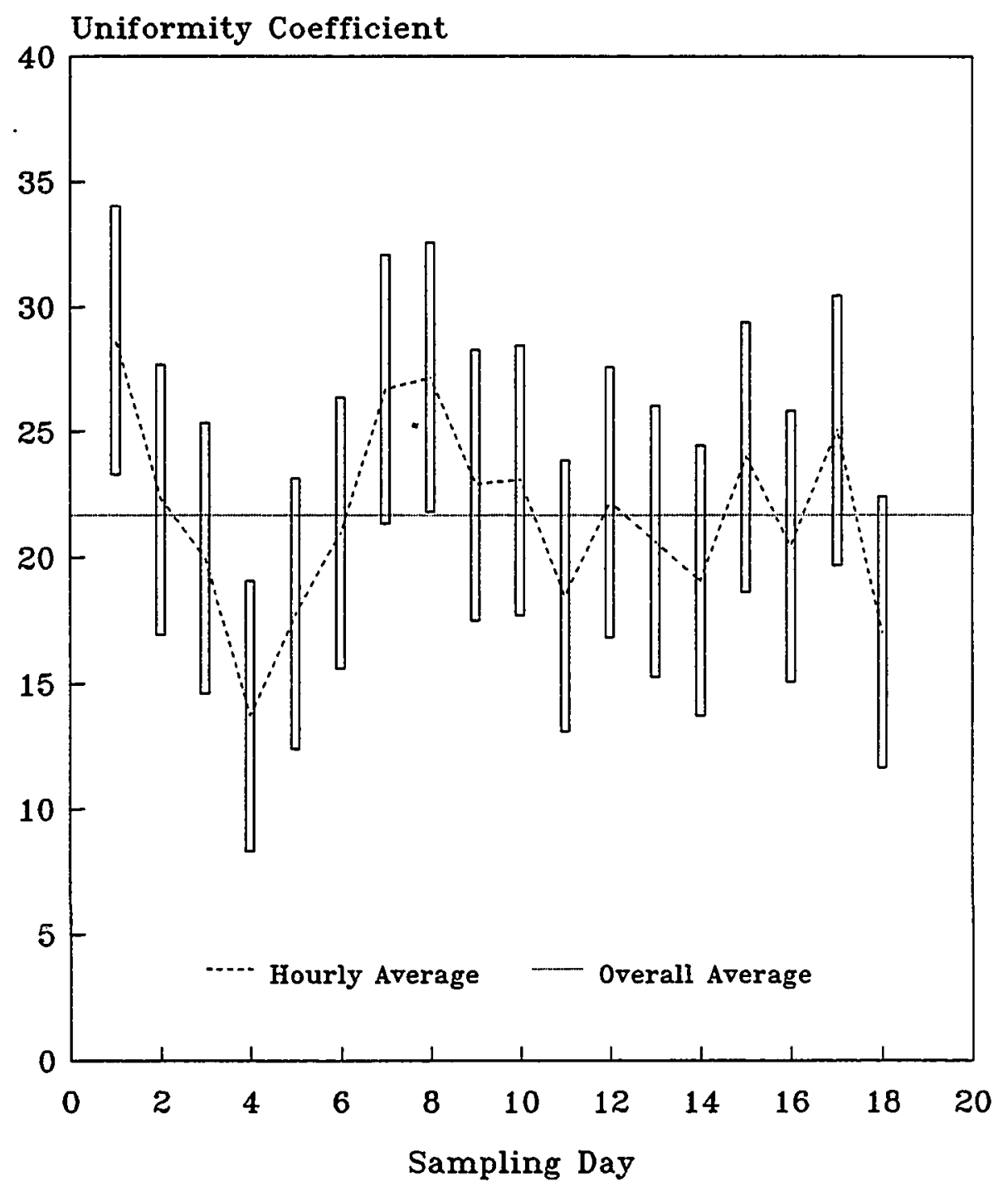

Figure '5.33 Uniformity Coefficient versus Samplind Day 124 


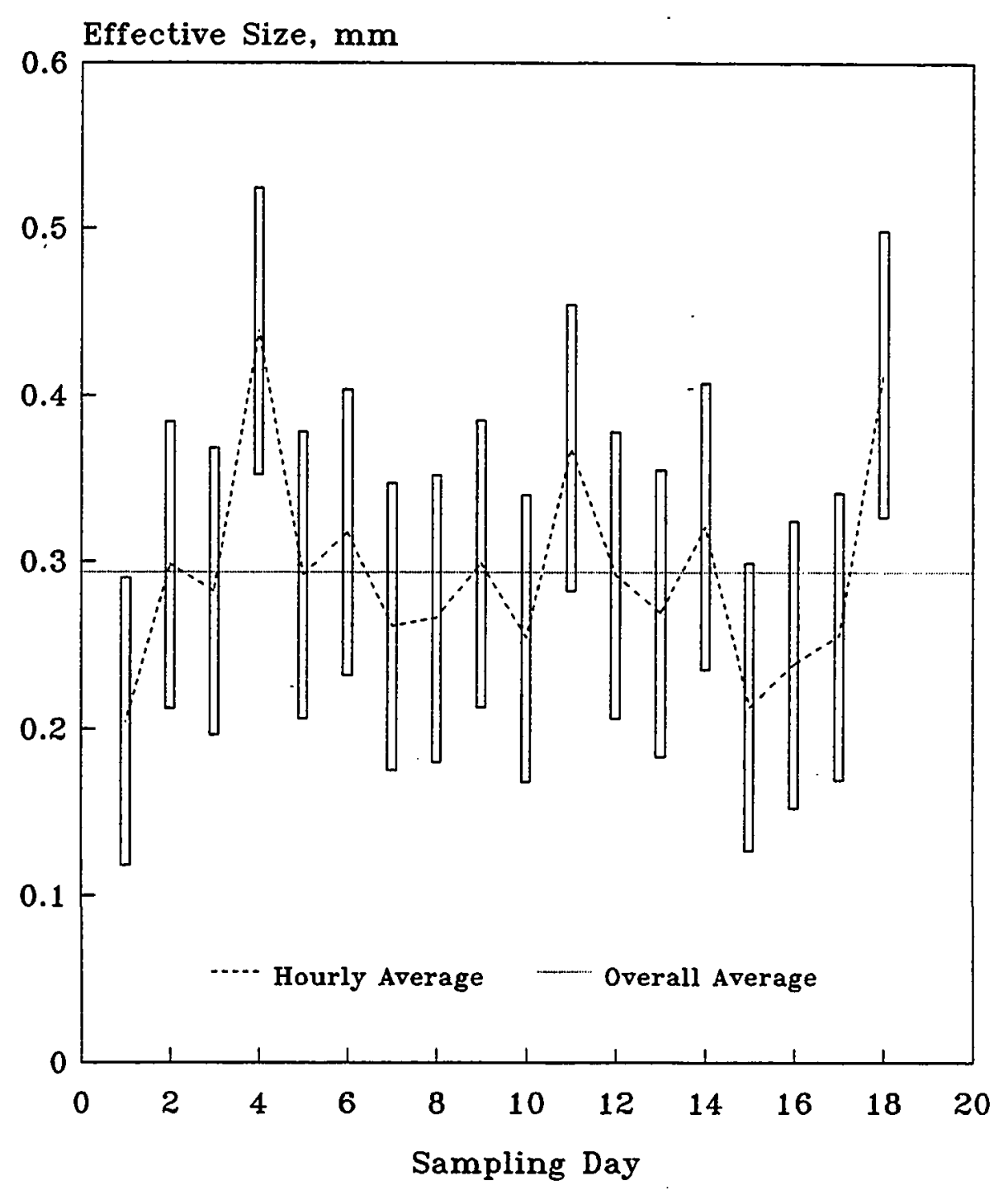

Figure 5.34 Effective Size versus Sampling Day

125 


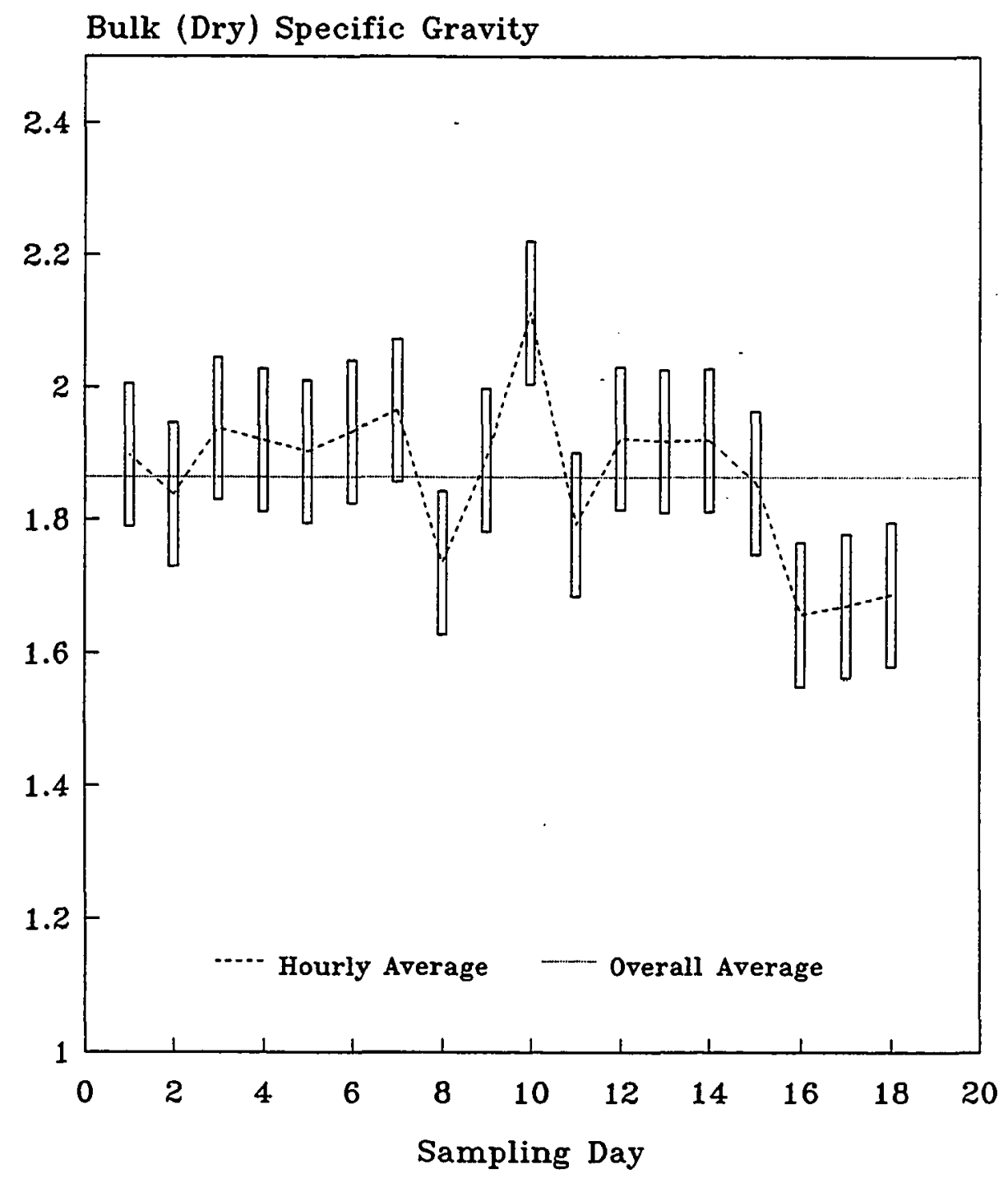

Figure 5.35 Bulk (Dry) Specific Gravity of Fine Ash versus Sampling Day

126 


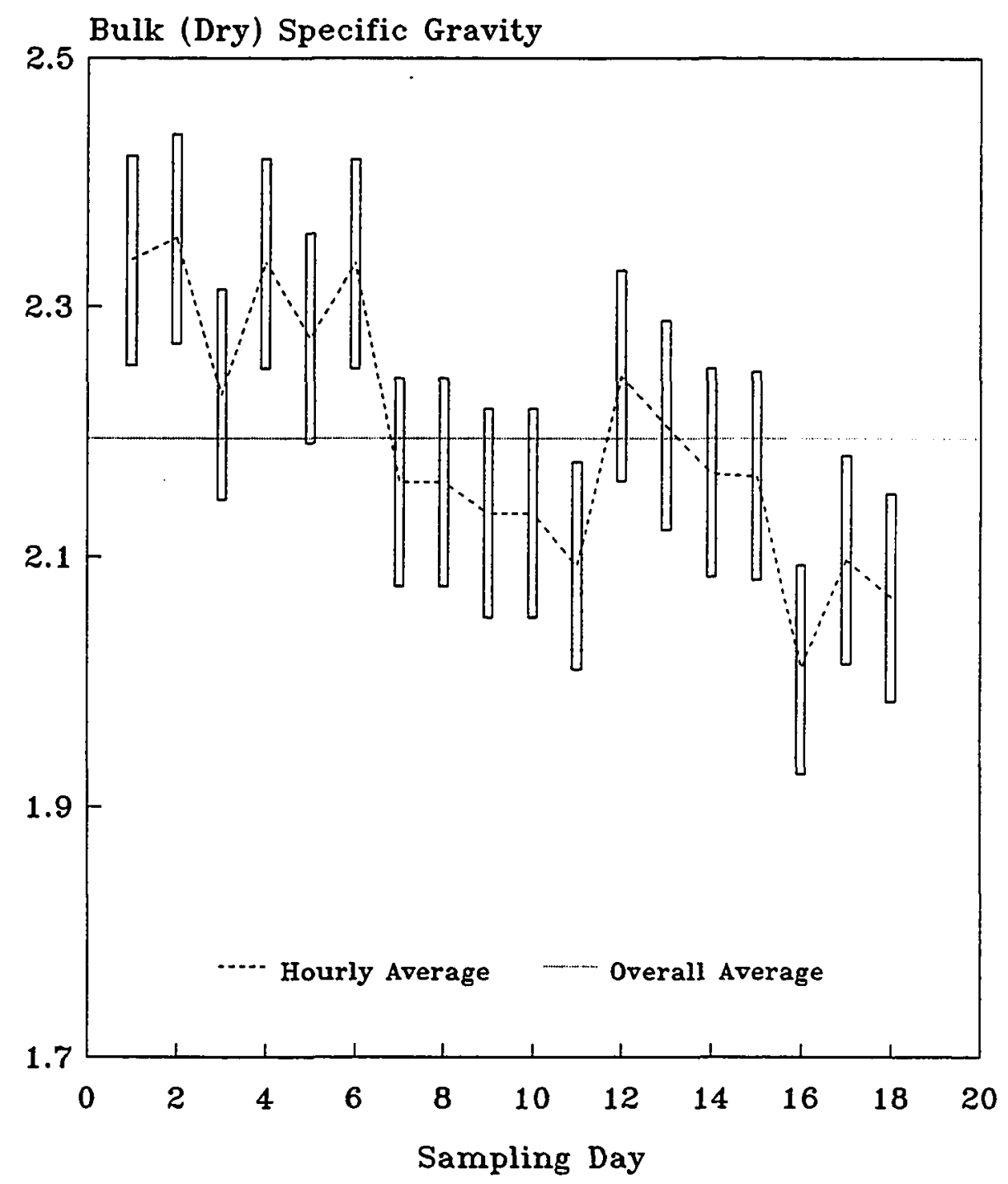

Fig. 5.36 Bulk (Dry) Specific Gravity of Coarse Ash versus Sampling Day 


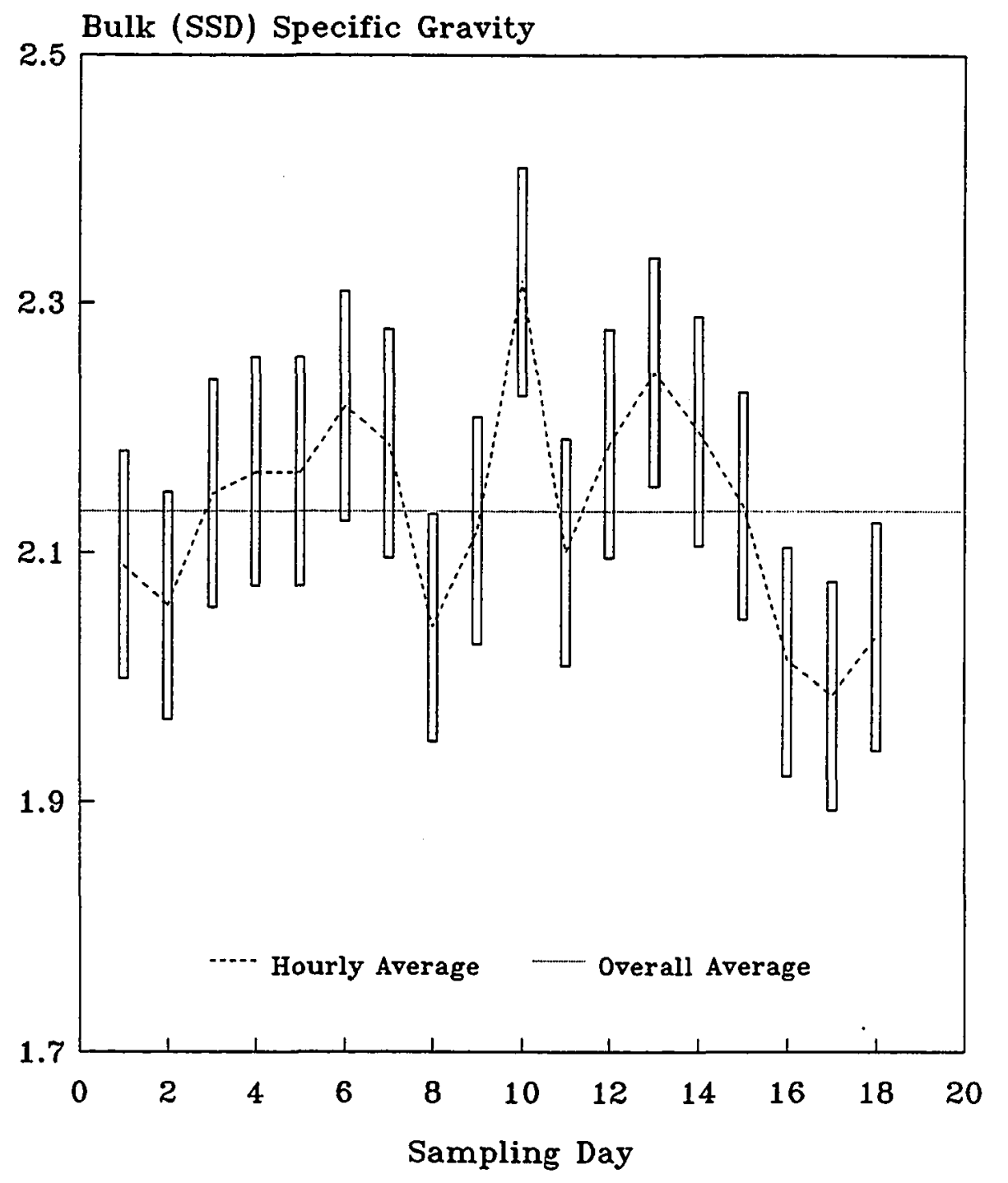

Figure 5.37 Bulk (SSD) Specific Dravity of Fine Ash versus Sampling Day

128 


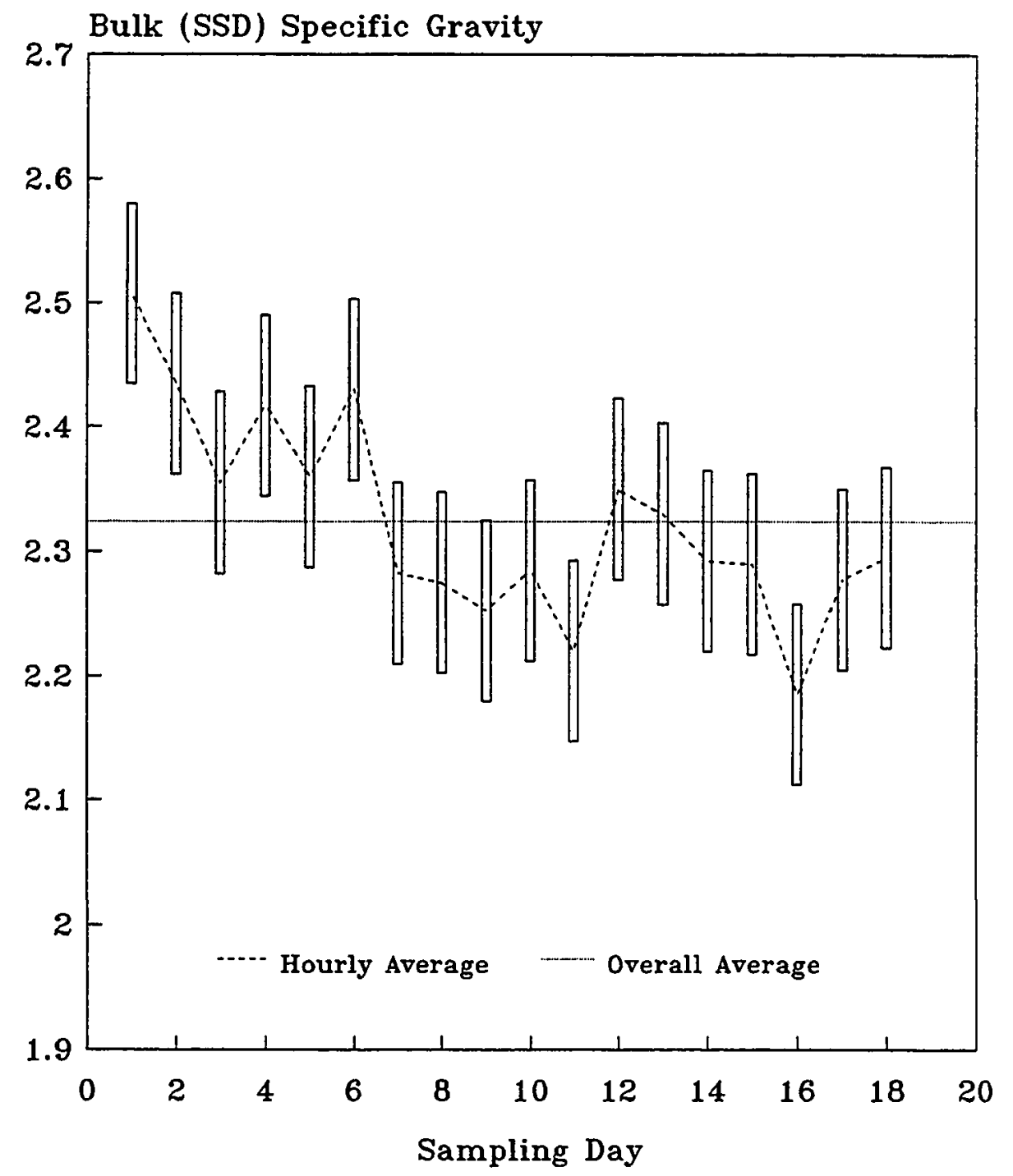

Fig. 5.38 Bulk (SSD) Specific Gravity of Coarse Ash versus Sampling Day 


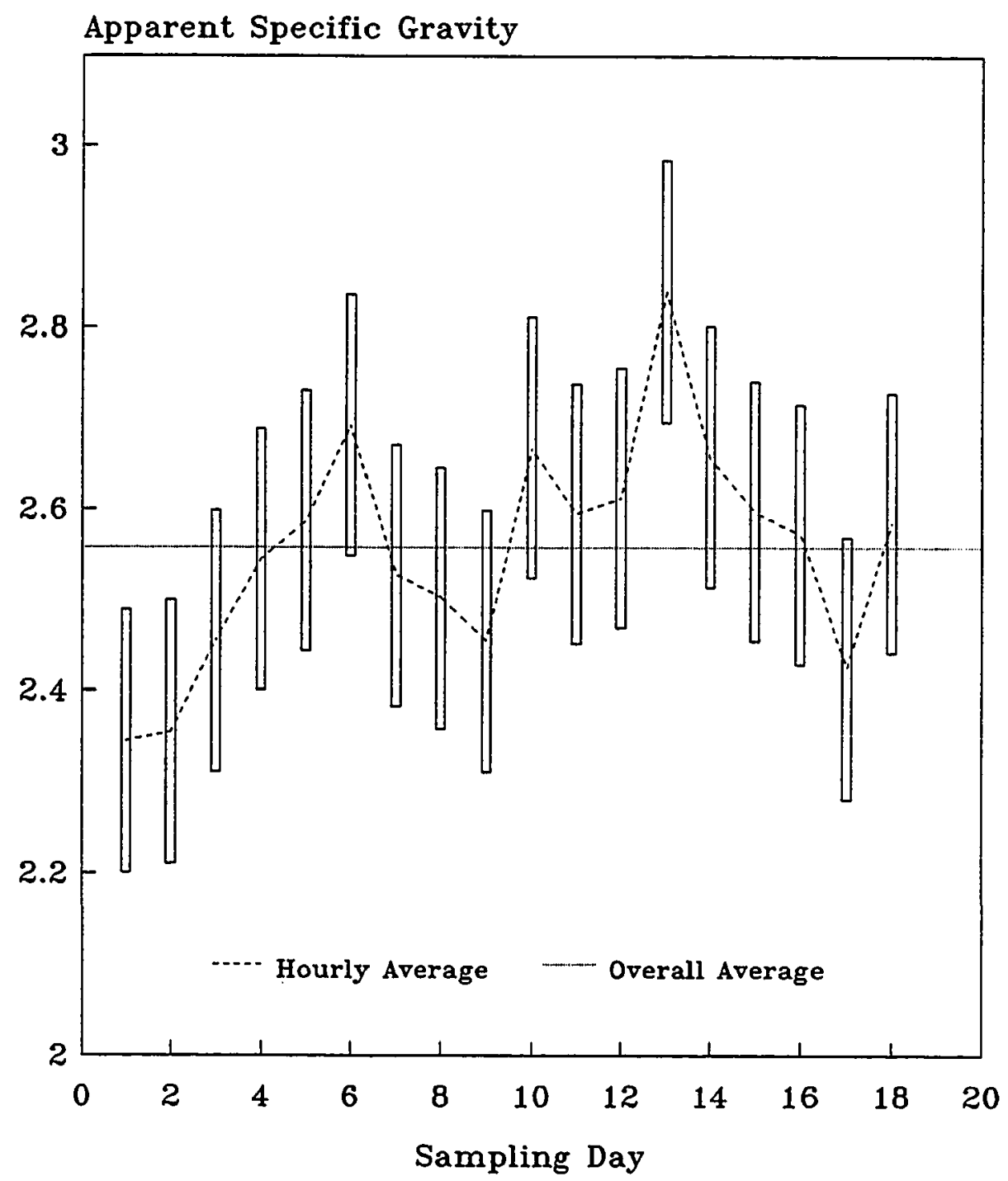

Figure 5.39 Apparent Specific Gravity of Fine Ash versus Sampling Day

130 


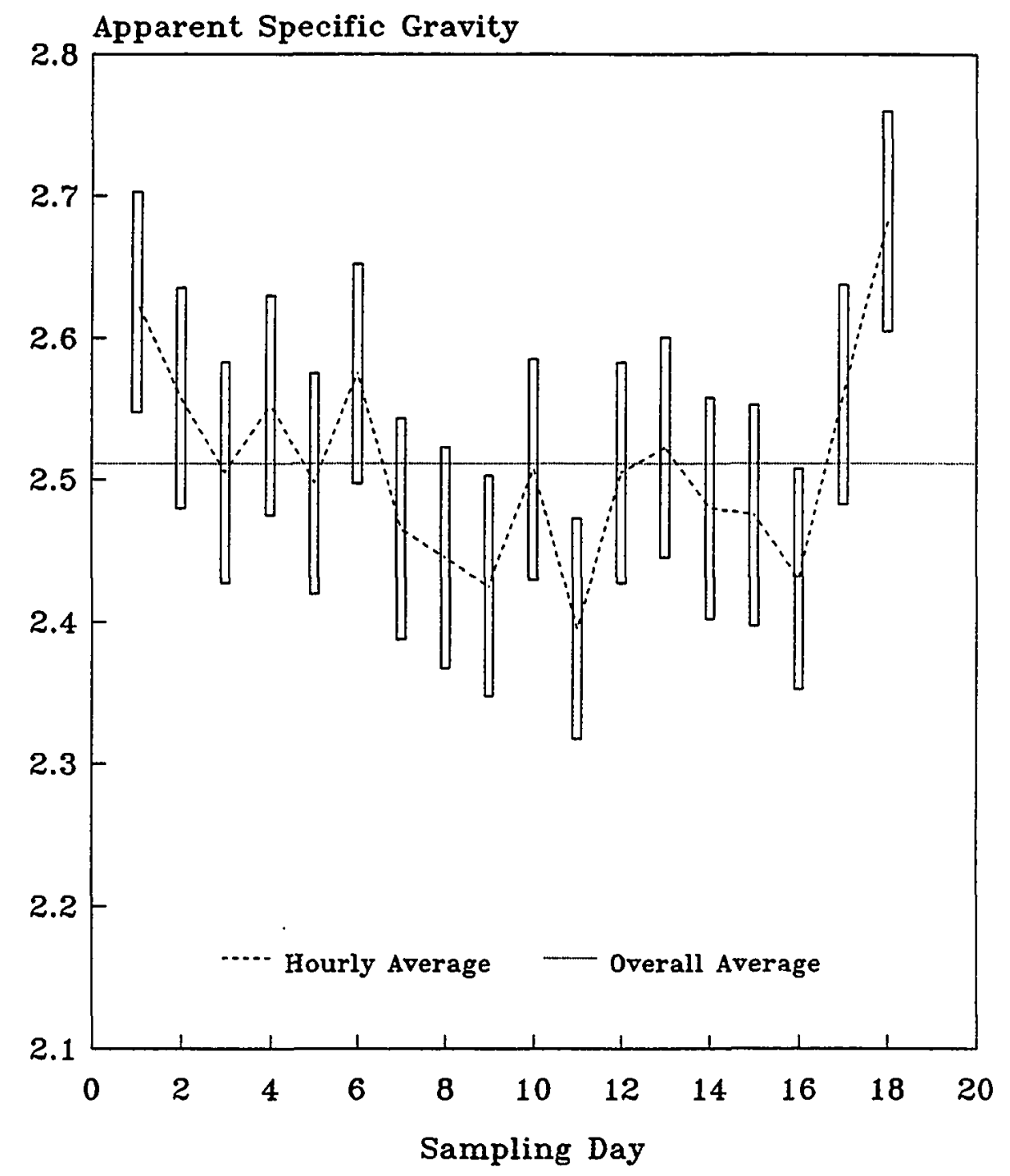

Fig. 5.40 Apparent Specific Gravity of Coarse Ash versus Sampling Day 


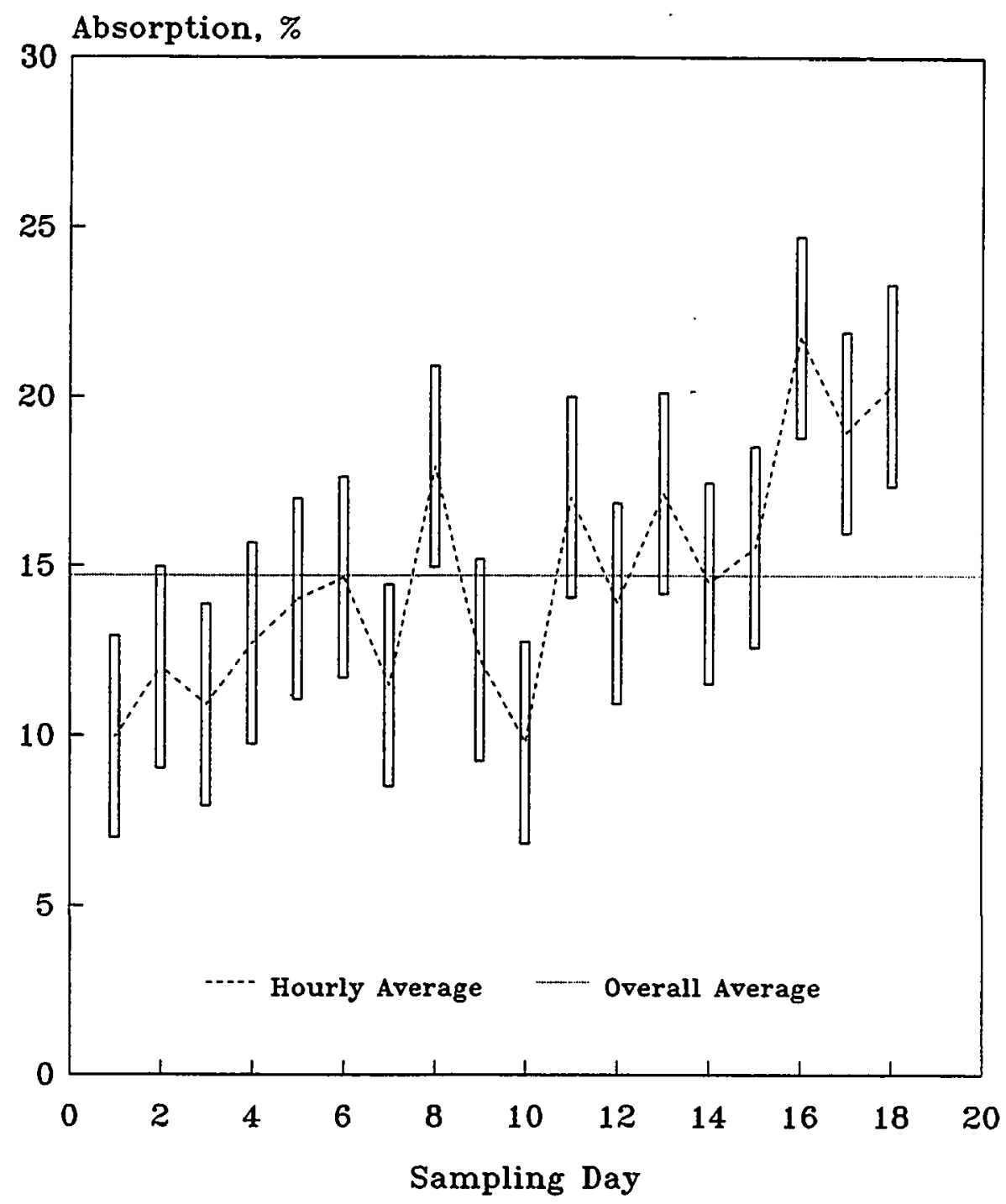

Figure 5.41 Absorption of Fine Ash versus Sampling Day 


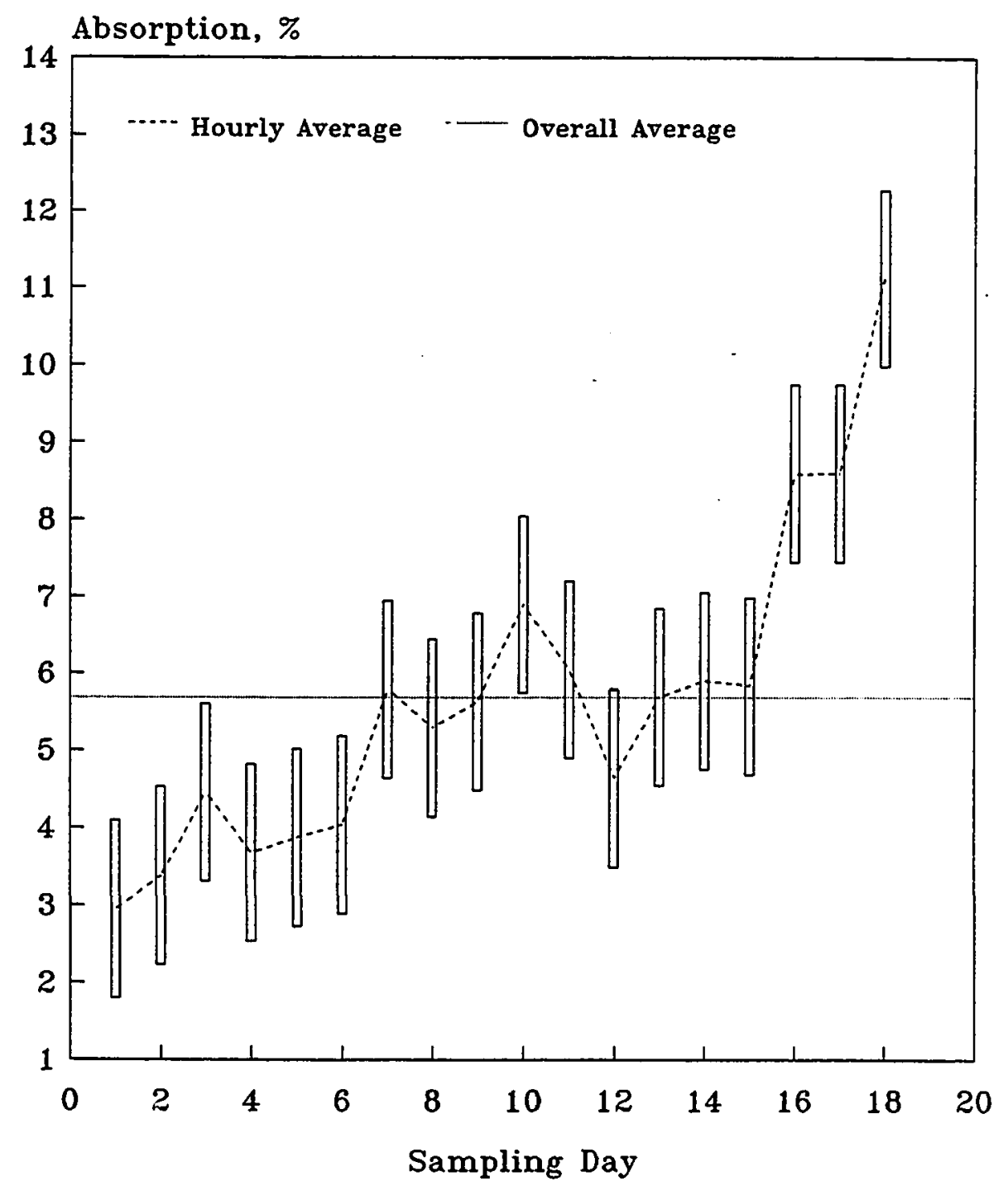

Figure 5.42 Absorption of Coarse Ash versus Sampling Day 
with an average of 2.32 .

Apparent Specific Gravity: Apparent specific gravity for fine ash ranged from 2.20 to 2.98 , with an average of 2.56 , and that for coarse ash ranged from 2.32 to 2.76 , with an average of 2.51 .

Absorption: Absorption for fine ash ranged from 6.8 to $24.7 \%$, with an average of $14.7 \%$, and that for coarse ash ranged from 1.8 to $12.3 \%$, with an average of $5.7 \%$. The variation of specific gravity and absorption exceed the ASTM C127 and C128 precision requirements. Collins et al. (12) stated that ASTM methods (ASTM C127 and ASTM C128) performed on ash residue are suitable with modification. The modification suggested includes 1) increased sample size, 2) the use of a larger-size pycnometer, and 3) the use of a wet bulb-dry bulb relative humidity procedure, instead of a weight loss measurement, to determine absorption. Even though the above measures were used, Collins et al. (12) concluded that the range of values is much wider than the normal range for conventional mineral aggregates.

Since bottom ash is a heterogeneous material and the difference in the specific gravity between bottom ash components is significant, any change in constituents from sample to sample will result in significant variation in specific gravity and absorption. No matter how much effort is made to minimize the test variation, it is expected that the range of values is wider than the normal range for conventional mineral aggregates.

It appears that bulk (dry) specific gravity of fine ash decreases slightly with increased sampling day, as shown in Figure 5.35, and bulk (SSD) specific gravity and apparent specific gravity vary inconsistently, as evidenced by Figure 5.37 and 5.39, respectively. 
Absorption increases with increased sampling day, as illustrated by Figure 5.41. Absorption increases with decreasing bulk (bulk) specific gravity, as would be expected, because as the bulk (dry) specific gravity decreases, the permeable voids of bottom ash increase.

It seems that bulk (dry) specific gravity of coarse ash decreases with increased sampling day, as shown in Figure 5.36, and bulk (SSD) specific gravity decreases slightly with increased sampling day (Figure 5.38). Apparent specific gravity varies inconsistently with sampling day as shown in Figure 5.40. Figure 5.42 indicates that absorption increases as sampling day increases.

The Loss on Ignition: LOI ranged from 3.2 to 10.0 , with an average of 6.4. It appears to be that LOI decreases with time as shown in Figure 5.43. However, this trend is not strongly supported by data because of large variation. The variation of LOI exceeds the ASTM C114 requirements. Since ash is heterogeneous, the sample size for LOI test was increased to 10 grams instead of 1 gram to minimize the variation. However, a significant variation was still observed. It was felt that it is very difficult to obtain a representative sample. A 10 gram of ash passing the No.4 sieve was used for each LOI test. It was not practical to obtain a sample such that it was equivalent to the ash population (100 -200 lb).

Ferrous Content: This test is a rough measure of the magnetic material present in bottom ash. This might provide an estimate of the ferrous material that could be recovered. It also gives a measure of a fraction of the ferrous content that influences specific gravity. Ferrous contents ranged from 11.9 to $39.6 \%$, with an average of $25.9 \%$. 


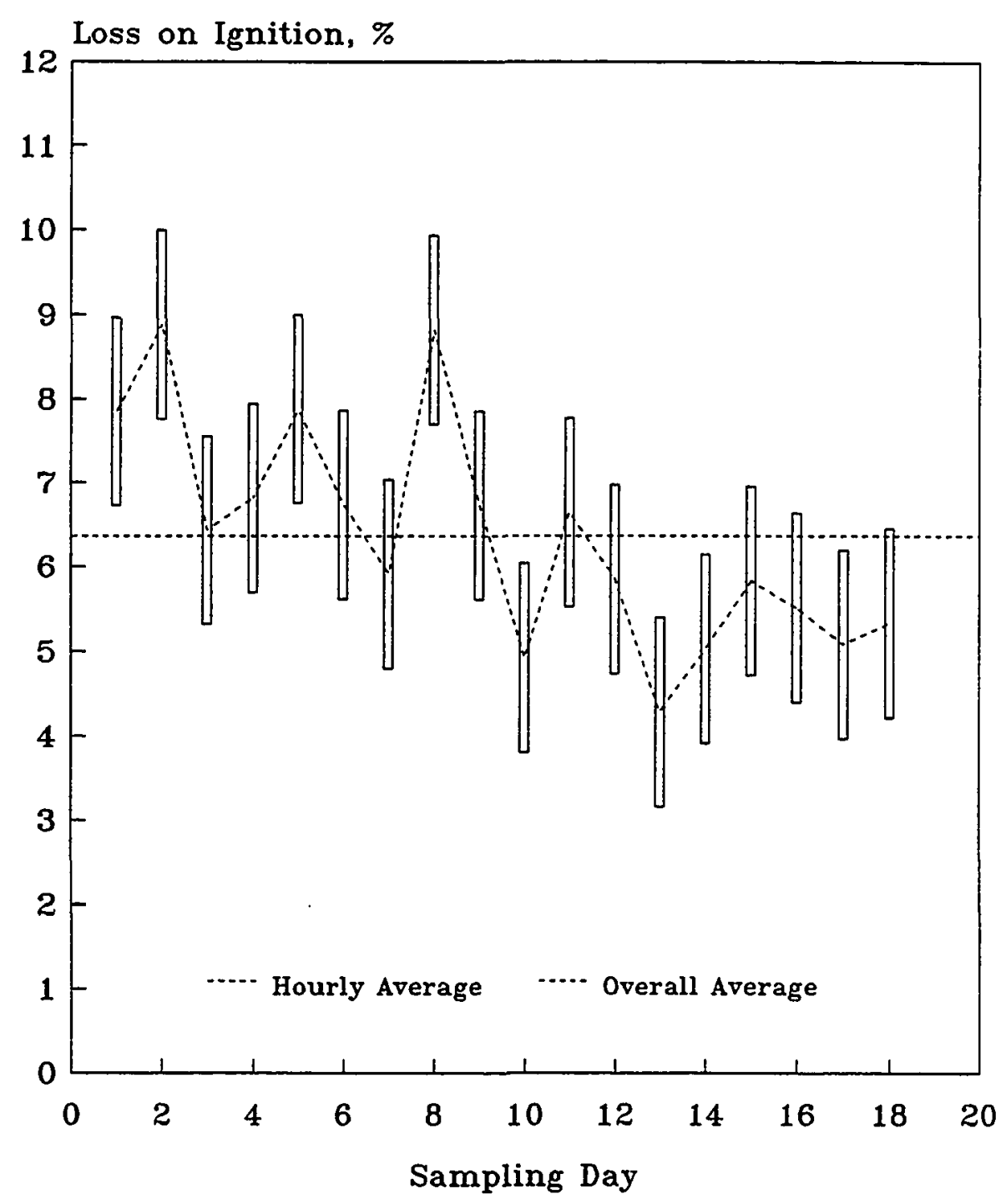

Figure 5.43 LOI versus Sampling Day 
Figure 5.44 indicates that the ferrous content varies with time. The variation is significant because of the nature of the test and the heterogeneous nature of the ash. Figure 5.45 shows the particle size distribution of the ferrous material. It is slightly coarser than the bottom ash.

\subsubsection{Daily Composite Samples}

The daily composite sample was created from 4 hourly samples. One daily composite is treated as one measurement. Means and confidence intervals were obtained in the same manner as for particle size distribution.

Table 5.8 presents the mean values and $95 \%$ confidence intervals for each property which has been tested on the hourly samples. Figure 5.46 through Figure 5.57 presents the physical property versus time plots.

Table 5.8 and Figure 5.46 through Figure 5.57 show that for each physical property investigated all daily composite data are within hourly data range and the daily composite data has much less variation than the hourly data. The reason for the observations seem obvious in that each daily composite sample was created by blending the 4 hourly samples together, resulting in daily composite samples are more representative. Unfortunately, variation of daily composite data still exceeds ASTM precision requirements.

A number of more intensive analyses on some physical properties of bottom ash were performed to better evaluate the bottom ash. These labor-intensive analyses were usually

conducted on either all the daily composites or on selected daily composite samples. Table 5.9 presents the mean values and confidence intervals of these physical properties. 


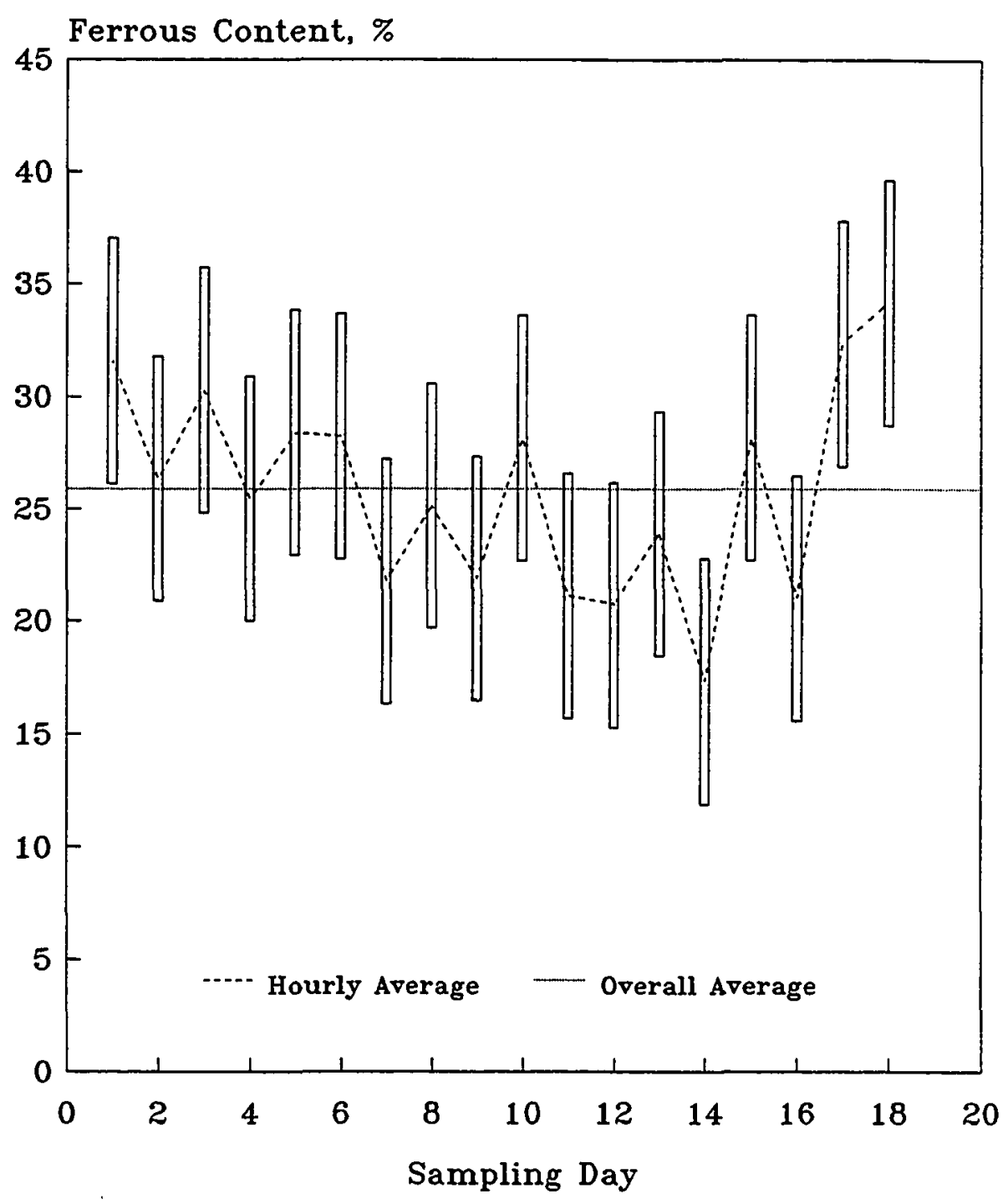

Figure 5.44 Ferrous Content versus Sampling Day

138 
Table 5.7 Statistics of Physical Properties

\begin{tabular}{|l|c|c|}
\hline \multicolumn{1}{|c|}{ Property } & Mean & Range \\
\hline Mass Rejected, \% & 32.944 & $20.828-50.172$ \\
\hline Mass < 3/4", \% & 67.056 & $49.828-79.172$ \\
\hline Water Content, \% & 37.853 & $22.365-60.560$ \\
\hline Uniform Coeff. & 21.683 & $8.337-34.035$ \\
\hline Effective Size (mm) & 0.293 & $0.118-0.524$ \\
\hline BSG, Fine & 1.864 & $1.550-2.220$ \\
\hline BSG, Coarse & 2.195 & $1.926-2.439$ \\
\hline BSG (SSD), Fine & 2.134 & $1.893-2.409$ \\
\hline BSG (SSD), Coarse & 2.324 & $2.112-2.580$ \\
\hline Apparent SG, Fine & 2.558 & $2.201-2.984$ \\
\hline Apparent SG, Coarse & 2.511 & $2.317-2.760$ \\
\hline Absorption, Fine & 14.705 & $6.810-24.713$ \\
\hline Absorption, Coarse & 5.691 & $1.797-12.278$ \\
\hline LOI, \% & 6.363 & $3.163-9.995$ \\
\hline Ferrous Content, \% & 25.878 & $11.852-39.623$ \\
\hline
\end{tabular}




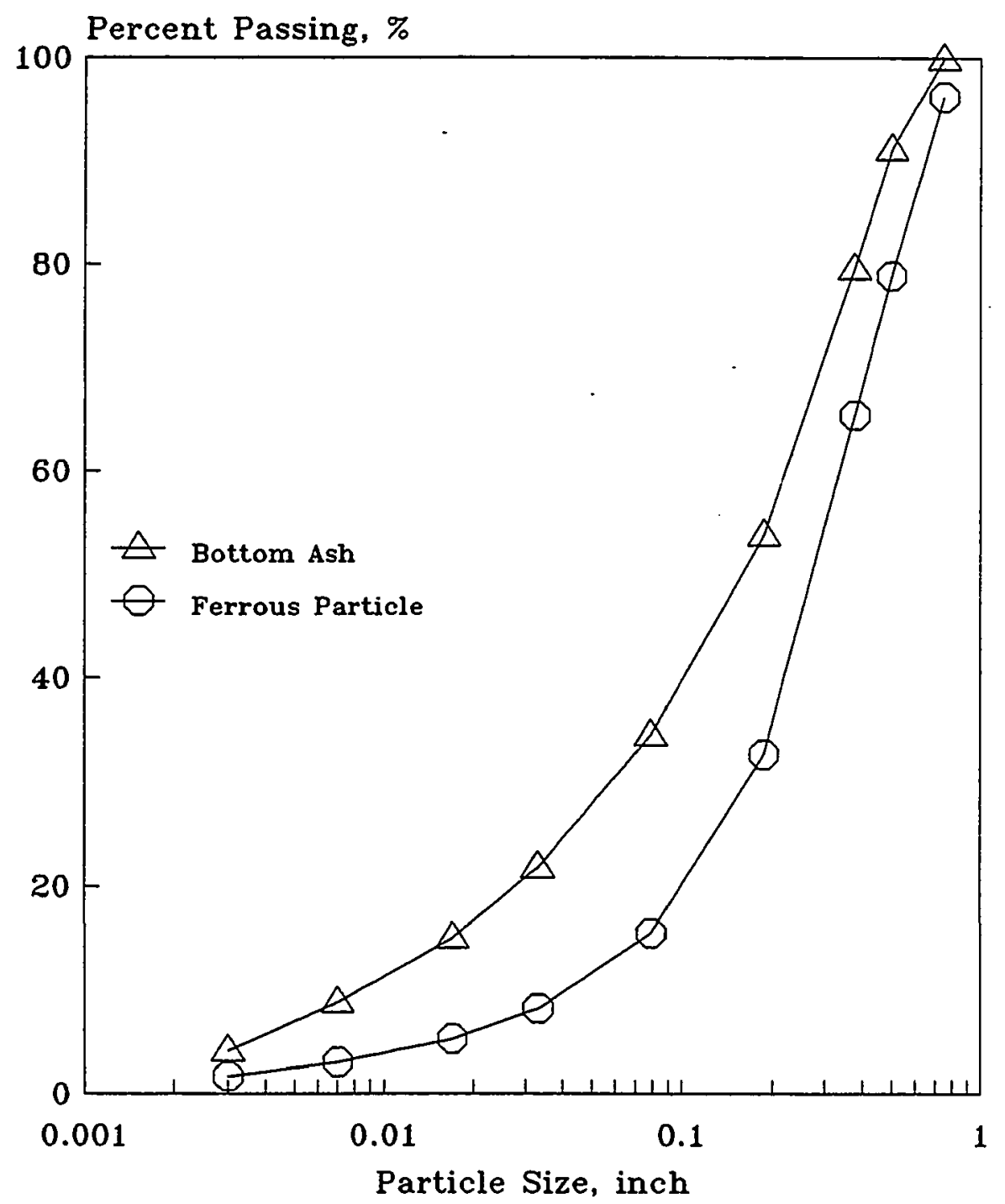

Figure 5.45 Gradation Of Ferrous Particle 
Table 5.8 Physical properties for Daily Composites

\begin{tabular}{|c|c|c|c|c|c|c|c|c|}
\hline \multirow[t]{2}{*}{ Property } & \multirow[t]{2}{*}{ Mo. } & \multirow[t]{2}{*}{ Meen } & \multicolumn{6}{|c|}{ Confidence Interval } \\
\hline & & & $75 \%$ & $90 \%$ & $95 \%$ & $97.5 \%$ & $99 \%$ & $99.5 \%$ \\
\hline Uniformity Coeff. & 20 & 27.76 & $26.37-29.16$ & $25.73-29.80$ & $25.30-30.23$ & $24.90-30.63$ & $24.40-31.13$ & $24.03-31.50$ \\
\hline Effective Size, mm & 20 & 0.209 & $0.201-0.218$ & $0.197-0.222$ & $0.194-0.225$ & $0.191-0.227$ & $0.188-0.230$ & $0.186-0.233$ \\
\hline BSG, Fine & 20 & 1.851 & $1.821-1.880$ & $1.807-1.894$ & $1.798-1.903$ & $1.790-1.911$ & $1.779-1.922$ & $1.771-1.930$ \\
\hline BSG, Coarse & 20 & 2.194 & $2.156-2.231$ & $2.139-2.249$ & $2.127-2.260$ & $2.116-2.271$ & $2.103-2.285$ & $2.093-2.295$ \\
\hline BSG (SSD), Fine & 20 & 2.133 & $2.110-2.156$ & $2.100-2.166$ & $2.093-2.173$ & $2.087-2.179$ & $2.079-2.188$ & $2.073-2.193$ \\
\hline BSG (SSD), coerse & 20 & 2.332 & $2.294-2.350$ & $2.281-2.363$ & $2.272-2.372$ & $2.264-2.380$ & $2.254-2.390$ & $2.246-2.398$ \\
\hline Apparent SG, fine & 20 & 2.592 & $2.565-2.619$ & $2.553-2.631$ & $2.545-2.639$ & $2.537-2.647$ & $2.528-2.656$ & $2.521-2.663$ \\
\hline Apparent SG, Coarse & 20 & 2.516 & $2.487-2.545$ & $2.473-2.559$ & $2.464-2.568$ & $2.456-2.576$ & $2.445-2.587$ & $2.437-2.595$ \\
\hline Absorption, Fine & 20 & 15.56 & $14.65-16.48$ & $14.23-16.90$ & $13.95-17.18$ & $13.69-17.44$ & $13.36-17.77$ & $13.12-18.01$ \\
\hline Absorption, Coarse & 20 & 6.003 & $5.229-6.708$ & $4.976-7.031$ & $4.760-7.247$ & $4.558-7.449$ & $4.304-7.703$ & $4.118-7.889$ \\
\hline Lol, $x$ & 20 & 7.533 & $7.089-7.977$ & $6.886-8.180$ & $6.750-8.316$ & $6.622-8.444$ & $6.462-8.604$ & $6.345-8.721$ \\
\hline Ferrous Content, $\%$ & 20 & 27.80 & $26.43-29.18$ & $25.80-29.81$ & $25.38-30.23$ & $24.99-30.62$ & $24.49-31.12$ & $24.13-31.48$ \\
\hline
\end{tabular}




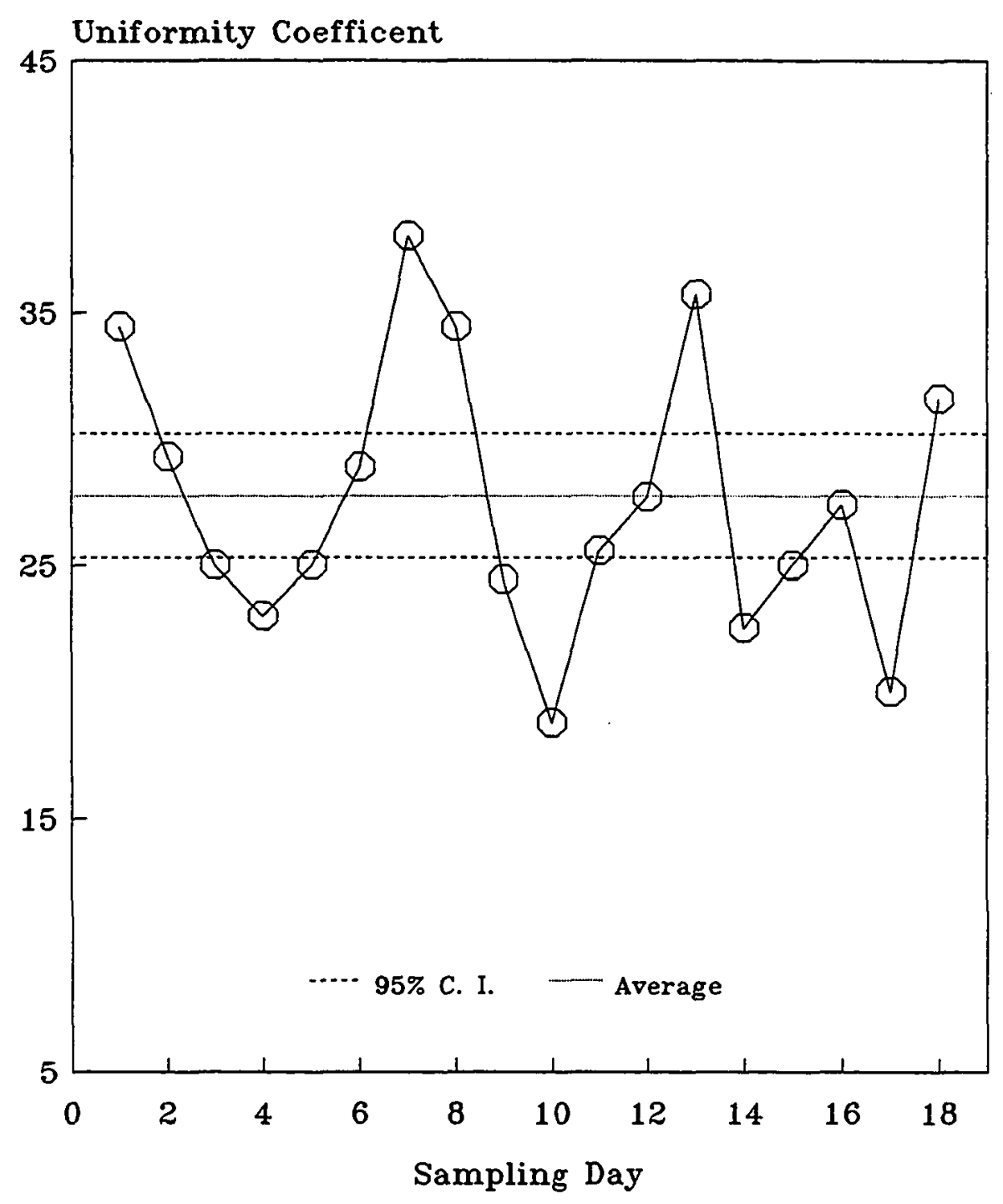

Figure 5.46 Uniformity Coefficent versus Sampling Day (Daily Composite)

142 


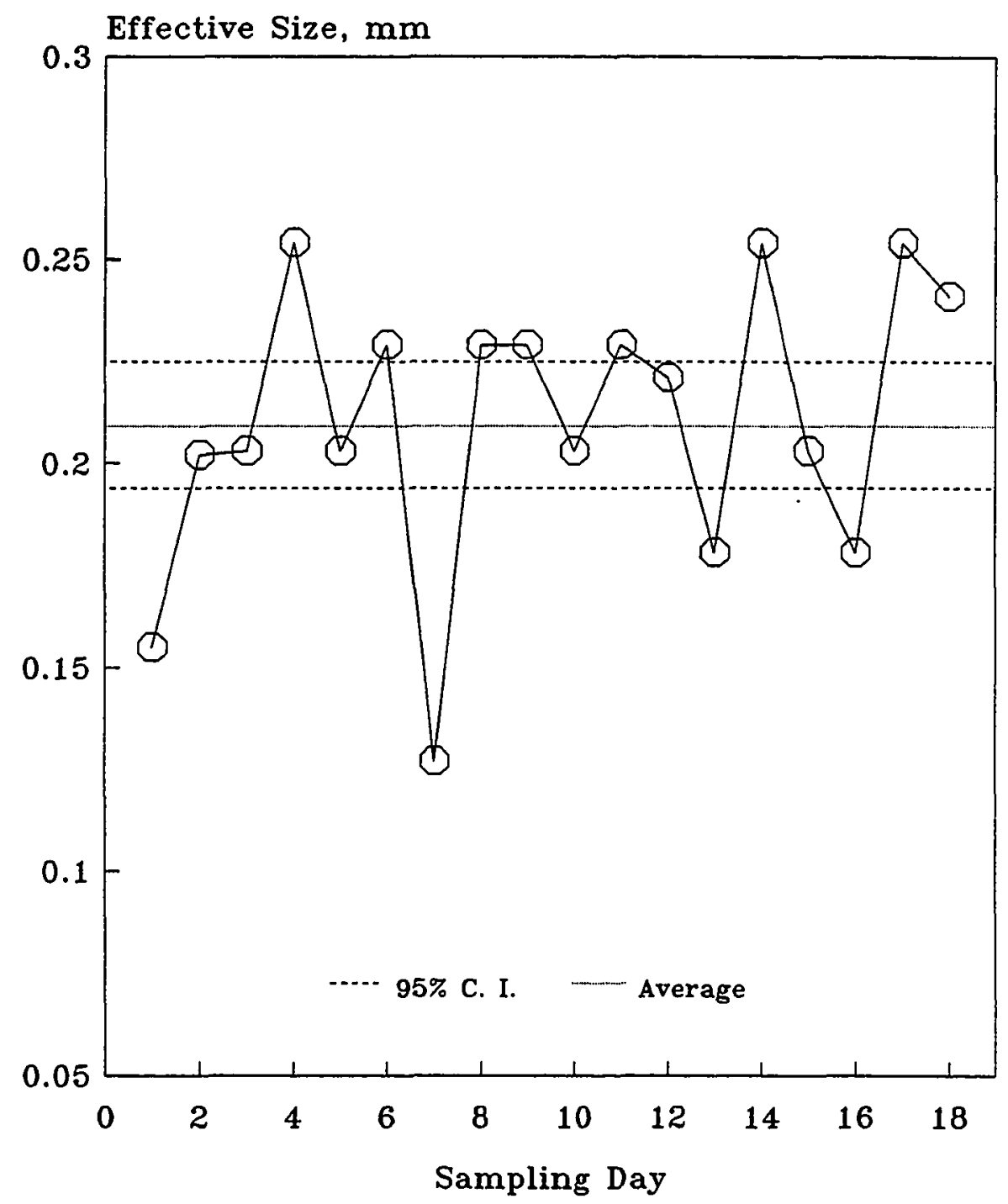

Figure 5.47 Effective Size versus Sampling Day

(Daily Composite)

143 


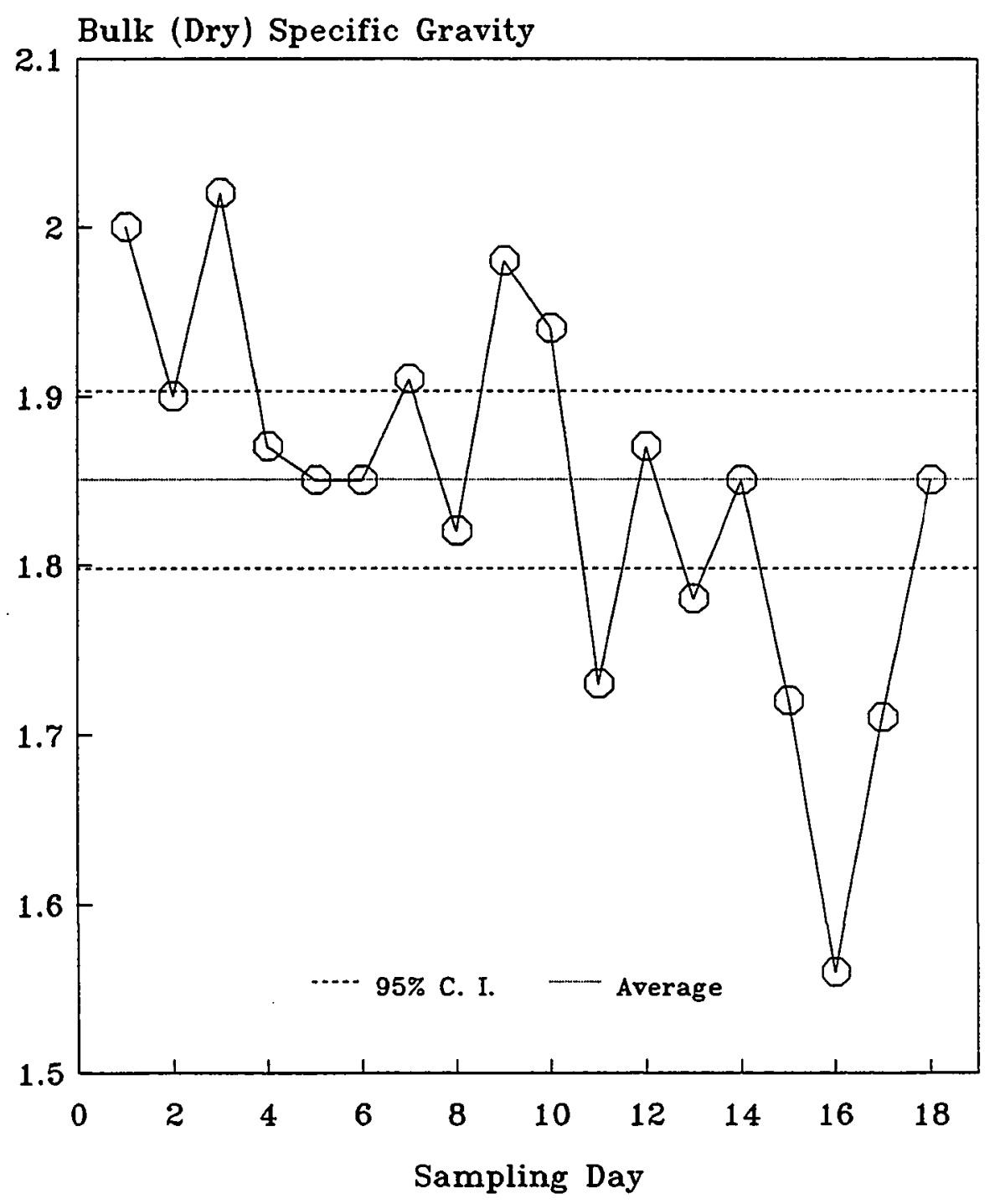

Figure 5.48 Bulk (Dry) Specific Gravity of Fine Ash versus Sampling Day (Daily Composite) 


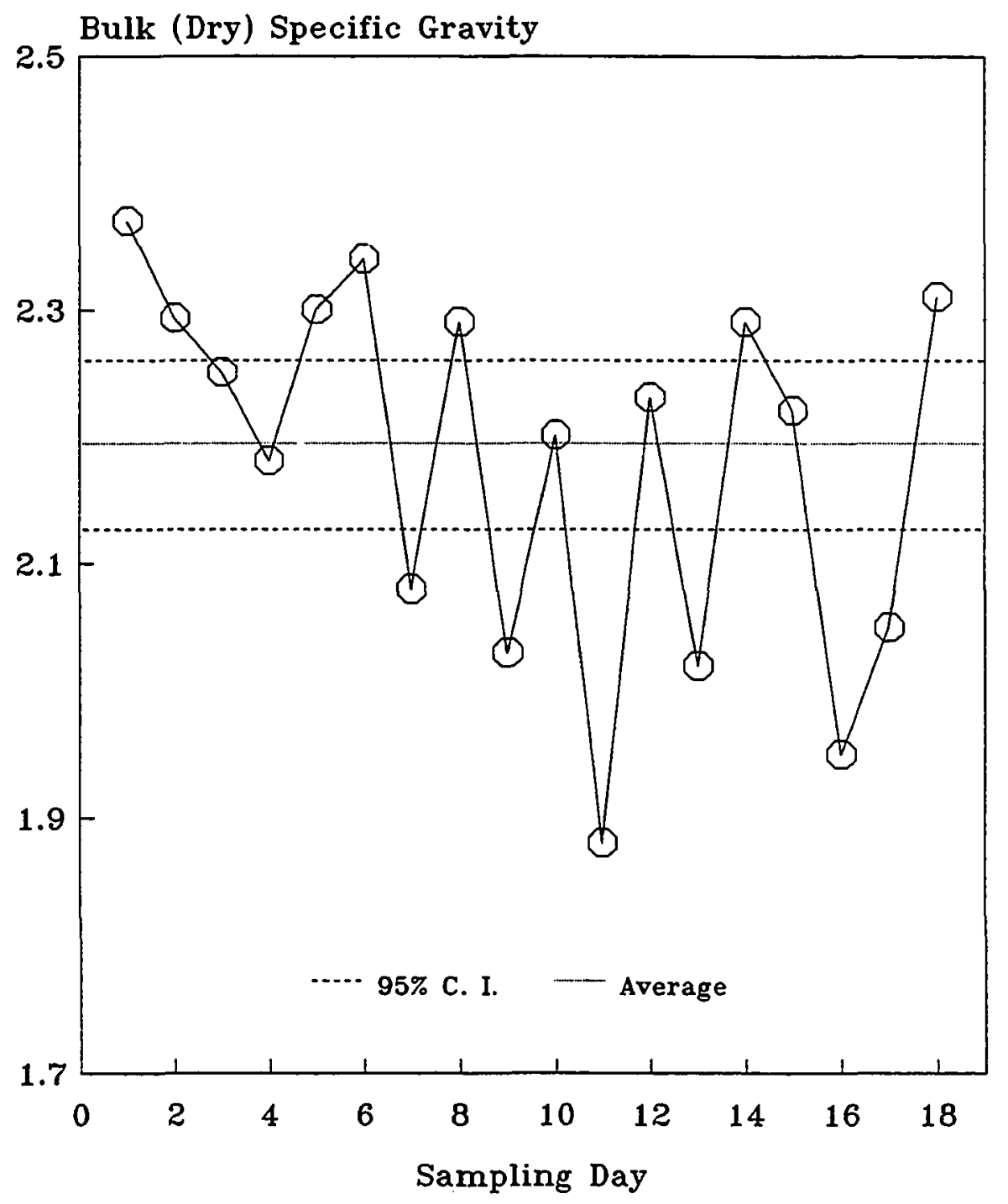

Fig. 5.49 Bulk (Dry) Specific Gravity of Coarse Ash versus Sampling Day (Daily Composite)

145 


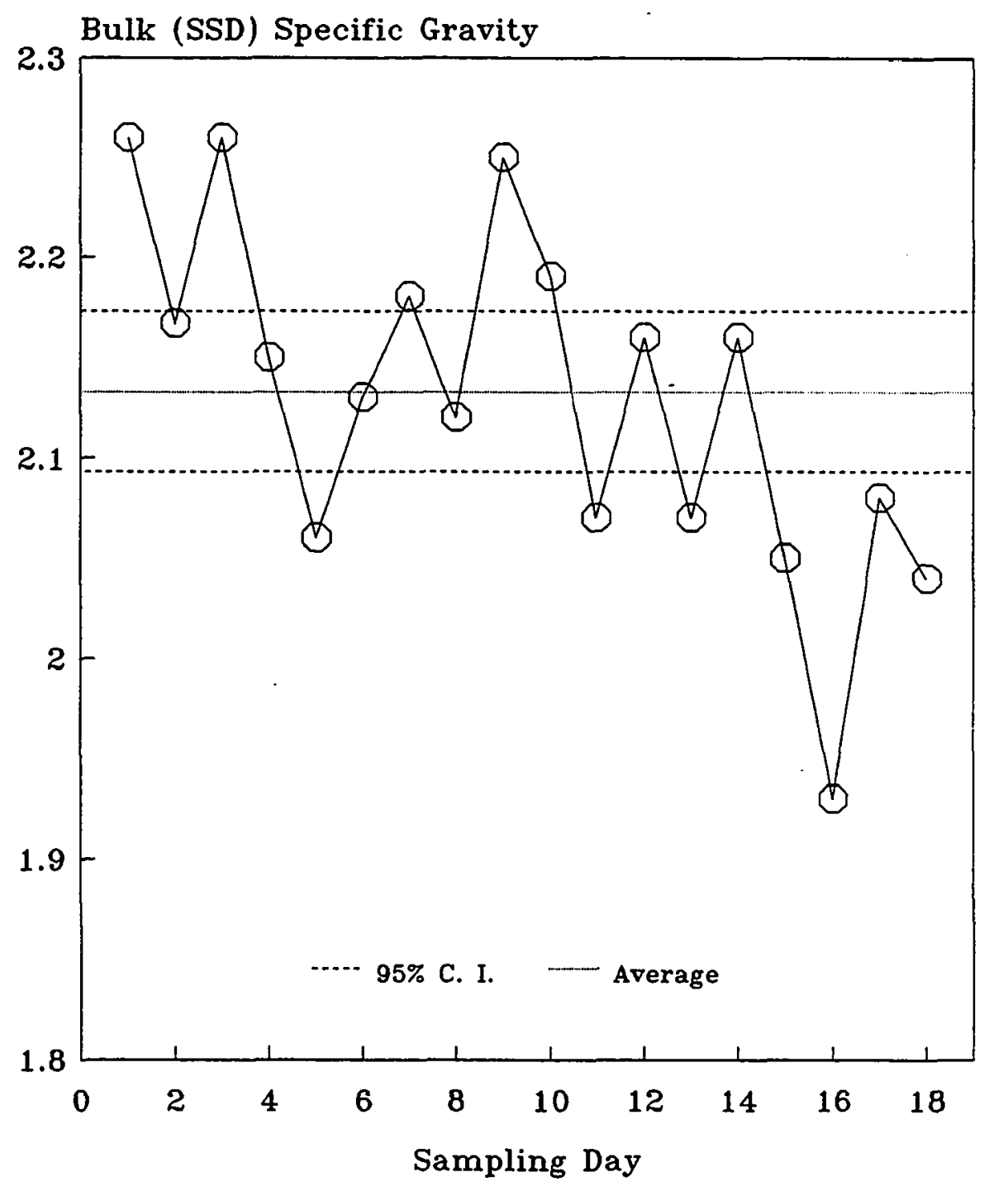

Figure 5.50 Bulk (SSD) Specific Gravity of Fine Ash versus Sampling Day (Daily Composite)

146 


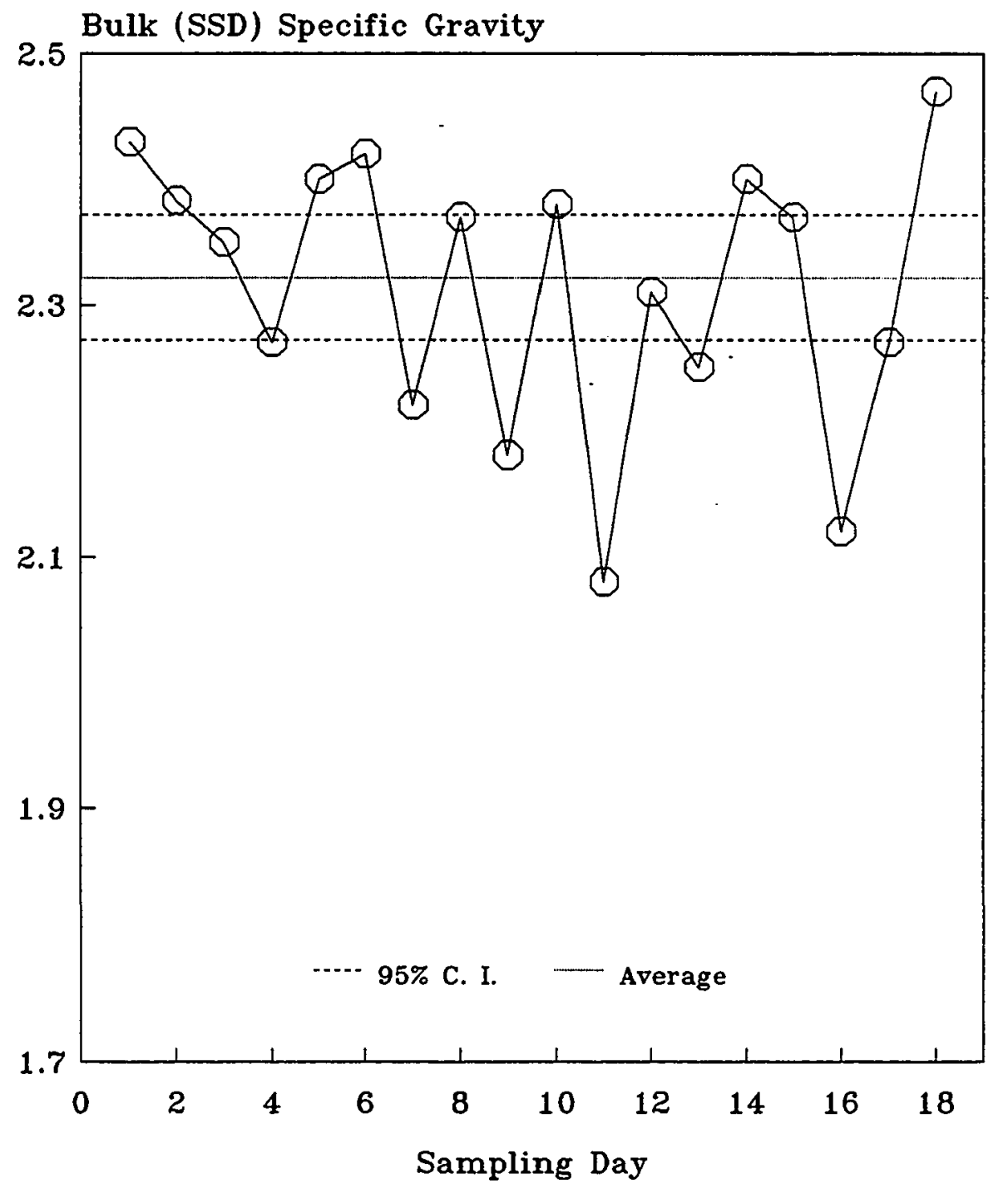

Fig. 5.51 Bulk (SSD) Specific Gravity of Coarse Ash versus Sampling Day (Daily Composite) 


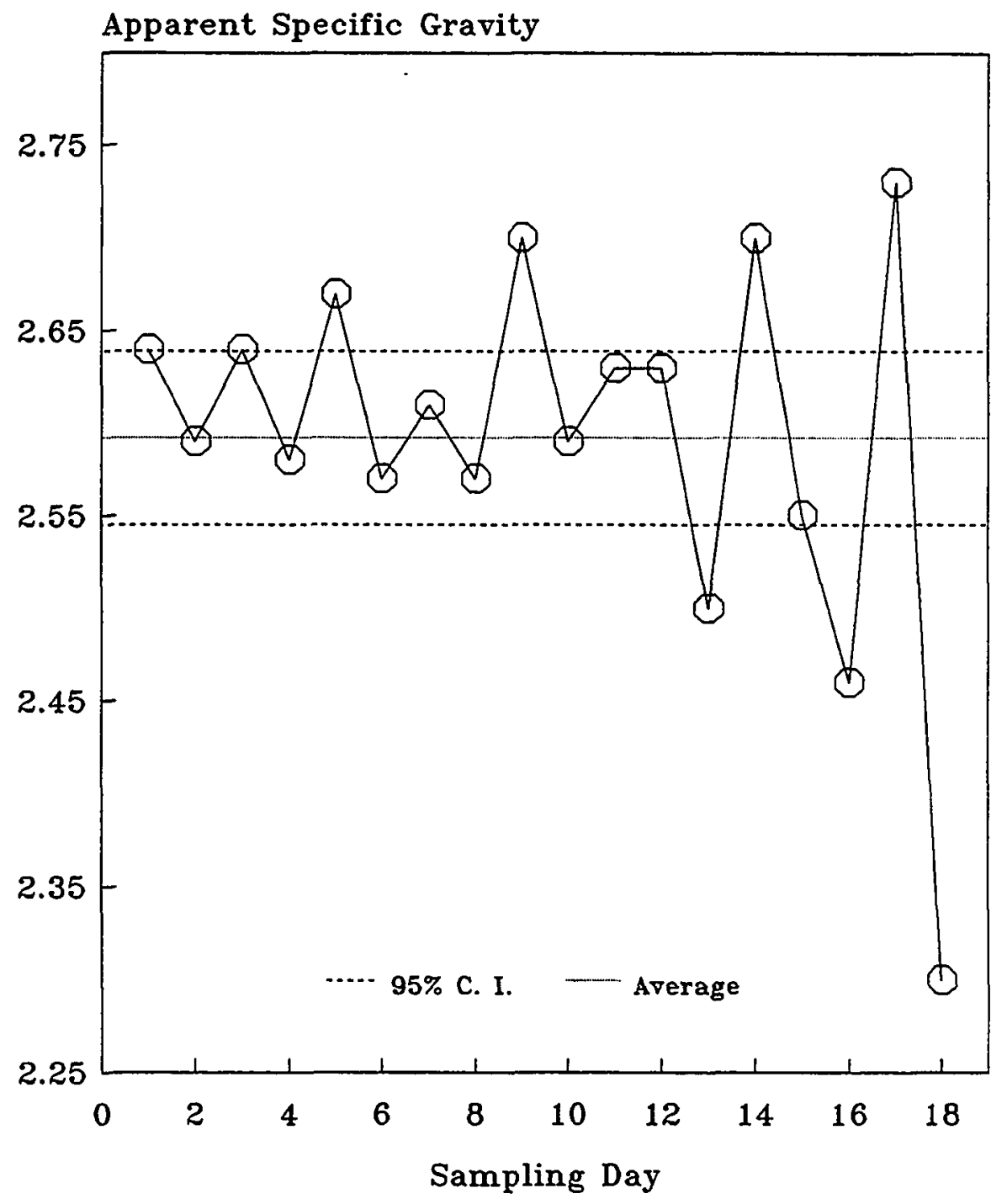

Figure 5.52 Apparent Specific Gravity of Fine Ash versus Sampling Day (Daily Composite)

148 


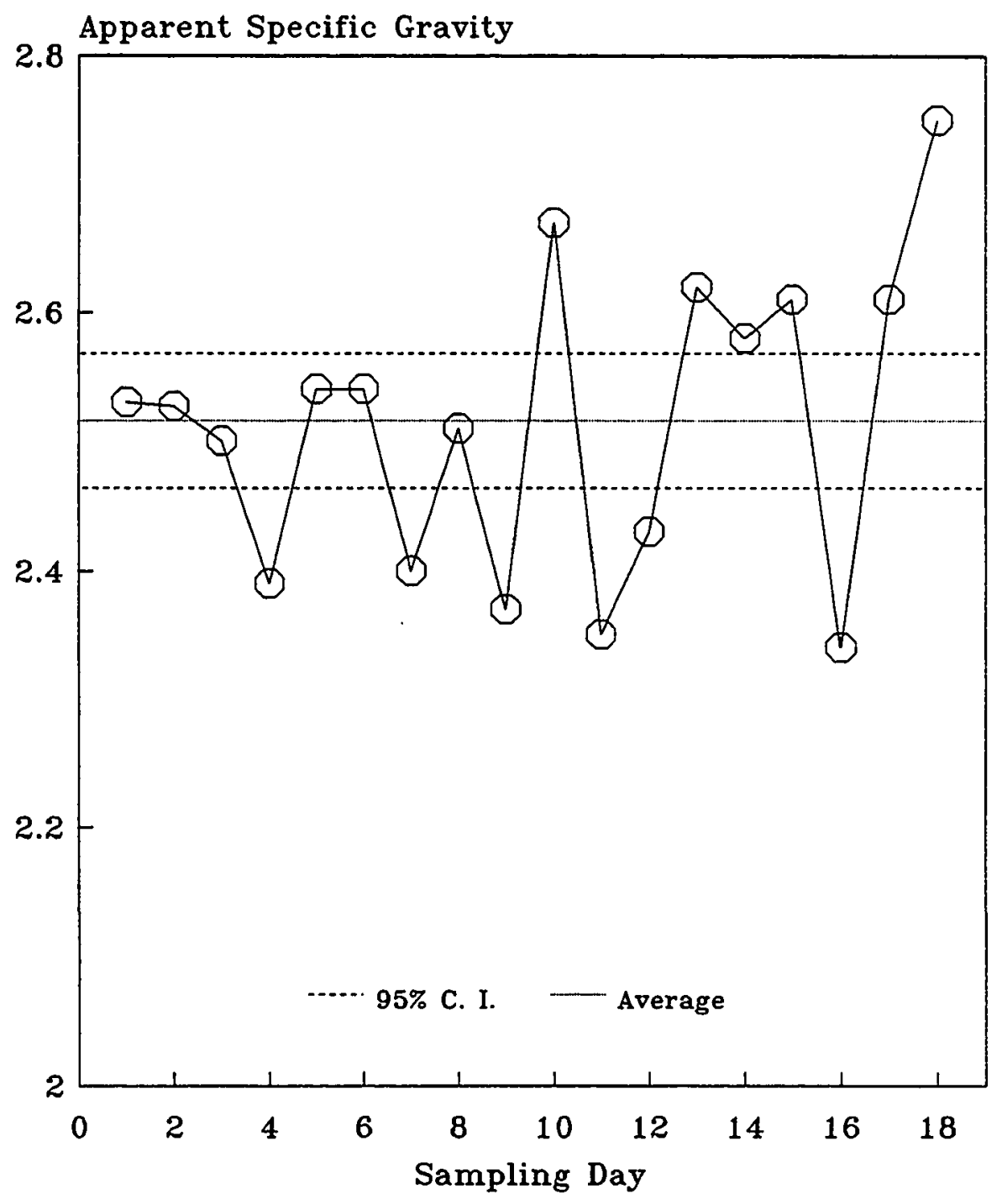

Fig. 5.53 Apparent Specific Gravity of Coarse Ash versus Sampling Day (Daily Composite) 


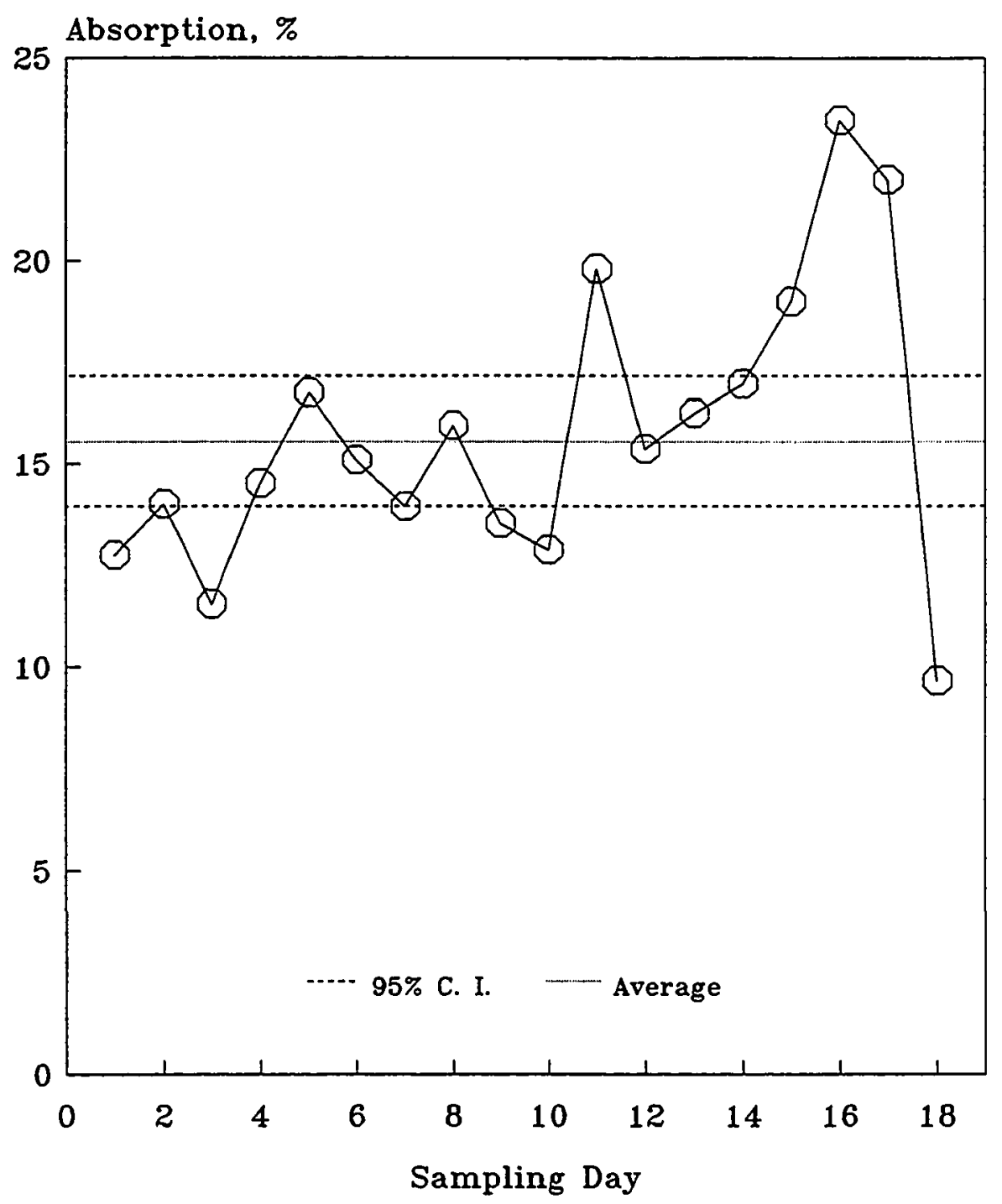

Figure 5.54 Absorption of Fine Ash versus Sampling Day (Daily Composite) 


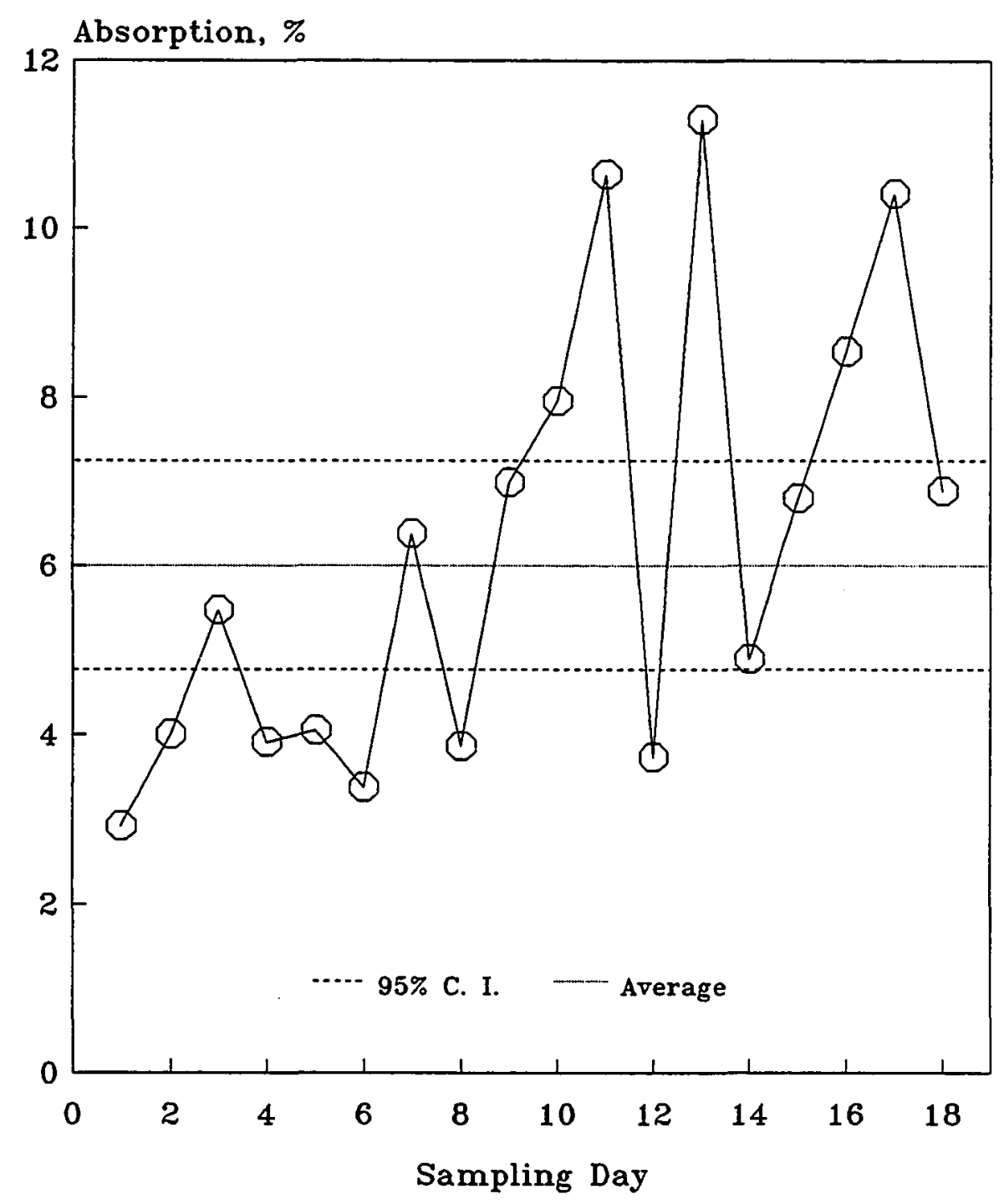

Figure 5.55 Absorption of Coarse Ash versus Sampling Day (Daily Composite)

151 


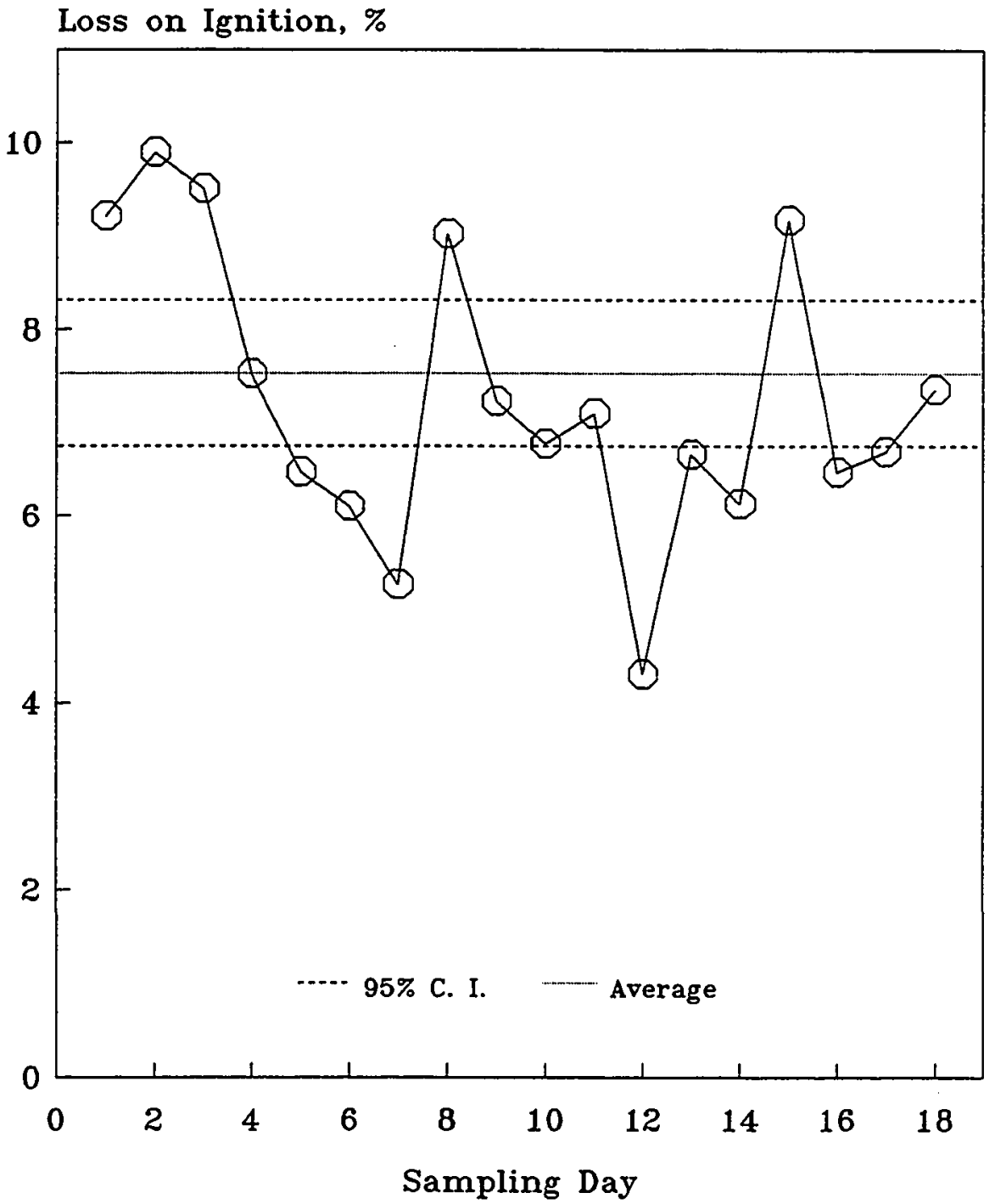

Figure 5.56 LOI versus Sampling Day (Daily Composite) 


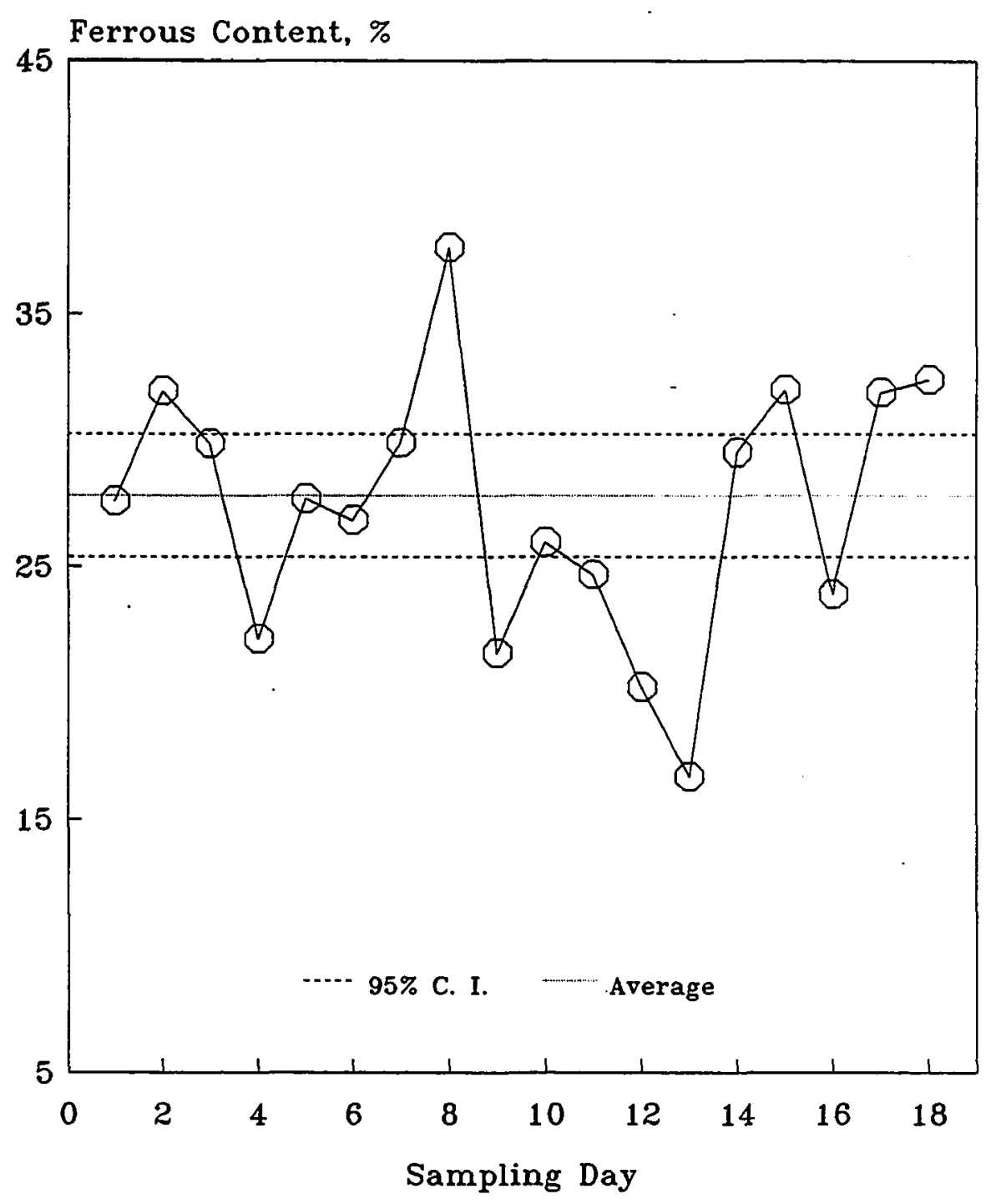

Figure 5.57 Ferrous Content versus Sampling Day (Daily Composite) 
Table 5.9 Physical Properties for Daily Composites (Continued)

\begin{tabular}{|c|c|c|c|c|c|c|c|c|}
\hline \multirow{2}{*}{ Property } & \multirow{2}{*}{ No. } & \multirow{2}{*}{ Mean } & \multicolumn{6}{|c|}{ Confidence Interval } \\
\hline & & & $75 x$ & $90 x$ & $95 \%$ & $97.5 \%$ & $99 \%$ & $99.5 \%$ \\
\hline Unit Weight, $t b / f t^{3}$ & 20 & 72.19 & $71.32-73.07$ & $70.91-73.48$ & $70.64-73.75$ & $70.39-74.00$ & $70.07-74.31$ & $69.84-74.55$ \\
\hline Volds in Aggregate, $x$ & 20 & 42.41 & $41.71-43.11$ & $41.39-43.43$ & $41.17-43.65$ & $40.97-43.85$ & $40.72-44.10$ & $40.53-44.28$ \\
\hline Opt imum Proctor Moisture, $x$ & 18 & 15.39 & $15.01-15.76$ & $14.84-15.94$ & $14.73-16.05$ & $14.62-16.16$ & $14.48-16.30$ & $14.38-16.40$ \\
\hline Proctor Density, $1 \mathrm{~b} / \mathrm{ft}^{3}$ & 18 & 108.56 & $107.6-109.5$ & $107.2-109.9$ & $106.9-110.2$ & 106.6-110.5 & $106.3-110.8$ & $106.1-111.1$ \\
\hline CBR at $0.1 ", x$ & 20 & 79.78 & $76.51-83.04$ & $75.02-84.53$ & $74.02-85.53$ & $73.08-86.47$ & $71.91-87.64$ & $71.05-88.50$ \\
\hline CBR at $0.211, \%$ & 20 & 110.3 & $107.0-113.6$ & 105.5-115.1 & $104.5-116.1$ & 103.5-117.0 & 102.4-118.2 & $101.5-119.1$ \\
\hline LA Abrasion (B), \% & 2 & 47.3 & - & - & & - & - & - \\
\hline LA Abrasion (C), $\%$ & 2 & 43.4 & - & - & $\cdot$ & - & - & - \\
\hline Soundness $\left(\mathrm{Na}_{2} \mathrm{SO}_{4}\right)$, Fine, $\%$ & 4 & 11.915 & - & - & $\cdot \cdot$ & $\cdot$ & - & $\cdot$ \\
\hline Soundness $\left(\mathrm{Na}_{2} \mathrm{SO}_{4}\right)$, Coarse, $\%$ & 2 & 2.635 & $\cdot$ & - & - & - & $\cdot$ & - \\
\hline
\end{tabular}


The physical properties as a function of time are shown in Figure 5.58 through 5.65.

Unit Weight and Void: Unit weight ranged from 70.6 to $73.8 \mathrm{lb} / \mathrm{ft}^{3}$ at $95 \%$ probability level, with an average of $72.2 \mathrm{lb} / \mathrm{ft}^{3}$. Unit weight of bottom ash varies randomly with time, as shown in Figure 5.58. Void content ranged from 41.2 to $43.7 \%$, with an average of $42.4 \%$. Void content of the ash varies with time randomly, as shown in Figure 5.59. ASTM C29 introduces three different unit weights, that is, unit weight by rodding, unit weight by jigging and loose unit weight. The unit weight by rodding was employed in this study. The variation of unit weight data exceeds the ASTM requirement for single-operator precision. Nevertheless, the variation of data are fairly small in view of fact that ash is an uncontrolled waste material. No precision requirements on void content are available. It was felt that unit weight and void data are affected by ash composition in the same way as for specific gravity.

Optimum Moisture Content and Proctor Density: The optimum moisture content ranged from 14.7 to $16.1 \%$ at $95 \%$ confidence level, with an average of $15.4 \%$. Four of 18 samples show relatively large variation, as shown in Figure 5.60. Precision of optimum moisture content data meet the ASTM D1557 requirement. Proctor density ranged from 106.9 to $110.2 \mathrm{lb} / \mathrm{ft}^{3}$ at $95 \%$ confidence level, with an average of 108.6 $\mathrm{lb} / \mathrm{ft}^{3}$. Proctor density varies randomly with time as shown in Figure 5.61 . The variation of density data are fairly small, meeting the ASTM D1557 precision requirement.

California Bearing Ratio (CBR): CBR test was conducted on samples as molded (unsoaked) at a moisture content of $16 \%$, the optimum moisture content for most samples. CBR at $0.1^{\prime \prime}$ penetration ranged from 74.0 to $85.5 \%$ at $95 \%$ confidence level, 


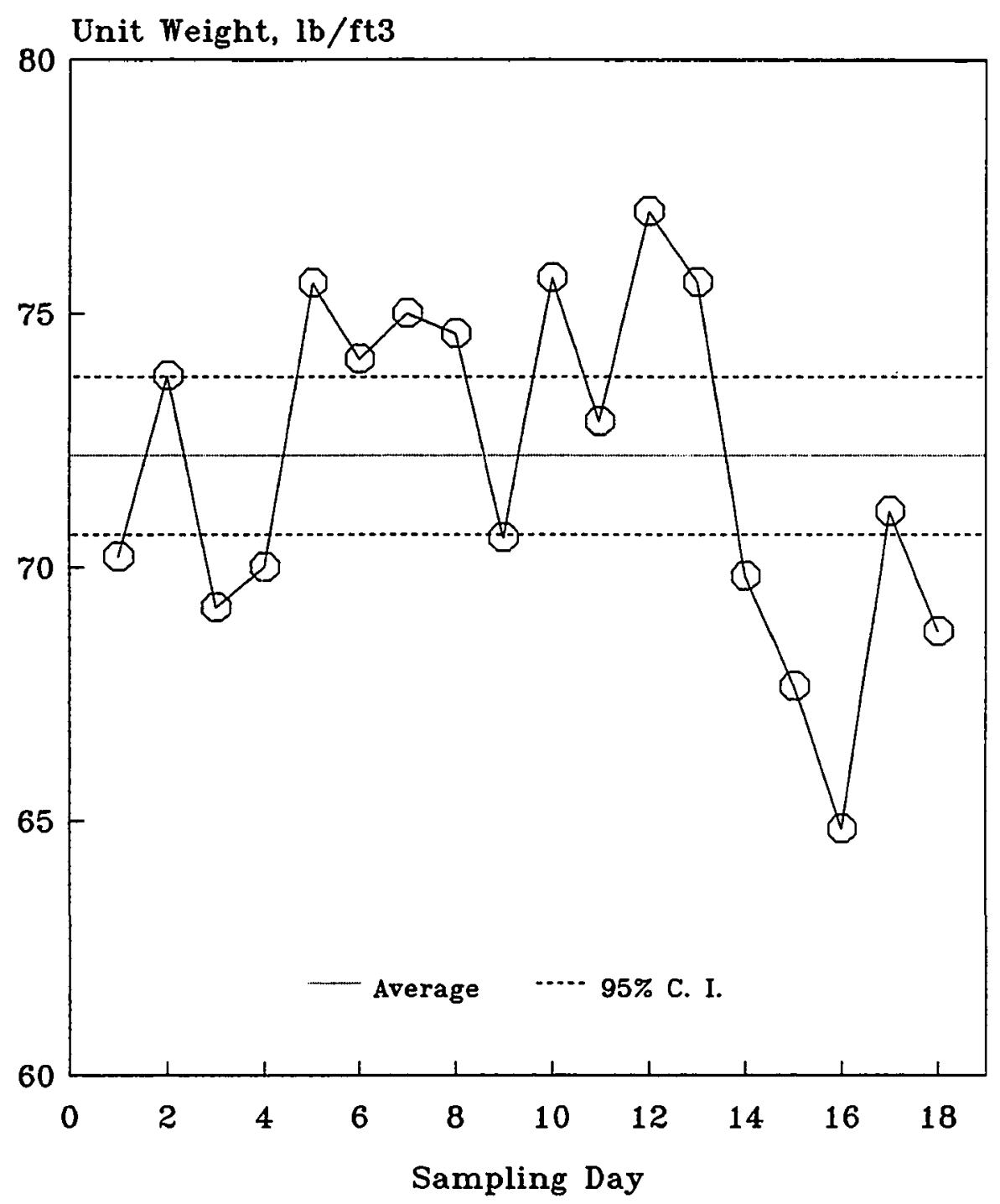

Figure 5.58 Unit Weight versus Sampling Day 


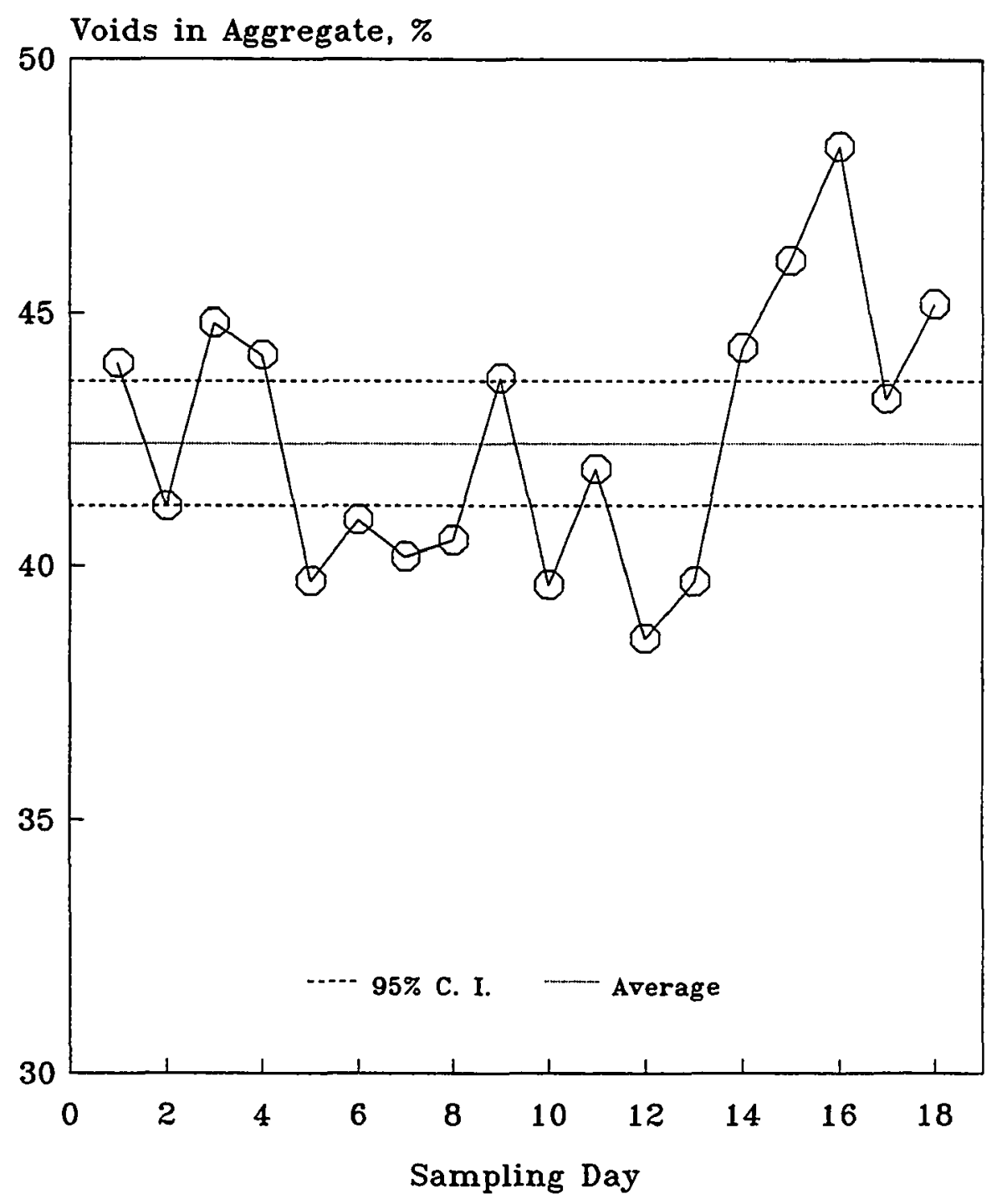

Figure 5.59 Voids in Aggregate versus Sampling Day 157 


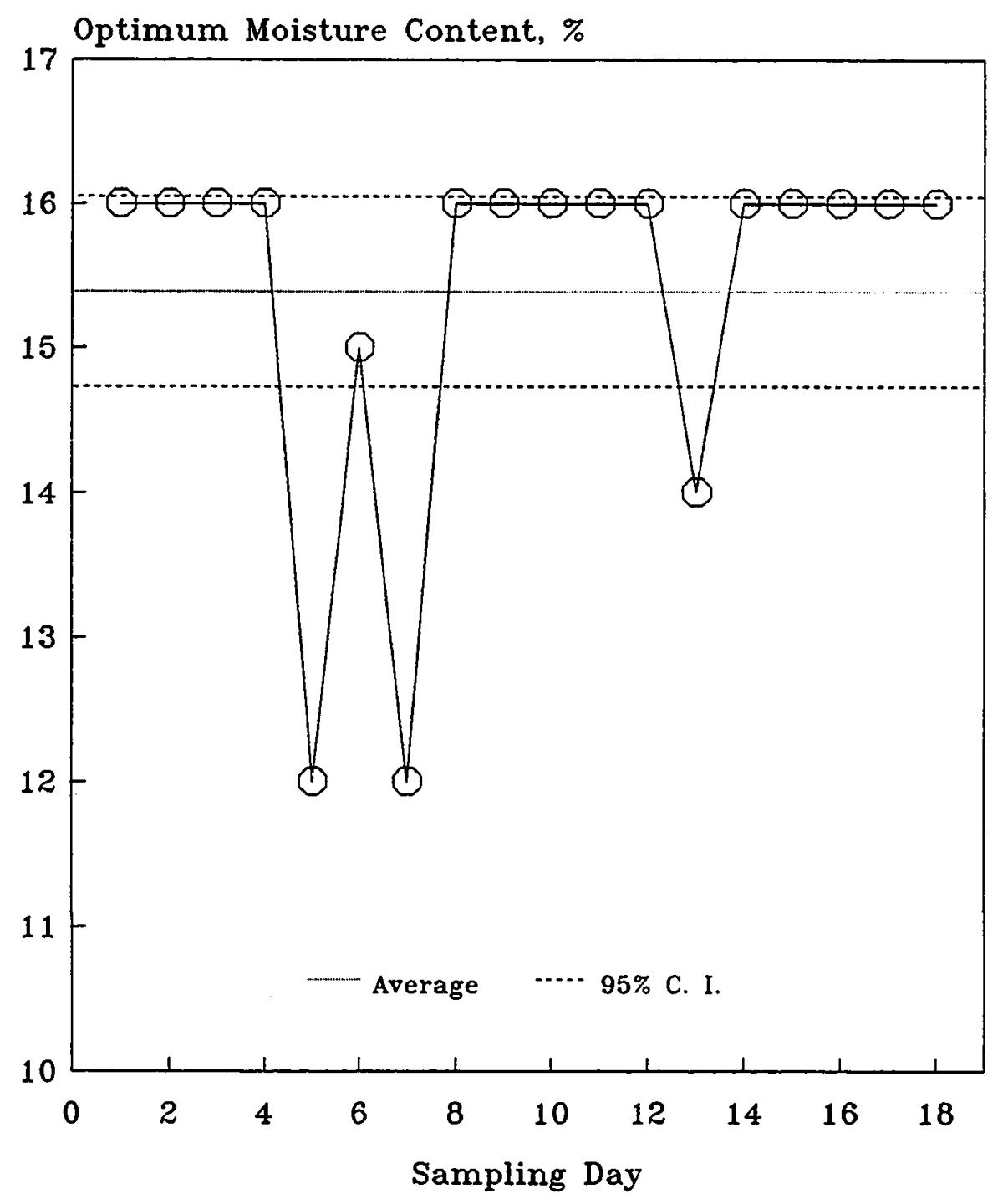

Figure 5.60 Optimum Moisture Content versus Sampling Day 158 


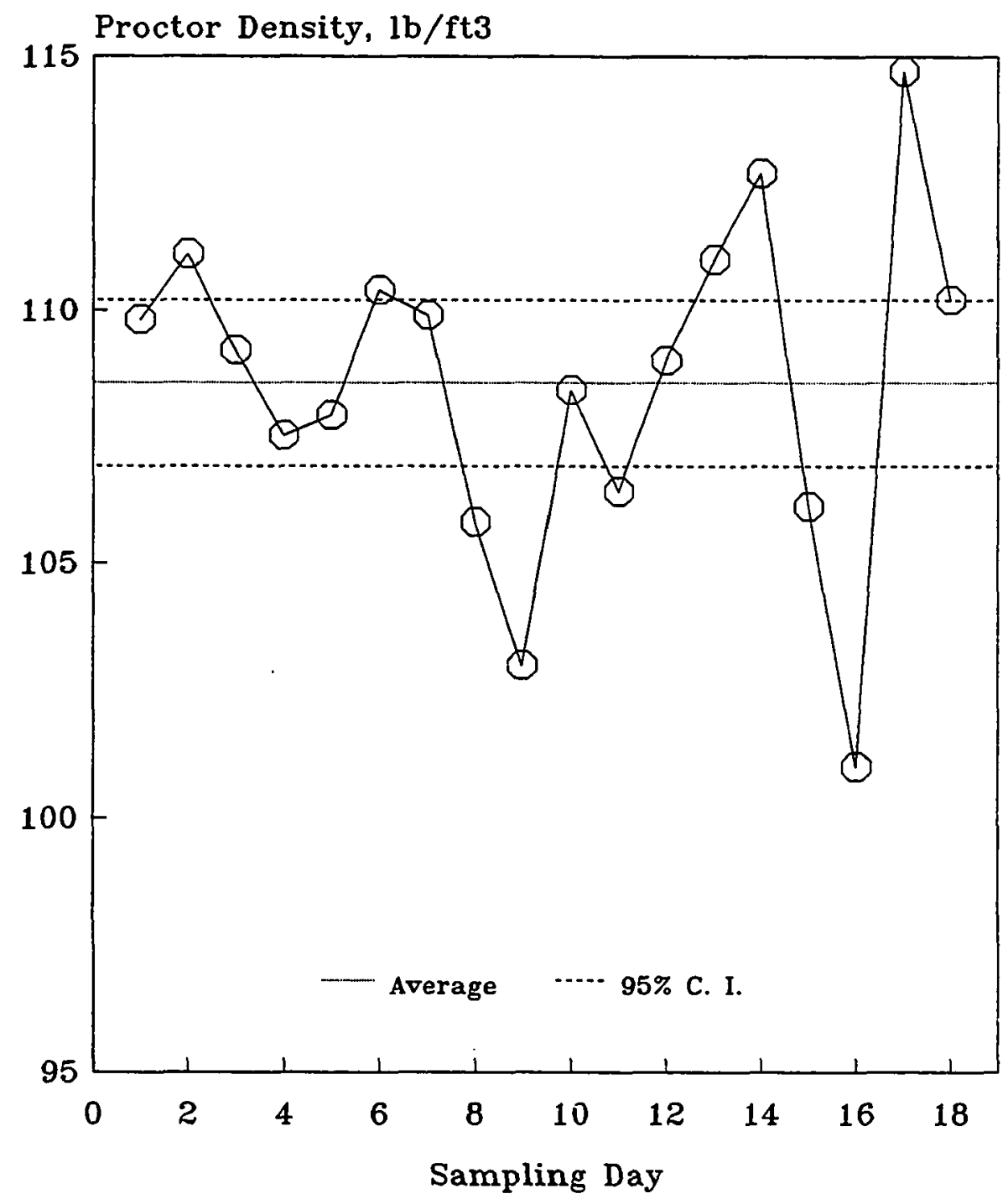

Figure 5.61 Proctor Density versus Sampling Day 159 
with an average of $79.8 \%$. CBR at $0.2^{\text {n }}$ penetration ranged from 104.5 to $116.1 \%$ at 95\% level, with an average of $110.3 \%$. The CBR data vary randomly with time, as shown in Figures 5.62 and 5.63. An ASTM precision requirement has not been established. It was felt that the factors that affect the CBR precision for the ash samples include composition and gradation.

The Los Angeles (L.A.) Abrasion: Only two daily composites samples were selected for this test. The average L.A. abrasion values for Grade B and Grade C are $47.3 \%$ and 43.4\%, respectively as shown in Figure 5.64. The variation meets the ASTM C131 precision requirements. It was felt that the test results were affected by ash composition, especially friable materials content.

Soundness by Use of Sodium Sulfate: Four daily composites samples were selected for this test for fine ash and two daily composites samples for coarse ash. Soundness for fine ash ranged from 10.4 to $14.3 \%$, with an average of $11.9 \%$, that for coarse ash ranged from 2.5 to $2.8 \%$, with an average of $2.6 \%$ as shown in Figure 5.65 . The variation for fine ash and coarse ash meets the ASTM C88 precision requirements. It was felt that the precision of data is affected by ash composition and physical properties such as porosity and pore size.

\subsection{Conclusions}

The following conclusions can be drawn from the statistical analysis of timedependent physical properties. 


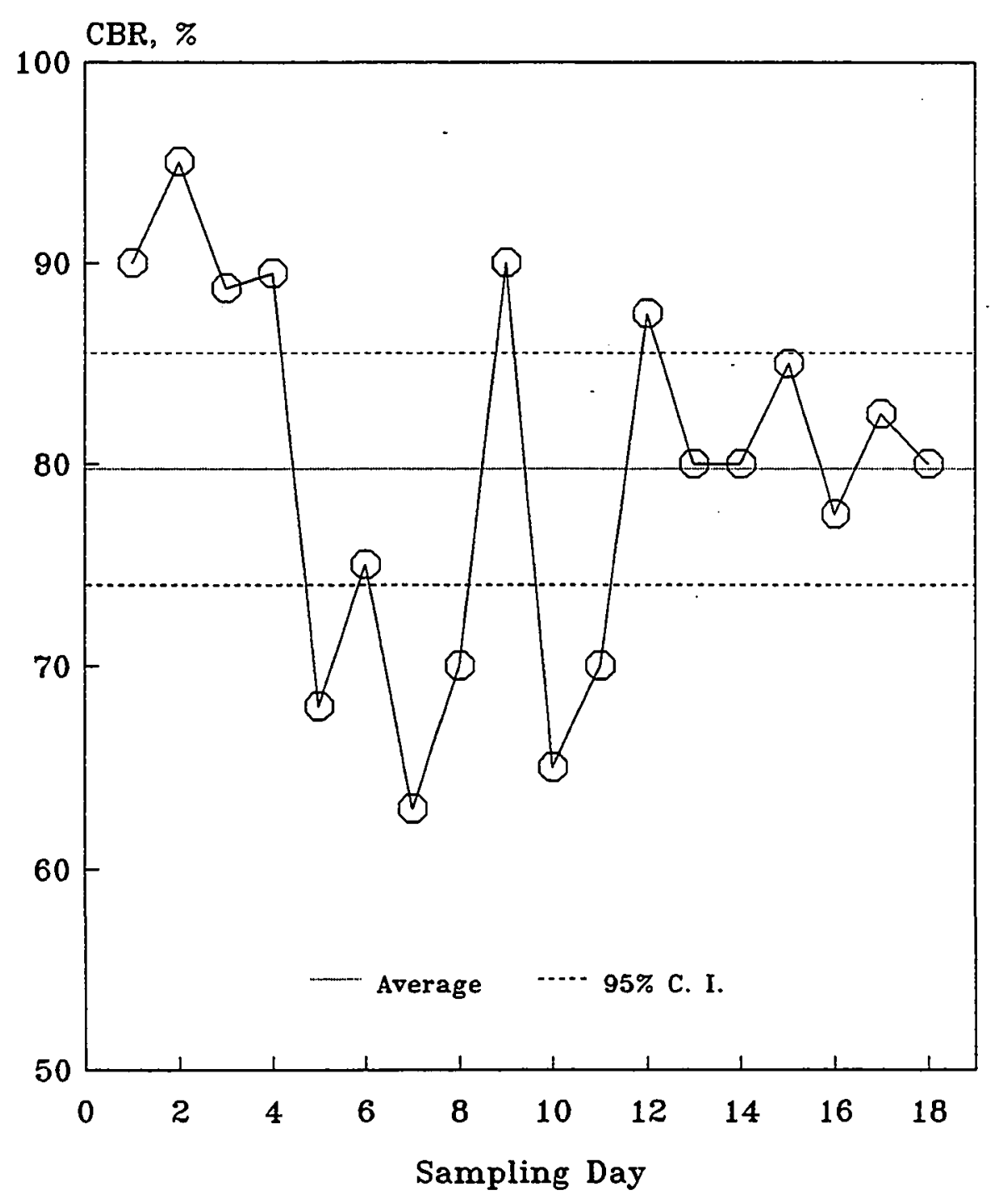

Figure 5.62 CBR at 0.1" Penetration versus Sampling Day 


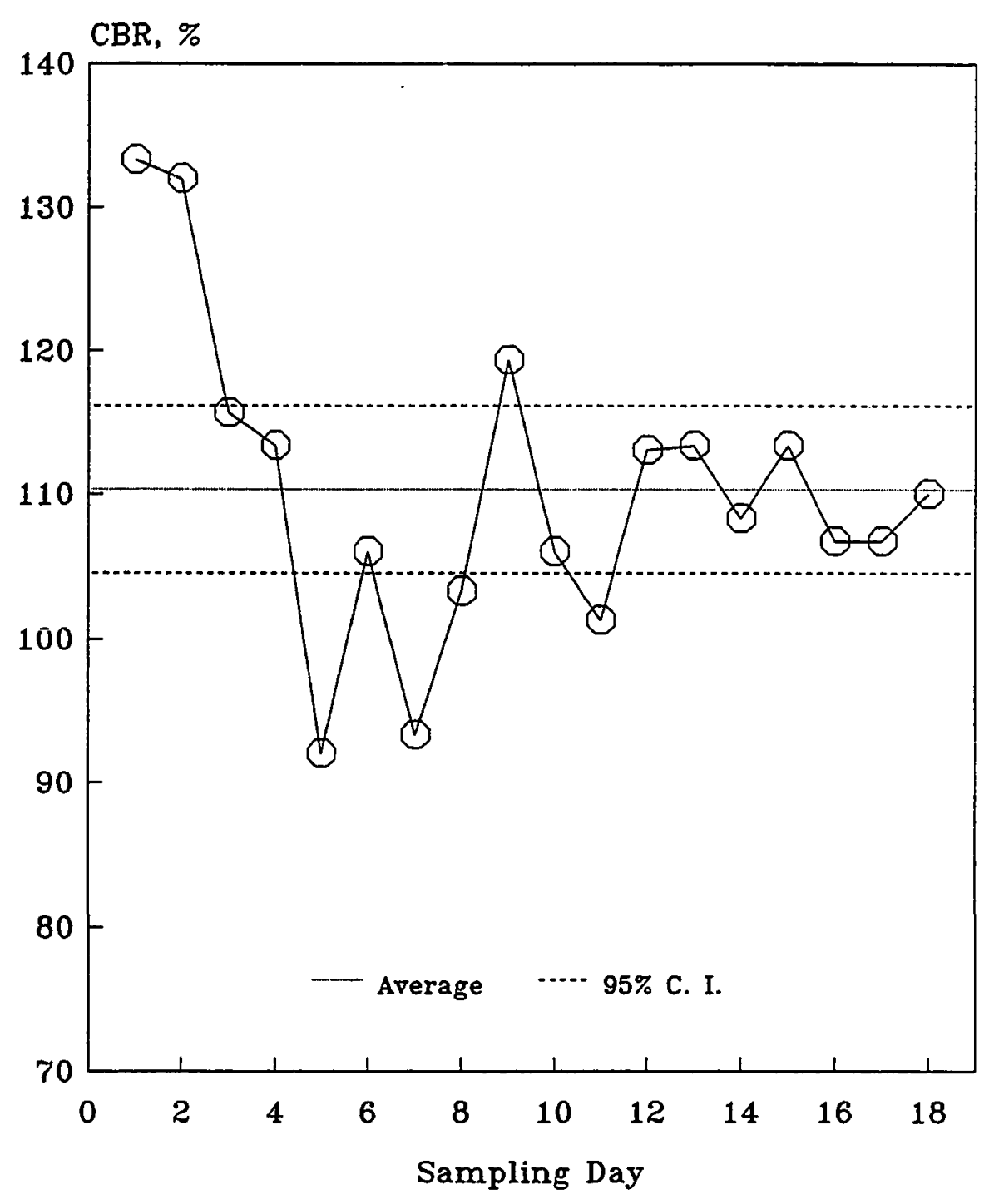

Figure 5.63 CBR at 0.2" Penetration versus Sampling Day 


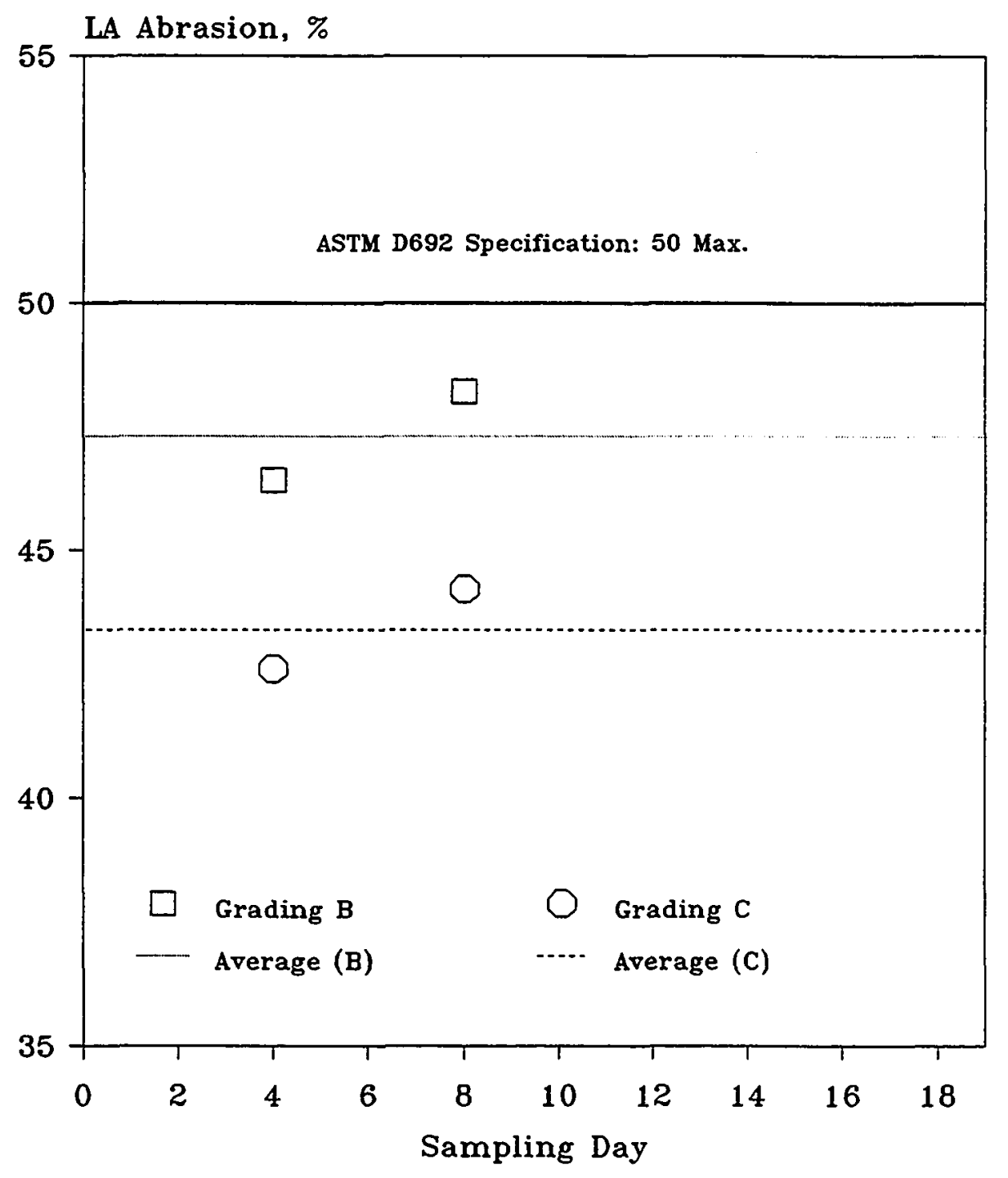

Figure 5.64 LA Abrasion versus Sampling Day 


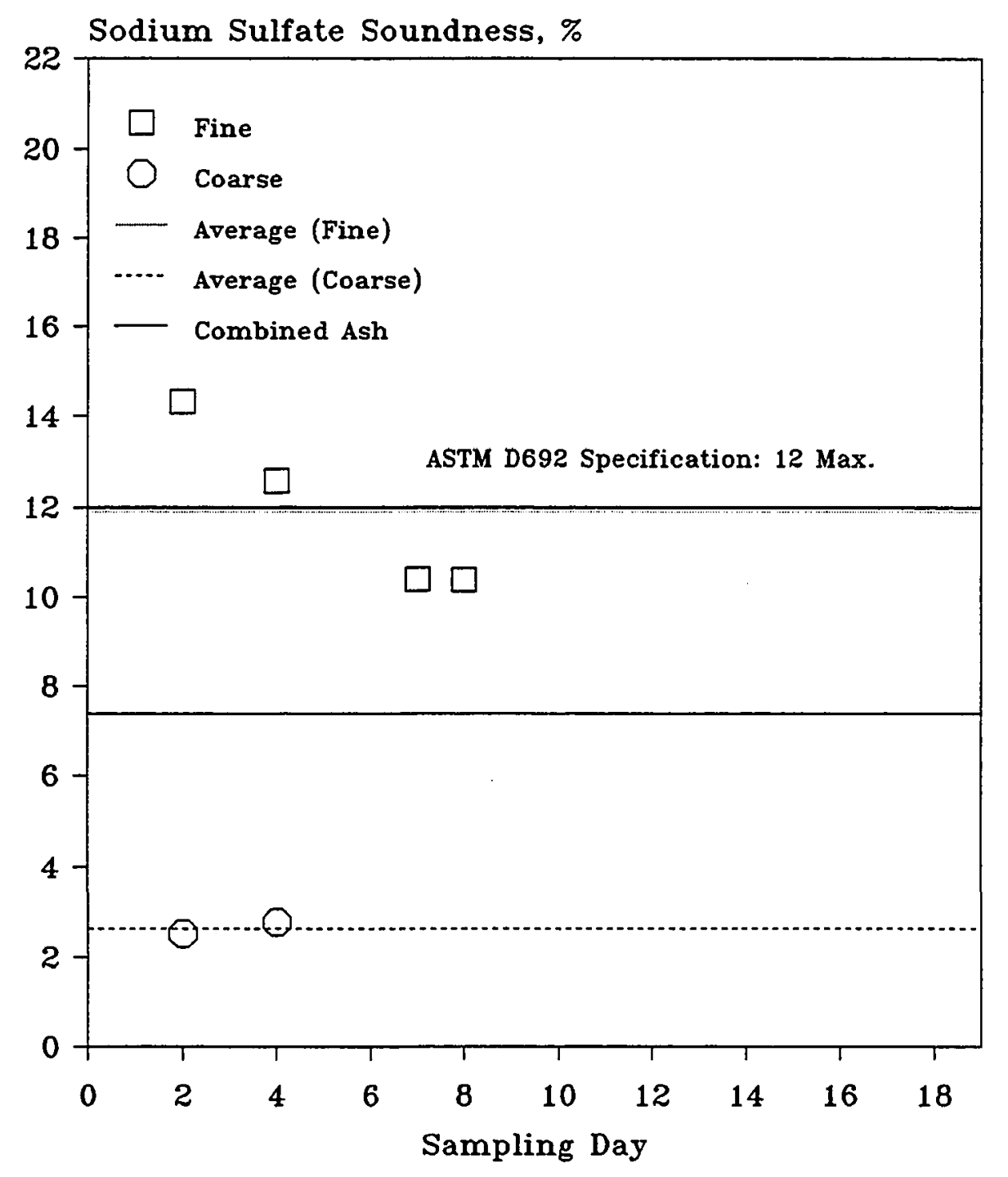

Figure 5.65 Sodium Sulfate Soundness versus Sampling Day 164 


\section{Particle Size Distribution}

\section{1). Hourly Samples}

1. The between-sampling day variation became more and more significant with decreased ash particle size.

2. The between-sampling hour variation varied with ash size, and was not significant.

3. The average gradation of bottom ash fell within the New Hampshire specification for type B binder mix, indicating the bottom ash was a well graded material.

2). Daily Composite Samples

1. The average gradation fell within the New Hampshire specification with the exception that the materials passing No.200 was marginal.

2. Bottom ash contained more fine materials in comparison to the $\mathrm{NH}$ desired gradation.

3. The variation of daily composite samples was much smaller than that of hourly samples.

4. The average gradation of daily composite was close to that of the hourly samples.

3). Source of Variation

1. The variation of gradation existed for all ash samples. The variation could be contributed to sample representativeness, and sieve analysis method.

\section{Qther Physical Properties}




\section{1). Hourly Samples}

1. The between-sampling day variation was significant, with the exception that variation of uniformity coefficient and effective size was not significant at $99 \%$ and 99.5\% level.

2. The between-sampling hour variation was not significant, with the exception that mass $\left(\geq 3 / 4^{\prime \prime}\right)$, mass $\left(<3 / 4^{\prime \prime}\right)$, and uniformity coefficient were marginal at $75 \%$ confidence level.

3. Mass ( $\geq 3 / 4^{\prime \prime}$ ) ranged from 20.8 to $50.2 \%$, with an average of $32.9 \%$. The significant variability was from the uncontrolled nature of incoming solid waste and the way bottom ash was sampled. The bulk of the rejected material was ferrous and nonferrous, fused materials, large pieces of slag, and unburned material.

4. The bottom ash passing the $3 / 4^{\text {" }}$ sieve ranged from 49.8 to $79.2 \%$, with an average of $67.1 \%$. The variation was in part due to the uncontrolled quality of incoming solid waste.

5. Moisture content ranged from 22.4 to $60.6 \%$, with an average of $37.9 \%$. Variation in MSW properties or combustor operation influenced water content.

6. Uniformity coefficient ranged from 8.3 to 34.0 , with an average of 21.7 . Effective size ranged from 0.12 to $0.52 \mathrm{~mm}$, with an average of $0.29 \mathrm{~mm}$. The two properties were sensitive to gradation data.

7. Specific gravity and absorption of coarse aggregate and fine aggregate:

Bulk (dry) specific gravity of fine ash ranged from 1.55 to 2.22 , with an average of 1.86, and that of coarse ash ranged from 1.93 to 2.44 , with an average of 2.20 . 
Bulk (SSD) specific gravity of fine ash ranged from 1.89 to 2.41 , with an average of 2.13 , and that of coarse ash ranged from 2.11 to 2.58 , with an average of 2.32 .

Apparent specific gravity of fine ash ranged from 2.20 to 2.98, with an average of 2.56, and that of coarse ash ranged from 2.32 to 2.76, with an average of 2.51.

Absorption of fine ash ranged from 6.8 to $24.7 \%$, with an average of $14.7 \%$, and that of coarse ash ranged from 1.8 to $12.3 \%$, with an average of $5.7 \%$.

The variation of specific gravity and absorption exceeded the ASTM C127 and C128 precision requirements. Ash had a heterogeneous nature. The difference in the specific gravity between ash components is significant. Any change in components from sample to sample would result in significant variation in specific gravity and absorption.

8. LOI ranged from 3.2 to 10.0 , with an average of 6.4. The variation of LOI exceeded the ASTM C114 requirements because of a heterogeneous nature of ash and difficulty in obtaining a representative sample. LOI was strongly associated with particle size, increasing significantly with the decreased particle size.

9. Ferrous content ranged from 11.9 to $39.6 \%$, with an average of $25.9 \%$. The true ferrous content should be lower than the above since the magnet was capable of picking up ash particle combined with iron. The variation was significant because of the nature of this test and the heterogeneous nature of the ash.

2). Daily Composite Samples

1. The daily composite data were within hourly data range and had much less variation than the hourly data. Variation of daily composite data did not meet the ASTM precision requirements. 
2. Unit weight ranged from 70.6 to $73.8 \mathrm{lb} / \mathrm{ft}^{3}$ at $95 \%$ level, with an average of 72.2 $\mathrm{lb} / \mathrm{ft}^{3}$. The variation exceeded ASTM requirement for single-operator precision. Nevertheless, the variation was fairly small in view of fact that ash is a uncontrolled waste material. Void content ranged from 41.2 to $43.7 \%$, with an average of $42.4 \%$. Precision requirements on void content are not available.

3. The optimum moisture content ranged from 14.7 to $16.1 \%$ at $95 \%$ confidence level, with an average of $15.4 \%$. Precision of optimum moisture content data met the ASTM D1557 requirement. Proctor density ranged from 106.9 to $110.2 \mathrm{lb} / \mathrm{ft}^{3}$ at $95 \%$ level, with an average of $108.6 \mathrm{lb} / \mathrm{ft}^{3}$. The variation were fairly small, meeting the ASTM D1557 precision requirement.

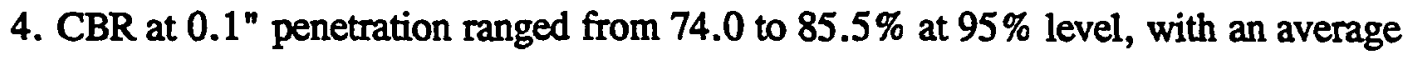
of $79.8 \%$. CBR at $0.2^{n}$ penetration ranged from 104.5 to $116.1 \%$ at $95 \%$ level, with an average of $110.3 \%$. The factors that affected the CBR precision for ash included ash composition and gradation.

5. L.A. Abrasion data were consistent, with an average of $47.3 \%$ and $43.4 \%$ for Grade B and Grade C, respectively. The variation met the ASTM C131 precision requirements.

6. Soundness of fine ash ranged from 10.4 to $14.3 \%$, with an average of $11.9 \%$, that of coarse ash ranged from 2.5 to $2.8 \%$, with an average of $2.6 \%$. The variation for fine ash and coarse ash met the ASTM C88 precision requirements. The precision of data was affected by ash composition and physical properties such as porosity and pore size. 


\section{MARSHALL DESIGN PROCEDURE}

\subsection{Introduction}

In the United States, consideration is being given to the use of bottom ash from municipal solid waste combustion as an aggregate substitute in construction materials (14). Consequently, the use of bottom ash is likely to be in bituminous base course, bituminous wearing course, bituminous stabilized aggregate base and concrete construction materials before it is used in granular subbase, structural fill or embankment applications due to environmental concern.

Earlier work in the United States by Walter $(54,55)$ presented hot mix formulations utilizing $50 \%$ bottom ash with asphalt cement contents of 5.5 to 6.5 percent by weight. Other researchers developed similar formulations which led to a number of demonstrations in the 1970's and early 1980's utilizing bottom ash in base course and wearing courses $(12,16,17,18,19)$. These studies suggest that optimum mixes for hot mix work can contain 50 to $75 \%$ bottom ash substituted for conventional aggregate.

Recent work by Chesner et al. (4) showed bottom ash from the Southwest Brooklyn, New York combustor is a viable aggregate substitute. Performance was as good as the control at the $30 \%$ substitution level.

The objective of this study was to develop the optimum designs for $\mathrm{NH}$ type $\mathrm{B}$ base course mix using Marshall design procedure (35). Hot mixture asphalt designs were 
investigated for a control mix, and $25 \%, 50 \%, 75 \%$, and $100 \%$ bottom ash blends.

\subsection{Materials and Methods}

The conventional aggregates used in this study were obtained from Pike Industries Inc., a materials supplier, asphaltic concrete producer and contractor, as well as Concord Sand and Gravel, a materials supplier. The 3/4", 1/2", 3/8n, dust and washed dust supplied by Pike Industries Inc. are manufactured crushed stone. The sand supplied by Concord Sand and Gravel is glacial in origin. The bottom ash used in this study was created by blending 8 daily composite samples collected during the first 8 sampling events. The physical properties of the control aggregates and bottom ash are presented in Table 6.1.

The gradation of the control aggregates is shown in Table 6.2. The control consisted of a unique combination of Pike aggregates, as shown in Table 6.2. Bottom ash was substituted on a weight basis for $25 \%, 50 \%, 75 \%$ and $100 \%$ boitom ash mixes. All gradations met the mid-point gradation requirements of a NH type B binder mix as shown in Figure 6.1.

An AC-20 asphalt supplied by Pike Industries Inc. had physical properties as listed in Table 6.3.

The Marshall method of mix design (35) was used. The mixing temperature required to provide an asphalt viscosity of $170 \pm 20$ centistokes was $295^{\circ} \mathrm{F}$. The compaction temperature required to provide an asphalt viscosity of $280 \pm 30$ centistokes was $284^{\circ} \mathrm{F}$. Three test samples were prepared for each asphalt content. 
Table 6.1 Physical Properties of Control Aggregates and Bottom Ash

\begin{tabular}{|l|l|l|l|l|}
\hline Aggregate Type & $\begin{array}{l}\text { Bulk (Dry) } \\
\text { S.G. }\end{array}$ & $\begin{array}{l}\text { Bulk (SSD) } \\
\text { S.G. }\end{array}$ & $\begin{array}{l}\text { Apparent } \\
\text { S.G. }\end{array}$ & $\begin{array}{l}\text { Absorption } \\
(q)\end{array}$ \\
\hline $3 / 4 "$ & 2.6081 & 2.6344 & 2.6761 & 0.95 \\
\hline $1 / 2 "$ & 2.6080 & 2.6299 & 2.6663 & 0.84 \\
\hline $3 / 8$ " & 2.5582 & 2.5957 & 2.6577 & 1.46 \\
\hline Concord Sand & 2.6077 & 2.6436 & 2.7050 & 1.38 \\
\hline Washed Dust & 2.6056 & 2.6458 & 2.6812 & 1.08 \\
\hline Dust & 2.6020 & 2.6353 & 2.6915 & 1.27 \\
\hline Ash (< No.4) & 1.9122 & 2.1596 & 2.5409 & 12.94 \\
\hline Ash ( $\geq$ No.4) & 2.2376 & 2.3736 & 2.5897 & 6.08 \\
\hline
\end{tabular}


Table 6.2 Gradation and Proportion of Control Aggregates in Control Mix

\begin{tabular}{|l|l|l|l|l|l|l|}
\hline \multirow{2}{*}{ Sieve Size } & \multicolumn{7}{|c|}{ Percent $\begin{array}{l}\text { Passing } \\
(8)\end{array}$} \\
\cline { 2 - 8 } & $3 / 4^{\prime \prime}$ & $1 / 2^{\prime \prime}$ & $3 / 8^{\prime \prime}$ & $\begin{array}{l}\text { Washed } \\
\text { Dust }\end{array}$ & Dust & $\begin{array}{l}\text { Concord } \\
\text { Sand }\end{array}$ \\
\hline 1" & 100 & 100 & 100 & 100 & 100 & 100 \\
\hline $3 / 4 "$ & 94 & 100 & 100 & 100 & 100 & 100 \\
\hline $1 / 2 "$ & 22 & 100 & 100 & 100 & 100 & 100 \\
\hline $3 / 8 "$ & 2 & 46 & 99 & 100 & 100 & 100 \\
\hline$\# 4$ & 1 & 3 & 32 & 98 & 99 & 94.5 \\
\hline$\# 10$ & 1 & 2 & 4 & 69 & 72 & 82 \\
\hline$\# 20$ & 1 & 2 & 3 & 44 & 49 & 60.2 \\
\hline$\# 40$ & 1 & 1 & 2 & 29 & 36 & 31.3 \\
\hline$\# 80$ & 1 & 1 & 1 & 11 & 21 & 7.1 \\
\hline$\# 200$ & 0.3 & 0.6 & 0.9 & 3.3 & 8.3 & 1.4 \\
\hline Control Mix, 8 & 23 & 12 & 23 & 17 & 15 & 10 \\
\hline
\end{tabular}




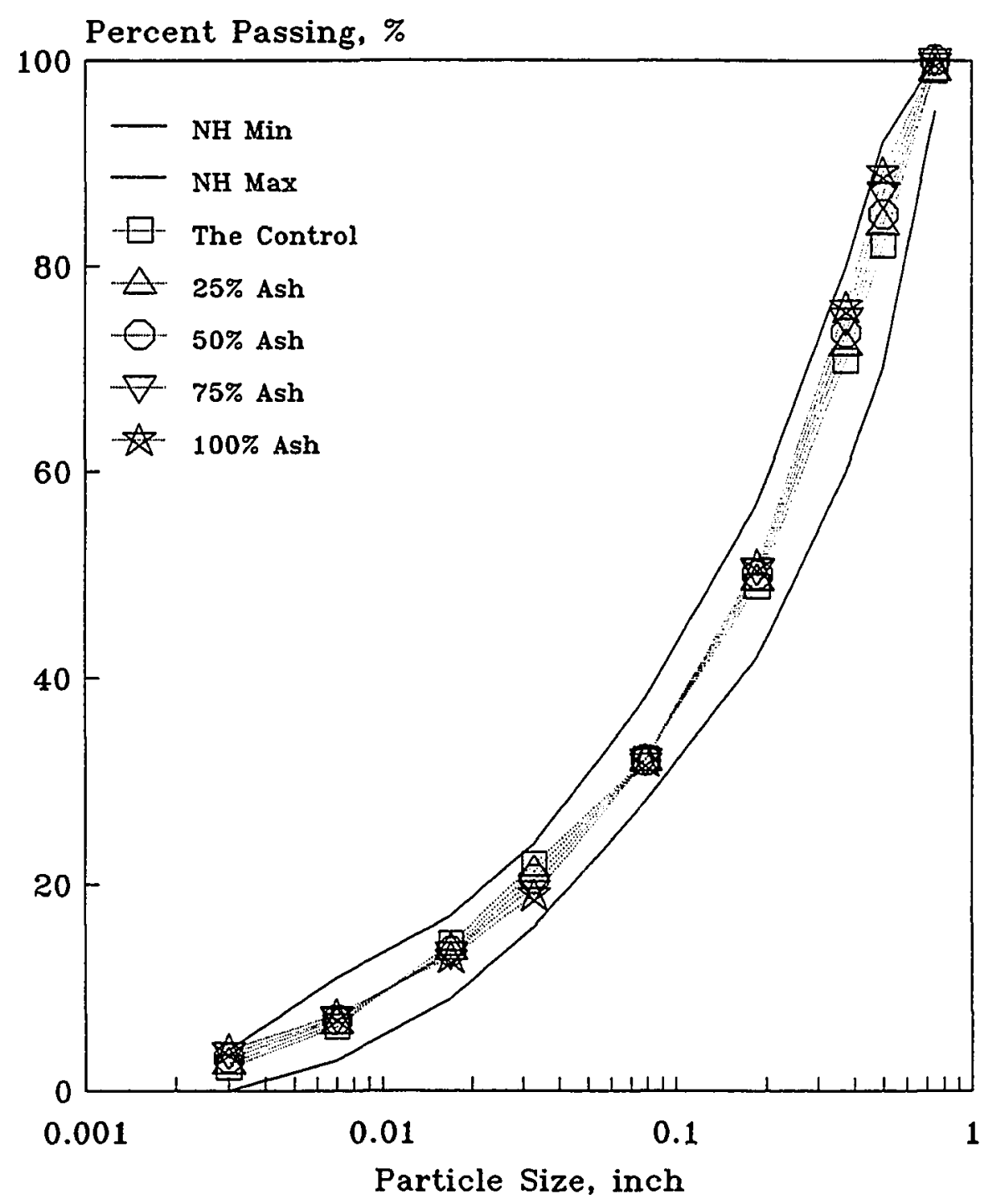

Figure 6.1 Gradation of Test Blends

173 
Table 6.3 Asphalt Properties

\begin{tabular}{|c|c|}
\hline Property & $A C-20$ \\
\hline Viscosity $60^{\circ} \mathrm{C}$ (poises) & 1978 \\
\hline Viscosity $135^{\circ} \mathrm{C}$ (centistokes) & 425 \\
\hline Penetration $25^{\circ} \mathrm{C}(0.1 \mathrm{~mm})$ & 74 \\
\hline Flash Point C.o.C. $\left({ }^{\circ} \mathrm{C}\right)$ & 312 \\
\hline Solubility in Trichloroethylene ( $\left.\frac{(}{b}\right)$ & 99.97 \\
\hline $\begin{array}{l}\text { Thin Film oven Test } \\
\text { Loss on Heating ( } \%) \\
\text { Viscosity } 60^{\circ} \mathrm{C} \text { (poises) }\end{array}$ & $\begin{array}{l}0.10 \\
4314\end{array}$ \\
\hline $\begin{array}{l}\text { Viscosity Ratio of Residue/Original } \\
\text { at } 60^{\circ} \mathrm{C}\end{array}$ & 2.18 \\
\hline $\begin{array}{c}\text { Rinematic Viscosity of Residue } \\
\text { at } 135^{\circ} \mathrm{C} \text { (centistokes) }\end{array}$ & 591 \\
\hline $\begin{array}{l}\text { Viscosity Ratio of Residue/Original } \\
\text { at } 135^{\circ} \mathrm{C}\end{array}$ & 1.39 \\
\hline Penetration of Residue at $25^{\circ} \mathrm{C}(0.1 \mathrm{~mm})$ & 39 \\
\hline Percent original Penetration $(\%)$ & 52.7 \\
\hline Specific Gravity $25 / 25^{\circ} \mathrm{C}$ & 1.0268 \\
\hline
\end{tabular}




\subsection{Results and Discussions}

\subsubsection{Aggregate Blends}

Figure 6.2 shows the unit weight and void relationships of the blends as a function of ash content. The unit weight of the aggregate blends decreases from 119.8 to 76.6 $\mathrm{lb} / \mathrm{ft}^{3}$ and the voids, by absolute volume, increase from 26 to $39 \%$ as the bottom ash increases from 0 to $100 \%$ by weight of aggregate blends.

Figure 6.3 shows the specific gravity of the aggregate blends and the effective porosity as a function of ash content. The specific gravities decrease with increased ash as would be expected. The fact the apparent specific gravity changes very little with increasing ash content relative to the bulk specific gravity gives an indication that most of the voids in the ash are interconnected and continuous. The effective porosity, defined as the percent water absorption by total volume of aggregate, indicates the quantity of continuous pores is relatively high compared to conventional aggregate. In that the ash has a much lower specific gravity, and the blends were created by substituting the ash on a weight basis, the mix volumes increase on a relative basis with increasing ash.

The water absorption as a function of ash content is illustrated in Figure 6.4. The absorbed water increases from 0.95 to $9.8 \%$ as ash content increases from 0 to $100 \%$. Water absorption in most cases can be used to predict an aggregate potential to absorb asphalt.

\subsubsection{Asphalt Concrete Mixes}




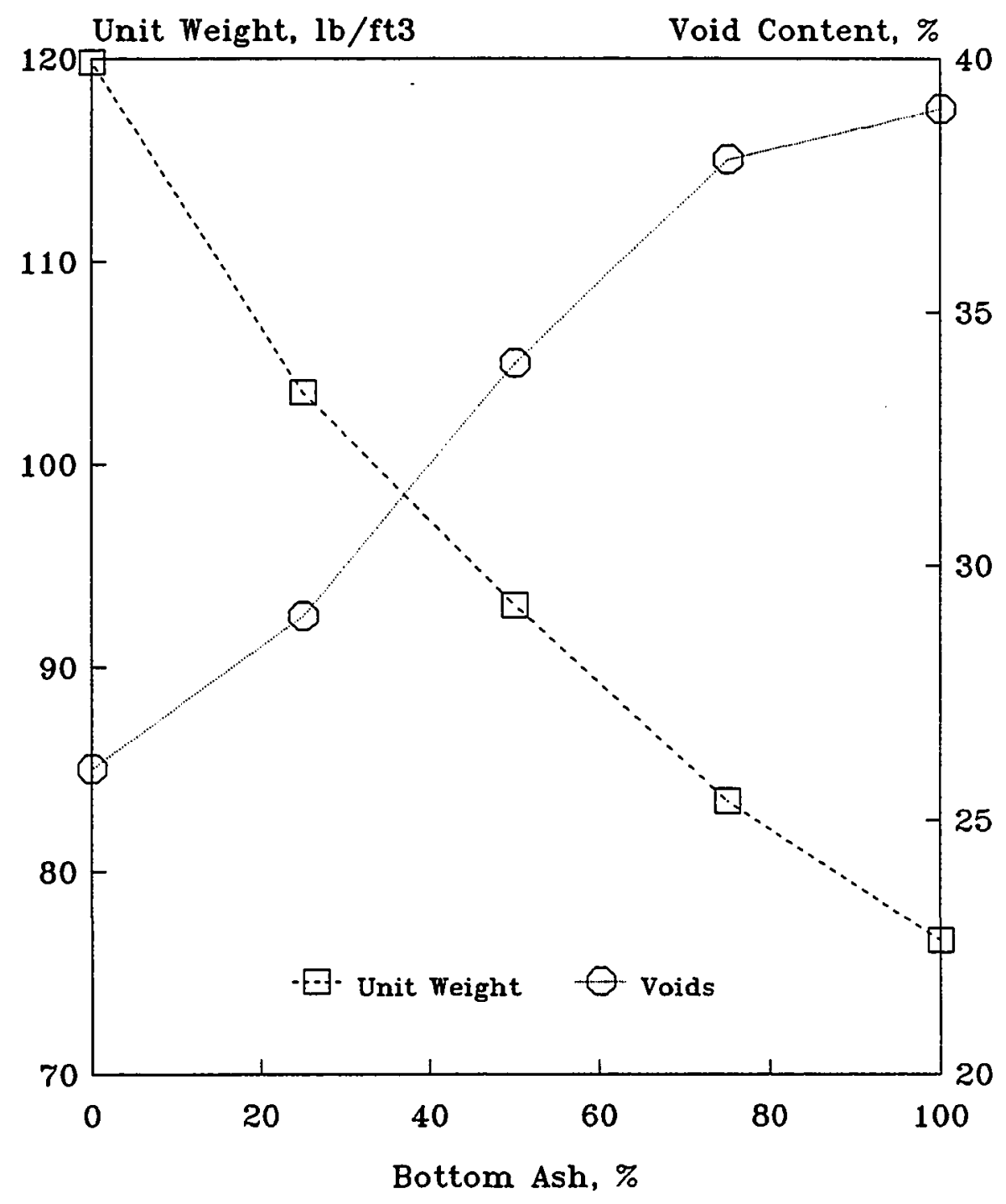

Figure 6.2 Unit Weight \& Void Content versus \% Bottom Ash 176 


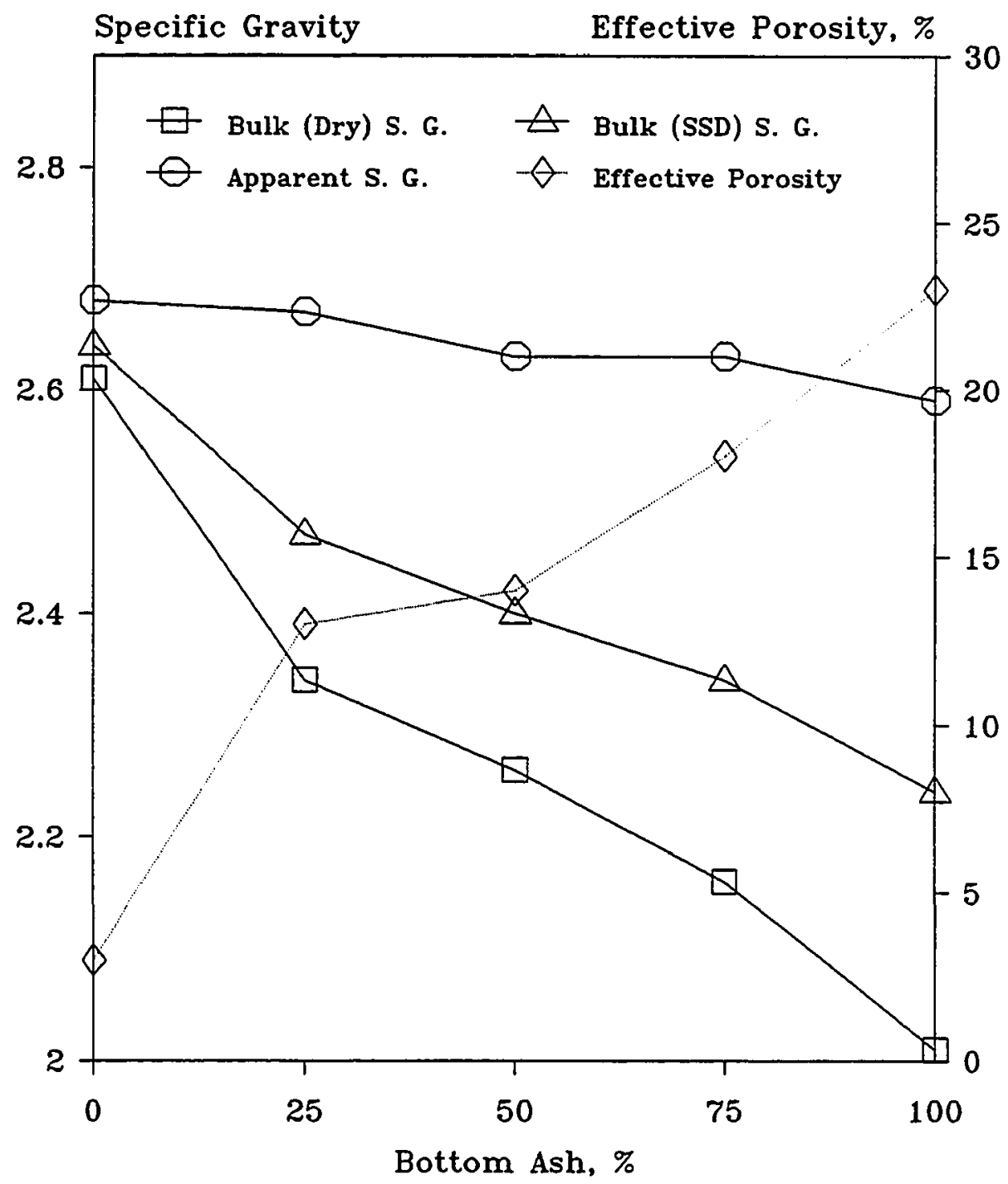

Figure 6.3 Specific Gravity \& Effective Porosity versus \% Bottom Ash 


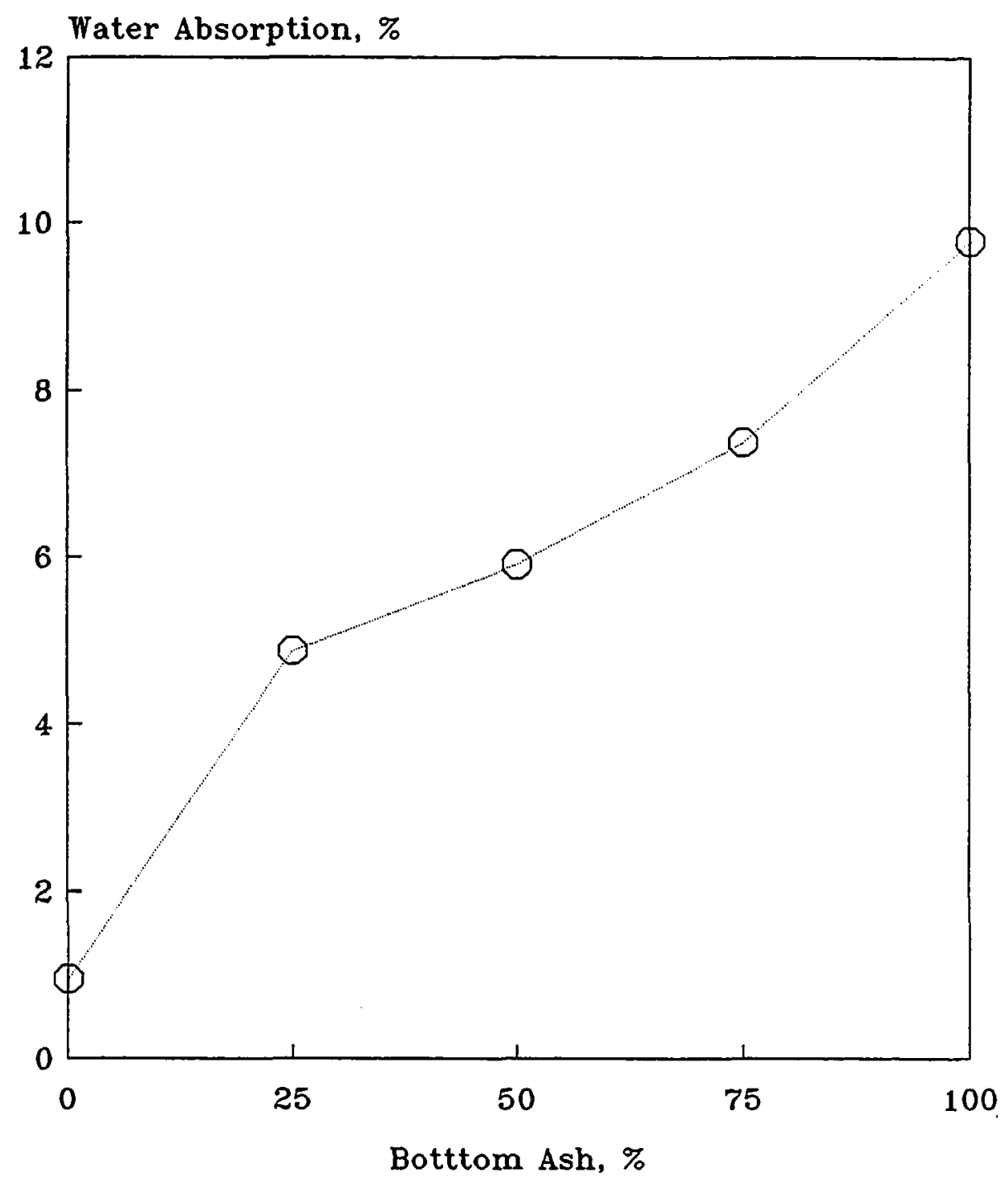

Figure 6.4 Water Absorption of Aggregate Blends

178 
The Marshall mix design method utilizing a 50 blow compactive effort (medium traffic) was used to develop the asphalt concrete mixes. The Marshall compaction effort simulates a density of in-place asphaltic concrete after $2-3$ years of traffic (34). An average of three test specimens was used in the Marshall mix design analysis. The Asphalt Institute design criteria for medium traffic-base course mix were employed to evaluate the hot asphalt mixes.

\subsubsection{Unit Weight (or Density)}

Figure 6.5 presents the unit weight as a function of asphalt content. The effect of the low specific gravity of the ash is indicated by the lower unit weights which range from 124.6 to $147.9 \mathrm{lb} / \mathrm{ft}^{3}$ as ash content decreases from $100 \%$ to $0 \%$. This reduced weight to volume relationship for the ash mixes has also been noted by Collins et al. (12).

In general, for dense-graded asphaltic paving mixes, the consistent pattern followed should be that the density value increases with increasing asphalt content up to a maximum after which the density decreases. Such a trend was not found for either control or ash mixes. One possible explanation for this result is that the aggregate particles for both control and ash are angular and therefore, have large surface area. The asphalt contents used may not have been sufficient to push the aggregate particles further apart. Hence, the trend of lower density at higher asphalt contents would not be observed. The variation of ash composition may also result in the inconsistency of some of the ash mixes. 


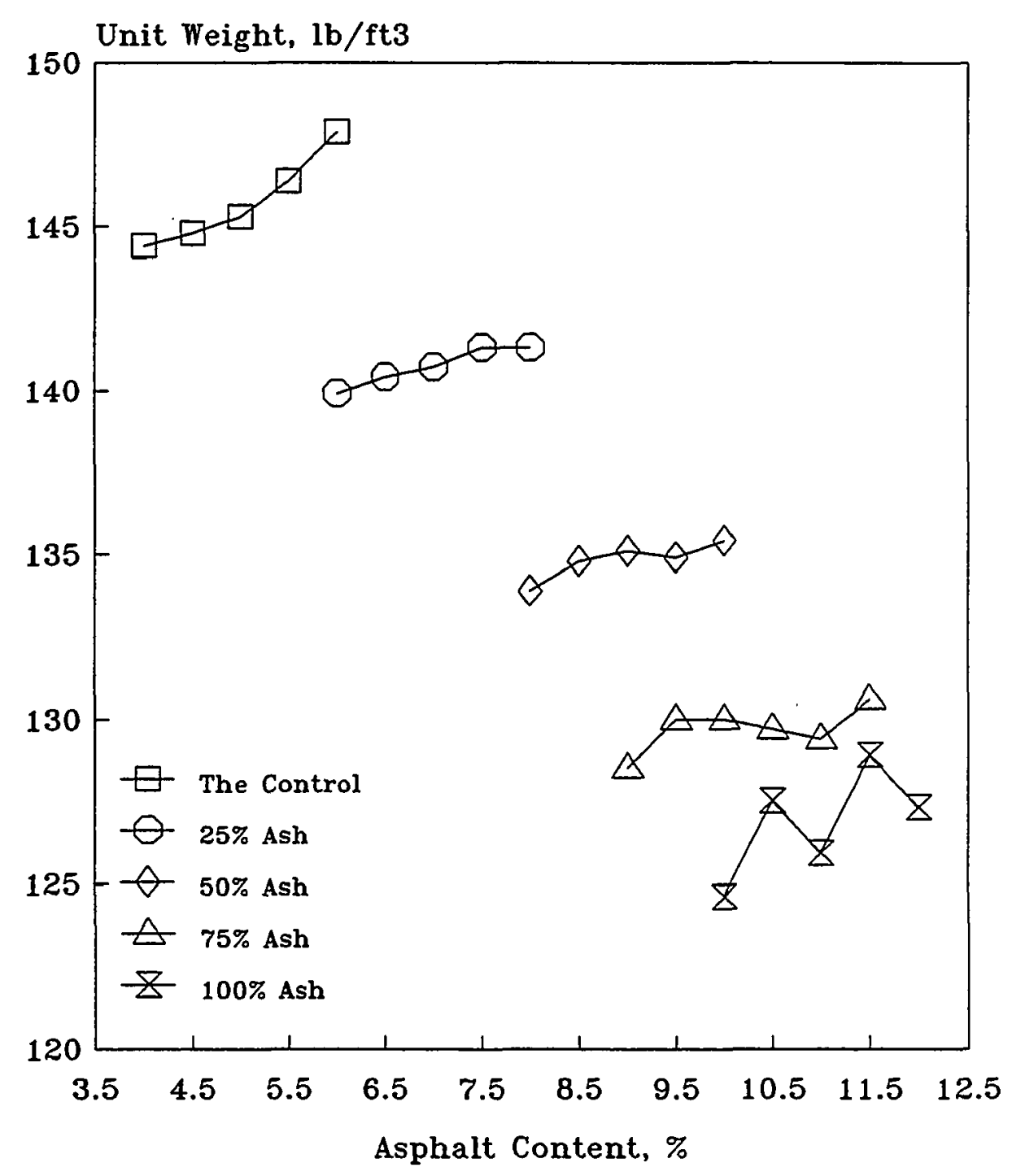

Figure 6.5 Unit Weight versus Asphalt Content

180 


\subsubsection{Stability}

Marshall stability is defined as the maximum load carried by a compacted specimen tested at $140^{\circ} \mathrm{F}$ at a loading rate of 2 inches $/ \mathrm{min}$. This stability is generally a measure of the mass viscosity of the aggregate-asphalt cement mixture and is affected significantly by the angle of internal friction of the aggregate and the viscosity of the asphalt cement at $140^{\circ} \mathrm{F}$. Marshall stability and field stability are not necessarily related.

Figure 6.6 presents Marshall stability as a function of asphalt content for control and ash mixes. The stability ranges from 1840 to $2903 \mathrm{lb}$, and exceeds the Asphalt Institute (MS-2) specification of $500 \mathrm{lb}$. The interesting aspect of the results is that Marshall stability of the ash mixes is comparable to that of the control. This could be, in part, due to the angularity of ash particle. The other reason for this could be that ash mixes contain more dust that may have the effect of making the asphalt cement/dust mixture act as a more viscous binder thus increasing the Marshall stability. While mixes having stability values between 500 and $1000 \mathrm{lb}$ are strong enough for traffic, they may have a tendency for exhibiting tenderness, shoving, and ravelling (56). Between 1000 and $3500 \mathrm{lb}$ is an acceptable range. Above $3500 \mathrm{lb}$ is a "red flag area" indicating that the mix is an atypical asphalt mix and the cause for that high stability value should be determined to see if mix performance is affected (50). All stability values were within the acceptable range with stabilities ranging from 1840 to $2903 \mathrm{lb}$.

\subsubsection{Flow}

Flow is measured at the same time as Marshall stability. Flow is defined as the 


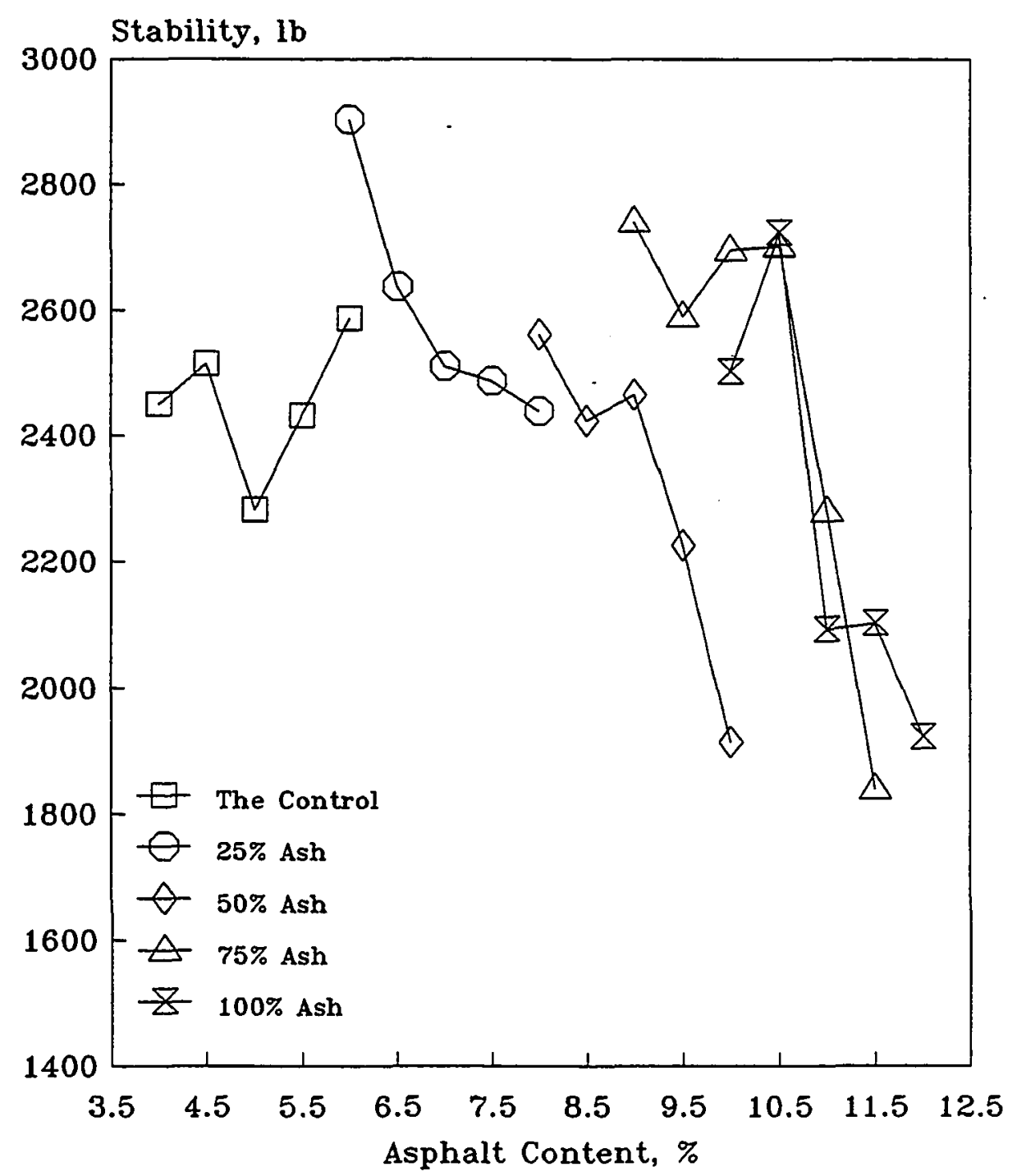

Figure 6.6 Stability versus Asphalt Content 
vertical deformation of the sample (measured from start of loading to the point at which stability begins to decrease) in hundredths of an inch. High flow values generally indicate a plastic mix that will experience permanent deformation under traffic, whereas low flow values may indicate a mix with higher than normal voids and insufficient asphalt for durability and one that may experience premature cracking due to mixture brittleness during the life of the pavement. Figure 6.7 shows flow as a function of asphalt content. The Asphalt Institute requires the flow to be in the 8-18 range for medium traffic. The flow of all mixes increases with increasing asphalt contents. The ash mixes exhibit higher flow values than the control mix due to the increased asphalt contents. Flows of the $75 \%$ and $100 \%$ ash mixes vary in an inconsistent manner with increasing asphalt content. Collins et al. (57) have reported that Marshall flow values for mixtures using ash residue are sometimes erratic due to variation of the ash properties.

\subsubsection{VMA and VFA}

The voids in the mineral aggregate, VMA, are defined as the intergranular void space between the aggregate particles in a compacted paving mixture that includes the air voids and the effective asphalt content, expressed as a percent of the total volume (35). The formula for VMA is listed as follows:

$$
\mathrm{VMA}=100-\left(\mathrm{G}_{\mathrm{mb}} \mathrm{P}_{\mathrm{s}} / \mathrm{G}_{\mathrm{sb}}\right)
$$

where,

$$
\begin{aligned}
& \text { VMA = voids in mineral aggregate (percent of bulk volume); } \\
& \mathbf{G}_{\mathbf{s b}}=\text { bulk specific gravity of aggregate; }
\end{aligned}
$$




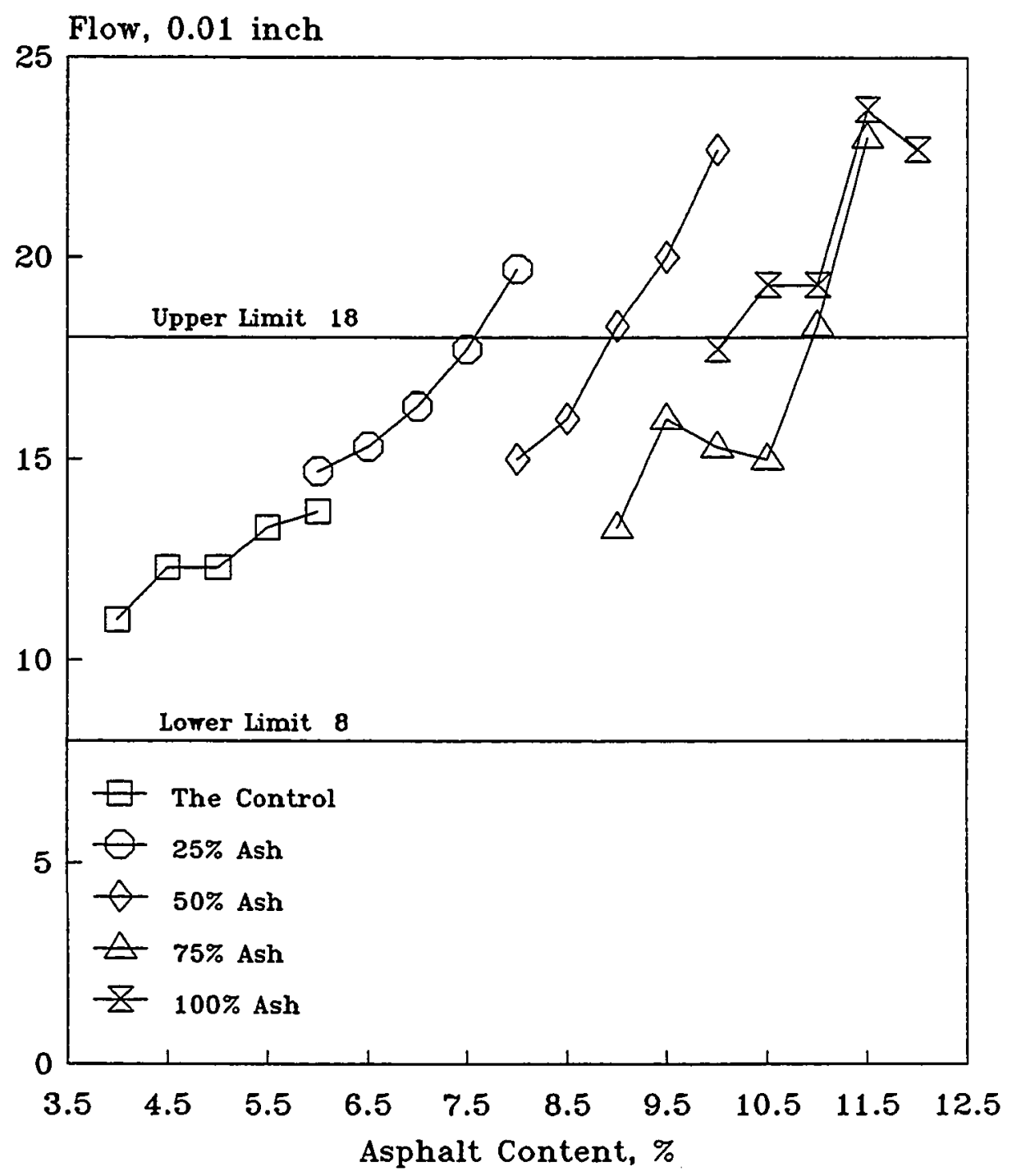

Figure 6.7 Flow versus Asphalt Content 
$\mathrm{G}_{\mathrm{mb}}=$ bulk specific gravity of compacted mixture (ASTM D2726); and

$\mathbf{P}_{\mathrm{s}}$ = aggregate, percent by total weight of mixture.

The formula for VFA is as follows:

$$
\text { VFA }=(\text { VMA }- \text { Air Void }) / \text { VMA }
$$

Both VMA and VFA have been considered as mixture design parameter specifications. The asphalt Institute and many state highway agencies have adopted minimum VMA or a range of VFA as a requirement for mixture design. On the other hand, others such as National Asphalt Pavement Association (58) have argued that there are insufficient performance data to justify these minimum and maximum requirements. Hence, VMA specification should be supported by field performance data, especially for the non-conventional materials such as bottom ash. It should be understood that if a specifying agency has both a VMA and a air void content criteria in the mix design procedure, they are also specifying VFA, because VFA is calculated from VMA and air void content.

The VMA relationship of the ash mixes is shown in Figure 6.8. The VMA significantly affects the performance of a mix because if it is too low, the mix may suffer durability problems and if too high the mix may show stability and bleeding problems. The Asphalt Institute requires a minimum VMA of $14 \%$ for a nominal maximum particle size of $3 / 4^{n}$. All mixes containing up to $75 \%$ ash pass the VMA requirement of a minimum of $14 \%$. The $100 \%$ ash mix does not meet the VMA requirement at any asphalt content tested. The $100 \%$ ash mix shows variation in VMA.

VFA is inversely related to the air voids. As the percentage of air voids approaches 


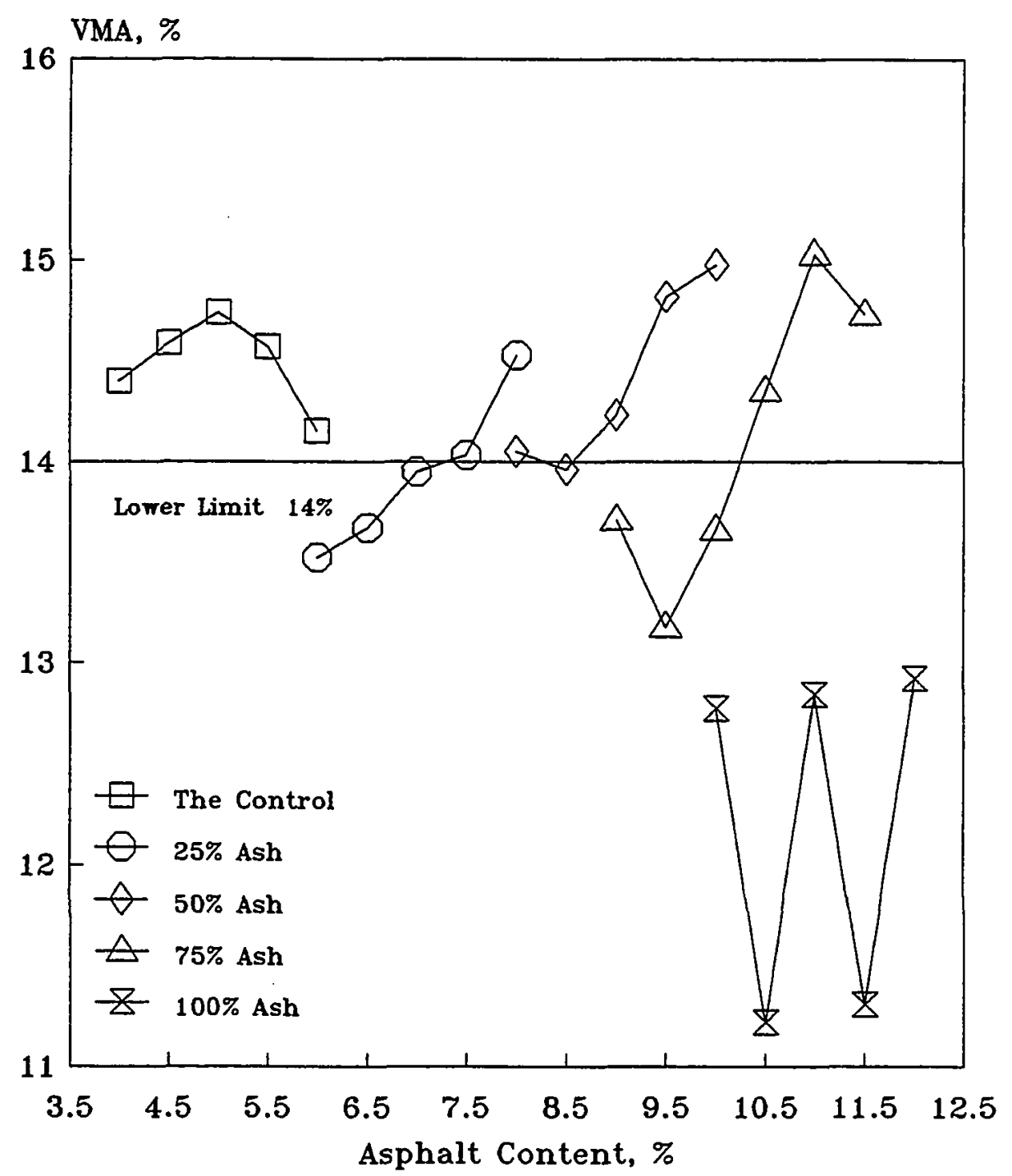

Figure 6.8 VMA versus Asphalt Content

186 
zero, VFA approaches 100 . The Asphalt Institute does not have VFA requirement. The VFA of 75-85 is suggested by NCHRP (36). The VFA increases as asphalt content increases for control and ash mixes, which would be expected, as shown by Figure 6.9. All mixes pass VFA specification at higher asphalt contents.

\subsubsection{Air Voids}

Air Voids in a compacted paving mixture consist of the small air spaces between the coated aggregate particles. The percentage of voids in a compacted mixture can be determined by the following equation:

$$
\text { Air Void }=\left(G_{m m}-G_{m b}\right) 100 / G_{m m}
$$

Where,

Air Void = air voids in compacted mixture, percent of total volume;

$\mathrm{G}_{\mathrm{mm}}=$ maximum specific gravity of paving mixture as determined by AASHTO T209; and

$\mathrm{G}_{\mathrm{mb}}=$ bulk specific gravity of compacted mixture as determined by AASHTO T166.

The air void content is one of the most important parameters in mix design. It is well known that an asphaltic concrete mixture that is compacted to a low air void content will have increased fatigue life, reduced permanent deformation, reduced distortion, reduced aging of the asphalt cement, and reduced moisture damage than will the same mixture that is compacted to a higher air void content (36).

Figure 6.10 shows the air void-asphalt content relationship of the Marshall mixes. The void content is based on the maximum theoretical specific gravity of the paving mix 


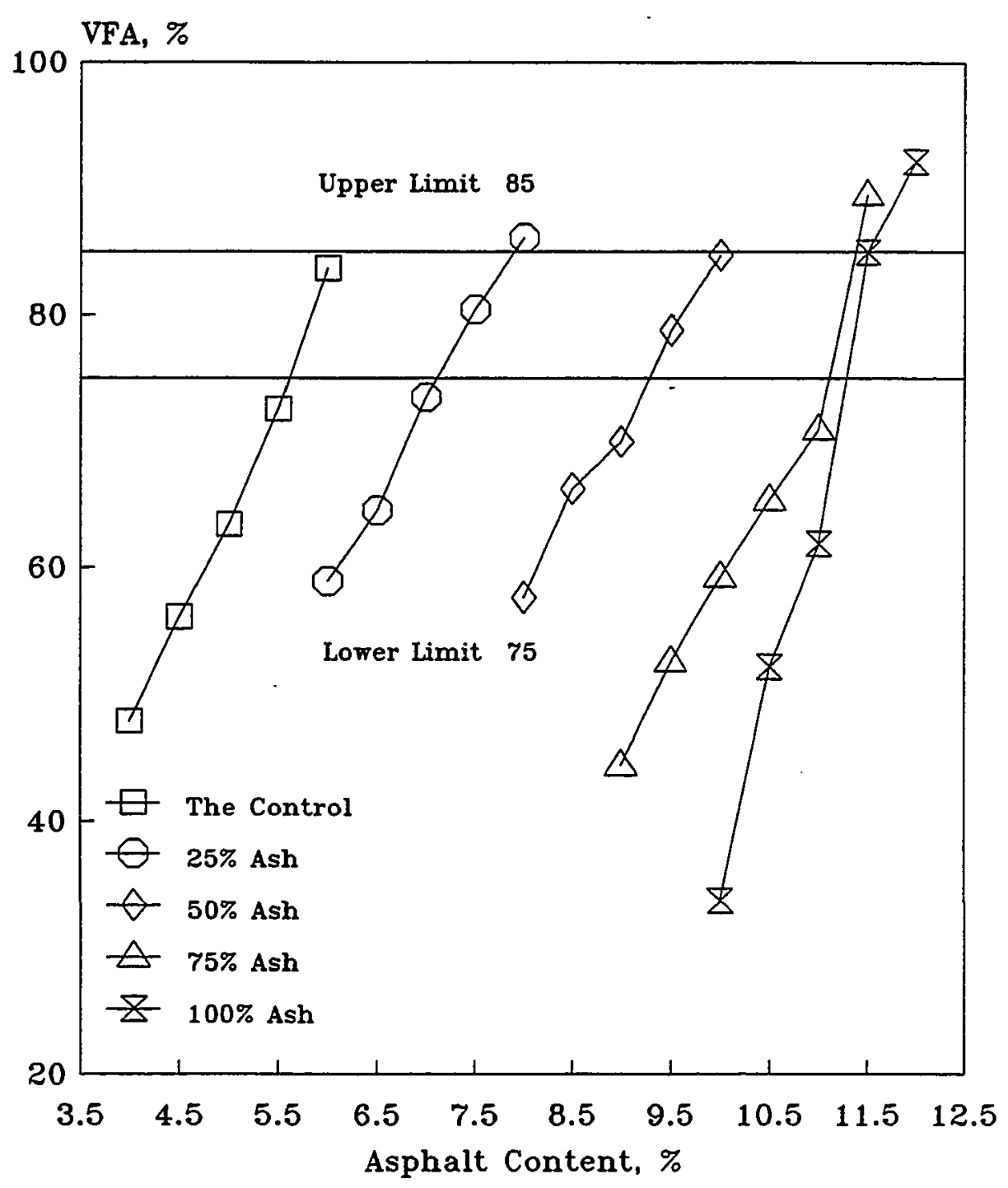

Figure 6.9 VFA versus Asphalt Content 


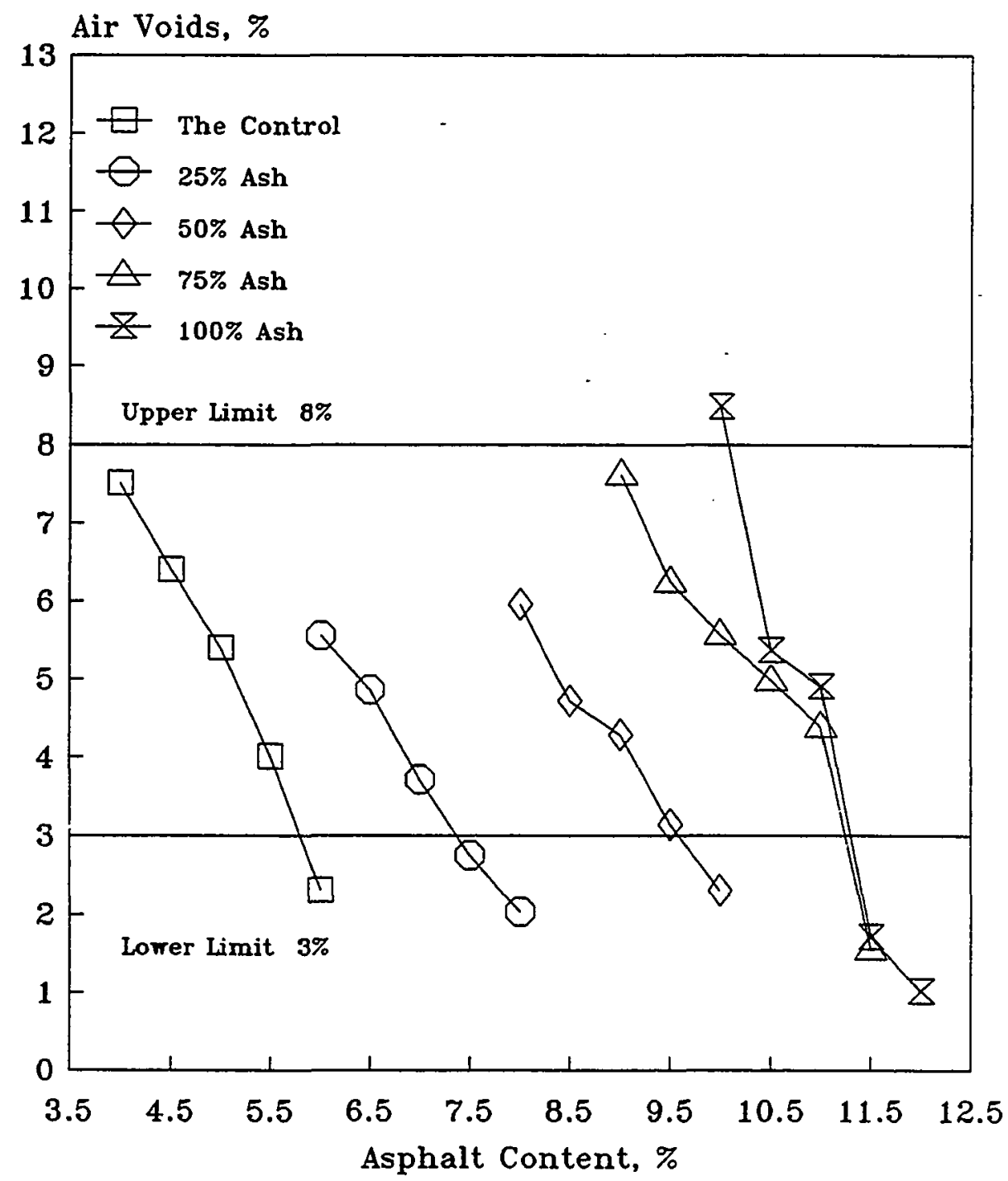

Figure 6.10 Air Voids versus Asphalt Content 
as determined by the Rice method. The air void decreases as asphalt content increases because the air void is being filled with asphalt cement. The void content criteria suggested by the Asphalt Institute for a base subject to medium traffic is between 3 and 8\%. The void content criteria suggested by the Pike Industries Inc. is between 3 and 5 , with a median value of 4 . The asphalt content required to meet the specification increases with increasing ash. The reason for this is that ash is much more absorptive than the control aggregates. Some asphalt is absorbed into ash, increasing the amount of asphalt required to complete coating ash particles in the mixes.

\subsubsection{Absorbed and Effective Asphalt}

\section{Absorbed Asphalt}

The phenomenon of asphalt absorption has been investigated by many researchers. All mineral aggregates in asphaltic concrete have porosity and tend to absorb asphalt. Absorbed asphalt must be considered in the laboratory design. Asphalt absorption can be calculated by:

$$
P_{b a}=G_{\mathrm{a}}\left(G_{\mathrm{se}}-G_{\mathrm{sb}}\right) 100 /\left(G_{\mathrm{sb}} G_{\mathrm{se}}\right)
$$

where,

$$
\begin{aligned}
& P_{b \mathrm{a}}=\text { percent absorbed asphalt by weight of aggregate; } \\
& G_{s e}=\text { effective specific gravity of the combined aggregate blend; and } \\
& G_{s e}=\left(100-P_{a}\right) /\left(100 / G_{m m}-P_{a} / G_{a}\right)
\end{aligned}
$$

Figure 6.11 presents the absorbed asphalt by weight of total mix (rather than aggregate) versus asphalt content. The absorbed asphalt by weight of total mix was 


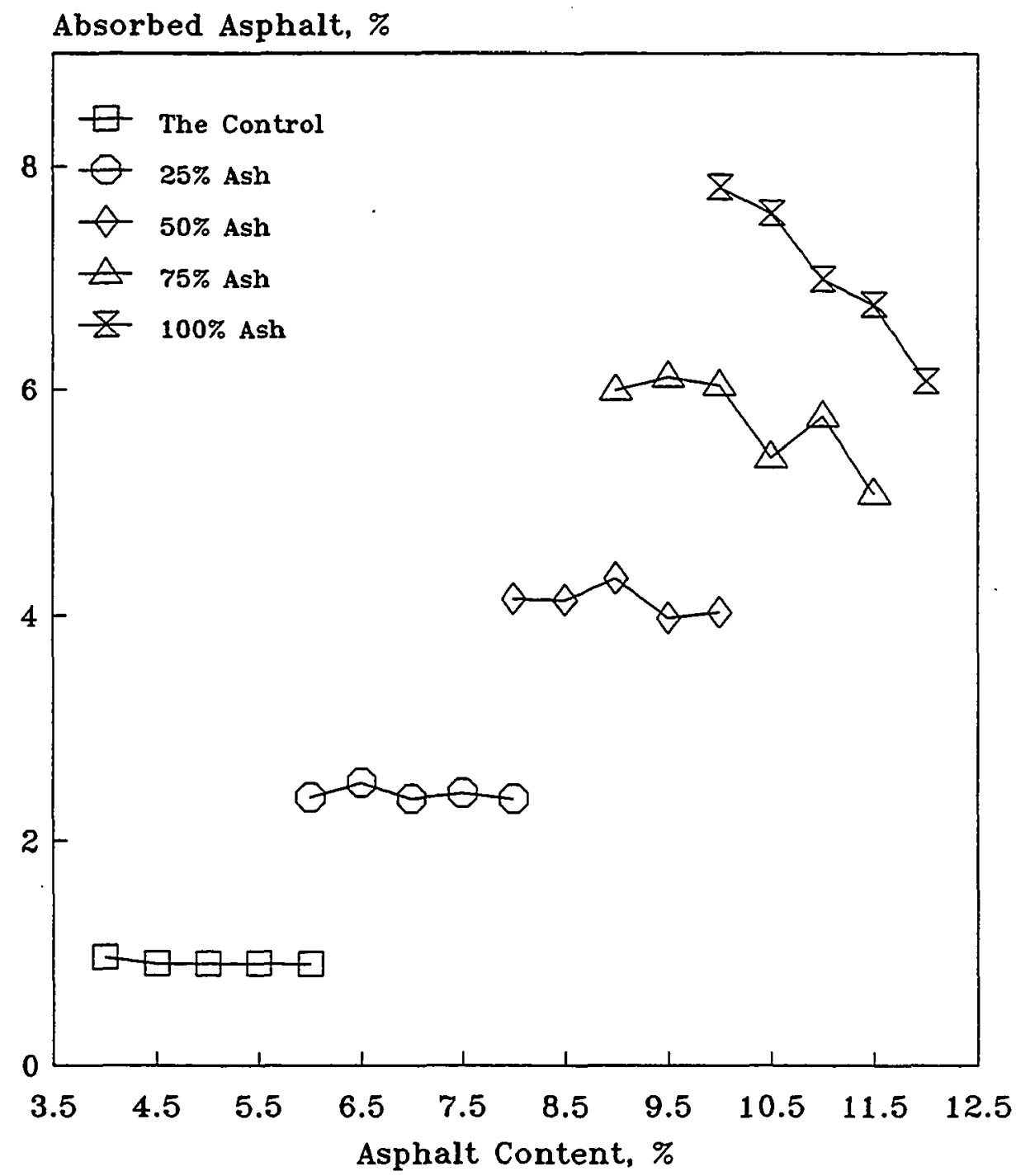

Figure 6.11 Absorbed Asphalt versus Asphalt Content

191 
calculated by subtracting, $P_{b e}$, the effective asphalt content by weight of total mix, from $\mathbf{P}_{\mathrm{a}}$. The asphalt absorption increases with increased ash content. The high porosity, especially the permeable pores, of bottom ash make it very absorptive. In concept, the amount of asphalt absorbed into the aggregate is not a function of asphalt content, as shown by the blends up to $50 \%$ ash. However, the higher ash blends show a decrease in absorbed asphalt with increasing asphalt cement content. One possible explanation is that Rice test overestimates asphalt absorption of the ash mixes at low asphalt contents because inter-connected pores of ash mixes at low asphalt content were not saturated and sealed with asphalt, and water was sucked into these pores, resulting in overestimating $G_{m m}$ and therefore $\mathbf{P}_{\mathbf{b a}}$.

\section{Effective Asphalt}

The effective asphalt content of a paving mix is the total asphalt content minus the quantity of asphalt lost by absorption into the aggregate particles. It is the portion of the total asphalt that remains as a coating on the outside of the aggregate particles, and is the asphalt content on which service performance of an asphalt paving mixture depends. The effective asphalt content on weight basis is calculated in accordance with the following equation:

$$
P_{b e}=P_{a}-P_{b a} P_{s} / 100
$$

where,

$$
\begin{aligned}
& \mathbf{P}_{\mathrm{be}}=\text { effective asphalt content, percent by total weight of mixture; } \\
& \mathbf{P}_{\mathrm{a}}=\text { asphalt, percent by total weight of mixture; } \\
& \mathbf{P}_{\mathrm{ba}}=\text { absorbed asphalt, percent by weight of aggregate; and }
\end{aligned}
$$


$P_{\mathrm{s}}=$ aggregate, percent by total weight of mixture.

Figure 6.12 presents the effective asphalt by weight of total mix versus asphalt content. As would be expected, the effective asphalt content increases with increasing of asphalt content. Since they have high asphalt absorption, the ash mixes demand more asphalt to obtain the same amount of effective asphalt contents as the control mix.

\subsubsection{Water Absorption by Bituminous Mixes}

The water absorption of bituminous specimens is determined in accordance with AASHTO T166. The formula is:

Percent Water Absorbed by Volume $=100(B-A) /(B-C)$

where,

$A=$ mass of dry sample in air;

B = mass of saturated surface-dry specimen in air; and

$\mathrm{C}=$ mass of sample in water after 4 minutes of immersion.

Figure 6.13 presents the water absorption as a function of asphalt cement content for ash mixes and control mix. The water absorption decreases with increased asphalt contents. As a result of high asphalt absorption by bottom ash, the ash mixes show low water absorption, comparable to the control mix. The high asphalt absorption of the ash mixes makes the ash mixes relatively impermeable to water.

\subsection{Selection of Mix Design}

There are two commonly used methods of selecting the optimum asphalt content: 1) 


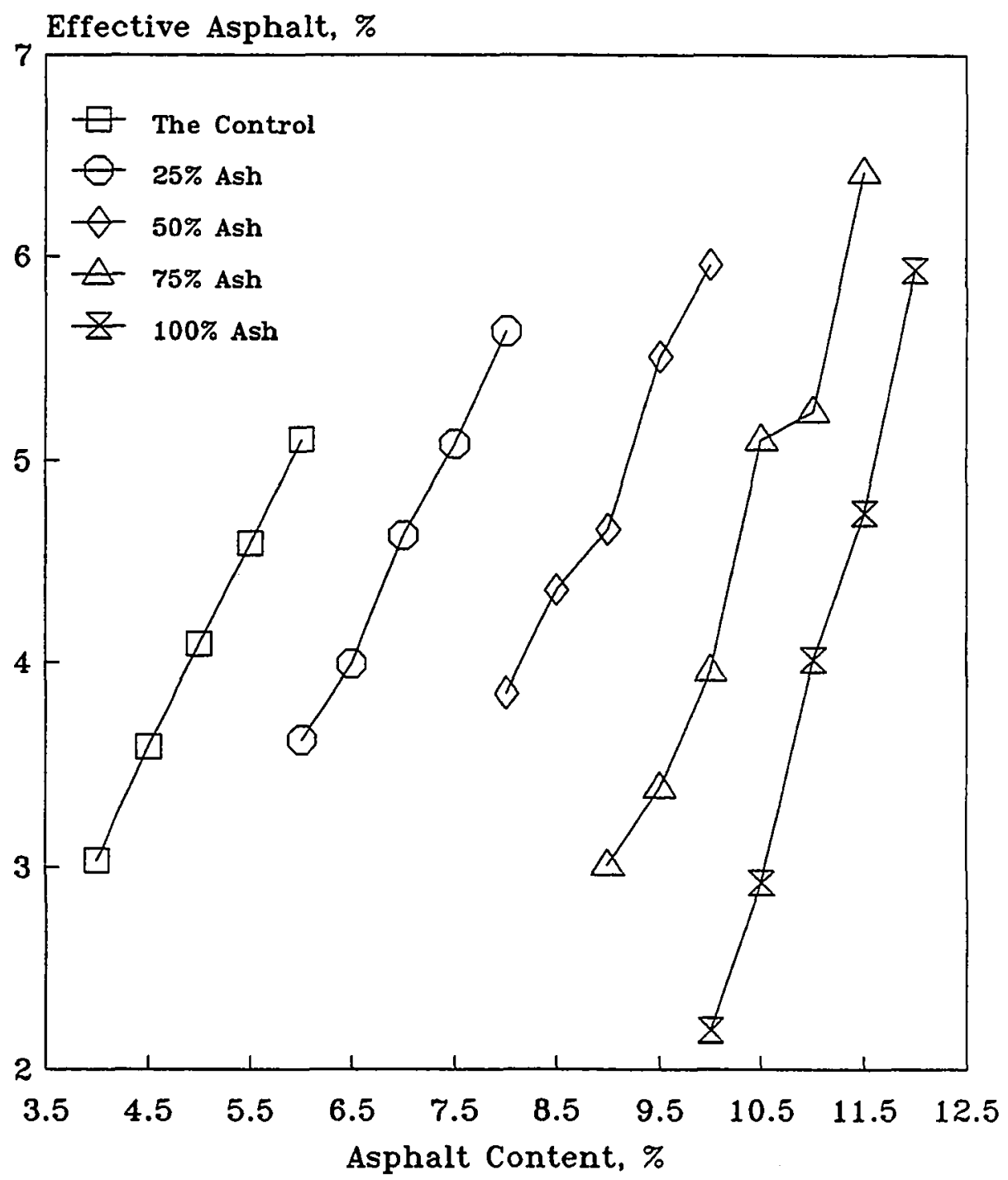

Figure 6.12 Effective Asphalt versus Asphalt Content 


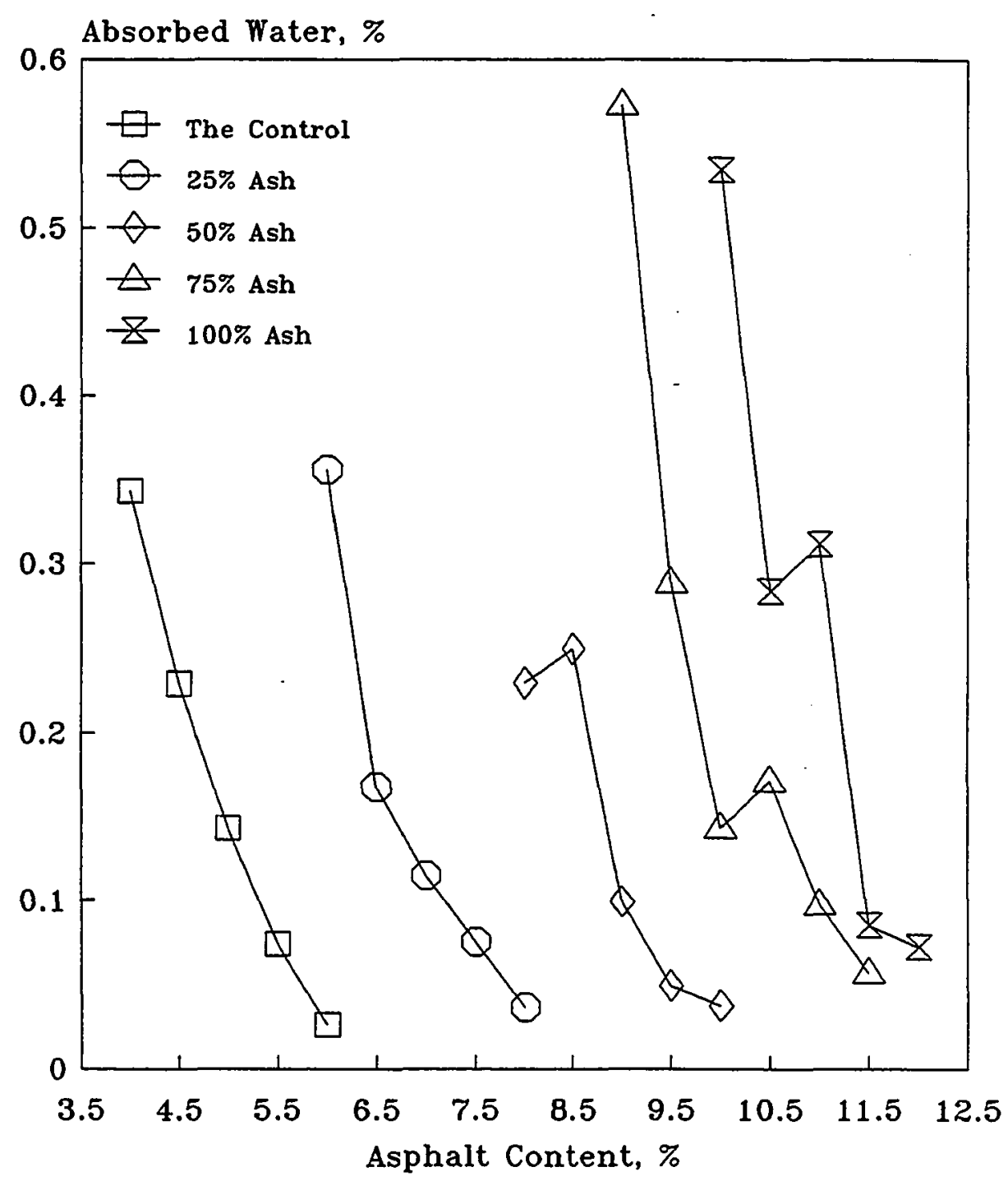

Figure 6.13 Absorbed Water versus Asphalt Content 195 
the optimum asphalt content is determined by first finding the asphalt content which corresponds to the median air void content of the specifications. That asphalt content is then used to determine the values for Marshall stability, VMA, flow and VFA. Each value is compared to the specification range for that property and if all are within the required range, the asphalt content at the specified air void is the optimum. If some value is outside the specification range, the mixture is redesigned, and 2) the optimum asphalt content is determined based on three requirements that the mix yield maximum stability, maximum unit weight and median of limits for air void content. The optimum asphalt content of the mix is then the numerical average of the values for the asphalt content as noted above. Method 1 was used in this study. A $4 \%$ air void required by Pike Industries Inc. in mix design was used as the air void content of the specifications.

Table 6.4 presents the asphalt contents determined by Method 1 for ash and control mixes. The mix properties and mix specifications are included in Table 6.4. None of mixes met all requirement if a $4 \%$ air void specification must be met. If the air void requirements of $3 \%-8 \%$ instead of $4 \%$ are employed for developing the optimum mix, satisfying the Asphalt Institute design criteria requires 5, 7.4, 8.6 and $10.5 \%$ asphalt cement for the $0,25,50$ and $75 \%$ ash mixes, as shown in Table 6.5 . The $100 \%$ ash mixes do not satisfy the design criteria at any asphalt content.

\subsection{Regression Analysis}

The test results have indicated that the properties of asphaltic concrete are affected by the bottom ash content. The relation between mix properties as a function of ash 
Table 6.4 Optimum Asphalt Content and Mix Properties

\begin{tabular}{|l|l|l|l|l|l|l|}
\hline Property & Control & $25 \%$ Ash & $50 \%$ Ash & $75 \%$ Ash & $100 \%$ Ash & Criteria \\
\hline Asphalt Content, \& & 5.50 & 6.87 & 9.12 & 11.07 & 11.14 & \\
\hline Stability, 1b & 2432 & 2544 & 2407 & 2218 & 2095 & $500 \mathrm{~min}$ \\
\hline \multirow{5}{*}{ Flow, 0.01" } & 13.30 & 16.04 & 18.71 & 18.96 & 20.53 & $8-18$ \\
\hline VMA, \& & 14.57 & 13.88 & 14.37 & 14.99 & 12.41 & $14 \mathrm{~min}$ \\
\hline VFA, \& & 72.48 & 71.08 & 72.05 & 73.47 & 68.28 & $75-85$ \\
\hline Air Voids, 8 & 4 & 4 & 4 & 4 & 4 & $3-5$ \\
\hline
\end{tabular}


Table 6.5 Optimum Asphalt Content by the Asphalt Institute Criteria

\begin{tabular}{|l|l|l|l|l|l|l|}
\hline Property & Control & $25 \%$ Ash & $50 \%$ Ash & $75 \%$ Ash & $\begin{array}{l}\text { Asphalt } \\
\text { Institute } \\
\text { Specification }\end{array}$ \\
\hline Asphalt, \& & 5.0 & 7.4 & 8.6 & 10.5 & \\
\hline Stability, 1b & 2282 & 2493 & 2432 & 2702 & $500 \mathrm{~min}$. \\
\hline Flow, 0.01" & 12.3 & 17.4 & 16.5 & 15.0 & $8-18$ \\
\hline VMA, 8 & 14.74 & 14.01 & 14.01 & 14.35 & $14 \mathrm{~min}$. \\
\hline Air Voids, \& & 5.40 & 3.00 & 4.63 & 4.98 & $3-8$ \\
\hline
\end{tabular}


content is useful information. Regression analysis (52) is conducted to investigate such a relation. The linear regression model can be written as,

$$
Y=b_{0}+b_{1} X
$$

where $b_{0}$ and $b_{1}$ are regression coefficients. The slope is $b_{1}$ and $b_{0}$ is the intercept, $X$ is the ash content, $\mathrm{Y}$ is the property of a hot asphalt mix or aggregate blends under investigation. The correlation coefficient $(r)$ is usually used as a measure of linearity and varies from -1 to +1 . An I value of -1 describes a perfect negative correlation when all experimental points lie on a straight line of negative slope. Similarly, when $r=+1$ a perfect positive correlation exists, with all points lying exactly on a straight line of positive slope. When there is no correlation between $X$ and $Y$ the value of $r$ is zero.

The water absorption of aggregate blends in Figure 6.14 shows a good linear correlation $(r=0.976)$. The absorption at any ash content can be predicted.

The unit weight of mixes as a function of ash content is illustrated in Figure 6.15. The linear correlation coefficient of $r=-0.994$ shows a good correlation between unit weight and ash content.

The excellent correlation $(\mathrm{r}=0.998)$ exists between the absorbed asphalt content and ash content, as evidenced in Figure 6.16.

The water absorption by Marshall samples as a function of ash content is shown in Figure 6.17. A correlation coefficient of 0.642 shows that linear relation between water absorption and ash content is not strong.

The asphalt contents at $4 \%$ air void is plotted as a function of ash content as shown in Figure 6.18. A fairly good linear relation $(r=0.973)$ between the two variables was 


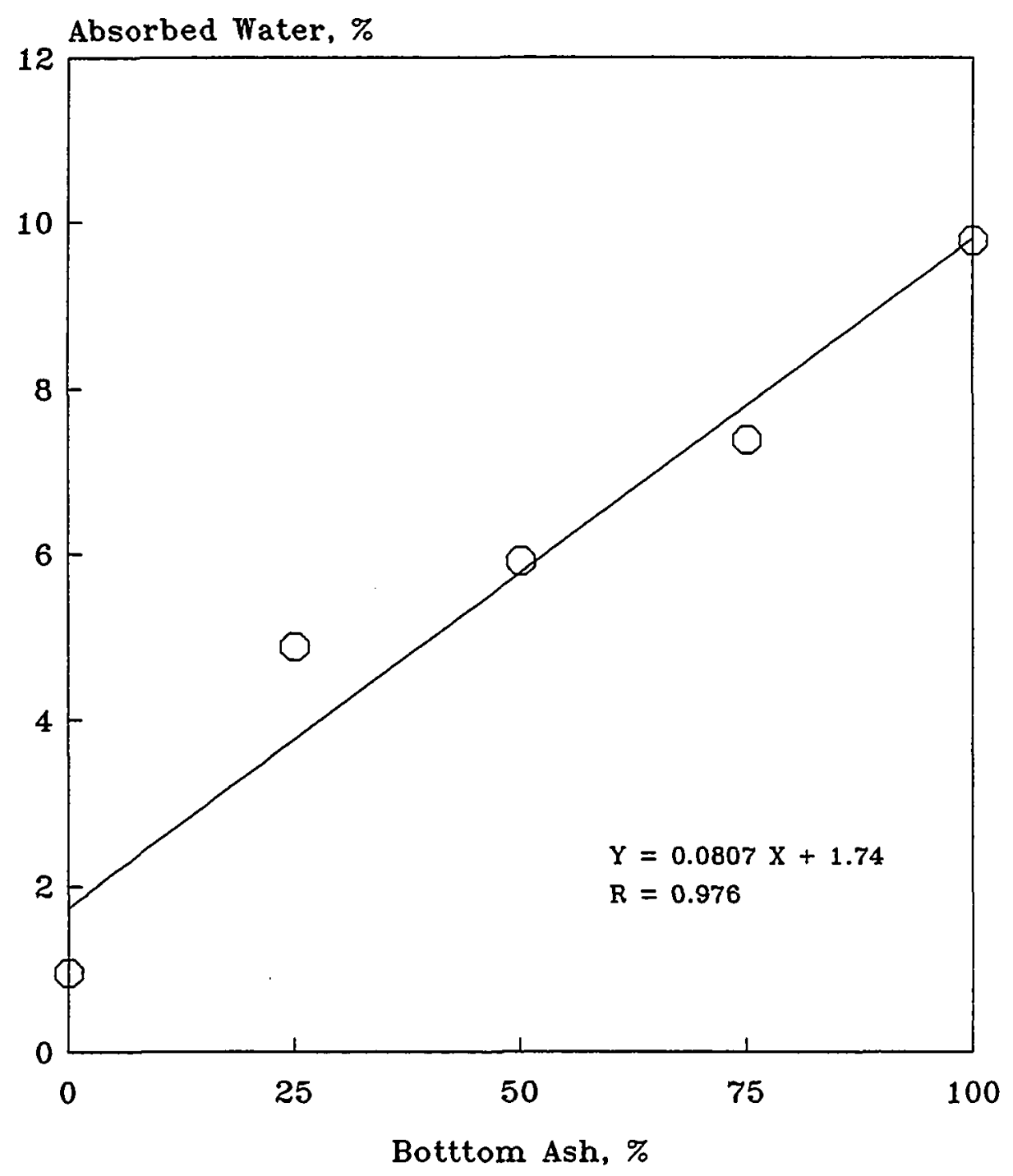

Figure 6.14 Water Absorption of Aggregate Blends 


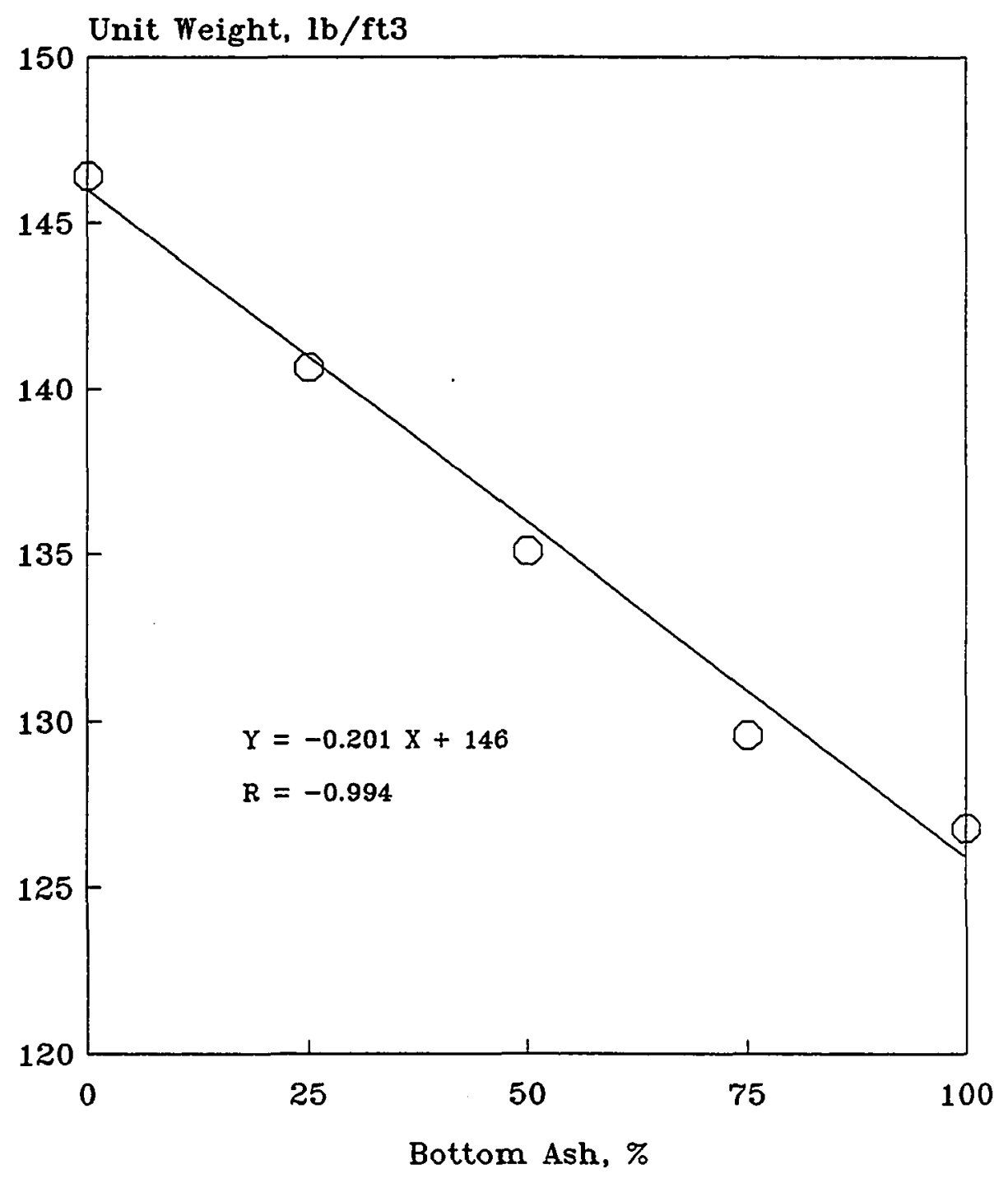

Figure 6.15 Unit Weight of Asphalt Mix (Air Voids $=4 \%$ ) 


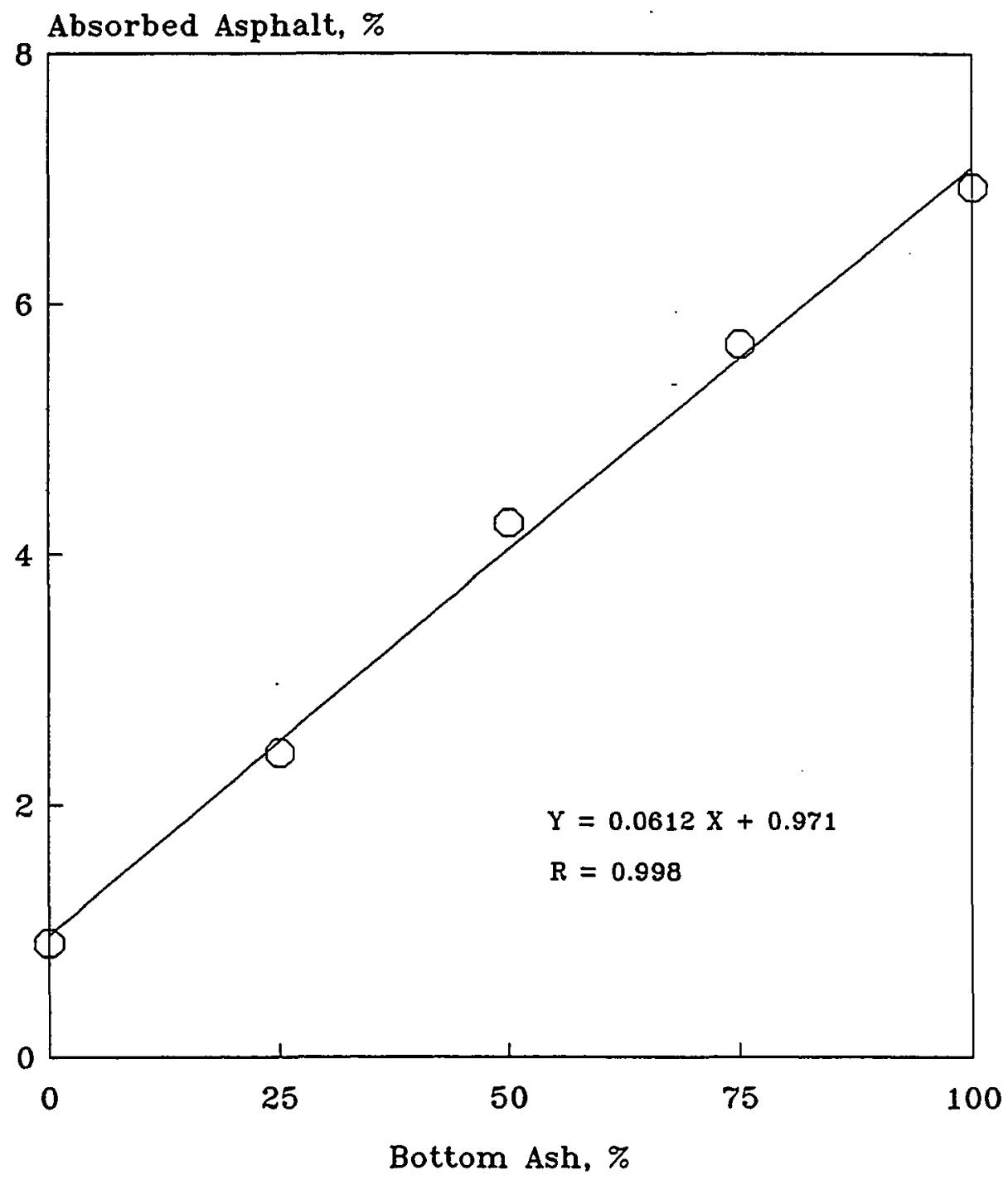

Figure 6.16 Absorbed Asphalt versus \% Bottom Ash

$($ Air Voids $=4 \%)$

202 


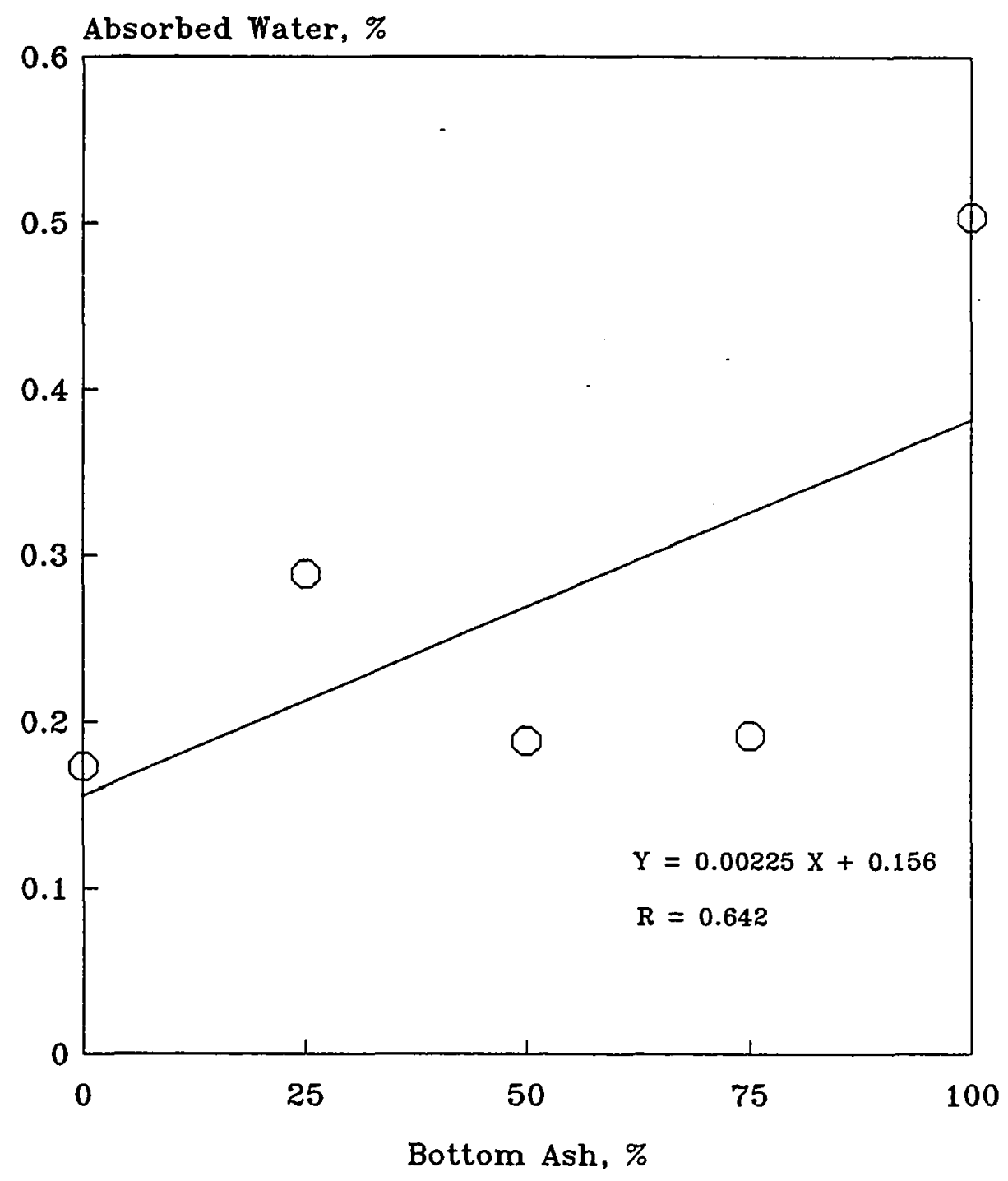

Figure 6.17 Water Absorption of Asphalt Mixes

(Air Voids $=4 \%$ )

203 


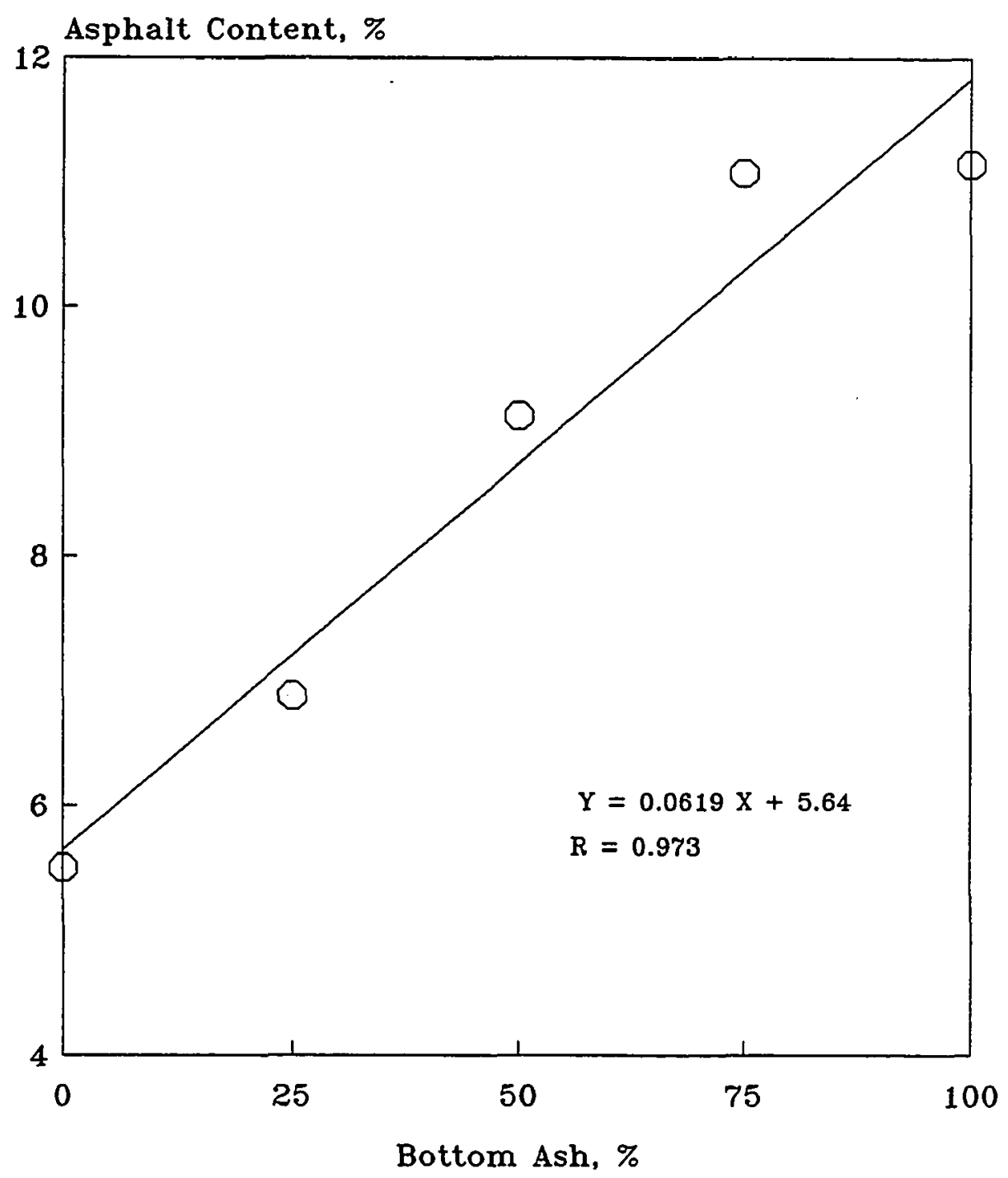

Figure 6.18 Asphalt Content at 4\% Air Voids versus $\%$ Bottom Ash

204 
found. The asphalt contents increase linearly with increasing ash content.

\subsection{Bottom Ash Degradation}

Aggregate degradation in bituminous mixtures has been extensively studied. The degradation of aggregates does occur due to construction compaction and traffic densification. Laboratory compaction procedures also resulted in the degradation of aggregate. Moavenzadeh et al. (59) studied three kinds of aggregates with different Los Angeles Abrasion values, and concluded that degradation varied with type of aggregate. In general, aggregates with high Los Angeles values resulted in more degradation than those with low Los Angeles values. They also concluded that the degree of degradation also depends on aggregate gradation, compactive effort, and particle shape. The effect of asphalt on the magnitude of degradation depends on other factors and can not be considered as an independent variable. Macnaughton $(60)$ noticed one of the features which has to be considered in the design of bituminous mixtures is degradation of aggregates during compaction. This degradation is due to considerable pressure developed at the points of contact between particles and to continual shifting and rearrangement of particles as they gradually attempt to occupy the least possible space. Pauls and Carpenter (61) concluded the principal cause of degradation is the rolling operation, and excessive degradation under the roller may cause raveling, excessive absorption of water, and progressive deterioration. The degradation may reduce the angularity of aggregate particles, and thus decrease the interlocking which in turn results in a loss in stability of the mixture with resulting shoving, distorting, and corrugating (59). 
The stability Marshall samples were used for the extraction test. The solvent was Neugenic 4175 from Rochester Midland Inc., NY. The procedures are: 1) the stability Marshall samples were heated at $300-325^{\circ} \mathrm{F}$ in oven for $2-2.5$ hours to remove retained moisture and then samples were separated, 2) the samples were cooled down to room temperature and the initial sample weight was determined, and 3) the centrifuge procedures of AASHTO T164-Method A were employed for extraction. The mixes selected for extraction were the control mix at $5.5 \% \mathrm{AC}, 25 \%$ ash mix at $7 \% \mathrm{AC}, 50 \%$ ash mix at $9 \% \mathrm{AC}, 75 \%$ ash mix at $11 \% \mathrm{AC}$ and $100 \%$ ash mix at $11 \% \mathrm{AC}$. It was assumed that the materials lost during the centrifuging procedure consist of asphalt and $<$ No.200 aggregate materials. The degradation of aggregate is evaluated by comparing the gradation before and after compaction. Since the washing process is involved during asphalt extraction test, it would be appropriate to compare the washed gradation before compaction with that after.

Figures 6.19 through 6.23 present the gradation of the control and ash mixes before and after laboratory compaction. The difference in gradation before and after compaction is shown in Figure 6.24. Degradation occurred in all mixes as shown by the figures. The gradation of the control mix after compaction is still within NH DOT specifications. Degradation of ash mixes increases with increasing ash content up to $50 \%$ ash and then remains reasonable constant. Degradation was associated with particle size and occurred more to the particles ranging from $1 / 2^{n}$ to No.40.

The gradation of bottom ash after compaction could meet gradation specifications if the affect of degradation is taken into consideration during the mix design. 


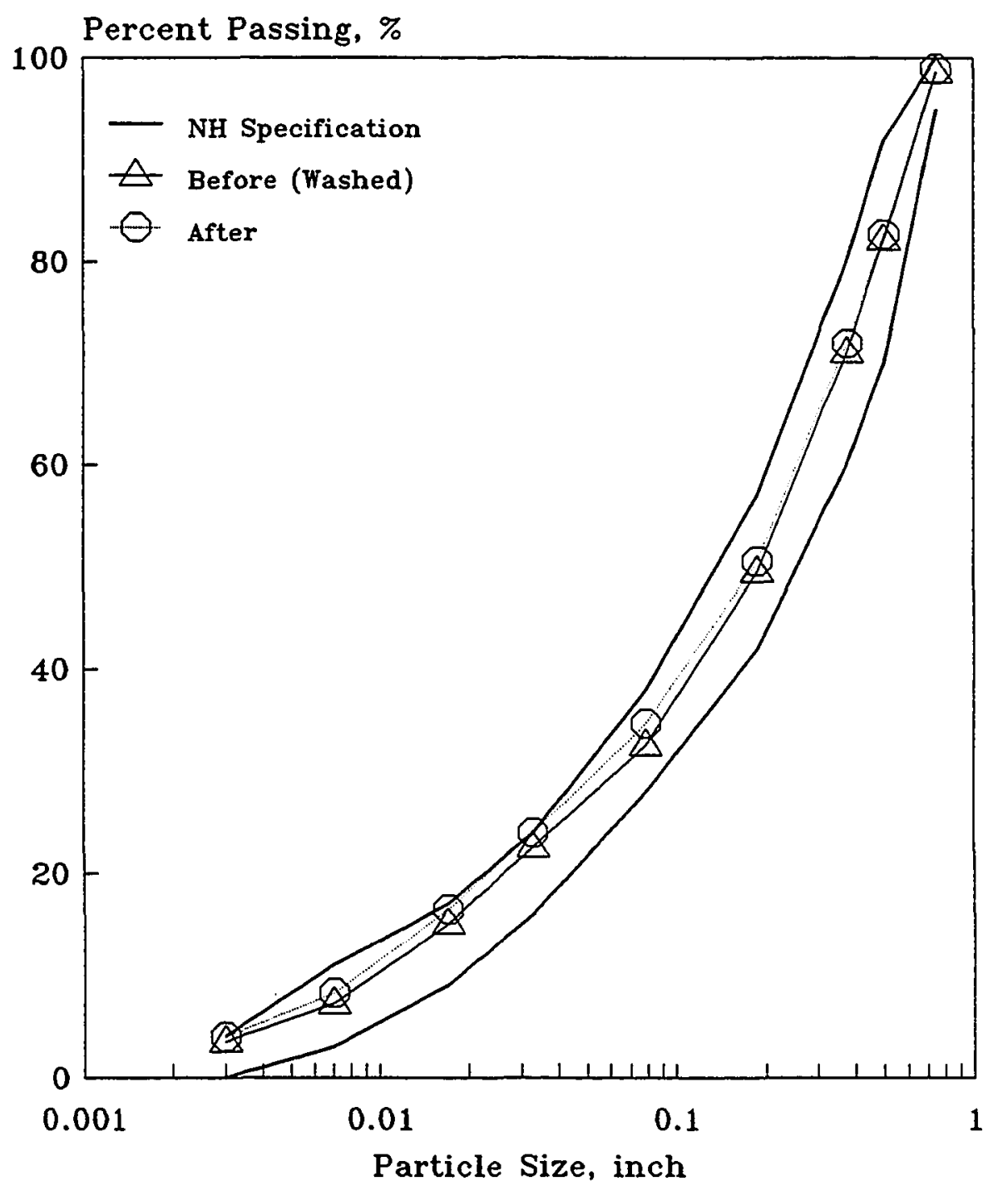

Figure 6.19 Degradation of the Control 


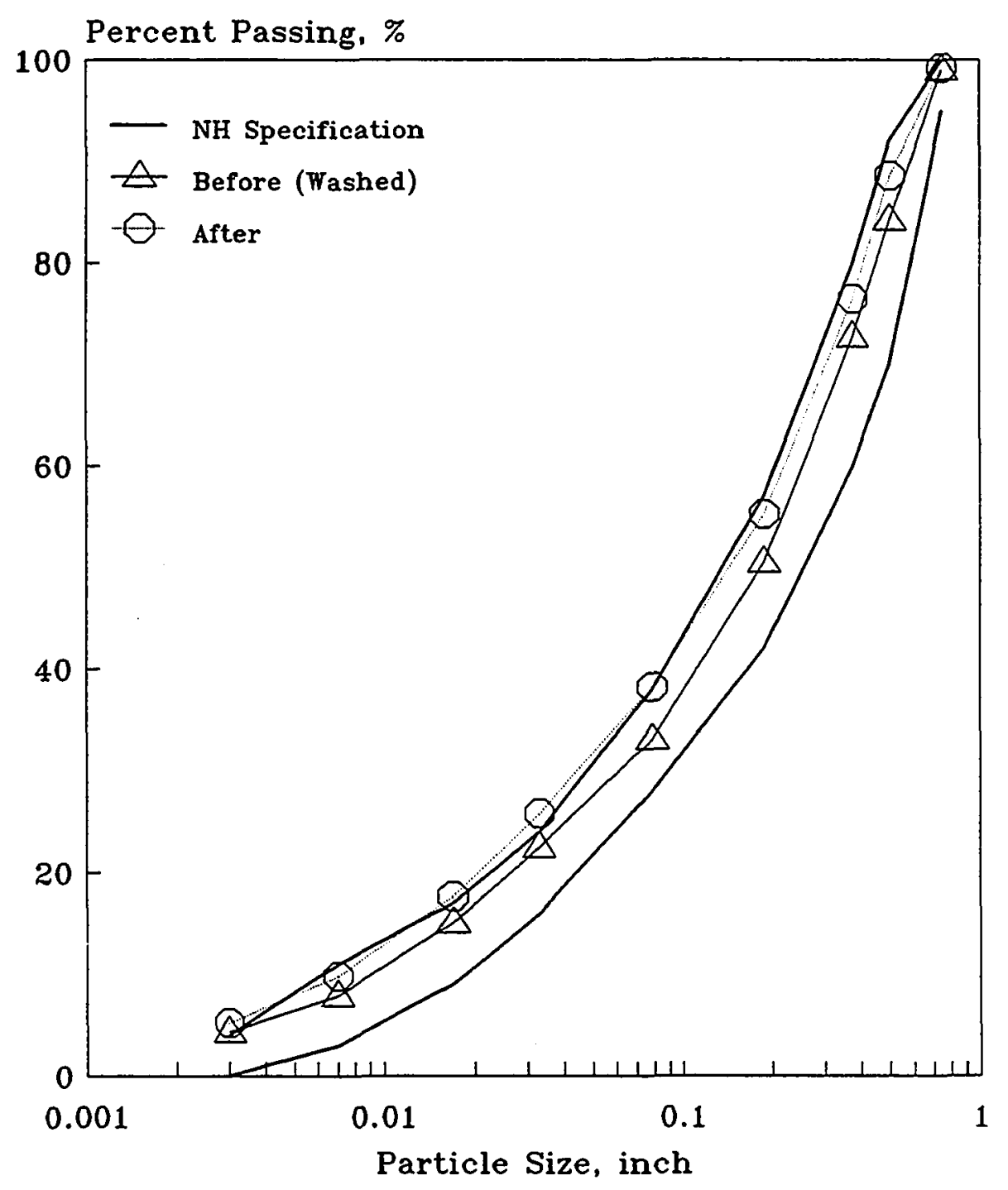

Figure 6.20 Degradation of the 25\% Ash 208 


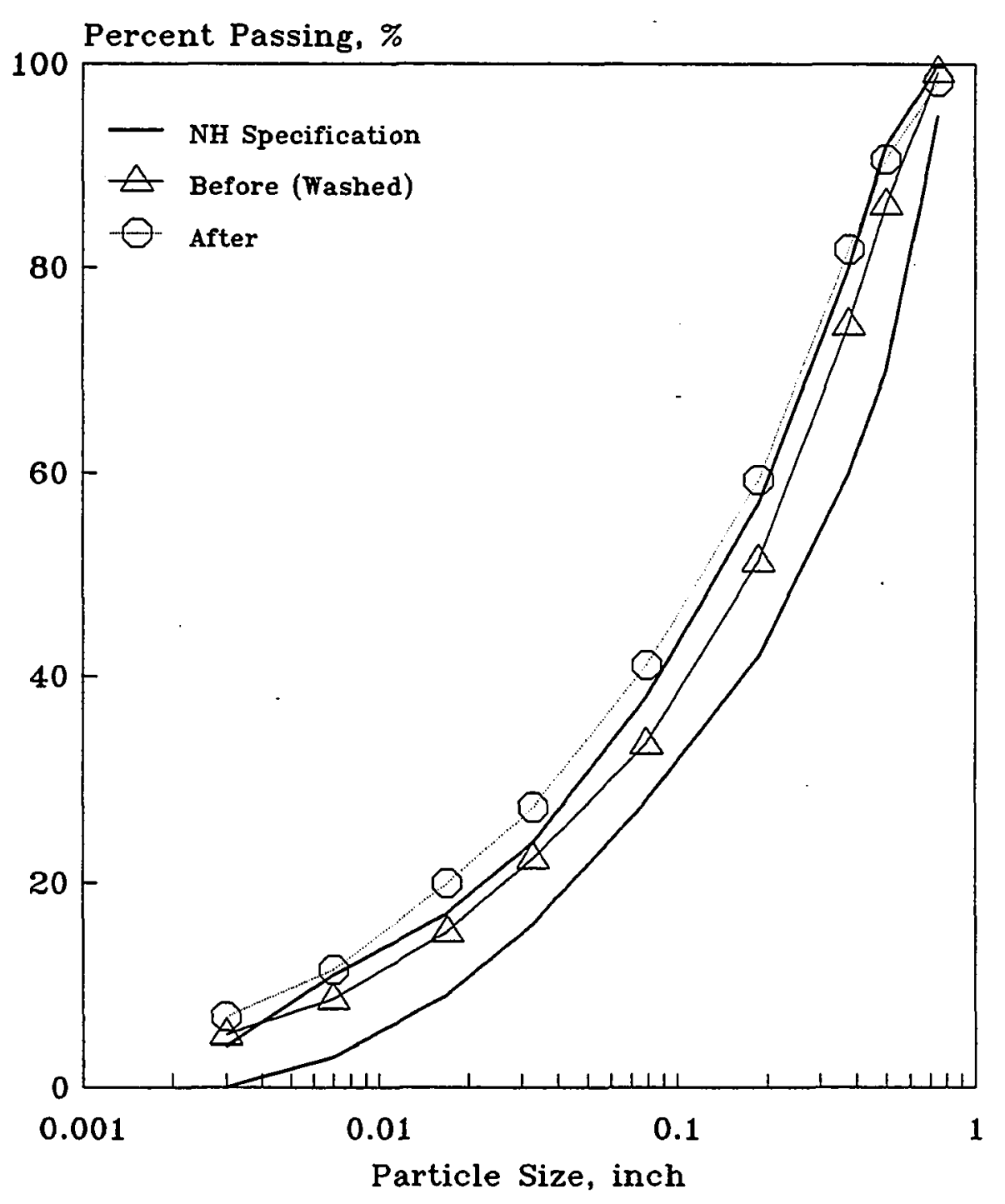

Figure 6.21 Degradation of the 50\% Ash 209 


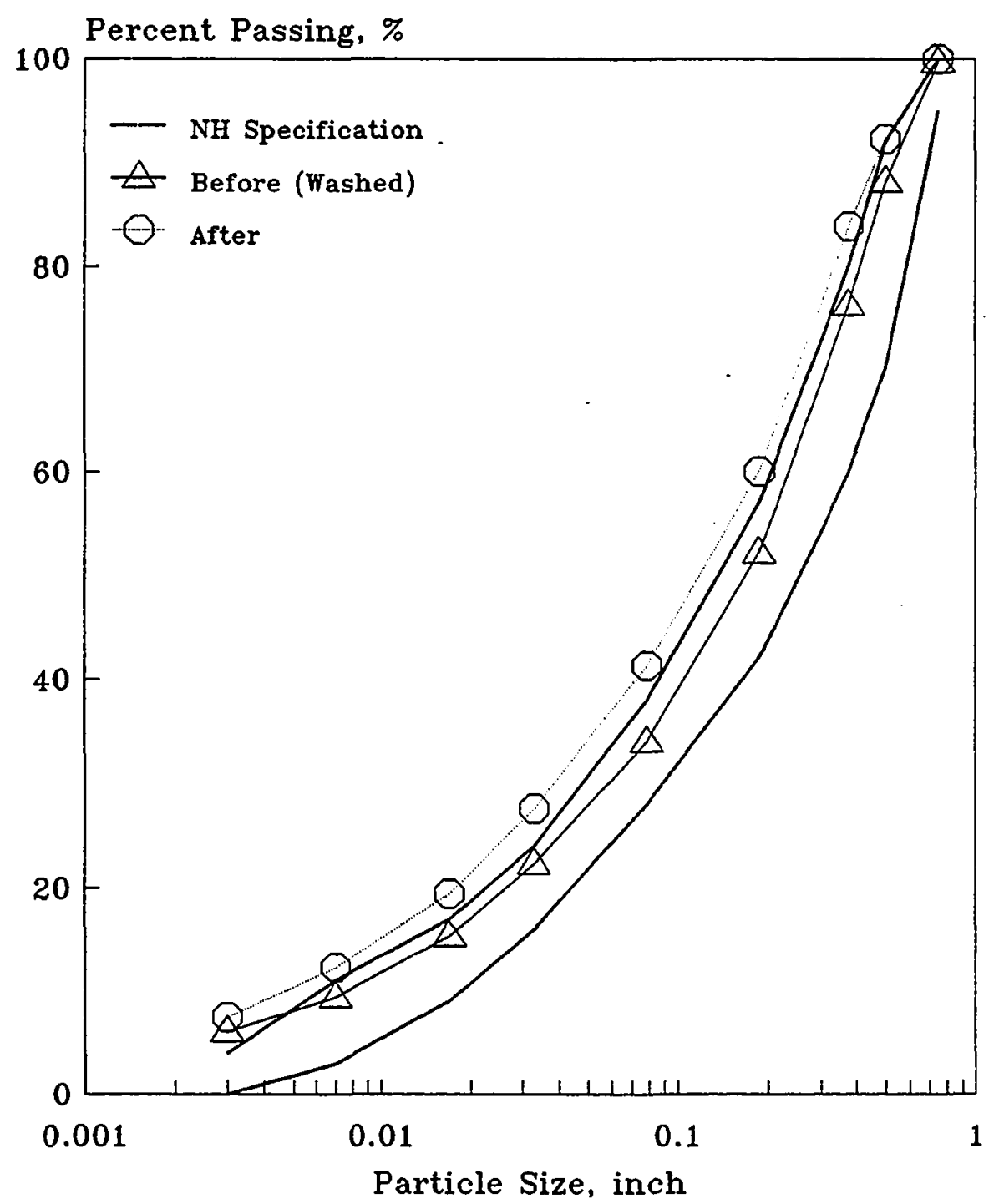

Figure 6.22 Degradation of the $75 \%$ Ash 210 


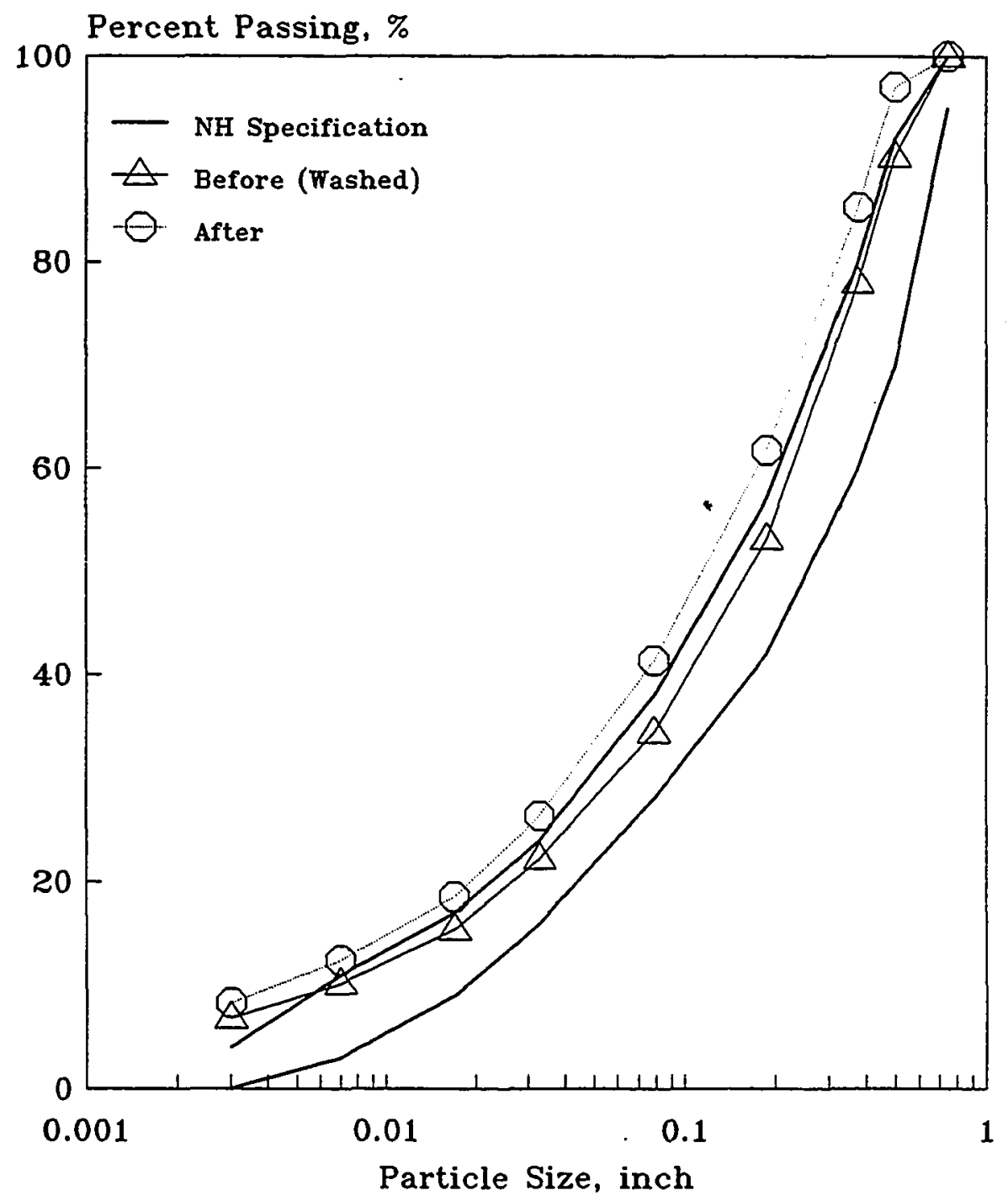

Figure 6.23 Degradation of the 100\% Ash 


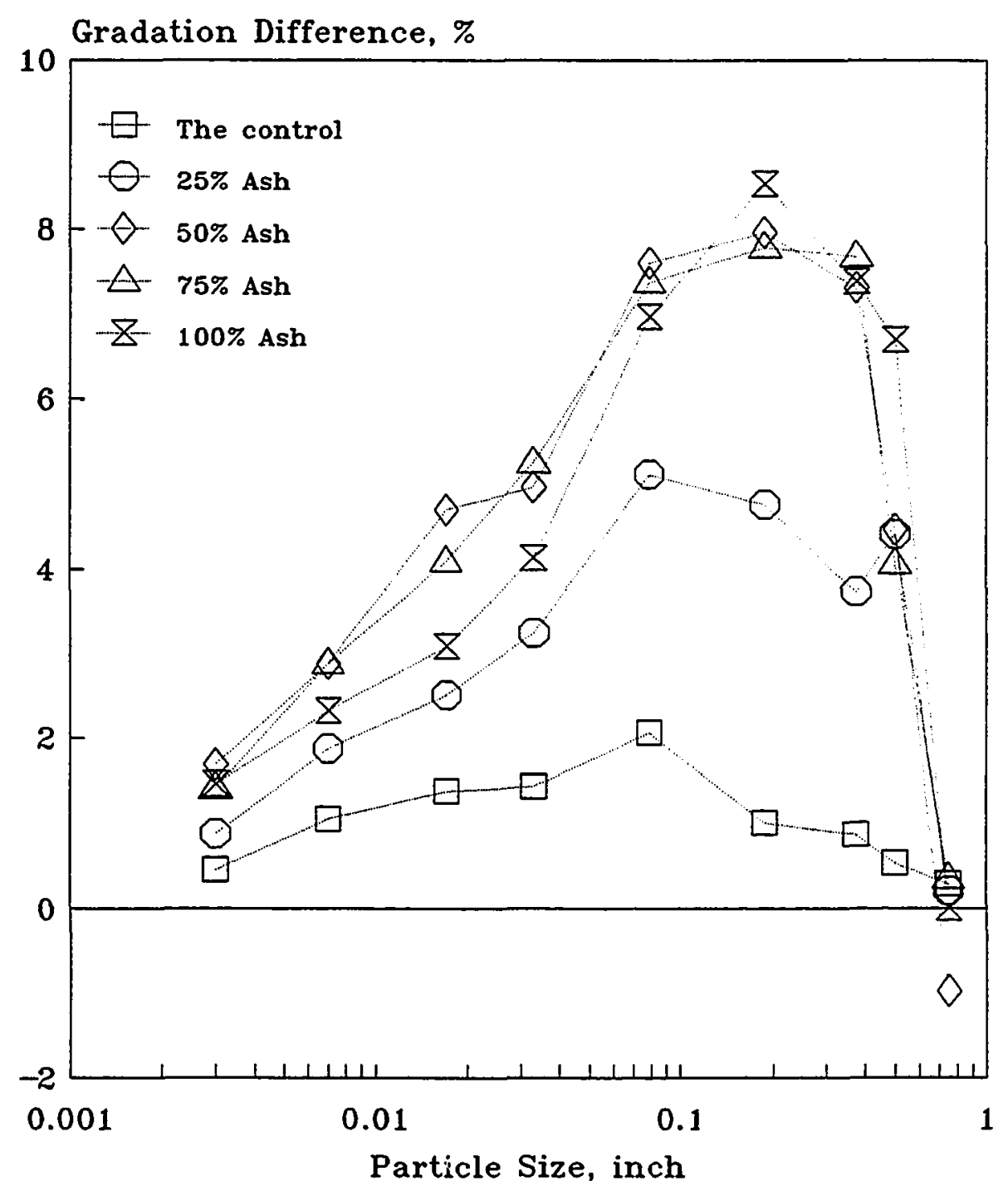

Figure 6.24 Ash Degradation 
A field study should be conducted to further investigate this phenomenon. It is expected that the degradation of bottom ash when used as base mix is not as severe as the laboratory data show. Experience has shown that even for aggregates with high Los Angeles abrasion values such as slag and soft limestones, the field performance is excellent (34).

\subsection{Conclusion}

The following conclusions can be drawn from this study:

1. The water absorption of aggregate blends increases with increasing ash content.

2. The unit weight of asphalt mixes decreases with increasing ash content.

3. The stability of all mixes ranges from 1840 to $2903 \mathrm{lb}$. Stability of the ash mixes is comparable to that of the control mix.

4. Flow increases with increasing asphalt contents. The ash mixes exhibit higher flow than the control mix due to increased asphalt contents.

5. The mixes containing up to $75 \%$ ash pass the VMA requirement of a minimum of 14\%. The $100 \%$ ash mix does not meet the VMA requirement at any asphalt content tested.

6. The asphalt content required to meet the specification of air void content increases as the ash content increases.

7. Asphalt absorption increases with increased ash.

8. The ash mixes show low water absorption, comparable to the control mix.

9. Bottom ash mixes can be designed to meet the Asphalt Institute specifications with 
up to $75 \%$ ash substitution.

10. Degradation of the mixes increases with increasing ash content up to $50 \%$ ash and then remains reasonably constant. 


\section{GYRATORY TESTING MACHINE DESIGN PROCEDURE}

\subsection{Introduction}

The objective of asphaltic concrete design is to select and combine asphalt binder, aggregate and, where necessary, modifiers such that the mix so obtained will be durable, be stable, and give the predicted performance. To accomplish this objective, the factors affecting the field mixes such as plant mixing, field construction, traffic, environment (climate), and structural section should be considered in the laboratory design procedure. The SUPERPAVE mix design system developed by SHRP permits the informed selection of materials and design of paving mixes that meet the requirement contained in the SUPERPAVE performance-based specifications for asphalt binders and asphalt-aggregate mixtures. It provides a compaction method and a series of conditioning procedures and accelerated performance tests to characterize the engineering capabilities of a paving mix (42).

SHRP considered the most important factor in the selection of a laboratory compaction device to be the ability to simulate field compaction, and, in particular, to ensure that engineering properties of laboratory compacted specimens are equivalent to those of in-place material (42). Comparisons of different compaction techniques have been performed to determine if specimens compacted with different devices have the same properties. One of the earlier comparative studies was performed by Fields (62) in 1958 
who compared various versions of the Marshall hammers and the Hveem kneading compactor. Fields found differences in Marshall stabilities between specimens compacted with the different devices, and developed compaction equivalencies between the Marshall hammer and Hveem kneading compactor. Epps et al. (63) conducted a compaction study in 1969 and also found differences in stabilities and strengths of mixtures compacted to the same air voids, but with different devices. The laboratory devices used in that study included the Texas gyratory, Corps of Engineers gyratory, Marshall hammer and California kneading compactor. NCHRP (36) has conducted the AAMAS project since 1985 in which five different types of laboratory compactors were used to prepare specimens in order to compare various properties between field and laboratory samples. Those compactors selected used in the study include 1) the Marshall hammer to represent an impact type compaction, 2) the California-kneading compactor to simulate a kneading type compaction, 3 ) the Texas gyratory shear compactor to simulate gyratory/kneading action, 4) the Arizona vibratory/kneading compactor to simulate the use of vibratory type compaction, and 5) the steel wheel simulator to simulate a rolling type compaction. The AAMAS study has effectively eliminated from contention both impact compaction and the Arizona vibratory/kneading compactor. It has successfully narrowed the search to three leading contenders; gyratory, kneading, and rolling-wheel compaction. SHRP initiated an extensive research project (SHRP A-003A: Performance Related Testing and Measuring of Asphalt-Aggregate Interactions and Mixtures) in 1991. Part of this project was to further evaluate the above three types of compaction devices, that is, Texas gyratory, kneading, and rolling wheel (64). This study indicates compaction methods 
significantly affect properties of the dense-graded mixtures evaluated herein, both in the statistical sense and in terms of practical engineering consequence. The likelihood is reasonably high that different kinds of mixtures might evolve from a comprehensive mixture analysis and design system depending on method of compaction. Among the three compaction methods examined, kneading specimens are generally most sensitive to aggregate characteristics and least sensitive to asphalt characteristics, gyratory specimens are least sensitive to aggregate characteristics and only slightly more sensitive than rolling-wheel specimens to asphalt characteristics, kneading compaction produced specimens having greatest resistance to permanent deformation, and gyratory compaction produced those having greatest resistance to fatigue cracking under controlled-stress loading. For both permanent-deformation and fatigue resistances, rolling-wheel specimens were ranked between gyratory and kneading specimens.

SHRP chose the gyratory compactor as a standard laboratory compaction equipment in the performance-based mix specification for several reasons (42): testing showed that it simulates field compaction reasonably well, equipment size and cost make it suitable for both central lab and field control operations, and its use permits real-time determination of specific gravity and air voids content during compaction. The SHRP gyratory compactor is very similar in size and appearance to the familiar Texas Gyratory Compactor. Specimens are compacted using a $1^{\circ}$ angle of gyration at a rate of 30 gyrations per minutes. Vertical pressure during compaction is 86 psi.

Since the SHRP gyratory compactor was not available to the present researcher, the Corps of Engineers Model 4C Gyratory Testing Machine with oil roller owned by Maine 
Department of Transportation was used in this study. This machine (65) developed by the Waterways Experiment Station, Vicksburg, Mississippi, is based on a compaction technique devised by the Texas Highway Department. The previous studies $(66,67,68,69,70)$ indicated the Corps of Engineers Gyratory Testing Machine (GTM) can be used to simulate the field initial compaction and traffic densification. Maine DOT $(71,72)$ has used the GTM in conjunction with Hveem procedure to design and control hot asphalt concrete. Their experience indicates an asphaltic hot mixture could be designed using the GTM exclusively rather than the Hveem procedure. More information is obtained with GTM: it can be used to predict initial density, density after several years, density under very severe traffic conditions, and density over a long period of exposure to traffic. It also will detect problems in mixes that are not detected by the Hveem or Marshall testing procedures. They are also using the GTM for other studies such as designing cold mixes and cold recycled mixes, and predicting compaction results in place of the Proctor test. The GTM is more elaborate than the SHRP gyratory compactor in that the angle of gyration and the vertical pressure of the former can be adjustable to better simulate the field condition and in that the physical properties and mechanical properties of mixtures can be monitored as compaction is in progress. Only the Corps of Engineers machine can test while it is compacting. The operator can see what is happening as it is happening.

A major objective of this study was to develop the optimum mix design (Job Mix Formulation) of a $50 \%$ bottom ash binder mix and a control binder mix for the planned test road project located in Laconia, New Hampshire. The Marshall design procedure was 
first used to develop such a mix which yielded an optimum asphalt content of $9.12 \%$ for the $50 \%$ bottom ash and $5.5 \%$ for the control mix. A comparison between Marshall data and the GTM data is made.

\subsection{Materials and Mix Preparation}

The conventional aggregates used in this study were the same as those in Chapter VI. The bottom ash used in this study was created by blending 18 daily composite samples collected during 18 intensive sampling events over a two year period. Bottom ash physical properties are shown in Tables 5.4 and 5.7. The ash data were an average of 72 hourly samples from 18 sampling events.

For $50 \%$ bottom ash mix, bottom ash was substituted on a weight basis of aggregate blends. The gradation for the $50 \%$ ash and the control mixes met the requirements of a NH type B binder mix as shown in Figure 7.1. The Pike aggregates and bottom ash were separated individually on each sieve and recombined to produce the formula under study. To minimize gradation variation each batch was prepared for only one specimen.

AC-20 asphalt used in this study was the same as that in Chapter VI.

The mass of materials prepared per batch was enough to produce a specimen with a dimension of approximately $4^{n}$ in diameter and $2.5^{n}$ in height. Aggregates and asphalt were heated separately. Mixing temperature determined to provide an asphalt viscosity $170 \pm 20$ centistokes was $295^{\circ} \mathrm{F}$, which simulated the plant mixing temperature. The mixing time was between 90 and 120 s. A mechanical mixer was employed. Three replicate samples were prepared per test. 


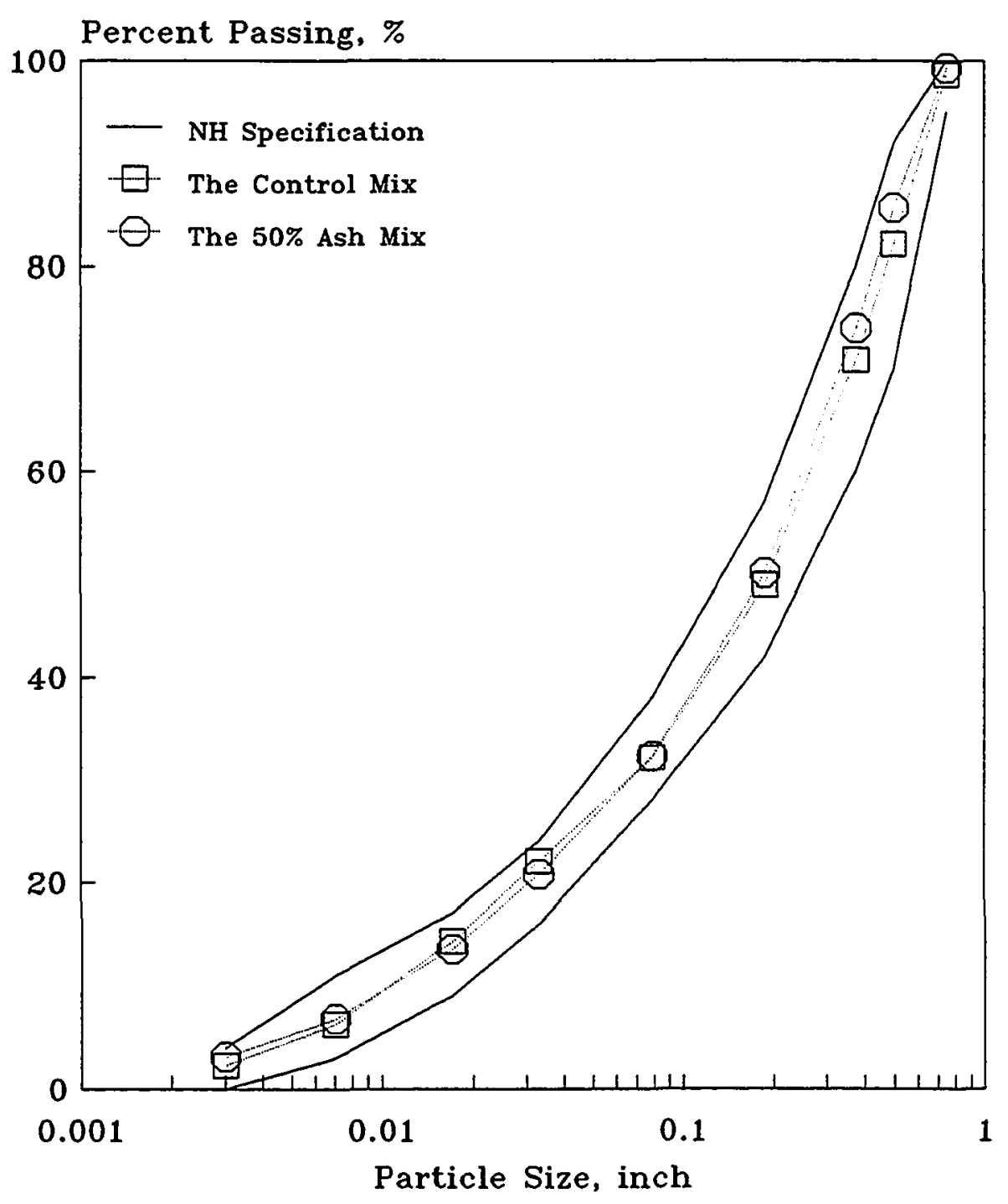

Figure 7.1 Gradation of Test Blends 
After initial mixing, the mixture was placed in a tray to uniform depth and then the tray was placed in a forced air oven set at $275^{\circ} \mathrm{F}$ for 3 hours. The purpose of this heating time (3 hours) is to simulate plant hardening (36). SHRP (42) suggests a heating time of 4 hours at $275^{\circ} \mathrm{F}$ which, based upon field validation data, simulates the aging that takes place through hot mix asphalt (HMA) production and about 3 to 5 years' pavement service. After initial heat conditioning, a representative sample of the mixture was taken and allowed to cool. The maximum theoretical specific gravity of this sample was determined in accordance with AASHTO T209.

\subsection{Mix Compaction and Tests}

In this study, the Corps of Engineers Model 4C GTM with oil roller (as specified by ASTM D3387) and a 4" diameter mold was used. Figure 7.2 presents a photograph of GTM. Figure 7.3 presents a schematic view of the gyrating mechanism of the Model 4C Gyratory Testing Machine (68). The hydraulic system may be adjusted to provide the desired ram pressure which is transmitted to the sample through the lower ram shaft $(F)$ and lower head $(\mathrm{H})$. The angle of gyration may be adjusted by raising or lowering the lower roller (C). Rollers (C) and (D) force the mold chuck and mold to pivot about the lower head $(\mathrm{H})$. The upper head $(\mathrm{G})$ is free to move in any direction horizontally. Rotation of the upper mechanism, including rollers (C) and (D), imparts a gyratory motion to the test specimen. The $1^{\circ}$ angle of gyration relates to the anticipated pavement deflection. The 120 psi ram pressure was selected as the anticipated tire contact pressure. The vertical ram pressure corresponds to the maximum anticipated tire contact pressure, 


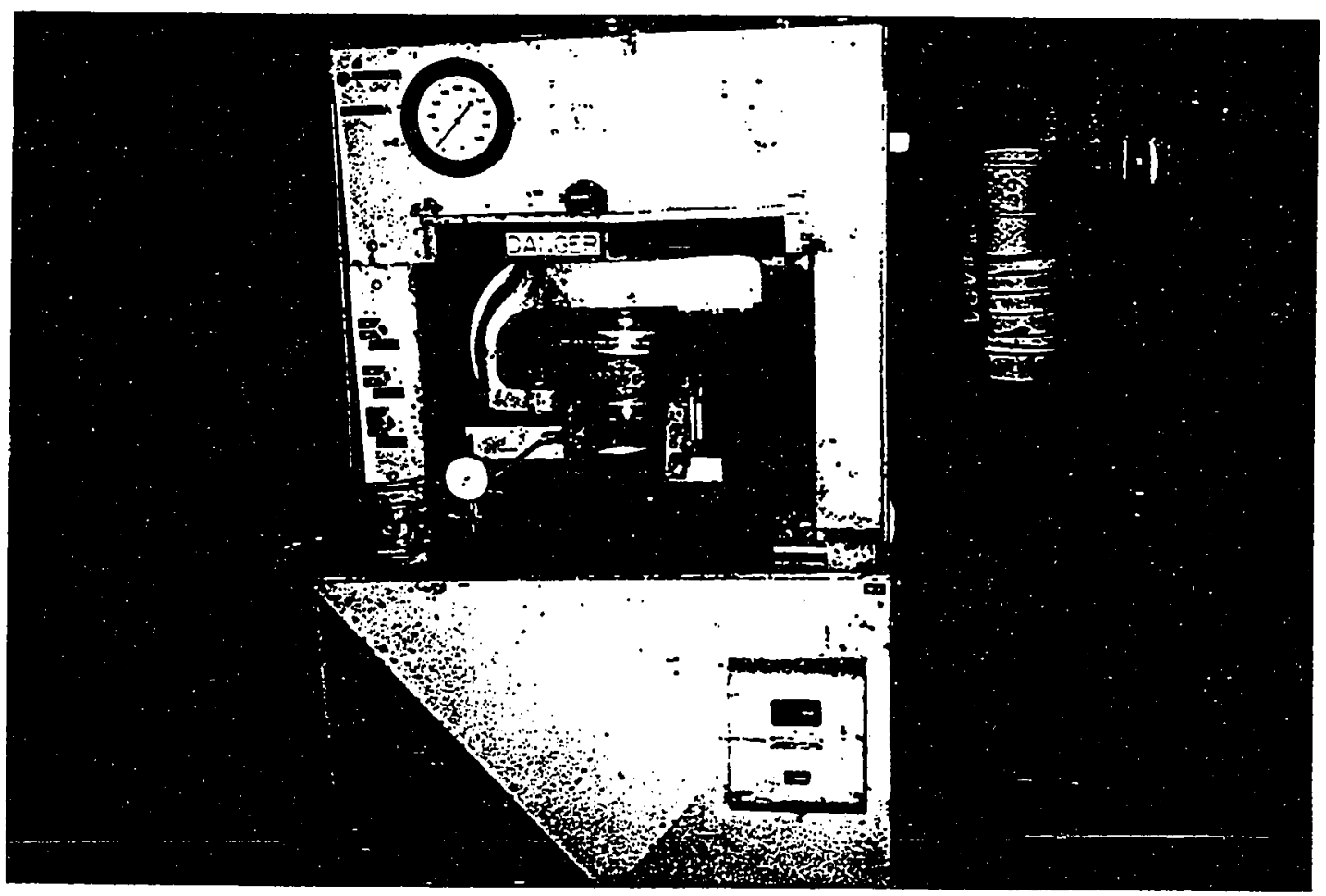

Figure 7.2 Gyratory Testing Machine 


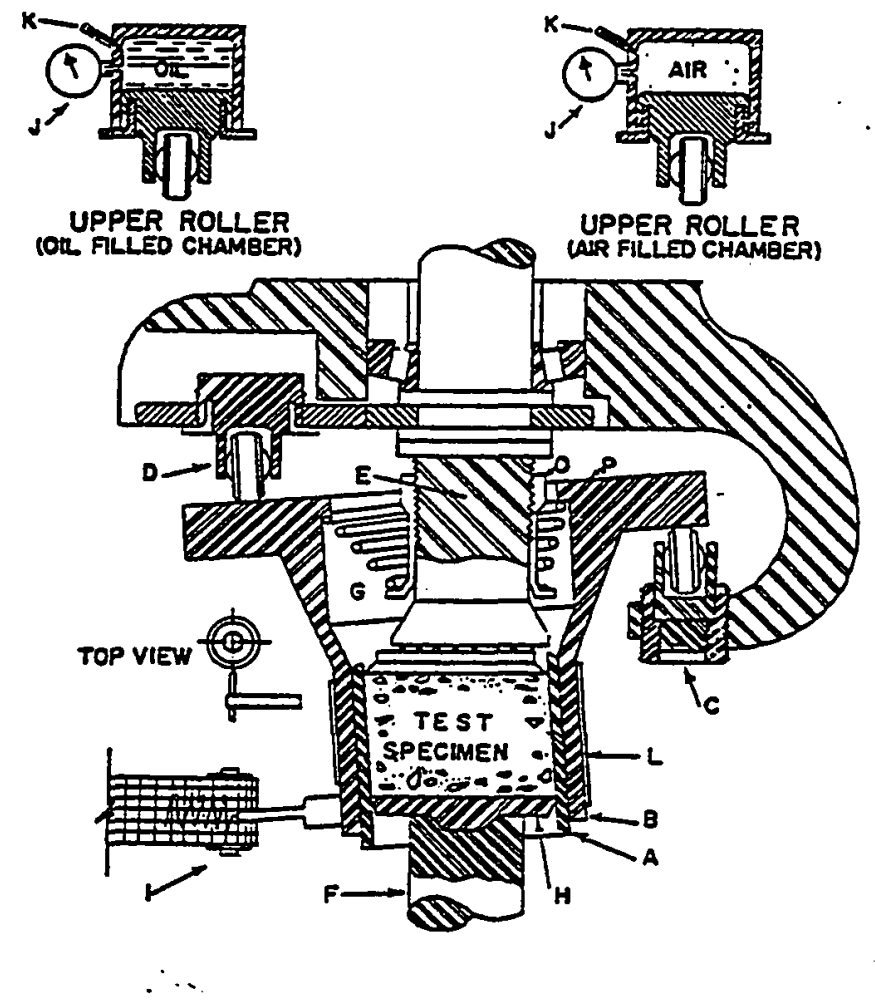

Key to Details
A. Specimen Mold
B. Mold Chuck
C. Lower Roller
D. Upper Roller
E. Upper Ram Shaft
F. Lower Ram Shaft
G. Upper Head
H. Lower Head

I. Gyrograph

J. Pressure Gage

K. Filling Valve

1. Heating Element

M. Chuck Flange

N. Recorder Pea

O. Spring Support Sleeve

P. Felical Spring

Fig. 7.3 Schematic View of the Gyrating Mechanism (Ref. 68) 
since the theoretical stress for compaction and maximum induced shear is based on the concept of employing realistic loads for the test. The compaction temperature was $230^{\circ} \mathrm{F}$. In this study the compaction effort of 60 and 300 revolutions was chosen based on Maine DOT experience $(71,72)$ to simulate the initial compaction and ultimate traffic densification respectively. Maine DOT uses a 125 psi ram pressure to simulate the tire pressure.

The National Center for Asphalt Technology (NCAT) (73) recently completed a fiveyear national study of rutting in hot mix asphalt pavements. They concluded that mixtures designed for heavy truck traffic are best evaluated on GTM for 300 revolutions, 1 degree gyration angle and 120 psi to determine the susceptibility ${ }^{-}$for rutting. NCHRP (36) recommends a $2^{\circ}$ angle of gyration, a ram pressure of 120 psi, and 12 revolutions for initial compaction, 300 revolutions for traffic densification.

Three replicate specimens were prepared at each test. Asphalt content of 50\% ash mix range from 6.0 to $9.5 \%$ and that of control mix from 4.0 to $6.0 \%$. Asphalt content was based on weight of total mix.

The sample weight was measured prior to compaction. The sample height and the oil roller pressure at three roller locations as per ASTM D 3387 were obtained at $30,60,90$, $120,150,200,300$ gyrations. The shear strain experienced by the mixture during compaction was recorded with gyrograph. After compaction, all specimens were cooled to room temperature and the bulk specific gravity, water absorption were determined in accordance with AASHTO T166. Using the information obtained, calculations were made to obtain the physical and engineering properties for each specimen $(71,72,74)$. In 
addition, Marshall stability and flow of all samples were tested. The degradation caused by GTM compaction was investigated.

\subsection{Results and Discussions}

All data, if not specified, is an average of 3 samples. In all figures presented in this section, C stands for "the control mix", and A for "the 50\% bottom ash mix".

\subsubsection{Unit Weight}

The unit weight of all samples was determined in accordance with AASHTO T 166. Figure 7.4 presents the unit weight as a function of GTM revolutions for the control and $50 \%$ ash mixes. The unit weight of the control and ash mixes increase with increasing GTM revolutions. Initially, the mixes were compacted at a fast rate, then the rate tends to decreases with increasing revolutions. Varying the asphalt content tends to shift the curves but does not change general shape. The same observation was noted by Kumar and Goetz (70). At each compaction (revolution), the average unit weight of the ash mix was 7 to $10 \mathrm{lb} / \mathrm{ft}^{3}$ lower than that of the control mix but the general shape of the curves for both mixes was quite similar.

The unit weight as function of asphalt content is shown in Figure 7.5. Marshall data are also included for comparison. Sixty and 300 GTM revolutions simulate initial compaction and traffic densification, respectively. Marshall compaction effort (50-75 blows/side) simulates a density of in-place asphaltic concrete after 2-3 years of traffic (34). The unit weight of the control mix at 300 revolutions was 3 to $4 \mathrm{lb} / \mathrm{ft}^{3}$ more than 


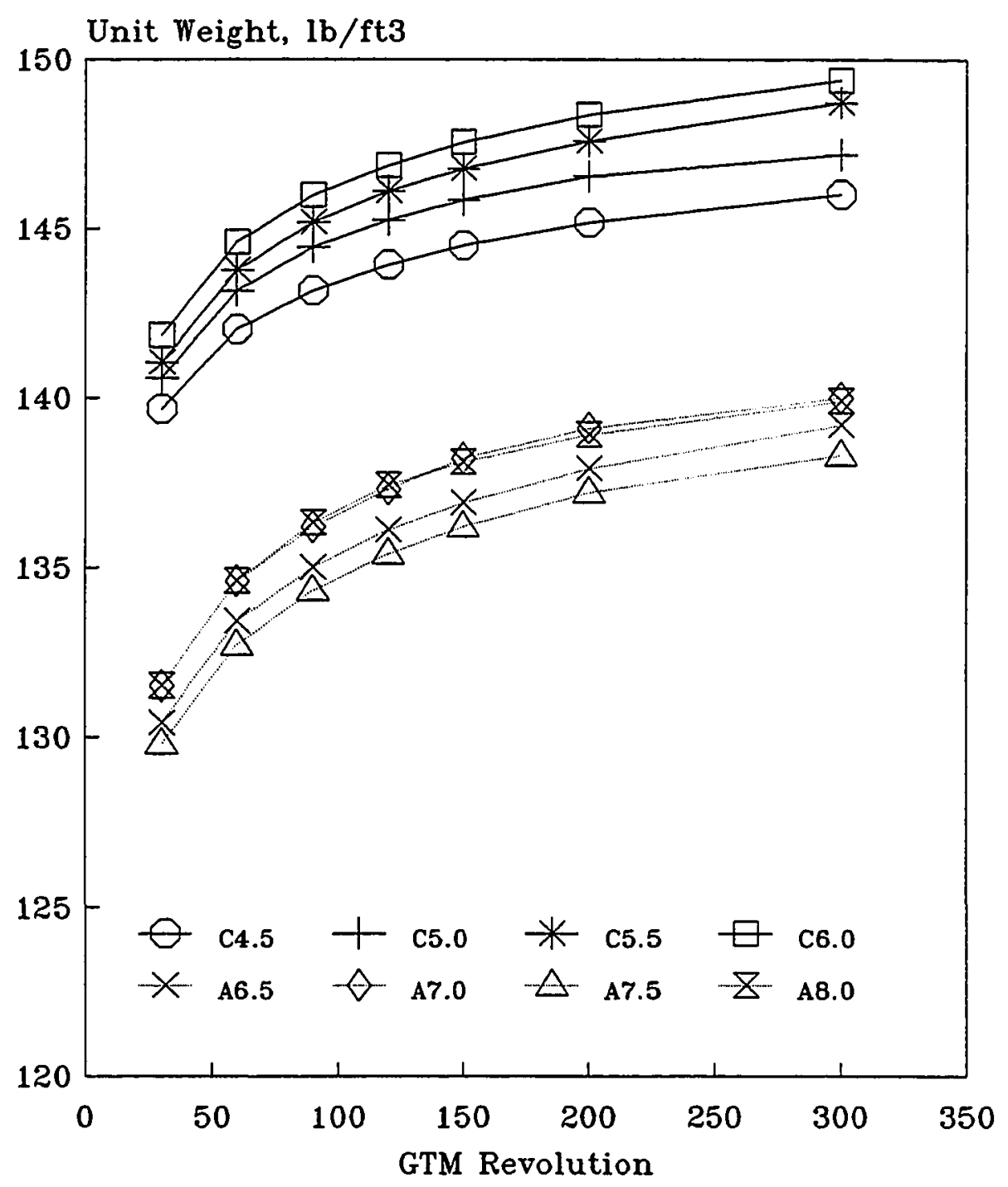

Figure 7.4 Unit Weight versus Revolution 226 


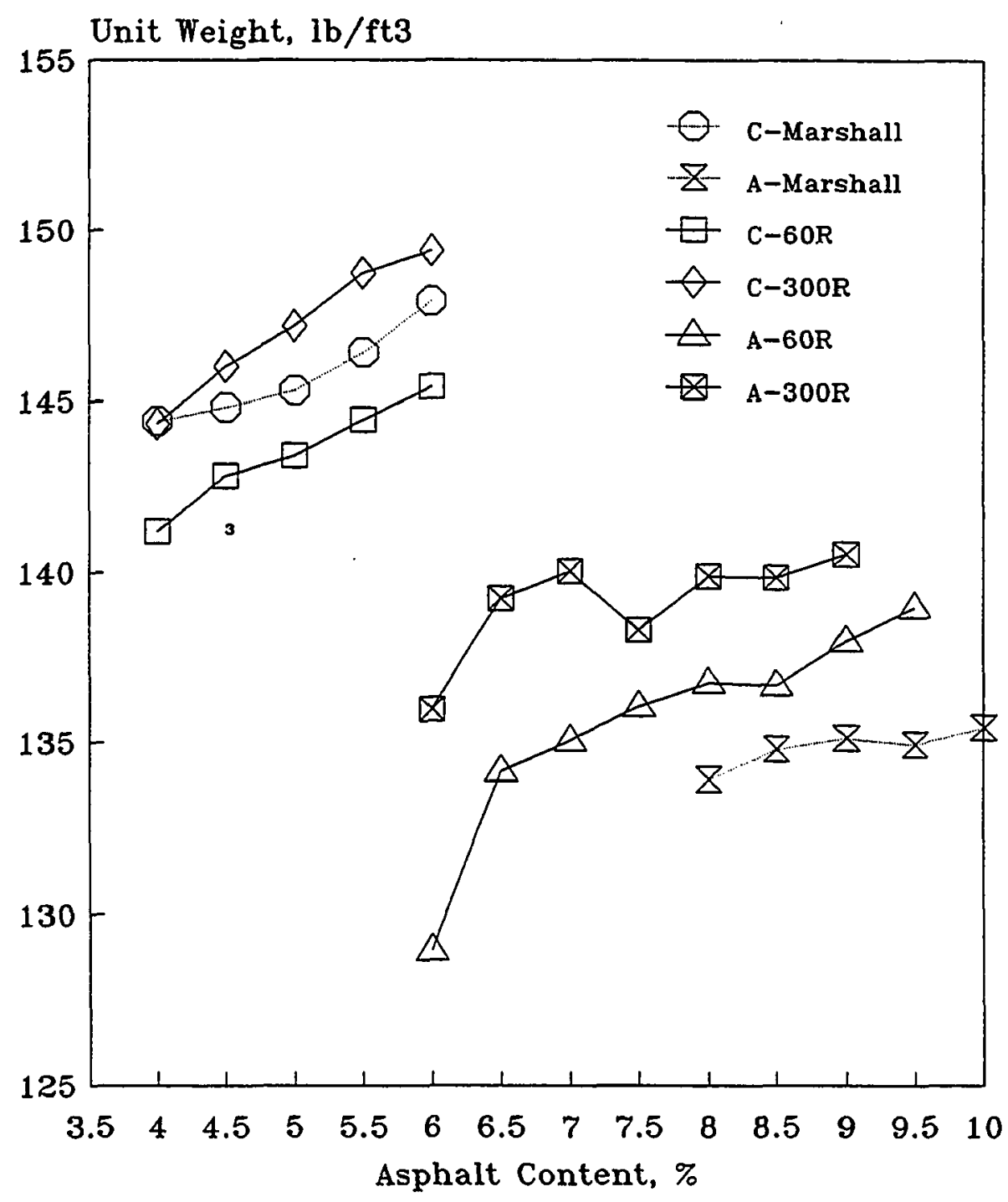

Figure 7.5 Unit Weight versus Asphalt Content 227 
at 60 revolutions, and that of the ash mix was 2 to $7 \mathrm{lb} / \mathrm{ft}^{3}$ more. Unit weight slightly increases with increasing asphalt content with the exception that the ash mix unit weight at 300 revolutions varies inconsistently with asphalt content. In concept, unit weight should increase initially as asphalt content increases, and reach a peak, and then begin to decrease. One explanation for the result in this study is that the aggregate particles for both control and ash are angular and therefore, have large surface area. The asphalt contents used were not sufficient enough to push the aggregate particles further apart. Hence, the trend of lower unit weight at higher asphalt contents was not observed. The variation in ash composition may result in the inconsistency for the ash mix.

Marshall unit weight of the control mix is between that at 60 and 300 revolutions, indicating the assumption that Marshall compaction simulates 2-3 years of traffic densification as stated by Reference (34) is adequate. The Marshall unit weight of the ash mix, however, is lower than that at either 60 or 300 revolutions. Bottom ash may not respond to these mix design procedures as do conventional materials. The specimens compacted with GTM at 60 and 300 revolutions were denser than those with Marshall compactor. The gyratory/kneading type of compaction such as GTM is more efficient than the impact type of compaction such Marshall compactor when compacting porous materials such as coral, porous lime stone and bottom ash. In addition, the 3 hour aging of uncompacted mixes at $275^{\circ} \mathrm{F}$ could increase absorbed asphalt, which resulted in decreasing the asphalt film thickness and volume of compacted mixes, increasing unit weight. This effect might be significant for ash mixes. It is not clear whether the asphalt absorption is affected by the GTM compaction. 


\subsubsection{Gyratory Compactibility Index (GCD)}

GCI is the ratio of the unit weight of asphaltic concrete at 30 revolutions of the GTM to those at 60 revolutions of the GTM (74). GCI is an indicator of the compactibility of the mix. The closer this index approaches unity, the easier the mix is to compact. Figure 7.6 presents the $\mathrm{GCI}$ as a function of asphalt contents for the control and ash mixes. The GCI of the ash mix ranges from 0.977 to 0.979 , with an average of 0.9777 and that of the control mix ranges from 0.981 to 0.984 , with an average of 0.9822 . The former has lower values than the latter. The ash mixes were more difficult to compact than the control mix.

\subsubsection{Air Voids}

Air voids in a compacted paving mixture consist of the small air spaces between the coated aggregate particles. This is without question the most important parameter in mix design. It is well known that an asphaltic concrete mixture that is compacted to a low air void content will have increased fatigue life, reduced permanent deformation, reduced distortion, reduced aging of the asphalt cement, and reduced moisture damage than will the same mixture that is compacted to a higher air void content (36). The effect of air voids on the mixture properties is shown in a conceptual plot on Figure 7.7 (75). It is also well known that air voids at a given time are dependent on tire pressure, wheel load magnitudes, traffic, and environmental conditions. Hence, the air void level at which the engineering properties are measured is critically important. The air void level after construction was specified from $5 \%$ to $8 \%$ and the air void level of $3 \%$ to $5 \%$ after 


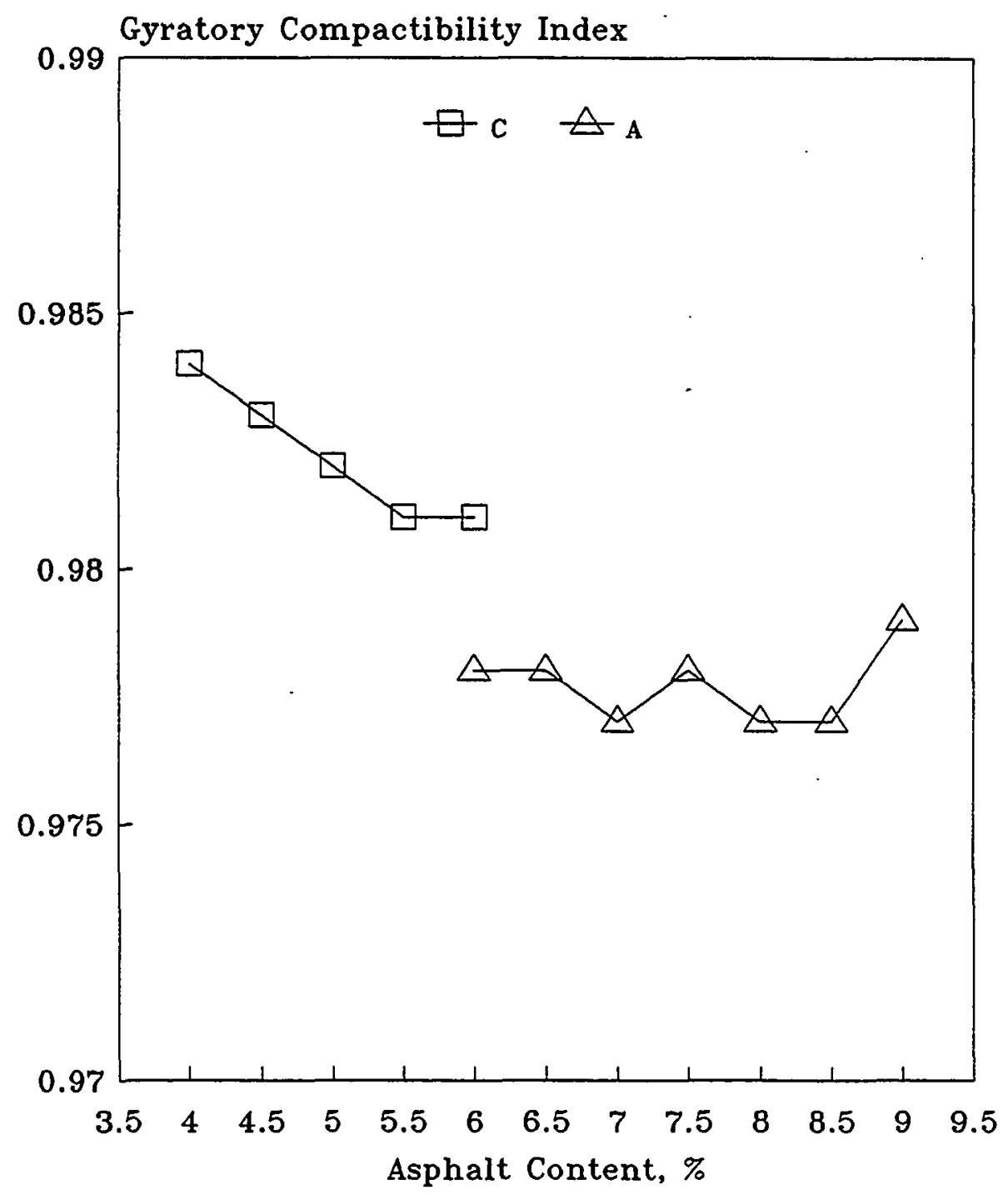

Figure 7.6 Gyratory Compactibility Index versus Asphalt Content 


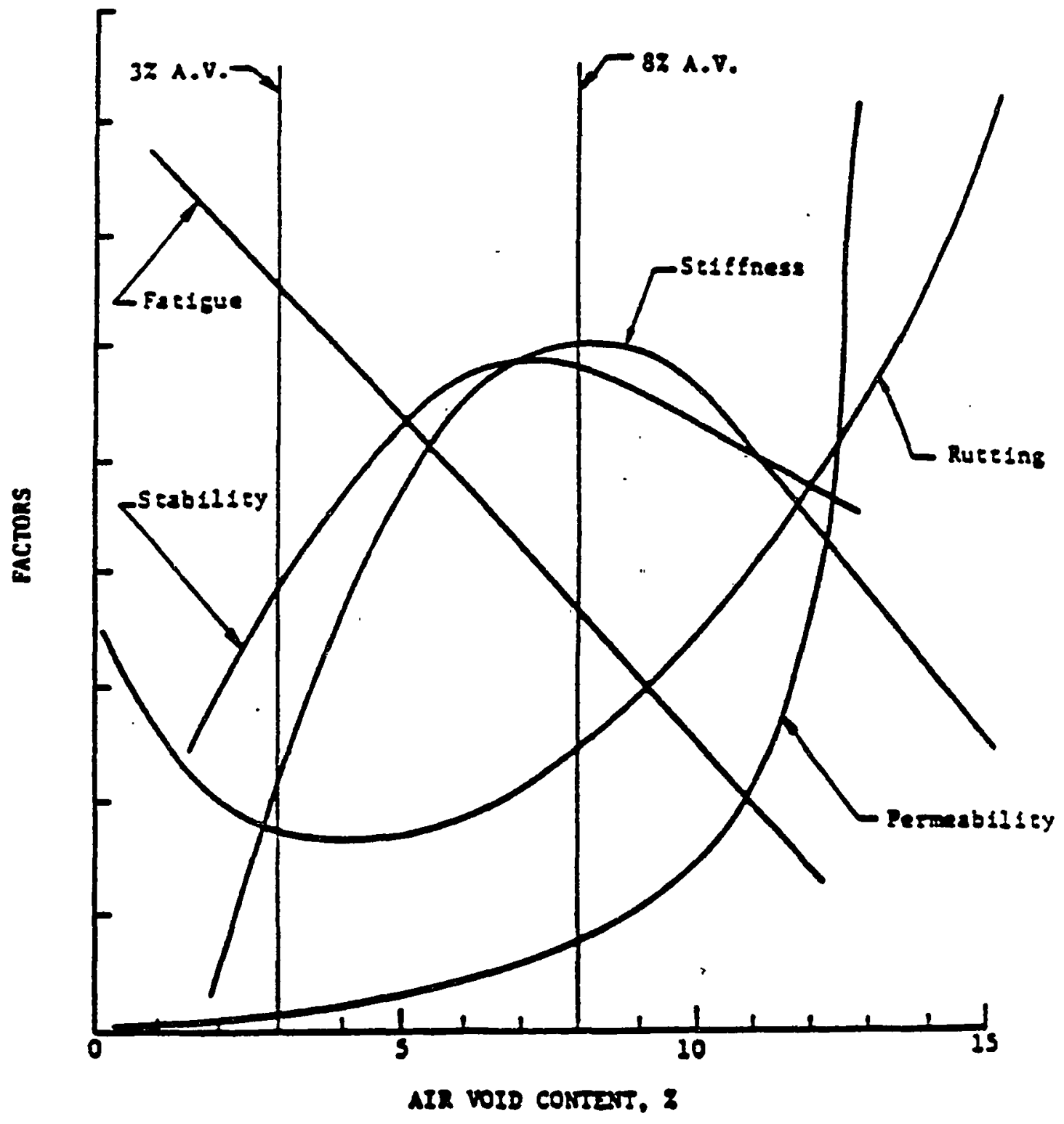

Figure 7.7 Relation Between Mix Properties and Air Voids (Ref. 75) 
traffic densification has been found to be acceptable in most environments for either surface mix or binder mix (36).

The theoretical maximum density, $G_{\mathrm{mm}}$, is determined from the Rice test. $G_{\mathrm{mm}}$ of the GTM procedure was determined after 3 hours of aging at $275^{\circ} \mathrm{F}$. The Marshall procedure, unlike the GTM procedure, does not include aging of the mix. The effect of aging on $\mathrm{G}_{\mathrm{mm}}$ is shown in Figure 7.8 (only one measurement for each data point). It appears that the aging resulted in the increase of $G_{m m}$.

Figure 7.9 presents the air voids as a function of revolutions. Air voids of the ash and control mixes decrease significantly at the beginning, then tend to be less affected with increased revolutions. Use of different percentages of asphalt content tends to shift the entire curve but does not change its general shape.

The effect of asphalt content upon air voids at 60 revolutions is shown in Figure 7.10. Both mixes exhibit the same trend. As a result of air voids being filled with asphalt, air voids decrease with increasing asphalt contents. To achieve the same air voids, the ash mix requires more asphalt cement (approximately 2.3 to $2.5 \%$ more) than the control mix because of the highly absorptive nature of ash. The asphalt content meeting the air voids specification of 5 to $8 \%$ ranges from 4.4 to $5.7 \%$ for the control mix and 7 to $8 \%$ for the ash mix.

Figure 7.11 presents the air voids at 300 revolutions as a function of asphalt content. Marshall data are also included for comparison. Air voids decrease with increasing asphalt content with the exception that there is a hump for the ash mix. The hump possibly resulted from the ash variation. At the same air voids content, the ash mix 


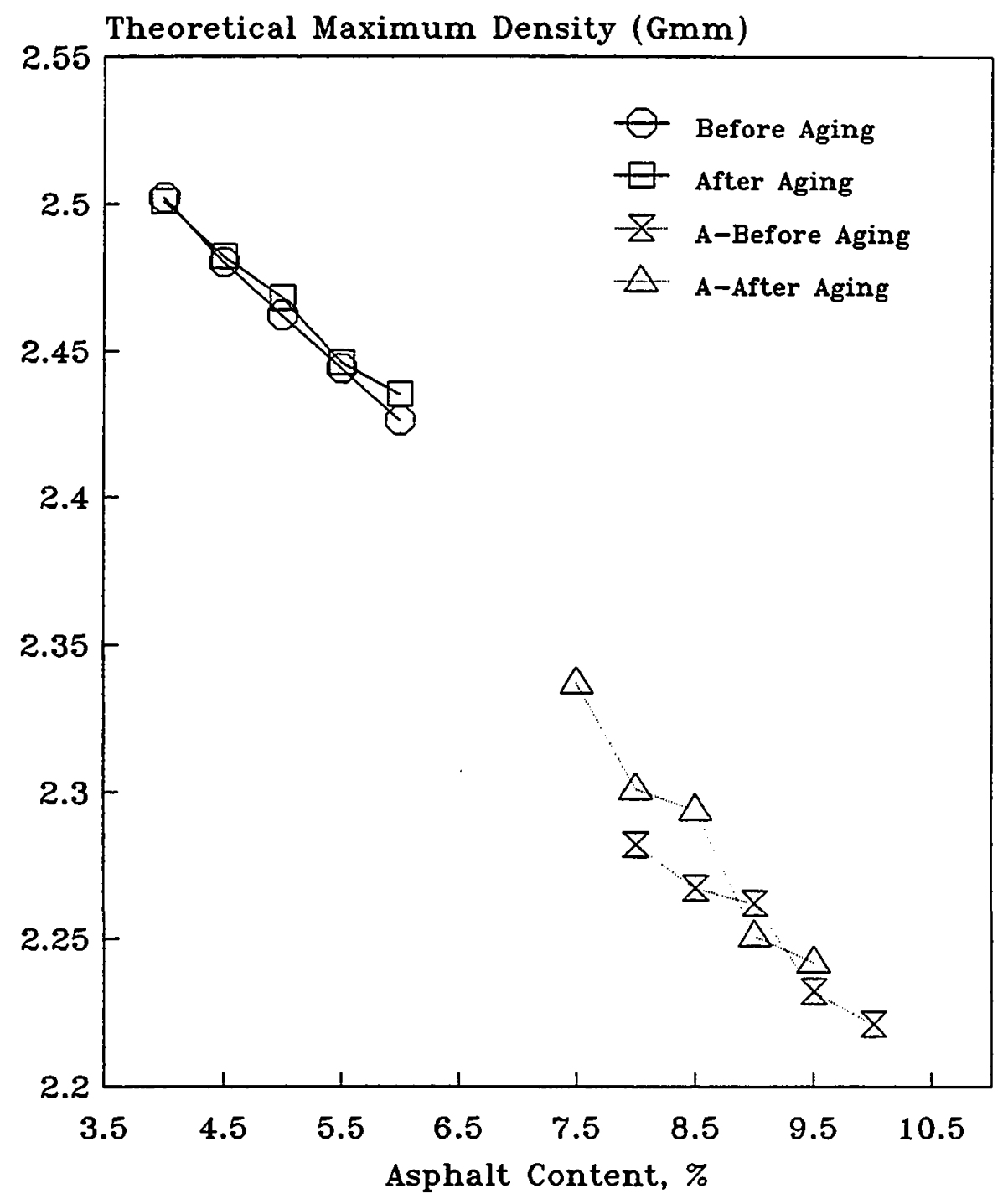

Figure 7.8 $\mathrm{Gmm}$ versus Asphalt Content 


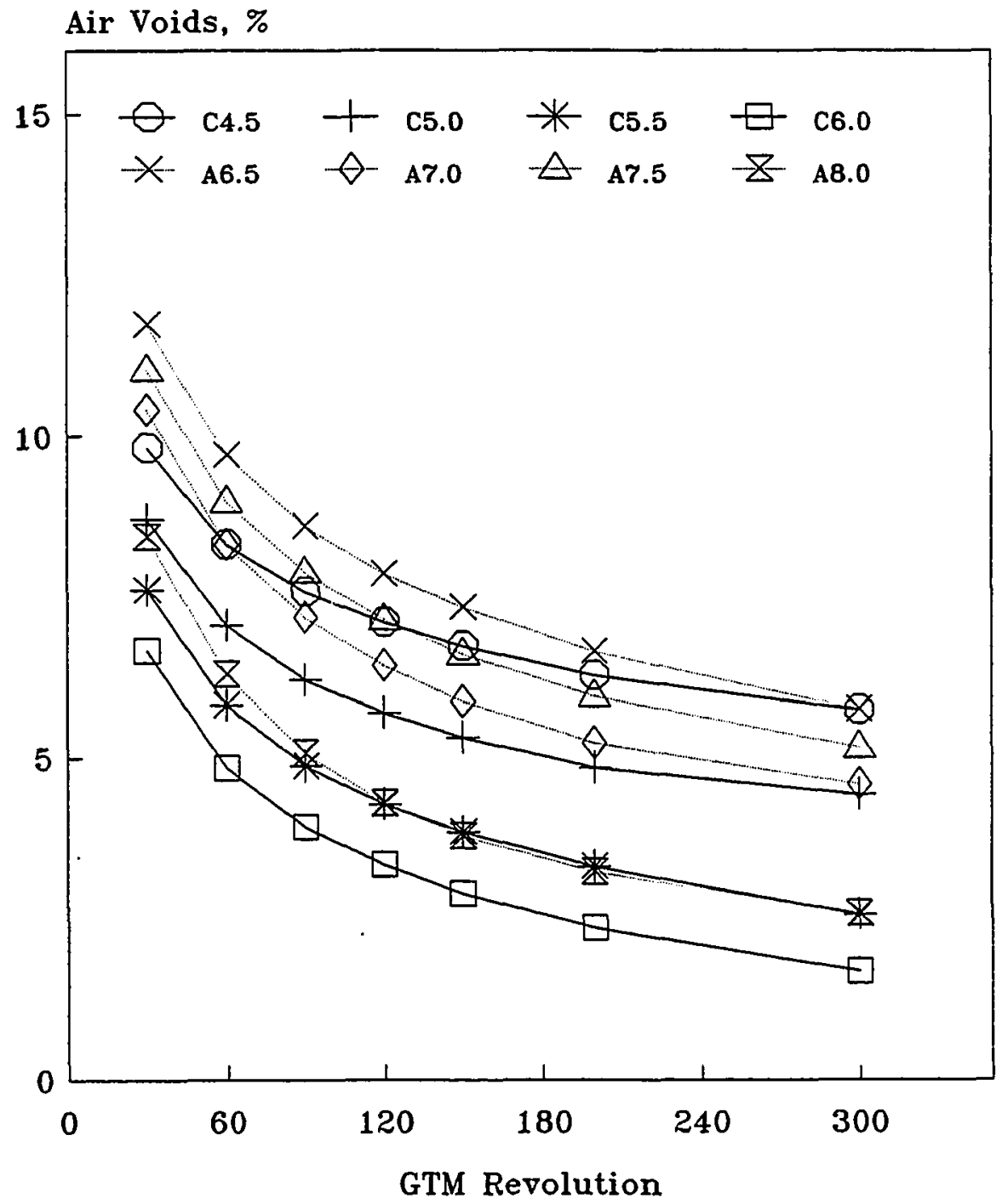

Figure 7.9 Air Voids versus Revolution 


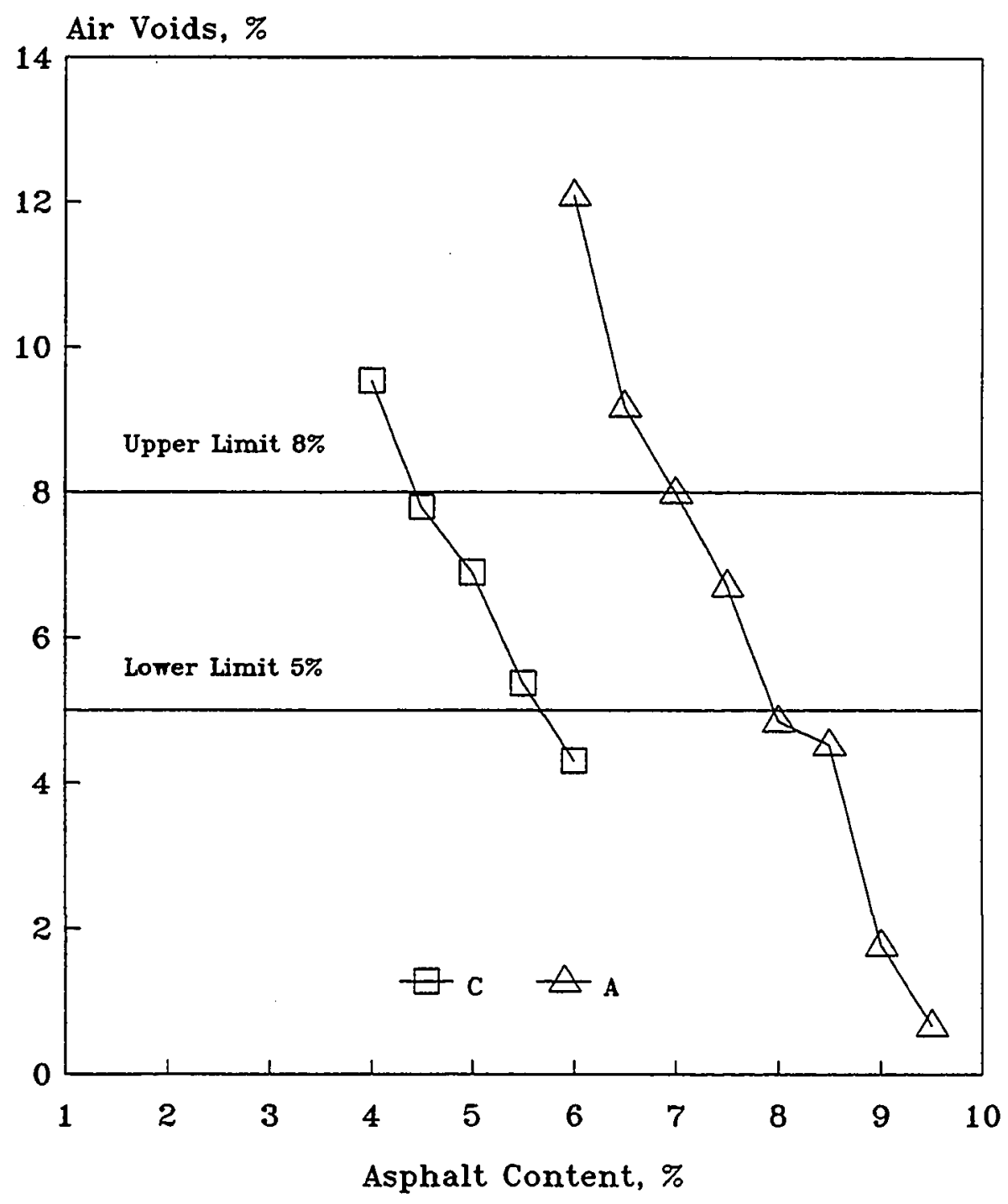

Figure 7.10 Initial Air Voids versus Asphalt Content (60 R) 


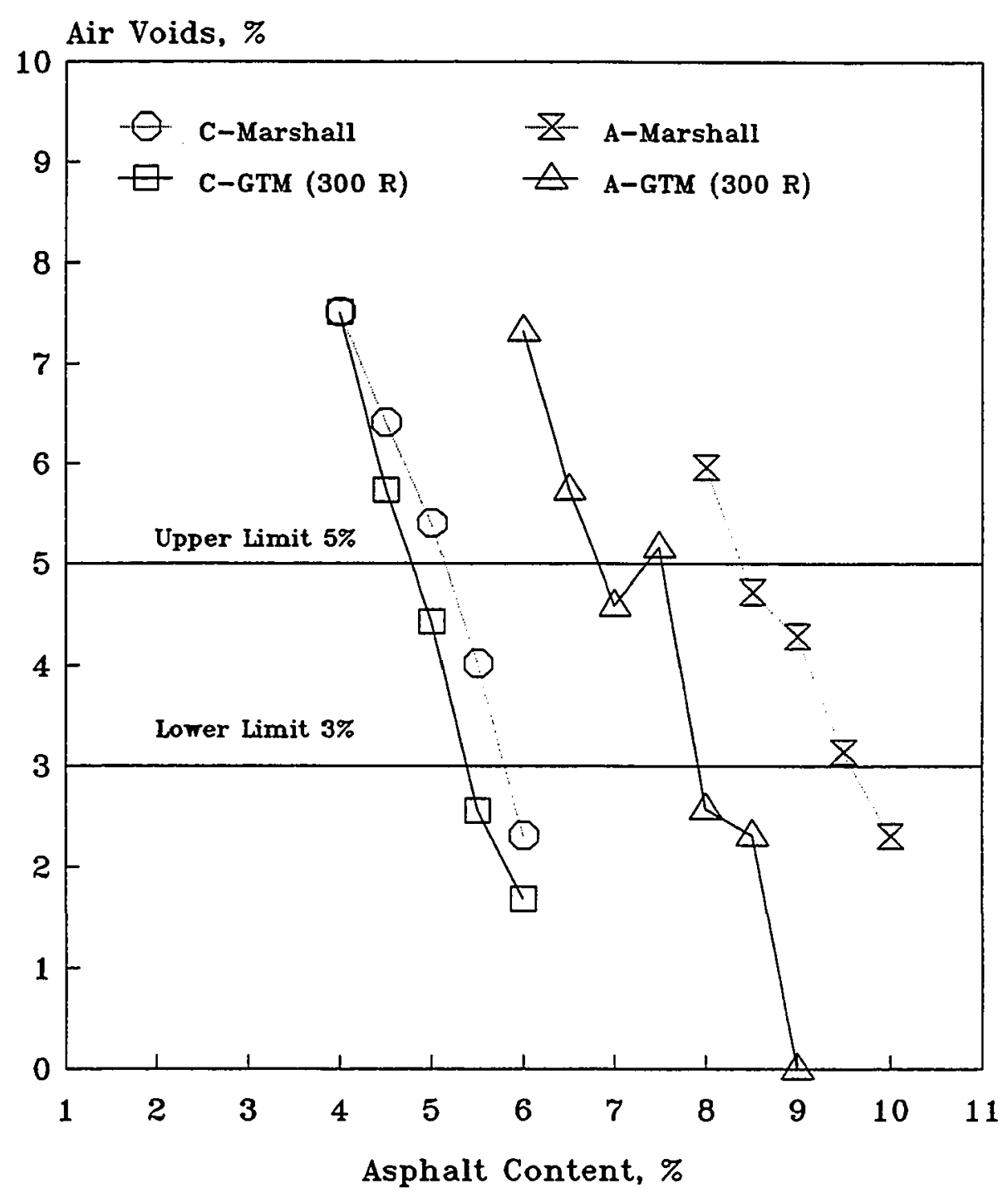

Figure 7.11 Final Air Voids versus Asphalt Content 
requires approximately 2 to $2.7 \%$ more asphalt by the GTM method and 3.3 to $4 \%$ more by the Marshall method than the control mix. The Marshall method provides less compactive effort than GTM methods and therefore more asphalt cement was needed to fill up air voids to obtain the same air void content. The ash mix is more sensitive to compaction methods than the control mix. The GTM data indicates the asphalt content meeting the air voids specification of 3 to $5 \%$ ranges from 4.8 to $5.3 \%$ for the control and 6.8 to $7.9 \%$ for the ash mix.

\subsubsection{VMA and VFA}

Both VMA and VFA have been considered as mix design parameter specifications. The asphalt Institute and many state highway agencies have adopted minimum VMA requirements for mixture design. The Corps of Engineers and Federal Aviation Administration have adopted limits on final air voids of 3 to 5\% and a VFA requirement of 75 to $85 \%$ to ensure the mixture's durability. On the other hand, others such as National Asphalt Pavement Association (58) have argued that there are insufficient performance data to justify these minimum and maximum requirements. NCHRP (36) investigated the effect of VMA on indirect tensile strength at a test temperature of $41^{\circ} \mathrm{F}$. The data do show a trend, but no distinguishable relationship was found to exist. Hence, the VMA specification should be supported by field performance data. Table 1 presents the guidelines for VMA and VFA (36).

Figure 7.12 presents VMA versus revolutions. The VMA for the ash and control

mixes decreases significantly at beginning, then the curve flattens with increased 
Table 7.1 The VMA and VFA Guidelines (36)

\begin{tabular}{lccc}
\hline Property & $\begin{array}{c}\text { Max. Aggregate } \\
\text { Size, in. }\end{array}$ & Mini. Value & Max. Value \\
\hline VMA & 1.5 & 12 & 20 \\
& 1 & 13 & 20 \\
& 0.75 & 14 & 21 \\
VFA & 0.5 & 15 & 21 \\
& - & 75 & 85 \\
\hline
\end{tabular}

revolutions. This finding is the same as that from the air void analysis. The average VMA of the ash mix is 3.2 to $4.8 \%$, lower than that of the control mix at each level of compaction.

The VMA as a function of asphalt content is shown in Figure 7.13. Marshall data are also included for comparison. The Marshall data for the control and ash mixes meet the $14 \%$ minimum requirement. The VMA of the control mix at 300 revolutions does not meet $14 \%$ minimum requirement, with the exception that the VMA at $4 \%$ asphalt does. The VMA of the ash mix at 300 revolutions does not meet the specification at any asphalt content, being 4.3 to $6 \%$ lower than the $14 \%$ minimum specification. The ash mix is more sensitive to compaction methods than the control mix in that the difference in VMA between GTM and Marshall methods for the ash mix is more significant than that for the control mix. The VMA is significantly affected by $G_{m b}$ when $P_{s}$ and $G_{s b}$ remain unchanged. For the ash mix, the $\mathrm{G}_{\mathrm{mb}}$ by the GTM is approximately $5 \mathrm{lb} / \mathrm{ft}^{3}$ higher than that by the Marshall. The GTM VMA is significantly lower than the Marshall. It can be concluded that the type of compaction (GTM gyratory/kneading or Marshall) influences the physical properties of nonconventional materials such as bottom ash more than that 


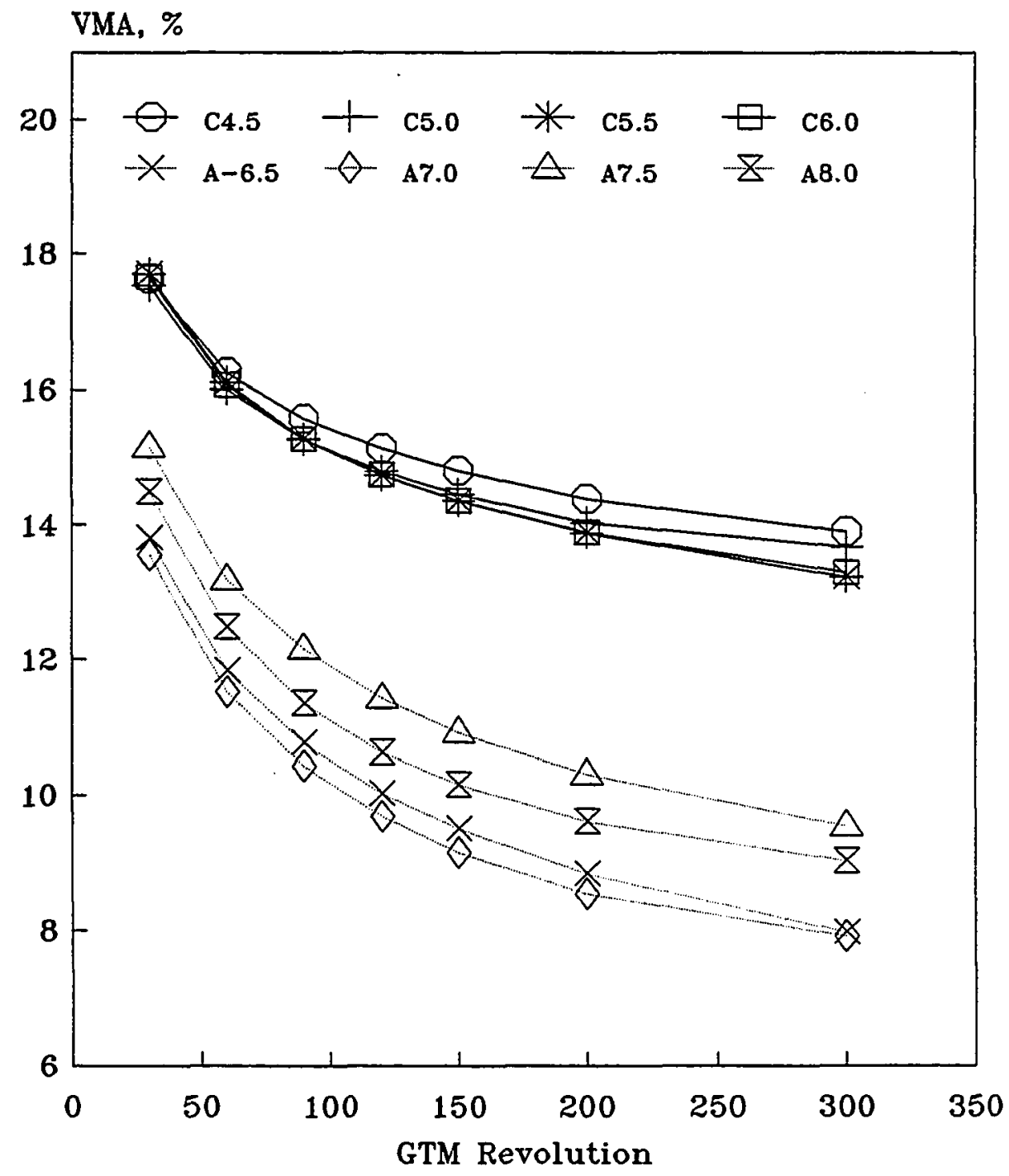

Figure 7.12 VMA versus Revolution 


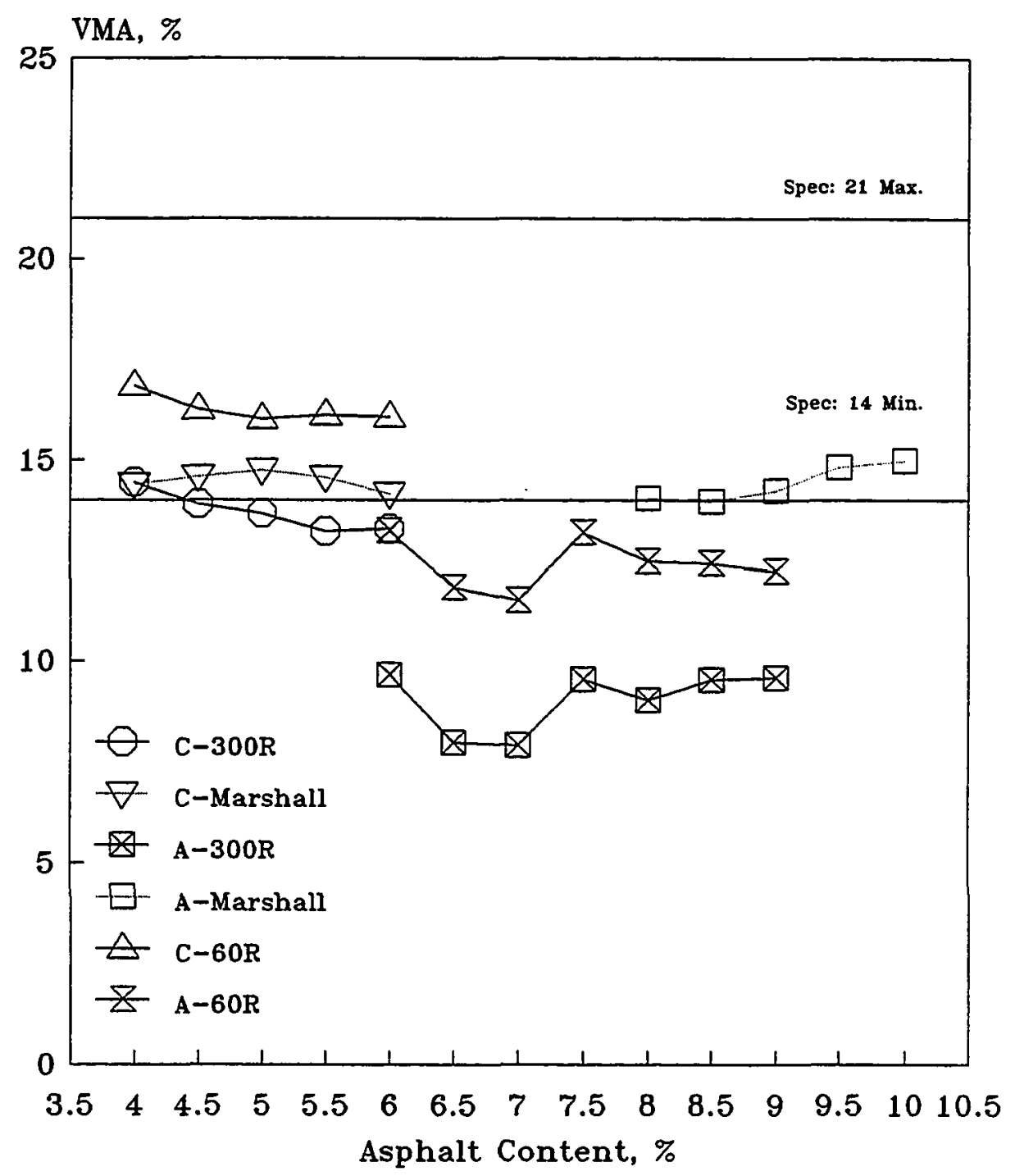

Figure 7.13 VMA versus Asphalt Content 
of conventional materials. In addition, the 3 hours of aging $275^{\circ} \mathrm{F}$ of the GTM samples before compaction may result in the increase in asphalt absorption, which, in turn, increases $G_{m b}$ of the ash mix.

It was also found from Figure 7.13 that the Marshall VMA of the control mix is between that at 300 and 60 revolutions, indicating the assumption that Marshall compaction simulates 2-3 years of traffic densification is adequate. However, the Marshall VMA of the ash mix is higher than that at either 60 or 300 revolutions, indicating the properties of the ash mix is significantly affected by compaction method.

VFA is inversely related to the air voids. As the percentage of the air voids approaches zero, VFA approaches 100 . The asphalt mix is initially constructed to some percentage of VFA (usually $50-70$ percent). This percentage increases as the asphalt mix continues to densify under traffic. When VFA exceeds approximately 80 to $85 \%$, the asphalt mix typically becomes unstable and rutting is likely to occur (34). When the air voids and VMA are used as the requirements for dense-graded mix, VFA is a redundant requirement.

The VFA as a function of revolutions is shown in Figure 7.14. All curves are asymptotic. The VFA increases directly with revolutions as would be expected because air voids decrease with increased revolutions. Varying asphalt content tends to shift the entire curve but does not change its general shape. The average VFA of the ash mix, are lower than that of the control mix. Figure 7.15 presents VFA versus asphalt content. Marshall data are also included for comparison. As would be expected, VFA increases with increased asphalt. The GTM VFA is higher than the Marshall VFA at any asphalt 


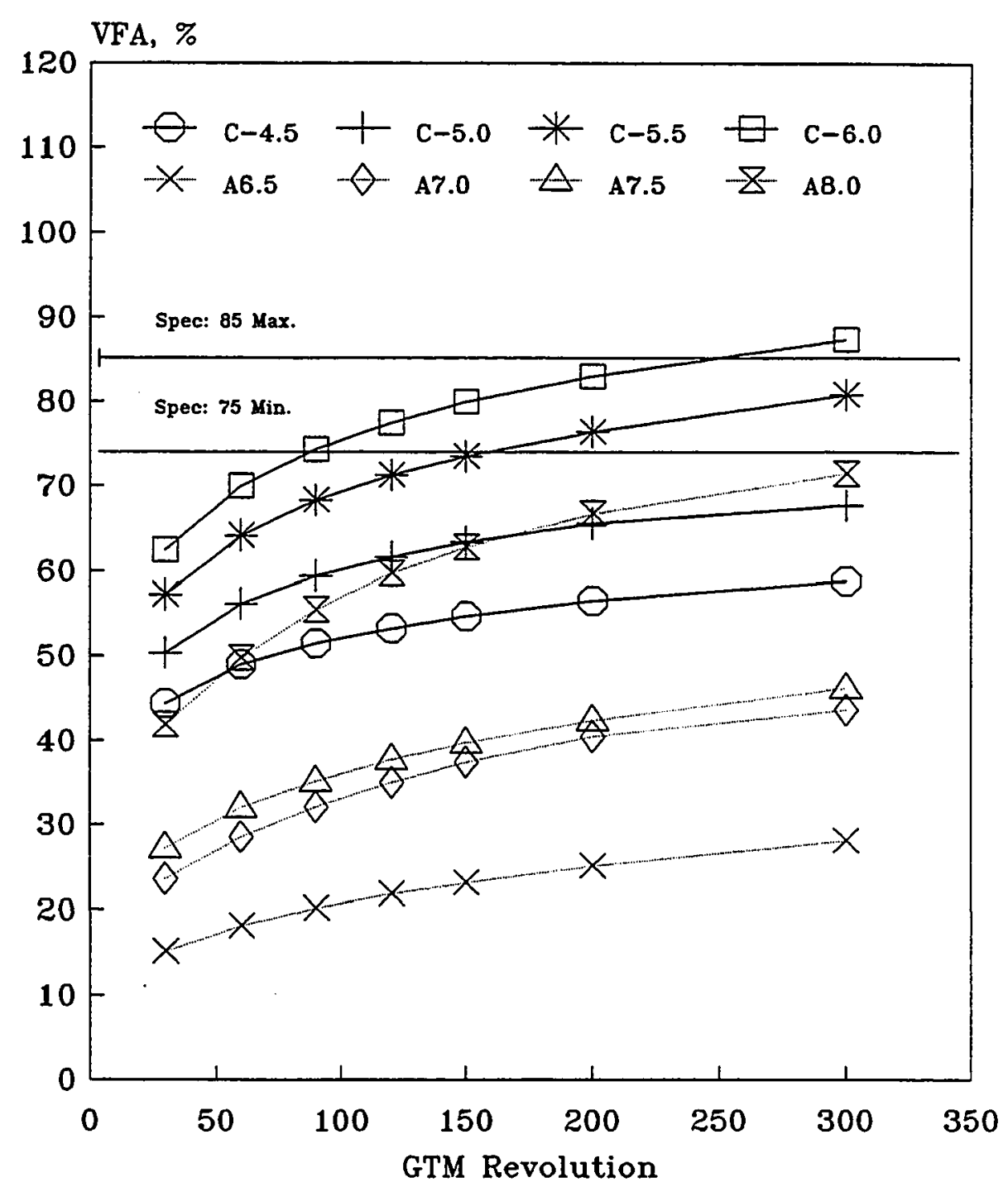

Figure 7.14 VFA versus Revolution 


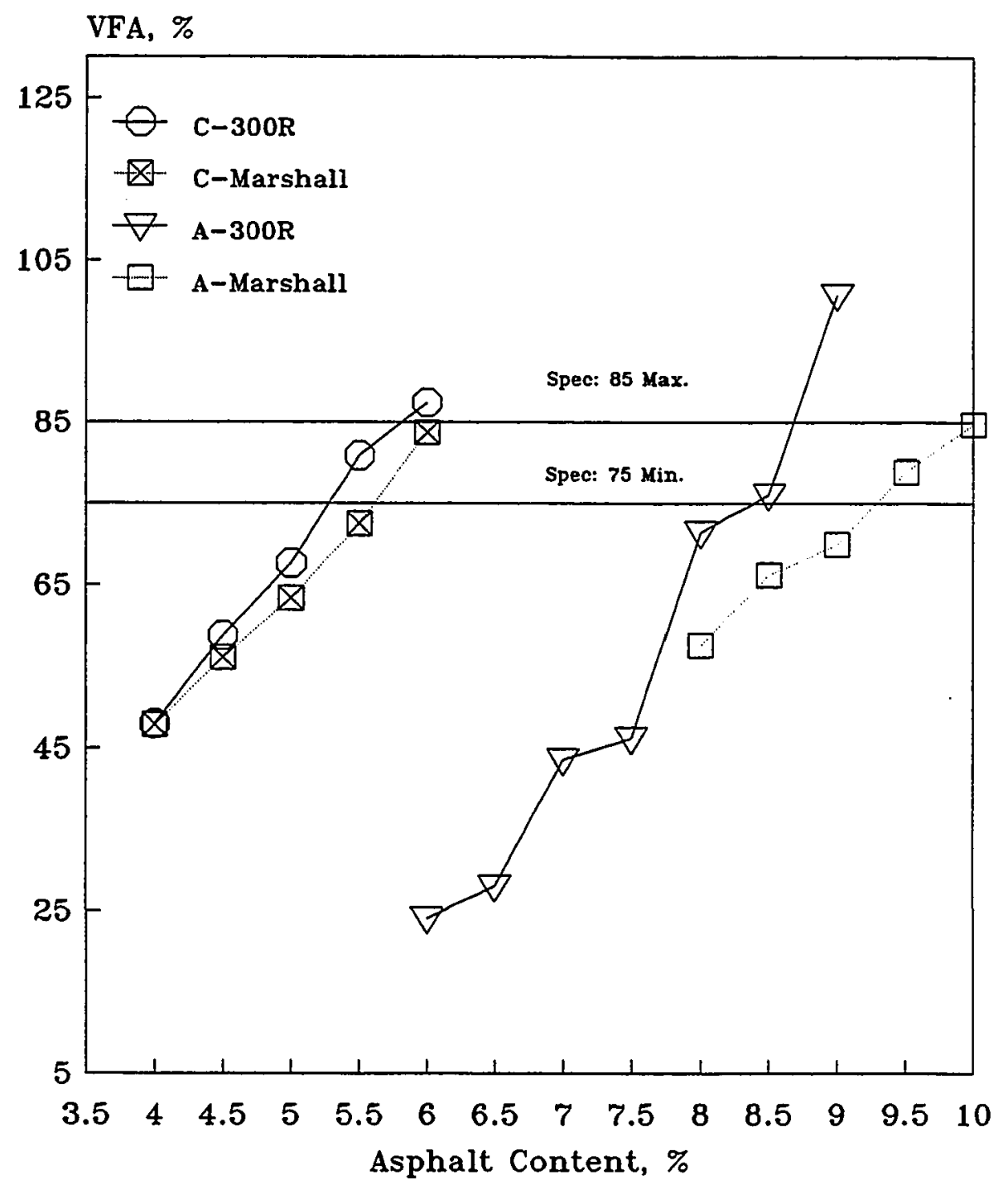

Figure 7.15 VFA versus Asphalt Content 
content. The asphalt content meeting 75 to $85 \%$ VFA requirement for the control mix ranges from 5.3 to $5.8 \%$ by the GTM method and 5.65 to $6 \%$ by the Marshall methods, and that of the ash mix ranges from 8.4 to $8.7 \%$ by the GTM method and 9.3 to $10 \%$ by the Marshall method.

\subsubsection{Absorbed and Effective Asphalt}

\subsubsection{Percent Asphalt on Volume Basis}

The behavior of asphaltic concrete is dependent on air voids, VMA and VFA, all of which are volume quantities. A paving mixture must first be analyzed on a volume basis, even though a weight basis is needed and used for practical reasons, such as plant and field control. The asphalt content by total bulk volume of mix, $V_{b}$, is calculated using the following equation:

$$
\mathrm{V}_{\mathrm{b}}=\mathrm{P}_{\mathrm{a}}\left(\mathrm{G}_{\mathrm{mb}} / \mathrm{G}_{\mathrm{a}}\right)
$$

where,

$$
\begin{aligned}
& P_{a}=\% \text { asphalt by total weight of mixture; } \\
& G_{a}=\text { specific gravity of the asphalt cement; and } \\
& G_{m b}=\text { bulk specific gravity of the compacted mixture. }
\end{aligned}
$$

The relation between $\%$ asphalt by total volume of mix and \% asphalt by total weight of mix is shown in Figure 7.16. The linear relations exist for the control and ash mixes. There is little difference between the GTM and Marshall curves for the control mix. There is a difference for the ash mix. There is also a difference between the control and 


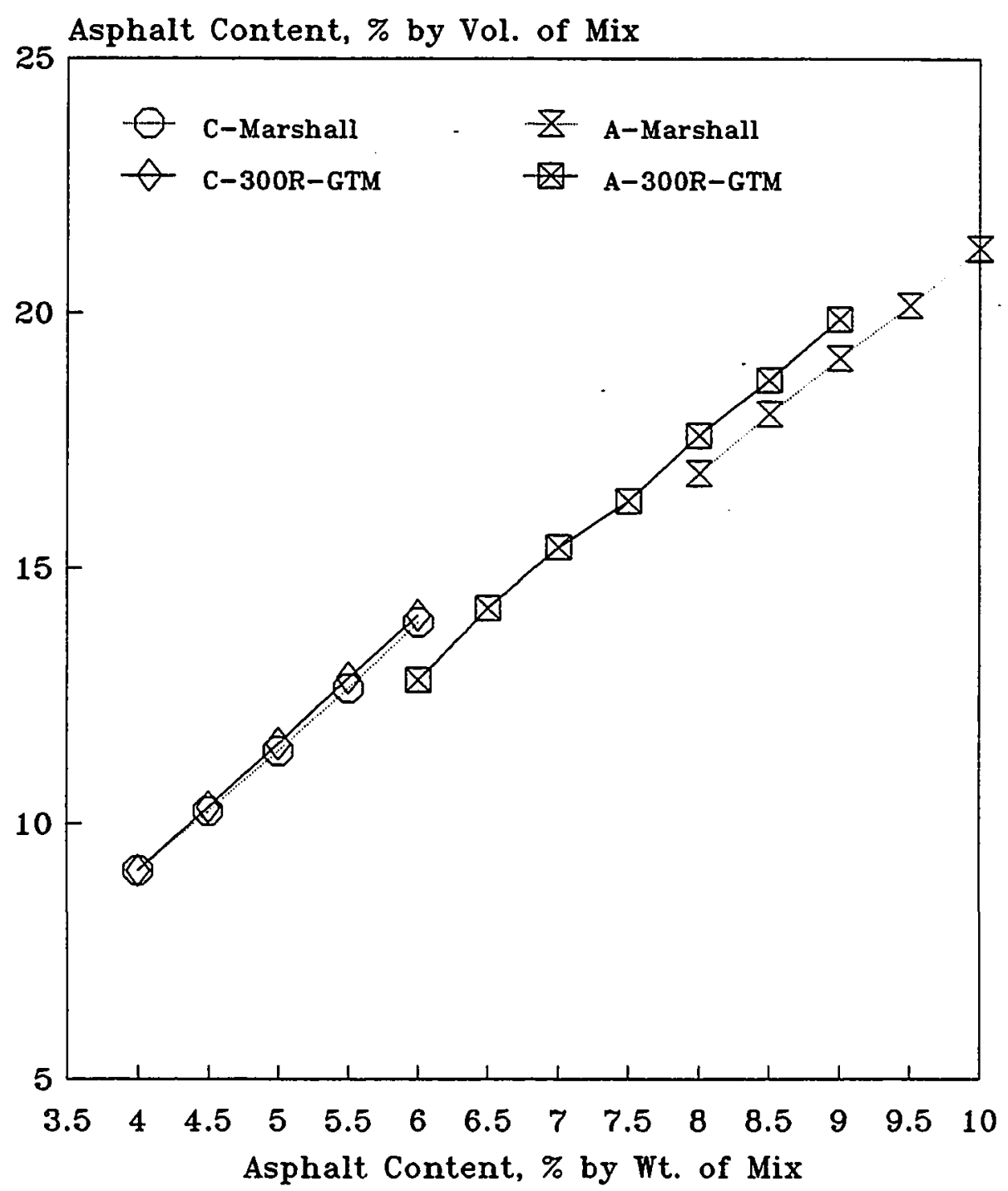

Figure $7.16 \%$ Asphalt by Vol. of Mix versus $\%$ Asphalt by Wt. of Mix

245 
the ash mix. All above observations can be explained by looking at the equation in which $V_{b}$ is dependent on $G_{m b}$. The higher $G_{m b}$ is, the higher $V_{b}$ when $P_{a}$ and $G_{a}$ are fixed.

\subsubsection{Absorbed Asphalt}

Asphalt absorption is a time and temperature - dependent variable (77). The laboratory investigation of absorption must consider plant and field conditions. In this study, a heating condition of 3 hours at $275^{\circ} \mathrm{F}$ was selected to simulate heating and time to compaction. The formula for asphalt absorption by weight of aggregate was presented in Chapter VI. The percentage of total volume of absorbed asphalt, $\mathrm{V}_{\mathrm{ba}}$, can be calculated with the following equation:

$$
V_{b a}=P_{b a} P_{s}\left(G_{m b} / G_{a}\right)
$$

Figure 7.17 presents the absorbed asphalt by weight of total mix versus asphalt content. The absorbed asphalt by weight of total mix was calculated by subtracting, $\mathrm{P}_{\mathrm{be}}$, the effective asphalt content by weight of total mix, from $\mathrm{P}_{\mathrm{a}}$. The asphalt absorption on volume basis is shown in Figure 7.18. Marshall data are also included for comparison. The Marshall samples were not subjected to aging before compaction. All data are based on one measurement. The control GTM sample absorptions range from 0.94 to $1.06 \%$ by weight ( 2.15 to $2.48 \%$ by volume) and the control Marshall sample absorptions range from 0.90 to $0.97 \%$ by weight ( 2.06 to $2.19 \%$ by volume). The ash GTM sample absorptions range 4.64 to $5.48 \%$ by weight (10.24 to $12.06 \%$ by volume) and the ash Marshall sample absorptions range 3.99 to $4.33 \%$ by weight ( 8.45 to $8.76 \%$ by volume). The ash mix absorbs asphalt cement approximately five times as much as the control mix. 


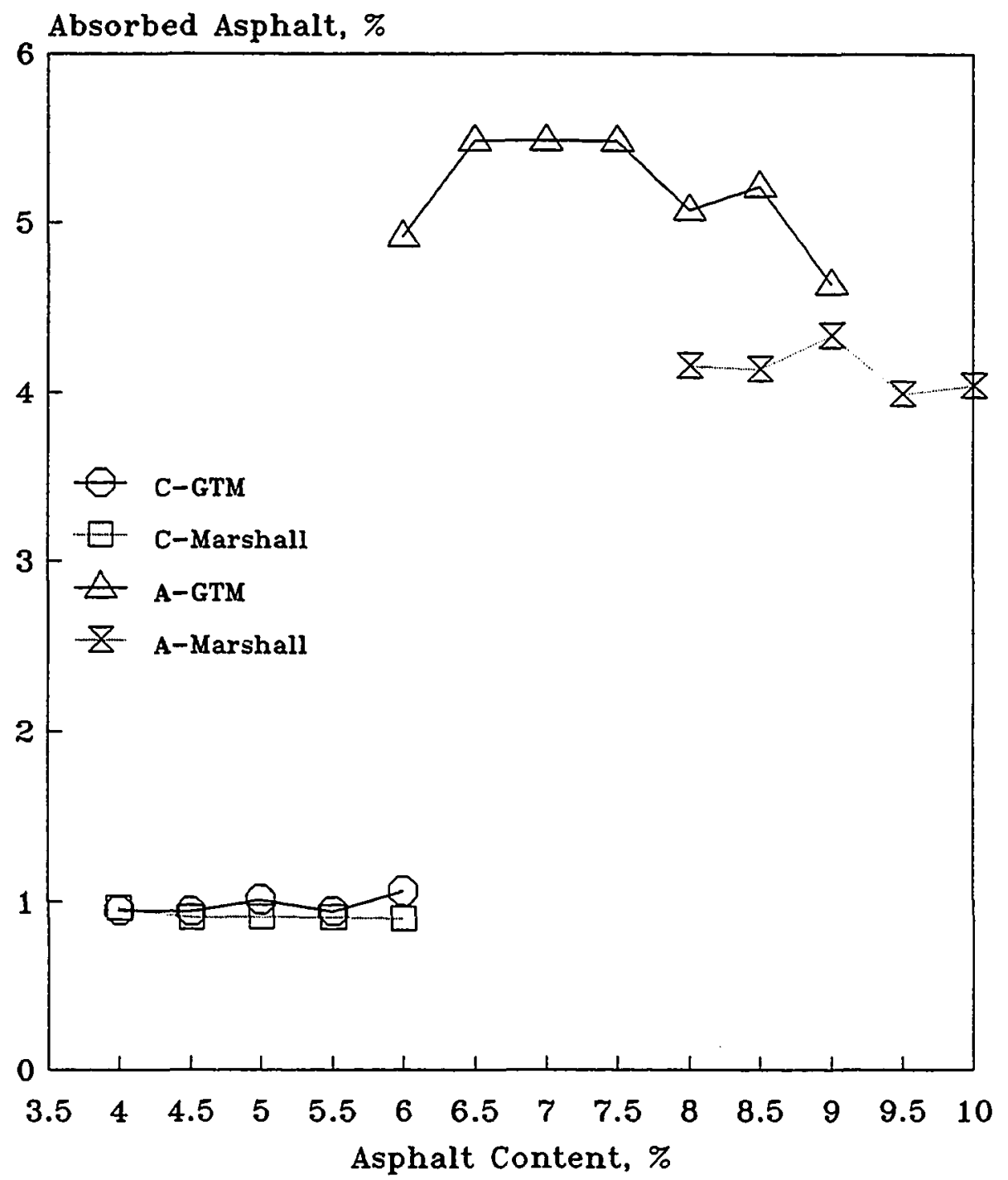

Figure 7.17 Absorbed Asphalt versus Asphalt Content 


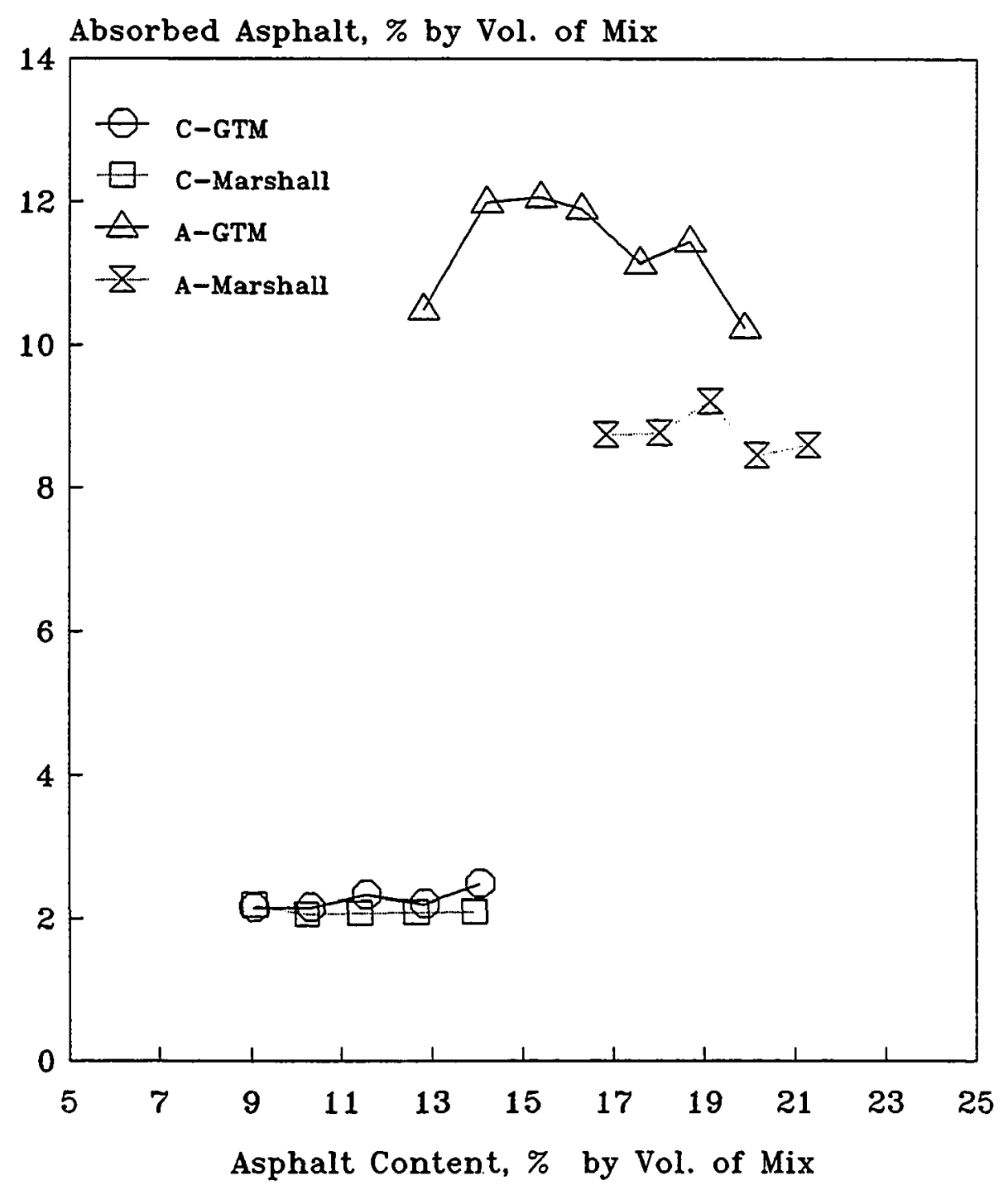

Figure 7.18 Absorbed Asphalt by Volume of Mix 
The permeable pores of the bottom ash make it absorptive. Aging increases the ash mix asphalt absorption more than the control mix asphalt absorption. The variation of the ash mix asphalt absorption is observed.

\subsubsection{Effective Asphalt}

The formula for the effective asphalt content on weight basis was presented in

Chapter VI. The effective asphalt content by total volume, $\mathrm{V}_{\mathrm{be}}$, is calculated by using the following formula:

$$
V_{b e}=G_{m b}\left(100 / G_{m m}-P_{s} / G_{s b}\right)
$$

Since asphalt absorption is a time and temperature dependent variable, the effective asphalt content is time and temperature dependent.

Figure 7.19 presents the effective asphalt by weight of total mix versus asphalt content. The asphalt absorption on a volume basis is shown in Figure 7.20. Marshall data are also included for comparison. The Marshall samples were not subjected to aging before compaction. All data are based on one measurement. The effective asphalt increases with increased asphalt content for the ash and control mixes. As a result of high asphalt absorption, the ash mix demands more asphalt cement to obtain the same degree of coating (effective asphalt) than the control mix. If there is not enough asphalt for complete coating of the aggregates, a durability problem could occur. Compared the GTM samples which were subject to aging to the Marshall samples which were not subject to aging, the aging decreased the effective asphalt of the ash mix more than that of the control mix. 


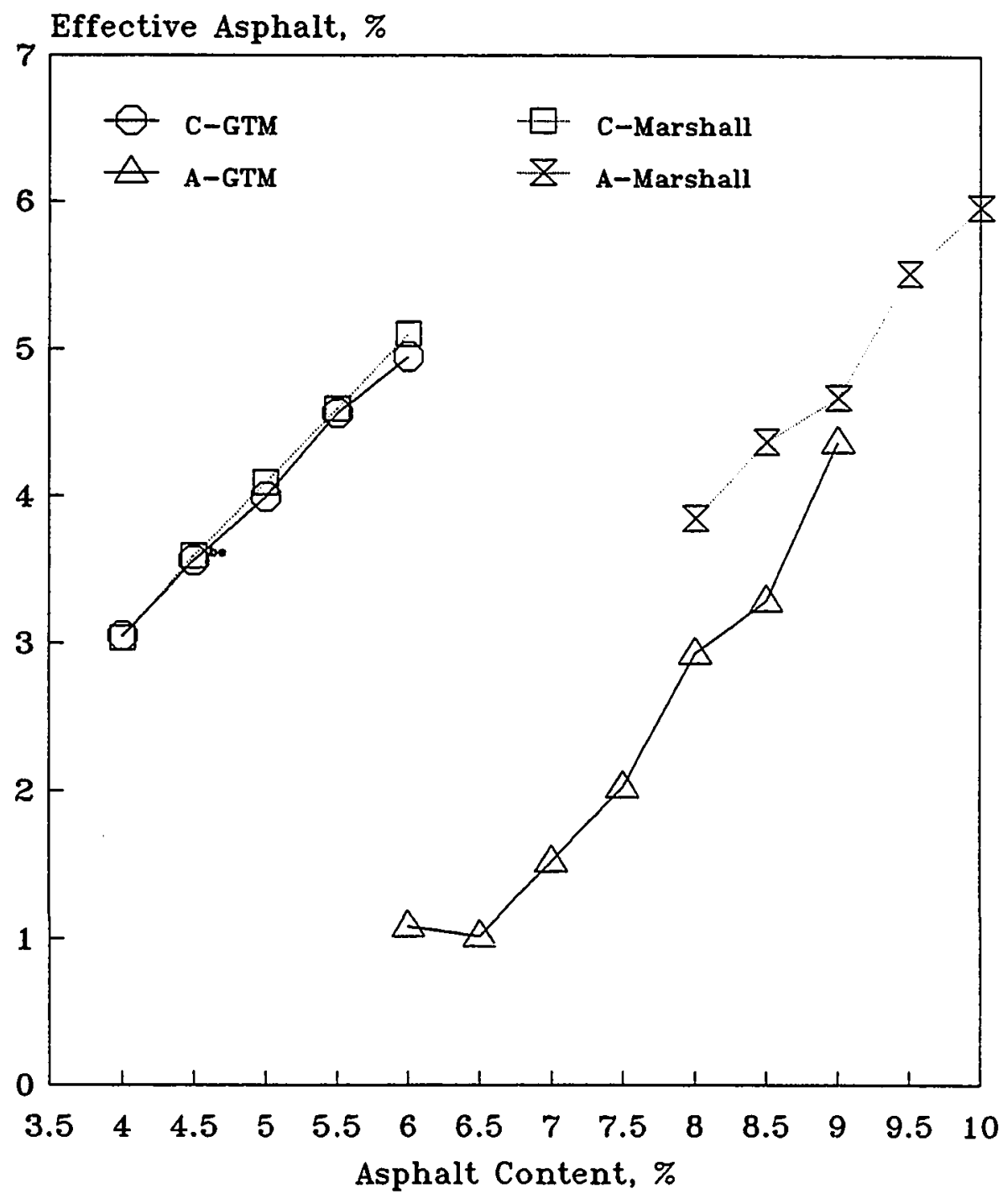

Figure 7.19 Effective Asphalt versus Asphalt Content 


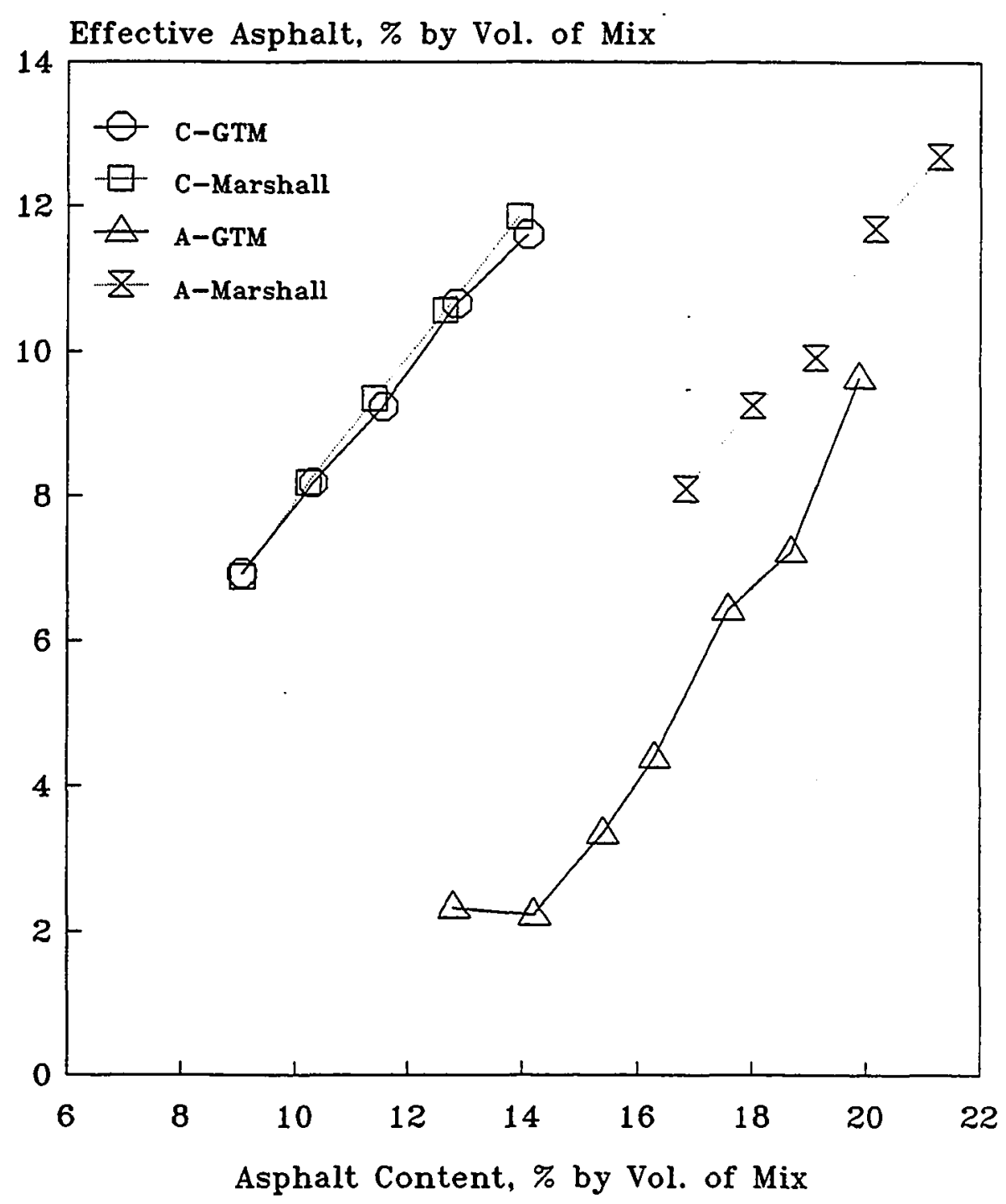

Figure 7.20 Effective Asphalt by Volume of Mix 
It is worth mentioning that the formulas for absorbed and effective asphalt work well for conventional materials. The data of the ash mix obtained by the formulas are questionable. For example, the absorbed and effective asphalt of the ash mix at 7\% AC are 5.48 and $1.52 \%$, respectively. However, visually, all particles of this mix were completely coated. It is unrealistic that all particles can be well coated with oniy $1.52 \%$ asphalt. It is felt that the Rice method of determining $G_{m m}$ is not suitable for the ash mix.

\subsubsection{Water Absorption of Bituminous Specimens}

Figure 7.21 presents the water absorption as a function of asphalt content. Marshall data are also included for comparison. Absorption decreases with increased asphalt content, indicating all samples become less permeable with increasing asphalt content. The absorption by the GTM samples at 300 revolutions is less than at 60 revolution at any asphalt content, showing that increased compaction effort has made the GTM samples less permeable. The GTM samples at 300 revolutions are less permeable than the Marshall samples at lower asphalt contents. The higher compactive effort applied by the

GTM makes the samples denser than by the Marshall procedure. At higher asphalt contents, the voids are almost completely filled with asphalt such that water absorption is reduced no matter what type of compaction or materials were used. The absorption of the ash mix is comparable to that of the control mix because the high asphalt absorption by the ash mix makes them less permeable.

\subsubsection{Gyratory Shear $\left(S_{g}\right)$}




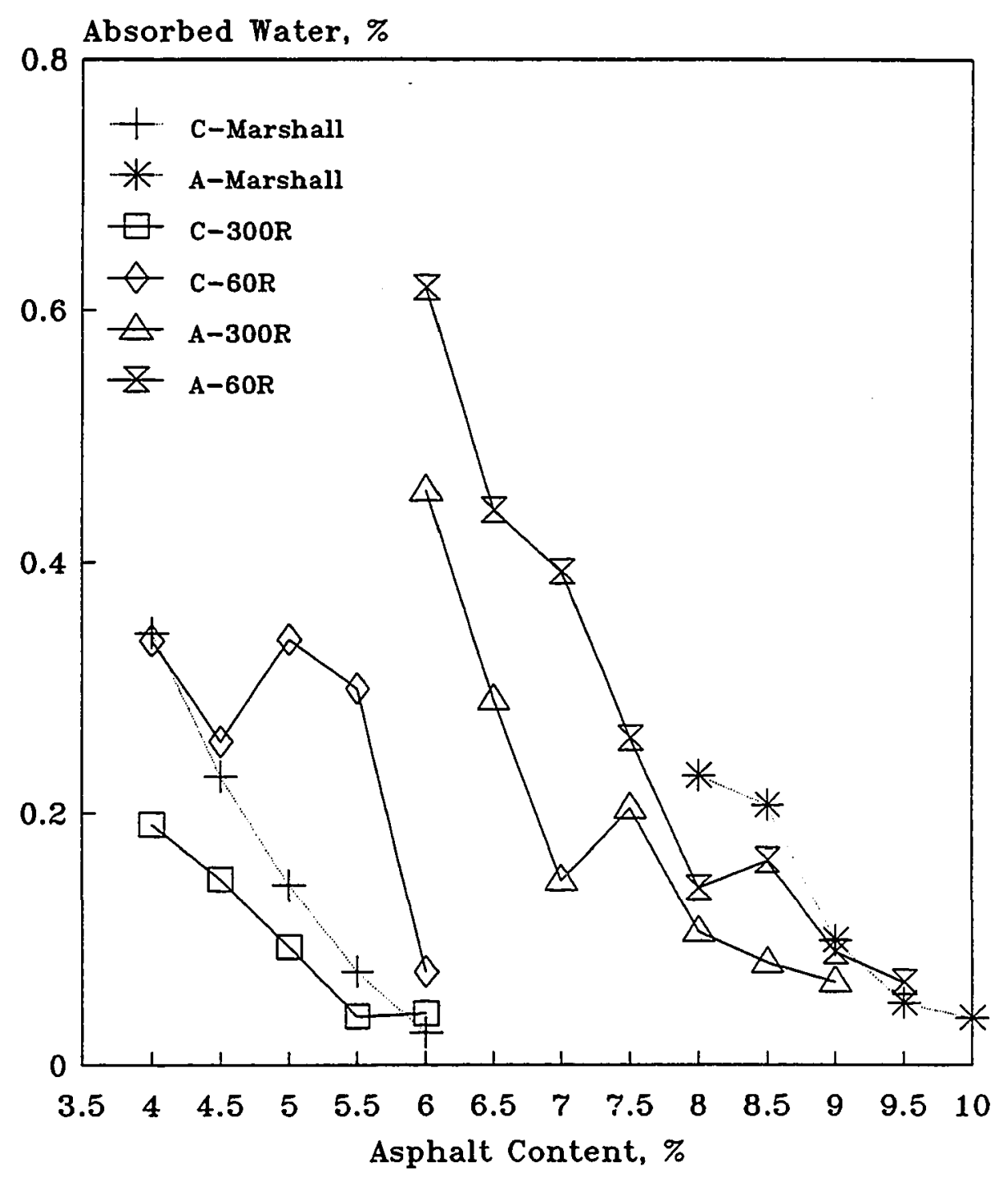

Figure 7.21 Water Absorption of Asphalt Mixes 
Gyratory shear, $S_{g}$, is the shear resistance of the specimen which is, among other things, a function of the imposed vertical pressure and degree of strain. Gyratory shear can be used to evaluate the stability of a mix.

\subsubsection{Development of Formula for Gyratory Shear}

Referring to the schematic in Figure 7.22 (ASTM D3387) and taking moments about 0 , the equation for gyratory shear, $S_{g}$, is developed as follows:

$$
\begin{gathered}
2 P L=S_{g} A h+2 F a-N b \\
S_{g}=[2(P L-F a)+N b] / A h
\end{gathered}
$$

The above equation is for the $\theta_{0}$ position; If the shear at the $\theta_{i}$ position is desired, it is approximated by assuming a linear stress-strain relationship and multiplying the previously calculated value by the ratio $\theta_{\mathrm{i}} / \theta_{0}$ so that the equation is then expressed as follows:

$$
S_{g}=[2(P L-F a)+N \text { b }]\left(\theta_{i} / \theta_{o}\right) / A ~ h
$$

where:

$$
\begin{aligned}
& \mathbf{P}=\text { load on upper roller; } \\
& \mathbf{L}=\text { distance from center of path of upper roller to vertical axis through center of } \\
& \text { sample; } \\
& \mathbf{N}=\text { normal vertical load on specimen and is equal to the total load on ram; } \\
& \mathbf{A}=\text { end area of specimen; } \\
& \mathrm{h}=\text { height of specimen; } \\
& \boldsymbol{\theta}_{0}=\text { initial gyratory shear angle; }
\end{aligned}
$$




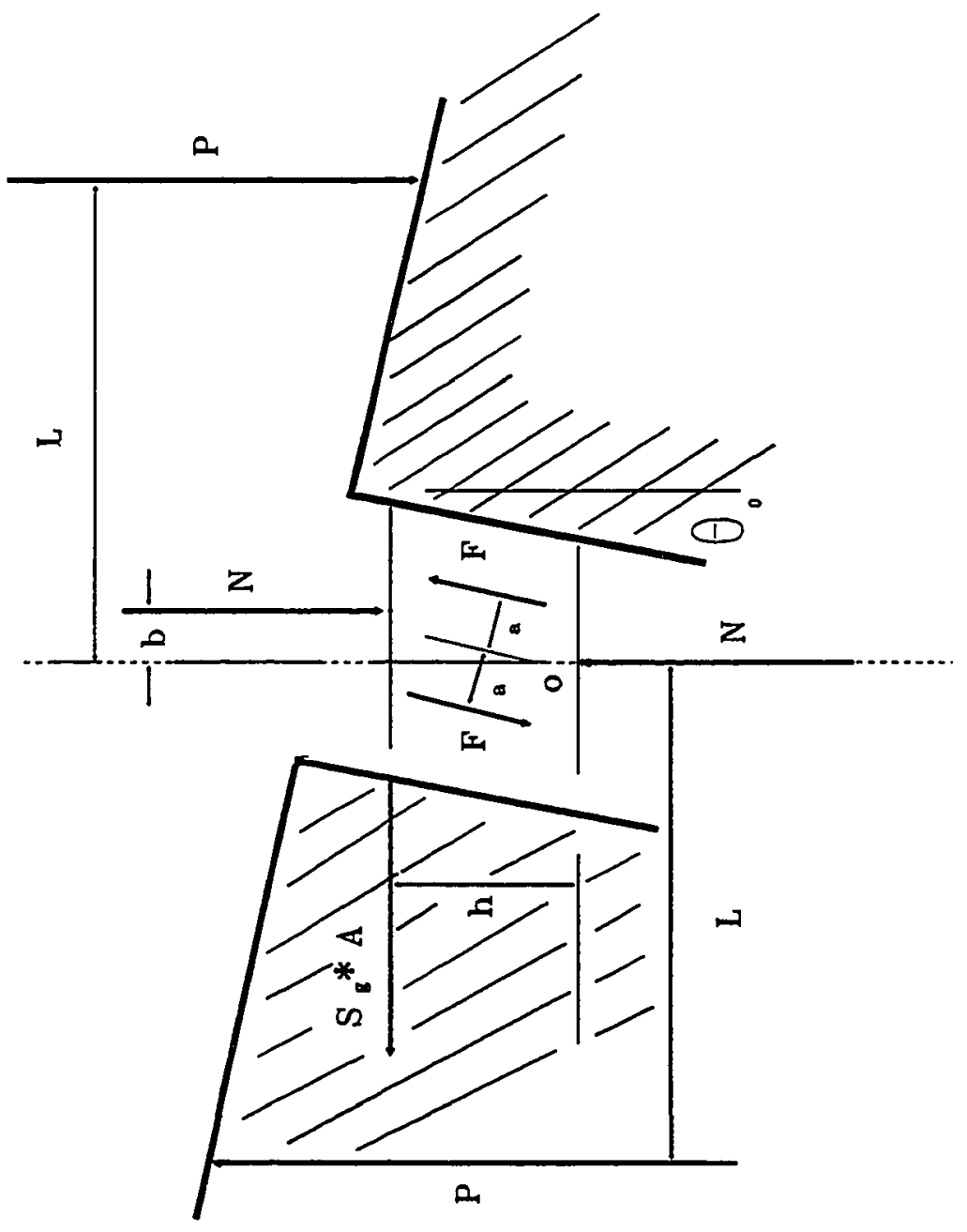

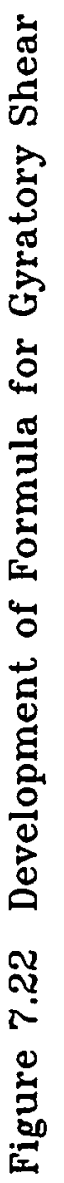


$\theta_{i}=$ intermediate gyratory shear angle;

$a=0.637 \times$ radius of mold (distance to the center of gravity for a circular arc equal

to one half of the periphery);

$b=$ arm of vertical force couple $=h \tan \theta_{o} ;$ and

$\mathbf{F}=$ force caused by wall friction.

Maine DOT calibrated their GTM machine and the formula for $S_{g}$ calculation is simplified as $(71,72)$ :

$$
S_{g}=4.00 \times \text { Oil Roller Pressure / height of specimen in inch }
$$

A reduction in oil-filled roller pressure or $S_{g}$ during the compaction process indicates loss of stability.

\subsubsection{Results and Discussion}

Currently, there is not an official specification for gyratory shear value. In general, stability is assured by specifying the gyratory shear $\left(\mathrm{S}_{\mathrm{g}}\right)$ value between 30 and 40 psi after traffic densification $(71,72)$. Maine DOT $(71)$ recommends that the minimum gyratory shear value of 35 psi after 300 revolutions be adopted as the minimum design value for most traffic conditions. If very heavy traffic conditions are expected such as at bus-stops, or city street intersections with traffic lights, then a minimum $S_{g}$ value of 30 psi after 500 revolutions should be used.

The $S_{g}$ as a function of revolutions is shown in Figure 7.23. The minimum $S_{g}$ value of 35 psi after 300 GTM revolutions recommended by Maine DOT was used to evaluate the test results. As would be expected, $S_{g}$ decreases with increased revolutions for the ash 


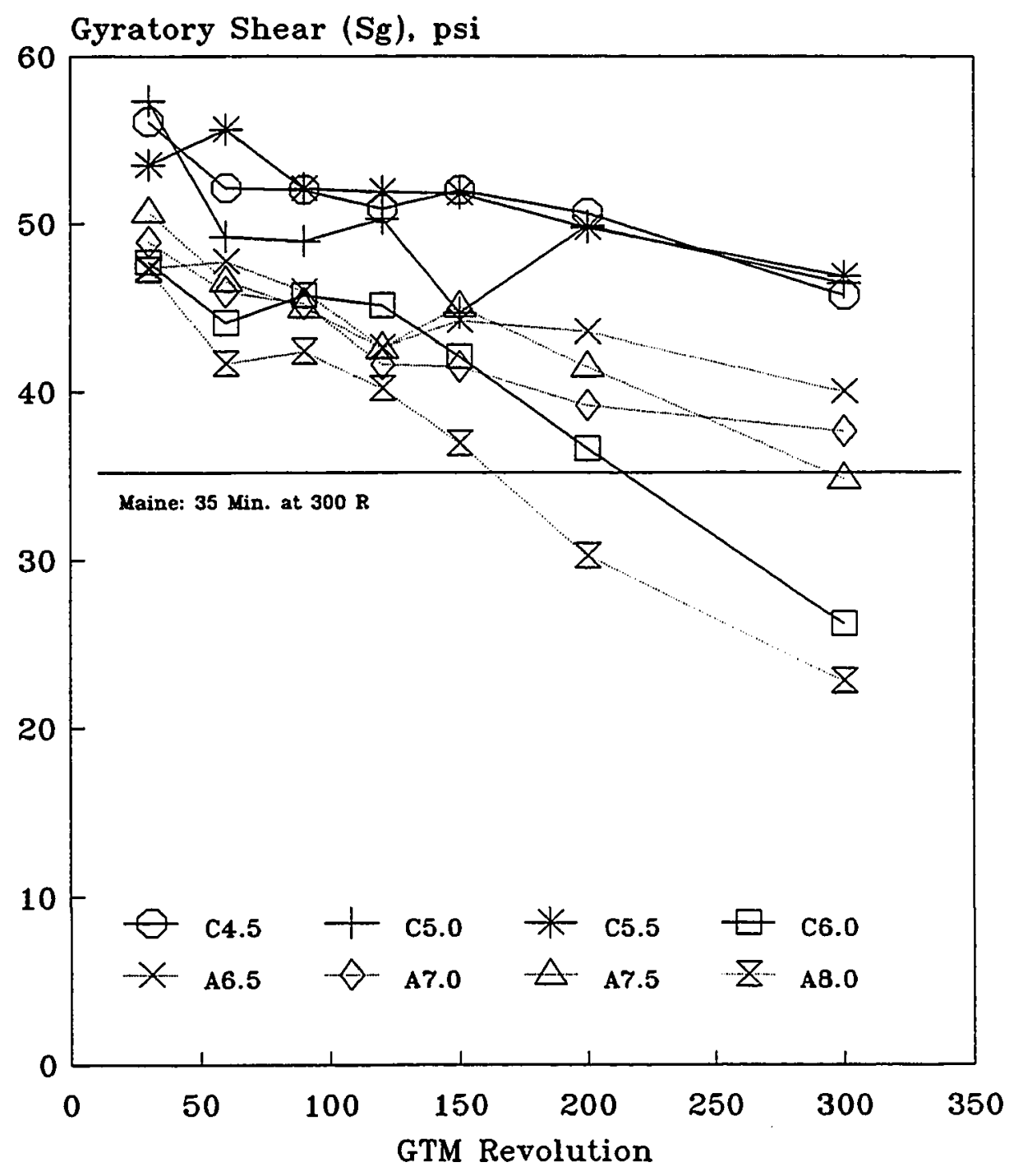

Figure 7.23 Gyratory Shear versus Revolution 
and control mixes. Figure 7.24 presents gyratory shear at 300 revolutions as a function of asphalt content. The ash mix with $\leq 7.5 \%$ asphalt contents and the control mix with $\leq 5.75 \%$ asphalt contents meet Maine DOT gyratory shear requirement of a minimum value of $35 \mathrm{psi}$. The $\mathrm{S}_{\mathrm{g}}$ for the ash mix decreases more significantly at low asphalt contents than at high asphalt contents. The $S_{g}$ for the control mix remains stable until asphalt content reaches $5.5 \%$.

\subsubsection{Gyratory Shear Factor (GSF)}

GSF is the ratio of the measured gyratory shear stress to the approximate theoretical maximum induced shear stress. This is a factor of safety type index with regard to failure in simple shear for the defined loading conditions. GSF must be interpreted with recognition of the assumption of plane maximum shear (the unit contact pressure divided by $\pi$ ) for a strip load on a homogeneous elastically isotropic mass.

The approximate theoretical maximum induced shear stress $(71,72)$ :

$$
\tau_{\max }=\text { Vertical Pressure } / \pi=120 / 3.14=38.2 \mathrm{psi}
$$

The gyratory shear factor $(71,72)$ :

$$
\mathrm{GSF}=\mathrm{S}_{\mathrm{g}} / \tau_{\max }
$$

Figures 7.25 and 7.26 present GSF as a function of revolutions for the ash and control mixes, respectively. GSF goes down with increased revolutions. The decrease in GSF with increasing revolutions becomes significant when the asphalt content is $\geq 8 \%$ for the ash mix and $6 \%$ for the control mix.

Figure 7.27 presents GSF as a function of asphalt content. As asphalt content 


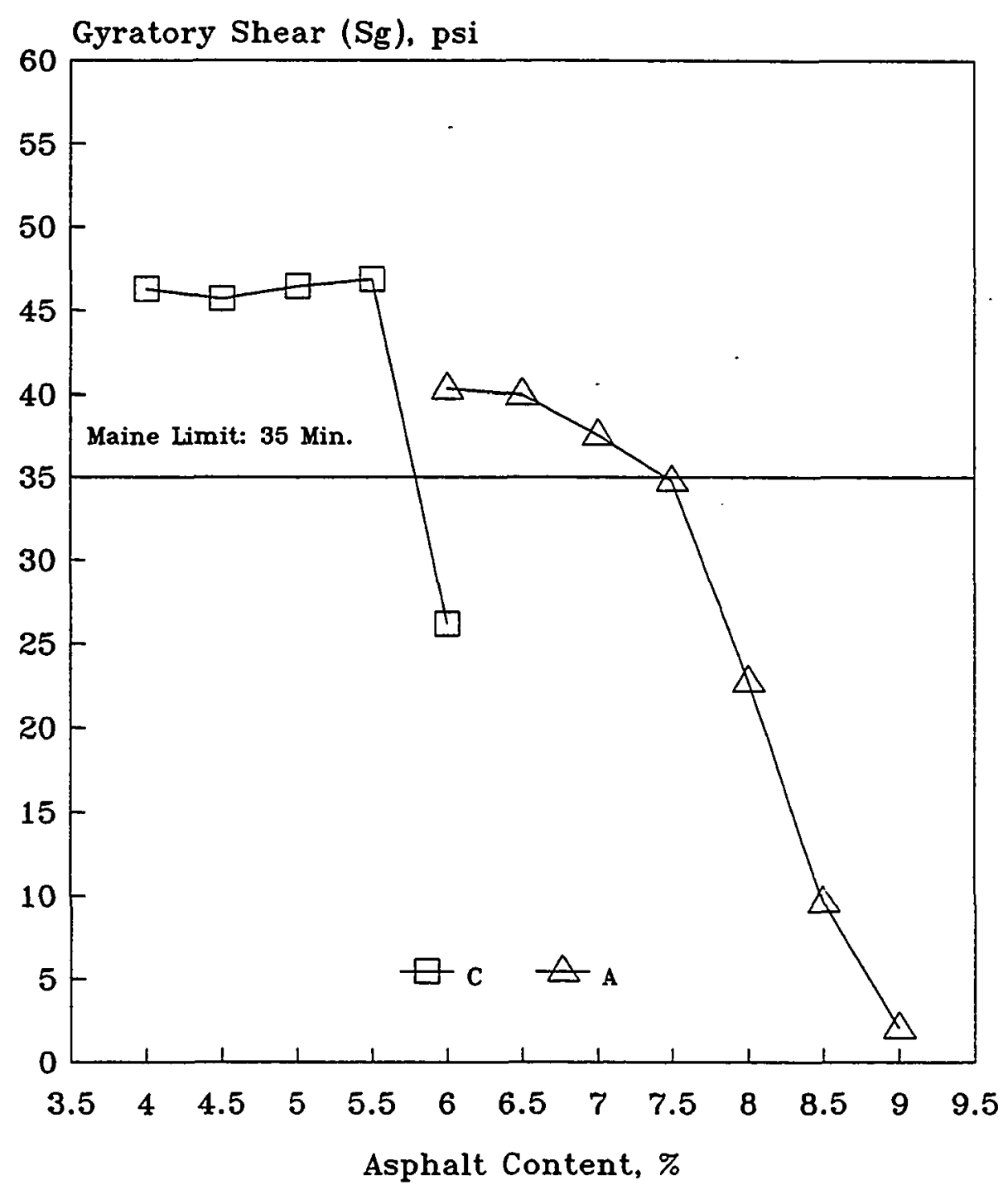

Figure 7.24 Gyratory Shear versus Asphalt Content 


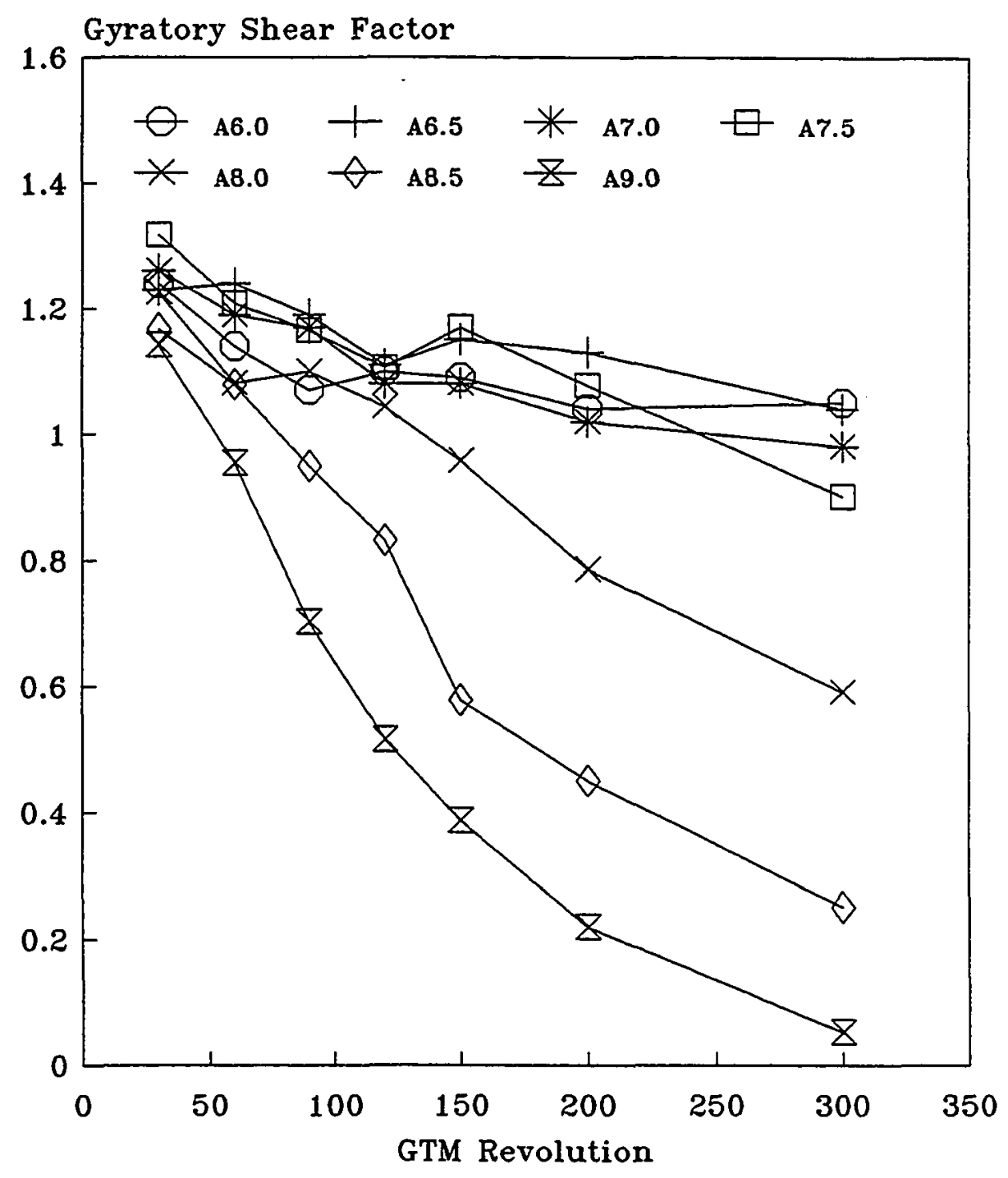

Figure 7.25 GSF versus Revolution (50\% Ash Mix) 


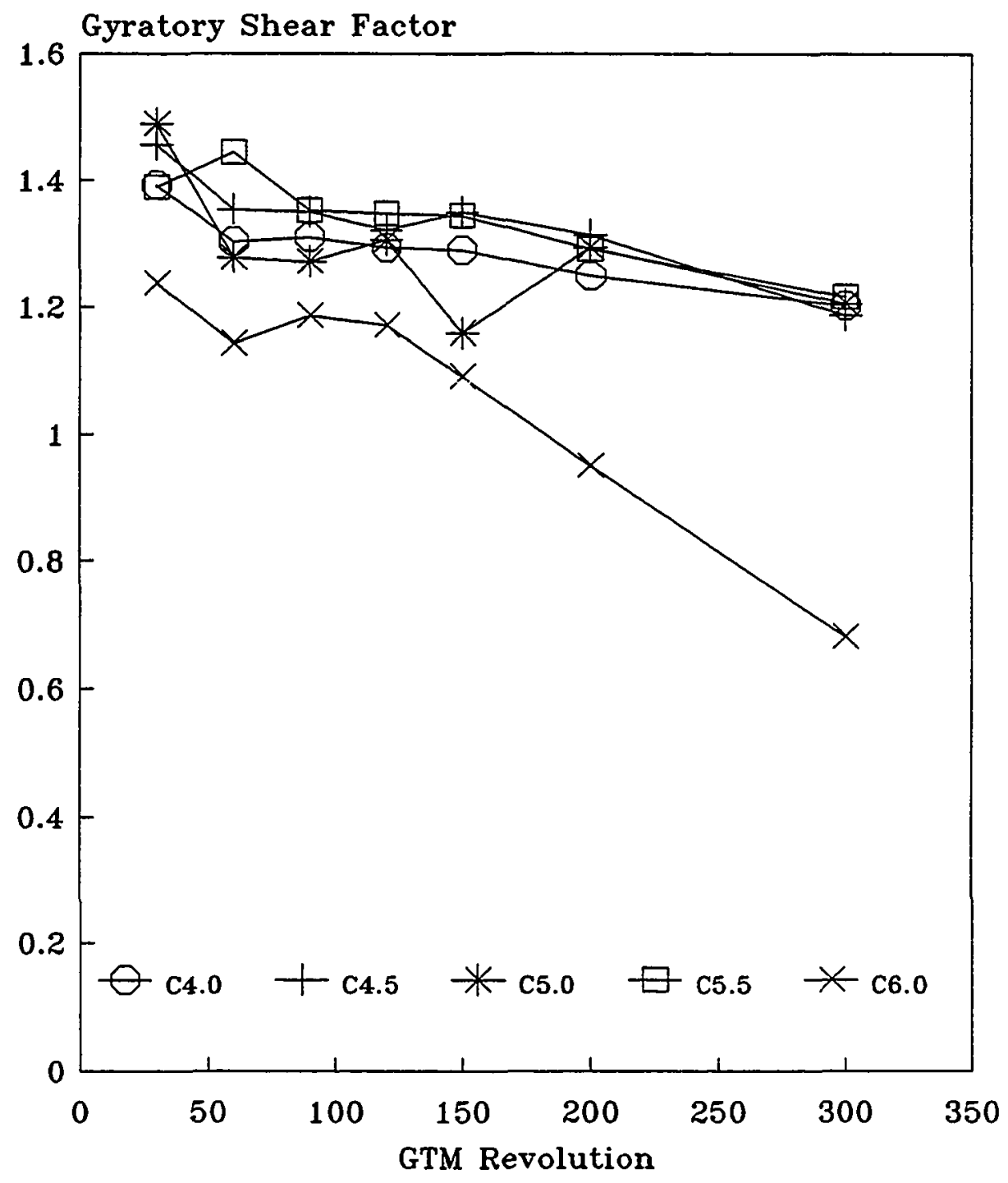

Figure 7.26 GSF versus Revolution (Control Mix) 


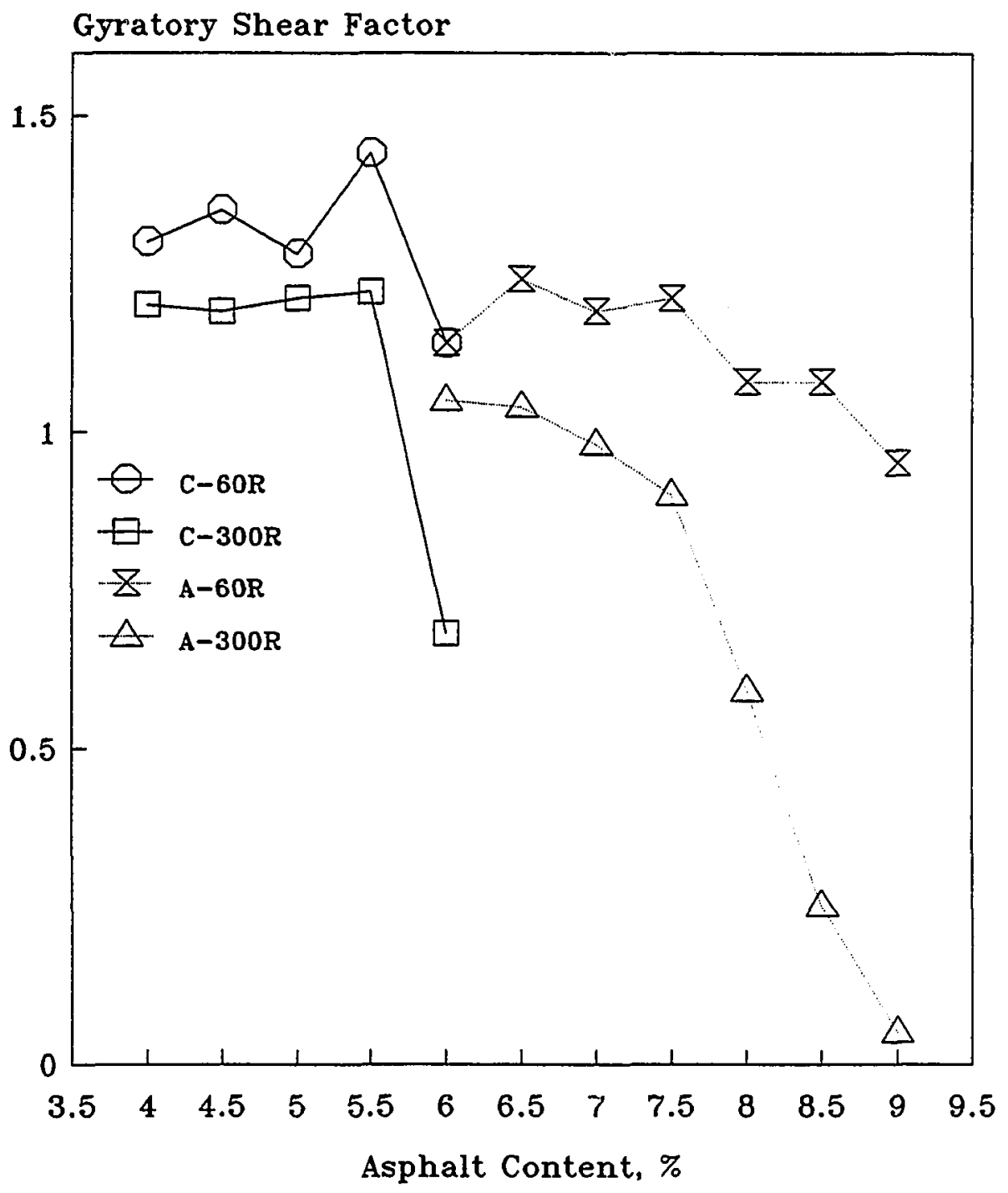

Figure 7.27 GSF versus Asphalt Content 
increases, GSF decreases. The control and ash mixes at 60 revolutions remain stable at any asphalt contents. At 300 revolutions, the ash mix becomes unstable as asphalt content is $>7.5 \%$ and the control mix becomes unstable as the asphalt content is $>5.5 \%$. Unstable means the mix does not have sufficient shear strength to resist shear failure.

\subsubsection{Gyratory Stability Index (GSI)}

GSI is the ratio of the maximum gyratory angle to the minimum gyratory angle.

$$
\text { GSI }=\theta_{\max } / \theta_{\min }
$$

The gyratory angle is a measure of the magnitude of the gyratory strain. GTM is equipped with a gyrograph recorder. The shear strain (or pavement rutting potential) experienced by the bituminous mixture during the compaction test can be investigated by looking at the gyrograph obtained during compaction. Figure 7.28 shows a typical gyrograph. No widening of the gyrograph indicates ideally stable condition at this asphalt content, also reflected in GSI value of unity. If it widens excessively, instability of the mix at this asphalt content occurs and rutting is anticipated. This is reflected in GSI value greater than unity. Ilinois studies (72) showed that the gyratory stability index (GSI) should not exceed 1.25 after 300 revolutions. If the GSI value exceeds 1.30 then rutting is practically a certainty. Canadian literature indicates a much more stringent specification to prevent rutting (72). This literature indicates that the GSI value should not exceed 1.06 after 500 revolutions using a ram pressure and compaction angle similar to those used by

Maine DOT. The research conducted by Maine DOT showed that GSI should be less than 1.15 after 300 revolutions to prevent pavement rutting. The criteria of GSI recommended 

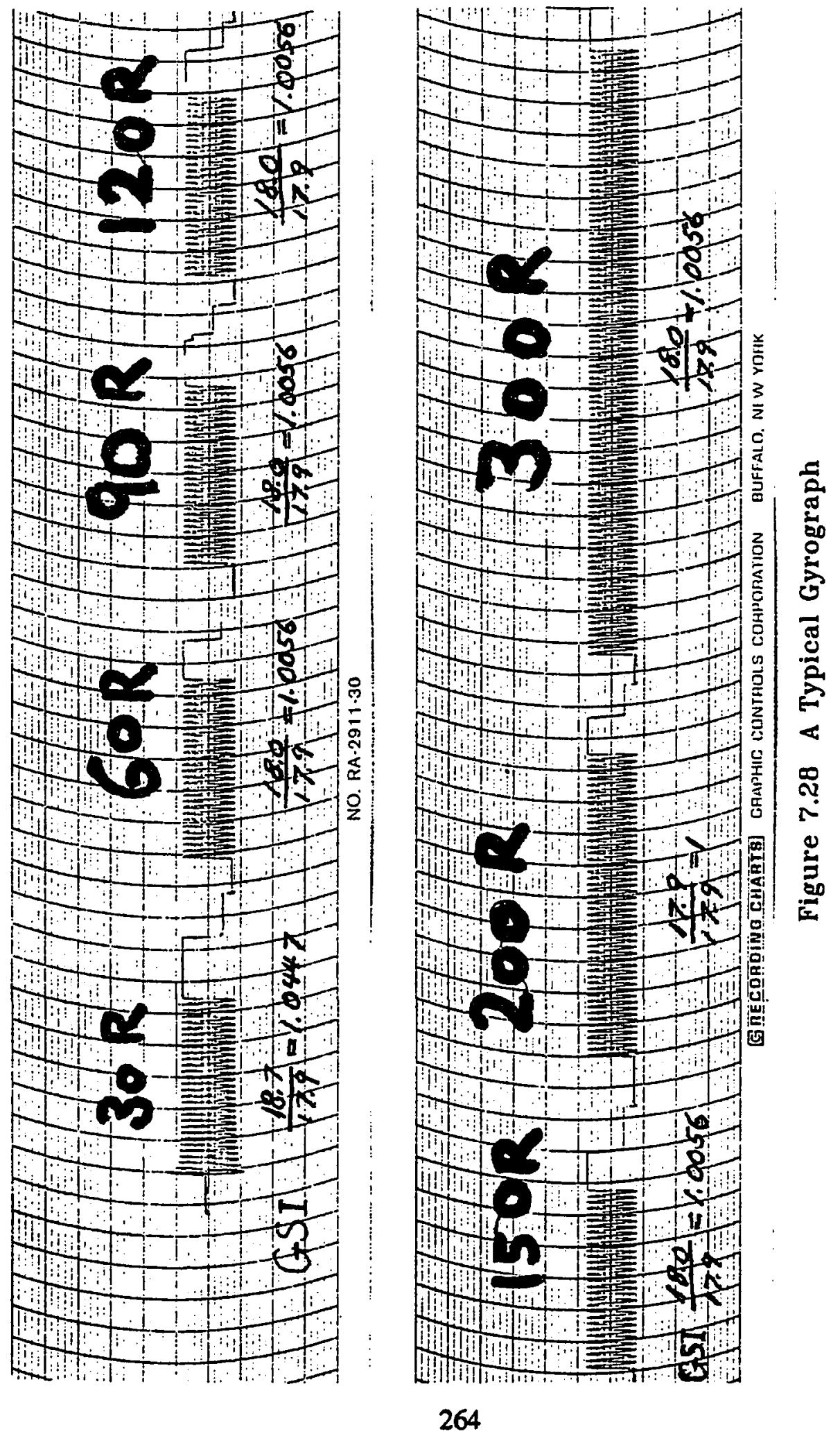
by Illinois and Maine are used in this study for evaluating test results.

GSI versus revolution is plotted as shown in Figures 7.29 and 7.30 for the ash and control mixes, respectively. It is obvious that at low asphalt contents ( $\leq 7.5 \%$ for the ash $\operatorname{mix}$ and $\leq 5.5 \%$ for the control mix), GSI does not vary significantly with increased revolutions, showing that the mixes remain stable. At high asphalt contents, GSI increases dramatically with revolutions, the mixes being unstable.

Figure 7.31 illustrates GSI as a function of asphalt content. At 60 revolutions, all mixes remain stable with GSI ranging from 1.005 to 1.07 for the ash mix and 1.011 to 1.024 for the control mix. At 300 revolutions, GSI increases appreciably with increased asphalt content, indicating the mixes become unstable with increased asphalt content. The ash mix with $\leq 7.5 \%$ asphalt can meet the Maine DOT GSI requirement of a maximum of 1.15 . The control mix with $\leq 5.75 \%$ asphalt meets the Maine requirement. The asphalt content required are approximately $1.75 \%$ more for the ash mix than the control mix. The reason for this is that bottom ash is more absorptive than the control.

\subsubsection{Gyratory Shear Modulus (GSM)}

GSM can be simply derived from Hook's Law in shear stress state $(71,72)$ :

$$
\begin{aligned}
& \text { Shear Stress }=\text { Shear Modulus } \times \text { Shear Strain } \\
& \qquad \begin{aligned}
S_{g} & =G_{g} \times \text { Shear Strain } \\
G_{g} & =S_{g} / \text { Shear Strain }
\end{aligned}
\end{aligned}
$$

where,

$$
\mathrm{G}_{\mathrm{g}}=\text { Gyratory Shear Modulus; }
$$




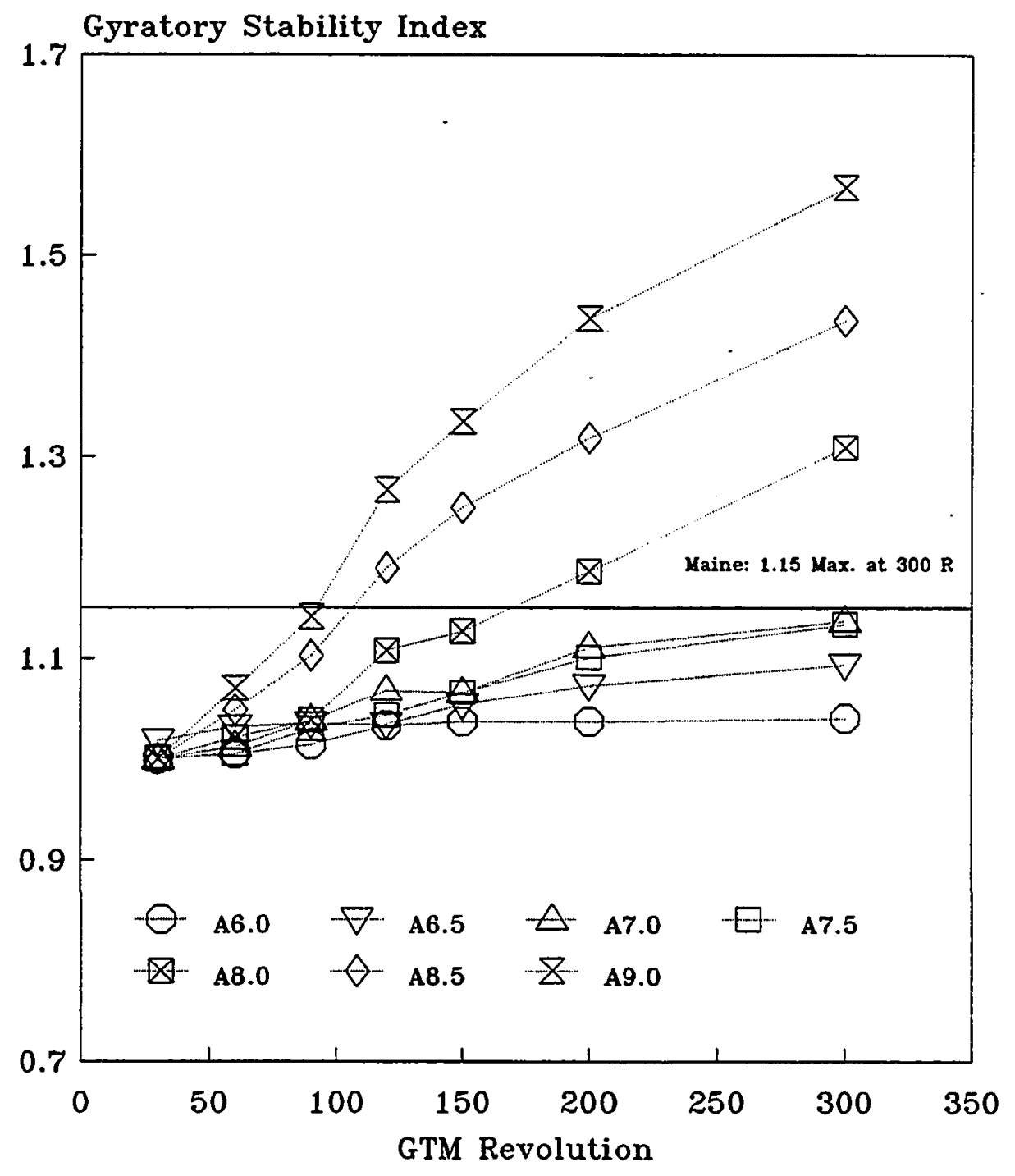

Figure 7.29 GSI versus Revolution (50\% Ash Mix) 


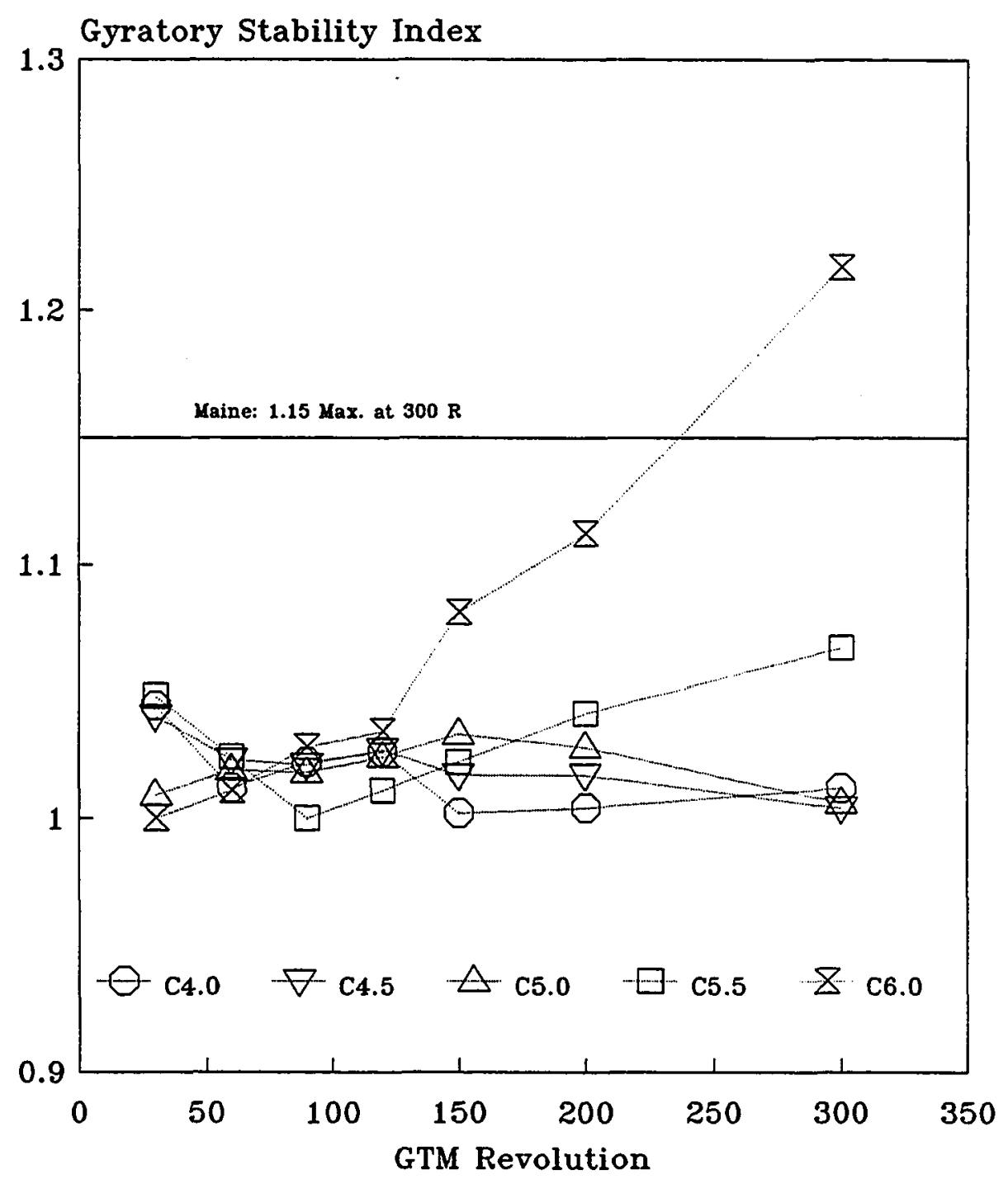

Figure 7.30 GSI versus Revolution (Control Mix) 


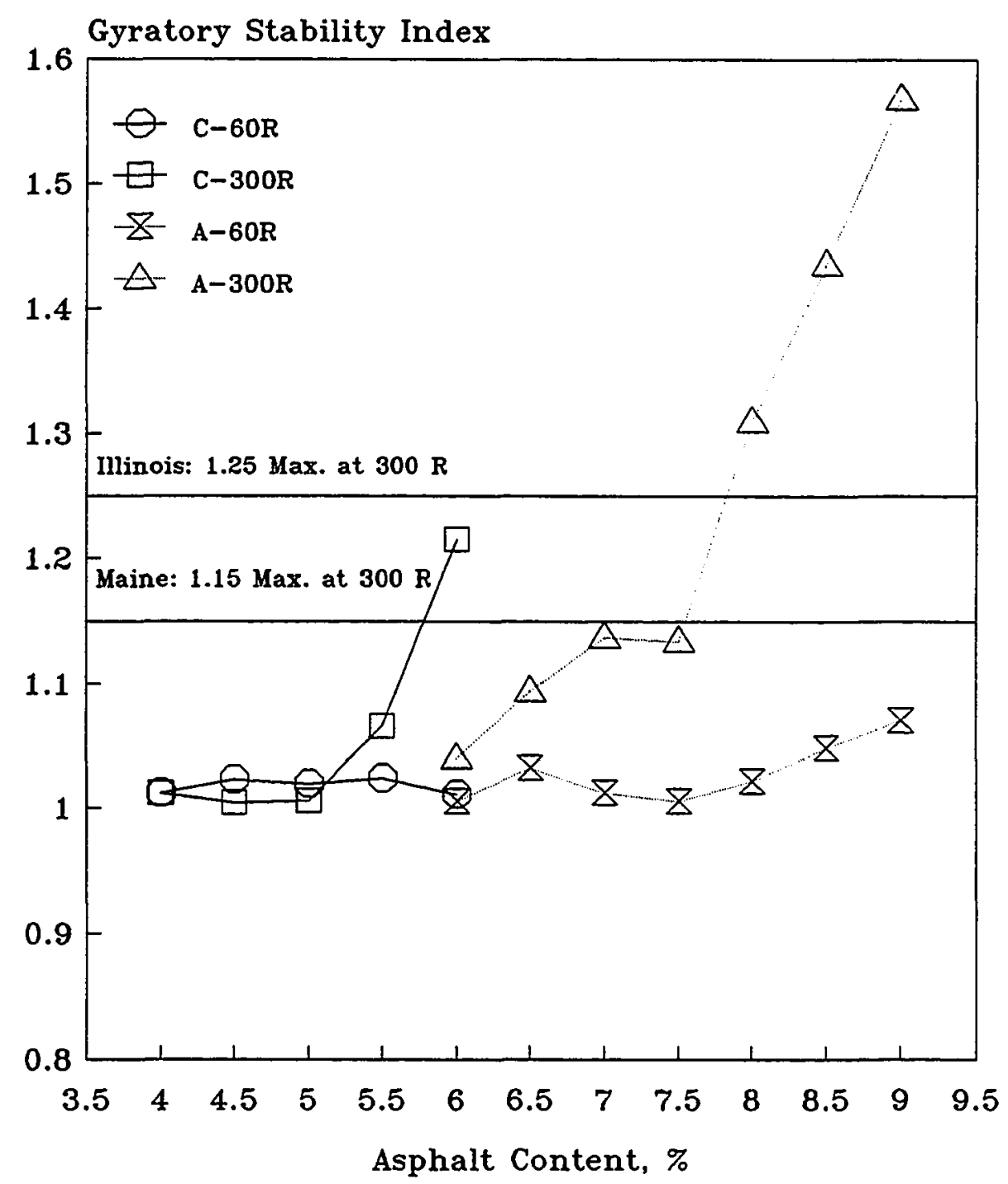

Figure 7.31 GSI versus Asphalt Content 
Shear Strain $=\left(\mathrm{W}_{\max } / \mathrm{W}_{\min }\right) \times(1.75 / 100)$;

$\mathrm{W}_{\max }$ are Max. Width of gyrograph; and

$\mathbf{W}_{\min }$ are Min. Width of gyrograph.

The coefficient, $1.75 / 100$, is an angle conversion factor from degrees to radians, that is, $\pi / 180=0.0175=1.75 / 100$. In using the above formula, it is assumed that there is a linear relationship between shear stress and shear strain, which might not be true for the materials used in the study. However, this approximation might be appropriate. GSM is a measurement of a materials' ability to resist shear deformation.

GSM as a function of revolutions is shown in Figure 7.32. GSM does not vary with revolutions significantly at lower asphalt contents. At higher asphalt contents ( $>7.5 \%$ for the ash mix and $>5.5 \%$ for the control mix), GSM decreases with increased revolutions, indicating the mixes are not capable of resisting shear deformation. It appears that at lower asphalt contents a aggregate framework can be created with the aggregate particles in contact with one another. The load from tire is carried by the aggregate through grain to grain contact. This framework is held in place by the binding action of asphalt cement and is capable of resisting shear deformation. But at higher asphalt contents the individual aggregate particles are dispersed, the framework of the aggregate has been destroyed, and the asphaltic concrete is incapable of carrying a sufficient load or resisting shear. The GSM of the ash mix is, on average, lower than that of the control mix at each level of compaction.

The plot of GSM versus asphalt content is presented in Figure 7.33. At 60 revolutions, all mixes remain stable with GSM ranging from 2653 to 1998 psi for the ash 


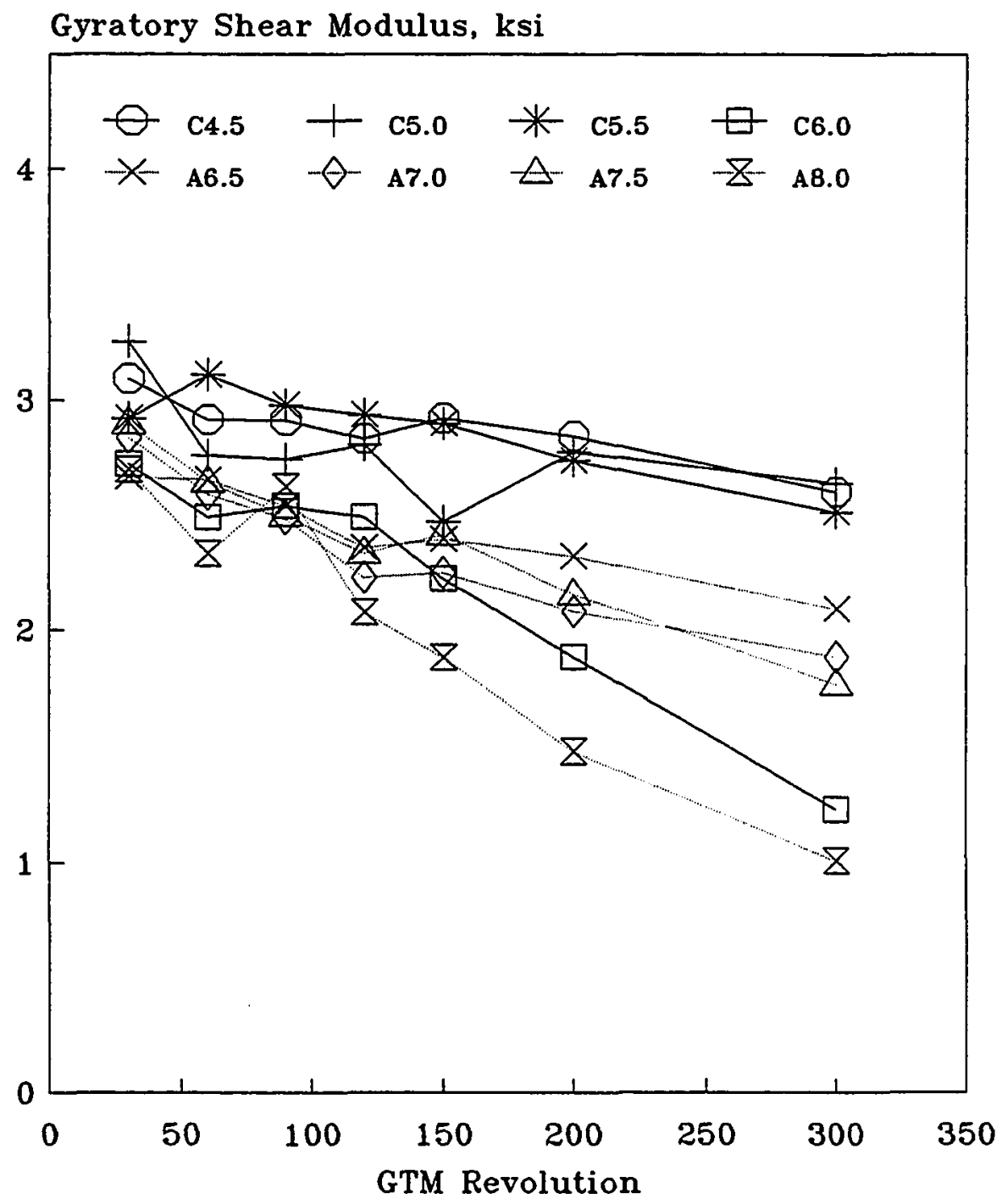

Figure 7.32 GSM versus Revolution 


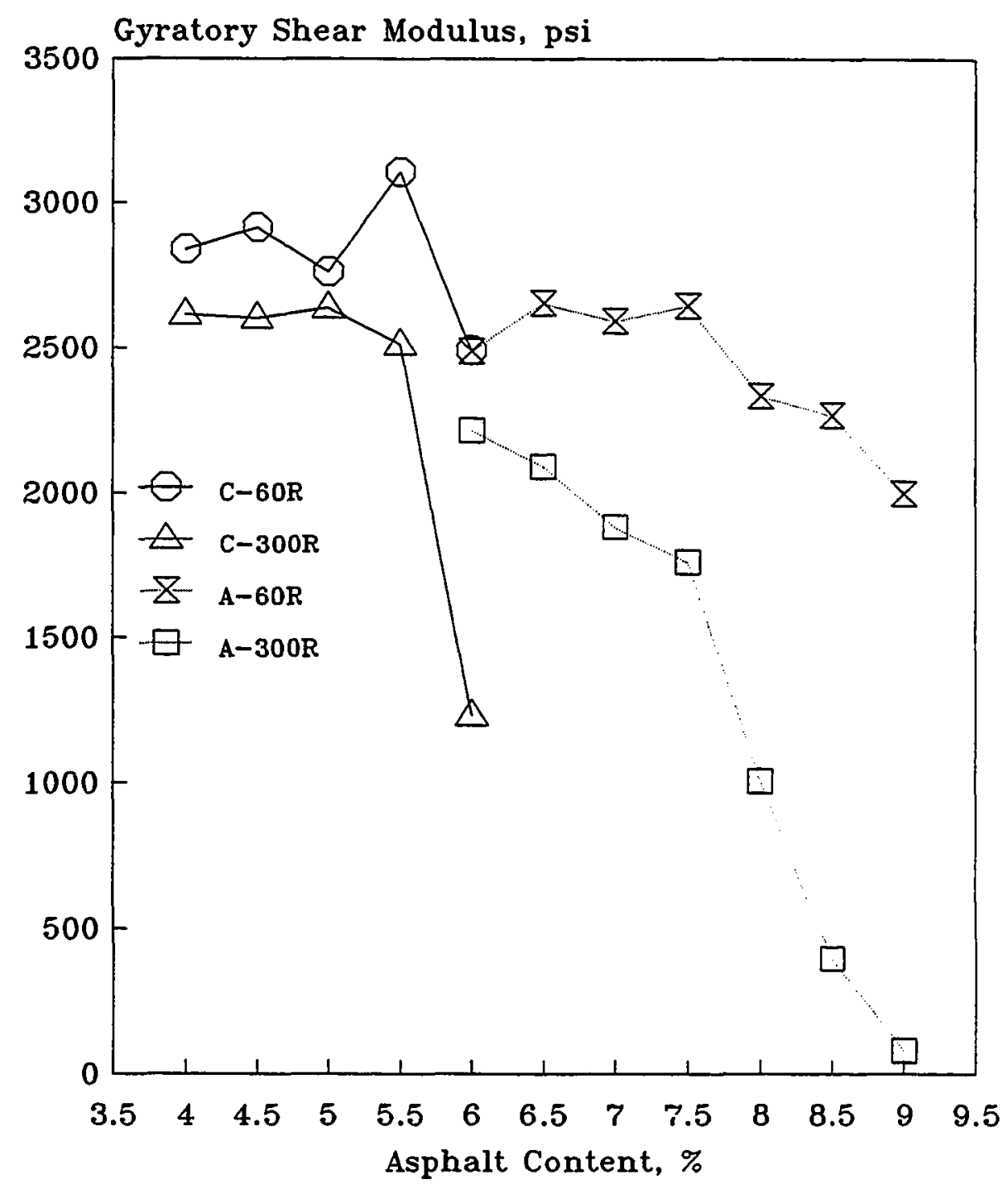

Figure 7.33 GSM versus Asphalt Content 
mix and 2914 to 2491 psi for the control mix. At 300 revolutions, GSM decreases appreciably with increased asphalt content, showing that the mixes become unstable and plastic. The ash mix with $\leq 7.5 \%$ asphalt content are still reasonably stable, with GSM ranging from 2215 to 1760 psi. The control mix with $\leq 5.5 \%$ asphalt content are stable, with GSM ranging from 2637 to 2511 psi.

\subsubsection{Gyratory Compressive Modulus (GCM)}

GCM can be calculated with the following formula $(71,72)$ :

$$
\begin{gathered}
\mathrm{E}_{\mathrm{g}}=2\left(\mathrm{G}_{\mathrm{g}}\right)(1+\mu), \quad \mu=\text { Poisson's ratio }=0.5 \\
\mathrm{E}_{\mathrm{g}}=3\left(\mathrm{G}_{\mathrm{g}}\right)
\end{gathered}
$$

where,

$\mathrm{E}_{\mathrm{g}}=$ Gyratory Compressive Modulus.

It should be kept in mind that using the formula for $E_{g}$ is only an approximation. Poisson's ratio is material and temperature dependent. GCM is a measurement of materials' ability to resist compressive deformation. GCM as a function of revolutions is illustrated in Figure 7.34. GCM does not vary with revolutions significantly at low asphalt contents. At high asphalt contents $(>7.5 \%$ for the ash mix and $>5.5 \%$ for the control mix), GCM decreases with increasing revolutions, indicating the mixes are incapable of sufficiently resisting compressive deformation. The ash mix GSM is, on average, lower than the control GSM at each level of compaction.

The plot of GCM versus asphalt content is presented in Figure 7.35. At 60 revolutions, all mixes remain stable. At 300 revolutions, GCM decreases appreciably with 


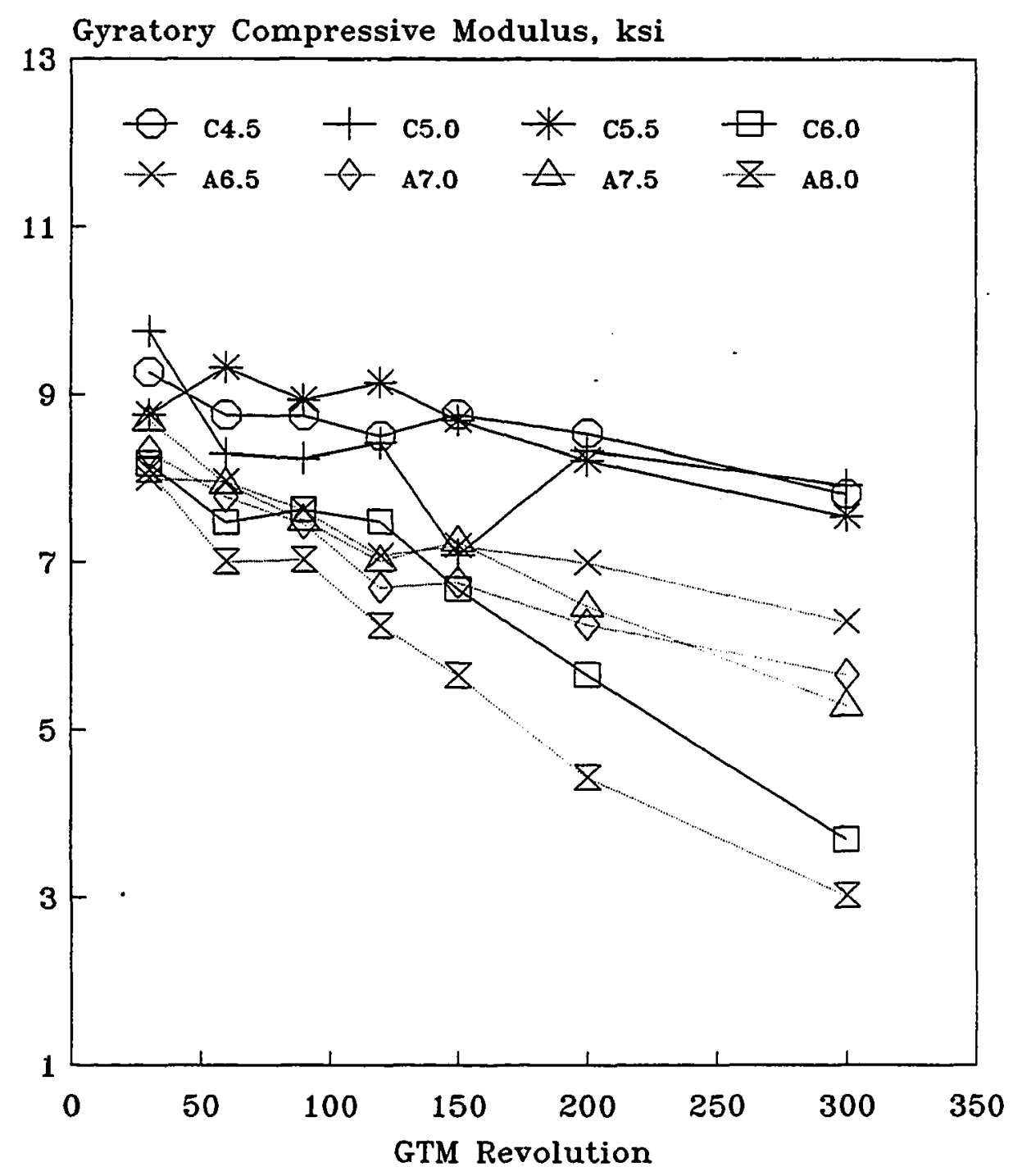

Figure 7.34 GCM versus Revolution

273 


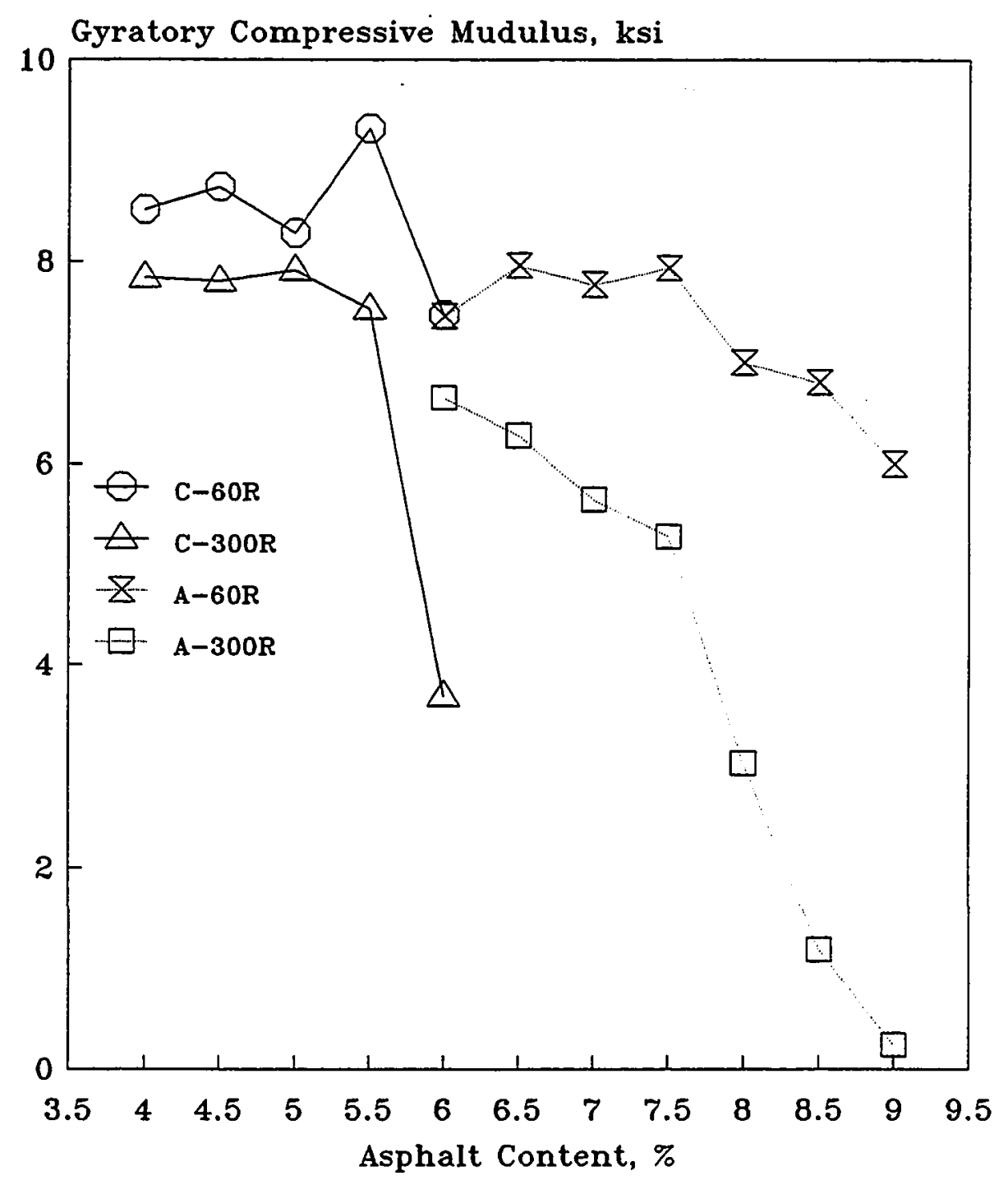

Figure 7.35 GCM versus Asphalt Content 274 
increasing asphalt content, indicating the mixes become unstable and plastic. The ash mix with $\leq 7.5 \%$ asphalt and the control mix with $\leq 5.5 \%$ asphalt are reasonably stable.

\subsubsection{Gyratory Compressive Strain (GCS)}

GCS is calculated by the following equation $(71,72)$ :

$$
\text { Gyratory Compressive Strain }=V / E_{g}
$$

where,

$$
\mathrm{V}=\text { Vertical or Tire Pressure }=120 \text { psi. }
$$

Figure 7.36 illustrates GCS as a function of revolution. GCS increases slightly with increased revolutions at low asphalt contents $(\leq 7.5 \%$ for the ash mix and $\leq 5.5 \%$ for the control mix) and increases significantly at high asphalt contents. GCS versus asphalt content is presented in Figure 7.37. At 60 revolutions, all mixes remain stable, with GCS ranging from 0.015 to 0.022 inch/inch for the ash mixes and from 0.013 to 0.016 inch/inch for the control mix respectively. At 300 revolutions, the ash mix starts losing stability at $8 \%$ asphalt because GCS increases appreciably with increasing asphalt content. The ash mix with $\leq 7.5 \%$ asphalt content are reasonably stable, with GCS ranging from 0.018 to 0.023 inch/inch. The control mix with $\leq 5.5 \%$ asphalt content are stable, with GCS ranging from 0.015 to 0.016 inch/inch.

\subsubsection{Bottom Ash Degradation in Asphaltic Mixes}

The procedures of extraction test were same as those introduced in Chapter VI. The samples chosen for extraction test included the ash mix GTM ones at 60 and 300 


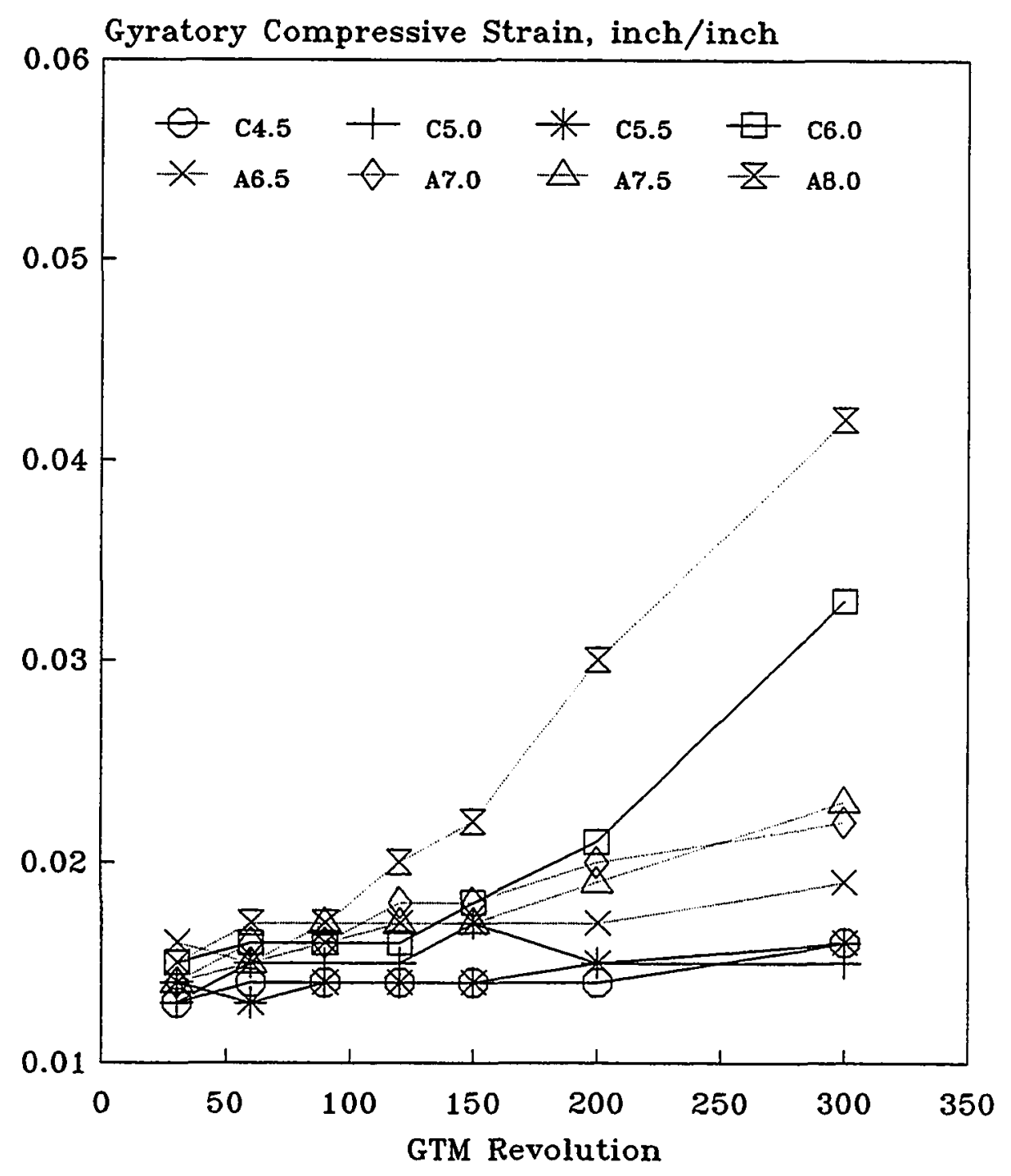

Figure 7.36 GCS versus Revolution 


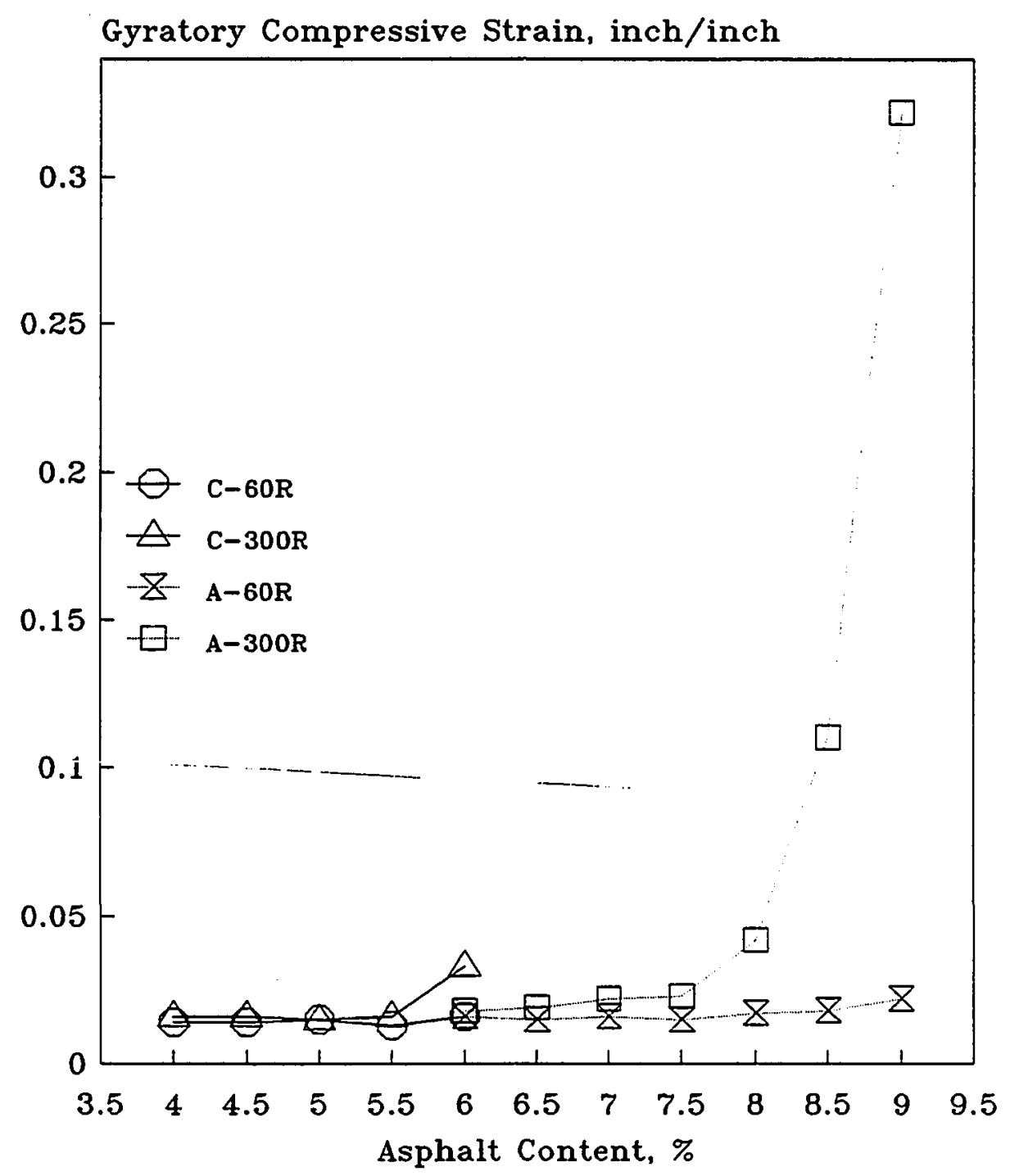

Figure 7.37 GCS versus Asphalt Content 
revolutions with $7.7 \%$ asphalt and the control mix GTM ones at 60 and 300 revolutions with $5.11 \%$ asphalt.

Figures 7.38 and 7.39 present the gradation of the control and ash mixes before and after laboratory compaction. The difference in gradation before and after compaction is shown in Figure 7.40. Degradation occurred in all mixes as shown by the figures and was associated with particle size, being more for particles ranging from $1 / 2^{\text {n }}$ to No.20. The ash mix degraded more than the control mix for particles in the $3 / 8^{n}$ to No. 20 size range. It appears that for both the ash and control mixes the difference between gradations at 60 and 300 revolutions are not significant, indicating the increased compaction effort does not increase degree of degradation significantly.

Compared to Marshall compaction, GTM compaction resulted in less degradation for the ash mix and more degradation for the control mix.

\subsubsection{Marshall Stability and Flow}

Figures 7.41 and 7.42 show Marshall stability of GTM samples as a function of asphalt content for the bottom ash and control mixes respectively. Added to these two

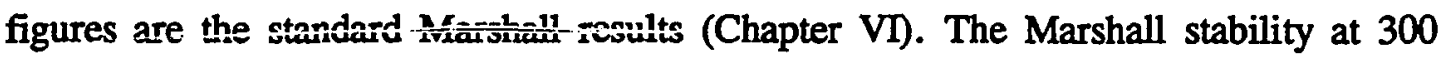
revolutions is higher than that at 60 revolutions. This is easily understood since the compaction of 300 revolutions make samples more densified. The stability of the ash mix at 60 revolutions ranges from 1368 to $2838 \mathrm{lb}$, and at 300 revolution ranges from 1991 to $3641 \mathrm{lb}$. The stability of the control $\mathrm{mix}$ at 60 revolutions ranges from 1494 to 2582 lb, and at 300 revolutions ranges from 2486 to $3864 \mathrm{lb}$. Hence, the Marshall stability of 


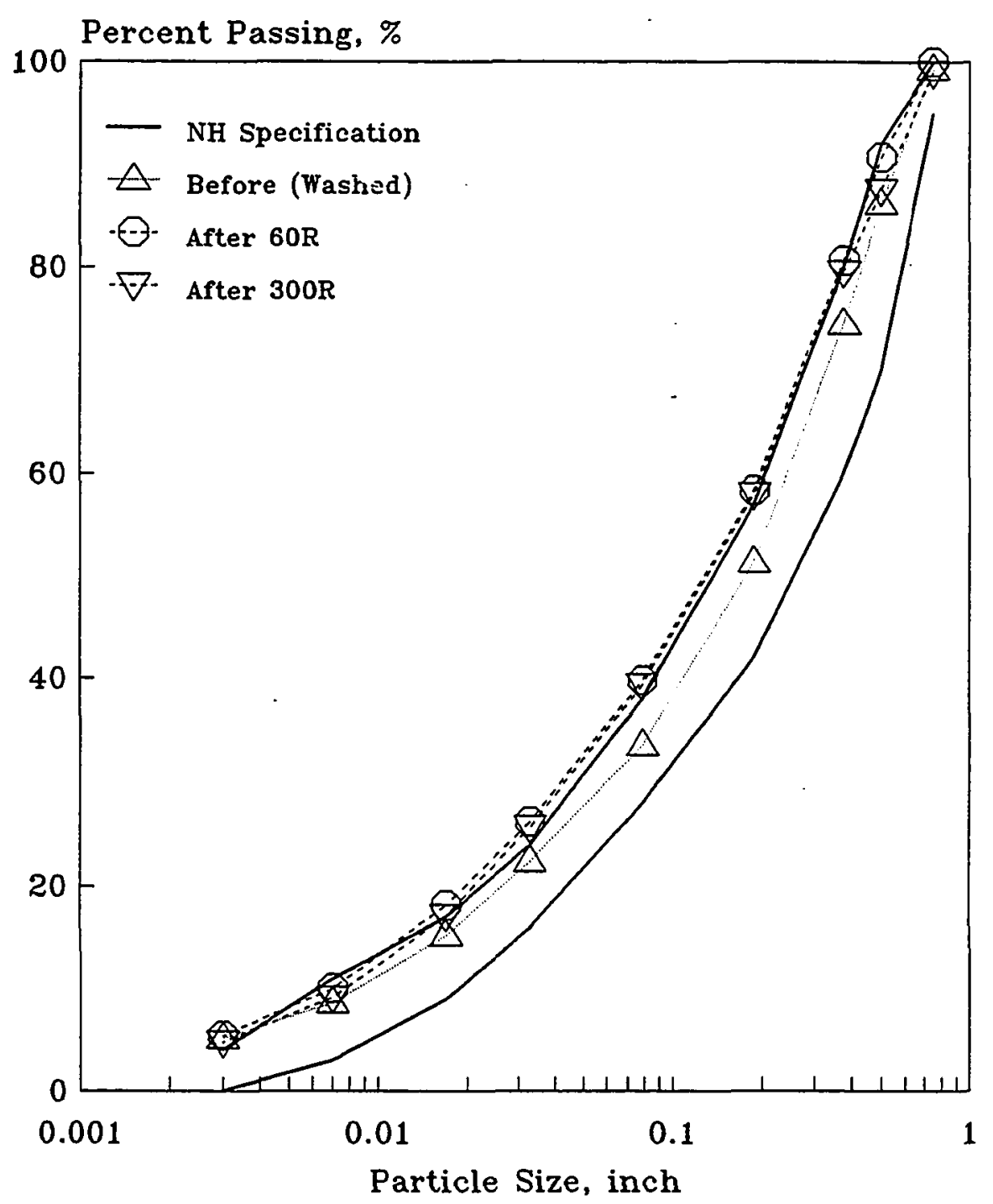

Figure 7.38 Degradation of $50 \%$ Ash Mix 279 


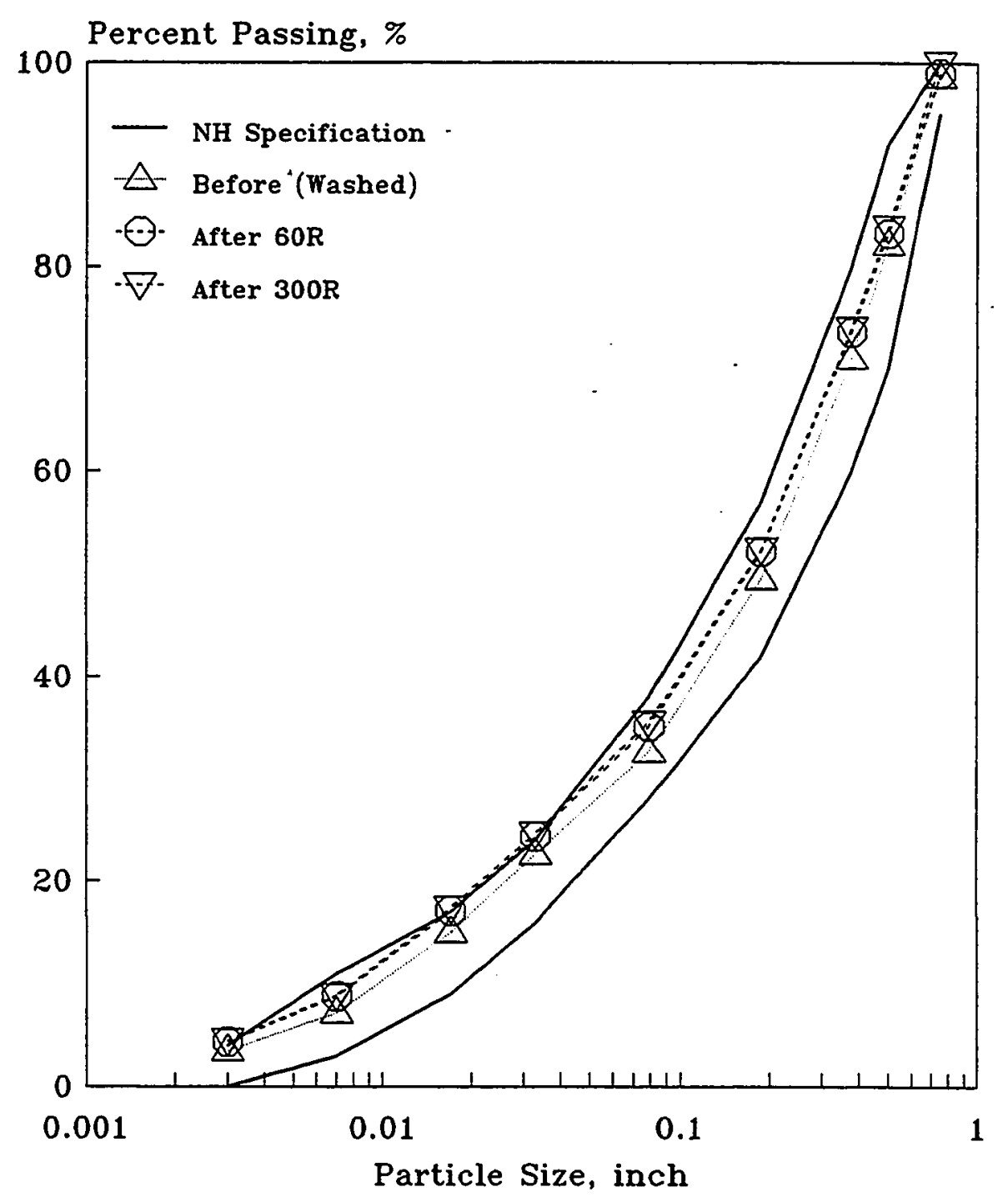

Figure 7.39 Degradation of Control Mix 


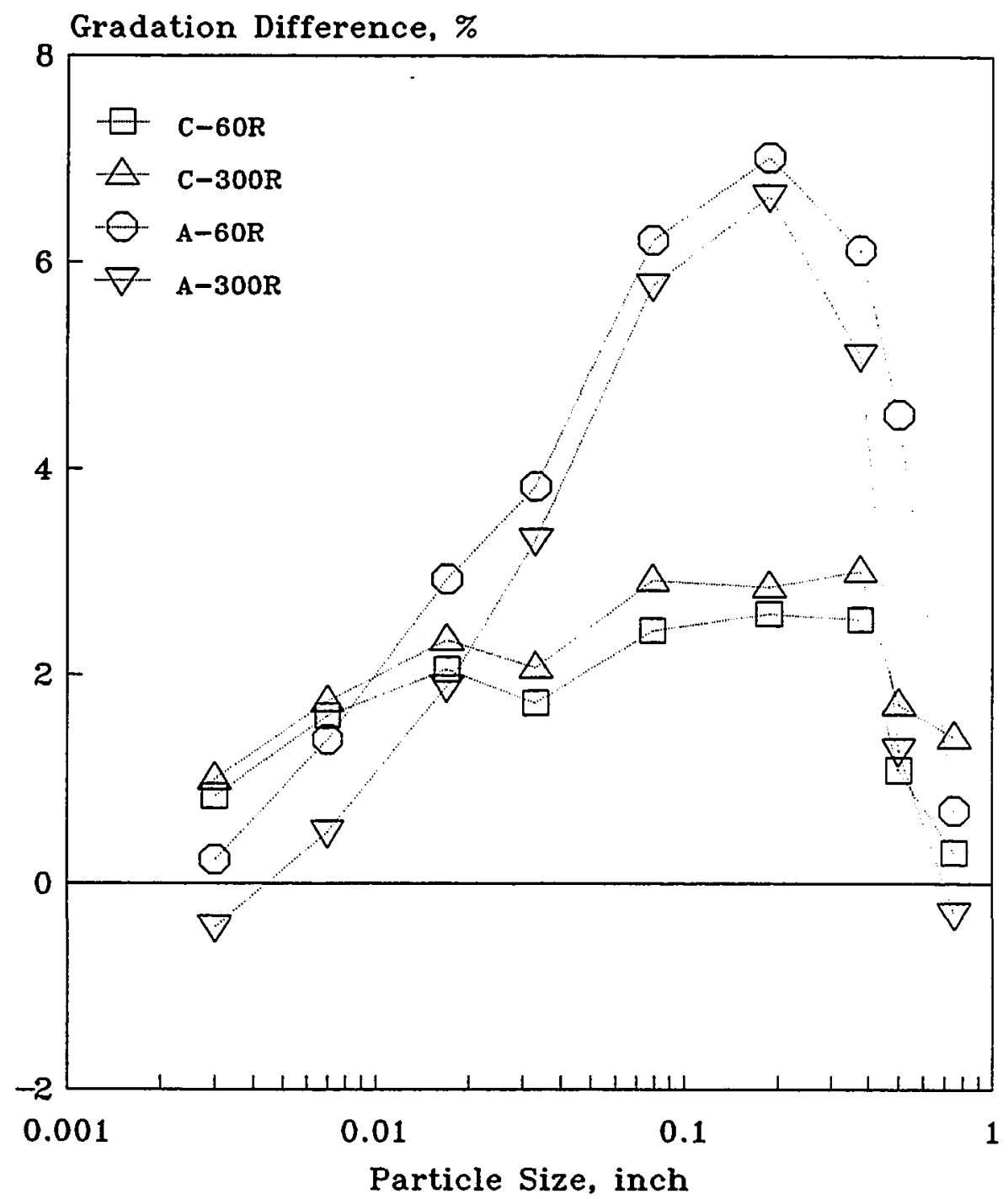

Figure 7.40 Ash Degradation 


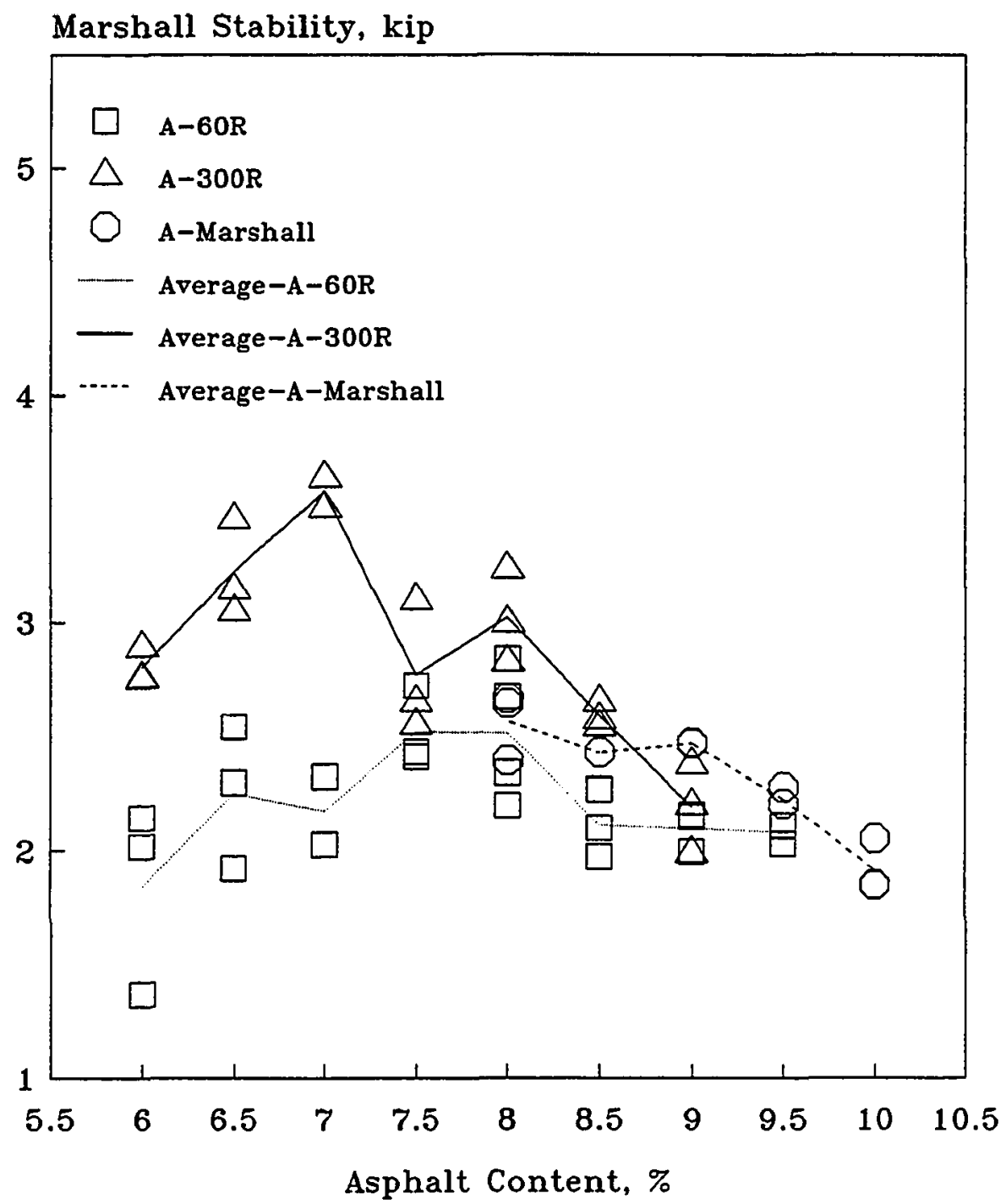

Figure 7.41 Marshall Stability of 50\% Ash Mix 


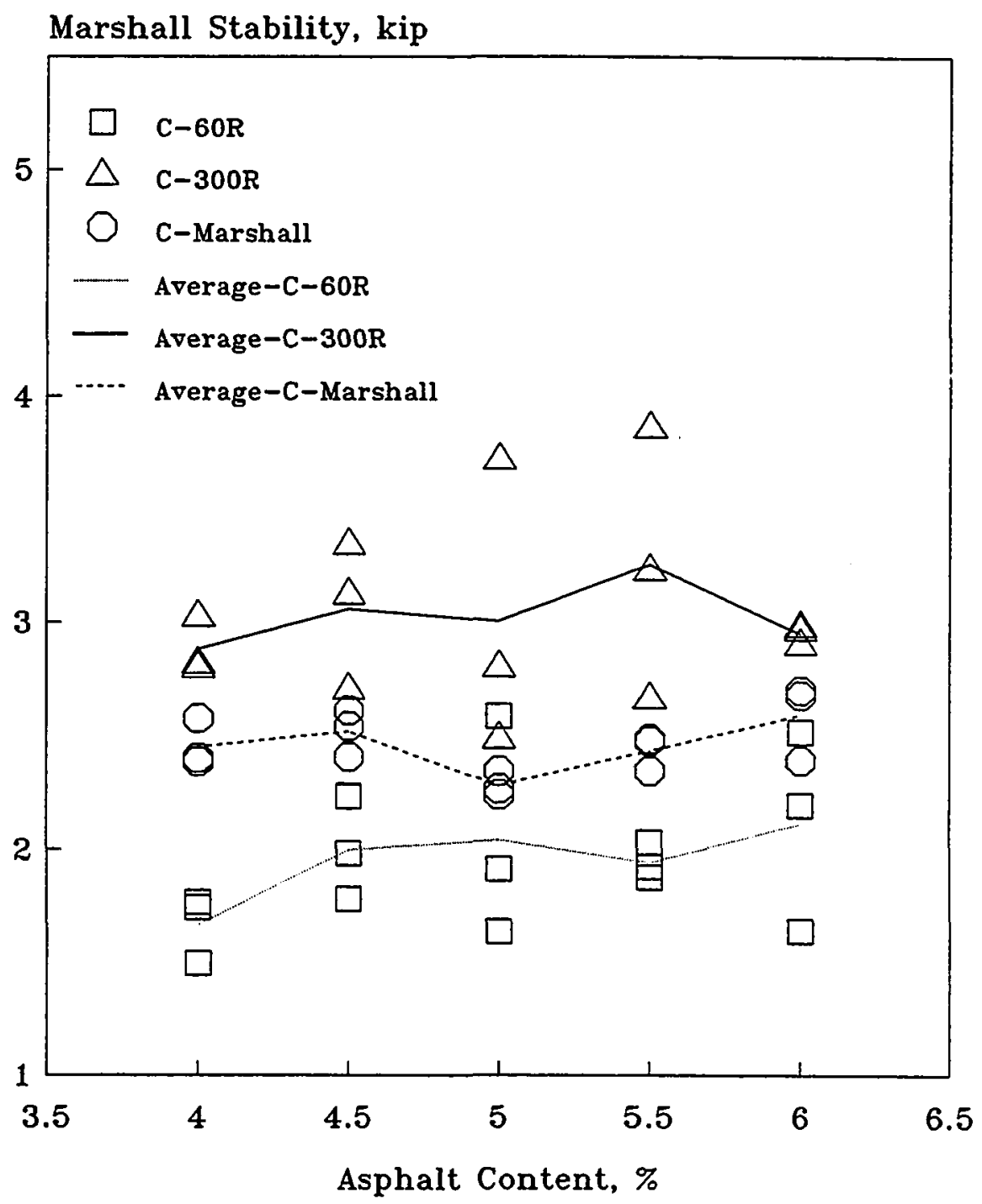

Figure 7.42 Marshall Stability of Control Mix

283 
the GTM samples of the ash mix is comparable to that of the control mix.

The stability of the Marshall samples of the ash mix at $\geq 8.0 \%$ asphalt is comparable to that of the GTM samples at either 60 or 300 revolutions (Marshall data at $<8 \%$ asphalt are not available). The stability of the Marshall samples of the control mix is between that at 60 and 300 revolutions, indicating the assumption that Marshall compaction simulates 2-3 years of traffic holds for conventional materials.

Marshall flow as a function of asphalt content for the ash and control mixes is illustrated in Figures 7.43 and 7.44. Significant variations were observed for all mixes. The control mix flow at 60 revolutions is higher than that at 300 revolutions, and for the ash mix this observation is true when asphalt content is $\leq 7.5 \%$. The flow of the Marshall samples is higher than that of the GTM samples at 300 revolution for the control mix, but for the ash mix the observation is opposite.

\subsection{Selection of Optimum Asphalt Content}

The selection of the optimum asphalt contents is based on the four most important requirements among all factors considered. They included stability index, gyratory shear stress, air void after initial compaction and air void after final compaction. Figure 7.45

presents the allowable ranges of asphalt contents that are defined as those values being within the minimum and maximum limits of the requirements. The design asphalt contents which were selected as the median value within the allowable range should be 7.25 and $5.11 \%$ for the ash and control mixes respectively. However, a lower limit of 7\% asphalt content instead of $7.25 \%$ was selected as the optimum asphalt content for the 


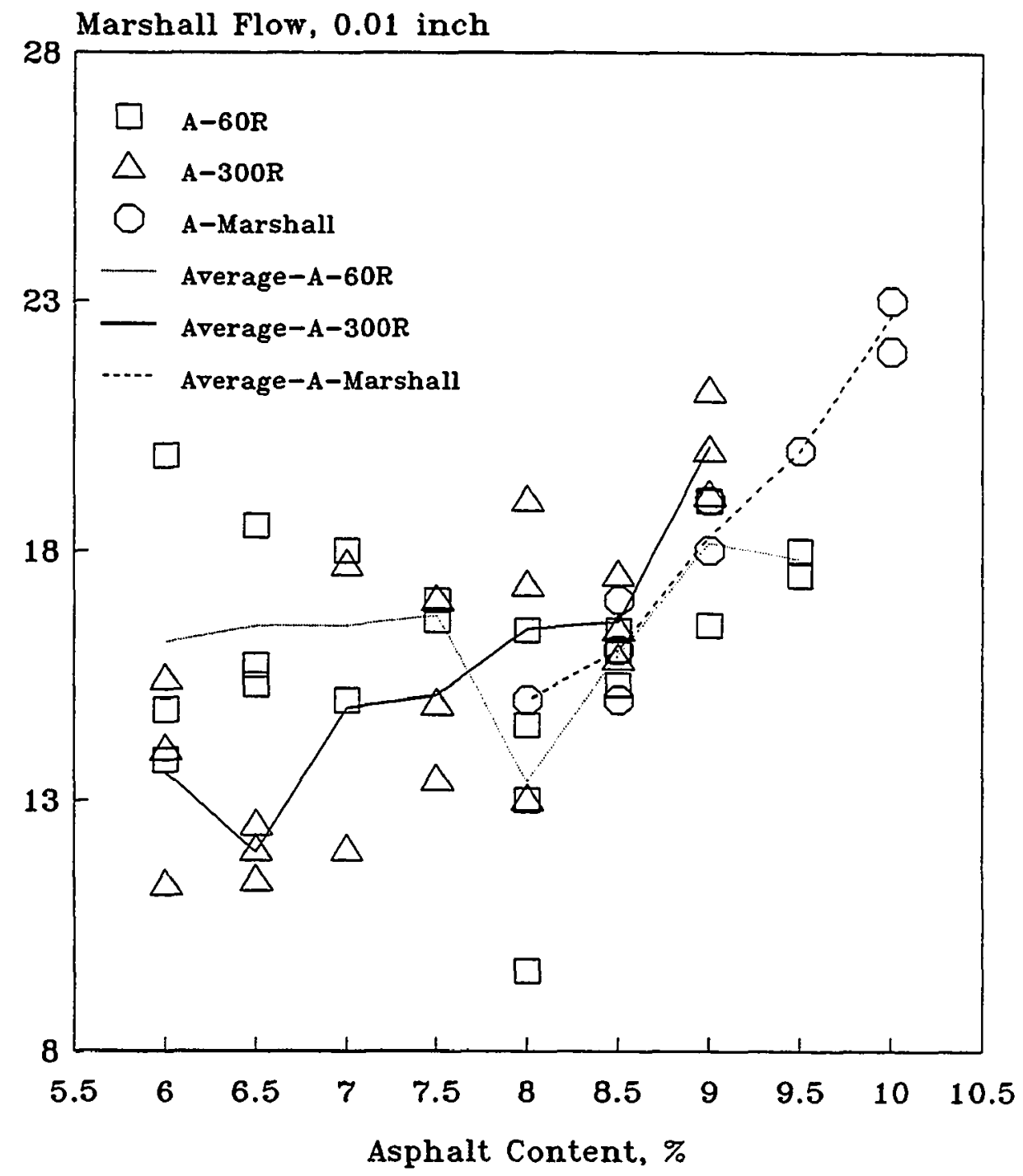

Figure 7.43 Marshall Flow of 50\% Ash Mix 285 


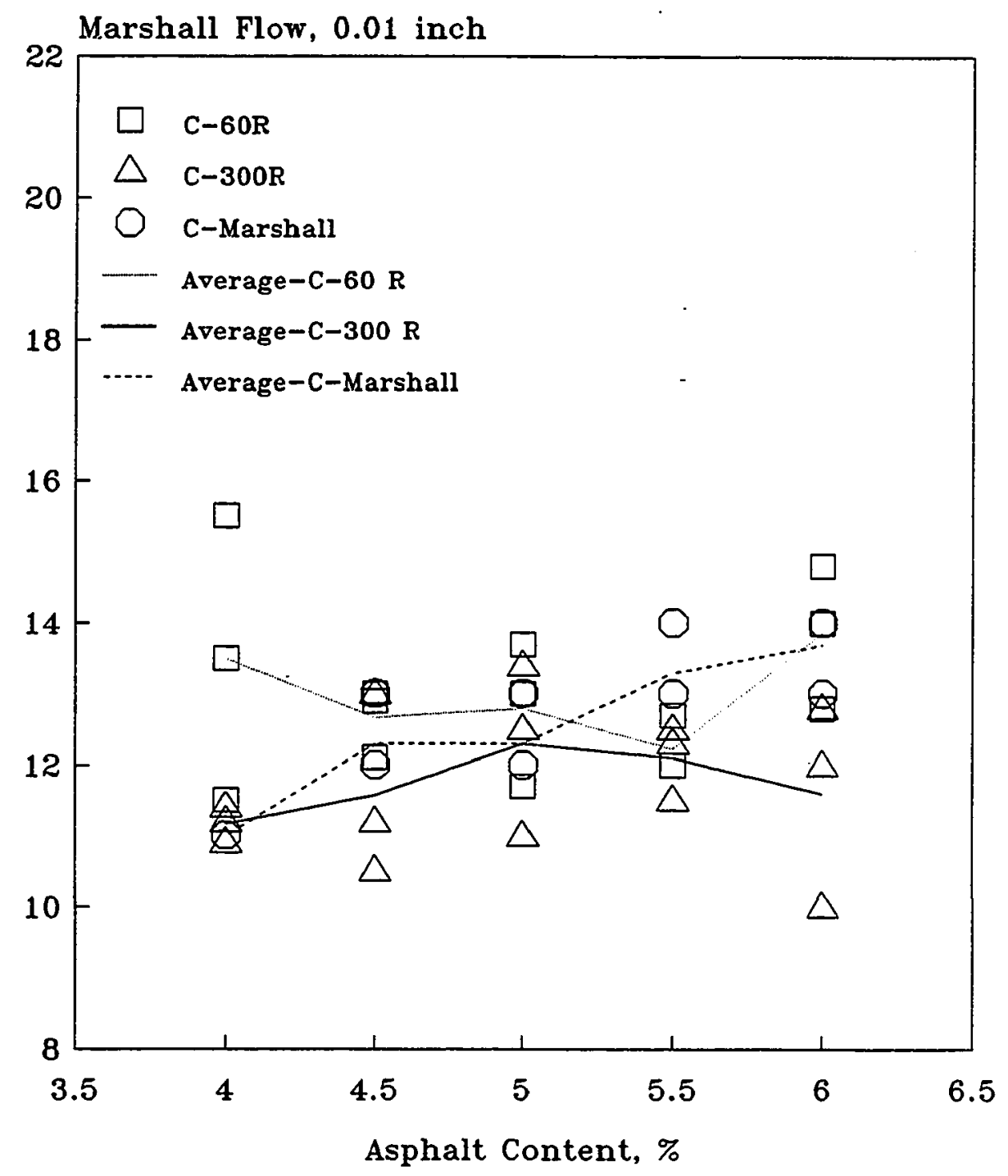

Figure 7.44 Marshall Flow of Control Mix 


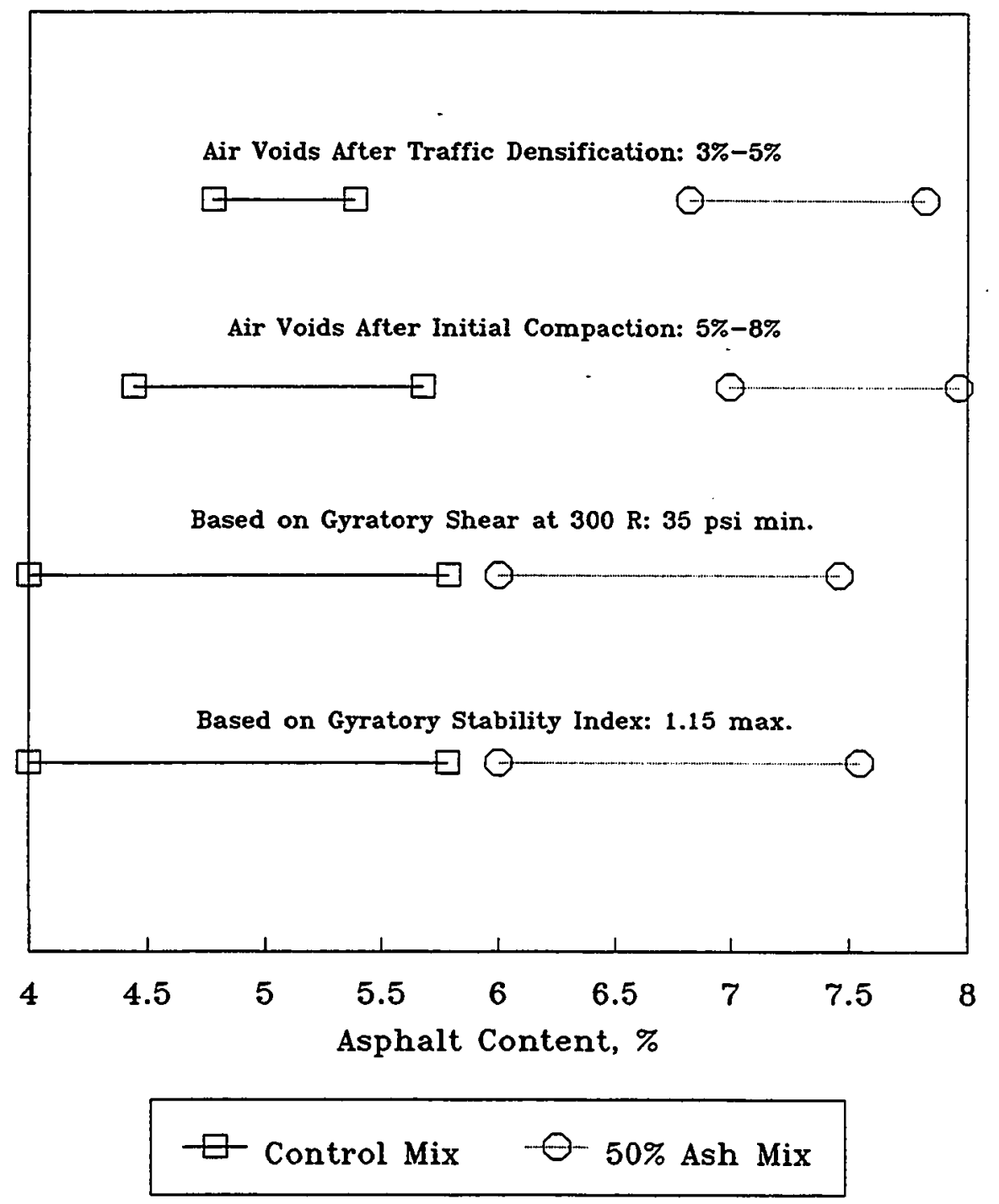

Figure 7.45 Allowable Range of Asphalt Content 
ash mix in order to save the test road cost. The physical and engineering properties of the ash and control mixes at these design asphalt contents are shown in Table 7.2. The VMA and VFA requirements are not met by either the ash or control mixes at the design asphalt contents. The reason for this has been previously investigated. However, experience indicates the asphaltic concrete which has the design similar to the control mix has performed well in the field. The performance of the ash mix can be only judged by a field study. A small test patch of the ash mix at the design asphalt content was built in Franklin Landfill, Franklin, NH in October of 1992, as shown in Figure 7.46. A small steel roller was used to compact the ash mix. A number of small alligator cracks were developed in six months based on visual observation, during which period the test patch was frequently subject to heavy traffic including heavy garbage trucks and front loaders. The field compacted mix was sampled and the average air void of the field samples as per AASHTO T269 was $11.64 \%$, with a standard deviation of $1.29 \%$. Apparently, the field mix was not compacted well during construction. A demonstration project including the ash and control mixes was successfully completed in Laconia, NH in May of 1993. Preliminary study indicated the ash section performs as well as the control. The various destructive and non-destructive testing techniques are used to evaluate their performance.

Figure 7.47 compares the optimum asphalt contents developed by the GTM and Marshall design methods. The GTM methods result in lower optimum asphalt contents than the Marshall method. The more ash the larger the difference in optimum asphalt content. Table 7.3 presents a comparison of types of compaction and average asphalt content - a study conducted by National Center for Asphalt Technology (76). The results 
Table 7.2 Properties of the Optimum Mix Designs

\begin{tabular}{|c|c|c|c|}
\hline Properties & $\begin{array}{l}\text { 50X Ash Mix at } \\
7.0 \% \text { AC }\end{array}$ & $\begin{array}{l}\text { Control Mix at } \\
5.11 \% \mathrm{AC} \\
\end{array}$ & $\begin{array}{l}\text { Suggested Value } \\
\text { From Literature }\end{array}$ \\
\hline Unit Height, lb/ft ${ }^{3}$ & 140.0 & 147.5 & $\ldots$ \\
\hline seI & 0.97 & 0.982 & $\ldots$ \\
\hline Initial Air Voids, $x$ & 7.99 & 6.56 & $5-8$ \\
\hline Final Air Voids, $x$ & 4.587 & 4.018 & 3-5 \\
\hline VMA, $x$ & 7.918 & 13.570 & $14-21$ \\
\hline VFA, $x$ & 43.56 & $70.5 ?$ & $75-85$ \\
\hline Absorbed Asphalt, $x$ & 5.482 & 0.996 & $\ldots$ \\
\hline Effective Asphalt, $x$ & 1.518 & 4.114 & $\ldots$ \\
\hline Hater Absorption, $x$ & 0.147 & 0.082 & $\ldots$ \\
\hline Gyratory Shear $(s g)$, psi & 37.57 & 46.50 & $35 \mathrm{~min}$. \\
\hline Gyratory Shear Factor & 0.98 & 1.21 & $\ldots$ \\
\hline Gyratory Stability Index & 1.137 & $1.04 \%$ & $1.15 \max$. \\
\hline Gyratory Shear Modulus, psi & 1882 & 2609.3 & $\ldots$ \\
\hline Gyratory Compressive Modulus, psi & 5645 & 7827.3 & $\ldots$ \\
\hline Gyratory Compressive Strain, inch/inch & 0.022 & 0.0152 & ... \\
\hline
\end{tabular}




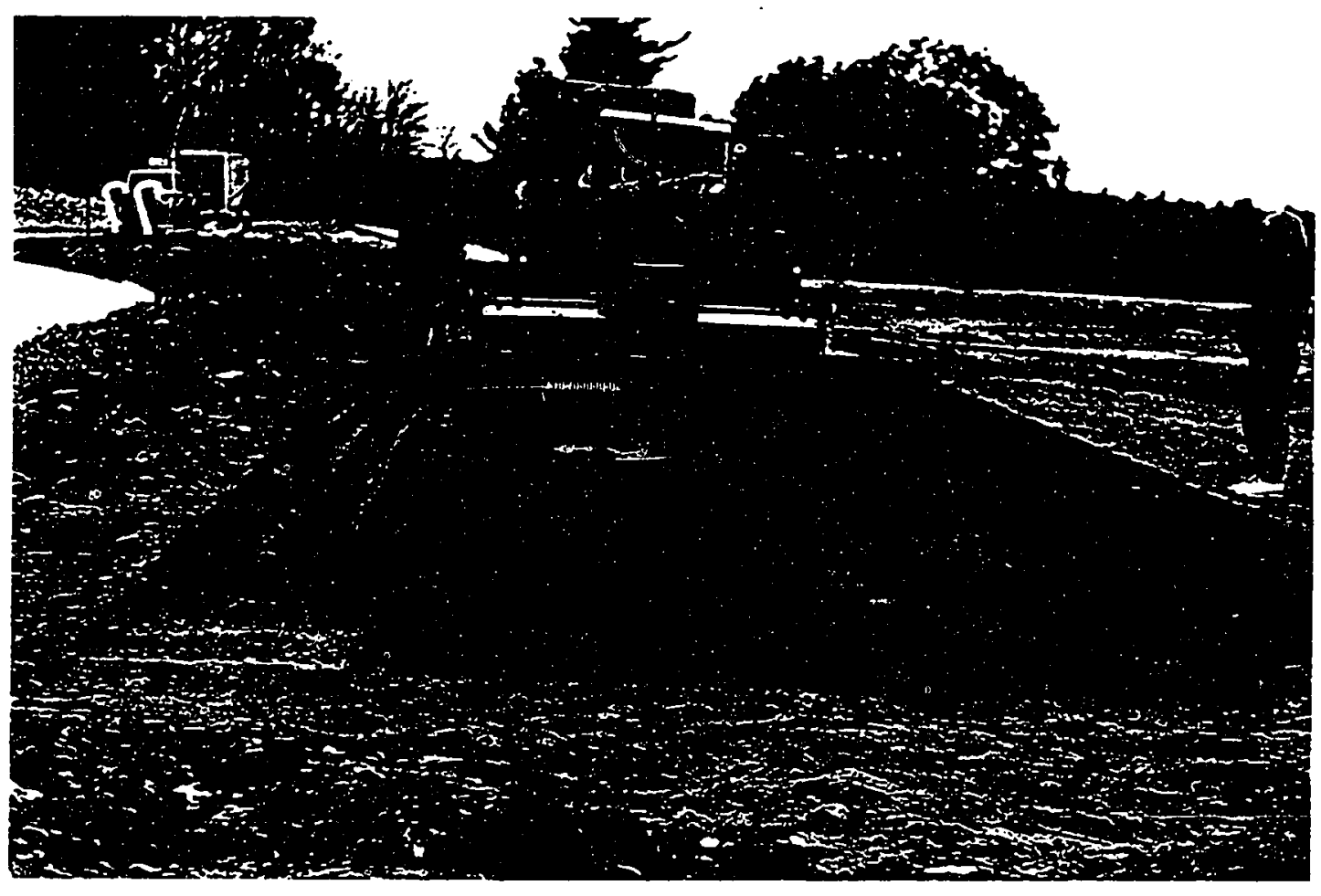

Figure 7.46 Ash Test Patch in Franklin Landfill, NH 


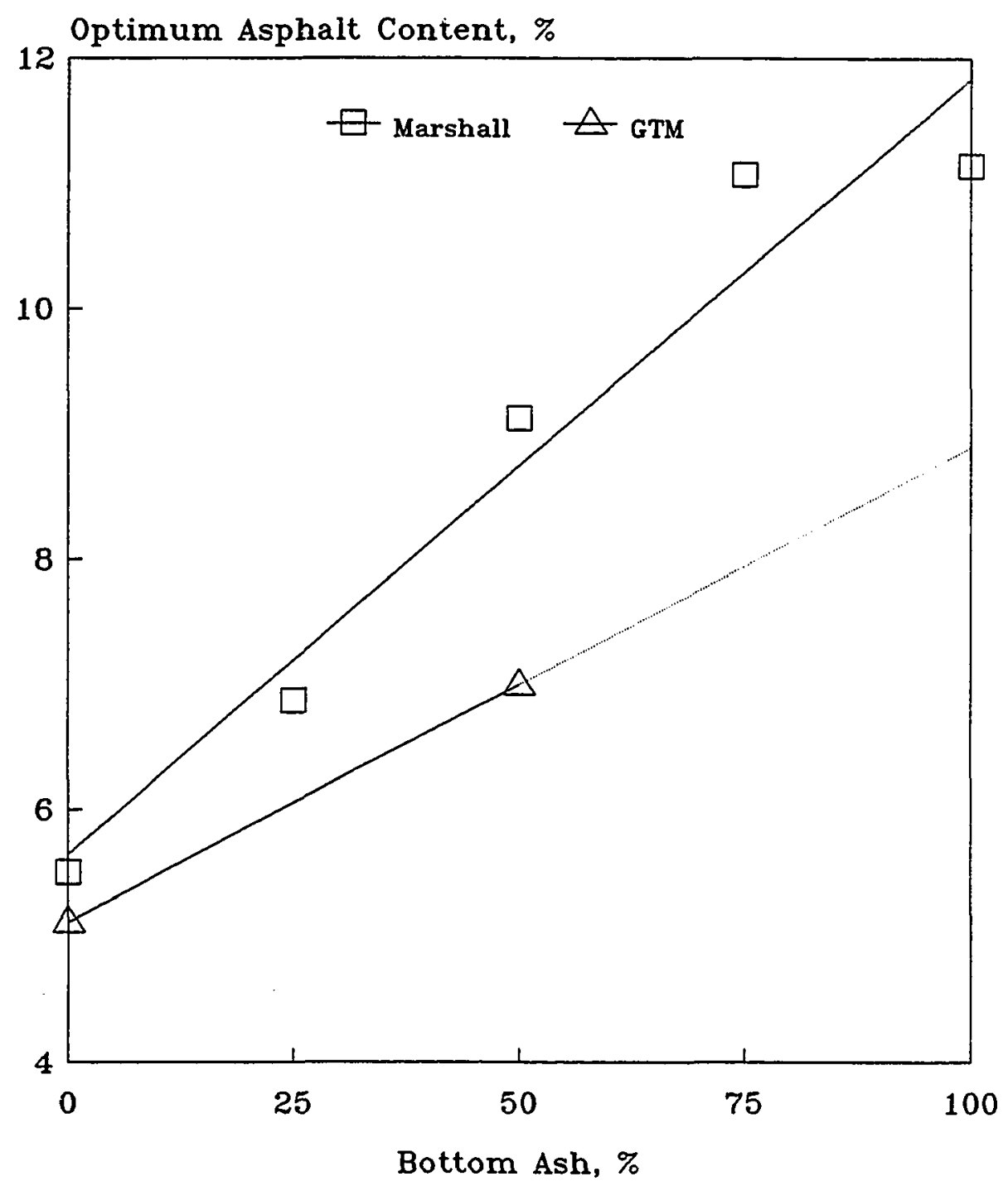

Figure 7.47 Optimum Asphalt Content versus \% Bottom Ash 291 
Table 7.3 Types of Compaction and Average Optimum Asphalt Content (Ref. 76)

\begin{tabular}{|l|l|c|c|c|c|}
\hline \multirow{2}{*}{ Compaction Method } & \multirow{2}{*}{ *o. of Labs } & \multicolumn{2}{|c|}{$\begin{array}{c}\text { Opt imm Asphalt Content } \\
\text { (Limestone) }\end{array}$} & \multicolumn{2}{|c|}{$\begin{array}{c}\text { Opt imm Ashpalt Content } \\
\text { (Gravel) }\end{array}$} \\
\cline { 3 - 6 } & & Average & $\begin{array}{c}\text { Standard } \\
\text { Deviation }\end{array}$ & Average & $\begin{array}{c}\text { Standard } \\
\text { Deviation }\end{array}$ \\
\hline Marshall Mechanical & 17 & 4.8 & 0.32 & 5.4 & 0.35 \\
\hline Marshall Manual & 10 & 4.7 & 0.28 & 5.1 & 0.34 \\
\hline $\begin{array}{l}\text { Marshall Mechanical (Slanted } \\
\text { Foot and Rotating Base) }\end{array}$ & 5 & 4.5 & 0.48 & 5.1 & 0.45 \\
\hline Texas Gyratory & 3 & 4.5 & 0.43 & 4.8 & 0.66 \\
\hline Corps of Engineers Gyratory & 2 & 4.6 & 0.21 & 4.8 & 0.04 \\
\hline Hveem & 4 & 4.5 & 0.33 & 4.8 & 0.26 \\
\hline
\end{tabular}


show that the Marshall mechanical hammer on the average provided the highest optimum asphalt content. The results also show high variability for optimum asphalt content between laboratories for any compaction method.

\subsection{Summary and Conclusion}

Based on the results and discussion as presented the following conclusions are drawn:

1. The unit weight is found to follow an asymptotic relationship with revolutions for both the ash and control mixes. The ash mix has lower density than the control at all revolutions.

2. The ash mix is more difficult to compact than the control mix.

3. The air voids cierease with increasing revolutions and asphalt contents. The ash mix meeting the initial and final air void requirements requires more asphalt cement than the control mix.

4. VMA decreases with increasing revolutions. The ash mix consistently has lower VMA than the control mix at each level of compaction and does not meet VMA requirements at any asphalt content.

5. The ash mix absorbs more asphalt cement than the control mix.

6. Effective asphalt contents increase with increasing asphalt content for both the ash and control mixes.

7. The ash and control mixes have low water absorption.

8. Gyratory shear and gyratory shear factor decrease with increasing revolutions and gyratory shear at 300 revolutions decreases with increasing asphail content, and decreases 
significantly at high asphalt contents.

9. GSI can be used to predict rutting potentials. All mixes at 60 revolutions remain stable with GSI ranging from 1.005 to 1.07 for the ash mix and 1.011 to 1.024 for the control. The GSI at 300 revolutions increases appreciably with increasing asphalt content, indicating the mixes become unstable with increasing asphalt content.

10. Gyratory shear modulus and gyratory compressive modulus decrease with increasing revolutions at high asphalt contents. All mixes at 60 revolutions remain stable. Gyratory shear modulus and gyratory compressive modulus at 300 revolutions decrease appreciably with increasing asphalt content, indicating the mixes become unstable and plastic with increasing asphalt content.

11. The gyratory compressive strain at 60 revolutions is very small and is not dependent upon asphalt content. The gyratory compressive strain at 300 revolutions increases with increasing asphalt content.

12. Degradation occurred in all mixes. The ash mix degraded more than the control mix for particles in the $3 / 8^{n}$ to No.20 size range. The difference between gradations at 60 and 300 revolutions for the ash and control mixes are not significant, indicating the increased compaction effort does not increase degree of degradation significantly.

Compared to Marshall compaction, GTM compaction resulted in less degradation for the ash mix and more degradation for the control mix.

13. The design asphalt contents are $7.0 \%$ and $5.11 \%$ for the ash and control mixes respectively. 


\section{ASPHALT ABSORPTION}

\subsection{Introduction}

The aggregates used in asphalt concrete have varying level of effective porosity and as such absorb asphalt. Although some absorption may lead to improved strength in a compacted mixture through particle interlocking, the portion of the asphalt that is absorbed is no longer available as binder (78). The situation is further aggravated because of the time-dependent nature of the absorption phenomenon. Moreover, the asphalt available in thin films serving as a binder may have different physical, chemical and rheological properties if selective absorption takes place (79). The absorption of asphalt in mineral aggregates may cause the following which may lead to premature failure of the asphalt paving mixtures $(78,80)$ :

1. Incorrect computation of the air voids, voids in mineral aggregate or voids filled with asphalt. Since one or more of these are generally used as criteria for asphalt mixture design, incorrect calculations may lead to mixtures lacking durability or stability.

2. Not having enough effective binder may lead to raveling, cracking, or stripping.

3. Possible premature age hardening and low temperature cracking as a result of changes in asphalt properties due to selective absorption.

4. Construction problems such as segregation and tender mixes.

Many investigators in the past have attempted to evaluate asphalt absorption of 
aggregates through correlations with absorption using other liquids. Hveem (81) devised the centrifuge kerosene equivalent test (CKE) in 1942. Lohn (82) correlated asphalt absorption of an aggregate with kerosene absorption. Since kerosene has wetting properties similar to that of asphalt it is a better absorption agent as compared to water $(83,84)$. Some investigators $(85)$ have tried oils to evaluate the absorptive capacity of coarse aggregates. However, because of the difference in wetting and viscosities properties, only approximate estimations can be made of the asphalt absorption of the aggregates. In 1936, a procedure was described by Reagel (86) for the determination of relative absorption of water and liquid bituminous material by coarse aggregate using water displacement. It was recommended that absorption of liquid bituminous material be estimated at 75 percent of the water absorption. In 1942, Goshorn and Williams (87) developed the immersion method. Since the aggregate is in contact with an unlimited supply of asphalt at relatively low viscosity for an extended period of time in this method, the absorpticn is much higher than would be expected in actual asphalt mixtures (80). Rice $(88,89)$ proposed vacuum procedure to determine the maximum specific gravity of the voidless asphalt mixture. A different approach was used by Larsen (90) who conducted a high pressure test instead of vacuum saturation to determine the effective specific gravity of the aggregate. Asphalt absorption was calculated as the percent of the volume of aggregate and ranged from 26 to 88 percent of the water absorption. The U.S. Army Corps of Engineers $(91,92)$ developed and uses the bulk impregnated specific gravity in the design and control of bituminous mixtures. Other methods of determining absorption of asphalt by aggregates include: colorimetric analysis with a photometer ( 80 ; 
cross-sectional measurements (80); the Methylene Blue test first developed in France (93). Franco and Lee (94) have recently studied the viability of using an air meter for determining the maximum specific gravity of asphaltic mixtures.

Kandhal and Khatri (77) conclude the following concerning the methods of asphalt absorption:

1. No single standard method is currently in use for evaluating and specifying the absorptive characteristics of aggregates with respect to asphalt cement.

2. The indirect estimation of asphalt absorption using water, oil and kerosene is neither realistic nor reliable.

3. The immersion method may be used to quantify the potential maximum absorptive capacity of a coarse aggregate. However, it cannot be used for the whole HMA mix consisting of coarse and fine aggregates.

4. The bulk impregnated specific gravity method can be used to determine the realistic maximum absorptive capacity of an aggregate but it has limitations due to the problem of removal of air bubbles.

5. The Rice method can be used for the whole HMA mix and is the most representative of all methods since it tests the actual HMA mix wherein asphalt is present only in thin films around the aggregate.

6. The phenomenon of asphalt absorption is very much time- dependent and needs to be evaluated as such.

7. The accurate determination of asphalt absorption by most methods is dependent on the accuracy of the determination of bulk specific gravity of the aggregates used in the 
HMA mixture.

8. There is an urgent need for adopting a realistic and suitable standard method for determining asphalt absorption so that reproducible results are obtained and the HMA mixes can be designed properly.

The National Center for Asphalt Technology at Auburn University (77) has investigated the asphalt absorption of mineral aggregate under SHRP Contract A-003B (Fundamental Properties of Asphalt-Aggregate Interactions Including Adhesion and Absorption). The Rice method is recommended for determining asphalt absorption after the HMA mix has aged for 4 hours at $290^{\circ} \mathrm{F}$ in an oven. Also, the asphalt absorption has been found to follow a hyperbolic relationship with time and reaches an ultimate (limiting) value at infinite time. It is possible, based on this relationship, to predict asphalt absorption at any given time if the absorption values just after mixing and at any other two aging times are known. However, they only studied single size coarse aggregates (passing $1 / 2^{n}$ sieve and retained on $3 / 8^{\prime \prime}$ sieve).

The objective of this research work undertaken was to investigate the asphalt absorption by bottom ash and various components of bottom ash using bulk impregnation and Rice methods, and to study the suitability of the asphalt absorption methods for bottom ash materials. Tests were run on the coarse fraction and/or entire samples of the bottom ash and control mixes.

\subsection{Materials}

Bottom ash, control aggregates and asphalt used in this study were same as those in 
Chapter VII. The samples of glass, clinker and clinker with ferrous metal were created by manually separating bottom ash into different components. The materials were broken down into different sizes and reblended to meet the average gradation of bottom ash.

Aggregate materials were dried before use in order to remove the effect of moisture.

\subsection{Methods and Procedures}

\subsubsection{Absorption by Bulk Impregnation Method}

The U.S. Army Corps of Engineers $(91,92)$ developed and uses the bulk impregnated specific gravity in design and control of bituminous paving mixture. The Corps' procedure involves heating about $1500 \mathrm{~g}$ of aggregate to constant weight at $230-290^{\circ} \mathrm{F}$. The asphalt is then separately heated to $280 \pm 5^{\circ} \mathrm{F}$ and poured into a gallon pail one-third full. A metal stirrer is inserted and the asphalt is allowed to cool to room temperature for a minimum of 8 hours. The pail with asphalt and stirrer is then weighed in both air and water. The asphalt pail and aggregate are then separately heated to $280 \pm 5^{\circ} \mathrm{F}$ until the temperature is stabilized. At this stage, the pail is removed from the oven and the aggregate is slowly added to it while stirring with the stirrer. Stirring is continued until the elapsed time from start of mixing is 2 minutes. The contents are then cooled to room temperature and air bubbles, if any, are removed using a flame. The pail with asphalt, aggregate and stirrer is then weighed in both air and water. The above measurements allow the computation of the bulk impregnated specific gravity and hence asphalt absorption. 
The formula for the bulk impregnated specific gravity is:

$$
\text { Bulk-impregnated specific gravity = A / [(D-E)-(B-C)] }
$$

where,
A = Weight of oven-dry aggregate;
B = Weight of pail plus stirrer plus asphalt in air;
$\mathbf{C}=$ Weight of pail plus stirrer plus asphalt in water;
$\mathrm{D}=$ Weight of pail plus stirrer plus asphalt plus aggregate in air; and
$\mathrm{E}=$ Weight of pail plus stirrer plus asphalt plus aggregate in water.

The formula for asphalt absorption is:

$$
P_{b s}=G_{a}\left(G_{b i}-G_{s b}\right) 100 /\left(G_{s b_{-}} G_{b i}\right)
$$

where,

$$
\begin{aligned}
& P_{b a}=\text { percent absorbed asphalt by weight of aggregate; } \\
& G_{\mathrm{ab}}=\text { bulk specific gravity of aggregate; and } \\
& G_{b i}=\text { bulk-impregnated specific gravity of aggregate. }
\end{aligned}
$$

Only coarse aggregates ( $\geq$ No.4) were investigated in this study, including: 1) control, 2) ash, 3) glass, 4) clinker with iron, and 5) clinker. Two samples were prepared for each material. A uniform oven temperature of $290^{\circ} \mathrm{F}$ was used at all stages of the test (77).

\subsubsection{Absorption by Rice Method}

The Rice method was originally proposed in $1956(88,89)$ to determine the maximum specific gravity of a bituminous mixture by using volumetric flasks. The absorption of 
asphalt by aggregate in a mixture can be calculated if the maximum specific gravity of the mixture, the asphalt content, and the bulk specific gravity of the aggregate used in the mixture are known. The asphalt absorption studied in this project was investigated by this approach.

\subsubsection{Mixes}

The trial mixes investigated included:

1. Ash at $11.14 \%$ asphalt content by weight of mix

Aging time: $0,1,2,4,8$, and 24 hours.

Three samples were tested at each aging time.

2. Coarse ash ( $\geq$ No.4) at $7.46 \%$ asphalt content by weight of mix

Aging time: $0,1,4$, and 24 hours.

Two samples were tested at each aging time.

3. Control at $5.5 \%$ asphalt content by weight of total mix

Aging time: $0,1,4$, and 24 hours.

Two samples were tested at each aging time.

4. Coarse control ( $\geq$ No.4) at $2.75 \%$ asphalt content by weight of mix

Aging time: 0,4 , and 24 hours.

Two samples were tested at each aging time.

The asphalt content was selected such that the quantities of asphalt cement should be enough for coating the aggregate particles completely and at the same time, the asphalt film should not be too thick to handle the mixes. The mixes were prepared using the 
standard practice for preparing mixture for the Marshall mix design method except that they were not compacted. The mix temperature determined to provide an asphalt viscosity $170 \pm 20$ centistokes was $295^{\circ} \mathrm{F}(35)$.

\subsubsection{Aging}

The trial mix after mixing was placed in a tray, with a dimension of $13^{n} \times 9^{n} \times 2^{n}$, to uniform depth. The mix was placed in a forced air oven set at $275^{\circ} \mathrm{F} \pm 2^{\circ} \mathrm{F}$ up to 24 hours to observe the available effective binder after aging of various asphalt contents. After heat conditioning, the mixture was allowed to cool.

The previous study (36) indicates a HMA heating time of 3 hour at $275^{\circ} \mathrm{F}$ can be used to simulate plant hardening (36). SHRP (42) suggests a HMA heating time of 4 hour at $275^{\circ}$ which, based upon field validation data, simulates the aging that takes place through hot mix asphalt (HMA) production and about 3 to 5 years of pavement service.

\subsubsection{Modification}

The maximum theoretical specific gravity of the mixes was determined in accordance with ASTM D2041 (or AASHTO T209), with modification. The modifications included (95) a temperature of $77^{\circ} \mathrm{F}$, a residual pressure of $30 \mathrm{~mm} \mathrm{Hg}$, and a vacuuming time of 15 minutes. Use of these optimum levels is expected to improve the reproducibility of the Rice method, especially when highly absorptive aggregates are used in the asphalt mixtures. 


\subsection{Results and Discussions}

\subsubsection{Absorption by Bulk impregnated Method}

The results of asphalt absorption and water absorption by the aggregate materials are presented in Table 8.1 and Figure 8.1. The control has the lowest asphalt absorption and the ash has the highest asphalt absorption. Based on the level of asphalt and water absorption, the materials are ranked as follows:

Bottom Ash $>$ Clinker $>$ Clinker with Iron $>$ Glass $>$ Control

It is found that asphalt absorption increases with increasing water absorption regardless of the type of aggregates investigated.

Asphalt absorption plotted as a function of water absorption relation is shown in Figure 8.2. The correlation coefficient $(r)$ of 0.981 shows a good linear correlation.

The asphalt absorption by this method as a percentage of water absorption is found to range from 87.5 to $120.4 \%$, as compared to 25 to $43 \%$ reported from SHRP study (77). The relation between asphalt and water absorption is associated with the characteristics of permeable pore of aggregates such as size, distribution, shape, etc. Hoque and Cabrera (96) found a reasonable correlation between mercury porosimeter pore size distribution and asphalt absorption for pores larger than 0.05 micron in radius. They stated that the small pores did not appear to absorb asphalt, but are penetrated by water. This was probably attributable to the higher viscosity of the asphalt as compared to water. The reason for the high ratio of asphalt absorption to water absorption for the aggregates investigated in this study might be that the permeable pores of aggregate 
Table 8.1 Asphalt Absorption by Bulk Impregnation Method

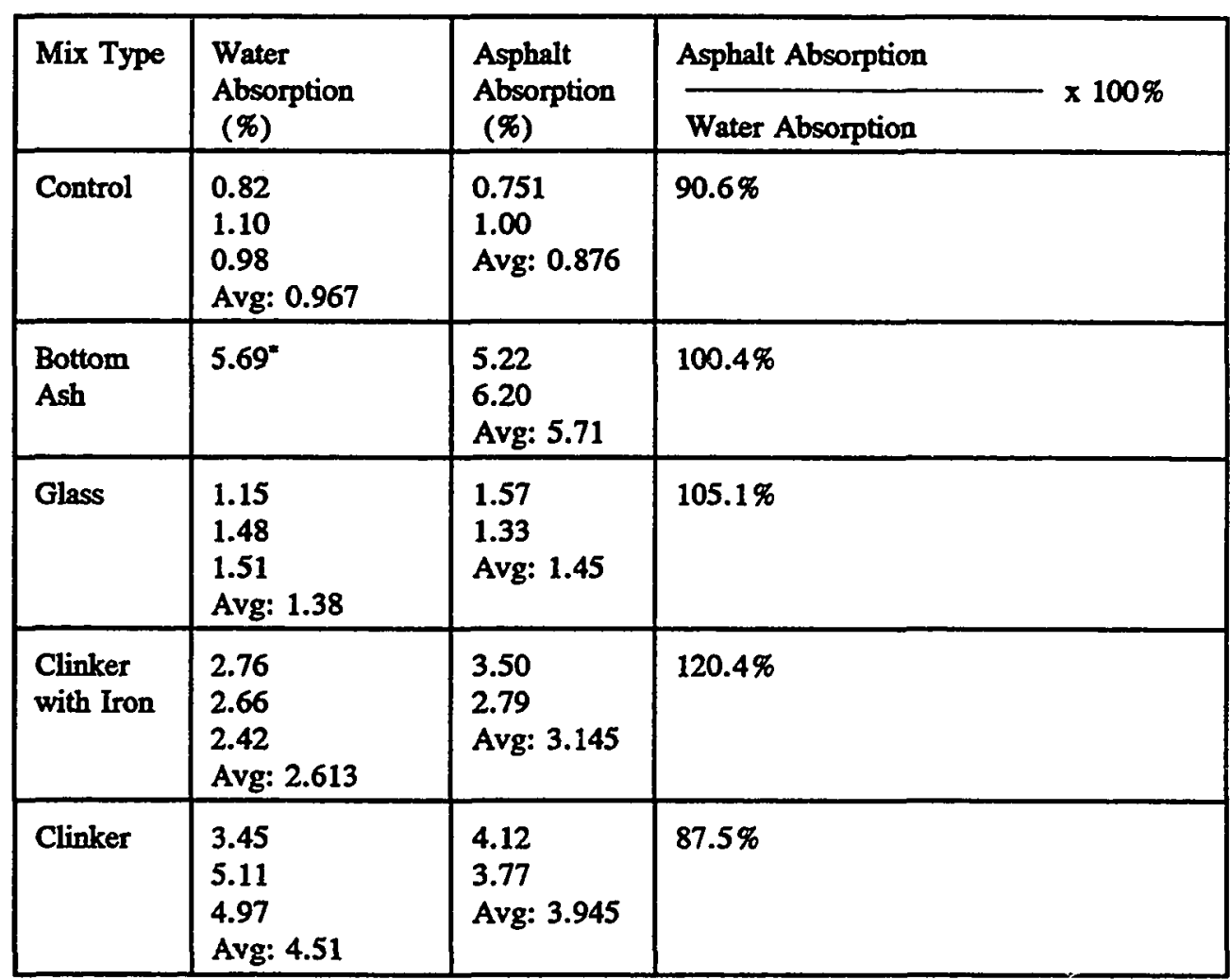

In Table 8.1, " an average of 72 samples 


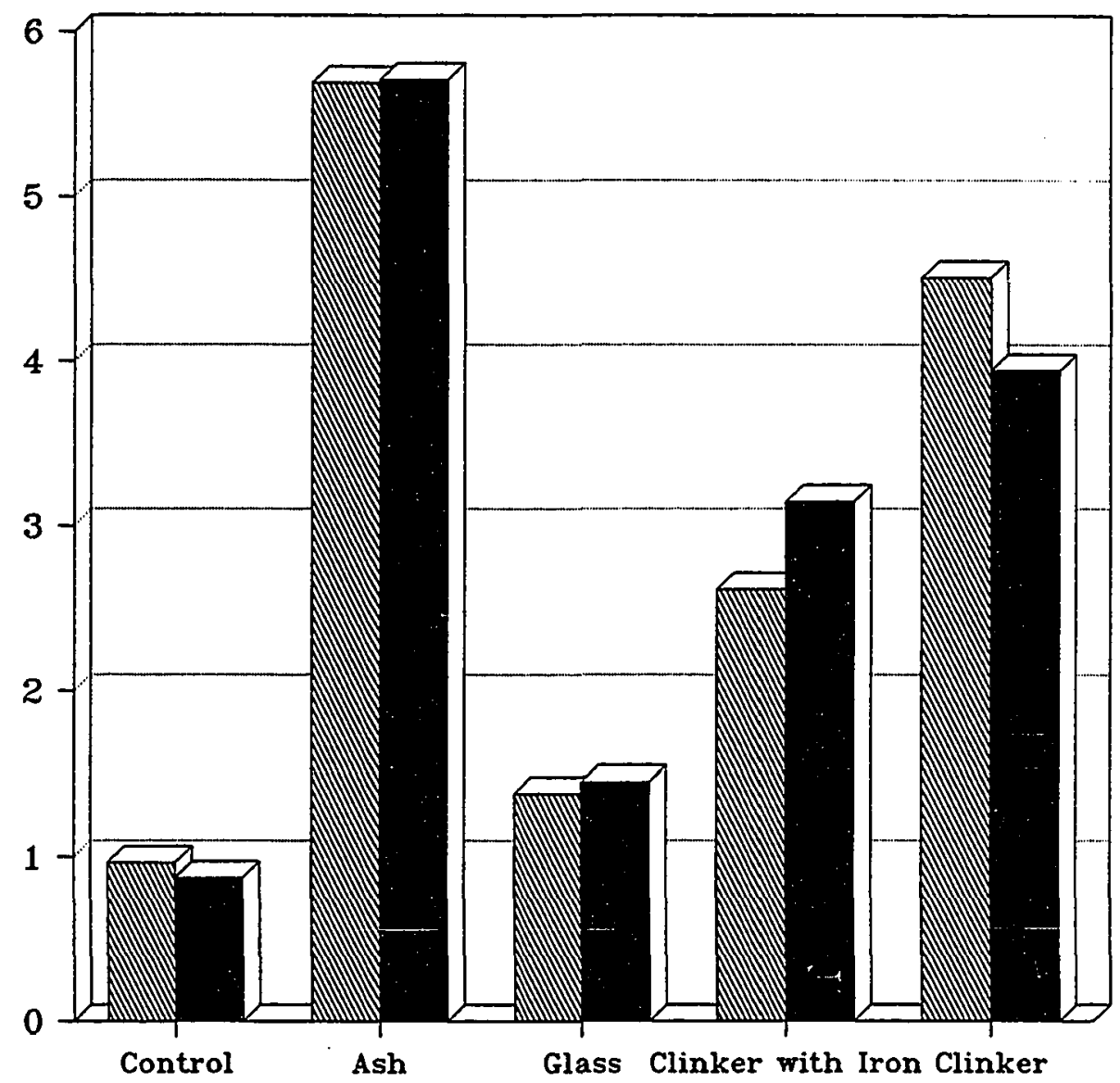

Water Absorption \% Asphalt Absorption \%

Figure 8.1 Water Absorption and Asphalt Absorption (Bulk Impregnation Method) 


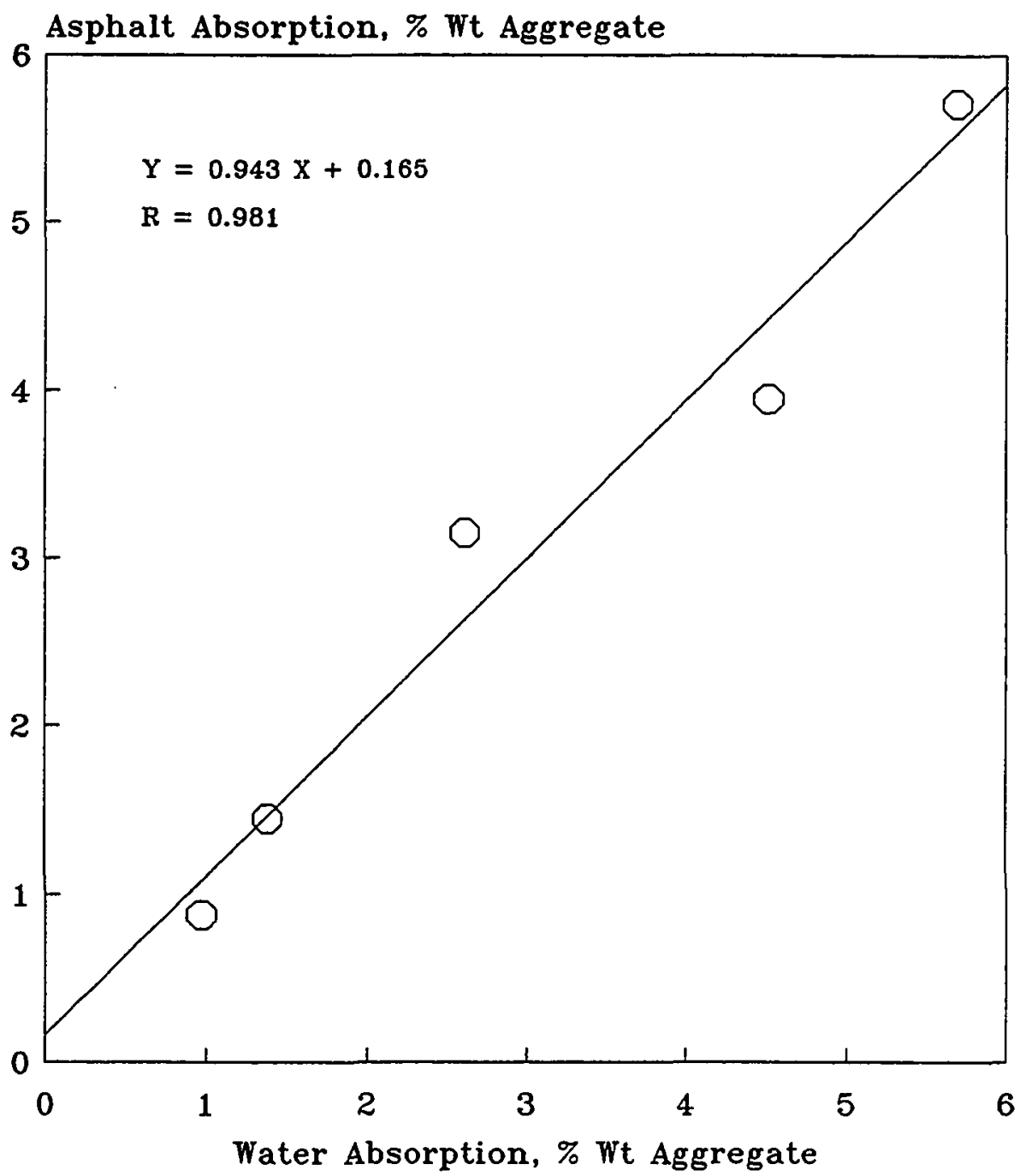

Figure 8.2 Absorbed Asphalt versus Absorbed Water (Bulk Impregnation Method)

306 
particles are relatively big, which can be penetrated by both water and asphalt even though asphalt has much higher viscosity than water.

\subsubsection{Absorption by Rice Method}

Asphalt in an asphalt mix is present in the form of thin films around the aggregate. Rice method can be applied to actual mixes. Figures 8.3 and 8.4 present the asphalt absorption as a function of aging time. The time - dependent absorption of the ash and coarse ash mixes is not obvious because of large variation in data. The absorption of the control and coarse control mixes varies little with increasing aging time. One explanation of such a time independence is that the size of the permeable pore of ash and control aggregates were either too big or too small. The big pores were filled with asphalt during mixing and the small pores did not absorb asphalt so that the aging did not affect significantly the amount of absorbed asphalt. The absorption of the coarse control mix is almost the same as that of the control. The absorption of the coarse ash mix is lower than that of the ash mix, indicating fine ash is more absorptive than coarse ash. As would be expected, the ash and coarse ash show higher absorption than the control and coarse control.

Figure 8.4 presents a comparison between Rice and bulk impregnation methods. The data of the coarse limestone in Figure 8.4 was reported by Kandhal and Khatri (77). The absorption of coarse limestone by the bulk impregnated specific gravity method, which is the second most commonly used method for asphalt absorption, appears to intersect the corresponding Rice absorption curves at about 4 hours ( 3 to 5 hours range) of aging time. 


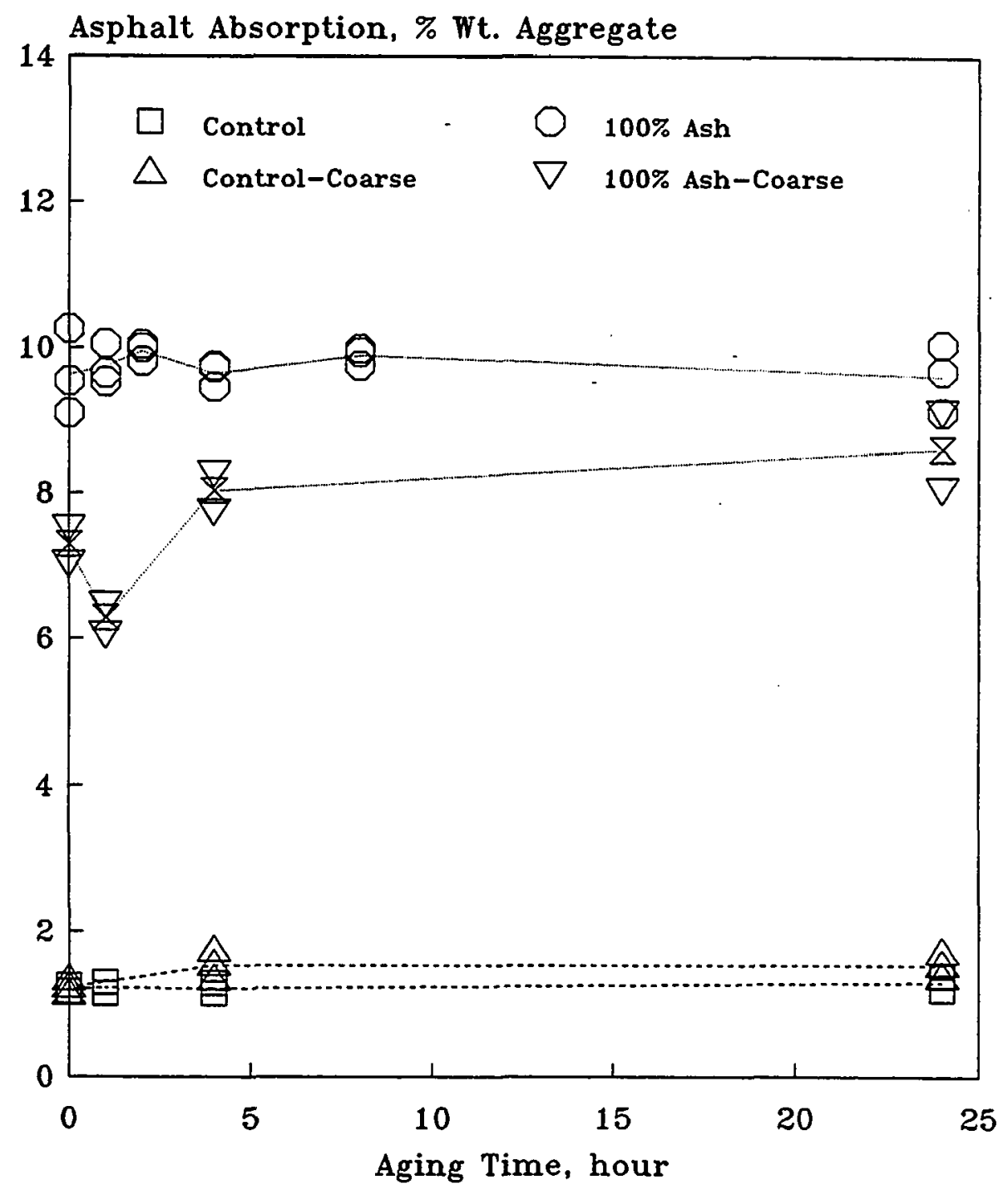

Fig. 8.3 Asphalt Absorption versus Aging Time (Rice Method) 308 


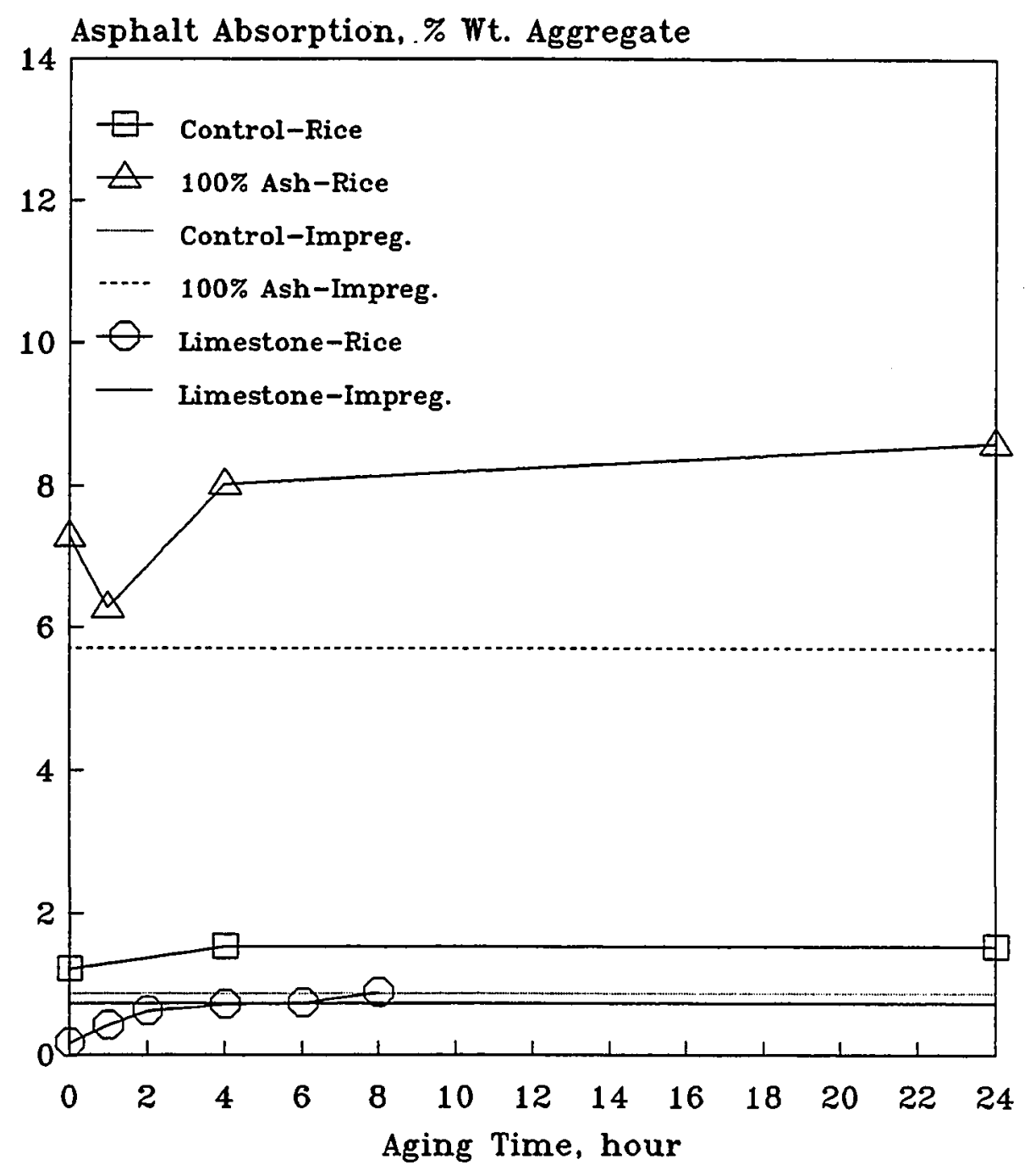

Figure 8.4 Asphalt Apsorption of Coarse Aggregate versus Aging Time 
Moreover, the curve for asphalt absorption appears to level off at about 4 hours aging time. However, the absorption of the coarse ash and coarse control by bulk impregnation method is lower than that by Rice method. Hence, the correlation of these two methods is associated with aggregate types.

The asphalt absorption by Rice method as a percentage of water absorption is found to range from 88.2 to $99.4 \%$ for the ash, 106.8 to $160.5 \%$ for the coarse ash, 97.6 to $118.2 \%$ for the control, and 128.4 to $196.8 \%$ for the coarse control.

\subsubsection{Suitability of The Two Methods}

\subsubsection{Rice Method}

It was stated in Chapter VII that the Rice method is not suitable for the ash. This can be investigated by looking at effective asphalt $\left(P_{b e}\right)$. The effective asphalt content $\left(P_{b c}\right)$ of a paving mix is the total asphalt content $\left(\mathrm{P}_{2}\right)$ minus the absorbed asphalt content $\left(\mathrm{P}_{\mathrm{b}_{\mathrm{a}}}\right)$. The effective asphalt is the portion of the total asphalt that remains as a coating on the outside of the aggregate particles, and is the asphalt content on which service performance of an asphalt paving mixture depends.

The $P_{a}, P_{b a}$, and $P_{b e}$ as a function of aging time are presented in Figure 8.5 through Figure 8.8. The effective asphalt content of the control and coarse control is about $4.3 \%$ and $1.4 \%$ respectively, which agree with visual observation. Visually, all particles are coated well with asphalt at any aging time studied. Coarse aggregates have less surface area, and therefore, require less asphalt cement to achieve complete coating as compared 


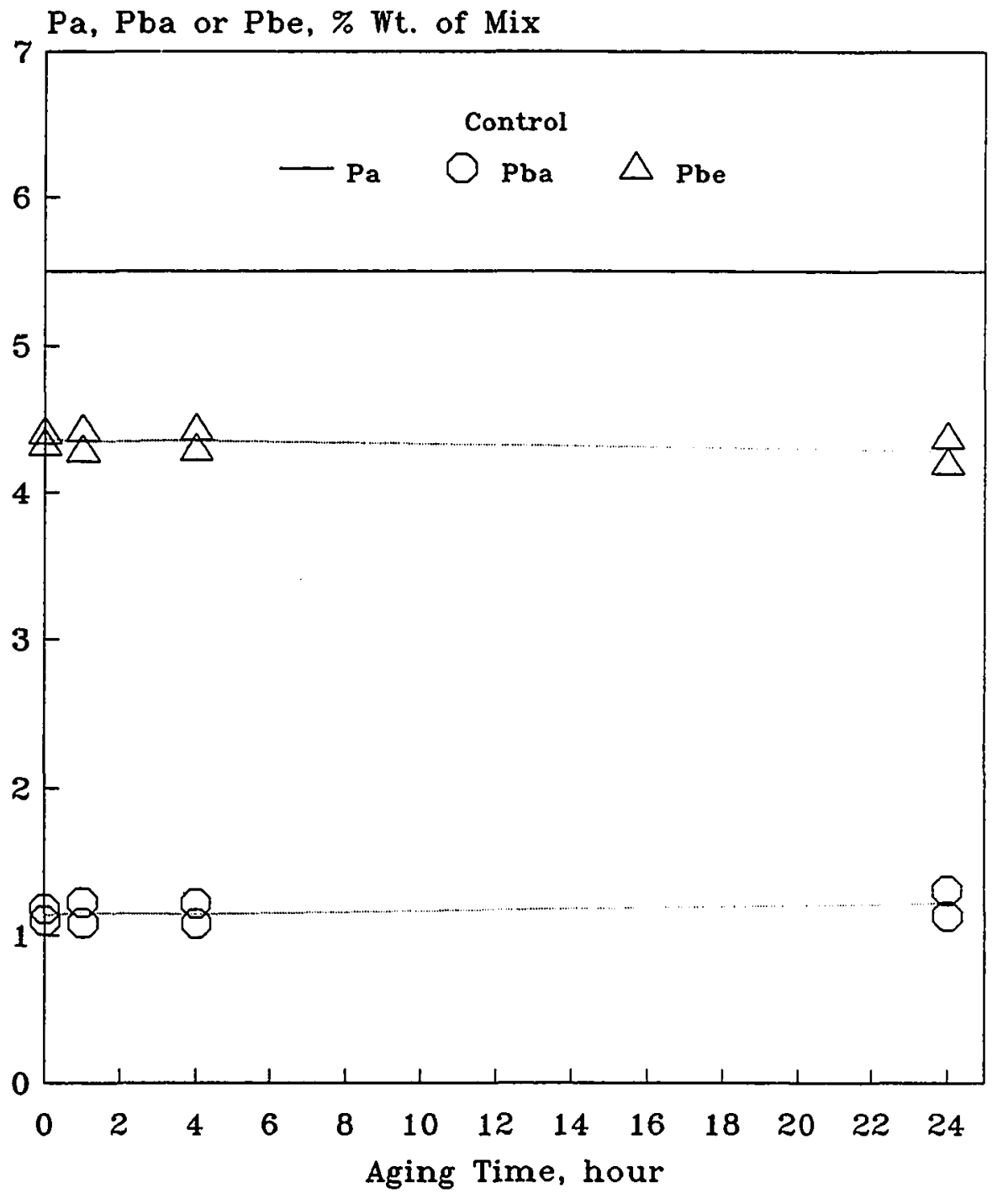

Figure 8.5 $\mathrm{Pa}, \mathrm{Pba}$ and $\mathrm{Pbe}$ versus Aging Time (Control)

311 


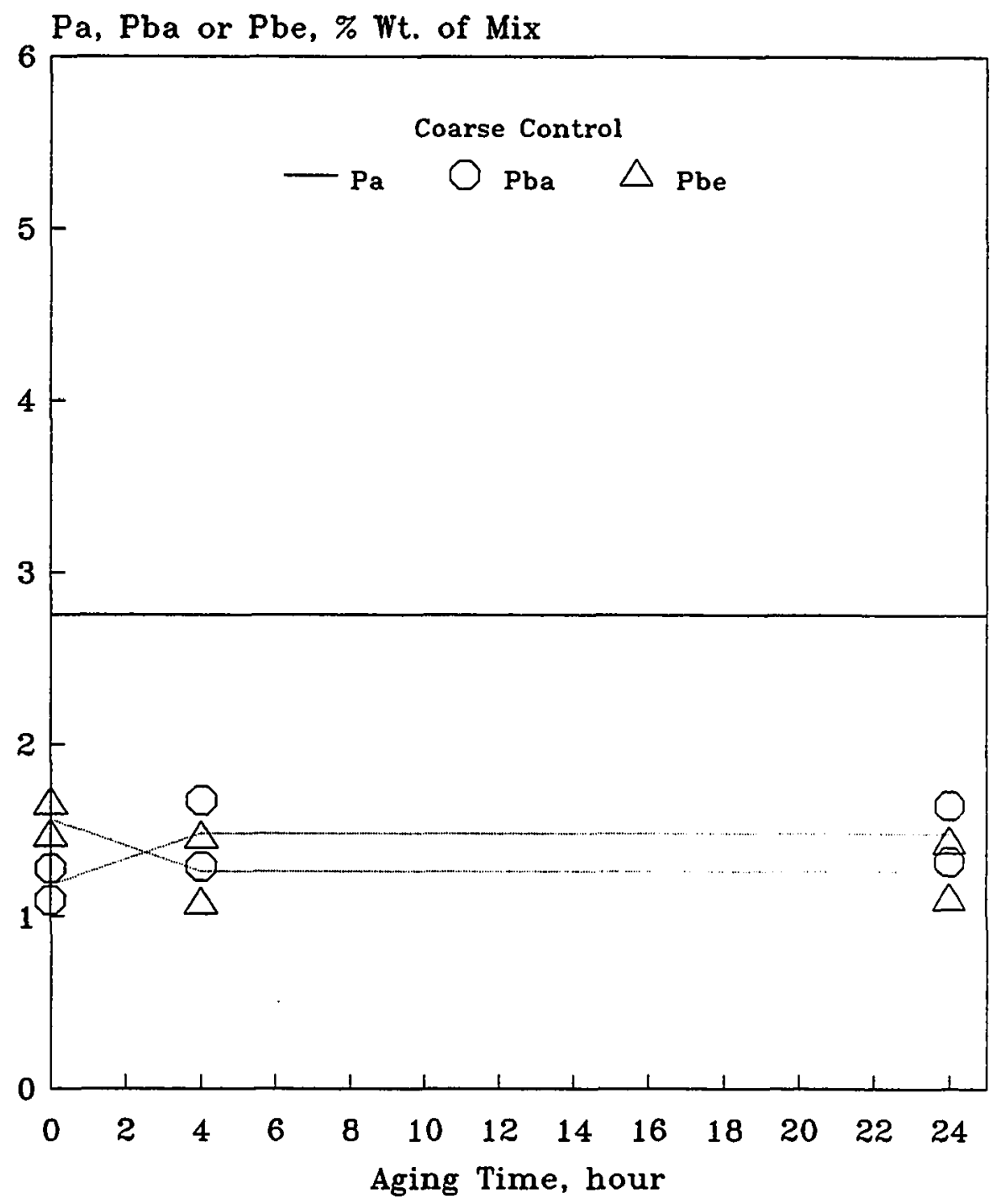

Figure 8.6 $\mathrm{Pa}, \mathrm{Pba}$ and $\mathrm{Pbe}$ versus Aging Time (Coarse Control) 


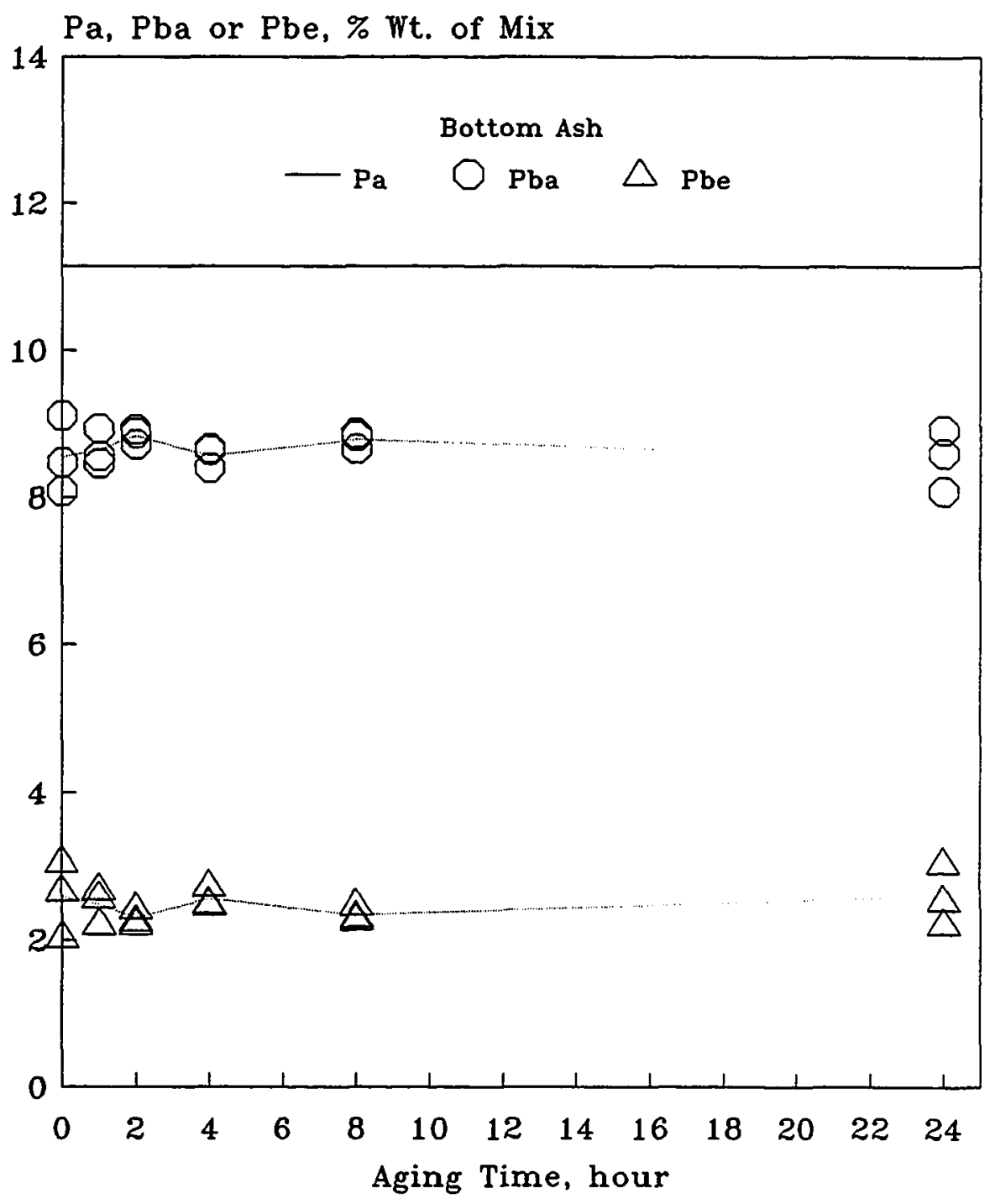

Figure 8.7 $\mathrm{Pa}, \mathrm{Pba}$ and $\mathrm{Pbe}$ versus Aging Time (Bottom Ash)

313 
$\mathrm{Pa}, \mathrm{Pba}$ or $\mathrm{Pbe}, \%$ Wt. of Mix

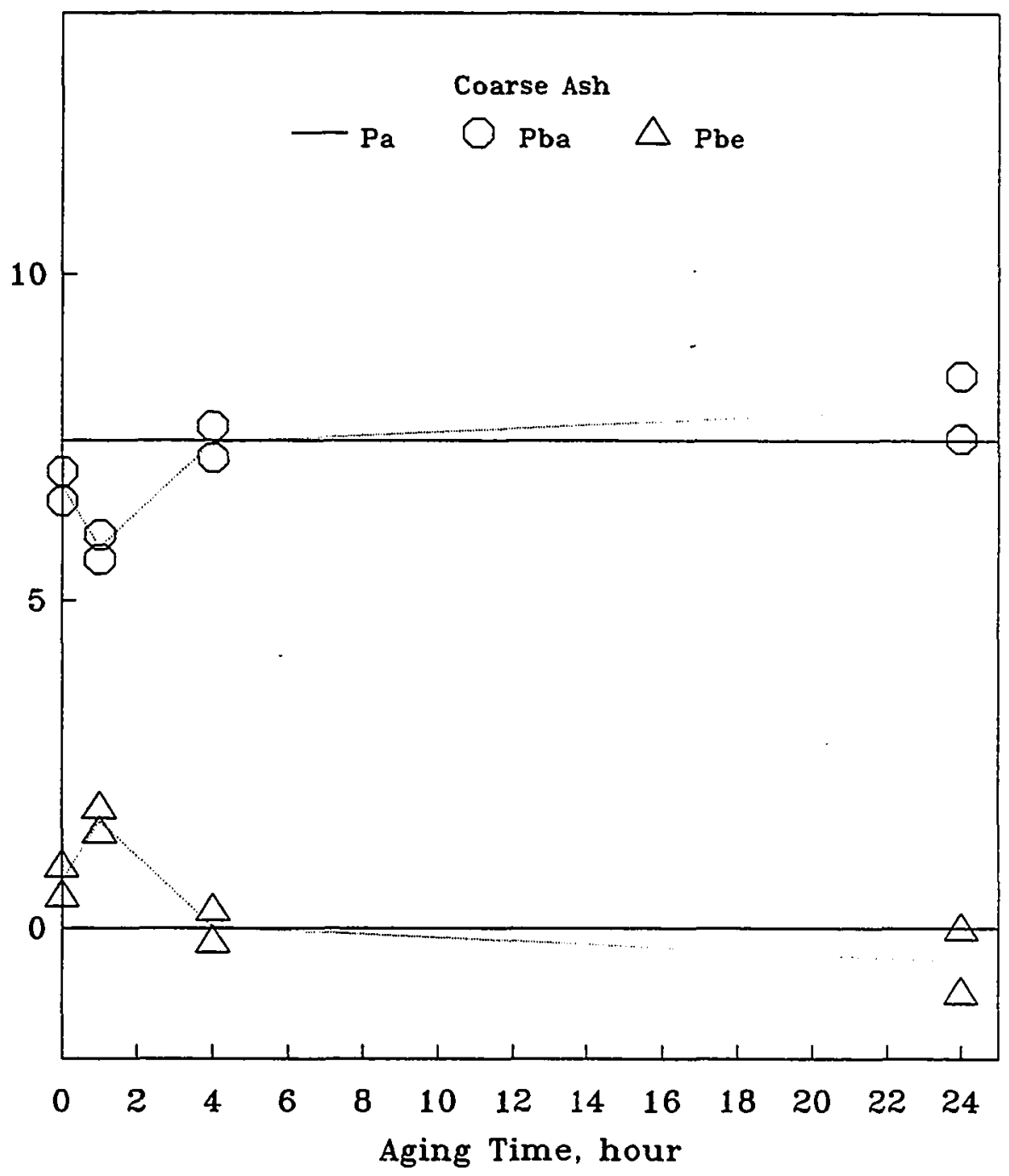

Figure 8.8 $\mathrm{Pa}, \mathrm{Pba}$ and $\mathrm{Pbe}$ versus Aging Time (Coarse Ash)

\section{4}


to fine aggregates. The effective asphalt content for the ash and coarse ash is about $2.5 \%$ and $0.5 \%$ respectively, which are not realistic and disagree with visual observation. Visually, most ash particles are coated well with asphalt at any aging time studied. Since it is more absorptive, angular and flaky than control ash requires more effective asphalt to achieve the complete coatings. However, the Rice method shows the effective asphalt content of the ash is less that of the control. One explanation is as follows:

It is well known that for conventional aggregates, $G_{s e} \geq G_{s b}>G_{m m}$. The $G_{s e}, G_{s b}$ and $G_{\operatorname{mm}}$ as a function of aging time are shown in Figures 8.9 through 8.12. It is found that,

$$
\begin{array}{ll}
\text { The control: } & \mathrm{G}_{\mathrm{se}}>\mathrm{G}_{\mathrm{sb}}>\mathrm{G}_{\mathrm{mm}} \\
\text { The coarse control: } & \mathrm{G}_{\mathrm{se}}>\mathrm{G}_{\mathrm{sb}}>\mathrm{G}_{\mathrm{mm}} \\
\text { The ash: } & \mathrm{G}_{\mathrm{se}}>\mathrm{G}_{\mathrm{mm}}>\mathrm{G}_{\mathrm{sb}} \\
\text { The coarse ash: } & \mathrm{G}_{\mathrm{se}}>\mathrm{G}_{\mathrm{mm}}>\mathrm{G}_{\mathrm{sb}}
\end{array}
$$

The results of the control and coarse control agree with those for conventional aggregates. But the results of the ash and coarse ash do not. It is felt that the pore size of the ash particles, especially for coarse particles, is much larger than that of the control aggregates and most pores of the ash can be penetrated by asphalt cement due to their relative pore size. More important, most of permeable pores of the ash particles are interconnected as compared to the control materials. The inter-connected pores of a ash hot asphalt mix are only partially saturated due to a limited supply of asphalt. When the Rice test is run on uncompacted ash mixes, the inter-connected pores which are only partially filled with asphalt still may be permeable to water, and therefore saturated with water 


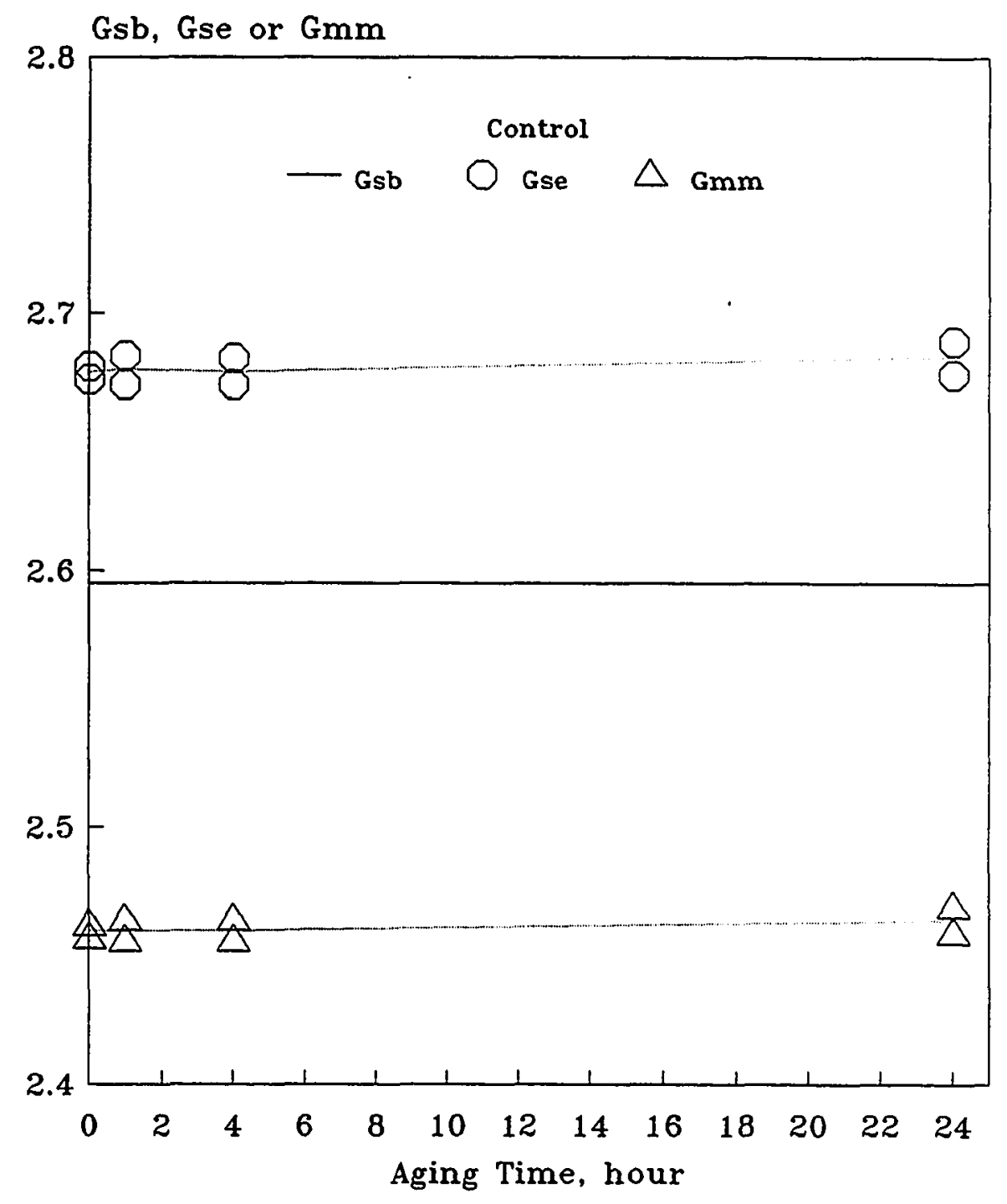

Figure 8.9 Gsb, Gse and Gmm versus Aging Time (Control) 


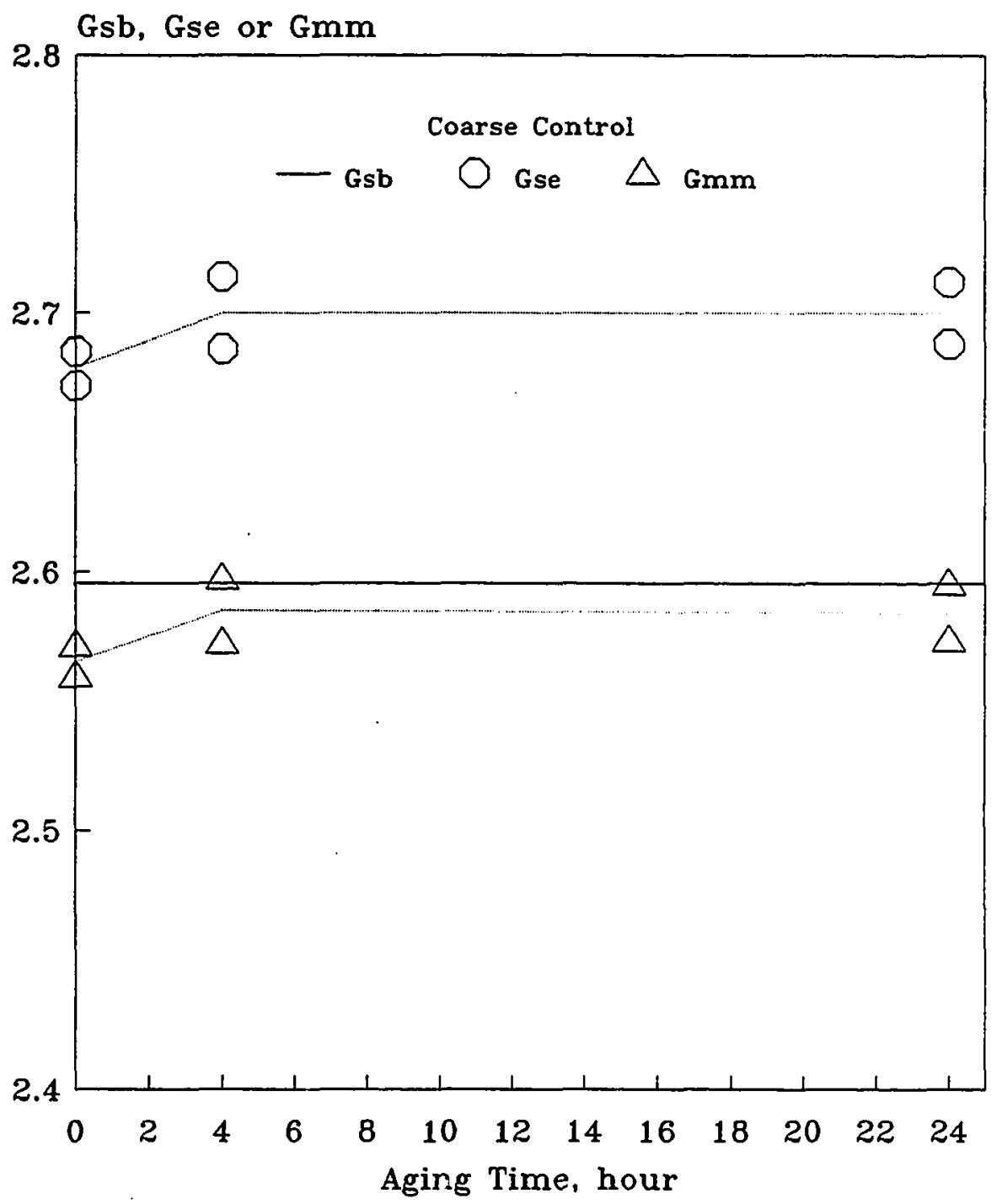

Figure 8.10 Gsb, Gse and Gmm versus Aging Time (Coarse Control)

317

Reproduced with permission of the copyright owner. Further reproduction prohibited without permission. 


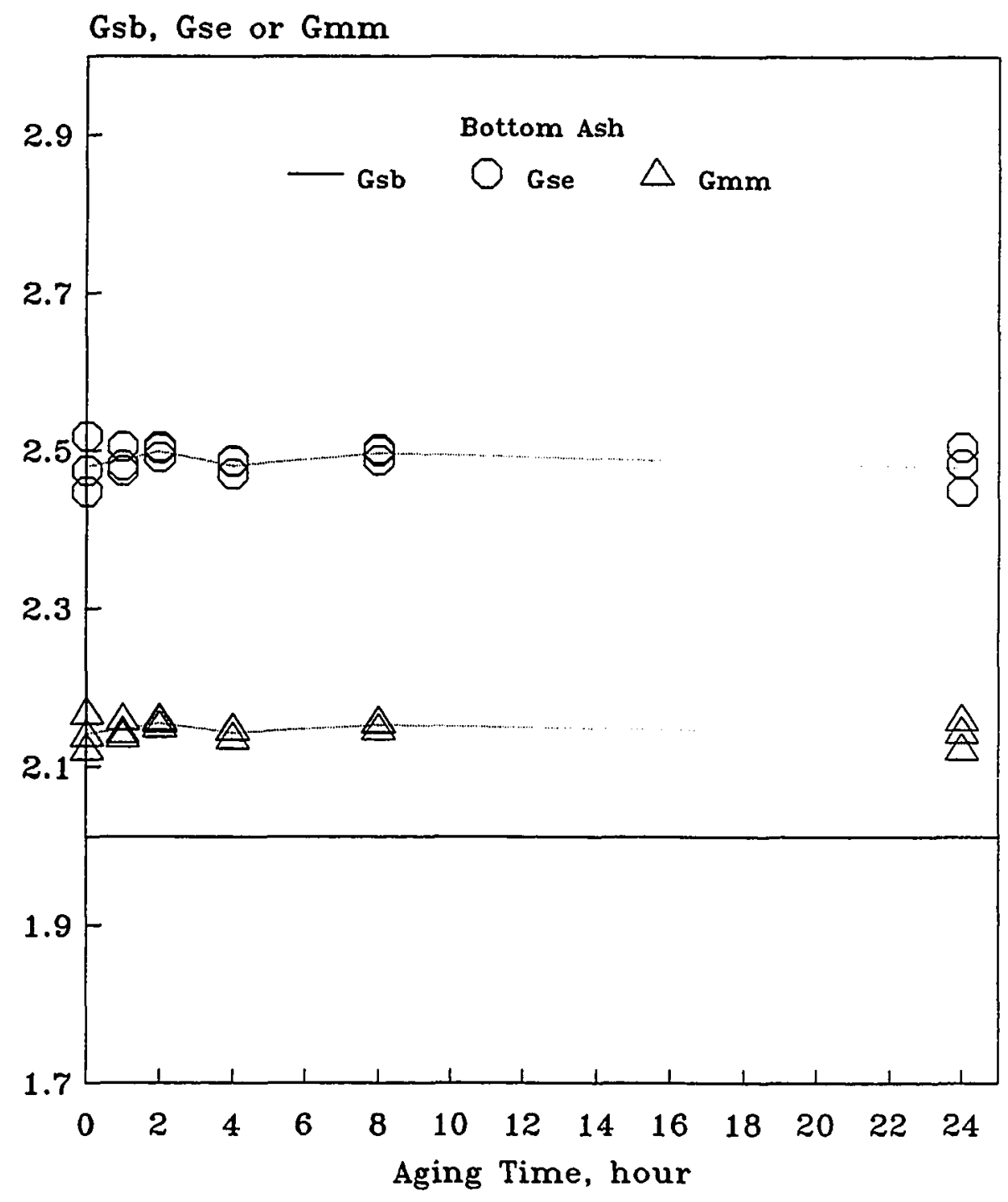

Figure 8.11 Gsb, Gse and Gmm versus Aging Time (Bottom Ash) 


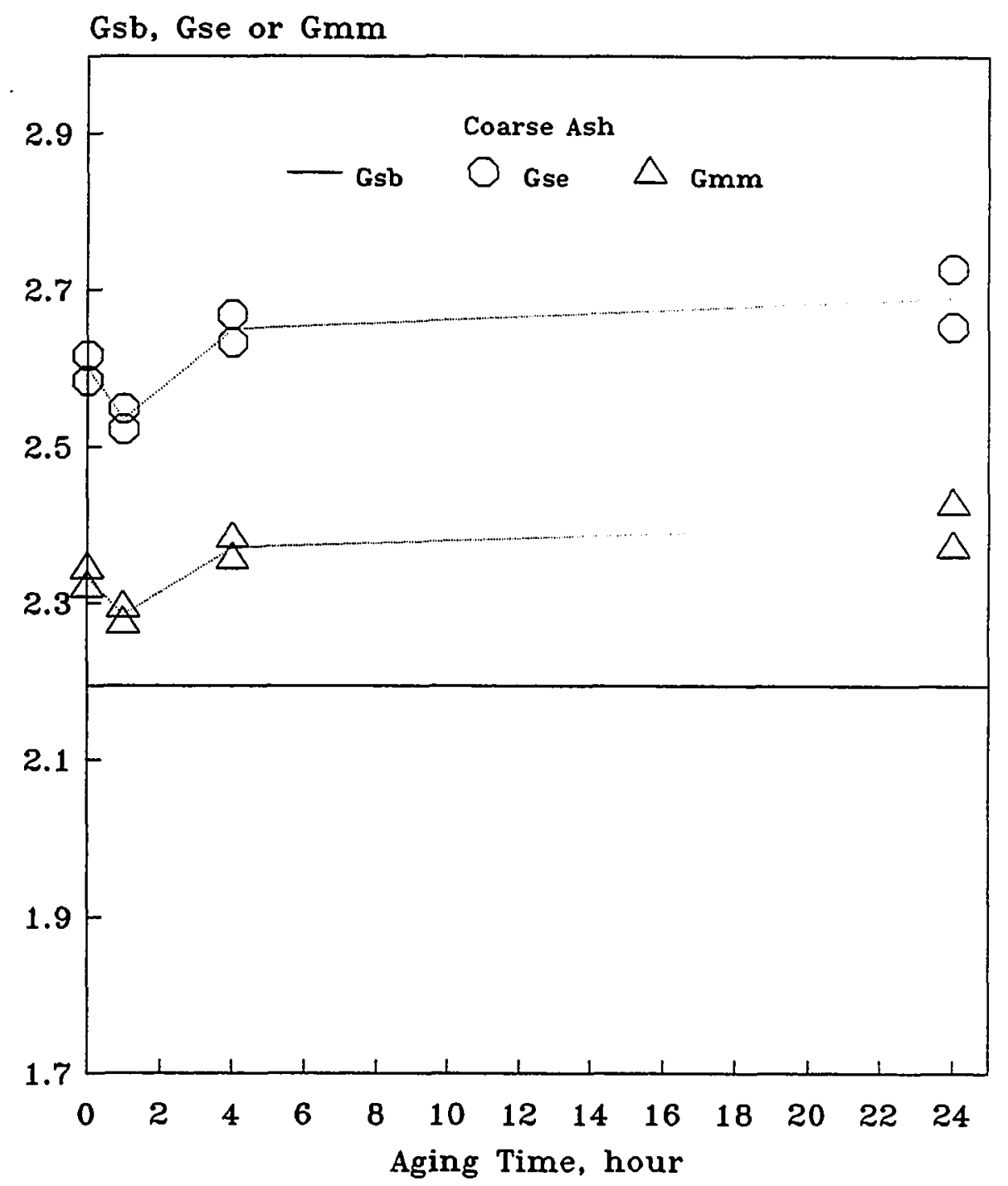

Figure 8.12 Gsb, Gse and Gmm versus Aging Time (Coarse Ash) 
during vacuuming phase of Rice test. Water absorption by bottom ash during the Rice test may result in a significant increase of $G_{\mathrm{mm}}$. The increase in $G_{\mathrm{mm}}$ results in increasing $G_{s e}$, which bring about an increased $P_{b a}$ or decreased $P_{b e}$. Obviously, the Rice test is not an adequate method for determining $\mathrm{G}_{\mathrm{mm}}$ of the ash mixes.

\subsubsection{Bulk Impregnation Method}

Bulk impregnation method appears suitable for the ash mixes because the mixes are not in contact with water during test. However, a standard 2 minutes of impregnation time requires more investigation. Bulk impregnation density of a HMA mix is associated with the impregnation time. The correlation between the density of a field mix and a laboratory mix should studied to determine a proper impregnation time.

\subsection{Conclusions and Recommendations}

Based on the asphalt absorption by two different methods using seven aggregates and one asphalt cement the following conclusions are drawn and recommendations made.

1. Based on the level of absorbed asphalt by the impregnation method the materials are ranked with regards to absorption as follows:

$$
\text { Bottom Ash }>\text { Clinker }>\text { Clinker with Iron }>\text { Glass }>\text { Control }
$$

2. The data by the impregnation method show asphalt absorption increases linearly with increasing water absorption regardless of the type of aggregates investigated.

3. The asphalt absorption by the impregnation method as a percentage of water absorption is found to range from 87.5 to $120.4 \%$. 
4. The asphalt absorption of the ash and coarse ash mixes by the Rice method does not exhibit time-dependence because of large variation in data.

5. The amount of absorption of the control by the Rice method is about same as that of the coarse control, and they do not show time-dependence.

6. The absorption of the coarse ash mix by the Rice method is lower than that of the ash mix.

7. The ash and coarse ash show higher absorption than the control and coarse control.

8. The asphalt absorption by Rice method as a percentage of water absorption is found to range from 88.2 to $196.8 \%$.

9. The Rice method overestimates $G_{m m}$ and $P_{b a}$, and underestimates $P_{b e}$ for the ash mixes.

10. The absorption of the coarse ash and coarse control by bulk impregnation method is lower than that by Rice method.

There is a need to improve the Rice method for better determining $G_{m m}$ and $P_{b a}$ for the ash mixes. The bulk impregnation method appears suitable for the ash mixes with modification. Other potential methods should also be investigated. 


\section{MICROSCOPIC STUDY}

\subsection{Introduction}

The asphalt absorption is associated with pore properties, chemical and mineral composition of aggregate, surface roughness, and wetting properties. There are two types of pores commonly found in a porous solid, permeable and impermeable pores. The pore system of a porous solid includes the volume of the pores and their structure: the size, shape, distribution, and continuity. The permeable pores are responsible for asphalt absorption. The amount of asphalt absorbed depends on the volume of permeable pores and their structure.

The objectives of the microscopic study was to qualitatively investigate pore properties of bottom ash and asphalt absorption using a Scanning Electron Microscopy and an Optical Microscopy.

\subsection{Materials}

\subsubsection{Aggregates}

The bottom ash used was the same as that in Chapter VII, with the exception that the bottom ash was separated individually and washed before use. The control aggregates used were the same as in Chapter VI. 


\subsubsection{Asphalt Mixes}

$\underline{100 \%}$ Bottom Ash Mixes

A Marshall specimen with $100 \%$ bottom ash and $11.1 \%$ asphalt content and $4 \%$ air voids was fabricated with Marshall procedures.

An uncompacted mix with $100 \%$ bottom ash and $11.1 \%$ asphalt content was made as per Marshall procedures except without compaction.

\section{0\% Bottom Ash Mixes}

A mix with $50 \%$ bottom ash and $7.0 \%$ asphalt content was compacted after 300 revolutions with GTM to fabricate a specimen with $4.4 \%$ air voids. The procedures followed were the same as in Chapter VII.

\section{Control Mixes}

A control mix with $5.1 \%$ asphalt content was compacted after 300 revolutions with GTM to make a specimen with $4.7 \%$ air voids. The procedures were the same as in Chapter VII.

An uncompacted mix with $5.1 \%$ asphalt content was prepared as per the procedures in Chapter VII except without compaction.

\subsection{Methods}

\subsubsection{Scanning Electron Microcopy (SEM)}

An AMR Model 1000 Scanning Electron Microscope at the UNH Instrumentation Center was employed in this study. The main parameters used were $20 \mathrm{KV}$ excitation, 
45000 counts, and a 30.0 degree tilt. Aggregate particles were glued to structural probes with conductive carbon paint and coated with gold before SEM. Only aggregates were investigated.

\subsubsection{Petrographic Analysis}

A standard optical microscope using transmitted light was employed. Thin sections of aggregates and asphalt Concrete were prepared. Hillquist A-B Epoxy was used to cement small particles together to make a big sample for easy cutting and polishing. Hillquist C-D Epoxy was used to cement a well polished sample to a glass slide.

\subsubsection{Procedures of Making An Aggregate Thin Section}

1. 7 parts of A to 3 parts of B were mixed well in a small paper cup. Aggregate particles were added into the cup slowly and stirred well with a small rod.

2. The cup was placed on a hot plate at $175^{\circ} \mathrm{F}$ and cured for 30 minutes.

3. The hardened specimen was removed from the paper cup.

4. The specimen was polished to levelness and smoothness on a steel wheel. The grinding powders used were in five grits: $240,400,600,1000$.

5. 4 parts of $C$ to 1 part of $D$ were mixed well in a container and three drops of the well mixed C-D epoxy was put on the well polished specimen.

6. A glass slide was put on the specimen and pressed to remove bubbles, Which was cured for 30 minutes on a hot plate at $175^{\circ} \mathrm{F}$.

7. The specimen was cut by means of a small circular diamond saw, so that the 
thickness was 60 to $70 \mu \mathrm{m}$ (excluding glass slide).

8. The specimen was ground on a diamond cup wheel so that the thickness was 3 to 7 $\mu \mathrm{m}$ (excluding glass slide).

\subsubsection{Procedures of Making An Asphalt Concrete Thin Section}

Neidel and Eriksen developed a procedure of making thin sections of asphalt concrete (97). The objectives of their research were 1) to adapt techniques of preparation of thin sections and plane sections of asphalt concrete for microscopical examination without damaging the internal structure, and 2) to investigate the compatibility between asphalt binder and impregnation materials. The procedure they developed was certainly helpful to this study. The procedure used in the study of bottom ash asphalt concrete were as follows.

\section{Uncompacted Mixes}

1. 7 parts of A to 3 parts of B were mixed well in a small paper cup. Asphalt-coated particles were added into the cup slowly and stirred well with a small rod.

2. The cup was placed in a room at room temperature for 3 days.

3. The hardened specimen was removed from the paper cup.

4. The specimen was cooled to 36 to $37^{\circ} \mathrm{F}$ and polished to levelness and smoothness on a steel wheel. The dripping water was ice-cooled. The specimen was polished for a period of max 1 minute at a time and put back in ice-cooled water for 5 minutes to keep the specimen cooled. The grinding powders used were in five grits: $240,400,600,1000$.

5. 4 parts of $C$ to 1 part of $D$ were mixed well in a container and three drops of the 
well mixed C-D epoxy was put on the well polished specimen.

6. A glass slide was put on the specimen and pressed to remove bubbles, Which was cured at room temperature for 3 days.

7. The spocimen was cooled to 36 to $37^{\circ} \mathrm{F}$ and cut by means of a small circular diamond saw, so that the thickness was 60 to $70 \mu \mathrm{m}$ (excluding glass slide). In cutting, cooling water was ice-cooled.

8. The specimen was ground on a diamond cup wheel so that the thickness was 3 to $7 \mu \mathrm{m}$ (excluding glass slide). In grinding, cooling water was ice-cooled.

\section{Compacted Mixes}

1. A compacted sample was cooled to 36 to $37^{\circ} \mathrm{F}$ and cut vertically to divide the sample into small parts by means of a circular diamond saw. Each part had a dimension of approximately $3^{n} \times 2^{n} \times 1 / 2^{n}$. In cutting, cooling water was ice-cooled.

The rest was the same as steps 4 to 8 for uncompacted mixes.

\subsection{Results and Discussions}

\subsubsection{Aggregates}

Bottom ash as received looks dark grey to black as shown in Figure 9.1. The big particle is coated with dust. Figure 9.2 presents a picture of bottom ash sample after it was separated on sieves, washed, and dried. Large particles such as glass, clinker, stone are easily identified. 


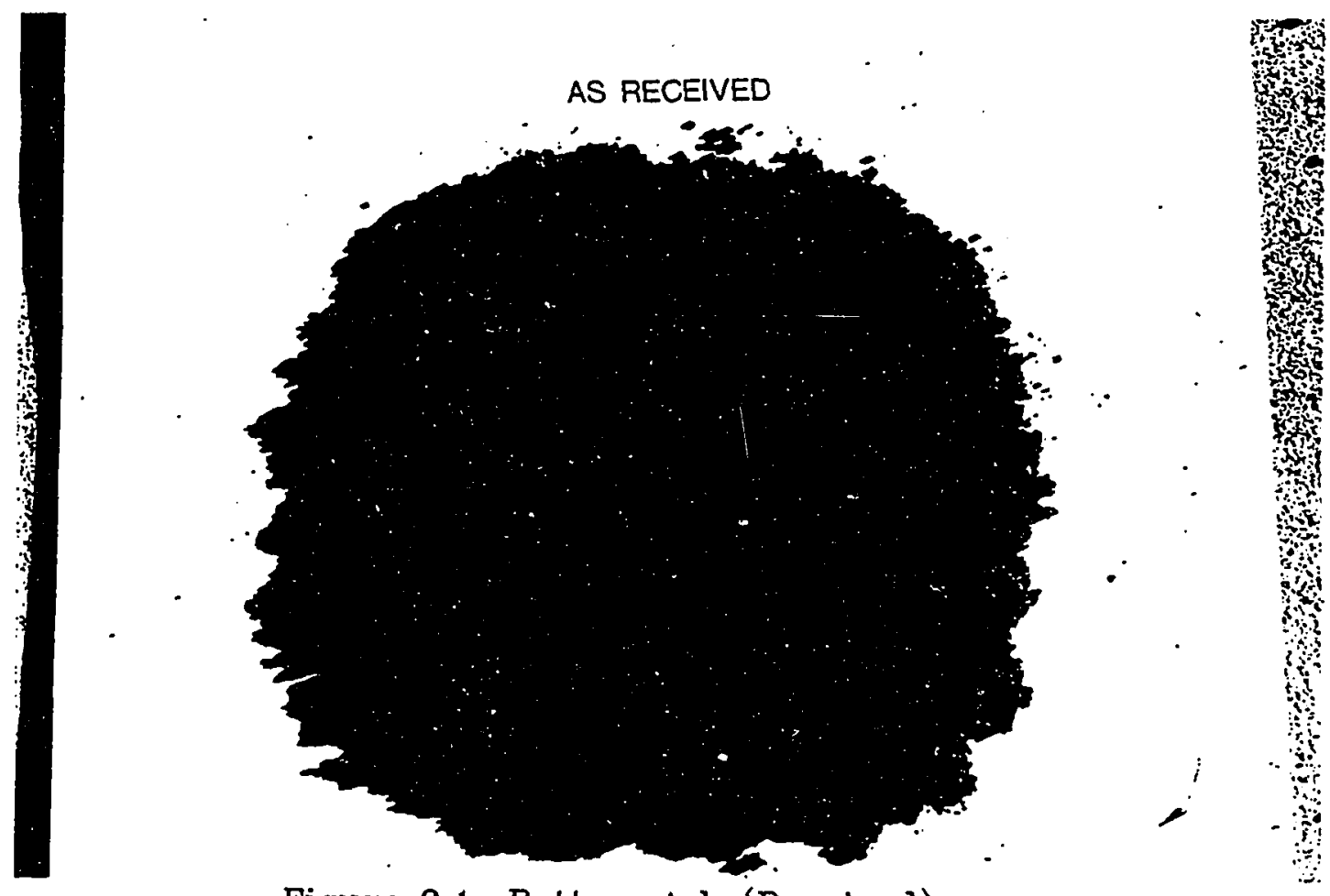

Figure 9.1 Bottom Ash (Received)

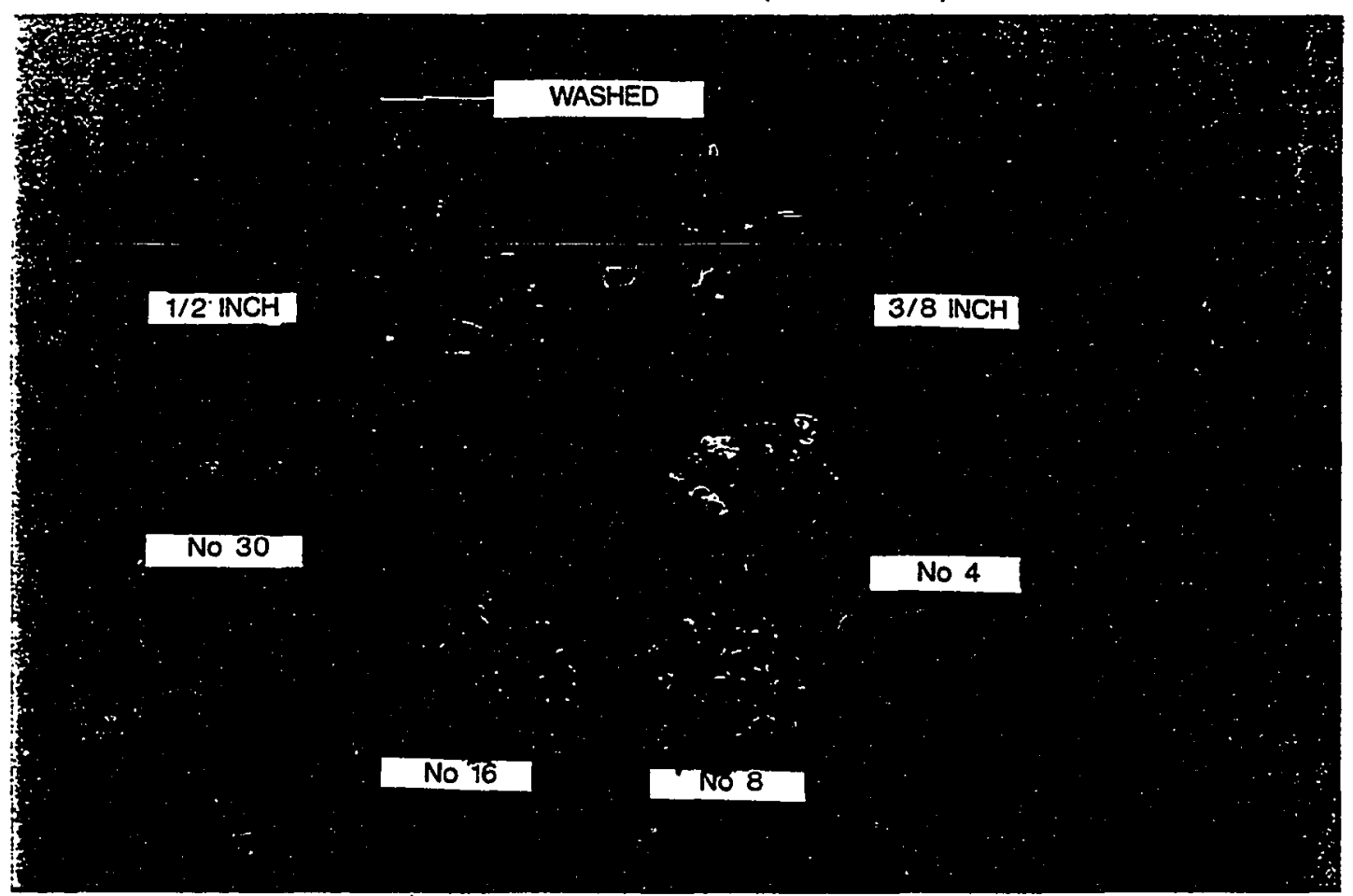

Figure 9.2 Bottom Ash (Washed and Separated)

327 


\subsubsection{SEM}

SEM was conducted on bottom ash and control aggregates. Particle sizes investigated included those particles retained on the No.80, No.200, and $<$ No.200 sieves.

Figures 9.3 through 9.12 present SEM photographs of bottom ash. Figures 9.13 through 9.17 present SEM photographs of control aggregates.

\section{Particle Shape}

Most bottom ash particles possess well-defined edges and corners, and therefore, are angular. A lot of ash particles are equidimensional. Some of bottom ash particles show that thickness is small relative to two other dimensions, and are flaky, or that length is considerably larger than the other two dimensions, and are elongated. Control particles are angular and equidimensional or elongated. In asphalt concrete, aggregates should be equidimensional and a combination of angular and rounded material. The aggregates which are angular, flaky and elongated require more asphalt cement to obtain the complete coating because of their large surface area.

\section{Surface Texture}

Surface texture is defined as the degree to which the aggregate surface is smooth or rough, is based on visual judgment. Most bottom ash particles show some degree of roughness and a honeycombed texture with visible pores. Some crystals resulting from the chemical reaction which could be salts precipating or carbonation are found on the surface of ash particles at high magnification, as shown in Figures 9.10 through 9.12. The visible pores are in different forms, as shown in Figures 9.5, 9.8 and 9.9. Control particles show some degree of roughness. The roughness of control results from crushing, 


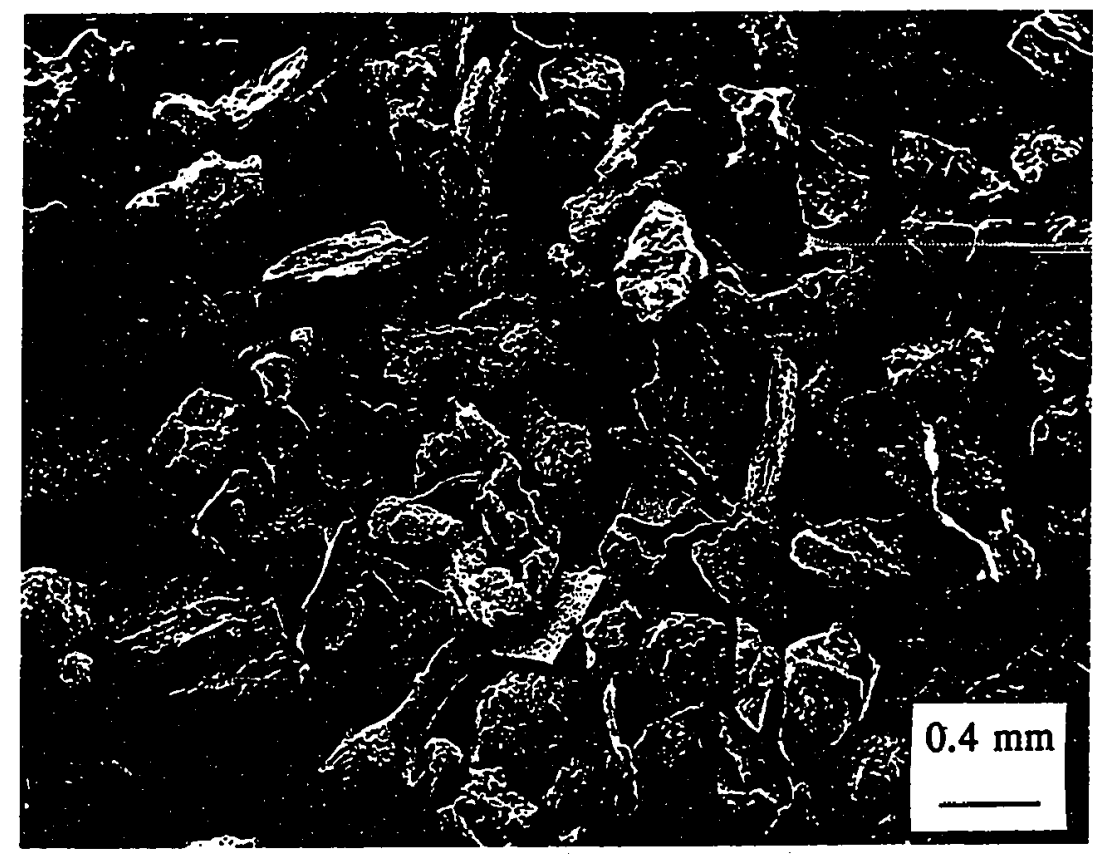

Figure 9.3 No.80 Bottom Ash (SEM Photograph)

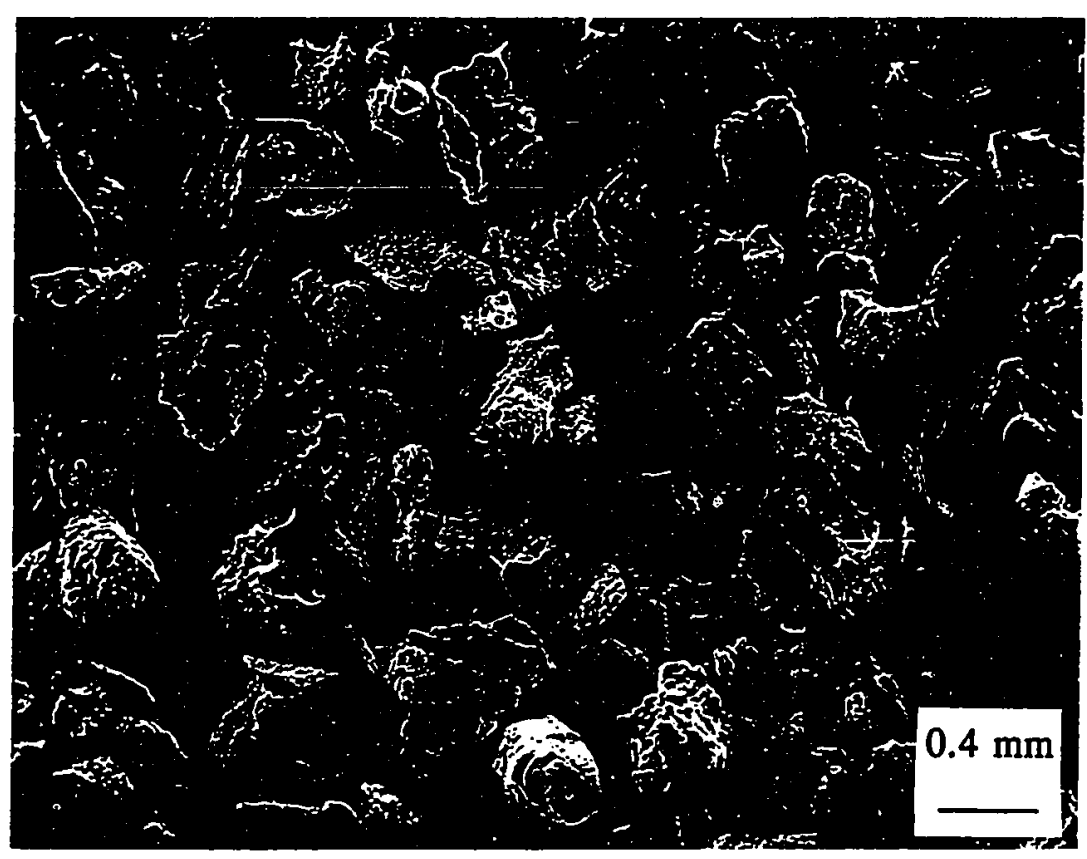

Figure 9.4 No.80 Bottom Ash (SEM Photograph) 


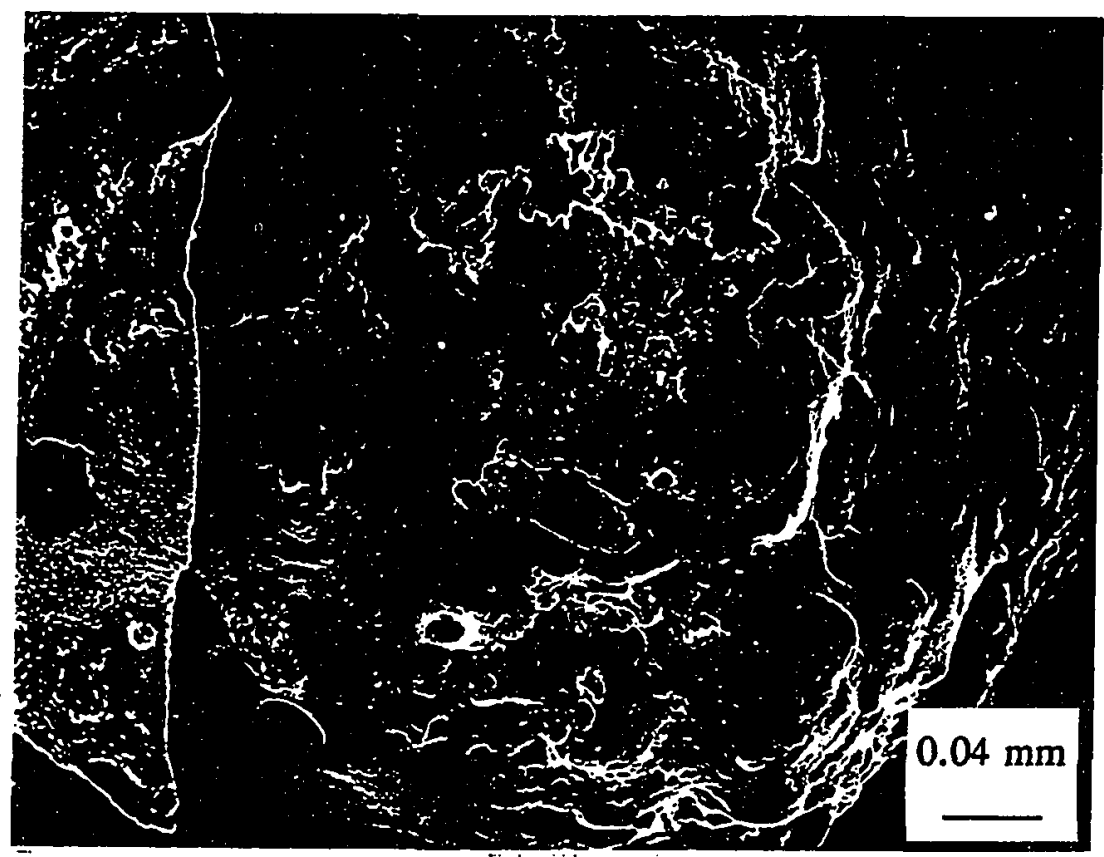

Figure 9.5 No.80 Bottom Ash (SEM Photograph)

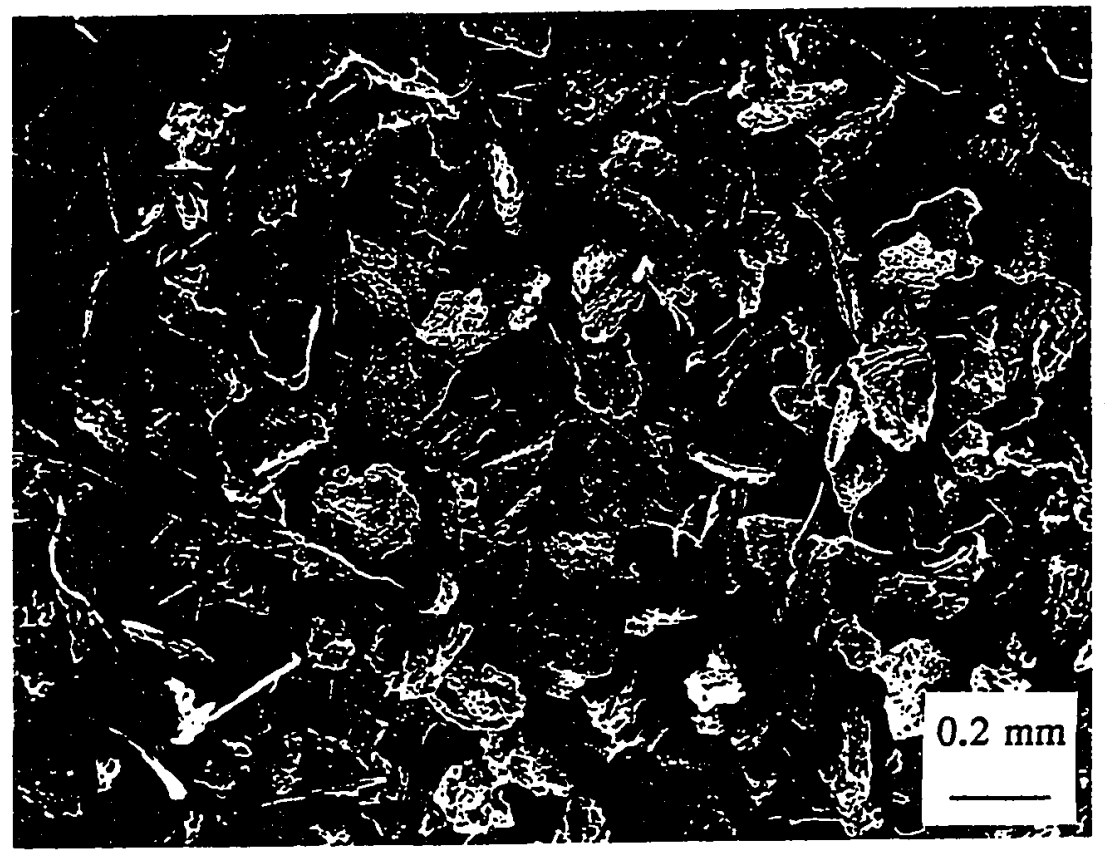

Figure 9.6 No.200 Bottom Ash (SEM Photograph) 


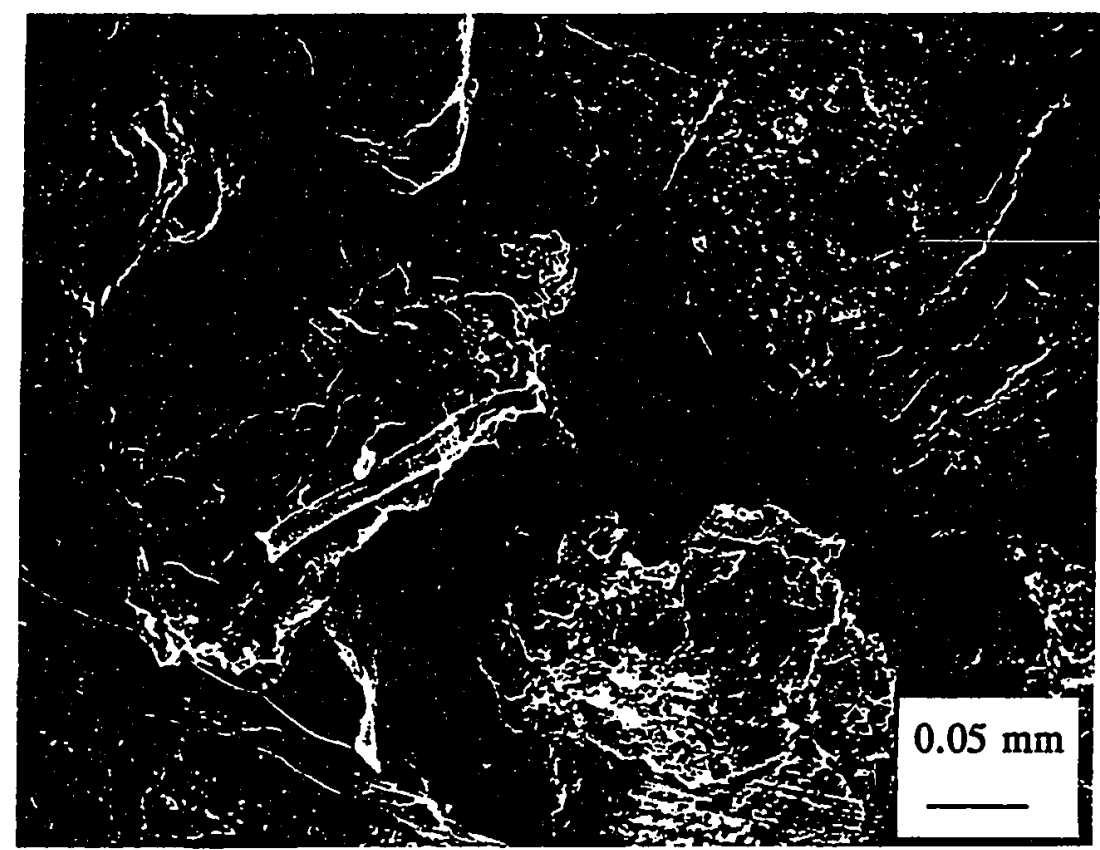

Figure 9.7 No.200 Bottom Ash (SEM Photograph)

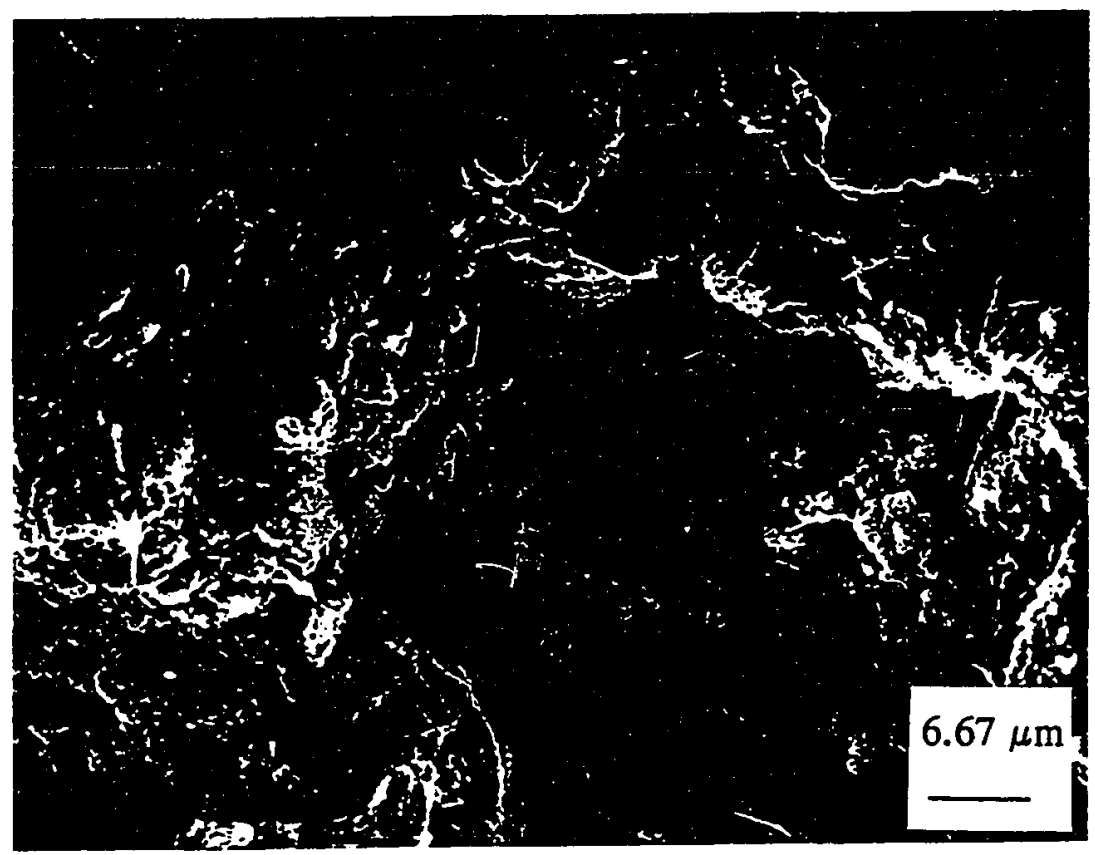

Figure 9.8 No.200 Bottom Ash (SEM Photograph) 


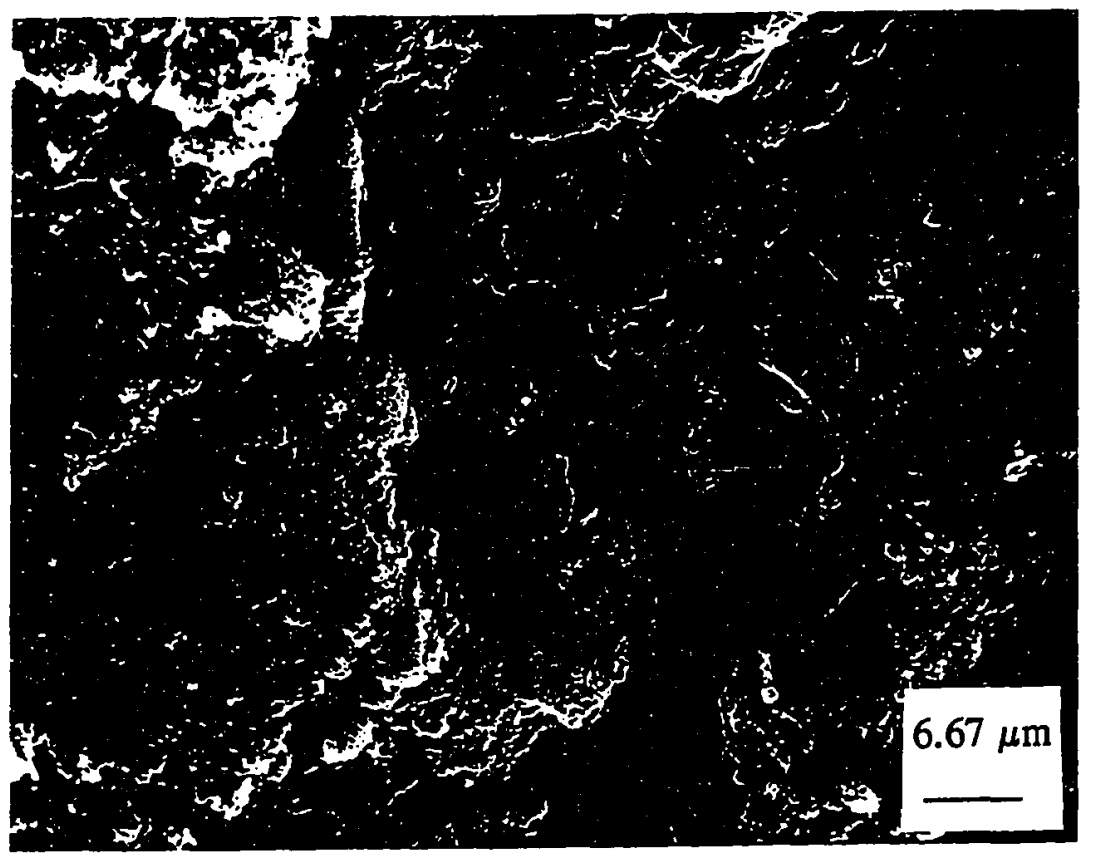

Figure 9.9 No.200 Bottom Ash (SEM Photograph)

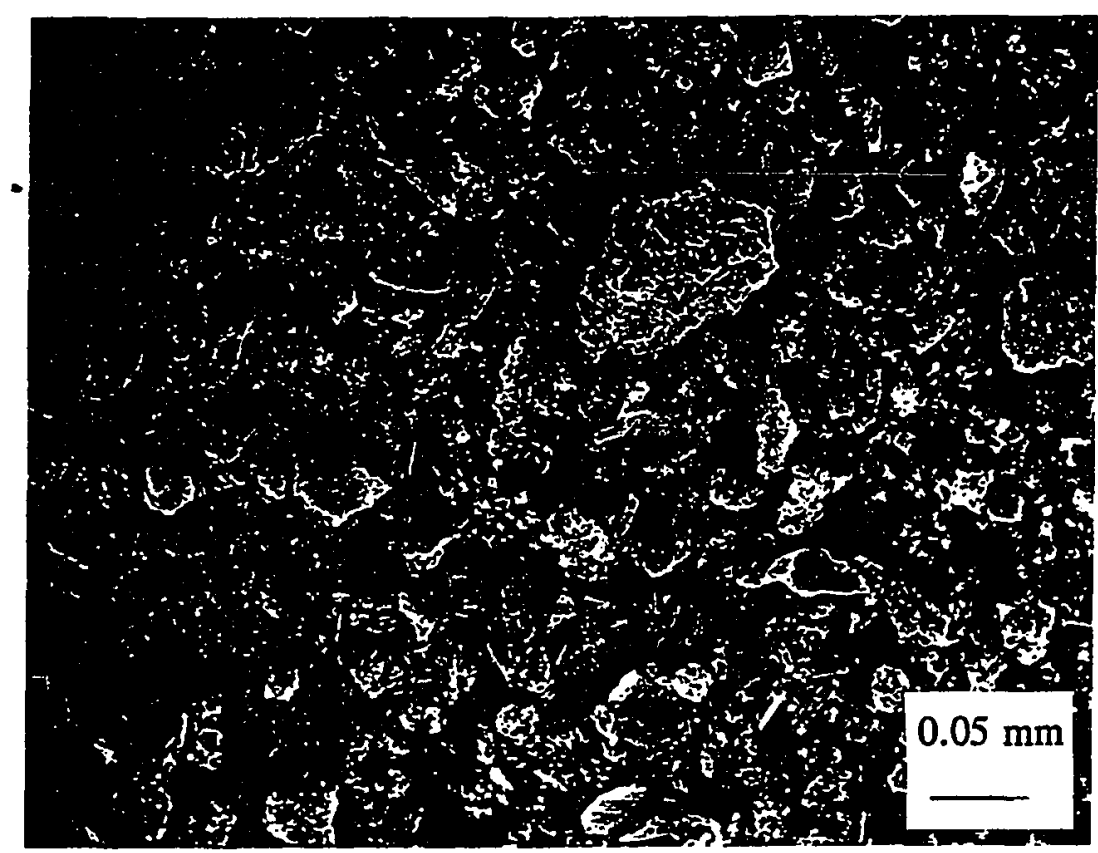

Figure $9.10<$ No.200 Bottom Ash (SEM Photograph) 


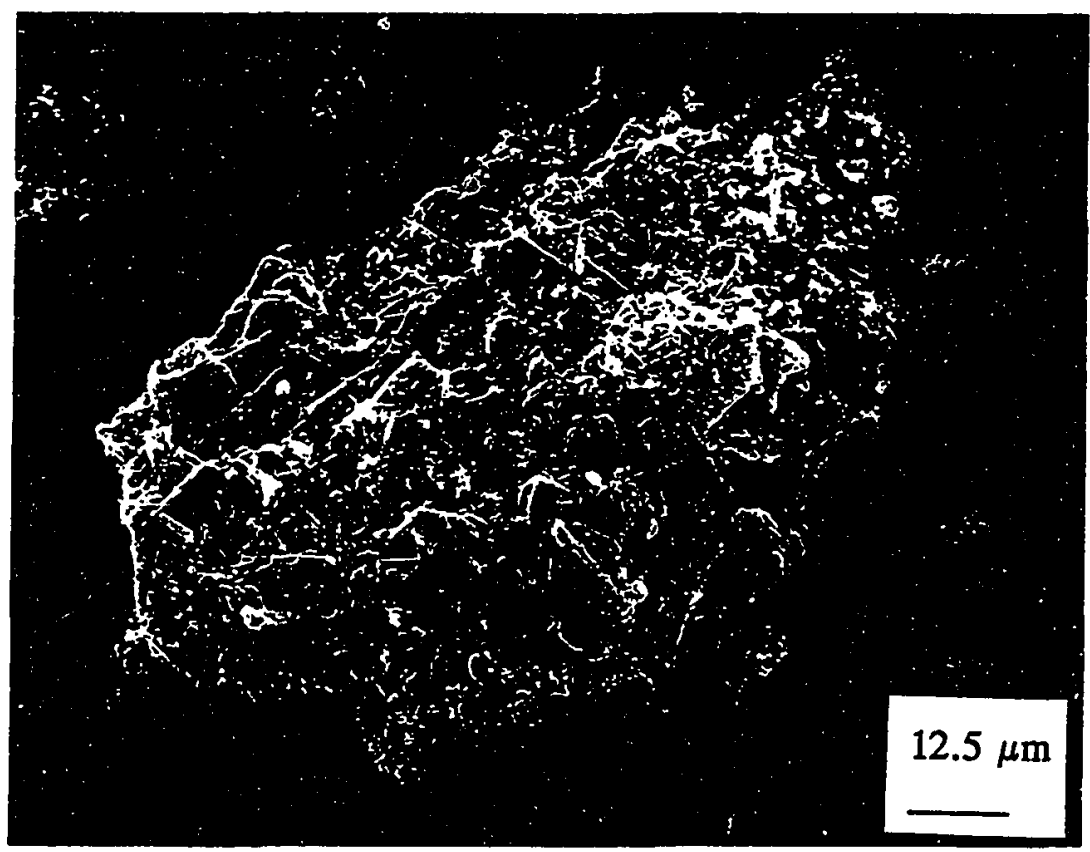

Figure $9.11<$ No.200 Bottom Ash (SEM Photograph)

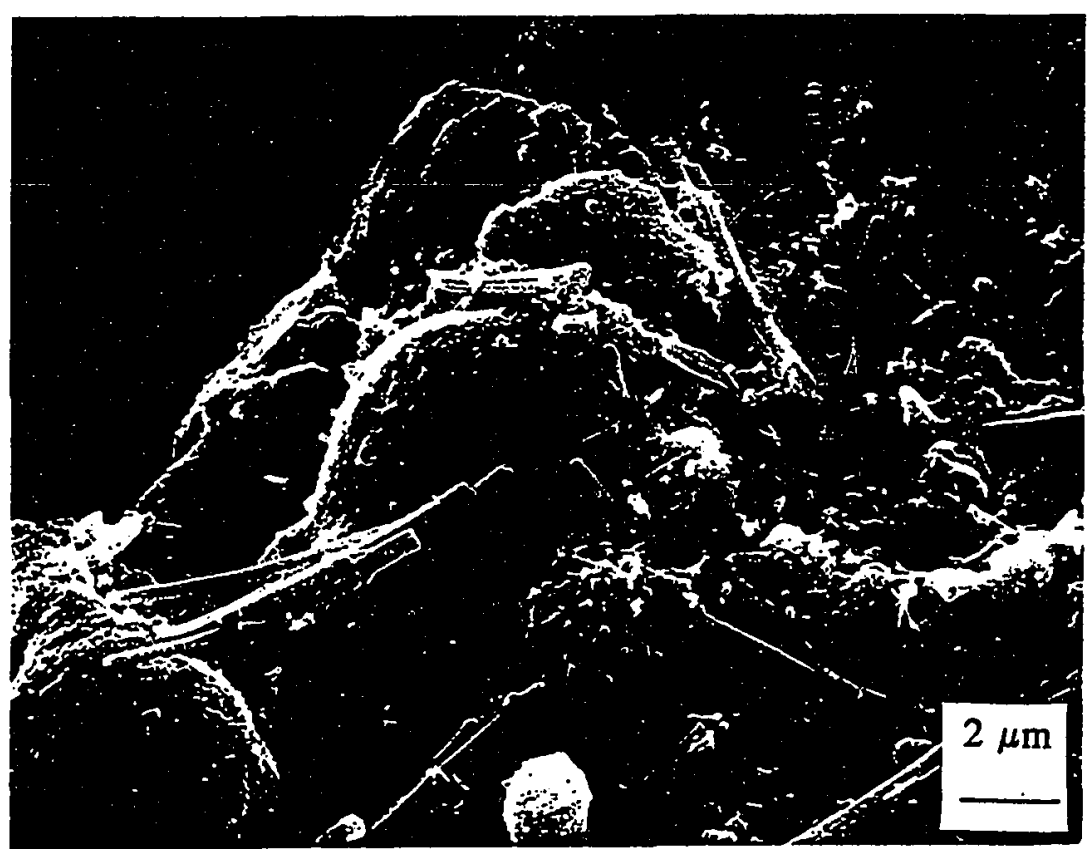

Figure $9.12<$ No.200 Bottom Ash (SEM Photograph) 


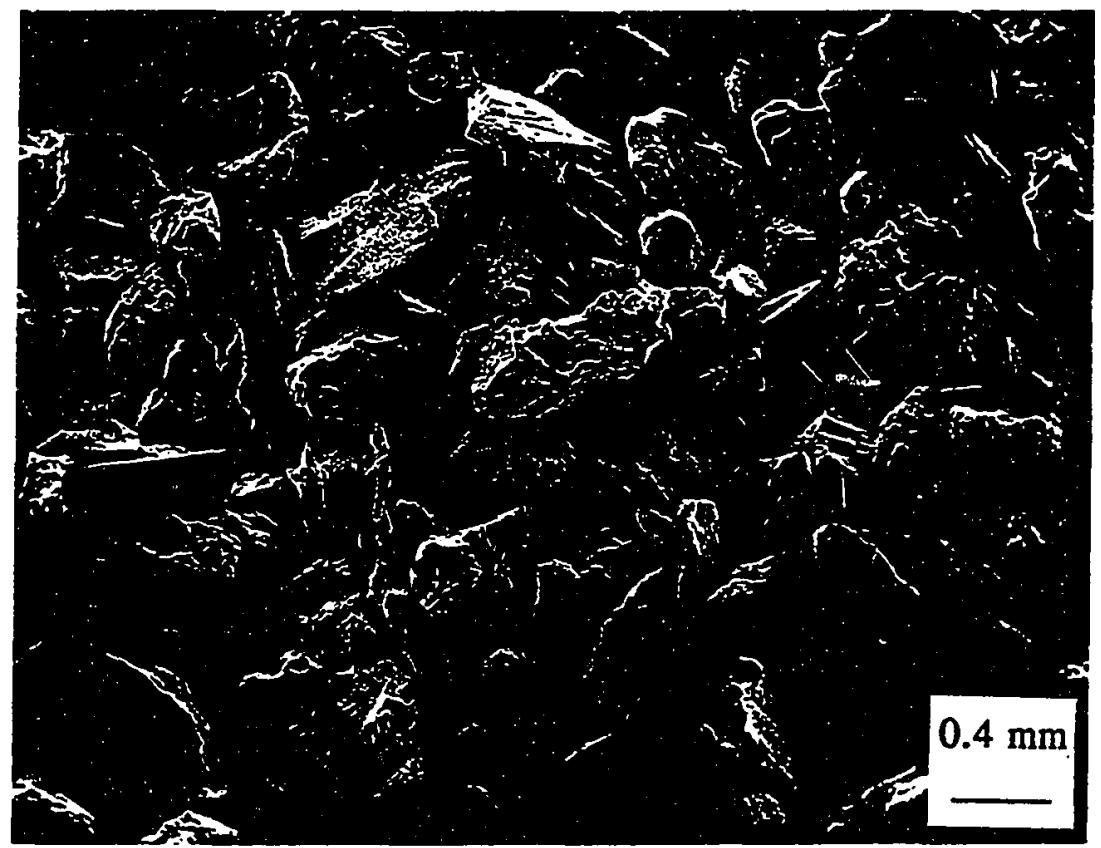

Figure 9.13 No.80 Control (SEM Photograph)

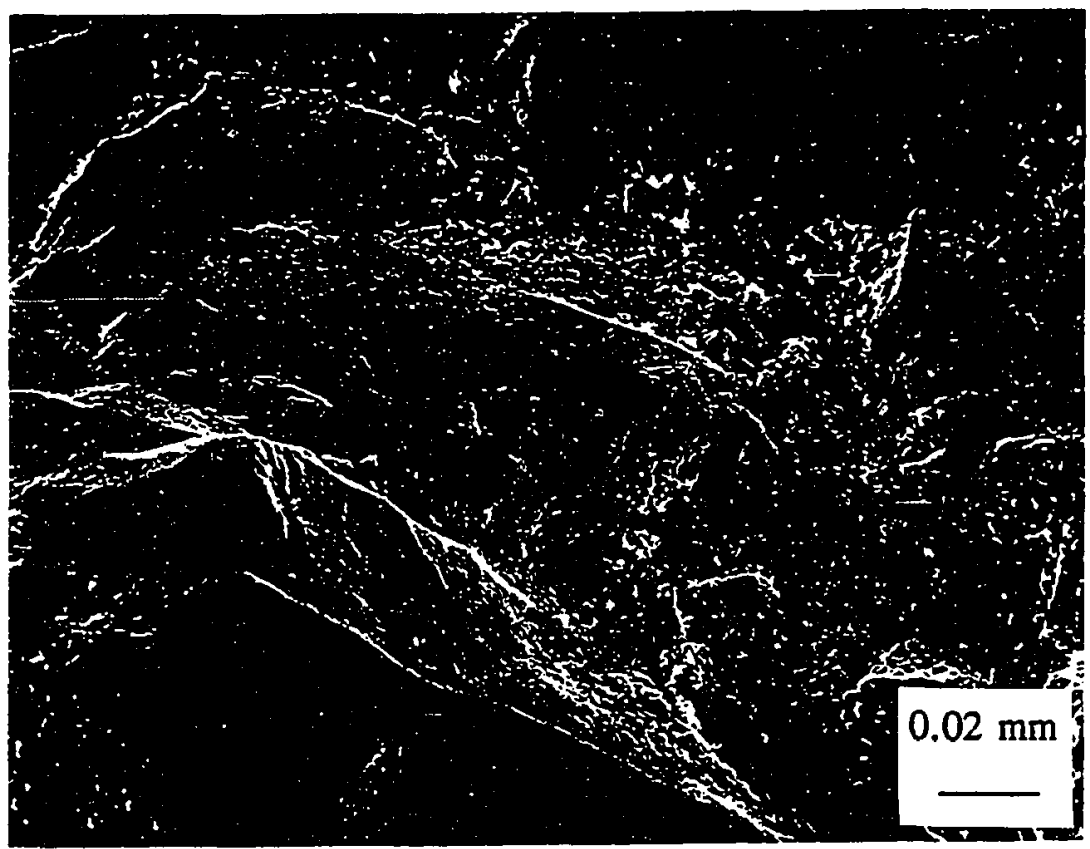

Figure 9.14 No.80 Control (SEM Photograph)

334 


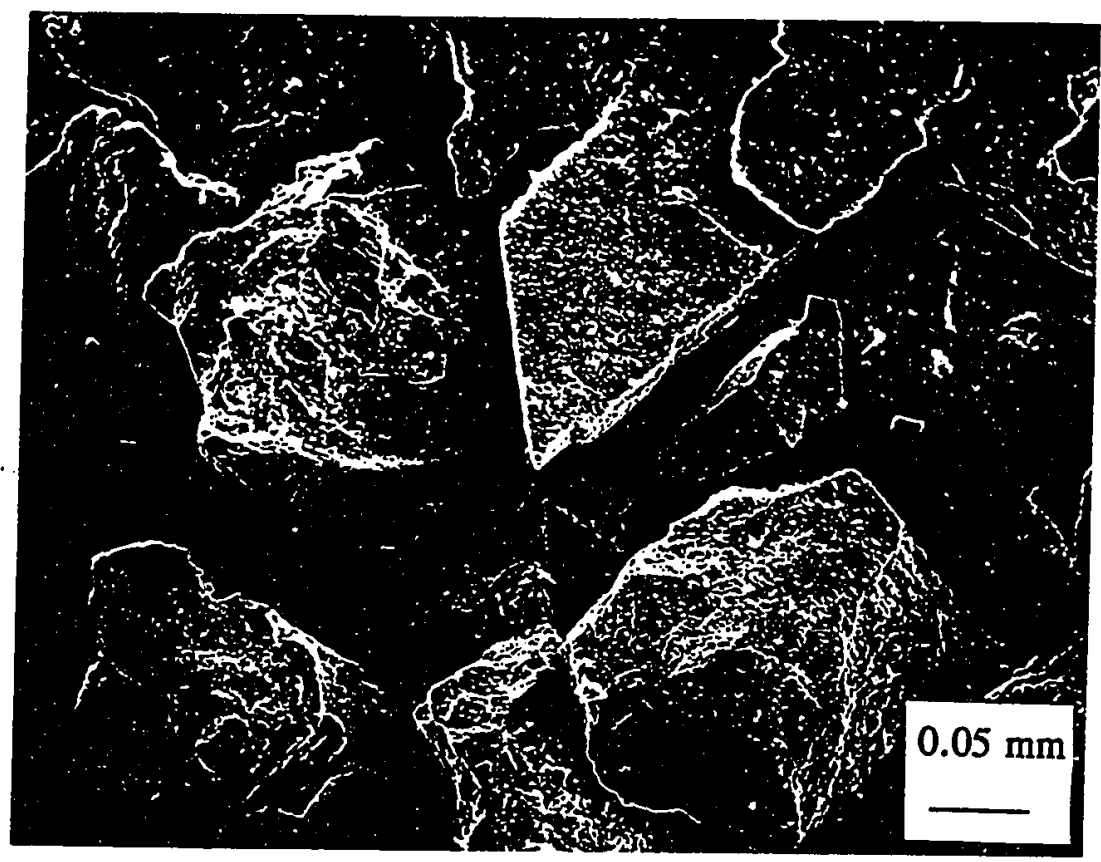

Figure 9.15 No.200 Control (SEM Photograph)

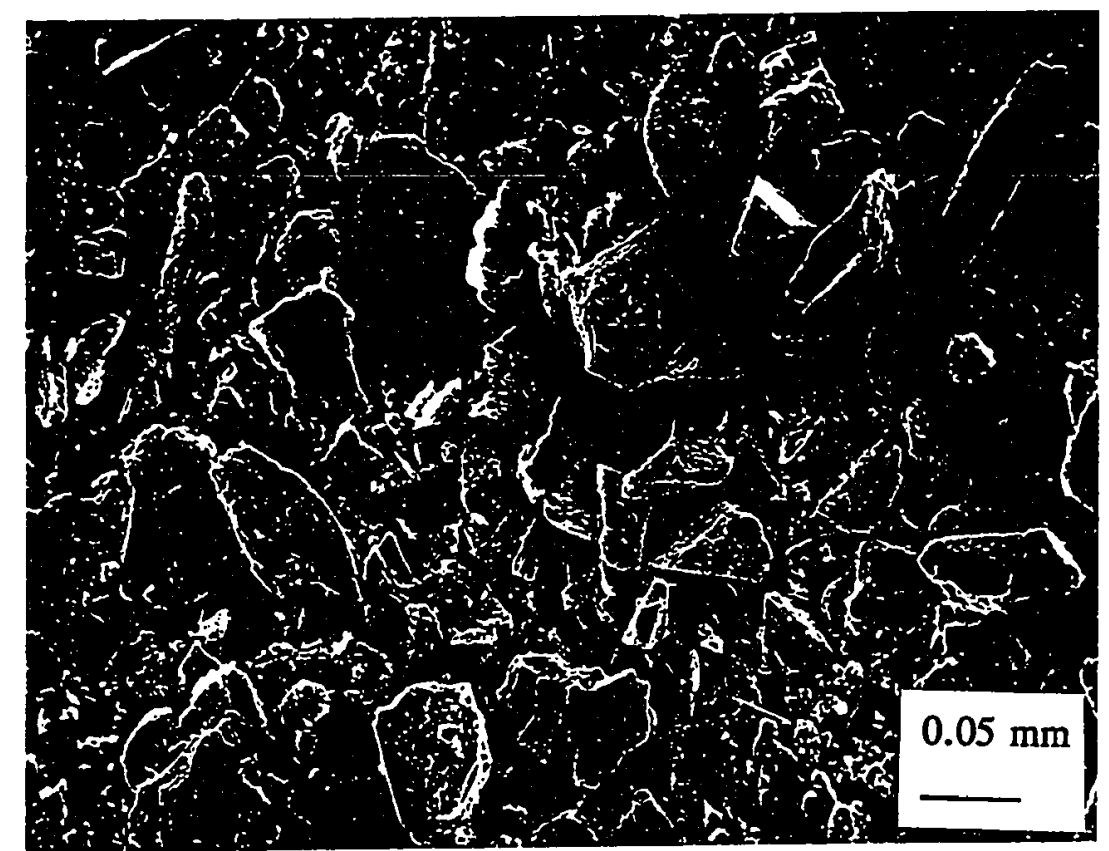

Figure $9.16<$ No.200 Control (SEM Photograph) 


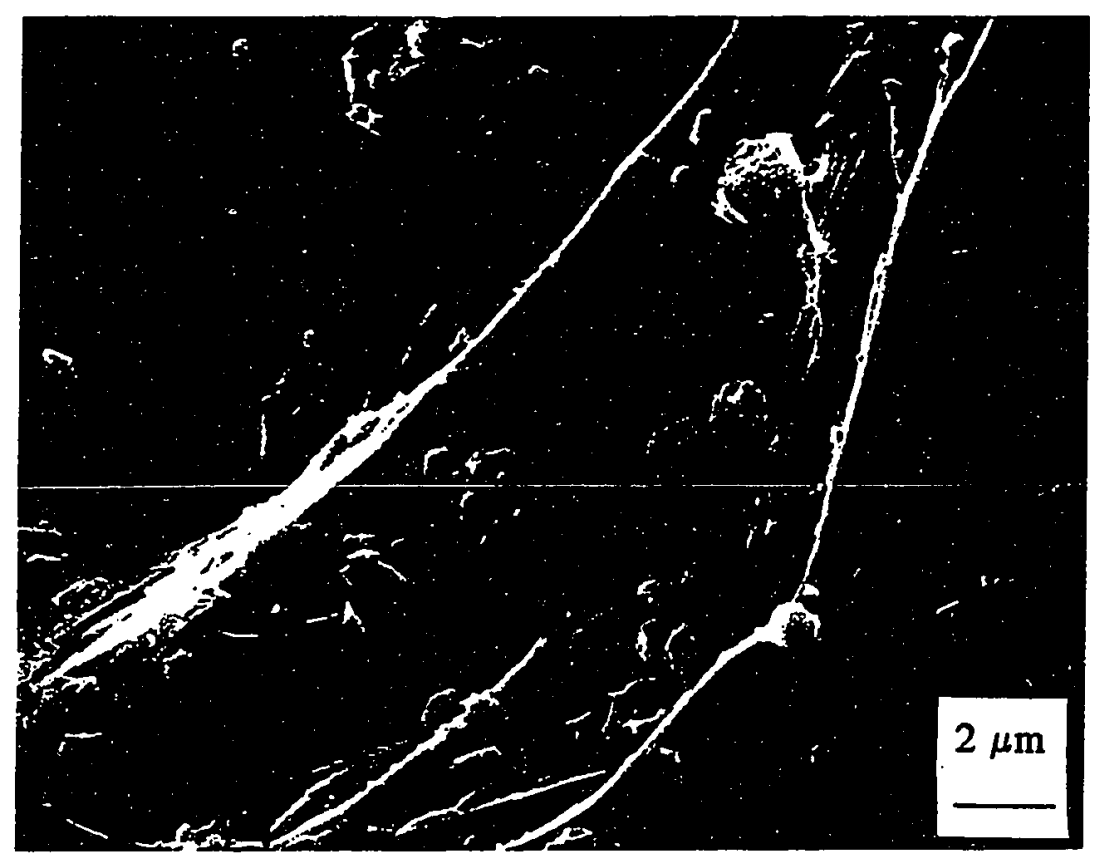

Figure $9.17<$ No.200 Control (SEM Photograph) 
as evidenced in Figure 9.17. In asphalt concrete, aggregates should be a combination of smoothness and roughness, and free of visible pores. The aggregates which are rough and show a honeycombed texture with visible pores require more asphalt to achieve complete coatings.

\section{Surface Coatings}

Bottom ash particles are partially covered with fine dust, as showed in Figure 9.1. Since bottom ash was washed prior to SEM to identify the ash surface properties, coatings of bottom ash are not obvious based on SEM photographs. Control aggregates are coated with a small amount of crusher dust, as shown in Figures 9.14 through 9.17. In asphalt concrete, excessive coatings affect bonding between asphalt and aggregates.

In conclusion, bottom ash is a combination of angular, equidimensional, flaky, elongated, rough, honeycombed particles. Bottom ash contains visible pores and are partially covered with fine dust. Control particles are a combination of angular equidimensional, elongated, rough particles. Control particles are covered with a small amount of crusher dust.

\subsubsection{Petrographic Analysis}

Figures 9.18 through 9.22 present thin section photographs of bottom ash. Figure 9.23 presents thin section photograph of control aggregates.

Bottom ash exhibits a high porosity which correlates with the results of physical tests (Chapters IV and V). The porosity seen here includes the permeable and impermeable voids. Figures 9.18 through 9.22 show that bottom ash contains various sizes of internal 


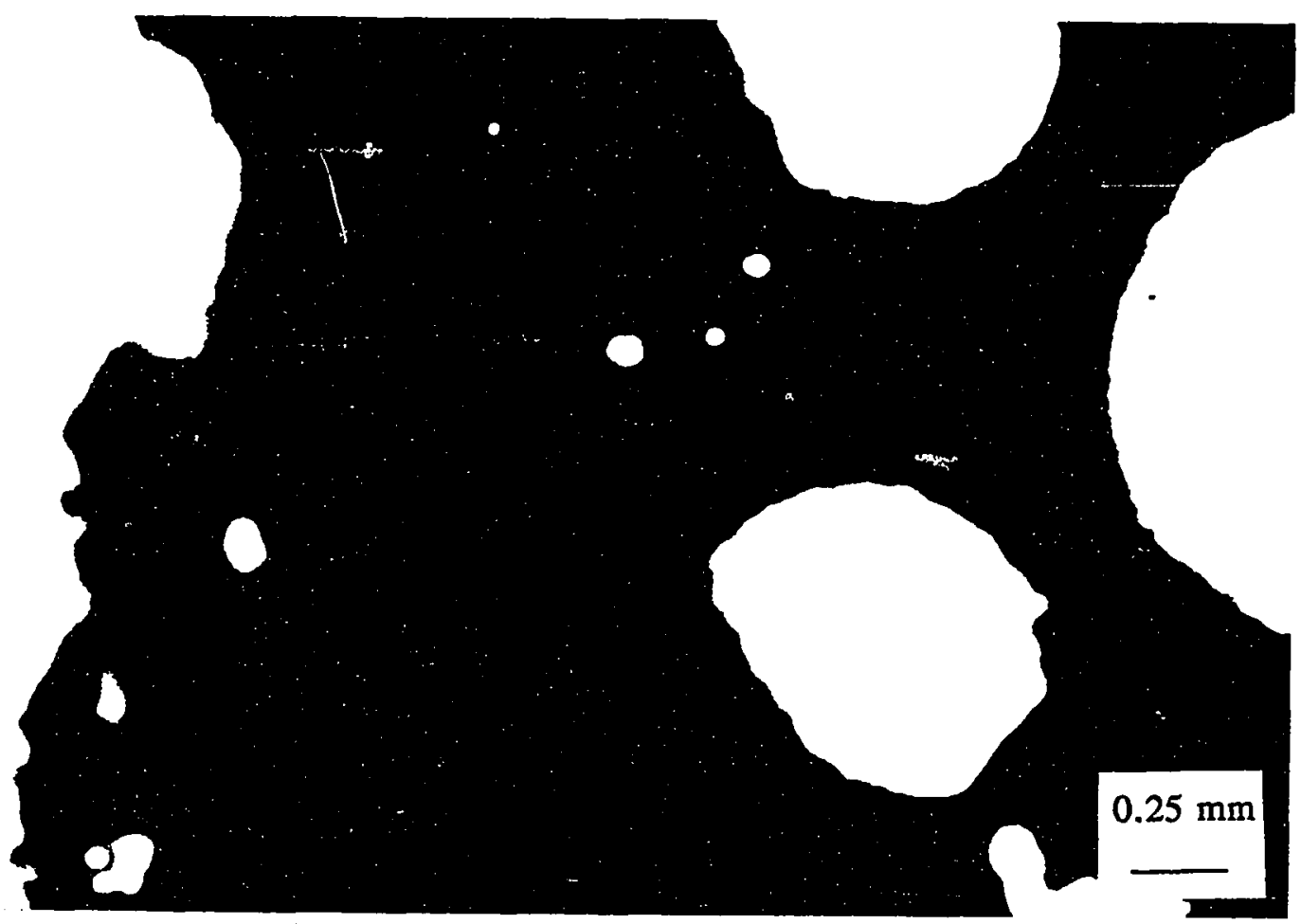

Figure $9.181 / 2^{\prime \prime}$ Bottom Ash (Thin Section Photograph)

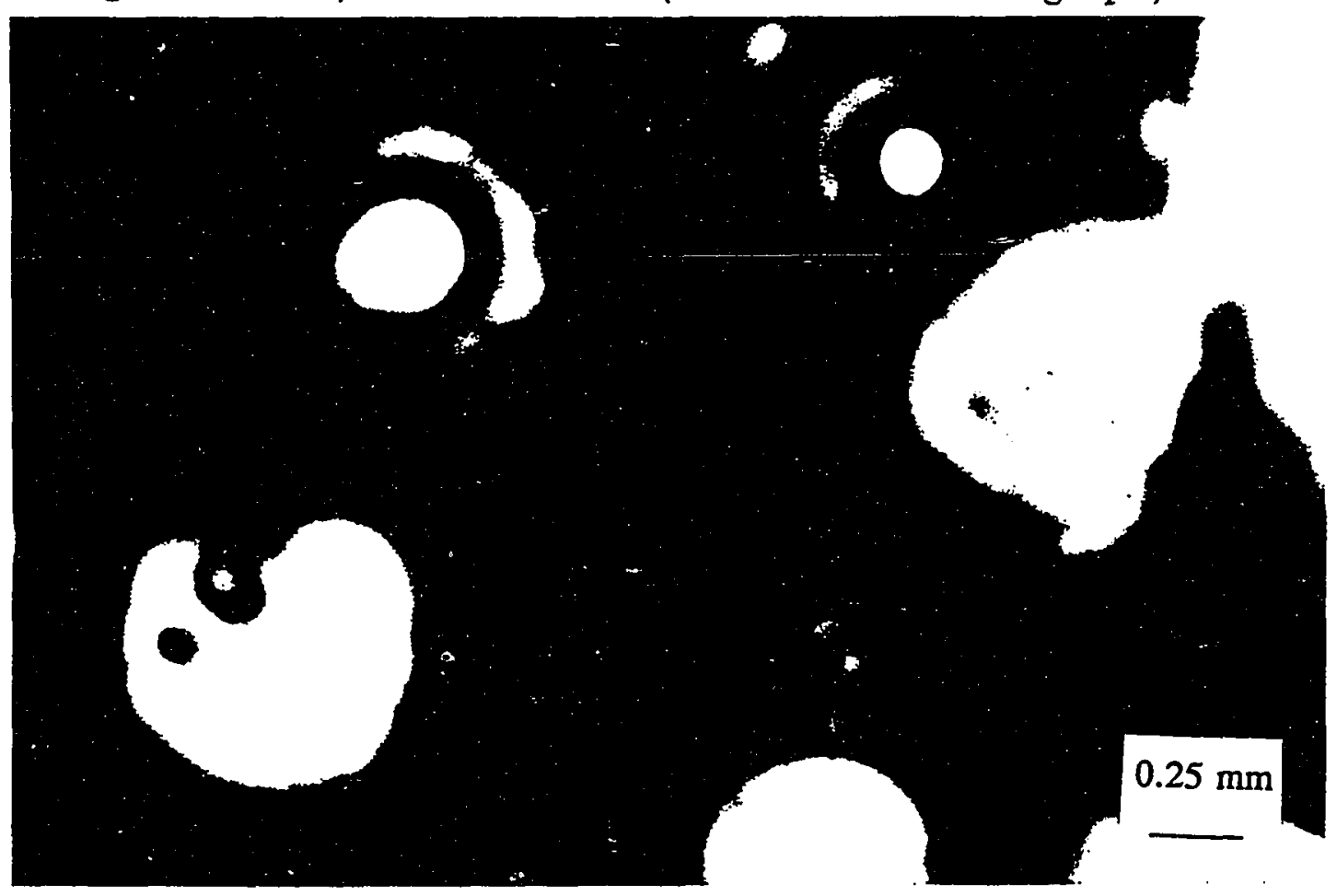

Figure 9.19 3/8" Bottom Ash (Thin Section Photograph) 


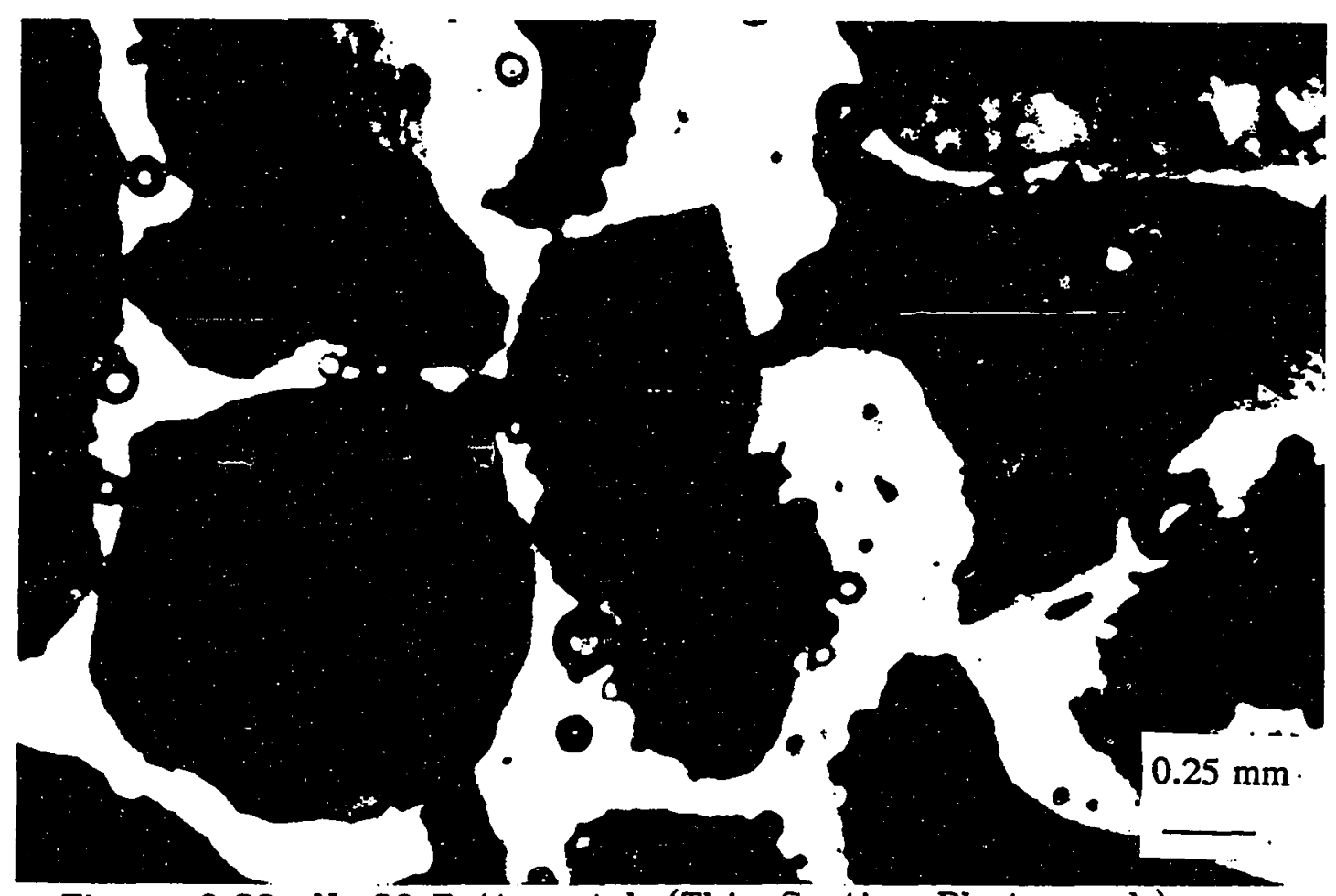

Figure 9.20 No.20 Bottom Ash (Thin Section Photograph)

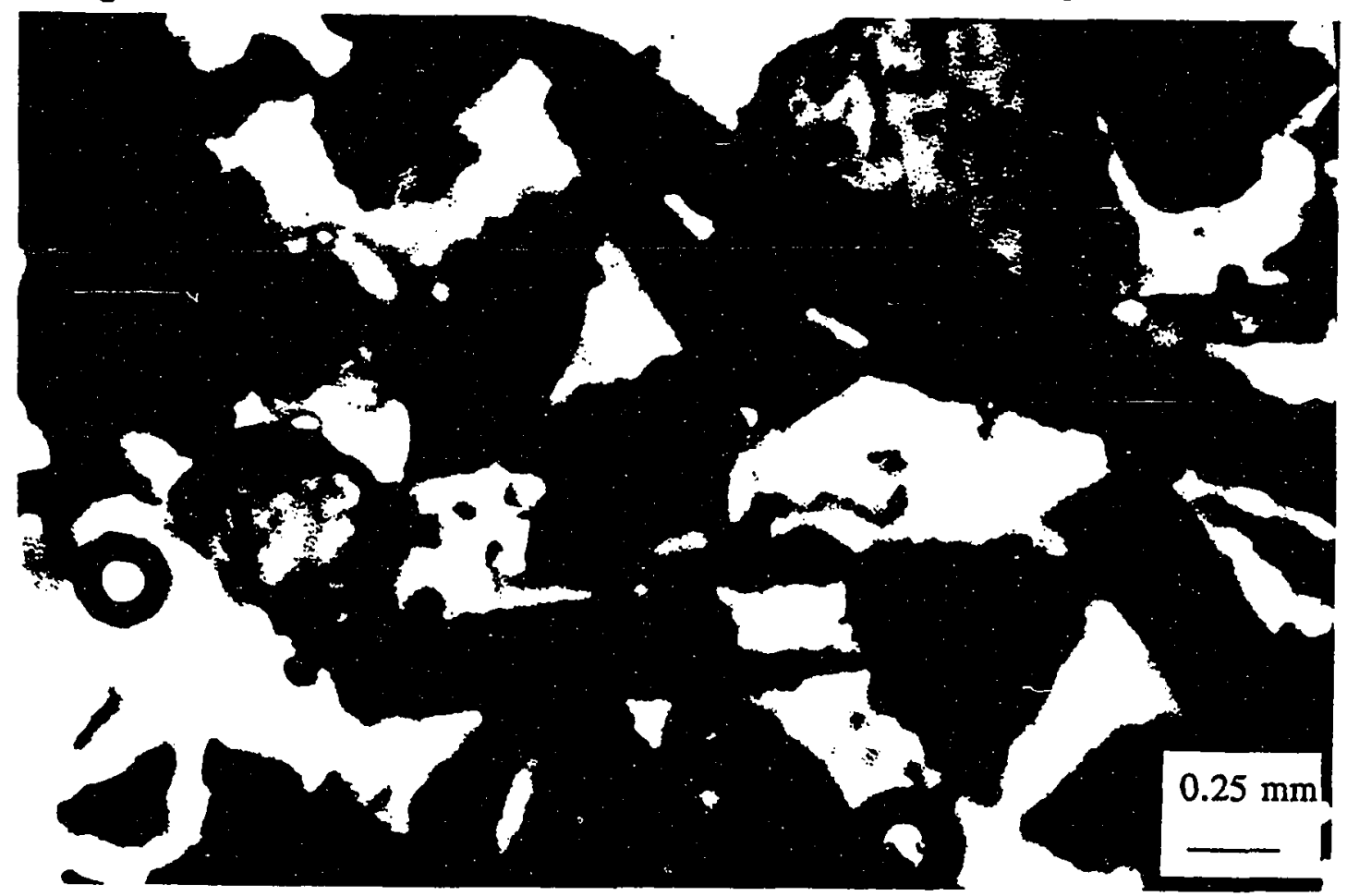

Figure 9.21 No.40 Bottom Ash (Thin Section Photograph) 


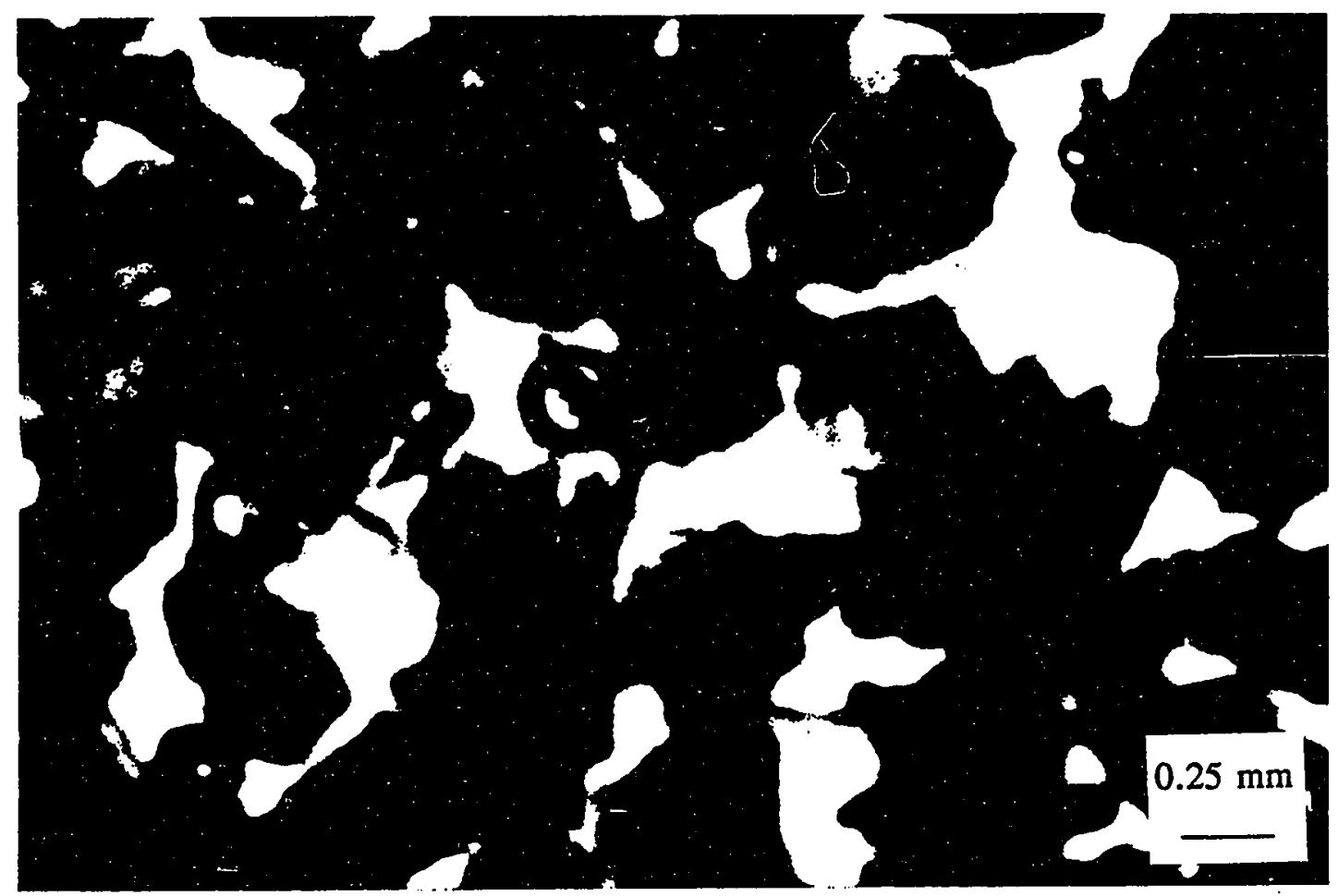

Figure 9.22 No.40 Bottom Ash (Thin Section Photograph)

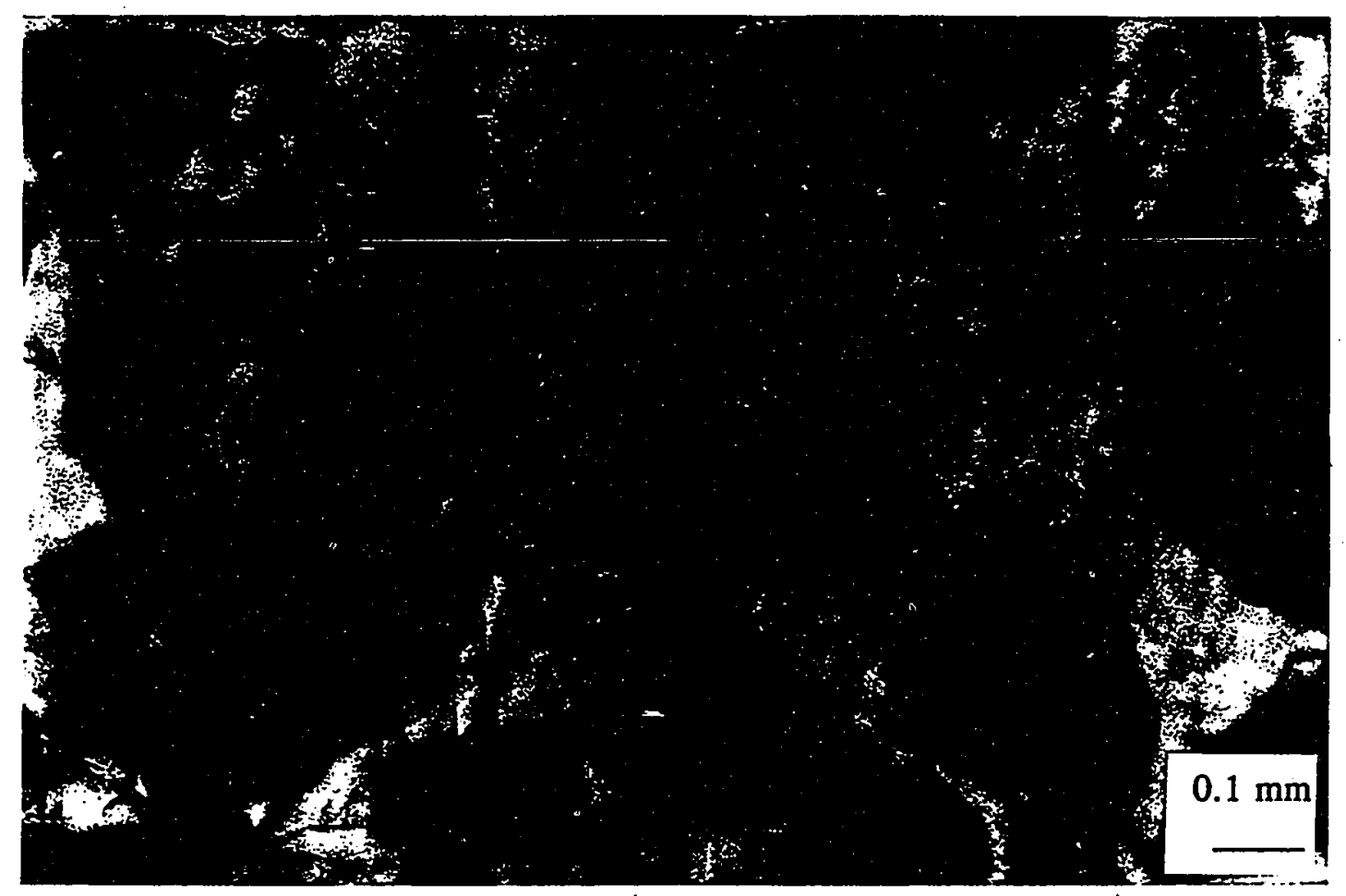

Figure 9.23 No.80 Control (Thin Section Photograph) 
and external pores. The internal pores are permeable if they are connected to external pores. The shape of pores is consistently spherical. Particle shape of bottom ash is a combination of angular, equidimensional and elongated particles. The flakiness of particles can not be investigated with petrographic thin section.

Control aggregates contain no noticeable internal and external voids. Instead, a few micro-cracks were observed. The particle shape is angular, equidimensional or elongated, as shown in Figure 9.23.

\subsubsection{Asphalt Concrete}

Petrographic thin section analysis was conducted on asphalt concrete.

\subsubsection{Uncompacted Samples}

Figures 9.24 and 9.25 show $100 \%$ bottom ash mix. It appears that ash particles are coated well with asphalt cement. A few permeable pores are only partially filled with asphalt cement. The impermeable pores which are penetrated by asphalt are also observed.

Figure 9.26 presents control mix. Aggregate particles are coated well with asphalt cement. It appears that asphalt is absorbed into the micro-cracks in aggregates. Since the color of asphalt in micro-cracks is lighter than that of the nonabsorbed asphalt, selective absorption possibly occurs. Selective absorption was studied by a few researchers $(78,80)$. They (78) concluded that when asphalt is absorbed into the pores of an absorptive aggregate, there may be preferential compositional changes in that the absorbed asphalt 


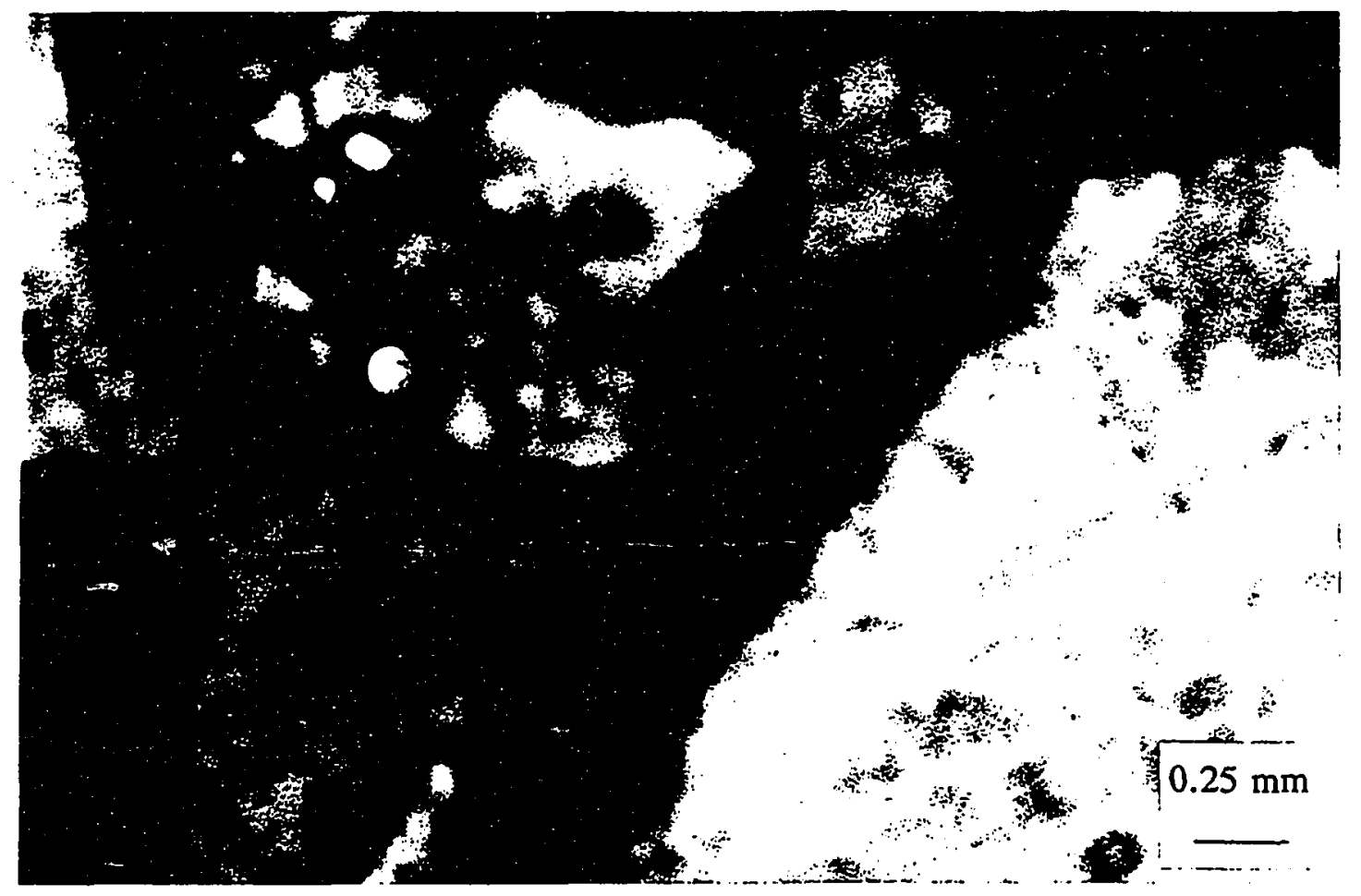

Fig. 9.24 Uncompacted 100\% Ash Mix (Thin Section Photo)

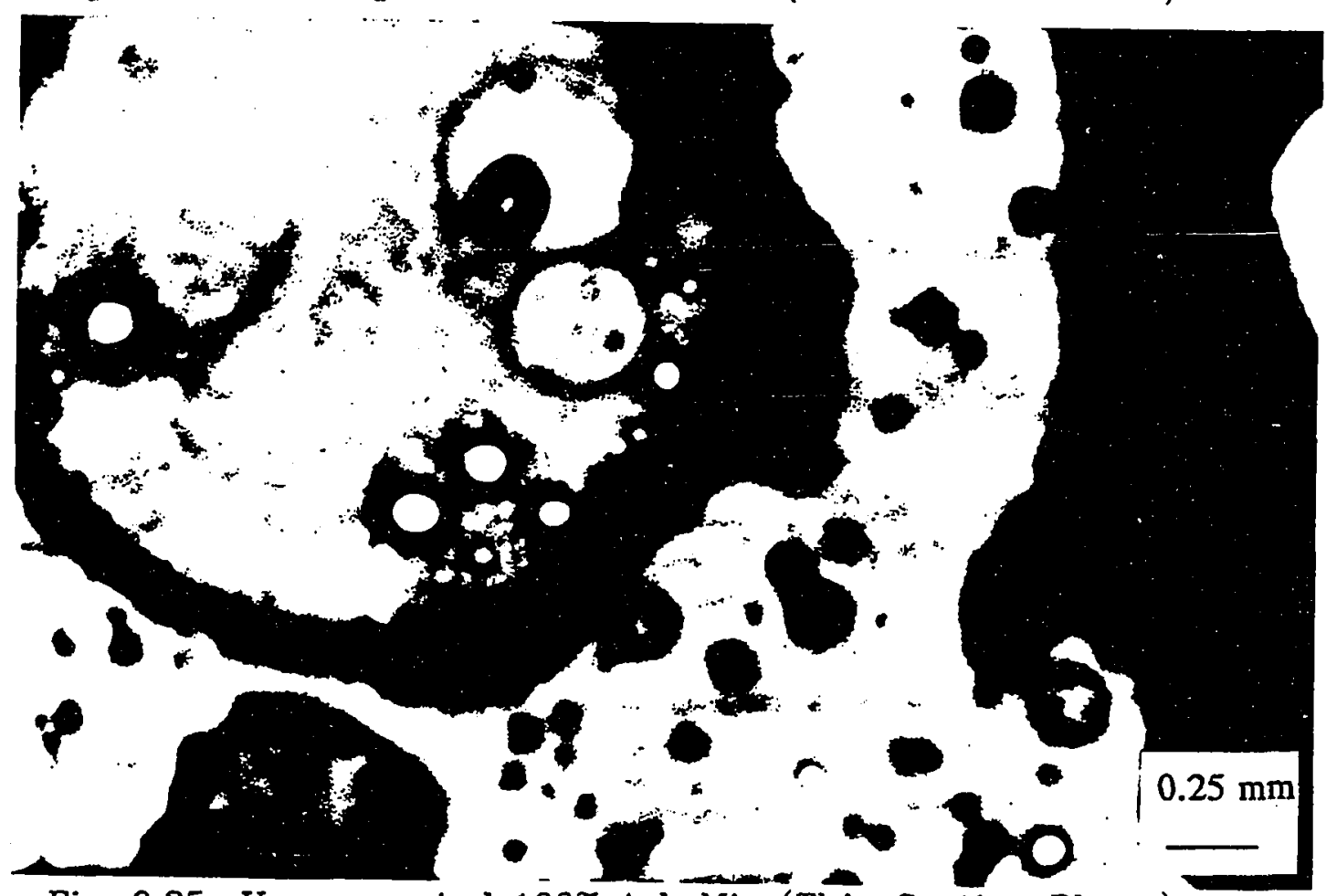

Fig. 9.25 Uncompacted 100\% Ash Mix (Thin Section Photo) 
inside the pores has a different composition than the nonabsorbed, or effective, asphalt film acting to bind the aggregate together; in turn, because of this selective absorption, the absorbed and nonabsorbed asphalt will have compositions different from the original bulk asphalt cement; and if the selective absorption occurs over several days or months, then the mix design could provide misleading results, and premature pavement distress could occur at a later date.

\subsubsection{Compacted Samples}

Figure 9.27 presents a Marshall sample made with $100 \%$ ash. Particles are well coated. A few permeable pores are partially filled with asphalt. Many pores are apparently empty, indicating that they are effectively impermeable.

Figure 9.28 presents GTM sample with $50 \%$ ash mix. The porous particles are bottom ash. The permeable pores are partially filled with asphalt. Many pores are empty, indicating that they are impermeable. The nonporous particles are control aggregates, which are well coated with asphalt.

Figure 9.29 presents GTM sample with control aggregate. The micro-cracks partially filled with lighter color asphalt were noticed. A triangle-shaped air void in asphalt mix was found.

\subsection{Conclusion}

Based on SEM and petrographic analysis, the following conclusions can be drawn:

1. Bottom ash contains angular, equidimensional, flaky, elongated, rough, 


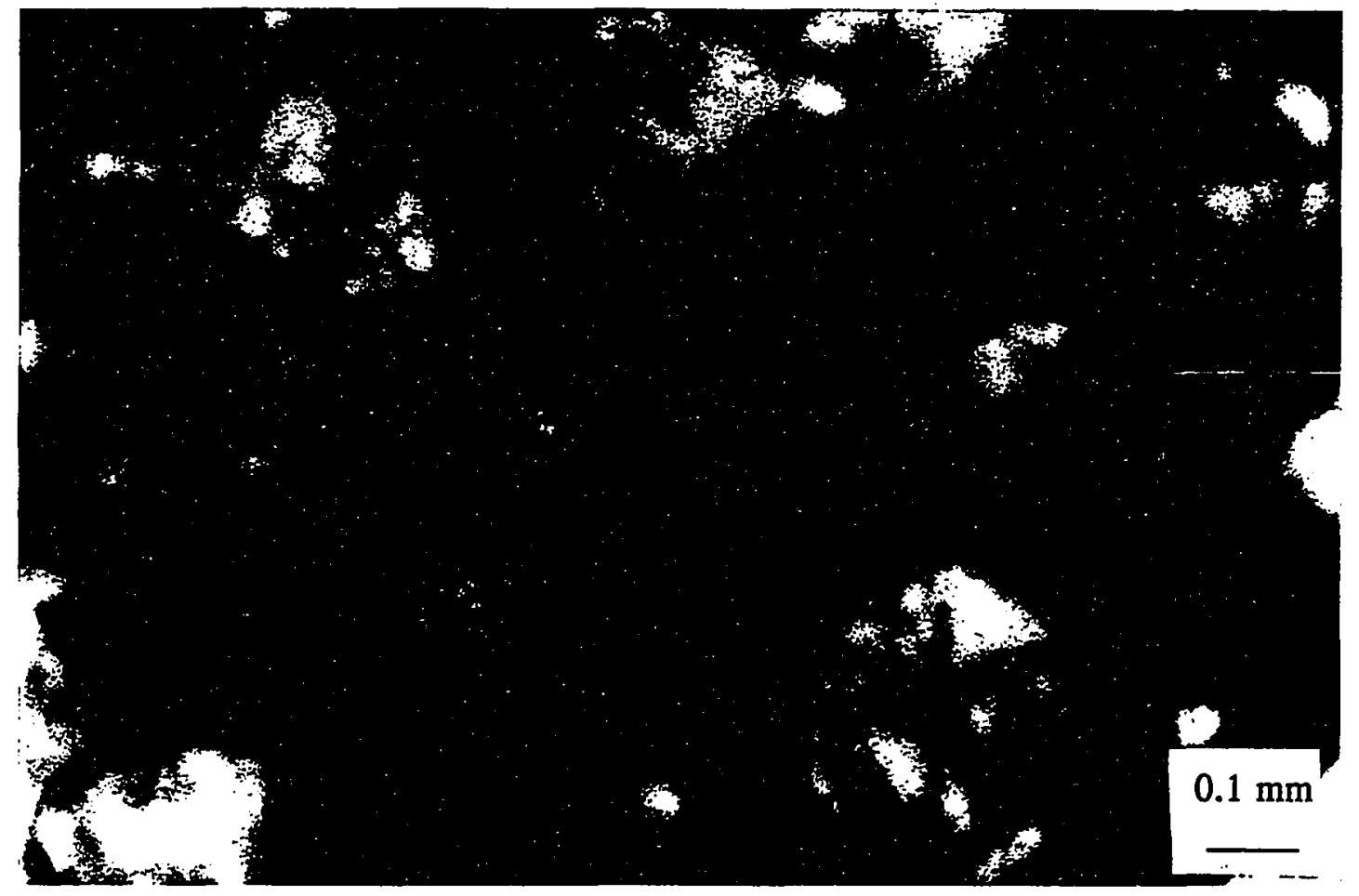

Fig. 9.26 Uncompacted Control Mix (Thin Section Photo)

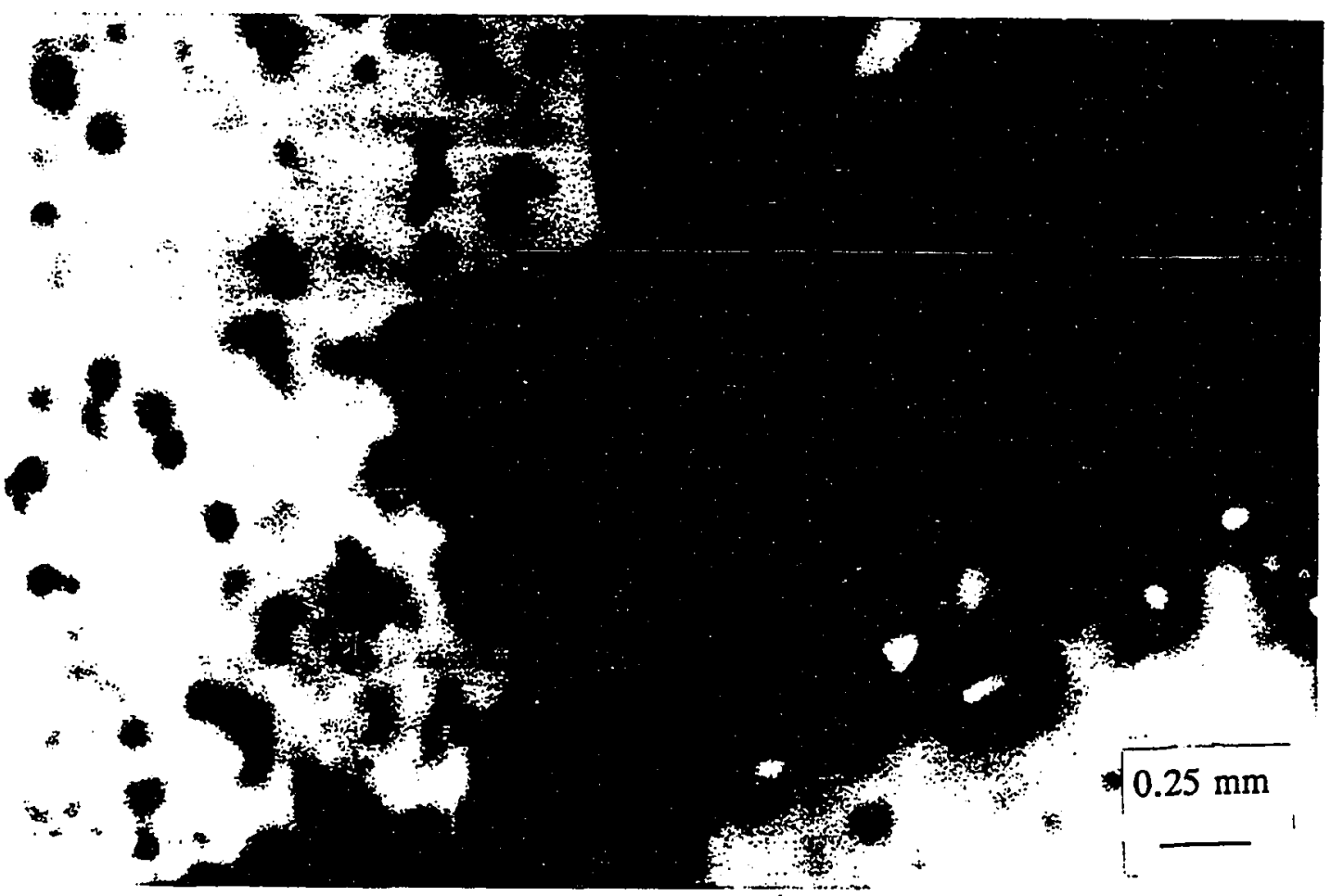

Fig. 9.27 Marshall 100\% Ash Sample (Thin Section Photo) 


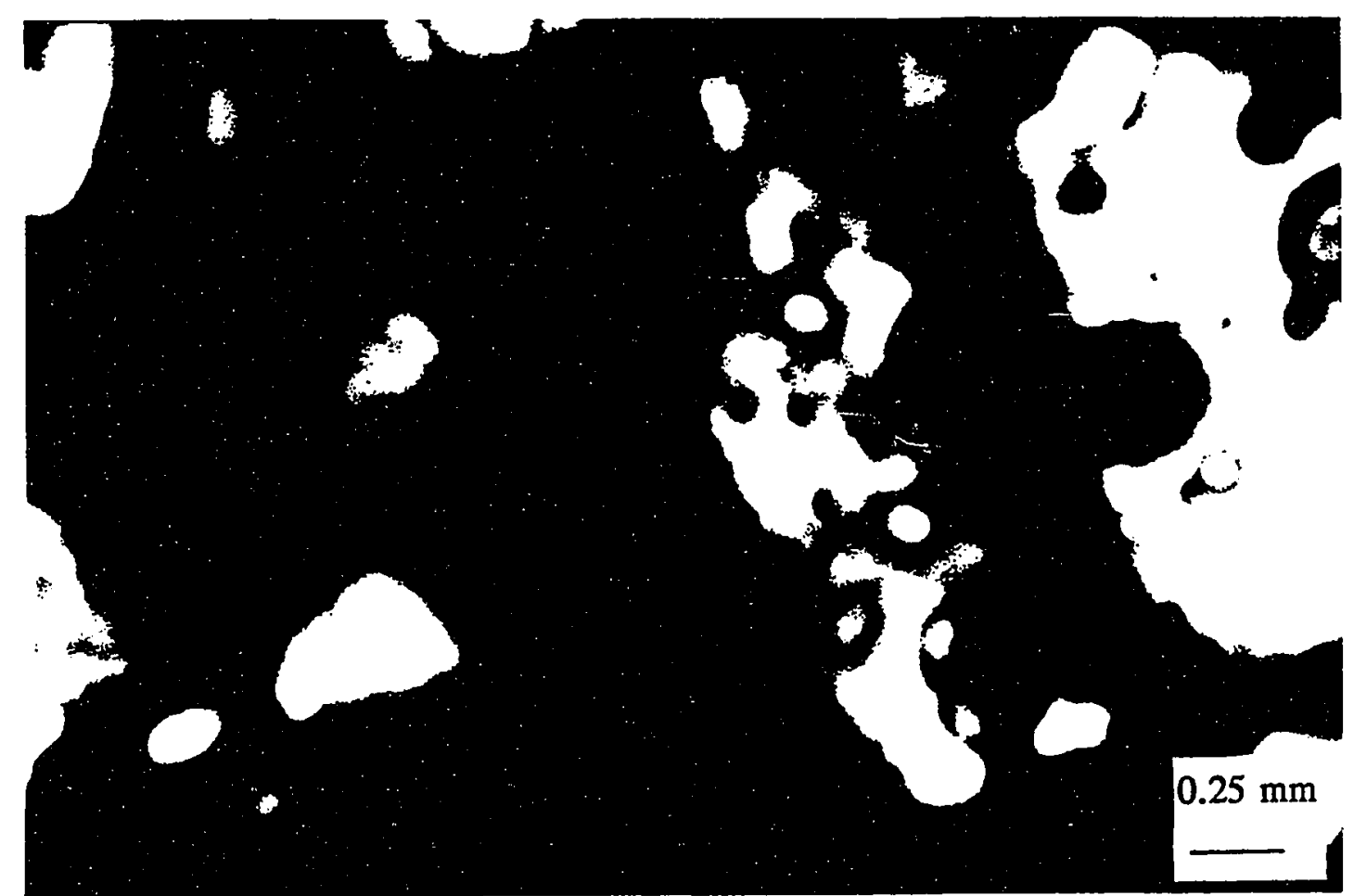

Fig. 9.28 GTM 50\% Ash Sample (Thin Section Photo)

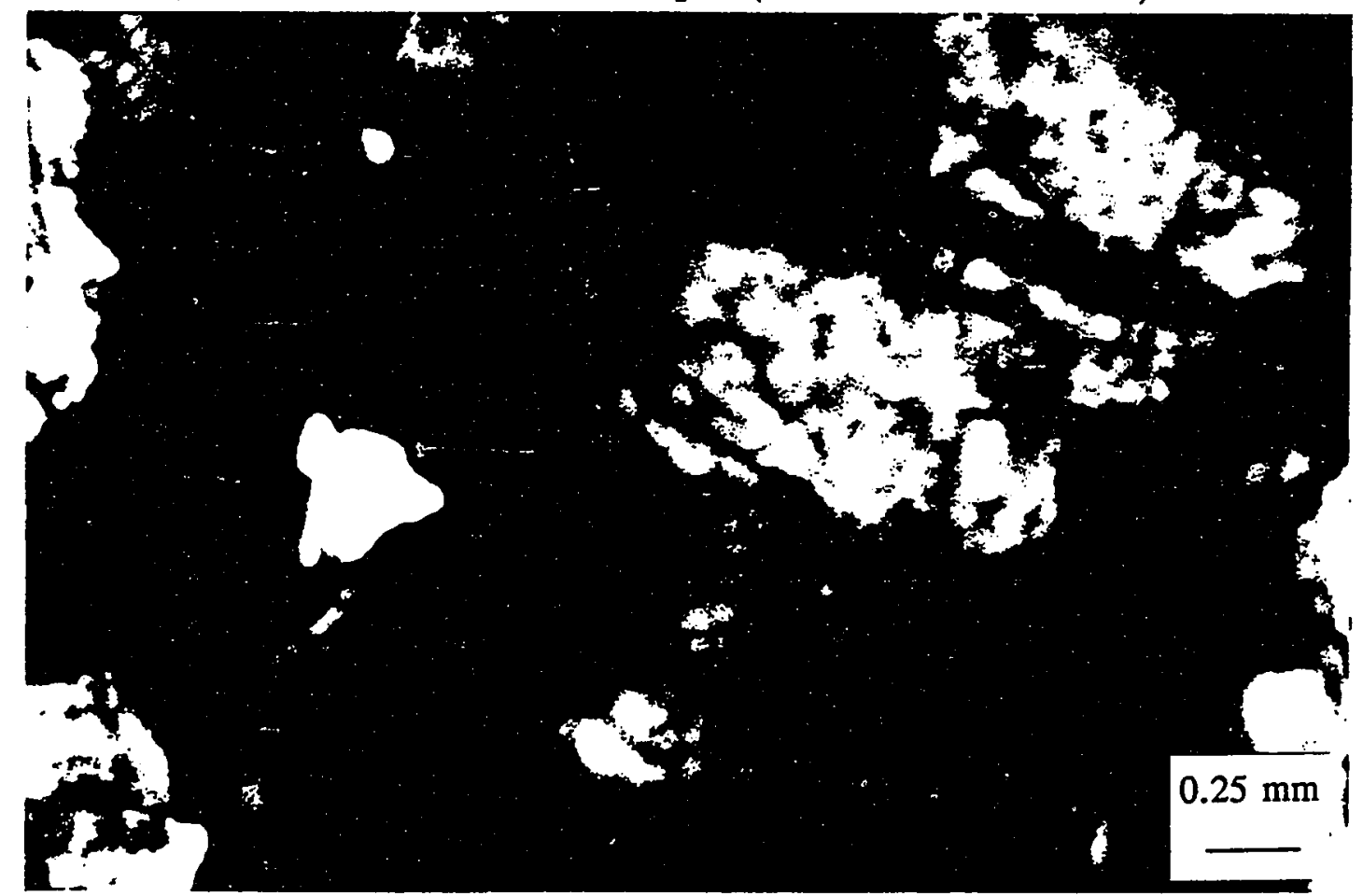

Fig. 9.29 GTM Control Sample (Thin Section Photo) 
honeycombed particles.

2. Bottom ash contains visible pores and are partially covered with fine dust.

3. Bottom ash contains various sizes of internal and external pores.

4. It appears that ash particles are coated well with asphalt cement.

5. Bottom ash contains many impermeable pores. 


\section{CONCLUSIONS AND RECOMMENDATIONS}

\subsection{Conclusions}

The conclusions drawn in each chapter are summarized as follows:

\subsubsection{Evaluation of Bottom Ash Properties}

1. Bottom ash is a heterogeneous material. Visual classification indicated that coarse fraction of bottom ash ( $\geq$ No.4) comprised, on average, $32.2 \%$ clinker, $36.6 \%$ clinker with ferrous, $22.9 \%$ glass, $4.1 \%$ ferrous, $1.6 \%$ ceramics and $2.5 \%$ other materials including non-ferrous metals (aluminum, copper, etc.), rock, brick pieces, concrete, wood, bone fragments, paper, chalk.

2. Moisture content of bottom ash as received exceeded that normally associated with conventional aggregate materials, with an average of $37.9 \%$.

3. LOI of bottom ash exceeded that normally associated with conventional materials for construction applications. LOI was also strongly associated with particle size, increasing significantly with decreased particle size.

4. The gradation of bottom ash met NH specifications for a type B binder mix, indicating that ash was a well graded aggregate material.

5. Washed-sieving differed from dry-sieving in that the former generated more fine materials. The percent passing No. 200 sieve for control sample increased by $53 \%$ (2.29\% 
versus $3.5 \%$ ) from dry to washed sieving, and that for ash samples increased by $73 \%$ (3.97\% versus $6.87 \%)$.

6. Specific gravity and absorption measurements indicated bottom ash was a lightweight, highly absorptive and porous material when compared to natural aggregate materials. The high absorptive nature of bottom ash was primarily associated with the fine fraction ( $<$ No.4) of bottom ash.

7. Unit weight measurements indicated that bottom ash was a light weight aggregate material. Unit weight values of bottom ash are typical of materials such as pumice or blast furnace slag.

8. Maximum dry densities and optimum moisture contents of bottom ash were within the normal range for a silt material. Proctor density testing resulted in the degradation of bottom ash.

9. Bottom ash CBR was well above the range of values for most natural materials, indicating that bottom ash had an excellent bearing capacity and would make an excellent subbase material for road construction. Degradation occurred during compaction and testing in the CBR test.

10. L.A. abrasion results of bottom ash met the ASTM D692 maximum 50\% requirement for use in bituminous paving mixtures. This test was considered to be overly aggressive for the pavement applications considered here because of the brittle, glassy nature of some of the bottom ash components.

11. The sodium sulfate soundness coarse fraction of bottom ash met the ASTM D692 specification of maximum $12 \%$ however the fine fraction of bottom ash marginally 
exceeded the maximum. However, since the fine fraction of bottom ash comprised approximately $50 \%$ of the bottom ash the natural combination of the coarse and fine fractions should pass the ASTM requirement.

\subsubsection{The Statistical Analysis of Physical Properties}

Particle Size Distribution:

1). Hourly Samples:

1. The between-sampling day variation became more and more significant with decreased ash size.

2. The between-sampling hour variation varied with ash size, and was not significant.

3. The average gradation of bottom ash fell within the New Hampshire specification for type B binder mix, indicating the bottom ash was a well graded material. 2). Daily Composite Samples

1. The average gradation fell within the New Hampshire specification with the exception that the quantity of materials passing No.200 was marginal.

2. Natural bottom ash contained more fine materials in comparison to $\mathrm{NH}$ desired gradation.

3. The variation of daily composite samples was much smaller than that of hourly samples.

4. The average gradation of daily composite was close to that of the hourly samples. 3). Source of Variation

1. The variation of gradation existed for all ash samples. The variation could be 
contributed to sample representativeness, and sieve analysis methods.

\section{Other Physical Properties:}

1). Hourly Sample

1. The between-sampling day variation was significant, with the exception that variation of uniformity coefficient and effective size was not significant at $99 \%$ and $99.5 \%$ level.

2. The between-sampling hour variation was not significant, with the exception that mass $\geq 3 / 4^{\prime \prime}$ and $<3 / 4^{n}$, and uniformity coefficient were marginal at $75 \%$ confidence level.

3. Mass $\geq 3 / 4^{n}$ ranged from 20.8 to $50.2 \%$, with an average of $32.9 \%$. The significant variability was from the uncontrolled nature of incoming solid waste and the way the bottom ash was sampled. The bulk of the rejected material was ferrous and non-ferrous, fused materials, large pieces of slag, and unburned material.

4. The bottom ash passing the $3 / 4^{\prime \prime}$ sieve ranged from 49.8 to $79.2 \%$, with an average of $67.1 \%$. The variation was in part due to the uncontrolled quality of incoming solid waste.

5. Moisture content ranged from 22.4 to $60.6 \%$, with an average of $37.9 \%$.

6. Uniformity coefficient ranged from 8.3 to 34.0 , with an average of 21.7 . Effective size ranged from 0.12 to $0.52 \mathrm{~mm}$, with an average of $0.29 \mathrm{~mm}$. The two properties were sensitive to gradation.

7. Specific Gravity and Absorption of Coarse Aggregate and Fine Aggregate:

Bulk (dry) specific gravity of fine ash ranged from 1.55 to 2.22 , with an average of 
1.86 , and that of coarse ash ranged from 1.93 to 2.44 , with an average of 2.20 .

Bulk (SSD) specific gravity of fine ash ranged from 1.89 to 2.41 , with an average of 2.13, and that of coarse ash ranged from 2.11 to 2.58 , with an average of 2.32 .

Apparent specific gravity of fine ash ranged from 2.20 to 2.98, with an average of 2.56, and that of coarse ash ranged from 2.32 to 2.76 , with an average of 2.51 .

Absorption of fine ash ranged from 6.8 to $24.7 \%$, with an average of $14.7 \%$, and that of coarse ash ranged from 1.8 to $12.3 \%$, with an average of $5.7 \%$.

The variation of specific gravity and absorption exceeded ASTM C127 and C128 precision requirements. The difference in specific gravity between ash components is significant.

8. LOI ranged from 3.2 to 10.0 , with an average of 6.4 . The variation of LOI exceeded the ASTM C114 requirements because of a heterogeneous nature of ash and difficulty in obtaining a representative sample. LOI was strongly associated with particle size, increasing significantly with decreased particle size.

9. Ferrous content ranged from 11.9 to $39.6 \%$, with an average of $25.9 \%$. The "real" ferrous content was lower since the magnet used for this test was strong enough to pick up ash particle containing nonferrous materials fused to ferrous particles. The variation was significant because of the nature of this test and the heterogeneous nature of the ash. 2). Daily Composite Sample

1. The daily composite data were within hourly data range and had much less variation than the hourly data. Variation of daily composite data did not meet ASTM precision requirements. 
2. Unit weight ranged from 70.6 to $73.8 \mathrm{lb} / \mathrm{ft}^{3}$ at the $95 \%$ confidence level, with an average of $72.2 \mathrm{lb} / \mathrm{ft}^{3}$. The variation exceeded ASTM requirement for single-operator precision. Nevertheless, the variation was small in view of fact that ash is an uncontrolled waste material. Void content ranged from 41.2 to $43.7 \%$, with an average of $42.4 \%$.

3. The optimum Proctor density moisture content ranged from 14.7 to $16.1 \%$ at the $95 \%$ confidence level, with an average of $15.4 \%$. Precision of optimum moisture content data met the ASTM D1557 requirement. Proctor density ranged from 106.9 to 110.2 $\mathrm{lb} / \mathrm{ft}^{3}$ at $95 \%$ level, with an average of $108.6 \mathrm{lb} / \mathrm{ft}^{3}$. The variation were small, meeting the ASTM D1557 precision requirement.

4. CBR at $0.1^{\prime \prime}$ penetration ranged from 74.0 to $85.5 \%$ at the $95 \%$ level, with an average of $79.8 \%$. CBR at $0.2^{n}$ penetration ranged from 104.5 to $116.1 \%$ at $95 \%$ level, with an average of $110.3 \%$.

5. L.A. Abrasion data were consistent, with an average of $47.3 \%$ and $43.4 \%$ for Grade B and Grade C, respectively. The variation met the ASTM C131 precision requirements.

6. Soundness of fine ash ranged from 10.4 to $14.3 \%$, with an average of $11.9 \%$, that of coarse ash ranged from 2.5 to $2.8 \%$, with an average of $2.6 \%$. The variation for fine ash and coarse ash met ASTM C88 precision requirements.

\subsubsection{Marshall Procedure}

1. Water absorption of aggregate blends increased as ash content increased.

2. Unit weight of hot asphalt mixes decreased with increased ash.

3. Stability of all mixes ranged from 1840 to $2903 \mathrm{lb}$. The stability of ash mixes was 
comparable to that of the control mix.

4. Flow values increased with increasing asphalt contents. Ash mixes exhibited higher flow than the control mix due to increased asphalt contents.

5. All mixes containing up to $75 \%$ ash passed the VMA requirement of a minimum of 14\%. The $100 \%$ ash mix did not meet the VMA requirement at any asphalt content tested.

6. The asphalt content required to meet the specification of air void content increased as the ash content increased.

7. Asphalt absorption increased with increased ash.

8. The ash mixes showed very low water absorption, comparable to the control mix.

9. Bottom ash mixes can be designed to meet the Asphalt Institute specifications with up to $75 \%$ ash substitution.

10. The ash mixes showed more degradation than the control mix.

11. The selected $50 \%$ ash mix had an asphalt content of $9.12 \%$ by weight of mix.

12. The selected control mix had an asphalt content of $5.5 \%$ by weight of mix.

\subsubsection{GTM Procedure}

1. The unit weight is found to follow an asymptotic relationship with revolutions for both the ash and control mixes. The ash mix has lower density than the control at all revolutions.

2. The ash mix is more difficult to compact than the control mix.

3. Air voids decrease with increasing revolutions and asphalt contents. The ash mix 
meeting the initial and final air void requirements requires more asphalt cement than the control mix.

4. VMA decreases with increasing revolutions. The ash mix consistently has lower VMA than the control mix at each level of compaction.

5. The ash mix absorbs more asphalt cement than the control mix.

6. Effective asphalt contents increase with increasing asphalt content for both the ash and control mixes.

7. The ash and control mixes have low water absorption.

8. Gyratory shear and gyratory shear factor decrease with increasing revolutions and gyratory shear at 300 revolutions decreases with increasing asphalt content, and decreases significantly at high asphalt contents.

9. GSI can be used to predict rutting potentials. All mixes at 60 revolutions remain stable with GSI ranging from 1.005 to 1.07 for the ash mix and 1.011 to 1.024 for the control. The GSI at 300 revolutions increases appreciably with increasing asphalt content, indicating the mixes become unstable with increasing asphalt content.

10. Gyratory shear modulus and gyratory compressive modulus decrease with increasing revolutions at high asphalt contents. All mixes at 60 revolutions remain stable. Gyratory shear modulus and gyratory compressive modulus at 300 revolutions decrease appreciably with increasing asphalt content, indicating the mixes become unstable and plastic with increasing asphalt content.

11. The gyratory compressive strain at 60 revolutions is very small and is not dependent upon asphalt content. The gyratory compressive strain at 300 revolutions 
increases with increasing asphalt content.

12. Degradation occurred in all mixes. The ash mix degraded more than the control mix for particles in the $3 / 8^{n}$ to No.20 size range. The difference between gradations at 60 and 300 revolutions for the ash and control mixes are not significant, indicating the increased compaction effort does not increase degree of degradation significantly.

Compared to Marshall compaction, GTM compaction resulted in less degradation for the ash mix and more degradation for the control mix.

13. The design asphalt contents are $7.0 \%$ and $5.11 \%$ by weight of mix for the ash and control mixes respectively.

\subsubsection{Asphalt Absorption}

1. Based on the level of absorbed asphalt by the impregnation method the materials are ranked with regard to absorption as follows:

$$
\text { Bottom Ash }>\text { Clinker }>\text { Clinker with Iron }>\text { Glass }>\text { Control }
$$

2. The data by the impregnation method show asphalt absorption increases linearly with increasing water absorption regardless of the type of aggregates investigated.

3. The asphalt absorption by the impregnation method as a percentage of water absorption is found to range from 87.5 to $120.4 \%$.

4. The asphalt absorption of the ash and coarse ash mixes by the Rice method does not exhibit time-dependence because of large variation in data.

5. The amount of absorption of the control by the Rice method is about same as that of the coarse control, and they do not show time-dependence. 
6. The absorption of the coarse ash mix by the Rice method is lower than that of the ash mix.

7. The ash and coarse ash show higher absorption than the control and coarse control.

8. The asphalt absorption by Rice method as a percentage of water absorption is found to range from 88.2 to $196.8 \%$.

9. The Rice method overestimates $G_{m m}$ and $P_{b a}$, and underestimates $P_{b e}$ for the ash mixes.

10. The absorption of the coarse ash and coarse control by bulk impregnation method is lower than that by Rice method.

\subsubsection{Microscopic Study}

1. Bottom ash contains angular, equidimensional, flaky, elongated, rough, honeycombed particles.

2. Bottom ash contains visible pores and are partially covered with fine dust.

3. Bottom ash contains various sizes of internal and external pores.

4. It appears that ash particles are coated well with asphalt cement. The permeable pores are only partially filled with asphalt cement.

5. Bottom ash contains many impermeable pores.

\subsection{Recommendations}

The recommendations for future research are as follows: 


\subsubsection{Laboratory Studies}

1. The $25 \%, 75 \%$ and $100 \%$ bottom ash mixes should be evaluated with GTM procedures.

2. In view of possible recovery of ferrous metal, the ferrous-free bottom ash mixes should be investigated.

3. Performance-related testing (moisture damage, thermal cracking, and fatigue cracking) should be performed on GTM samples with bottom ash to better predict field performance.

4. An improved Rice method or other methods should be developed to better characterize the $G_{m m}$ of bottom ash mixes.

5. The bulk impregnation method appears suitable for the ash mixes. Investigation is required to determine the impregnation time for the ash mixes.

6. Microscopic studies should be conducted to investigate air void size and distribution, the interaction between asphalt and bottom ash, and their impact on performance.

\subsubsection{Field Studies}

1. The construction of $50 \%$ bottom ash and control test road was completed. Its long term performance should be monitored.

2. Demonstration projects using different percentage of bottom ash should be considered.

3. A practical procedure regarding bottom ash production including processing, storage, transportation, and quality assurance should be developed. 
4. A practical procedure regarding production of bottom ash hot mix including plant mixing, transportation, and placement should be developed.

5. Economical assessment and marketing should be performed.

\subsubsection{Other}

Laboratory and field studies should be conducted to investigate other potential uses of bottom ash as construction materials.

1. Bottom ash mixes as asphalt wearing courses.

2. Bottom ash as unbound base or subbase materials.

3. Bottom ash as an aggregate substitute in portland cement concrete application.

In conclusion, the research presented here was unique in that while the standard methods used in other ash utilization studies were employed in this study, a new method (GTM) was introduced to evaluate bottom ash performance in HMA.

The results from the laboratory studies indicate that variability of the physical properties of the bottom ash produced during the two years study period is relatively small in view of the fact that the bottom ash is an uncontrolled waste material. In comparison to conventional aggregates bottom ash shows more variation. The bottom ash is a heterogeneous, well graded, highly absorptive, porous and lightweight aggregate material. The abrasion resistance and durability of the bottom ash as measured by L. A. abrasion and sodium sulfate soundness tests pass ASTM requirements. The CBR tests show that the bottom ash has an excellent bearing capacity and would make an excellent 
subbase and base material in road application.

GTM and Marshall methods were employed to study the properties of HMA. Results show that the bottom ash can be used as an aggregate substitute in HMA. Results also indicate that GTM and Marshall methods do not make much difference in developing the optimum mix design for the conventional aggregate mix. However, they make a significant difference for the bottom ash mix. The GTM method results in much lower optimum asphalt content than the Marshall method for the bottom ash mix. GTM, unlike Marshall, is an unique tool in predicting the mix performance. It is anticipated that the bottom ash mix developed with the GTM method will perform much better than a mix developed with the Marshall method. A demonstration project including the $50 \%$ ash and control mixes both designed with GTM method was successfully completed in Laconia, NH in May of 1993. Preliminary studies indicate the ash section performs as well as the control section. The long term performance of the test road is being monitored with various destructive and nondestructive testing techniques. 


\section{REFERENCES}

1. T. Austin. Waste to Energy? The Burning Question. Journal of Civil Engineering, Volume 61, 1991, pp.35-38.

2. United States Environmental Protection Agency. Characterization of Municipal Solid Waste Combustor Ashes and Leachates from Municipal Solid Waste Landfills, Monofills, and Codisposal Sites. U. S. Department of Commerce National Technical Information Service (Springfield, VA). Volume I and Volume V, 1987.

3. A.M. Ujihara and M. Gough. Managing Ash from Municipal Waste Incinerators. Final Report, Center for Risk Management, Resources for the Future, Washington, D.C., 1989.

4. W. H. Chesner, R.J. Collins, and T. Fung. An Assessment of the Potential Suitability of Southwest Brooklyn Incinerator Residue in Asphaltic Concrete Mixes. Final Report, Chesner Engineering, P.C. 2171 Jericho Turnpike, Commack, New York 11725, July 1989.

5. T.T. Eighmy, S.F. Bobowski, T.P. Balestero, and M.R. Collins. Investigations into Leachate Characteristics from Amended and Unamended Combined Ash and Scrubber Residues. Environmental Research Group, Department of Civil Engineering, University of New Hampshire, Durham, NH, 1989.

6. S. Law. Metals in Ash Materials Filtered from Municipal Incinerator Effluents. Resource Recovery and Conservation, Volume 3, 1978, pp.19-39.

7. S. Law and G. Gordon. Sources of Metals in Municipal Incinerator Emissions. Environ. Sci. Technol., Volume 13, No.4, 1979, p.435.

8. D. Pindzola and R.J. Collins. Technology for Use of Incinerator Residue as Highway Material - Identification of Incinerator Practices and Residue Sources. Report No. FHWA-RD-75-81 (Interim Report). Federal Highway Administration, July 1975.

9. D. Pindzola and R.C. Chou. Synthetic Aggregate from Incinerator Residue by a Continuous Fusion Process. Report FHWA/RD-74/23. 1974.

10. D. Pindzola. Large Scale Continuous Production of Fused Aggregate from 
Incinerator Residue. Report FHWA/RD-76/115. 1976.

11. R.R. Snyder. Evaluation of Fused Incinerator as a Paving Material. Report FHWATS-88-229. 1980.

12. R.J. Collins, R.H. Miller, S.K. Ciesielski, E.M. Wallo, M.J. Boyle, D. Pindzola, and J. Tropea. Technology for Use of Incinerator Residue as Highway Material. Report FHWA/RD-77/151. October 1976.

13. R.J. Collins, et al. Guidelines for the Use of Incinerator Residue in Highway Construction. Report FHWA-RD-77-72. 1976.

14. W.C. Ormsby. Paving with Municipal Incinerator Residue. Proceedings of the First International Conference on Municipal Solid Waste Combustor Ash Utilization, Philadelphia, PA, October 13-14, 1988.

15. J. Haynes and W.B. Ledbetter. Incinerator Residues in Bituminous Base Construction. FHWA/RD-76/12. 1976.

16. D.J. Teague and W.B. Ledbetter. Three Year Results on the Performance of Incineration Residues in Bituminous Base. FHWA/RD-88/002. 1978.

17. J. Ederly and W.B. Ledbetter. Field Performance of Littercrete (Incinerator Residue) in a Bituminous Base. FHWA/RD-88/022. 1981.

18. R.D. Pavlovich, H.J. Lentz, and W.C. Ormsby. Incinerator Residue as Aggregate for Hot-Mix Asphalt Base Course. Transportation Research Record 734, Washington, D.C., 1979, pp.38-44.

19. G. Bastanza. Summary Update of Research Projects with Incinerator Bottom Ash Residue. Department of Environmental Management Document, 1982.

20. W.C. Ormsby and D.G. Fohs. Use of Waste and By-Products in Highway Construction. The 69th Annual Meeting of the Transportation Research Board, Washington, D.C., Jan. 7-11, 1990.

21. R.R. Snyder. Evaluation of Fused Incinerator Residue as a Paving Material. FHWATS-88-229. 1980.

22. D.G. Mehan and W.F. Hooper. Processed Ash Demonstration Project. Proceedings of the Second Annual International Specialty Conference (Municipal Waste Combustion), AWWA, Pittsburgh, Penn., 1991, pp.627-641.

23. W.H. Chesner. Environmental Issues Associated with the Use of MSW Combustor 
Ash in Asphalt Paving Mixes. Proceedings of the Second Annual International Conference (Municipal Waste Combustion), AWMA Press, Pittsburgh, Penn., 1991, p.608.

24. Taylor Eighmy, David Gress, Xishun Zhang, Scott Tarr, and Ingrid Whitehead. Bottom Ash Utilization Evaluation for the Concord, New Hampshire Waste-to-Energy Facility. Interim Report, Environmental Research Group, Department of Civil Engineering, University of New Hampshire, May 1992.

25. H.A. Van der Sloot. Personal Communication, 1990.

26. O. Hjelmar. Regulatory and Environmental Aspects of MSWI Ash Utilization in Denmark. Proceedings of the Third International Conference on Municipal Solid Waste Combustor Ash Utilization, UNH Press, Durham, NH, 1991, pp.59-70.

27. J. Vehlow. Management of Residues from MSWI in the FRG. Proceedings of the Third International Conference on Municipal Solid Waste Combustor Ash Utilization, UNH Press, Durham, NH., 1991, pp.71-84.

28. D. Stämpfli. Personal Communication, 1991.

29. J. Hartlén. Regulatory Aspects of Ash Utilization in Sweden. Proceedings of the Second International Conference on Municipal Solid Waste Combustor Ash Utilization, UNH Press, Durham, N.H., 1990, pp.213-250.

30. S. Gotoh. Availability of Ash Data (Japan). Ministry of Health and Welfare, Tokyo, 1988.

31. F.E. Hoffman and D.S. Kosson. Municipal Solid Waste Combustion Residue Utilization Demonstration Project Summaries - United States of America. EPA Draft Report. November 1991.

32. P. Leenders. Municipal Solid Waste Residues in the Netherlands. Proceedings of Waste Materials in Construction, Elsevier, Amsterdam, 1991, pp.593-599.

33. P.S. Kandhal and W.S. Koehler. Marshall mix design method: Current Practices. Proceedings of Association of Asphalt Paving Technologists, Volume 54, 1985.

34. Freddy L. Robert, Prithvi S. Kandhal, E. Ray Brown, Dah-Yinn Lee, and Thomas W. Kennedy. Hot Mix Asphalt Materials, Mixture Design, and Construction. First Edition, The National Asphalt Pavement Association (NAPA) Education Foundation, Lanham, Maryland, 1991.

35. The Asphalt Institute. Mix Design Methods for Asphalt Concrete and Other Hot-Mix 
Types. Manual Series No.2 (MS-2), Fourth Edition, March 1974.

36. H.L. Von Quintus, J.A. Scherocman, C.S. Hughes, and T.W. Kennedy. AsphaltAggregate Mixture Analysis System (AAMAS). National Cooperative Highway Research Program Report 338, Transportation Research Board, National Research Council, Washington, D.C. March 1991.

37. Ian Jamieson. The Strategic Highway Research Piogram: Asphalt- Aggregate Interactions and Mixtures. Hot Mix Asphalt Technology, Volume 5, No.1, 1990.

38. James S. Moulthrop, Ronald J. Cominsky, Thomas W. Kennedy, and Edward T. Harrigan. Strategic Highway Research Program Asphalt Research - An Overview. Asphalt Paving Technology, Volume 60, 1991.

39. John R. Tabb. Strategic Highway Research Program 1990 Annual Report. National Research Council, October 1990.

40. Jack Youtcheff. Update on the SHRP Binder Specification. FOCUS, the newsletter of the Strategic Highway Research Program, Washington, D.C., August 1992.

41. SHRP Asphalt Research program. Classification of Materials Reference Library Asphalts Using Draft Binder Specification 7G. Technical Memorandum \#6, July 1992.

42. Rita B. Leahy. Compaction Method and Accelerated Performance Tests for the SUPERPAVE Mix Design System. SHRP Asphalt Research Program Technical Memorandum \#7, August 1992.

43. Larry Flynn. SHRP Mix Designs Offer Stronger Pavements. Road and Bridges, September 1992.

44. NCHRP. Field Procedures and Equipment to Implement SHRP Asphalt Specifications - NCHRP Research Project Statement. Transportation Research Board, National Research Council, 1993.

45. Paul Irick. Concepts and Principles of Statistical Quality Control. Proceedings, Association of Asphalt Paving Technologists, Volume 37, 1968, p.259.

46. Tom Fiesinger, W. H. Chesner, Frank J. Roethel, et al. The Potential for Beneficial Use of Waste-to-Energy Facility Ash. Engineering Property Data Report No.4, Prepared by Long Island Regional Planning Board, Hauppauge, New York, June 1990.

47. C.B. Kenahan, P.M. Sullivan, J.A. Ruppert, and E.F. Spano. Composition and 
Characteristics of Municipal Incinerator Residues. U.S. Department of Interior, Bureau of Mines, Report of Investigations No. 7204, Washington, D.C., December 1968.

48. W.H. Chesner et al. Long Island Ash Management Study. Interim Technical Memorandum, Task 1.5, Physical Characterization Program, December 12, 1988.

49. Portland Cement Association. Design and Control of Concrete Mixtures. Engineering Bulletin, Thirteenth Edition, 1990.

50. E. J. Yoder and N. W. Witczak. Principles of Pavement Design. 2rd Ed., John Wiley \& Sons, Inc., 1975.

51. E. A. Maxwell. Introduction to Statistical Thinking. PRENTICE-HALL., Englewood Cliffs, New Jersey, 1983.

52. Chris Bauer. Statistics and Experimental Design. Printing Service, University of New Hampshire, Durham, 1991.

53. Minitab, Inc. Minitab Statistical Software. Reference Manual-Release 6.1, January 1988.

54. C.E. Walter. Asphalt Road Composition and Process of Making Sand. U.S. Patent No. 3,907,582. U.S. Patent Office, Washington, D.C., 1973.

55. C.E. Walter. Practical Refuse Recycling. Journal of Environmental Engineering Division, ASCE, February 1976, pp.139-148.

56. Richard W. Smith. The Marshall Method for the Design and Control of Asphalt Paving Mixtures. Humboldt MFG. Co., Chicago, IL., 1987.

57. R. J. Collins, R.H. Miller, and S.K. Ciesielski. Guidelines for Use of Incinerator Residue as Highway Construction Material. Report FHWA-RD-77-150. FHWA, U.S. Department of Transportation, 1977.

58. National Asphalt Pavement Association. The Effect of Voids in Mineral Aggregate on Pavement Performance. Information Series 9/6/86, 1986.

59. F. Moavenzadeh and W. H. Goetz. Aggregate Degradation in Bituminous Mixtures. Highway Research Record No.24, 1963, pp.106-137.

60. M.F. Macnaughton. Physical Changes in Aggregates in Bituminous Mixtures Under Compaction. Proc. Assoc. of Asphalt Paving Tech., Jan. 1937, p.8. 
61. J.T. Pauls and C.A. Carpenter. Mineral Aggregate for Bituminous Construction. ASTM Spec. Tech. Publ., 1948, p.83.

62. F. Field. Correlation of Laboratory Compaction with Field Compaction for Asphaltic Concrete Pavement. Proc., Canadian Technical Asphalt Association, Vol. 4, 1959.

63. J.A. Epps, R.M. Gallaway, W.J. Harper, W.W. Scott Jr., and J.W. Seay. Compaction of Asphalt Concrete Pavements. Research Report 90-2F, Texas Transportation Institute, The Texas Highway Department, July, 1969.

64. J.B. Sousa, J. Harvey, L. Painter, J.A. Deacon, and C.L. Monismith. Evaluation of Laboratory Procedures for Compacting Asphalt-Aggregate Mixtures. SHRPA/UWP-91-523, Strategic Highway Research Program, National Research Council, Washington, D.C., 1991.

65. J.L. McRae. Gyratory Testing Machine Technical Manual. Engineering Developments Company, Inc., Vicksburg, Mississippi, 1965, Revised September, 1970.

66. U.S. Army Engineer Waterways Experimental Station. Development of the Gyratory Testing Machine and Procedures for Testing Bituminous Paving Mixtures. Technical Report No.3-595, February 1962.

67. R. E. Hughes. Use of a Gyratory Testing Machine to Apply Simulated Traffic to Bituminous Concrete. M.S. Thesis, Purdue University, January 1964.

68. B. E. Ruth and J. H. Schaub. Gyratory Testing Machine Simulation of Field Compaction of Asphaltic Concrete. Proceedings of the Association of Asphalt Paving Technologists, Vol. 35, 1966.

69. C.F. Potts. The Simulation of Traffic with the Gyratory Testing Machine. M.S. Thesis, West Virginia University, 1967.

70. Arun Kumar and W. H. Goetz. The Gyratory Testing Machine as a Design Tool and as an Instrument for Bituminous Mixture Evaluation. Proceedings of the Association of Asphalt Paving Technologists, Vol. 43, 1974.

71. Dave Rand. Comments About Use and Results of Corps of Engineers Gyratory Testing Machine. Personal Letter, Maine Department of Transportation. August 5, 1992.

72. Maine Department of Transportation. Evaluation of Gyratory Testing Machine Mixrure Design Results for Work Performed in 1991. Research Report No. Problem Solving 92-21, August 1992. 
73. The National Center for Asphalt Technology. A National Study of Rutting in Asphalt Pavements. Research Report, Auburn University, AL, 1992.

74. American Society for Testing and Material (ASTM) D3387. Stan:tard Test Method for Compaction and Shear Properties of Bituminous Mixtures by iteans of the U.S. Corps of Engineers Gyratory Testing Machine. Annual Book of ASTM Standard, Vol. 04.03, 1983.

75. F.L. Robert. Importance of Compaction of Asphalt Mixtures. ARE, INC., Austin, Texas, January 1980.

76. The National Center for Asphalt Technology. Asphalt Technology News. Volume 4, No.1, Spring 1992.

77. P. S. Kandhal and M. A. Khatri. Evaluation of Asphalt Absorption by Mineral Aggregates. Proc. AAPT, Vol. 60, 1991.

78. D.Y. Lee, J. A. Guin, P. S. Kandhal, and R. L. Dunning. A Literature Review: Absorption of Asphalt into Porous Aggregates. Prepared for Strategic Highway Research Program Contract A-003B, 1990.

79. P. S. Kandhall. Asphalt Absorption As Related to Pore Characteristics of Aggregates. Master Thesis, Iowa State University, 1969.

80. D. Y. Lee. Study of Absorptive Aggregates in Asphalt Paving Mixture. Research Report-HR-127, Engineering Research Institute, Iowa State University, Ames, February 1968.

81. F. N. Hveem. Use of Centrifuge Kerosene Equivalent As Applied to Determine the Required Oil Content for Dense Graded Bituminous Mixtures. Proc. AAPT, Vol. 13, 1942.

82. R. N. Lohn. A Method To Determine Aggregate Absorption and Control of Bituminous-Aggregate Properties. Proc. AAPT, Vol. 16, 1947.

83. J. A. Donaldson, R. J. Loomis, and L. C. Krchma. The Measurement of Aggregate Absorption. Proc. AAPT, Vol. 16, 1947.

84. L. C. Krchma and H. G. Nevitt. Absorption of Liquid Bituminous Cement by Aggregates. Proc. AAPT, Vol. 13, 1942.

85. L. A. Lattier, D. F. Fink, N. B. Wilson, and F. F. Fraley. Mechanism of Absorption of Bituminous Material Aggregates. Proc. AAPT, Vol. 18, 1949. 
86. F. V. Reagel. Absorption of Liquid Bituminous Material by Coarse Aggregate. Highway Research Abstracts No.40, HRB, 1937.

87. J. H. Goshorn and F. M. Williams. Absorption of Bituminous Materials by Aggregates. Proc. AAPT, Vol. 13, 1942.

88. J. M. Rice. Maximum Specific Gravity of Bituminous Mixtures by Vacuum Saturation Procedure. ASTM Special Technical Publication, 191, 1956.

89. J. M. Rice. New Test Method for Direct Measurement of Maximum Density of Bituminous Mixtures. Crushed Stone Journal, September 1953.

90. O. Larson. Development and Use of High Pressure Apparatus for Determining Voids in Compacted Bituminous Concrete Mixtures. Proc. AAPT, Vol. 26, 1957.

91. W. C. Ricketts, J. C. Sprague, D. D. Tabb, and J. L. McRae. An Evaluation of Specific Gravity of Aggregates for Use in Bituminous Mixtures. Proc. ASTM, Vol. 54, 1954.

92. U. S. Corps of Engineers Waterways Experiment Station. Investigation of the Penetration of Asphalt into Porous Aggregates as Related to and Affecting the Specific Gravity of the Aggregate. Corps of Engineers Misc. Paper No. 4-88, 1954.

93. N. L. Tran. The Methylene Blue Test. Bulletin de Liaison des Ponts et Chaussees, $107,1980$.

94. C. A. Franko and K. W. Lee. Development of a Pressure Method to Determine Theoretical Specific Gravity of Bituminous Paving Mixtures. Paper presented at the 69th Annual Meeting of the Transportation Research Board in Washington D. C., January 7-11, 1990.

95. P. S. Kandhal and M. A. Khatri. Improved Rice Method for Determining Theoretical Maximum Specific Gravity of Asphalt Paving Mixtures. Paper presented at the 7lth Annual Meeting of the Transportation Research Board in Washington D. C., January 12-16, 1992.

96. A.M. Hoque and J.G. Cabrera. Adsorption in Manufactured Soil Aggregates. ASCE Journal of Transportation Engineering, Volume 109, 1983, pp.800-814.

97. Kirsten Eriksen. Summary Report on Specimen Preparation. Strategic Highway Research Program, National Research Council, Washington, D.C., October 1990. 


\section{APPENDIX A}

Sieve Analysis Data of Bottom Ash

Reproduced with permission of the copyright owner. Further reproduction prohibited without permission. 


\begin{tabular}{|c|c|c|c|c|c|c|c|c|}
\hline & 염 & 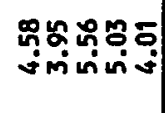 & 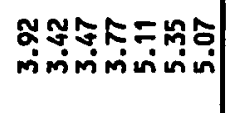 & 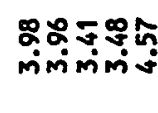 & 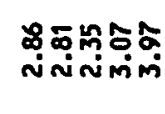 & 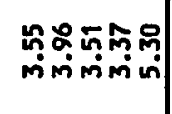 & 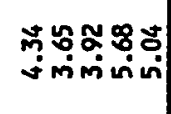 & 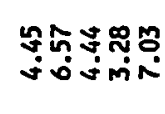 \\
\hline & $\begin{array}{l}\text { 여 } \\
\text { 울 }\end{array}$ & 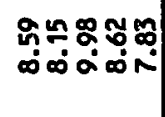 & 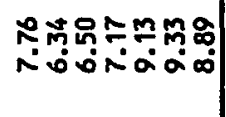 & 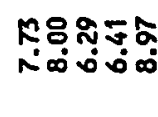 & 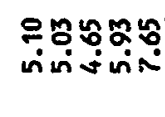 & 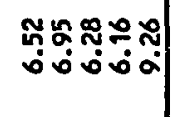 & 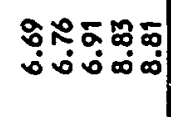 & 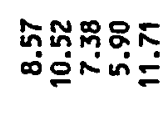 \\
\hline & $\begin{array}{l}\text { 움 } \\
\text { 우 }\end{array}$ & 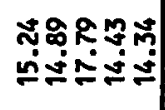 & 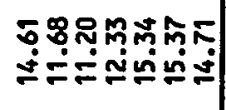 & 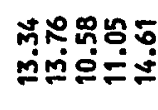 & 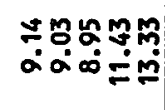 & 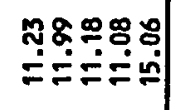 & 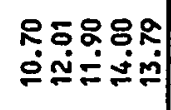 & 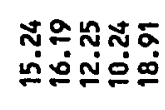 \\
\hline & 옹 & 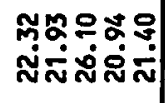 & 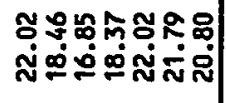 & 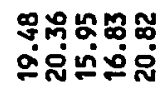 & 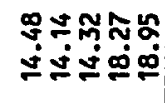 & $\mid$ & 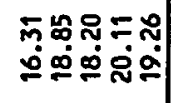 & 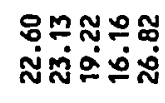 \\
\hline & $\begin{array}{l}\circ \\
\text { 요 }\end{array}$ & 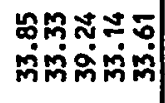 & 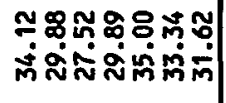 & 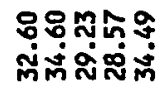 & 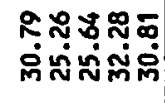 & 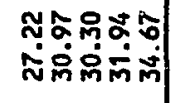 & 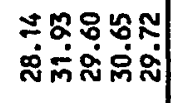 & 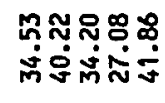 \\
\hline 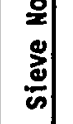 & ํ. & 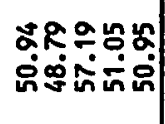 & 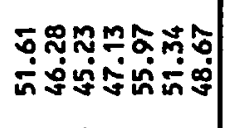 & 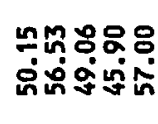 & 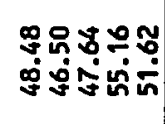 & 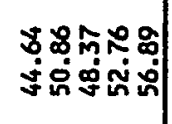 & 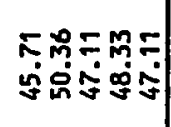 & 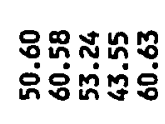 \\
\hline & के & 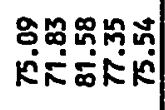 & 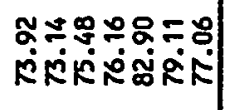 & 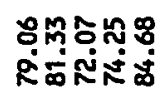 & 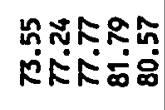 & 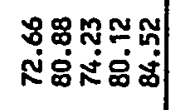 & 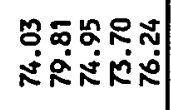 & 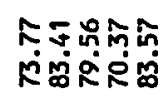 \\
\hline & 空 & 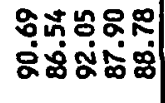 & 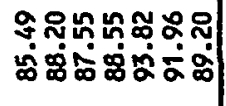 & 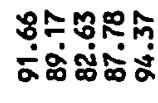 & 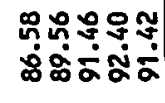 & 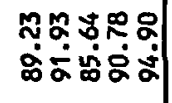 & 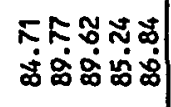 & 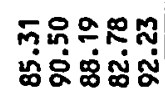 \\
\hline & हैं & 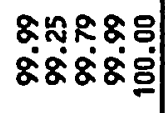 & 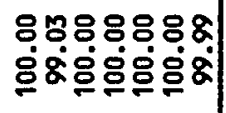 & 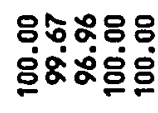 & 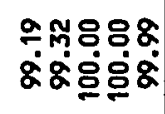 & 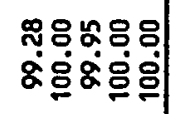 & 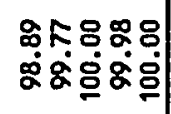 & 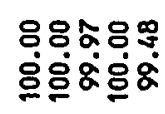 \\
\hline $\begin{array}{l}0 \\
\stackrel{0}{0} \\
\text { 言 }\end{array}$ & & 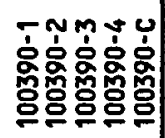 & 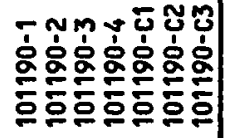 & 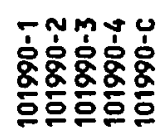 & 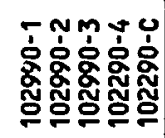 & 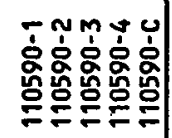 & 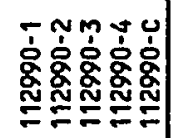 & 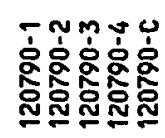 \\
\hline
\end{tabular}




\begin{tabular}{|c|c|c|c|c|c|c|c|}
\hline 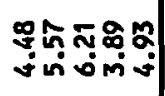 & 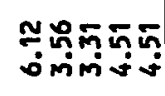 & 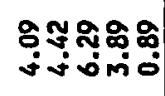 & 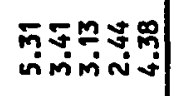 & 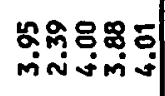 & 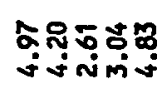 & 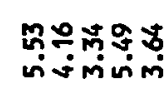 & 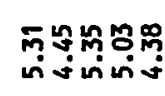 \\
\hline 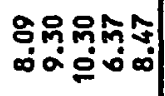 & 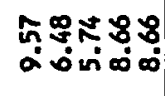 & 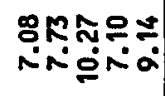 & 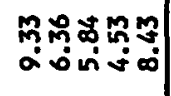 & 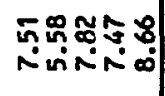 & 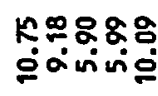 & 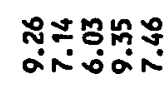 & 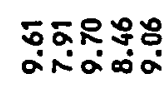 \\
\hline 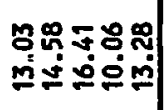 & 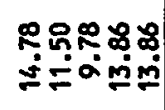 & 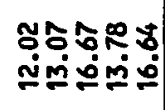 & 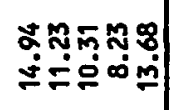 & 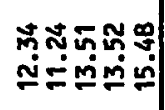 & 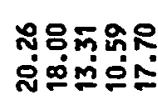 & 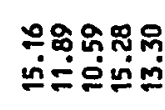 & 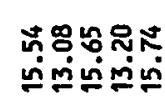 \\
\hline 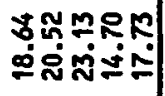 & 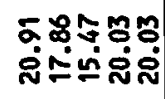 & 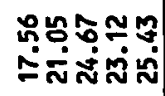 & 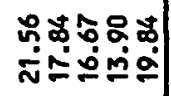 & 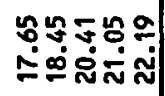 & 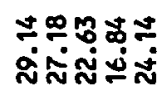 & 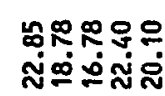 & 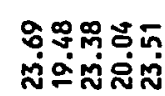 \\
\hline 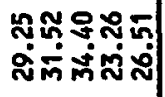 & 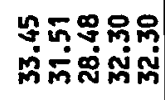 & 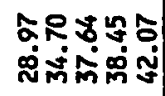 & 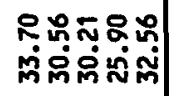 & 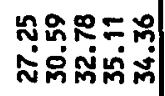 & 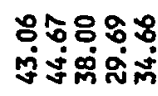 & 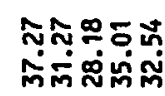 & 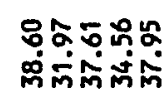 \\
\hline 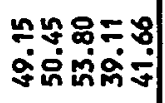 & 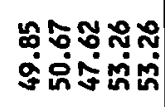 & 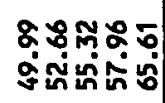 & 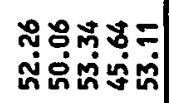 & 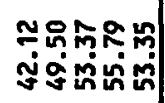 & 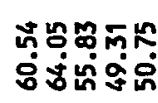 & 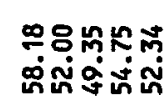 & 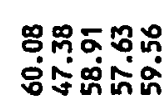 \\
\hline 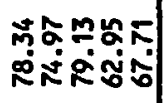 & 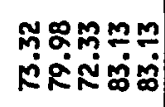 & 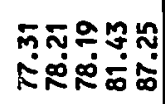 & 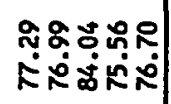 & 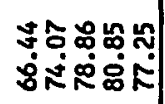 & 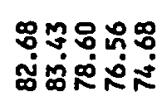 & 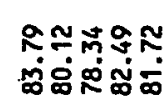 & 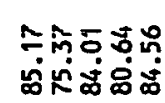 \\
\hline 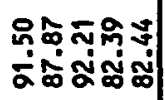 & 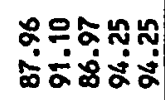 & 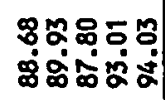 & 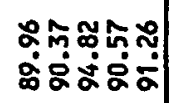 & 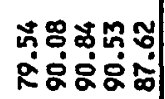 & 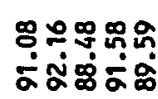 & 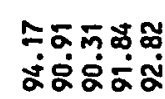 & 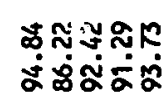 \\
\hline $\begin{array}{l}\text { ㅎㅇㅇㅇㅇㅇ } \\
\text { \&்ㅇㅇㅇㅇㅇㅇ }\end{array}$ & 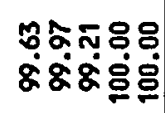 & 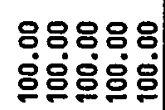 & 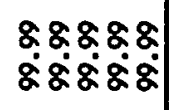 & $\begin{array}{l}8888 \% \\
80 \\
80\end{array}$ & $\begin{array}{l}\text { 융용ㅇㅇㅇ } \\
\text { 영용ㅇㅇㅇ }\end{array}$ & 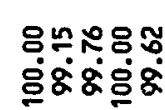 & $\begin{array}{l}88 k 88 \\
\text { த் }\end{array}$ \\
\hline 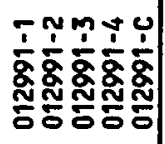 & 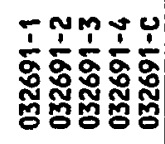 & 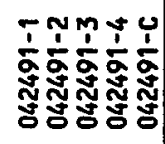 & 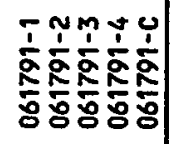 & 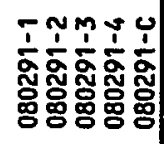 & 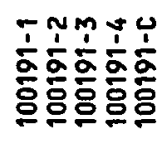 & 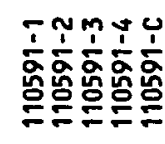 & 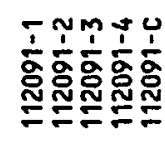 \\
\hline
\end{tabular}




\begin{tabular}{|c|c|c|}
\hline 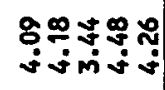 & 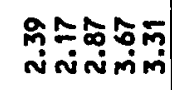 & 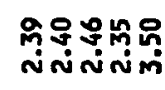 \\
\hline 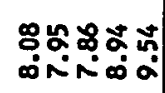 & 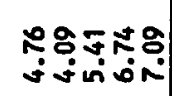 & 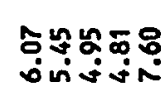 \\
\hline 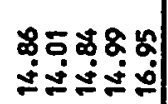 & 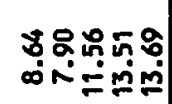 & 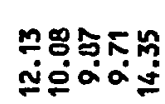 \\
\hline 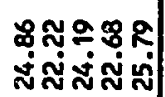 & 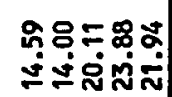 & 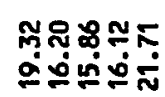 \\
\hline 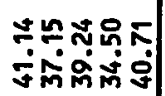 & 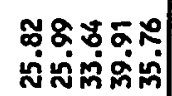 & 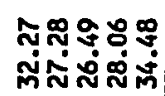 \\
\hline 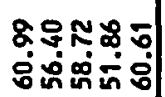 & 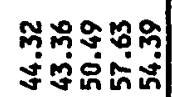 & 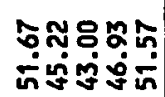 \\
\hline 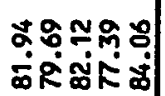 & 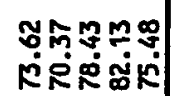 & 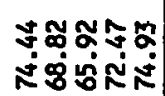 \\
\hline 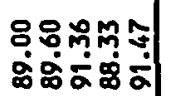 & 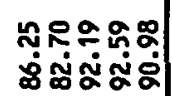 & 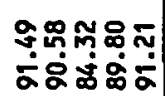 \\
\hline 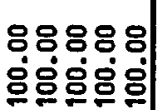 & 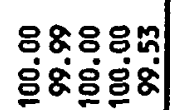 & 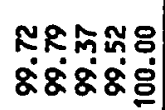 \\
\hline 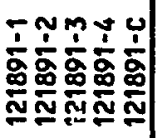 & 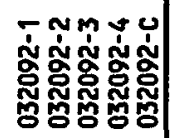 & 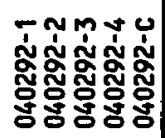 \\
\hline
\end{tabular}


APPENDIX B

Bottom Ash Physical Properties

Reproduced with permission of the copyright owner. Further reproduction prohibited without permission. 


\begin{tabular}{|c|c|c|c|c|c|c|}
\hline$\widehat{\mathbf{x}}$ & 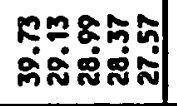 & 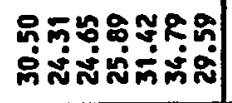 & 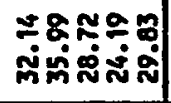 & 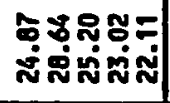 & 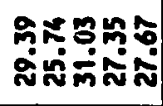 & กิ่ं \\
\hline $\bar{\Xi}$ & & 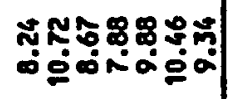 & & & & i: \\
\hline \multirow{2}{*}{ 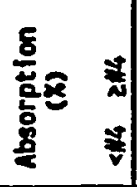 } & 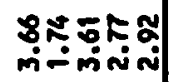 & 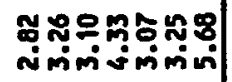 & 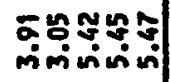 & 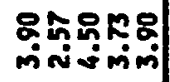 & 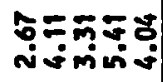 & isions \\
\hline & 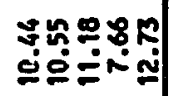 & 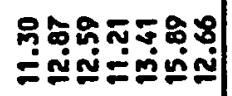 & 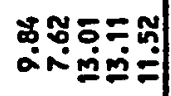 & 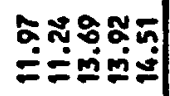 & 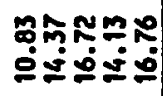 & 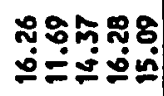 \\
\hline \multirow{2}{*}{ 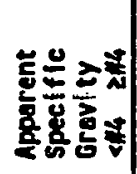 } & 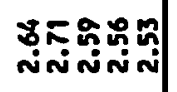 & 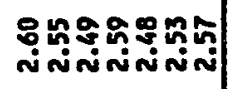 & 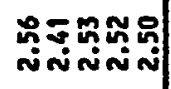 & 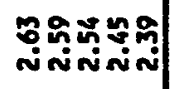 & 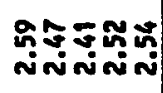 & 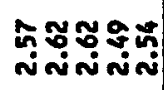 \\
\hline & 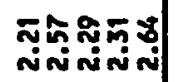 & 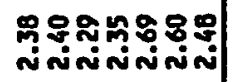 & ำ & 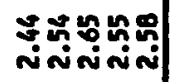 & 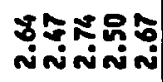 & \\
\hline \multirow{2}{*}{ 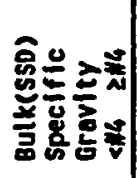 } & 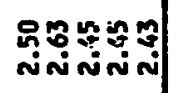 & 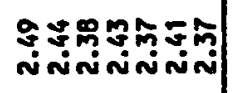 & 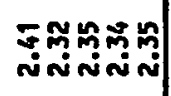 & 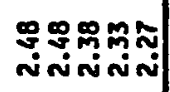 & 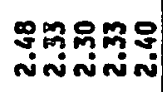 & F⿱艹 \\
\hline & 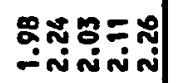 & 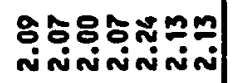 & సพ⿳亠口冋: & 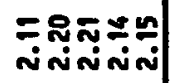 & 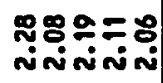 & S: \\
\hline \multirow{2}{*}{ 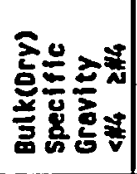 } & 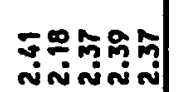 & 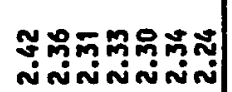 & 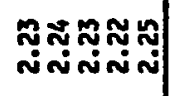 & 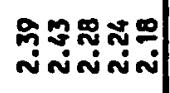 & 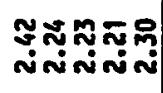 & 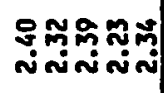 \\
\hline & 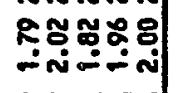 & 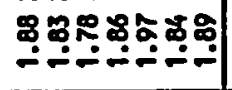 & 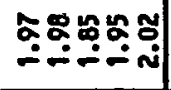 & 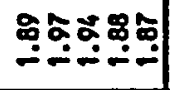 & 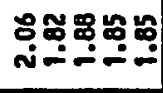 & ప్ర்: \\
\hline 运官 & 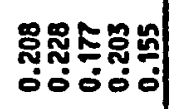 & 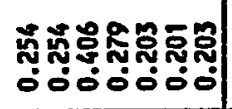 & 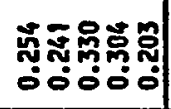 & 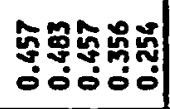 & 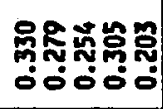 & 兽昂 \\
\hline 웅 & 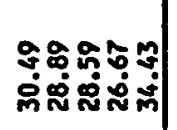 & 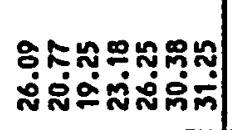 & 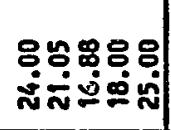 & 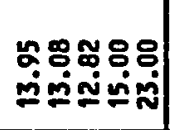 & 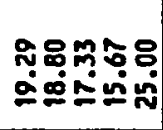 & 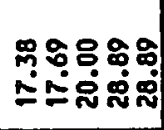 \\
\hline 눙 & 的急品等。 & 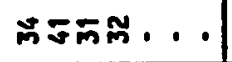 & ตำ的品 & 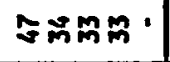 & 엉ำㄴ. & 昌果盟每。 \\
\hline 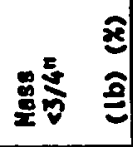 & 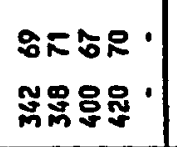 & 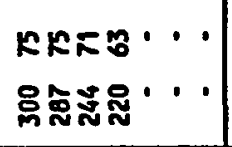 & 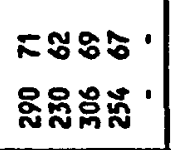 & 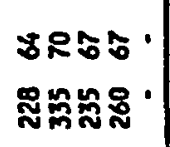 & 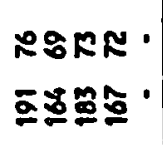 & 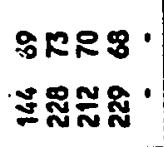 \\
\hline : & 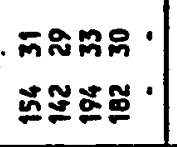 & 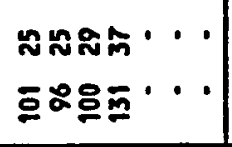 & 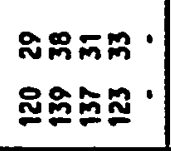 & 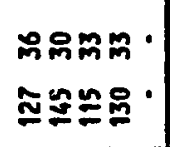 & 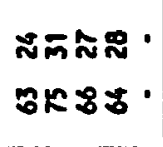 & 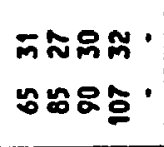 \\
\hline$\infty$ & & & & IN . & & \\
\hline $\begin{array}{l}\frac{0}{0} \\
\frac{0}{8} \\
\frac{8}{5}\end{array}$ & 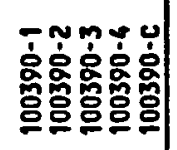 & 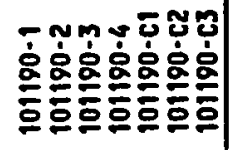 & 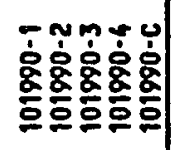 & 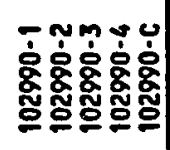 & 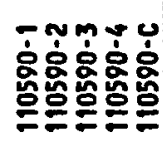 & 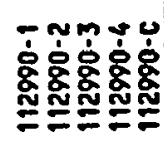 \\
\hline
\end{tabular}

373 


\begin{tabular}{|c|c|c|c|c|c|c|}
\hline 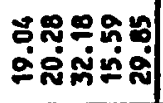 & 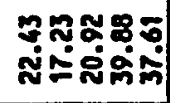 & 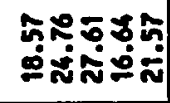 & 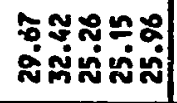 & 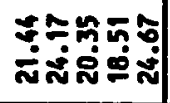 & 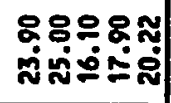 & 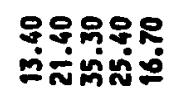 \\
\hline 品疋 & 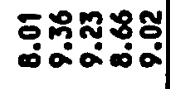 & 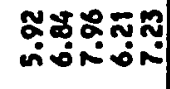 & 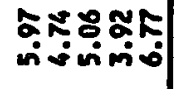 & 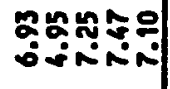 & 둥영 & 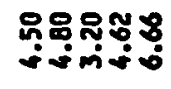 \\
\hline :ㅁำ & 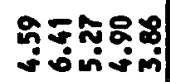 & 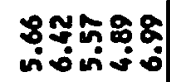 & 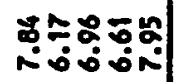 & 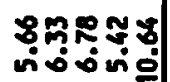 & 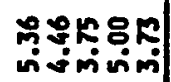 & 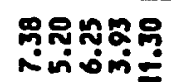 \\
\hline 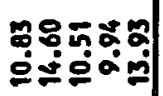 & 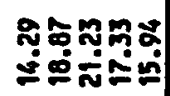 & 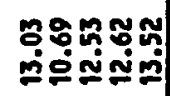 & 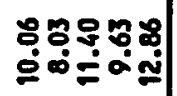 & 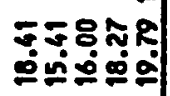 & 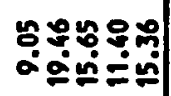 & 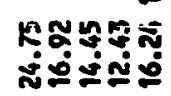 \\
\hline 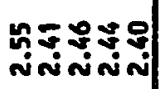 & 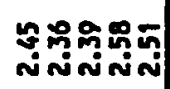 & 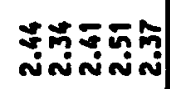 & 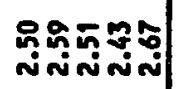 & మొ & 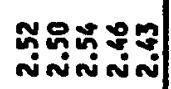 & 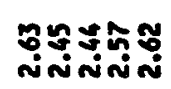 \\
\hline 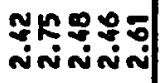 & 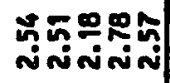 & 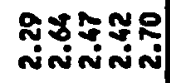 & 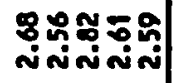 & 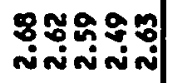 & 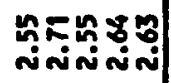 & 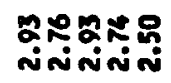 \\
\hline 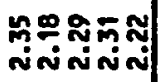 & 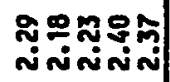 & 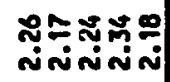 & 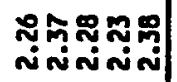 & 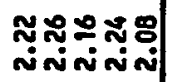 & 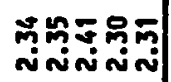 & 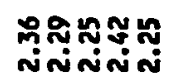 \\
\hline 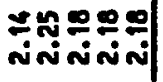 & 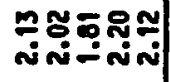 & 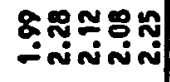 & Nేpำ & 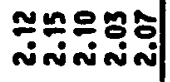 & 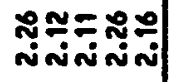 & 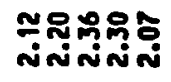 \\
\hline 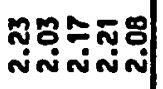 & 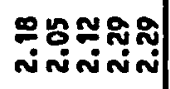 & 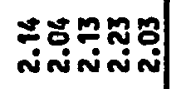 & 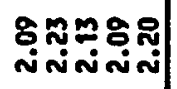 & 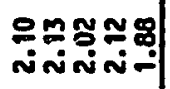 & 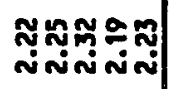 & 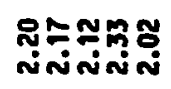 \\
\hline 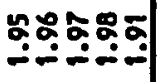 & 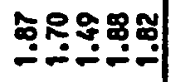 & 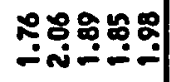 & 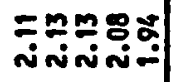 & 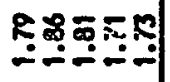 & 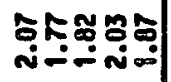 & 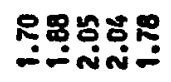 \\
\hline 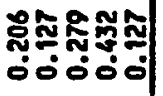 & 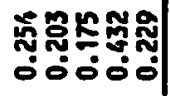 & 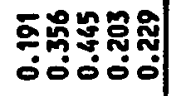 & 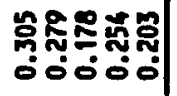 & 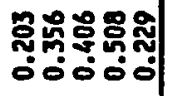 & 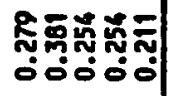 & 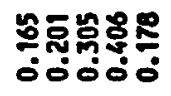 \\
\hline 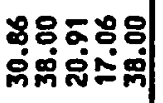 & 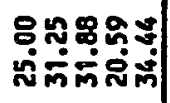 & 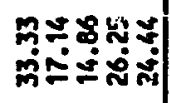 & 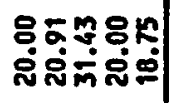 & 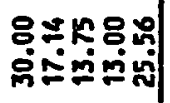 & 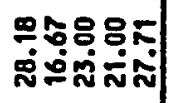 & 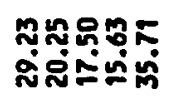 \\
\hline กีกลี & mañ & =으. & $\bar{m} \bar{m}$ 只品. & 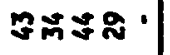 & 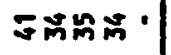 & กำనึన \\
\hline NNE\% & 8549 & 동 $88^{\circ}$ & 的思只 & 58981 & 8NR8. & ㅁR․ \\
\hline 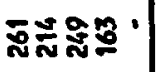 & శ్ํํํํํำ & กิన్నే & జ్ & 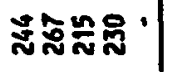 & 品品品怘 & 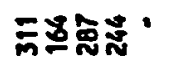 \\
\hline 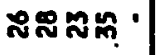 & 옹ำ & 可出的的・ & 구웜인 & mNEN & กัก๊ล์. & స욤오․ \\
\hline よあズ・ & 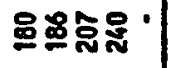 & 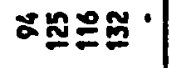 & 초욤요 & 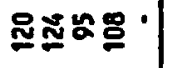 & 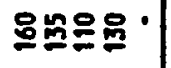 & 을토. \\
\hline & & NNNN. & & in. & v n . & \\
\hline 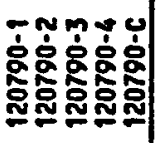 & 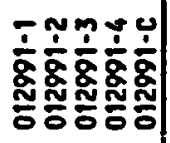 & 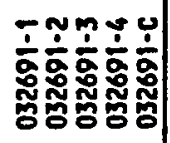 & 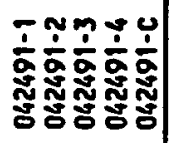 & 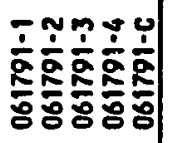 & 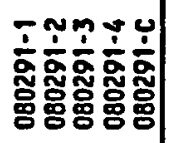 & 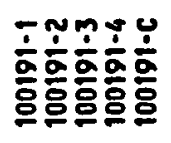 \\
\hline
\end{tabular}




\begin{tabular}{|c|c|c|c|c|}
\hline 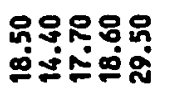 & 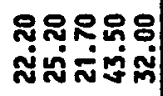 & 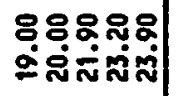 & 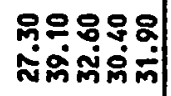 & 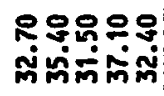 \\
\hline 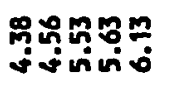 & 꽁영영 & 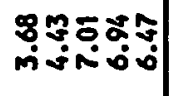 & 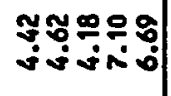 & 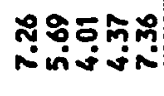 \\
\hline 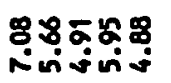 & 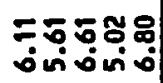 & 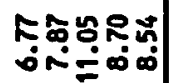 & 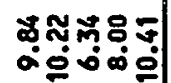 & 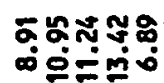 \\
\hline 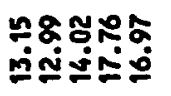 & 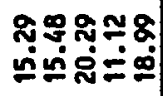 & 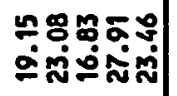 & 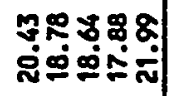 & 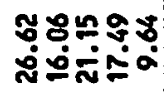 \\
\hline 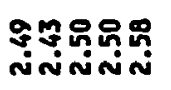 & 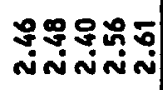 & 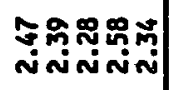 & 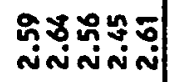 & 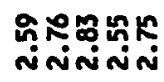 \\
\hline 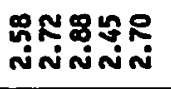 & 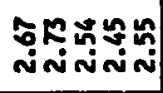 & 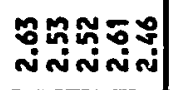 & 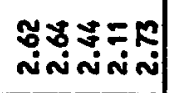 & 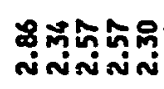 \\
\hline 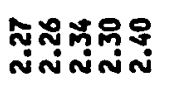 & సูํำ & 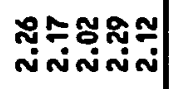 & 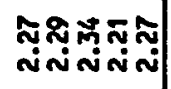 & 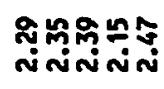 \\
\hline 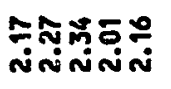 & 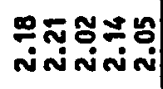 & 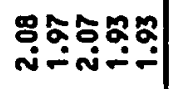 & 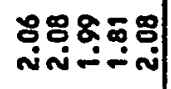 & 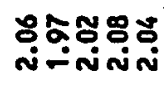 \\
\hline 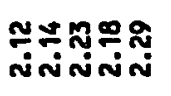 & 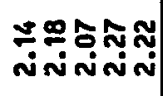 & 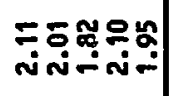 & 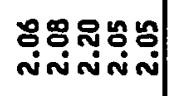 & 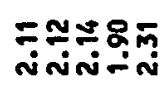 \\
\hline 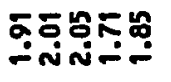 & 염ำ & K8틈ำ & 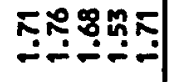 & 요요유. \\
\hline 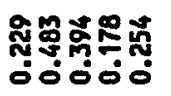 & 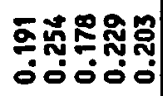 & 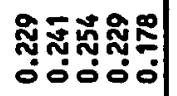 & 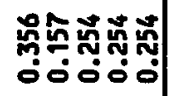 & 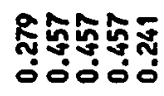 \\
\hline 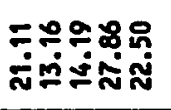 & 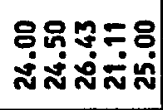 & 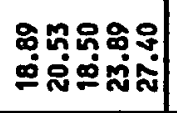 & 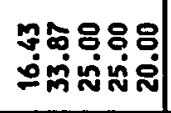 & 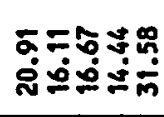 \\
\hline 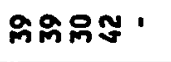 & 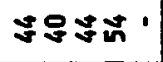 & 고ำํํㅇ & 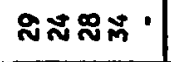 & 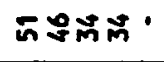 \\
\hline 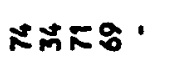 & ススホす & ミRス8. & 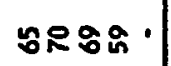 & 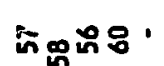 \\
\hline 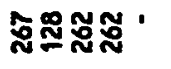 & 怘出怘怘 & 㣽怘症 & 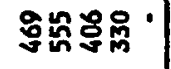 & 옹윰으몸 \\
\hline 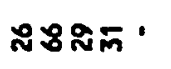 & 옴욤ำ & సనని & 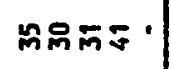 & 켱영 \\
\hline 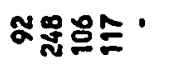 & ஜロำ & 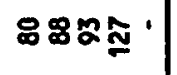 & 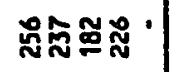 & 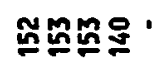 \\
\hline & N & NNNN. & NNNN. & NNNN \\
\hline 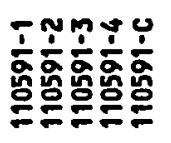 & 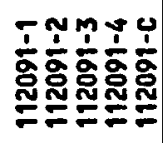 & 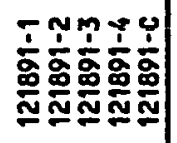 & 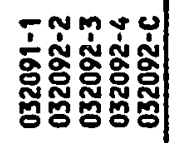 & 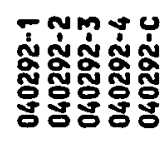 \\
\hline
\end{tabular}




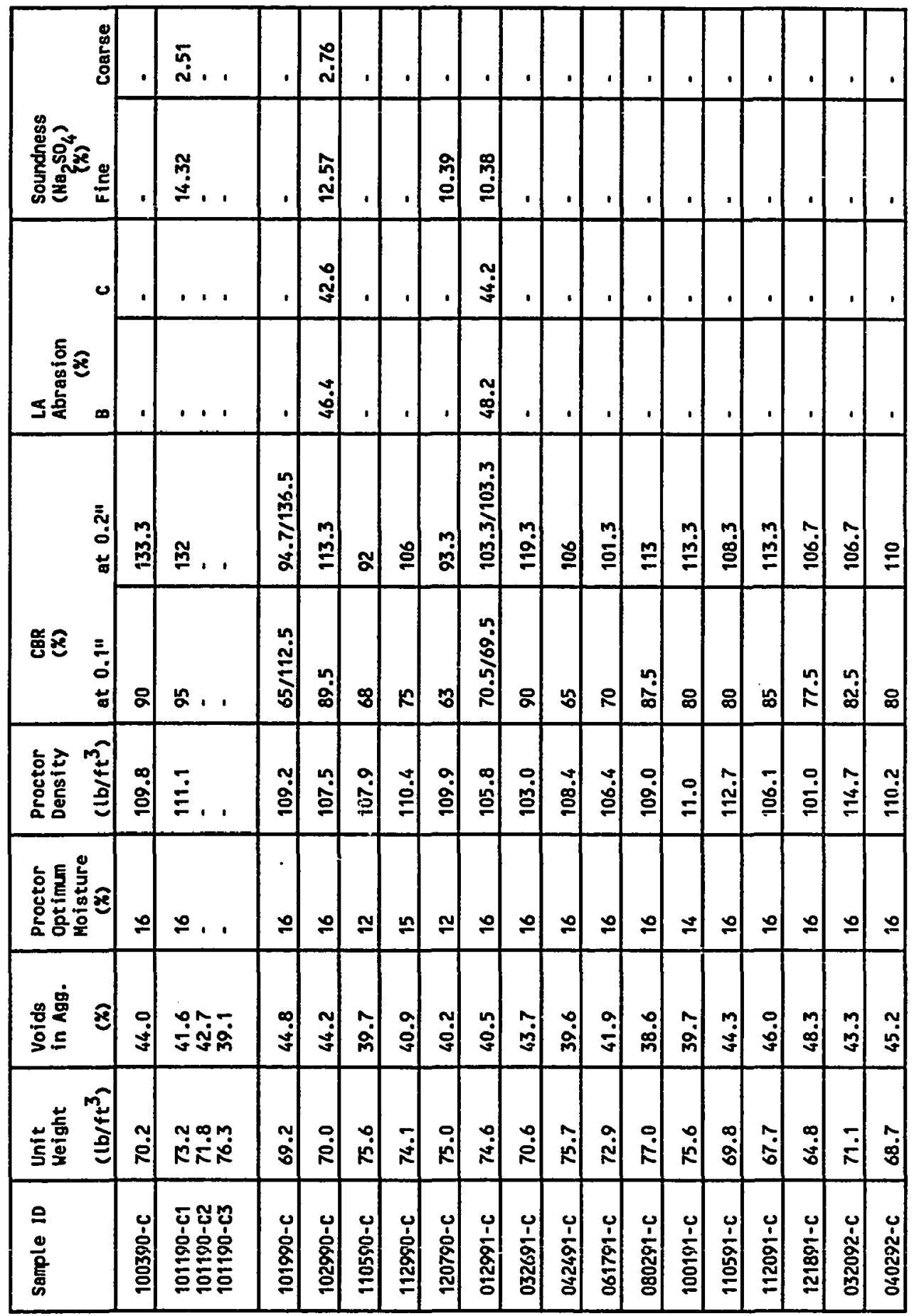

